Hans Pitlik

\title{
Politische Ökonomie des Föderalismus
}




\section{Hans Pitlik}

\section{Politische Ökonomie des Föderalismus}

Nicht zuletzt durch den fortschreitenden Prozeß der europäischen Integration hat das wissenschaftliche Interesse an der Zuordnung finanzpolitischer Kompetenzen auf gebietskörperschaftliche Entscheidungsträger zugenommen. Während die traditionelle Theorie des Fiskalföderalismus auf die kostenminimale Bereitstellung von Kollektivgütern mittels föderativer Strukturen abstellt, sieht die politische Ökonomik die Hauptfunktion eines föderativen Systems in der Begrenzung staatlicher Macht durch vertikale Gewaltenteilung. In dieser Arbeit werden die Argumentationslinien beider Ansätze ausführlich dargestellt und im Rahmen eines konstitutionell-ökonomischen Denkansatzes integriert.

Hans Pitlik wurde 1963 in Stuttgart geboren. Nach einer kaufmännischen Ausbildung 1987 bis 1991 Studium der Wirtschaftswissenschaften an der Universität Hohenheim. Seit 1992 ist er wissenschaftlicher Mitarbeiter am Lehrstuhl für Finanzwissenschaft der Universität Hohenheim. Promotion 1996. 
Politische Ökonomie des Föderalismus

Hans Pitlik - 978-3-631-75479-5

Downloaded from PubFactory at 01/11/2019 04:28:26AM

via free access 


\section{Hohenheimer Volkswirtschaftliche Schriften}

Herausgegeben von

Prof. Dr. Rolf Caesar, Prof. Dr. Harald Hagemann,

Prof. Dr. Klaus Herdzina, Prof. Dr. Jörn Kruse,

Prof. Dr. Renate Ohr, Prof. Dr. Walter Plesch, Prof. Dr. Ingo Schmidt, Prof. Dr. Peter Spahn, Prof. Dr. Gerhard Wagenhals, Prof. Dr. Helmut Walter

Band 26

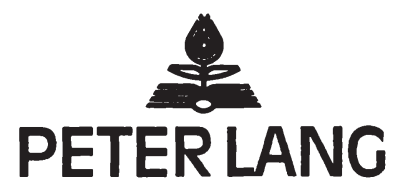

Frankfurt am Main - Berlin - Bern · New York · Paris · Wlen 


\section{Hans Pitlik}

\section{Politische Ökonomie des Föderalismus \\ Föderative Kompetenzverteilung im Lichte der konstitutionellen Ökonomik}

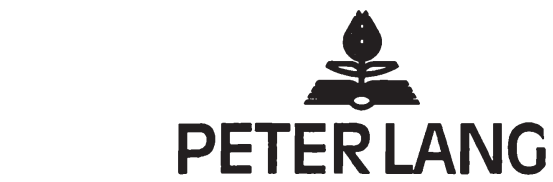

Frankfurt am Main - Berlin - Bern · New York · Paris · Wien 
Die Deutsche Bibliothek - CIP-Einheitsaufnahme

Pitlik, Hans:

Politische Ökonomie des Föderalismus : föderative Kompetenzverteilung im Lichte der konstitutionellen Ökonomik / Hans Pitlik. - Frankfurt am Main ; Berlin ; Bern ; New York ; Paris ; Wien : Lang, 1997

(Hohenheimer Volkswirtschaftliche Schriften ; Bd. 26) Open Access: The online version of this publication is published on www.peterlang.com and www.econstor.eu under the international Creative Commons License CC-BY 4.0. Learn more on how you can use and share this work: http://creativecommons. org/licenses/by/4.0.

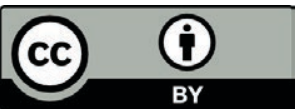

This book is available Open Access thanks to the kind support of ZBW - Leibniz-Informationszentrum Wirtschaft.

Zugl.: Hohenheim, Univ., Diss., 1996

ISBN 3-631-31800-6

\author{
D 100 \\ ISSN 0721-3085 \\ ISBN 3-631-31800-6 \\ ISBN 978-3-631-75479-5 (eBook) \\ (c) Peter Lang $\mathrm{GmbH}$ \\ Europäischer Verlag der Wissenschaften \\ Frankfurt am Main 1997 \\ Alle Rechte vorbehalten.
}

Das Werk einschließlich aller seiner Teile ist urheberrechtlich geschützt. Jede Verwertung außerhalb der engen Grenzen des

Urheberrechtsgesetzes ist ohne Zustimmung des Verlages unzulässig und strafbar. Das gilt insbesondere für Vervielfältigungen, Übersetzungen, Mikroverfilmungen und die Einspeicherung und Verarbeitung in elektronischen Systemen.

Printed in Germany $1234 \quad 67$ 


\section{VORWORT}

Um es vorweg zu nehmen: Spektakuläres sollte der Leser dieses Vorwortes nicht erwarten. Im Grunde gleicht es eher dem flüchtigen Winken ("hallo schaut mal, ich bin im Fernsehen!") in die Kamera bei der Hitparade oder, alternativ, den Grüßen in diversen Radiosendungen mit Zuschauerwünschen. Toll ist natürlich, wenn man davon eine Video- oder Audioaufzeichnung hat. Diese einzigartigen Dokumente sind gewiß auch noch nach Jahrzehnten des Darbens in der anonymen Masse der von den Medien Unbeachteten ein Quell der Freude nicht nur des Grüßenden, sondern auch der Gegrüßten.

Es erweist sich aber als geradezu unmögliches Unterfangen, all jenen zu danken, die mir im Laufe der zurückliegenden Jahre die Unterstützung zukommen ließen, die ein Gelingen der Arbeit überhaupt erst möglich gemacht haben.

Zuallererst - und keineswegs nur obligatorisch - gilt dieser Dank meinem Doktorvater, Herrn Prof. Dr. Rolf Caesar, für seinen fachlichen Rat und seine menschliche Unterstützung in meinen persönlichen 'Arbeitskrisen'. Weiterer Dank gilt Herrn Prof. Dr. Jörn Kruse für die Übernahme des Zweitgutachtens und Herm Prof. Dr. Gerhard Wagenhals für die Mitwirkung am Promotionsverfahren.

Besonderen Dank schulde ich unserer Sekretärin, Frau Silke Dahlke, deren Beitrag zu einer einzigartig guten Arbeitsatmosphäre nur durch ihren unermüdlichen Einsatz zum Wohle des Lehrstuhls übertroffen wird.

Ebenso sei meinen Kolleginnen und Kollegen Elke Anderl, Dr. Karin Beckmann, Dr. Steffen Binder, Uwe Burkert, Dr. Alexander Burger, Andreas Friese, Annette Fritz, Ingrid Gruber, Claudia Hafner, Petra König, Barbara Kohler, Jürgen Kulle, Oliver Letzgus, Alexander Rieger, Günther Schmid, André Schmidt, Renate Strobel, Margit Ströbele, Markus Wasser, Klaus Weißenberg und allen (natürlich auch Maja) vom Lehrstuhl für Statistik und Ökonometrie gedankt. Gerne hätte ich noch Ausführungen über Ramones-Perücken, zerrissene Bettlaken, Bananenröckchen o.ä. gemacht. Aber wenigstens im Vorwort möchte ich mich einmal kürzer fassen.

U N TE R STOTZT

D U A C H D I E

(1)

S T I F T U N 6
Ein Dankeschön sei auch an die LG Stiftung Ausbildung, Fort- und Weiterbildung gerichtet, die mich mit einem großzügigen Druckkostenzuschuß unterstützt hat.

Schließlich: Ohne die Unterstützung meiner Eltern, meiner Schwester Ursula und meiner Frau Ariane, die die berühmt-berüchtigte Endphase mit viel Geduld ertragen hat, sowie all meiner Freunde und ehemaligen WG-Mitbewohner wäre alles viel schwerer gewesen. Ihnen allen sei deshalb besonders gedankt.

Ohne Widmung. Die in Frage kommenden Personen profitieren mehr davon, wenn ich ihnen in Zukunft mehr Zeit schenke. 
Hans Pitlik - 978-3-631-75479-5

Downloaded from PubFactory at 01/11/2019 04:28:26AM

via free access 


\section{INHALTSVERZEICHNIS}

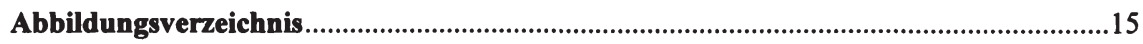

Symbolverzeichnis ..................................................................................................................

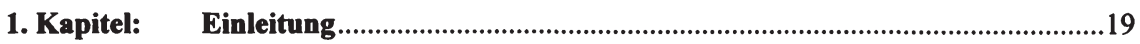

A. Problemstellung und Ziel der Arbeit .....................................................................19

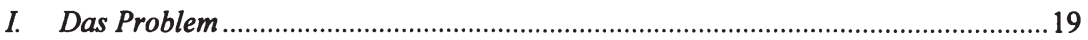

1. Eine 'fiktiv-metaphysische' Sicht.........................................................................19

2. Subsidiaritätsprinzip und Föderalismus als Probleme der Politischen Ökonomie................................................................................20

II. Föderalismus als Gegenstand unterschiedlicher Wissenschaftsdisziplinen ................21

1. Föderalismus in der Staatsrechtslehre.................................................................21

2. Föderalismus in der Politologie .....................................................................21

3. Föderalismus in der traditionellen Ökonomik ...................................................22

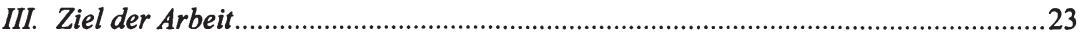

B. Vorgehensweise ………………..............................................................................24

2. Kapitel: Der Staat als Organisation: Grundzüge einer polit-ökonomischen Theorie des Staates...........................................................................................27

A. Die Logik ökonomischer Organisationen ....................................................................27

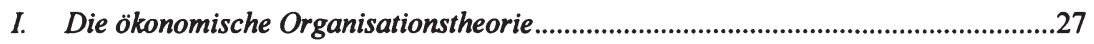

1. Das Erkenntnisinteresse der Neuen Institutionenökonomik .................................27

2. Die Begriffe der "Institution" und der "Organisation" .........................................28

II. Methodologische Grundlagen der ökonomischen Analyse von Organisationen .........30

1. Die verhaltenstheoretischen Annahmen der Neuen Institutionenökonomik ........30

2. Die Analyseinstrumente der Neuen Institutionenökonomik..................................31

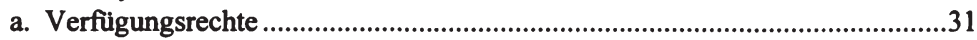

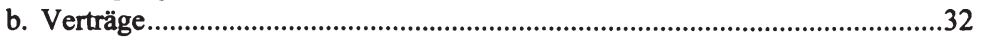

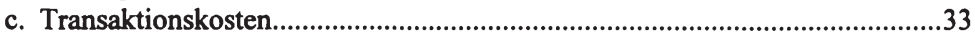

3. Die Auswahl effizienter Koordinationsstrukturen ...............................................34

III. Der konstitutionelle Ansatz für eine ökonomische Theorie der Organisationen.........37

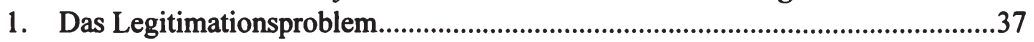

2. Kooperationsprobleme als soziale Dilemmata ……………....................................39

a. Die spieltheoretische Interpretation des Kooperationsproblems.......................39

b. Die transaktionskostentheoretische Interpretation des Kooperations-

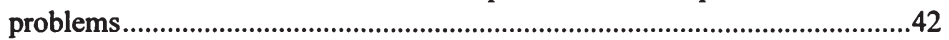

c. Das Kooperationsproblem aus Sicht der konstitutionellen Ökonomik .............43

3. Ressourcenzusammenlegung und Organisationsverfassung..................................43

a. Das grundlegende Dilemma der Organisation ....................................................43

b. Abwanderung und Widerspruch .....................................................................44 
B. Die ökonomische Logik des Staates

I. Die Notwendigkeit der Existenz eines Staates ………............................................47

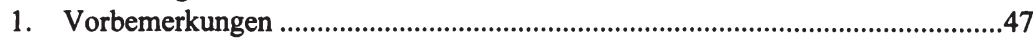

2. Der protektive Staat .................................................................................................47

a. Die staatslose Gesellschaft...............................................................................47

b. Die Garantie von Besitz- und Tauschsicherheit durch den protektiven Staat............................................................................49

3. Der produktive Staat ...........................................................................................51

a. Marktliche versus staatliche Koordination...........................................................51

b. Marktversagen als Konsequenz hoher Transaktionskosten ...............................52 aa. Fehlende Ausschließbarkeit und das Problem der Externalitäten ...............52

bb. Steigende Skalenerträge und das Monopolproblem..................................53

cc. Öffentliche Güter ...................................................................................54

dd. Stabilisatorisches Marktversagen: Arbeitslosigkeit und Inflation ..............55 ee. Soziale Sicherung und Umverteilung ..........................................................57

c. Der produktive Staat als potentiell transaktionskosteneinsparende Organisation ................................................................................59

II. Die Notwendigkeit und die Möglichkeiten einer Begrenzung des Staates...................60

1. Beschränkungen des protektiven Staates: Das ungelöste konstitutionelle Dilemma ................................................................60

2. Die Logik konstitutioneller Beschränkungen des produktiven Staatshandelns...61

a. Der unbegrenzte Staat und die Notwendigkeit konstitutioneller Beschränkungen ..................................................................61

b. Die demokratische Widerspruchsoption ..........................................................63 aa. Das Interdependenzkostenkonzept von Buchanan und Tullock..................63 bb. Verringerung der Interdependenzkosten durch indirekte Demokratie ......65

c. Beschränkungen des produktiven Staates durch Föderalismus?.......................67

C. Zusammenfassende Thesen zum zweiten Kapitel..........................................................68

3. Kapitel: Die Theorie des Fiskalfoderalismus............................................................69

A. Die Wesensmerkmale der Theorie des Fiskalfoderalismus .............................................69

B. Regelungen für den protektiven Staat ...........................................................................70

I. Der Regelungsbedarf auf konstitutioneller Ebene ……….............................................70

II. Überlegungen zu einer Theorie optimaler Rechtsräume .............................................70

1. Die Nutzen und Kosten der Bildung des protektiven Staates................................70

a. Die Nutzen der Rechtsvereinheitlichung ........................................................70

b. Die Durchsetzungskosten des protektiven Staates ..............................................71

2. Die optimale personelle Größe des protektiven Staates:

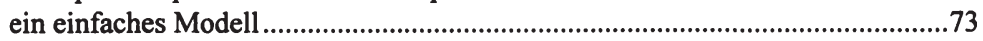

3. Die Implikationen für die föderative Aufgabenverteilung......................................76 
C. Regelungen für den produktiven Staat

I. Der Regelungsbedarf auf konstitutioneller Ebene .........................................................77

1. Bereitstellungszuständigkeit und Durchfuhrungszuständigkeit..............................77

2. Alternative Organisationsformen der Zuordnung von Bereitstellungskompetenzen ..........................................................................79

II. Die Zuordnung der Allokationsfunktion ...................................................................8

1. Fiskalische Äquivalenz und Informationskosten................................................80

a. Kollektivgüter, räumliche Nutzengrenzen und das Prinzip fiskalischer Äquivalenz.................................................................................80

b. Fiskalische Clubs und lokale öffentliche Güter ..............................................82

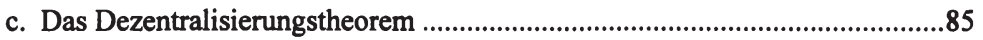

aa. Das Modell von Oates .................................................................................85

bb. Eine informationsökonomische Begründung ...............................................87

d. Die Implikationen für die Zuordnung der Bereitstellungskompetenzen..........88

2. Spillover-Effekte, Skalenvorteile im Konsum und Koordinationskosten ............89

a. Die Wohlfahrtsverluste bei nicht-kooperativem Verhalten der subzentralen Einheiten ..............................................................................89

b. Potentielle Wohlfahrtsgewinne bei kooperativem Verhalten der subzentralen Einheiten ...........................................................................91

aa. Horizontale Verflechtungen ...........................................................................91

bb. Vertikale Verflechtungen: Kooperativer Föderalismus ...............................93

c. Die Implikationen für die Zuordnung der Bereitstellungskompetenzen..........94

3. Die Präferenzoffenbarung durch Wanderungen: Das Tiebout-Modell..................96

a. Die Grundgedanken von Tiebout und die herkömmliche Kritik am

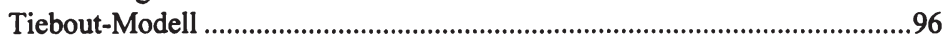

b. Zur räumlichen Mobilität von Arbeit und Kapital .............................................99

aa. Migrationstheorie und räumliche Mobilităt des Faktors Arbeit ..................99

bb. Räumliche Mobilităt des Faktors Kapital ............................................100

c. Zum Problem der Migrationsexternalitäten ..................................................101

aa. Die effiziente räumliche Allokation von Arbeit und Kapital ...................101

bb. Dezentrale Bereitstellungskompetenzen und effiziente räumliche

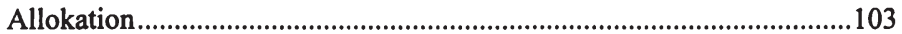

cc. Kapitalisierung und Ausschluß als Voraussetzung fur Tiebout-Effizienz ................................................................................106

d. Zum Problem des Fiskalwettbewerbs ................................................................108

aa. Unterversorgung mit konsumtiven Kollektivgütern? .................................108

bb. Unterversorgung mit produktiven Kollektivgütern?.................................113

cc. Exkurs: Besteuerung nach dem Wohnsitzprinzip als Ersatz für Steuerharmonisierung? .........................................................................115

e. Die Implikationen furr die Zuordnung der Bereitstellungskompetenzen........116

4. Ein Zwischenfazit ..............................................................................................117

III. Die Zuordnung der Stabilisierungsfunktion ..........................................................118

1. Die geldpolitischen Zuständigkeiten .............................................................118

2. Zentrale oder dezentrale finanzpolitische Stabilisierungskompetenzen? ...........120

a. Argumente für dezentrale finanzpolitische Stabilisierungskompetenzen .....120

b. Argumente für zentrale finanzpolitische Stabilisierungskompetenzen..........121 
3. Die Implikationen für die Zuordnung der Bereitstellungskompetenzen.............123

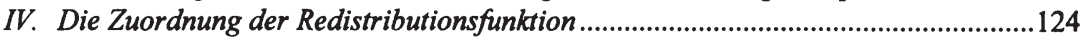

1. Interpersonale und interregionale Umverteilungsziele ......................................124

2. Zentrale oder dezentrale redistributionspolitische Kompetenzen?....................124

a. Argumente für dezentrale redistributionspolitische Kompetenzen................124

b. Argumente für zentrale redistributionspolitische Kompetenzen....................126

aa. Spillover-Effekte dezentraler Redistributionspolitik.............................126

bb. Redistributionspolitik bei räumlicher Mobilität

von Arbeit und Kapital ......................................................................127

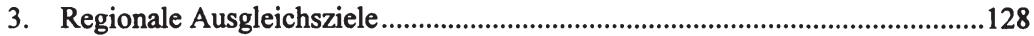

4. Die Implikationen für die Zuordnung der Bereitstellungskompetenzen.............131

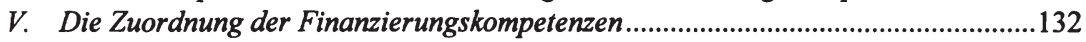

1. Die Zuordnung der Finanzierungskompetenzen als Teilproblem der Zuordnung von Bereitstellungskompetenzen ...........................................132

a. Die institutionelle Symmetrie von Aufgaben- und Finanzierungskompetenzen...................................................................132

b. Alternative Organisationsformen der Zuordnung von

Finanzierungskompetenzen ...................................................................133

c. Die Kriterien für eine optimale Zuordnung von

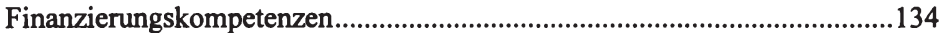

2. Die Grundprobleme der Zuordnung von Finanzierungskompetenzen...............135

a. Zur Zuordnung der Besteuerungskompetenzen im föderativen Staat............135

aa. Zur Übereinstimmung von Nutzern und Kostenträgern ..........................135

bb. Zum instrumentalen Charakter von Steuern .........................................136

cc. Zum Steuerwettbewerbsargument .......................................................136

dd. Zur regionalen Streuung der Bemessungsgrundlagen..............................136

b. Zur Zuordnung der Verschuldungskompetenzen im föderativen Staat ........137

aa. Zur Übereinstimmung von Nutzern und Kostenträgern .........................137

bb. Zum instrumentalen Charakter öffentlicher Verschuldung.....................137

cc. Zum Argument der externen Effekte des Wettbewerbs subzentraler Einheiten ................................................................................................138

dd. Zum Argument der unterschiedlichen Zugangsmöglichkeit zum

Kapitalmarkt..................................................................................139

3. Die Implikationen für die Zuordnung der Finanzierungskompetenzen .............139

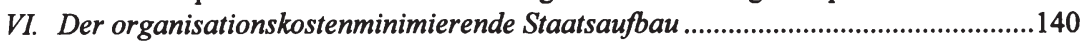

1. Das Organisationskostenkonzept von Breton und Scott...................................140

2. Die organisationskostenminimale Staatsstruktur.........................................143

3. Die Reduzierung der Organisationskosten durch multifunktionale Einheiten ...147

4. Eine kritische Würdigung des Organisationskostenkonzepts von Breton und Scott .................................................................................148

D. Zusammenfassende Thesen zum dritten Kapitel ...............................................150 
4. Kapitel: Eine Public Choice-Analyse politischer Entscheidungsprozesse im foderativen System

A. Die Wesensmerkmale der Public Choice-Theorie.

B. Die neoinstitutionalistische Perspektive politischer Entscheidungsprozesse

I. Das Interaktionsgeflecht politischer Akteure im Überblick...................................152

II. Die ökonomische Theorie des politischen Wettbewerbs um Wählerstimmen ............153

1. Die Ziele der Wähler, der Politiker und der Parteien.

2. Die These von der Effizienz des politischen Wettbewerbs um Wählerstimmen

3. Die Unvollkommenheiten des Wettbewerbs um Wählerstimmen......................155

a. Intransitive Ergebnisse und Stimmentausch ............................................155

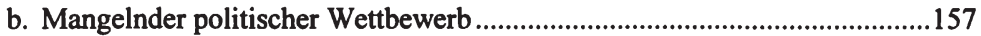

c. Rationale Unwissenheit der Wähler..........................................................159

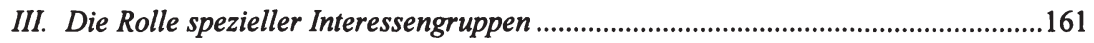

1. Die Ziele spezieller Interessengruppen ...........................................................161

2. Die These von der Effizienz des Wettbewerbs spezieller Interessengruppen....162

a. Pluralismustheorie und 'countervailing powers'...........................................162

b. Der Ansatz von Becker .............................................................................162

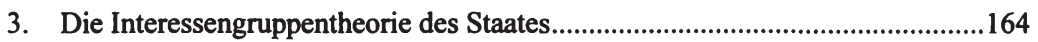

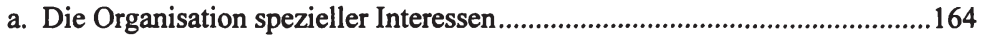

b. Die Bedeutung der Informationsasymmetrien ...........................................165

c. Ressourcenverschwendung im Kampf um Distributionsvorteile:

Die Theorie des rent seeking...................................................................167

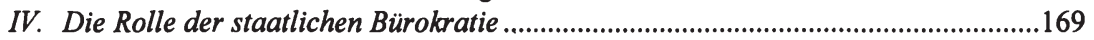

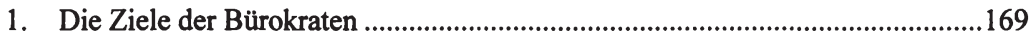

2. Die These von der Dominanz der Legislative über die staatliche Bürokratie ...170

a. Die Bürokratie in sozialwissenschaftlichen Hierarchiemodellen..................170

b. Principal-Agent Modelle der legislativen Dominanz über die Bürokratie....171

3. Die These von der Dominanz der Exekutive über die Legislative .....................172

4. Die Bürokratie in der Interessengruppentheorie des Staates .............................174

V. Ein Totalmodell politischer Entscheidungsprozesse:

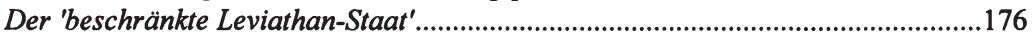

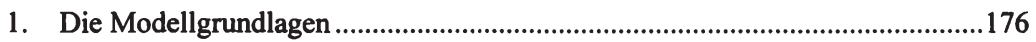

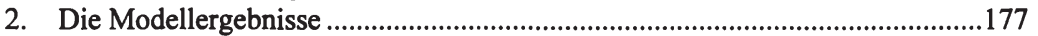

a. Stimmenmaximierende Kandidaten .........................................................177

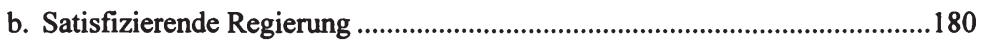

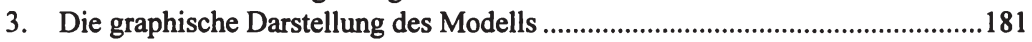

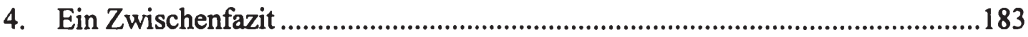


C. Die politischen Entscheidungsprozesse in foderativen Staaten

I. Der Vergleich unitarischer und föderativer Strukturen als komparative Institutionenanalyse.

II. Die Konsequenzen der Föderalisierung für den

Wettbewerb um Wählerstimmen

1. Die Implikationen für die diskretionären Handlungsspielräume der Politiker ..185

2. Die Implikationen für den Informationsstand der Wähler ..................................187

3. Das Konzept des interjurisdiktionellen Rangordnungswettbewerbs ...................189

a. Rangordnungswettbewerb und Wettbewerb um Wählerstimmen....................189

b. Rangordnungswettbewerb als Entdeckungsverfahren ....................................191

III. Die Konsequenzen der Föderalisierung für den

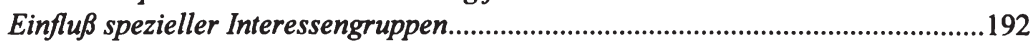

1. Die Organisation spezieller Interessen im föderativen System ..........................192

a. Konsequenzen für die Organisierbarkeit spezieller Interessen ........................192

b. Relative Organisationskosten und staatliche Umverteilungstätigkeit............194

2. Die Konsequenzen verstärkten politischen Wettbewerbs um Wählerstimmen .198

IV. Die Konsequenzen der Föderalisierung für den

Einfluß der staatlichen Bürokratie .....................................................................201

1. Bürokraten als Anbieter von Leistungen: Die Kontrolle der Bürokratie............201

2. Bürokraten als Nachfrager von Leistungen .......................................................202

V. Ein Totalmodell politischer Entscheidungsprozesse im föderativen Staat .................203

1. Die Modellergebnisse ........................................................................................203

2. Die graphische Darstellung des Modells ...........................................................205

3. Die Implikationen für die föderative Aufgabenverteilungsdiskussion ................208

D. Zusammenfassende Thesen zum vierten Kapitel. 209

\section{Kapitel: Polit-ökonomische Theorien des Wettbewerbs-}

foderalismus.

A. Die Wesensmerkmale polit-ökonomischer Theorien des Wettbewerbsföderalismus

I. Das Tiebout-Modell als Vorläufer ...........................................................................211

II. Die Konzepte polit-ökonomischer Theorien des Wettbewerbsföderalismus..............213

1. Wettbewerb zwischen Staaten ............................................................................213

2. Wettbewerb zwischen Regierungen in der Leviathan-Theorie des Staates ........213

3. Wettbewerb zwischen Regierungen in der Interessengruppentheorie des Staates

4. Wettbewerb um Kompetenzen..........................................................................215 
B. Der Wettbewerb zwischen Regierungen in der Leviathan-Theorie des Staates ......216

I. Die Beschränkung des Leviathan durch Abwanderungsoptionen ............................216

1. Die Dezentralisierungshypothese von Brennan und Buchanan ........................216

a. Die Grundaussagen von Brennan und Buchanan.....................................216

b. Die empirische Überprüfung der Dezentralisierungshypothese...................218 aa. Die methodische Vorgehensweise bei den empirischen Tests ................218

bb. Die Ergebnisse der empirischen Untersuchungen.................................220

2. Immobile Faktoren und Abwanderungsoptionen ..........................................224

a. Die Ausbeutung immobiler Faktoren durch den Leviathan ...........................224

b. Schutz immobiler Faktoren durch Standortwettbewerb? ..............................2225

3. Interjurisdiktioneller Wettbewerb und räumliche spillover-Effekte...................227

II. Die Beschränkung der Abwanderungsoptionen durch den Leviathan .....................230

1. Die Beschränkung der Abwanderungsoptionen als Ziel subzentraler

Leviathan-Regierungen.............................................................................2230

2. Praktiken zur Steigerung von Abwanderungskosten ......................................231

a. Emigrationssteuern als Austrittsgebühren ................................................231

b. Stärkung der lokalen Identität ................................................................2232

c. Immigrationssteuern als versunkene Kosten? ..........................................2232

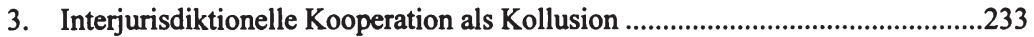

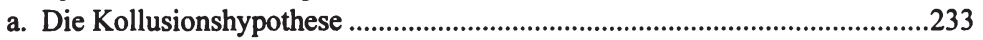

b. Kollusion durch vertikale Verflechtung..................................................236

aa. Vertikale Finanzzuweisungssysteme ...................................................2236

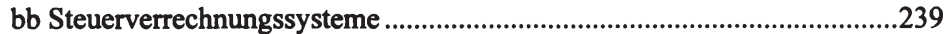

III. Die Implikationen für die föderative Aufgabenverteilung ......................................242

1. Radikale Dezentralisierung ............................................................................242

2. Der organisationskostenminimale Staatsaufbau aus Sicht der

Leviathan-Theorie.

C. Der Wettbewerb zwischen Regierungen in der Interessengruppentheorie

des Staates.

I. Methodische Vorüberlegungen ............................................................................245

II. Abwanderung und Widerspruch bei Mobilität der unorganisierten Wähler ............246

1. Die Widerspruchsoption der Wähler ..............................................................246

a. Dominanz der Abwanderungsoption?.....................................................246

b. Gestiegene Anreize zur Formulierung von politischem Widerspruch? ........249

2. Die rent seeking-Anreize der speziellen Interessengruppen .............................251

a. Der Effekt gesunkener Abwanderungskosten der Organisationsmitglieder .251

b. Der Effekt gesunkener Abwanderungskosten der unorganisierten Wähler ..251

3. Die Implikationen für den politischen Entscheidungsprozeß: Standortpolitik..253 
III. Abwanderung und Widerspruch bei Mobilität der organisierbaren Interessen. .255

1. Zur Abwanderungsoption spezieller Interessengruppen....................................255

2. Die Politische Ökonomie des Protektionismus.................................................257

a. Erklärungsinteresse und Grundidee der Politischen Ökonomie des Protektionismus

b. Die wichtigsten Ergebnisse der Politischen Ökonomie des Protektionismus

3. Protektionismus und polit-ökonomische Theorie des Wettbewerbsföderalismus

a. Zur Relevanz der Argumentation im Bundesstaat .....................................261

b. Protektionismus auf dezentraler Ebene und interjurisdiktionelle Faktormobilität......................................................................................262

IV. Die Implikationen für die Ausgestaltung der föderativen Staatsverfassung.............265

1. Dezentralisierung zur Beschränkung der Rentenumverteilung .........................265

2. Aspekte einer föderativen Wettbewerbsordnung ............................................265

a. Die Notwendigkeit einer föderativen Wettbewerbsordnung..........................265

b. Ausgestaltungs- und Zuordnungsprobleme .............................................267

3. Spezifisch föderative Arrangements zur Begrenzung der Zentralebene............269

a. Die Notwendigkeit und das Problem der Begrenzung der Zentralebene ......269

b. Reverse Revenue Sharing ......................................................................270

c. Die Stärkung subzentraler Einflüsse bei zentralstaatlichen Entscheidungen ...................................................................................272

d. Funktionale Differenzierung und Separierung der Delegationsfelder ..........273

D. Zusammenfassende Thesen zum funften Kapitel ...............................................273

6. Kapitel: Möglichkeiten für eine foderative Finanzverfassung ..............................275

A. Theorie des Fiskalfoderalismus und Public Choice...............................................275

B. Eine Skizze einer föderativen Finanzverfassung …...........................................276

C. Einige Anmerkungen zur Implementierung konstitutioneller Reformen ...............278

Anhang

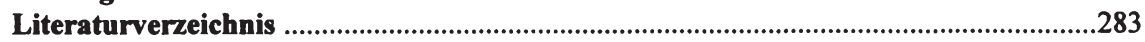




\section{ABBILDUNGSVERZEICHNIS}

Abbildung 2.1 Auszahlungsmatrix bei Kooperationsspielen................................................40

Abbildung 2.2 Das optimale Zustimmungserfordernis............................................................64

Abbildung 3.1 Die Durchsetzungskosten des protektiven Staates..............................................73

Abbildung 3.2 Die optimale personelle Größe des protektiven Staates....................................75

Abbildung 3.3 Das Dezentralisierungstheorem ......................................................................86

Abbildung 3.4 Allokationswirkungen räumlicher spillover-Effekte.........................................90

Abbildung 3.5 Pareto-Inferiorität nicht-kooperativer Strategien .............................................90

Abbildung 3.6 Suboptimale Bereitstellung von Kollektivgütern bei Steuerwettbewerb .......110

Abbildung 3.7 Fehlender Kooperationsanreiz lokaler Einheiten bei Steuerwettbewerb .......112

Abbildung 3.8 Ruinöse Konkurrenz bei Bereitstellung lokaler öffentlicher Vorleistungen?.

Abbildung 3.9 Regionale Ausgleichszahlungen zur Verbesserung der räumlichen Allokation

Abbildung 3.10 Organisatorische Aktivitäten und Zentralisierungsgrad.................................145

Abbildung 3.11 Organisationskostenminimum und Zentralisierungsgrad ...............................146

Abbildung 4.1 Das Interaktionsgeflecht politischer Entscheidungen .....................................153

Abbildung 4.2 Wohlfahrtsverluste durch rent-seeking ..........................................................168

Abbildung 4.3 Ein Totalmodell politischer Entscheidungsprozesse......................................182

Abbildung 4.4 Intrajurisdiktionelle Homogenität und staatliche Transfertätigkeit ...............196

Abbildung 4.5 Politischer Wettbewerb und staatliche Transfertätigkeit ................................199

Abbildung 4.6 Ein Totalmodell politischer Entscheidungsprozesse im föderativen System ..............................................................................206

Abbildung 4.7 Wohlfahrtsverluste durch intensiven politischen Wettbewerb im föderativen Staat ..................................................................................208

Abbildung 5.1 Jurisdiktionelle Konsolidierung und Ausbeutungspotentiale ........................217

Abbildung 5.2 Ergebnisse empirischer Tests der 'Dezentralisierungshypothese' ..................221

Abbildung 5.3 Öffentliche Vorleistungen und Besteuerungsbasis .........................................226

Abbildung 5.4 Steuerharmonisierung und Kollusionshypothese ...........................................234

Abbildung 5.5 Gemeinsame Steuerbasis föderativer Ebenen im Leviathan-Staat..................240

Abbildung 5.6 Abwanderungsoptionen und die Formulierung von Widerspruch.................247

Abbildung 5.7 Rent-seeking bei elastischer und unelastischer Nachfrage ............................252

Abbildung 5.8 Beschränkung staatlicher Transfertätigkeit

bei Mobilität der Steuerzahler...................................................................254

Abbildung 5.9 Protektionistische Strategie und Rentenverluste immobiler Faktoren...........264

Abbildung A.1 Allokative Vorteile der Verhandlungslösung..................................................281 
Hans Pitlik - 978-3-631-75479-5

Downloaded from PubFactory at 01/11/2019 04:28:26AM

via free access 


\section{SYMBOLVERZEICHNIS (Auswahl)}

A administrative Kosten

b Parteidifferential

C Kosten der Produktion und Bereitstellung eines öffentlichen Konsumgutes

c Kosten des Wählens

D Kosten der Produktion und Bereitstellung eines öffentlichen Produktionsfaktors

d Durchsetzungsgrad der property rights, Zusatznutzen der Wahlteilnahme

$E_{i} \quad$ Staatsausgaben für gesellschaftliche Gruppe i

e Effizienzfaktor

G Menge eines öffentlichen Konsumgutes

H Menge eines öffentlichen Produktionsfaktors

K Gesamtkapitalbestand, Koordinationskosten

k Kapitalbestand in einer lokalen Jurisdiktion

L Menge des Faktors Boden

M Mobilitätskosten

N Gesamtbevölkerung

n Anzahl der Mitglieder einer lokalen Jurisdiktion, Menge des Faktors Arbeit

$\mathrm{O}^{\mathrm{B}} \quad$ Organisationskosten der Bürger

$\mathrm{O}^{\mathrm{R}} \quad$ Organisationskosten der Regierung

p Bodenrente, politischer Druck

P Anzahl der Armen

$P_{i} \quad$ Netto-Vorteile für gesellschaftliche Gruppe i

Q Sozialprodukt

$\mathrm{R}$ Durchsetzungskosten des protektiven Staates, Anzahl der Reichen

$R_{\text {ext }} \quad$ externe Durchsetzungskosten des protektiven Staates

$\mathbf{R}_{\text {int }} \quad$ interne Durchsetzungskosten des protektiven Staates

r Kapitalzinssatz

S Präferenzoffenbarungskosten

s Spezifikationsgrad der property rights

T Steueraufkommen

U Nutzen

$\mathrm{V}_{\mathrm{i}} \quad$ Wăhlerstimmen der gesellschaftlichen Gruppe i

w Lohnsatz

$\mathrm{X} \quad$ Menge eines privaten Gutes

Y Einkommen

$Y_{p} \quad$ Einkommen der Armen

$Y_{r} \quad$ Einkommen der Reichen

$\alpha \quad$ Fühlbarkeit individueller Lobbyingbeiträge

$\beta \quad$ Effektivität individueller Lobbyingbeiträge

$\gamma \quad$ Zentralisierungsgrad des Staatsaufbaus

$\Theta \quad$ relativer Interessengruppeneinfluß

$\pi \quad$ Wahrscheinlichkeit der Beeinflussung des Wahlausgangs durch Stimmabgabe

$\tau^{\mathbf{k}} \quad$ Kapitalsteuersatz

$\tau^{\mathrm{L}} \quad$ Bodensteuersatz

$\tau^{\mathrm{n}} \quad$ Kopfsteuersatz 
Hans Pitlik - 978-3-631-75479-5

Downloaded from PubFactory at 01/11/2019 04:28:26AM

via free access 


\section{Kapitel: Einleitung}

\section{A. Problemstellung und Ziel der Arbeit}

\section{Das Problem}

\section{Eine 'fiktiv-metaphysische' Sicht}

Aristoteles, de Tocqueville, Lincoln und Papst Pius XI treffen sich zu ihrer jährlichen Diskussionsrunde im ökonomischen Nirwana und beobachten die aktuellen tagespolitischen Probleme. Ihr Blick schweift über Europa, wo die Staatsmänner versuchen, die Gemeinschaft in eine föderative Union umzuwandeln. Kopfschüttelnd wenden sie sich ab und konzentrieren ihre Beobachtungen auf das wiedervereinigte Deutschland. Dort werden zur gleichen Zeit Möglichkeiten und Notwendigkeiten einer Neugliederung des Bundesgebiets debattiert ${ }^{1}$ und Vorschläge für die Neugestaltung des innerstaatlichen Finanzausgleichs, ausgelöst durch die chronische Finanzkrise von Bund, Ländern und Gemeinden, von Wissenschaft und Politik äußerst kontrovers erörtert. ${ }^{2}$ In Belgien, Spanien, Italien und Frankreich stellen die vier eine Dezentralisierung und eine Stärkung der regionalen Autonomie fest. Etwas weiter östlich sehen sie auf der politischen Landkarte, daß dort, wo vormals die Union der Sozialistischen Sowjetrepubliken war, eine Vielzahl neuer, unabhängiger Staaten existiert. Auch die Tschecho-Slowakische Föderative Republik gibt es nicht mehr. Und in Kanada scheitert ein Referendum über den Austritt Quebecs aus der kanadischen Föderation. ${ }^{3}$

Aristoteles eröffnet die Diskussion: "Es gehört sich aber auch, nicht zu übersehen, um welche Dinge sich der Örtlichkeit nach viele Obrigkeiten zu kümmern haben und über welche überall nur ein Amt zu entscheiden braucht ...."4

De Tocqueville pflichtet ihm bei und führt weiter aus: "Um die verschiedenen Vorteile miteinander zu verbinden, die den Völkern aus ihrer Größe und aus ihrer Kleinheit erwachsen, wurde das System des Bundesstaates geschaffen."5

Papst Pius XI hat auch schon eine Lösung parat: "Wie dasjenige, was der Einzelmensch aus eigener Initiative und mit seinen eigenen Kräften leisten kann, ihm nicht entzogen und der Gesellschaftstätigkeit zugewiesen werden darf, so verstößt es gegen die Gerechtigkeit, das, was die kleineren und untergeordneten Gemeinwesen leisten und zum guten Ende führen können, für die weitere und übergeordnete Gemeinschaft in Anspruch zu nehmen ... Je besser durch strenge Beobachtung des Prinzips der Subsidiarität die Stufenordnung der verschiedenen Gesellschaftungen innegehalten wird, ... um so besser und glücklicher ist es auch um den Staat bestellt."6

Dem Politiker Lincoln ist diese Formulierung zu wenig griffig. Er äußert deshalb knapp seine Forderung: "Let the nation take hold of the larger works, and the states of the smaller ones."7

Zu einem Überblick siehe etwa Laufer, $H$. (1992), S. $203 \mathrm{ff}$.

Siehe etwa Peffekoven, R. (1990) oder Bundesministerium der Finanzen (1995).

Zu einem Überblick siehe die Beiträge in Kramer, J. (1993) sowie Wildasin, D.E. (1996).

Aristoteles (1989), S. 238.

De Tocqueville, A. (1955), S. 131.

Pius XI, zitiert nach Süsterhenn, A. (1956/1969), S. 15f.

Abraham Lincoln, zitiert nach Schmölders, G. (1970), S. 42. 


\section{Subsidiaritätsprinzip und Föderalismus als Probleme der Politischen Ökonomie}

Die ökonomische Theorie ist in den letzten Jahren zunehmend von der Einsicht geprägt, daß die Analyse institutioneller Rahmenbedingungen der wirtschaftlichen und sozialen Prozesse Kernbestandteil ihres wissenschaftlichen Erkenntnisinteresses sein sollte. Dahinter steht die Überzeugung, daß alles menschliche Handeln durch die Präferenzen der Individuen einerseits und durch ihre Handlungsrestriktionen andererseits bestimmt wird und daß daher die Gestaltung der institutionellen Ordnung von fundamentaler Bedeutung für die Ergebnisse ökonomischer und politischer Entscheidungen ist: "institutions matter!"8

Diese Entwicklung steht in der intellektuellen Tradition der "Politischen Ökonomie", wie sie von Smith, Mill und Ricardo vertreten wurde. ${ }^{9}$ Dabei untersucht die Politische Ökonomie im heutigen Verständnis explizit die Zusammenhänge von politischen, soziologischen und ökonomischen Faktoren - im Gegensatz zur Nationalökonomie der 1950er und 1960er Jahre, die die nichtökonomischen Aspekte nur als exogen festgelegten Datenkranz interpretierte. ${ }^{10}$

Eine Konsequenz des wiedererstarkten wirtschaftswissenschaftlichen Interesses an der Analyse des gesellschaftlichen Ordnungsrahmens ist die Anwendung der ökonomischen Denkweise auf traditionell der Politik- oder der Rechtswissenschaft zugeordnete Fragestellungen. Zum Bereich der Schnittmenge dieser wissenschaftlichen Disziplinen gehört auch die Föderalismusforschung. Die Aussagen von Aristoteles, De Tocqueville, Lincoln und Pius XI belegen, daß das Problem der optimalen Gliederung eines Staatswesens schon seit jeher einen zentralen Aspekt gerade der (politischen) Philosophie bildet, und wohl kaum ein anderer Terminus wurde dabei mehr strapaziert als das oben zitierte Subsidiaritätsprinzip. ${ }^{11}$

Tatsächlich ist jedoch dessen Aussagekraft im Hinblick auf die Beantwortung der Frage nach der Zuordnung von Kompetenzen auf staatliche Ebenen äußerst eingeschränkt. ${ }^{12}$ Das Subsidiaritätsprinzip ist allem Anschein nach ohne eine weitere Interpretationshilfe nur eine inhaltslose Leerformel und liefert für sich genommen keine brauchbare Handlungsanweisung für die Organisation eines politischen Systems. ${ }^{13}$ Das liegt zum einen an den mit dem Begriff verbundenen Ambiguitäten und zum anderen daran, daß auch im wissenschaftlichen Verständnis unklar ist, inwieweit Subsidiarität als Individual- versus Gruppenprinzip und/oder als Territorialprinzip der Verfassungsgestaltung aufzufassen ist. ${ }^{14}$ Es verwundert daher nicht, daß es sowohl den Gegnern als auch den Befürwortern einer Zentralisierung von Zuständigkeiten als

8 Furubotn, E.G./Richter, R. (1984), S. 2. Siehe etwa auch Frey, B.S. (1990), S. 4 ff.

9 Vgl. Buchanan, J.M. (1990), S. 9ff.

10 Vgl. Bernholz, P./ Breyer, F. (1994), S. 2.

11 Dieses vielzitierte Grundprinzip der Katholischen Soziallehre hat auch in Art. 3b Satz 2 des EU-Vertrags Eingang gefunden. Dort heißt es: "In den Bereichen, die nicht in ihre ausschließliche Zuständigkeit fallen, wird die Gemeinschaft nach dem Subsidiaritătsprinzip nur tătig, sofern und soweit die Ziele der in Betracht gezogenen Maßnahmen auf Ebene der Mitgliedsstaaten nicht ausreichend erreicht werden können und daher wegen ihres Umfangs oder ihrer Wirkungen besser auf Gemeinschaftsebene erreicht werden können."

12 So die ubereinstimmende Auffassung in Politologie, Ökonomik und Rechtswissenschaft. Vgl. Frenkel, M. (1986), S. 112, Vaubel, R. (1993), S. 3ff. und Easterbrook, F.H. (1994), S. 126.

13 Es wäre deshalb erst zu ermitteln, worin die "verschiedenen Vorteile, ... die den Volkern aus ihrer Großße und aus ihrer Kleinheit erwachsen" (De Tocqueville), bestehen, welches die "larger works" und die "smaller ones" (Lincoln) sind und welche Aufgaben "die kleineren und untergeordneten Gemeinwesen leisten und zum guten Ende fuhren" (Pius XI) können.

14 Vgl. etwa Sturm, R. (1995), S. 57. 
Rechtfertigung offensichtlich völlig konträrer Positionen dient. ${ }^{15}$ Im weiteren Verlauf der Arbeit soll aus diesem Grunde auch vom Begriff Subsidiaritätsprinzip kein Gebrauch gemacht werden.

Es mag überraschen, daß zwar in Rechts-, Politik- und Wirtschaftswissenschaft die Vorzüge eines föderativen Staatsaufbaus nahezu einmütig betont werden, daß aber die konkreten inhaltlichen Zielvorstellungen, die mit einem föderativ organisierten Staatswesen verfolgt werden sollen, z.T. beträchtlich voneinander abweichen. Entsprechend differieren die Definitionen, was in den verschiedenen Disziplinen unter Föderalismus verstanden wird. Es sei deshalb im folgenden ein kurzer Blick auf die unterschiedlichen Auffassungen geworfen.

\section{Föderalismus als Gegenstand unterschiedlicher Wissenschaftsdisziplinen}

\section{Föderalismus in der Staatsrechtslehre}

Ausgangspunkt der Staatsrechtslehre ist die Gegenüberstellung von Bundesstaat (Föderation), Staatenbund (Konföderation) und Einheitsstaat. Dabei wird der Bundesstat definiert als eine "... staatsrechtliche Verbindung von Staaten, bei der die Mitglieder Staaten bleiben oder werden (Gliedstaaten) ... und die Verbindung selbst auch ein Staat wird oder bleibt (Gesamtstaat)." 16 Im Unterschied zur völkerrechtlichen Konstruktion des Staatenbundes ist der Bundesstaat durch einheitliches staatliches Verfassungsrecht verbunden. Gemeinsames Merkmal aller staatsrechtlichen Bundesstaatsdefinitionen ist die, allerdings nicht unbedingt mit dem Gesamtstaat gleichrangige, Eigenstaatlichkeit der Gliedstaaten. ${ }^{17}$ Hierin liegt die Abgrenzung zum Einheitsstaat, dessen Glieder nur unselbständige Verwaltungsbezirke sind. ${ }^{18}$

Die Staatsrechtslehre sieht die Funktionen des Bundesstaates einem Wandel unterworfen. Historisch sei die Hauptfunktion des bundesstaatlichen Prinzips der "Schutz einer gewissen Eigensphäre" 19 meist vormals eigenständiger Staaten, die sich zu einer Föderation zusammengeschlossen haben. Moderne Begründungen für einen bundesstaatlichen Aufbau 20 bestehen nach Auffassung des Staatsrechtlers Münch in der Verbesserung der politischen Mitgestaltungsmöglichkeiten der Bürger im Staat, in der verstärkten Kontrolle politischer Macht durch vertikale Gewaltenteilung, in einer höheren Sachnähe von Entscheidungen auf dezentraler Ebene und in der Schaffung von Wettbewerb zwischen den gliedstaatlichen Einheiten. ${ }^{21}$

\section{Föderalismus in der Politologie}

Die Beschäftigung mit dem föderativen Staatsaufbau hat in der Politikwissenschaft eine lange Tradition, die von Montesquieu und de Toqueville bis hin zu modernen Vertretern wie Riker,

15 Vgl. Bohley, P. (1993), S. 36f. und Donat, M. von (1995), S. 9.

16 Münch, I. von (1993), S. 196. Im Original teilweise fett und kursiv.

17 Vgl. Münch, I. von (1993), S. 198. Die verschiedenen staatsrechtlichen Lehren vom Bundesstaat speziell fur die Bundesrepublik Deutschland werden kurz erlăutert in Stein, E. (1993), S. 112ff. Im juristischen Foderalismusverstăndnis sind die Gemeinden keine dritte Staatsebene.

18 Vgl. Stein, E. (1993), S. 112.

19 Münch, I. von (1993), S. 207.

20 Zum Subsidiaritătsprinzip als Grundlage fur einen foderativen Staatsaufbau aus juristischer Perspektive siehe auch Isensee, $J$. (1990).

21 Vgl. Münch, I. von (1993), S. 207f. 
Elazar, Ostrom und Beer reicht.22 Zentrales Element ist die Lehre von der Gewaltentrennung, nach der politische Freiheitsrechte der Bürger vor staatlichen Übergriffen nur gesichert seien, wenn die Ausübung der legislativen, exekutiven und richterlichen Hoheitsbefugnisse von verschiedenen, sich gegenseitig kontrollierenden Personen(gruppen) wahrgenommen werde. ${ }^{23}$ Grundgedanke eines föderativen Systems ist, daß das Prinzip der strikten horizontalen Gewaltenteilung durch eine vertikale Trennung der Hoheiten auf unterschiedliche Ebenen im Staat verstärkt werde, um eine doppelte Sicherung der individuellen Freiheitsrechte zu erreichen. ${ }^{24}$

Wie die Staatsrechtslehre betont auch die politische Wissenschaft die Notwendigkeit der verfassungsmäßigen Absicherung der vertikalen Gewaltentrennung, denn nur die nahezu unwiderrufliche föderative Machtaufteilung "... constitutes a safeguard of liberty that is missing from unitary systems because the latter can give to the decentralization of power no exceptional protection."25 Die konstitutionelle Verankerung der Hoheitsrechte unterschiedlicher staatlicher Ebenen markiert im politologischen Föderalismusverständnis den Unterschied zur Konföderation und zum Einheitsstaat. ${ }^{26}$ Konföderale Gebilde beruhen danach auf der einseitigen Delegation von Funktionen durch die Mitgliedsstaaten an die übergeordnete Ebene. Sie sind mithin dadurch gekennzeichnet, daß die Zentralautorität nicht 'über die Bürger der Mitgliedstaaten', sondern 'über die Gliedstaaten selbst' regiert, die dem Zentralgebilde die zugewiesenen Kompetenzen jederzeit wieder entziehen können. ${ }^{27}$ Den Gegenpol bildet der unitarische Staat, bei dem die Kompetenz zur Dezentralisierung von Verantwortlichkeiten nur der gebietskörperschaftlichen Zentralebene zugeordnet ist. Unter einem föderativen System wird dann eine Organisationsform des Staates verstanden, bei der die Bürger gleichzeitig mehreren Regierungen unterstehen, zwischen denen die staatlichen Funktionen aufgeteilt sind.

\section{Föderalismus in der traditionellen Ökonomik}

Auch die ökonomische Theorie als drittes Glied der klassischen Staatswissenschaften hat sich insbesondere seit Beginn der 1950er Jahre wieder verstärkt der Analyse föderativer Staatswesen gewidmet. Während in älteren finanzwissenschaftlichen Beiträgen v.a. praxisnahe Fragestellungen im Vordergrund standen ${ }^{28}$, ist in neueren ökonomischen Arbeiten eine Hinwendung zur theoretischen Analyse föderativer Staatssysteme festzustellen. Das klassische Begriffsverständnis des Föderalismus in der ökonomischen Theorie stammt von Oates. Er definiert ein föderatives System als

22 Montesquieu, C.L. (1951); de Toqueville, A. (1955); Riker, W.H. (1964); Ostrom, V. (1971); Beer, S.H. (1977); Elazar, D.J(1984).

23 Vgl. etwa Kluxen, K. (1957/1969), S. 131.

24 Vgl. z.B. Rosenfeld, M. (1993), S. $245 \mathrm{ff}$.

25 Beer, S.H. (1977), S. 22.

26 "Federalism as constitutional decentralization differs from federalism as contingent decentralization in that the authority of the states under constitutional decentralization is guaranteed as a matter of organic, constitutional law." Aranson, P.H. (1990), S. 20. (Hervorhebungen im Original)

27 Vgl. Riley, P. (1973), S. 94.

28 Besondere Bedeutung hat dabei das Popitz'sche Gesetz erlangt. Siehe Popitz, A. (1929). 
"a public sector with both centralized and decentralized levels of decision-making in which choices are made at each level concerning the provision of public services of the residents (and perhaps others who carry on activities) in the respective jurisdiction." 29

Die für Rechts- und Politikwissenschaft zentralen Probleme der Machtbegrenzung im Staat spielen bei den rein ökonomischen Betrachtungen des Föderalismus traditionell keine Rolle. Aus ökonomischer Perspektive existieren bei Bereitstellungsentscheidungen über öffentliche Leistungen bestimmte Vorteile dezentraler Verantwortlichkeiten (insbesondere die auch in der Staatsrechtslehre betonte höhere Sachnähe) bzw. zentraler Zuständigkeiten (Skalenvorteile und Internalisierung externer Effekte); die Gegenüberstellung der Nutzen und Kosten der Bereitstellung in verschieden großen Entscheidungskollektiven definiert dann deren optimale Größe. Ein föderativer Staatsaufbau ist damit Ergebnis eines Optimierungskalküls, das für unterschiedliche staatliche Leistungen verschieden große effiziente Bereitstellungskollektive prognostiziert.

Der ökonomische Ansatz zur Föderalismustheorie weicht insoweit vom rechts- und politikwissenschaftlichen Föderalismusverständnis ab. Dezentrale Kompetenzen sind kein festgeschriebenes Element der Staatsverfassung, sondern Aktionsparameter zur Realisierung wohlfahrtsmaximierender Strukturen. Aus Sicht des Politikwissenschaftlers Beer ist daher "Oates ... not talking about federalism but about the larger subject of multilevel government." 30

\section{Ziel der Arbeit}

Gleichwohl sind der ökonomische Ansatz und der politologische bzw. staatsrechtliche Ansatz nicht unvereinbar. Mit Entwicklung der "Konstitutionellen Ökonomik"31 hat das Problem der Machtbegrenzung im Staat durch die Gestaltung der Verfassung auch Einzug in die ökonomische Disziplin gehalten. Der positive Zweig dieser Richtung geht der Frage nach, wie die Handlungen der Individuen von ökonomischen und politischen Rahmenbedingungen beeinflußt werden, die normativ ausgerichtete konstitutionelle Ökonomik sucht aus den Erkenntnissen der positiven Theorie Schlüsse für die optimale Gestaltung des institutionellen Rahmens zu ziehen. Konstitutionelle Politische Ökonomie versteht sich als eine Ordnungstheorie für den öffentlichen Sektor. 32

In der vorliegenden Arbeit soll versucht werden, die Prinzipien der normativen konstitutionellen Ökonomik auf die Frage nach der optimalen föderalen Gliederung des Staates anzuwenden. Dabei wird die Absicht verfolgt, Vorschläge für ein Finanzverfassungs-Regelsystem zu entwickeln, das sowohl dem politischen Ziel der Machtbegrenzung als auch dem ökonomischen Ziel der Kostenminimierung gerecht wird.

Nach Schmölders ist die Finanzverfassung eines Staates der "... Inbegriff aller rechtlichen Normen, die für die öffentliche Finanzwirtschaft im ganzen, in Einnahmen und Ausgaben, gelten." 33 Der hier verwendete Begriff der Finanzverfassung umschließt auch die politische

29 Oates, W.E. (1972), S. 17.

30 Beer, S.H. (1977), S. 22.

31 Als deren wichtigster Vertreter gilt Buchanan. Siehe auch dessen Beitrag "Constitutional Economics" (1987a) in "The New Palgrave".

32 Vgl. Kirchgässner, G. (1988), S. 69ff.

33 Schmölders, G. (1970), S. 16. 
Verfassung und bezieht insbesondere die Regeln mit ein, nach denen im Staat Entscheidungen getroffen werden (sollen). ${ }^{34}$ Aufgrund dieser umfassenden Themenstellung können einige Fragen, die im Zusammenhang mit einer polit-ökonomischen Analyse des Föderalismus möglicherweise erwartet werden, nicht oder nur am Rande behandelt werden; insbesondere findet die Dynamik föderativer Zusammenschlüsse im Popitz'schen Sinne keine explizite Berücksichtigung. 35

Die Integration zu einer geschlossenen Theorie kann jedoch nur fruchtbar sein, wenn es gelingt, die Vor- und Nachteile föderativer Strukturen aus Sicht verschiedener Disziplinen mit einem einheitlichen Instrumentarium zu erfassen. Die Transaktionskostenökonomik, urprünglich als Teilbereich der modernen Industrieökonomie entwickelt, hat hierzu wertvolle Vorarbeit geleistet, weil sie die Kosten opportunistischen Verhaltens in Interaktionsbeziehungen (hier: in der Machtbeziehung der staatlichen Akteure zu den Bürgern) explizit in ihre Analysen einbezieht. Auf die dort erarbeiteten Konzepte wird deshalb im Verlauf der Arbeit häufig zurückgegriffen.

\section{B. Vorgehensweise}

Die weitere Vorgehensweise kann folgendermaßen präzisiert werden: Im 2. Kapitel wird zunächst die Frage diskutiert, welche generellen Probleme mit der ökonomischen Analyse von Institutionen und Organisationen verbunden sind. Es soll aufgezeigt werden, wie sich aus ökonomischer Sicht das Problem der Koordination menschlicher Interaktionen darstellt, und welche Einflußfaktoren die Wahl der Koordinationsform bestimmen. Im Anschluß an diese allgemeinen Darlegungen erfolgt die Anwendung der herausgearbeiteten Kriterien auf die Organisation Staat. Dem liegt die Überlegung zugrunde, daß ohne eine Konkretisierung der mit der Gründung eines Staates verbundenen Zielvorstellungen und Probleme die ökonomischen und politischen Rechtfertigungen föderativer Staatsstrukturen nicht vollständig erfaßt würden. Es soll deshalb dargestellt werden, wie das Erfordernis staatlichen Handelns begründet wird, um danach mit Hilfe des institutionenökonomischen Instrumentariums die Notwendigkeit der Begrenzung staatlicher Macht zu erörtern. Diese Schritte bilden die Grundzüge einer polit-ökonomischen Theorie des Staates, die im 2. Kapitel skizziert wird.

Im 3. Kapitel wird die traditionelle ökonomische Theorie des Föderalismus aufgearbeitet, in der das Problem der Beschränkung staatlicher Macht noch keine explizite Rolle spielt. In einem ersten Schritt werden dabei Einflußfaktoren diskutiert, die die optimale Größe eines Staates als Durchsetzungsinstanz des Privatrechts ("protektiver Staat" ${ }^{36}$ ) bestimmen. Im Anschluß wird, ausgehend von der allokations-, stabilisierungs- und distributionspolitisch begründeten Notwendigkeit staatlicher Aktivitäten, hinterfragt, welche unterschiedlichen Ergebnisse aus der Zuweisung von Entscheidungsverantwortlichkeiten auf subzentrale bzw. zentrale Ebenen im "produktiven Staat" 37 resultieren. Die Vorgehensweise besteht darin, daß sukzessive die unter dem Oberbegriff "Fiscal Federalism" 38 meist unverbunden nebeneinan-

$34 \mathrm{Zu}$ dieser weiten Interpretation des Begriffs der Finanzverfassung aus okonomischer Perspektive siehe Brennan, G. (1984), S. 124. Vgl. auch West, E.G./Corke, C. (1980), S. 399f.

35 Siehe hierzu etwa Hansmeyer, K.-H. (1967) oder speziell für die Europăische Union Vaubel, R. (1992).

36 Buchanan, J.M. (1975/1984), S. 97.

37 Buchanan, J.M. (1975/1984), S. 97.

38 Oates, W.E. (1972). 
der stehenden Einzelansătze in ein transaktionskostentheoretisch fundiertes Gesamtmodell überführt werden. In einer ausführlichen Diskussion werden allgemeine Faktoren ermittelt, die aus der Sicht der Theorie des Fiskalföderalismus für die Ausgestaltung der Finanzverfassung von Bedeutung sind. Dabei soll gezeigt werden, daß selbst bei einer Vernachlässigung auftretender Machtprobleme föderative Entscheidungsstrukturen im Staat sinnvoll sein können.

Die politische Dimension des Staatsaufbaus wird im 4. Kapitel einbezogen. Das analytische Instrumentarium zur Untersuchung dieser Fragestellungen liefert die Public Choice-Theorie. Ausgangspunkt ist die Überlegung, daß durch demokratische Entscheidungsbeteiligung der Bürger eine Begrenzung staatlicher Macht erreicht werden kann. Dabei werden, zunächst ohne konkreten Bezug auf die jeweilige staatliche Ebene, die politischen Entscheidungsprozesse in einer indirekten Demokratie untersucht. Im Anschluß daran wird in einer theoretischen Analyse demokratischer Entscheidungen im föderativen Staat diskutiert, wie föderative Strukturen die Erfolgsaussichten des politischen Widerspruchs (voice) im Vergleich zum unitarisch aufgebauten Staat verändern. Aus der positiv-theoretischen Untersuchung sollen normative Rückschlüsse für das im 3. Kapitel abgeleitete Gesamtmodell gezogen werden.

Im dezentralen System ist die Möglichkeit einer Begrenzung staatlicher Macht nicht nur auf den politischen Widerspruch beschränkt, sondern kann auch durch Abwanderung (exit) aus dem fiskalischen Hoheitsgebiet der subzentralen Regierungen erfolgen. Kapitel 5 beschäftigt sich zunächst isoliert mit der Wirkungsweise der Abwanderungsoption als Reaktion auf Fehlentwicklungen im Staat. Es wird der Frage nachgegangen, inwieweit sich durch 'räumliche politische Mobilität' zwischen dezentralen Einheiten in einem System des Wettbewerbsföderalismus eine Begrenzung der Opportunismusgefahren staatlichen Handelns erreichen läßt. Die Möglichkeit der Abwanderung beeinflußt aber voraussichtlich auch die Erfolgschancen des politischen Widerspruchs, so daß im Anschluß daran untersucht wird, wie durch das Zusammenwirken der beiden Mechanismen exit und voice die wahrscheinlichen Ergebnisse politischer Prozesse verändert werden. Abschließend werden die sich daraus ergebenden Implikationen für die Gestaltung der Finanzverfassung diskutiert.

Im 6. Kapitel sollen aus den Ergebnissen der vorangegangenen Kapitel einige normative Schlußfolgerungen fur die optimale Gestaltung des Staatsaufbaus gezogen werden. Hierzu werden zunächst die zentralen Gemeinsamkeiten und Unterschiede der dargestellten Theorieansătze hervorgehoben. Im Anschluß erfolgt eine knappe Skizzierung der Regeln einer hypothetischen Finanzverfassung, wie sie sich aus den angestellten Überlegungen ableiten läßt. Abschließend sollen die Erfolgsaussichten einer konstitutionellen Radikalreform kurz diskutiert werden. 
Hans Pitlik - 978-3-631-75479-5

Downloaded from PubFactory at 01/11/2019 04:28:26AM

via free access 


\section{Kapitel: Der Staat als Organisation: Grundzüge einer polit-ökonomischen Theorie des Staates}

\section{A. Die Logik ökonomischer Organisationen}

\section{Die ökonomische Organisationstheorie}

\section{Das Erkenntnisinteresse der Neuen Institutionenökonomik}

Ausgangspunkt der ökonomischen Institutionentheorie ist die Feststellung, daß die Knappheit von Ressourcen - der Kern aller ökonomischen Probleme - eine Arbeitsteilung vorteilhaft macht. ${ }^{1}$ Zugleich erfordert die Spezialisierung ein System von Regeln, nach denen sich die Leistungsbeziehungen zwischen den Individuen einer Gesellschaft in einem ordnenden Rahmen vollziehen können. ${ }^{2}$

Die Analyse der gesellschaftlichen Rahmenbedingungen des menschlichen Handelns hat in der ökonomischen Theorie eine lange Tradition. ${ }^{3}$ Im Zentrum des Erklärungsinteresses der klassischen Ökonomik (Smith, Mill) stand die Frage, wie menschliches Verhalten durch institutionelle Gegebenheiten in bestimmte Richtungen kanalisiert wird. ${ }^{4}$ Auch in der Folgezeit wurde der Untersuchung der Institutionen des ökonomischen Handelns von der Älteren (Roscher) und der Neueren Historischen Schule (Schmoller), dem Amerikanischen Institutionalismus (Commons), der Österreichischen Schule (von Hayek) und der deutschen Ordoliberalen Schule (Eucken) Aufmerksamkeit gewidmet.

Trotz dieser Vielfalt unterschiedlicher Ansätze blieb die Neoklassik von Marshall und Walras seit ihrem Entstehen gegen Ende des 19. Jahrhunderts dominierendes Paradigma in den Wirtschaftswissenschaften. Im Gegensatz zu den genannten Vorläufern der modernen Organisationsökonomik behandeln die neoklassischen Ansätze den institutionellen Rahmen des menschlichen Handelns lediglich als Datum ${ }^{5}$, was ihnen den Vorwurf eingebracht hat, in einem "institutionellen Vakuum"6 $\mathrm{zu}$ argumentieren. ${ }^{7}$

Erst in jüngerer Zeit sind mit der Entwicklung der Neuen Institutionenökonomik ${ }^{\mathbf{8}}$ die Abkehr von der für die Neoklassik typischen Untersuchung ökonomischen Handelns innerhalb einer vorgegebenen rechtlich-institutionellen Struktur und eine Rückbesinnung auf die Analyse der

1 Vgl. Picot, A. (1991), S. 105.

2 "... if we are to realize the benefits of specialization, we must have some structure of rules that allows the billions of people scattered around the world to interact with each other in a cooperative way." Lee, D.R./McKenzie, R.B. (1987), S. 17.

3 Zu einem knappen Überblick siehe etwa Feldmann, H. (1995).

4 Vgl. Elsner, W. (1986), S. $1 \mathrm{ff}$.

5 Vgl. Schüller, A. (1983a), S. VIII; Furubotn, E.G./Richter, R. (1991), S. 2.

6 Hartwig, K.-H. (1988), S. 34.

7 "It is as if one studied the circulation of the blood without having a body." Coase, R.H. (1984), S. 230.

8 Die Begriffsschöpung "New Institutional Economics" wird Williamson zugeschrieben. Siehe Williamson, O.E. (1975), S. 1. Zum Begriff der "New Institutional Economics" siehe auch Coase, R.H. (1984); Williamson, O.E. (1985); North, D.C. (1986). Zur Unterscheidung von neuem und altem Institutionalismus siehe Hutchison, T.W. (1984) und Reuter, N. (1994). 
Rahmenbedingungen sozialer Interaktionen der Menschen festzustellen. ${ }^{9}$ Im Zentrum des Erkenntnisinteresses der Neuen Institutionenökonomik stehen die folgenden Fragen: 10

- Wie beeinflussen alternative soziale Regelsysteme die ökonomischen Ergebnisse?

- Weshalb gibt es für verschiedene ökonomische Aktivitäten unterschiedliche Regelsysteme?

- Welche ökonomische Logik steht hinter den unterschiedlichen Regelungen?

Freilich stellt die Neue Institutionenökonomik bis heute kein einheitliches Theoriegebäude dar. ${ }^{11}$ Unter dem Begriff 'Ökonomische Institutionenanalyse' werden in der einschlägigen Literatur ${ }^{12}$ unterschiedliche Ansätze wie die 'Neue Politische Ökonomie', die 'Ökonomische Analyse des Rechts' oder die 'Theorie der Firma' subsumiert. Gleichwohl ist diesen Ansätzen gemeinsam

"1) that the theoretical framework should be capable of integrating neo-classical theory with an analysis of the way institutions modify the choice set available to human beings; and 2) that this framework must build upon the basic determinants of institutions, so that we can not only define the choice set really available to people at any time, but also analyze the way in which institutions change ..."13

Mithin sind die Unterschiede zwischen den einzelnen Theorievarianten nicht grundsätzlicher Art, sie liegen vielmehr bei der Akzentuierung in der Auswahl der Forschungsobjekte und der $\mathrm{zu}$ untersuchenden Institutionen. $\mathrm{Zu}$ nennen wären etwa die Anwendung der ökonomischen Analyse auf politikwissenschaftliche Fragen (Theorien des Staates, des Wahlverhaltens, der Bürokratie), auf Fragen der Rechtsprechung und Gesetzgebung oder auf die Erklärung und die Entwicklung wirtschaftlicher und sozialer Institutionen wie Märkte, Unternehmungen und Gewerkschaften. ${ }^{14}$ Nach Tietzel zählen deshalb alle Forschungsbereiche zur Neuen Institutionenökonomik, die sich mit der Entstehung, Geltung und Wirkung von Regeln, denen mehrere Individuen in wiederholten Entscheidungssituationen folgen, befassen. ${ }^{15}$

\section{Die Begriffe der "Institution" und der "Organisation"}

Auch wenn die Neue Institutionenökonomik auf prominente Vorläufer und eine längere Entstehungsgeschichte zurückblicken kann, herrscht nach wie vor keine Einigkeit darüber, wie der Begriff der Institution inhaltlich konkretisiert werden kann. Mit Richter, als einem der führenden Vertreter dieses Forschungsansatzes, soll hier eine Institution definiert werden als

9 Albert spricht in diesem Zusammenhang von der "institutionalistischen Revolution" der økonomischen Theorie. Albert, H. (1977), S. 203.

10 Siehe z.B. Eggertsson, T. (1990), S. 4f.

11 Vgl. Picot, A. (1991), S. 105.

12 Siehe z.B. Boettcher, E. (1983); Furubotn, E.G./Richter, R. (1984); Buchanan, J.M. (1987a); Eggertsson, T. (1990); Richter, R. (1990a); (1990b) und (1994); Tietzel, M. (1991), S. 17ff.

13 North, D.C. (1986), S. 230. Ebenso Eggertsson, T. (1990), S. 7ff. oder Furubotn, E.G./Richter, R. (1991), S. 1. Die neoklassische Fundierung unterscheidet die 'neue' von der 'alten', theorielosen und deskriptiven

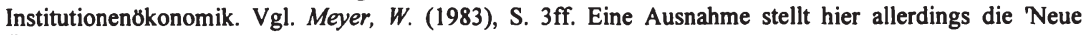
Österreichische Schule' dar, die ebenfalls zur Neuen Institutionenઠkonomik gezahlt wird, die neoklassische Konzeption jedoch fundamental kritisiert.

14 Siehe Richter, R. (1990b), S. 71.

15 Vgl. Tietzel, M. (1991), S. 5. 
"... auf ein bestimmtes Zielbündel abgestelltes System von Normen einschließlich deren Garantieinstrumente, mit dem Zweck, das individuelle Verhalten in eine bestimmte Richtung zu steuern." 16

Institutionen sind zweckorientierte Regelsysteme, die die Aktivitäten mehrerer Individuen so koordinieren, daß deren Pläne und Verhaltensweisen der Realisierung ex ante definierter Ziele dienen. Sie bestehen aus informellen Beschränkungen, formal kodifizierten Regeln und Sanktionsmechanismen, die ein bestimmtes Verhalten der Individuen bei sich wiederholenden Entscheidungen induzieren ${ }^{17}$ und so das Leben der Menschen strukturieren und dessen Unsicherheiten reduzieren. ${ }^{18}$ Bei dieser Definition bleibt allerdings offen, wie das regelgebundene Verhalten der Individuen erreicht wird. Frey unterscheidet deshalb zwischen (i) Entscheidungssystemen, (ii) Normen, Traditionen und anderen Konventionen und (iii) Organisationen als Formen institutioneller Arrangements. ${ }^{19}$

Folgt man Frey, so sind Organisationen mithin nur eine mögliche Erscheinungsform von Institutionen, alle drei genannten Formen stehen aber meist in einem untrennbaren Zusammenhang. ${ }^{20}$ Zur Abgrenzung gegenüber dem Überbegriff der Institution wird von Organisationen nach herrschender Meinung nur gesprochen, wenn zur Zweckgerichtetheit des Normensystems als weitere Merkmale hinzutreten

- dauerhafte, arbeitsteilige Mitgliedschaftsbeziehungen. ${ }^{21}$ Die Mitgliedschaft unterscheidet Organisationen von anderen Institutionen, die den Individuen lediglich zur Benutzung zur Verfügung stehen. Organisationen sind insofern "korporative Gebilde"22 und weisen neben informellen Beziehungen auch formale, bewußt geschaffene Beziehungen zwischen den Organisationsmitgliedern auf. 23

- eine zentrale Leitungsinstanz, der die Vertretung des Zusammenschlusses nach innen und nach außen obliegt. ${ }^{24}$

Damit handelt es sich bei Organisationen um zweckgerichtete, auf Dauer angelegte, bewußt entworfene und arbeitsteilige Zusammenschlüsse von Individuen (Organisationsmitgliedern), die unter einer zentralen Koordinationsinstanz institutionelle Arrangements zur Erleichterung kollektiven Handelns schaffen. 25

16 Richter, R. (1994), S. 2. Vgl. auch Schotter, A. (1981), S. 11 oder Elsner, W. (1986), S. $198 \mathrm{ff}$.

17 Vgl. Elsner, W. (1986), S. 199ff. und (1987), S. 5 und North, D.C. (1989), S. 239.

18 Vgl. Richter, R. (1994), S. 2.

19 Vgl. Frey, B.S. (1990), S. 2 f.

20 Vgl. Frey, B.S. (1990), S. 3 und auch North, D.C. (1990/1992), S. 5.

21 Vgl. Boettcher, E. (1983), S. 9.

22 Vanberg, V. (1983), S. 55.

23 Vgl. dazu Hayek, F.A. von (1969), S. 41 f. und S. 212f. sowie Eschenburg, R. (1977), S. 5. Nach Hayek sind die "Regeln, die das Handeln innerhalb einer Organisation leiten, ... Regeln fur die Durchfuhrung zugewiesener Aufgaben ..." Im Gegensatz dazu sind "Regeln, die eine spontane Ordnung lenken, unabhăngig von einem Zweck ... und auf eine unbekannte und unbestimmte Anzahl von Personen und Fällen anwendbar." Hayek, F.A. von (1980), S. $72 \mathrm{f}$.

24 Vgl. Büschges, G. (1983), S. 21f.

25 Vgl. Arrow, K.J. (1974), S. 25ff.; North, D.C. (1990/1992), S. 5. 


\section{Methodologische Grundlagen der ökonomischen Analyse von Organisationen}

\section{Die verhaltenstheoretischen Annahmen der Neuen Institutionenökonomik}

Das analytische Instrumentarium der Neuen Institutionenökonomik wird in weiten Teilen von der neoklassischen Analyse übernommen. So wird auch beispielsweise die Verwendung des Marginalkalküls von den meisten Vertretern beibehalten, allerdings werden bestimmte Annahmen der Neoklassik modifiziert:26

- Allein maßgebende Handlungseinheit ist das Individuum. Organisationen handeln nicht als organische Einheit, Kollektiventscheidungen sind vielmehr das Ergebnis von Interaktionen der einzelnen Mitglieder des Kollektivs (methodologischer Individualismus). ${ }^{27}$

- Unabhängig davon, unter welchen Nebenbedingungen die Menschen ihre Entscheidungen treffen, ist ihr Handeln stets auf individuelle Nutzenmaximierung gerichtet. ${ }^{28}$ In Erweiterung des neoklassischen Denkens betont die Institutionenökonomik aber, daß die Ausrichtung auf das Eigeninteresse auch die Zuhilfenahme von List, Täuschung und bewußter Informationsverzerrung impliziert (Eigennutzmaximierung und Opportunismus). ${ }^{29}$ Die Präferenzen der Individuen sind exogene Faktoren und werden als konsistent und stabil angenommen. 30

- Ein zentraler Aspekt der modernen Institutionenökonomik liegt in der Betonung, daß Information nicht kostenlos ist. ${ }^{31}$ Im Hinblick auf das zweckrationale Verhalten der Menschen haben sich daraus zwei verschiedene Ansichten entwickelt. ${ }^{32}$ Die Annahme der 'begrenzten Rationalität' unterstellt, daß sich die Individuen lediglich intendiert rational und aufgrund ihrer beschränkten Informationsverarbeitungskapazität deshalb nicht stets zielgrößenmaximierend verhalten. ${ }^{33}$ Der neoklassischen Analyse näherstehend ist der zweite Ansatz, der von Eggertsson als "Neoinstitutional Economics"34 bezeichnet wird. Hier wird die Annahme des hyperrationalen, zielgrößenmaximierenden Menschen beibehalten; allerdings werden kostenbedingte Informationsbeschränkungen explizit in die

26 Vgl. dazu den Überblick bei Furubotn, E.G./Richter, R. (1991), S. 4f.

27 "Organizations do not have preferences and they do not choose in the conscious and rational sense that we attribute to people... The behavior of the organization is the equilibrium behavior of a complex contractual system made up of maximizing agents with diverse and conflicting objectives... Construction of a theory of organizations involves creating a theory ... where the individual agent is the elementary unit of analysis." Jensen, M.C. (1983), S. 327.

28 Allein durch symmetrische Verhaltensannahmen unabhängig von den institutionellen Rahmenbedingungen wird der Forderung nach methodologischer Konsistenz der Analyse Rechnung getragen; siehe Brennan, G./Buchanan, J.M. (1985/1993), S. 65ff.

29 Vgl. Williamson, O.E. (1985/1990), S. 54. In der Literatur findet sich hierfur auch oft der Begriff 'shirking'. Siehe Alchian, A.A./Demsetz, H. (1972); Eggertsson, T. (1990), S. 41.

30 Vgl. Richter, R. (1990a), S. 573.

31 Grundlegend hierzu Hayek, F.A. von (1945) und Stigler, G.J. (1961).

32 Siehe etwa den Überblick bei Williamson, O.E. (1985/1990), S. 50ff.

33 Vielmehr wird angenommen, die Menschen streben lediglich ein 'befriedigendes Niveau' an: sie verhalten sich 'satisfizierend'. Zum 'satisficing' siehe die Arbeit von Simon, H. (1957).

34 Eggertsson, T. (1990), S. 6 (Hervorhebung H.P.). 
Analysen einbezogen. ${ }^{35}$ Dem letztgenannten Ansatz soll im Rahmen dieser Arbeit, aus Gründen der einfacheren formalen Handhabung, der Vorzug gegeben werden.

Der so beschriebene Mensch wird häufig als "REMM"36 bezeichnet, der vernunftbegabt ist ('resourceful'), seine Bedürfnisse und Präferenzen subjektiv bewertet ('evaluative') und die Alternative wählt, die ihm einen maximalen Gesamtnutzen stiftet ('maximizing man'). 37

\section{Die Analyseinstrumente der Neuen Institutionenökonomik}

\section{a. Verfügungsrechte}

Von zentraler Bedeutung für die ökonomische Analyse von Institutionen sind die Begriffe des Verfügungsrechts (property right), des Vertrages und der Transaktionskosten. Mit Hilfe dieser drei Elemente können Aussagen über die zieladäquate Gestaltung institutioneller Designs gemacht werden. Im folgenden sollen daher die Konzepte kurz vorgestellt und ihre Bedeutung für die institutionellen Regelungen aufgezeigt werden.

Ausgangspunkt der Überlegungen zur Theorie der Verfügungsrechte ${ }^{38}$ ist die Abkehr vom physischen Gutsbegriff der neoklassischen Theorie und die Hinwendung zum Begriff des "effektiven Gutes"39. Die moderne Institutionenökonomik betont, daß neben den physischen Gutseigenschaften die rechtliche Verfügungsgewalt über Ressourcen zentrale nutzenstiftende Eigenschaft für den Eigentümer ist. Diese property rights - im weiteren auch als Verfügungsoder Eigentumsrechte ${ }^{40}$ bezeichnet - sind Teilrechte eines oder mehrerer Inhaber an einem knappen Gut. Man unterscheidet das Recht auf die Nutzung einer Sache oder Leistung, das Recht auf die Erträge aus der Nutzung, das Recht zur Änderung von Form und Substanz des Gutes und das Recht auf Veräußerung der Teilrechte. ${ }^{41}$ Der Begriff des Verfügungsrechts erfaßt damit sowohl den Komplex der Entscheidungen über individuelle Aktionen als auch den der Entscheidungen über Interaktionen, die als Austausch von Verfügungsrechten über Ressourcen interpretiert werden. 42

Zentrale These ist, daß die Ausgestaltung der property rights "... affects the allocation and use of resources in specific and predictable ways"43 über die Anreiz- und Sanktionswirkungen, die von unterschiedlichen Eigentumsrechtsstrukturen ausgehen. Property rights-Strukturen bestimmen, wie die Nutzen und Kosten, die aus individuellen Entscheidungen resultieren, zwischen dem Entscheidungsträger und anderen alloziiert werden. ${ }^{44}$ Der Anreiz, Ressourcen effizient einzusetzen, ist daher um so größer, je stärker die Inhaber eines Verfügungsrechtes

35 Beide Ansătze können zum selben Ergebnis fuhren, "... sofern alle relevanten Kosten berlucksichtigt werden." Williamson, O.E. (1985/1990), S. 51. Vgl. auch van den Doel, H. (1979), S. 22f.; Eggertsson, T. (1990), S. 7ff.

36 Meckling, W.H. (1976), S. 548.

37 Vgl. Ulrich, P. (1987), S. 240.

38 Grundlegend: Demsetz, H. (1964) und (1967); Furubotn, E.G./Pejovich, S. (1972); Alchian, A.A. (1977).

39 Demsetz, H. (1967), S. 347.

40 Zum Problem der adăquaten Übersetzung des Terminus 'property right' vgl. Eschenburg, $R$. (1978), S. 9ff.

41 Vgl. Alchian, A.A./Demsetz, H. (1972), S. 783 oder Furubotn, E.G./Richter, R. (1991), S. 6.

42 Vgl. Eschenburg, R. (1978), S. 10.

43 Furubotn, E.G./Pejovich, S. (1972), S. 1139 (Hervorhebung im Original).

44 Vgl. De Alessi, L. (1980), S. 3. 
von den positiven und negativen Konsequenzen ihres Handelns betroffen sind. ${ }^{45}$ Die Stärke der Verfügungsrechte wird durch ihre Durchsetzbarkeit bestimmt. ${ }^{46}$ Nur wenn die Mißachtung der Rechte wirkungsvoll sanktioniert werden kann, haben sie einen Wert für den Eigentümer. Verfügungsrechte definieren damit das Recht, Handlungen vorzunehmen ${ }^{47}$ und von anderen das Unterlassen bestimmter Handlungen verlangen zu können. Mithin regeln sie die Beziehungen zwischen den Individuen einer Gesellschaft im Hinblick auf den Umgang mit knappen Gütern. 48

\section{b. Verträge}

Ein Wesensmerkmal des modernen institutionenökonomischen Ansatzes ist die Interpretation sozialer Interaktionen als Verträge. ${ }^{49}$ Mittels vertraglicher Abmachungen entstehen und vergehen Verfügungsrechte, und es erfolgt der Transfer von property rights zwischen den Individuen. Die dabei entstehenden Interdependenzen zwischen den Interaktionsbeteiligten werden von der agency-Theorie betrachtet. ${ }^{50}$ Eine agency-Relation ist durch eine vertragliche Beziehung zweier Individuen gekennzeichnet, wobei einer als Stellvertreter ('Agent') und ein anderer als Vertretener ('Prinzipal') handelt. Handlungen des Agenten beeinflussen dabei sowohl dessen eigene Nutzenposition als auch die des Prinzipals. ${ }^{51}$ Das Ergebnis der Vertragsbeziehung ist dabei nicht nur vom Handeln des Agenten, sondern auch durch exogene Faktoren (Umwelteinflüsse) bestimmt, die es dem Prinzipal erschweren, die Handlungen des Agenten wirksam zu überwachen. 52

In der neoklassischen Welt spielen Probleme bei vertraglichen Arrangements aufgrund der Annahme kostenloser Information keine Rolle, da alle Eventualitäten vor Vertragsschluß umfassend geregelt werden können und die festgelegten Leistungspflichten vollständig und kostenlos durchsetzbar sind. Informationen sind aber nicht kostenlos, und aufgrund der hieraus resultierenden Unsicherheit über den zukünftigen Zustand der Welt einerseits und das Verhalten der Vertragspartei(en) andererseits ist die umfassende vertragliche Regelung aller Eventualitäten kostspielig. Daher sind Verträge durch Unvollständigkeit der Abmachungen und fehlenden Rechtszwang gekennzeichnet ("unvollständiger Kontrakt"53). Weil die Ziele der beiden Vertragsparteien jedoch nicht notwendigerweise kongruent sind, entsteht die Gefahr opportunistischen Verhaltens der Vertragspartner.

45 Vgl. Alchian, A.A. (1977); De Alesssi, L. (1990), S. 47 und Richter, R. (1994), S. $10 \mathrm{f}$.

46 Vgl. Alchian, A.A./Demsetz, H. (1973), S. 17.

47 "An owner of property rights possesses the consent of fellowmen to allow him to act in particular ways." Demsetz, H. (1967), S. 347.

48 "A central point noted is that property rights do not refer to relations between men and things but rather to the sanctioned behavioral relations among men that arise from the existence of things and pertain to their use." Furubotn, E.G./Pejovich, S. (1972), S. 1139 (Hervorhebung im Original).

49 "New institutional economics is at base a study of contracting, both political and economic..." North, D.C. (1986), S. 231. Dieses 'Denken in Vertrăgen' laßt sich als heuristisches Prinzip auch auf Falle anwenden, in denen im formal-juristischen Sinne gar kein Vertrag vorliegt. Vgl. Richter, R. (1990a), S. $580 \mathrm{f}$.

50 Grundlegend: Spence, M./Zeckhauser, R.J. (1971); Ross, S.A. (1973). Einen Überblick uber die PrincipalAgent-Theorie geben Arrow, K.J. (1985) oder Pratt, J.W./Zeckhauser, R.J. (1985).

51 Vgl. Arrow, K.J. (1985), S. 37; Pratt, J.W./Zeckhauser, R.J. (1985), S. 2; Stiglitz, J.E. (1987), S. 967.

52 Vgl. Arrow, K.J. (1985), S. 38.

53 Macneil, J.R. (1974); (1985). Siehe auch Goldberg, V.P. (1976). 
Man unterscheidet mehrere Erscheinungsformen von Opportunismus. Ex ante-Opportunismus äußert sich in 'adverse selection'-Problemen ${ }^{54}$, womit der Umstand bezeichnet wird, daß die potentiellen Vertragspartner vor Vertragsschluß die Qualität der angebotenen Gegenleistung nicht exakt beobachten können und deshalb mit einer Täuschung durch die Vertragsgegenseite rechnen müssen. Ex post-opportunistisches Verhalten findet seinen Ausdruck in der 'moral hazard'-Problematik. 55 'Moral hazard' liegt vor, wenn ein Vertragspartner Handlungen des anderen nicht kontrollieren kann und damit rechnen muß, daß letzterer bei der Ausführung der ihm übertragenen Pflichten nicht die notwendige Sorgfalt walten läßt. In beiden Fällen bestehen asymmetrische Informationsbeziehungen, bei denen eine Seite über Informationen verfügt, die der anderen Vertragsseite nicht, oder nur zu hohen Kosten, zugänglich sind. 56

Eine weitere Erscheinungsform von Opportunismus nach Vertragsschluß ist der "hold up"57 (Raubüberfall). Dem liegt folgende Überlegung zugrunde: Ist ein vertragliches Arrangement getroffen, sind häufig von einem Vertragspartner transaktionsspezifische, d.h. nur für diesen speziellen Zweck einsetzbare, Investitionen vorzunehmen. Eine ursprünglich wettbewerbliche Situation erfährt durch die Tätigung der Investition eine "fundamentale Transformation" $58 \mathrm{zu}$ einem bilateralen Monopol. Für den spezifischen Investor entsteht dadurch eine strategische Abhängigkeit, die vom stärkeren Vertragspartner im Extremfall so weit ausgenützt werden kann, daß dieser sich die gesamte Quasi-Rente ${ }^{59}$ der schwächeren Seite aneignen kann. ${ }^{60}$

\section{c. Transaktionskosten}

Der Transaktionskostenansatz hat seine Wurzel in der Arbeit von Coase zur "Nature of the Firm"61. Darin stellt Coase die Frage, warum nicht alle ökonomischen Aktivitäten über Märkte abgewickelt werden, sondern auch über Unternehmen. Coase kommt zum Schluß, daß die Nutzung des marktlichen Preismechanismus mit Kosten verbunden ist, die sich aus den Kosten der Anbahnung und des Abschlusses von Verträgen sowie denen der Überwachung und Durchsetzung vertraglicher Leistungspflichten zusammensetzen (Transaktionskosten). ${ }^{62}$ Unternehmen dienen nach Coase dem Zweck, Transaktionskosteneinsparungen zu erzielen. Umgekehrt verursacht auch die unternehmensinterne Koordination Kosten, so daß nach dem

54 Vgl. z.B. Akerlof, G.A. (1970).

55 Vgl. Arrow, K.J. (1963a); Pauly, M.V. (1968); Spence, M./Zeckhauser, R.J. (1971).

56 In der Principal-Agent-Theorie werden diese beiden Erscheinungsformen des Opportunismus unter den Stichworten 'hidden information'und 'hidden action' behandelt. Vgl. Arrow, K.J. (1985). Sie sind aber im wesentlichen deckungsgleich mit den Begriffen 'adverse selection' und 'moral hazard'.

9 Hierunter versteht man die Mehr-Erträge, die eine eingesetzte Ressource im Vergleich zu ihrer năchstbesten Verwendung erzielt. Vgl. Marshall, A. (1948). Vgl. auch Alchian, A.A./Woodward, S. (1987), S. 113.

60 Vgl. auch Alchian, A.A./Woodward, S. (1988).

61 Coase, R.H. (1937).

62 Vgl. auch Richter, R. (1990a), S. 576f. Ihre Existenz ist damit darauf zurlckzufuhren, daß Information nicht kostenlos ist. Vgl. North, D.C. (1990/1992), S. 32ff. oder Dahlman, C.J. (1979), S. 148. Nicht ganz unproblematisch ist dabei die Abgrenzung von Transaktionskosten und neoklassischen Produktionskosten. Vgl. z.B. Terberger, E. (1994), S. 128ff. Unter letzteren subsumiert North die Kosten fur den Einsatz von Faktoren zur Transformation der physischen Gutseigenschaften ("Transformationskosten"), die erst gemeinsam mit den Transaktionskosten den gesamten Ressourcenverzehr zur Gutererstellung ergeben. 
Marginalkalkül solange Aktivitäten innerhalb von Unternehmen vorgenommen werden, bis die Grenzkosten marktlicher und interner Transaktionen gleich groß sind.63

Aufbauend auf den Gedanken von Coase, auf der Basis der property rights-Theorie und des Vertragsdenkens hat sich die Transaktionskostentheorie als dritter Baustein der Neuen Institutionenökonomik entwickelt. Elementar für das Verständnis dieses Ansatzes ist, daß aufgrund der Unvollständigkeit der Austauschverträge und des zu erwartenden Opportunismus der Beteiligten Vereinbarungen abgesichert werden müssen. Die vor Vertragsschluß anfallenden ex ante-Transaktionskosten sind "... Kosten für Entwurf, Verhandlungen und Absicherung einer Vereinbarung." 64 Ex post-Kosten entstehen für alle Aufwendungen, die nach Vertragsschluß infolge der unvollständigen Regelung entstehen. Hierzu zählen u.a. Kosten der Neuverhandlungen nach Vertragsschluß, der Beilegung von Streitigkeiten und die Kosten vertragswidrigen Verhaltens. ${ }^{65}$ Diese Transaktionskostenarten stehen in einer trade-off-Beziehung: Je mehr Ressourcen für die Spezifizierung der vertraglichen Leistungspflichten und die konkrete Regelung aller Eventualitäten vor Abschluß der Verträge eingesetzt werden, desto geringer sind die ex post-Kosten und umgekehrt. ${ }^{66} \mathrm{Im}$ weitesten Sinne bezeichnen daher Transaktionskosten die "costs of running the economic system"67.

Der Transaktionskostenbegriff wird allerdings nicht einheitlich verwendet. ${ }^{68}$ In der weiten Begriffsauslegung der Vertragstheorie werden unter den Kosten einer agency-Beziehung neben Überwachungskosten des Prinzipals und Sicherheitsleistungen des Agenten zur Garantie der Vertragseinhaltung auch die Nutzenverluste zusammengefaßt, die auf der unvollständigen Regelung vertraglicher Beziehungen beruhen. ${ }^{69}$ Diese Nutzenverluste beinhalten sowohl Kosten des Opportunismus als auch entgangene Koordinationsgewinne. Damit umfassen die Transaktionskosten fiktive Ressourceneinbußen, die sich nur durch den Vergleich der tatsächlichen Situation mit der (neoklassischen) Referenzsituation einer friktionslosen Welt ermitteln lassen. ${ }^{70}$ Einer solchen weiten Begriffsfassung soll hier gefolgt werden.

\section{Die Auswahl effizienter Koordinationsstrukturen}

Die Institutionenökonomik verfolgt das Ziel der Ermittlung von Koordinationsstrukturen, die bei gegebenen Transaktionseigenschaften zur Minimierung von Transaktionskosten führen. 71 Es geht somit um die Suche nach effizienten Koordinationsstrukturen (institutional choice). ${ }^{72}$

63 Vgl. Coase, R.H. (1937), insbes. S. 390ff.

64 Williamson, O.E. (1985/1990), S. 22.

$65 \mathrm{Vgl}$. Williamson, O.E. (1985/1990), S. 24.

66 Vgl. Williamson, O.E. (1985/1990), S. 24f.

67 Arrow, K.J. (1977), S. 68.

68 Siehe Terberger, E. (1994), S. 77ff.

69 Vgl. Jensen, M.C./Meckling, W.H. (1976), S. 308.

70 Vgl. Eggertsson, T. (1990), S. 44; Terberger, E. (1994), S. $132 \mathrm{ff}$.

71 Vgl. Richter, R. (1990a), S. 579.

72 Eine schematische Darstellung des Auswahlprozesses unterschiedlicher institutioneller Alternativen findet sich bei Schenk, K.-E. (1983). Die Verwendung des Begriffs 'Effizienz' wirft in diesem Zusammenhang Probleme auf: Die Institutionenökonomik analysiert die Rahmenbedingungen des menschlichen Handelns. Diese sind Restriktionen im Maximierungskalkul der Individuen. Differierende Nebenbedingungen fuhren aber zu unterschiedlichen Optimalløsungen. "On this view, a system's solutions are always efficient if they meet the constraints that characterize it." De Alessi, L. (1983), S. 69. Notwendig wăre daher, zwischen 
Kernaussage des Transaktionskostenansatzes ist, daß die Gestaltung des institutionellen Rahmens erhebliche Bedeutung für die Höhe der Transaktionskosten hat; umgekehrt verlangen unterschiedliche Transaktionsumstände auch nach verschiedenen institutionellen Arrangements. ${ }^{73}$ Damit stellt sich die Frage nach den institutionellen Alternativen, die nach dem Kriterium der Transaktionseffizienz auf ihre Vorteilhaftigkeit geprüft werden. Zwei Designs, zwischen denen gewählt werden kann, sind "Markets and Hierarchies"74.

Marktliche Koordination ist durch Freiwilligkeit der Tauschbeziehungen charakterisiert. Sie ist mit dem Vorteil verbunden, daß prinzipiell individuelle Entscheidungsfreiheit und Autonomie gewährleistet sind. ${ }^{75}$ Charakteristisch für Marktstrukturen ist die "... direkte gegenseitige Verhaltenskontrolle und -steuerung der am Austausch beteiligten Akteure."76 Die Koordination der Aktivitäten einer Vielzahl von Individuen erfolgt über den Preismechanismus. ${ }^{77}$ Im Gegensatz dazu sind Hierarchien durch ein Subordinationsverhältnis charakterisiert, bei dem eine Vertragspartei über die andere Partei innerhalb bestimmter, ex ante festgelegter Grenzen Weisungsrechte besitzt; hierarchische Koordination ist durch Beschränkungen der Entscheidungsautonomie einer Vertragsseite gekennzeichnet. ${ }^{78}$ Die Existenz eines zentralen Koordinationsagenten sei, so die These, vorteilhaft, wenn dadurch die Zahl der zur Durchführung von Transaktionen erforderlichen Verträge reduziert wird. ${ }^{79}$ Hierarchische Beziehungen könnten daher in bestimmten Fällen zu einer Reduzierung von Transaktionskosten führen. 80

Freilich ist nicht von einer Dichotomie zwischen beiden Erscheinungsformen auszugehen. Vielmehr gibt es eine Vielzahl denkbarer Arrangements, die weder der einen noch der anderen Ausgestaltung exakt zuzuordnen sind. ${ }^{81}$ So ist die Frage, ob eine bestimmte Leistung über den Markt, private Unternehmungen oder den Staat erstellt werden sollte, auch nicht als entweder-oder-Entscheidung zu umschreiben, sondern vielmehr in einem weiten Spektrum unterschiedlicher Koordinationsformen anzusiedeln, die sich durch ein unterschiedliches Mischungsverhältnis von privatautonomer Entscheidung und Subordination beschreiben las$\operatorname{sen} .82$

vermeidbaren und unvermeidbaren Restriktionen zu unterscheiden. Transaktionskostenminimierende Institutionen sind dann diejenigen, die die Abweichungen vom first best-Ideal der transaktionskostenfreien Welt minimieren. Zu einer ausfuhrlichen Diskussion uber die Anwendbarkeit des Effizienzkriteriums in diesem Zusammenhang siehe etwa Furubotn, E.G. (1986); Eggertsson, T. (1990), S. 20ff.; Furubotn, E.G./Richter, $R$. (1991), S. $11 \mathrm{ff}$.

73 Vgl. auch Schenk, K.-E. (1992), S. 351.

74 So der Titel der Monographie von Williamson, O.E. (1975).

75 Vgl. Miller, G.J. (1992), S. 38f.

76 Vgl. Vanberg, V. (1982), S. 161.

77 Vgl. Bössmann, E. (1981), S. 667.

78 "Hierarchy can be defined as the asymmetric and incompletely defined authority of one actor to direct the activities of another within certain bounds." Miller, G.J. (1992), S. 16.

79 Die Vorteile hierarchischer Koordinationsstrukturen diskutieren Williamson, O.E. (1975), S. 57f. und Miller, G.J. (1992), S. 39ff.

80 Vgl. Schenk, K.-E. (1992), S. 354 f.

81 Entsprechend unterscheidet Williamson auch (i) Beherrschung und Überwachung durch den Markt; (ii) Dreiseitige Beherrschungs- und Überwachungssysteme; (iii) Zweiseitige Beherrschungs- und Überwachungssysteme und (iv) einheitliche Beherrschungs- und Überwachungssysteme. Vgl. Williamson, O.E. (1985/1990), S. $81 \mathrm{ff}$.

82 Vgl. Barzel, Y. (1989), S. 52ff. 
Um konkrete Aussagen über eine zieladäquate Gestaltung der Koordinationsmechanismen zu gewinnen, müssen Faktoren ermittelt werden, die eine Vorteilhaftigkeit bestimmter Organisationsformen prognostizieren lassen. Mit Williamson sind drei Dimensionen von Transaktionen zu unterscheiden, die eine herausragende Rolle für die Wahl des Organisationsdesigns spielen.

- Die Spezifität transaktionsrelevanter Investitionen ist nach Williamson der bedeutendste Einflußfaktor. ${ }^{83}$ Mit der Bildung transaktionsspezifischer Aktiva werden alternative Einsatzmöglichkeiten der Ressourcen verringert, und der Anteil der Quasi-Rente an den Erträgen der Ressource steigt. ${ }^{84}$ Für Transaktionen, die eine hohe Spezifität aufweisen, bietet sich nach Williamson eine "vereinheitlichte Kontrolle"85 an, da Neuverhandlungen für die eingeschlossene Vertragsseite mit Risiken eines hold up durch die andere Vertragsseite verbunden sind und diesen durch die Begründung von Weisungsrechten entgegengetreten werden kann. 86

- Die zweite Dimension betrifft die Häufigkeit von Transaktionen. ${ }^{87}$ Spezialisierte Organisationen bieten bei wiederholten Transaktionen den Vorteil einer höheren Auslastung und der Realisierung von Skalenerträgen bei der Abwicklung der Transaktionen. Je häufiger daher spezifische Transaktionen vorgenommen werden, desto eher ist es sinnvoll, deren Abwicklung speziell für diesen Zweck gebildeten Organisationen zu überlassen.

- Unsicherheit von Transaktionen ${ }^{88}$ begründet das Risiko opportunistischen Verhaltens der Vertragsgegenseite. Hierarchische Koordinationsstrukturen könnten durch die Etablierung von Weisungsrechten die Risiken des Opportunismus begrenzen.

Natürlich führt hierarchische Koordination selbst wieder zu Kosten. Eine Aussage über die Vorteilhaftigkeit eines Koordinationsmechanismus kann daher erst getroffen werden, wenn in den Vergleich zwischen Märkten und Hierarchien auch diejenigen Kosten einbezogen werden, die durch Opportunismus innerhalb der hierarchischen Struktur entstehen. ${ }^{89}$ Folglich wird von der Neuen Institutionenökonomik der Vergleich idealisierter Zustände mit real existierenden, fehlerbehafteten Institutionen abgelehnt; erforderlich sei dagegen eine komparative Institutionenanalyse. ${ }^{90}$ Durch Gegenüberstellung institutioneller Designs wird versucht, die damit eng verbundene normative Fragestellung nach der optimalen institutionellen Struktur zu beantworten. Es geht nicht um die Erreichung einer hypothetischen Wohlfahrtsgrenze, sondern um die Wahl der Koordinationsstrukturen, die aus der Vielzahl denkbarer Arrangements realisierbare Alternativen darstellen. ${ }^{91}$ Das Allokationsoptimum bei vollständiger Information

83 Vgl. Williamson, O.E. (1985/1990), S. 60ff. In seiner Arbeit uber Mărkte und Hierarchien aus dem Jahre 1975 verwendete Williamson noch den Ausdruck "ideosyncracy"; Williamson, O.E. (1975), S. 29. Der Begriff 'asset specificity' wurde fur diesen Sachverhalt von Klein, B./Crawford, R./Alchian, A.A. (1978) eingefuhrt.

84 Vgl. Schumann, J. (1992), S. 441.

85 Williamson, O.E. (1985/1990), S. 89.

86 Vgl. auch Hart, O. (1990).

87 Vgl. Williamson, O.E. (1985/1990), S. 69.

88 Vgl. Williamson, O.E. (1985/1990), S. 64ff.

89 Siehe Williamson, O.E. (1985/1990), Kap. 6 und (1964); (1967). Vgl. auch Schenk, K.-E. (1992), S. 367f.

90 "The view that now pervades much public policy economics implicitly presents the relevant choice as between an ideal norm and an existing 'imperfect' institutional arrangement. This nirvana approach differs considerably from a comparative institution approach in which the relevant choice is between alternative real institutional arrangements." Demsetz, H. (1969), S. 1 (Hervorhebung im Original).

91 Vgl. Richter, R./Bindseil, U. (1995), S. 133. 
wird lediglich als fiktive Referenz für die Beurteilung der relativen Effizienz unterschiedlicher Koordinationsmechanismen herangezogen.

\section{Der konstitutionelle Ansatz für eine ökonomische Theorie der Organisationen}

\section{Das Legitimationsproblem}

Wie oben festgestellt, bedeutet korporatives Handeln in Hierachien den Verzicht auf individuelle Entscheidungsautonomie und Etablierung von Herrschaft. ${ }^{92}$ Nun ist die Existenz hierarchischer Organisationsformen a priori nicht mit dem individuellen Eigeninteresse der Gesellschaftsmitglieder vereinbar, denn sie bedeutet immer eine Beschränkung persönlicher Freiheitsspielräume. ${ }^{93} \mathrm{Im}$ individualistischen Sinne ist das Ideal in einer herrschaftsfreien Gesellschaft zu sehen, in der niemand das Recht hat, Entscheidungen für andere und über andere $\mathrm{zu}$ fällen. ${ }^{94}$ Damit stellt sich als Problem einer ökonomischen Theorie von Organisationen die Frage nach der Legitimation solcher Einschränkungen. ${ }^{95}$ Mit dieser Fragestellung befassen sich die Konstitutionalisten. ${ }^{96}$ Abgeleitet aus dem individualistischen Prinzip betonen sie die Kriterien des Verfahrens der Institutionenwahl.97

Im Rahmen des konstitutionellen Ansatzes sind der evolutionstheoretische und der kontrakttheoretische Denkansatz zu unterscheiden. Evolutionstheoretiker ${ }^{98}$ erklären die Entstehung von Regeln aus der Interaktion der Individuen. Ihre Kernaussage ist, daß der wettbewerbliche Auswahlmechanismus selbst für die Etablierung effizienter Institutionen sorgt. Rational handelnde Individuen wählen aus der Vielzahl denkbarer institutioneller Arrangements aufgrund des Wettbewerbsdrucks stets das ökonomisch vorteilhafteste Design. ${ }^{99}$ Dagegen wird der planvolle, gestalterische Entwurf einer Ordnung als "rationalistischer Konstruktivismus" 100 abgelehnt. Aufgrund der beschränkten Informationsverarbeitungskapazität der Menschen sei es unmöglich, Regeln zu konstruieren, die die Komplexität des menschlichen Zusammenlebens sinnvoll und zielgerichtet steuern. ${ }^{101}$ Die längerfristige Überlebensfähigkeit von Regelsystemen im Wettbewerb unterschiedlichster institutioneller Ordnungen wird somit zum Legitimationskriterium für die Evolutionstheoretiker.

92 Vgl. Vanberg, V. (1982), S. 171; Lindblom, C.E. (1965), S. $25 \mathrm{ff}$.

93 Vgl. Homann, K. (1983), S. 328f.

94 Vgl. Buchanan, J.M. (1975/1984), S. 130.

95 Unter Legitimităt versteht der Soziologe Luhmann "... die rein faktisch verbreitete Überzeugung von der Gultigkeit des Rechts, von der Verbindlichkeit bestimmter Normen oder Entscheidungen oder von dem Wert der Prinzipien, an denen sie sich rechtfertigen." Luhmann, N. (1975), S. 27.

96 Nach Buchanan, J.M. (1977), S. 83 ist "constitutionalism ... the science of rules".

97 Vgl. Böbel, I. (1988), S. 54. Die legitime Geltung von Regeln ist also davon abhăngig, daß der Prozeß der Regelsetzung als legal angesehen wird; vgl. Eschenburg, $R$. (1977), S. $8 \mathrm{ff}$.

98 Hier ist vor allem von Hayek zu nennen. Hayek, F.A. von (1971); (1980); (1981a); (1981b).

$99 \mathrm{Vgl}$. Hayek, F.A.von (1968), S. 10.

100 Hayek, F.A. von (1969), S. 75ff. Siehe dazu auch Vanberg, V. (1981), S. $12 \mathrm{ff}$.

101 "Es ist sehr unwahrscheinlich, daß es jemandem gelingen würde, verstandesgemaß Regeln zu konstruieren, die ihrem Zweck besser dienen als jene, die sich allmăhlich herausgebildet haben." Hayek, F.A. von (1971), S. 84. 
Kontrakttheoretiker ${ }^{102}$ sehen die wesentliche Schwäche des evolutorischen Ansatzes darin, $\mathrm{da} ß$ "... to the evolutionist all existing law is legitimate." 103 Jede Abweichung vom Ideal des vollkommenen Wettbewerbs der institutionellen Strukturen berge das Risiko, daß sich auf Dauer ineffiziente Regelsysteme durchsetzen und konservieren. 104 Sie stellen daher dem evolutorischen Ansatz als Legitimationskriterium die einstimmige Billigung von Regeln durch alle Betroffenen gegenüber (Konsenskriterium). ${ }^{105}$ Der Grundgedanke ist, daß freiheitsbegrenzende Arrangements nur dann legitim sind, wenn sie auf der Zustimmung aller Individuen zu dieser Beschränkung beruhen, da die Bestimmung der Werte, an denen sich die Aufstellung der Regeln mißt, ausschließlich aus den Werthaltungen der Individuen einer Gesellschaft erfolgen kann (normativer Individualismus). 106

Nach dem kontrakttheoretischen Ansatz muß deshalb zwischen zwei unterschiedlichen Entscheidungsebenen differenziert werden: einer konstitutionellen Ebene, auf der die Entscheidung über die in Zukunft geltenden Regeln erfolgt, und einer post-konstitutionellen (operationellen) Ebene, auf der die Individuen Entscheidungen innerhalb der vorher festgelegten Regeln treffen. ${ }^{107}$ Damit ein Regelsystem legitim ist, muß auf der konstitutionellen Ebene Konsens über die Inhalte der Organisationsverfassung erzielt werden. ${ }^{108}$ Die Individuen werden den Regeln, die eine Beschränkung ihrer eigenen Handlungsfreiräume darstellen, nur zustimmen, wenn sie sich damit im Vergleich zur Ausgangssituation ohne Regeln besser stellen. Dem liegt die Vorstellung zugrunde, daß sich jemand nur dann auf einen Vertragsabschluß einläßt, wenn dieser seinen individuellen Interessen entspricht. 109

Von besonderer Relevanz ist die längerfristige Gültigkeit der Ordnungsregeln. Erst durch die Wiederholung sozialer Interaktionen innerhalb dauerhaft angelegter Institutionen ergibt sich die allgemeine Vorteilhaftigkeit der Regelbefolgung. ${ }^{110}$ Sind Regeln auf längere Zeit angelegt, besteht im Stadium der Entscheidung über alternative Regelsysteme Unsicherheit darüber, wie sich bestimmte Arrangements auf die eigene Position in der post-konstitutionellen Phase auswirken. Für die Entscheidungsbeteiligten besteht aufgrund dieser Unsicherheit eine

102 Als deren Hauptvertreter gelten Buchanan und Rawls. Vgl. Buchanan, J.M./Tullock, G. (1962); Buchanan, J.M. (1977) und (1975/1984); Brennan, G./Buchanan, J.M. (1985/1993); Rawls, J. (1971/1975). Eine Position zwischen Evolutions- und Kontrakttheorie nimmt Nozick ein, dessen Legitimationsgrundlage als 'evolutorischer Konsens' bezeichnet werden kann. Siehe Nozick, R. (1974/1976).

103 Buchanan, J.M. (1977), S. 127. "Der schwache Punkt der evolutionistischen Perspektive ... liegt darin, daß sie keinerlei Grundlage bietet, um Vorschläge fur Reformen oder fur Verănderungen in den vorhandenen, die soziale Ordnung bildenen Institutionen zu bewerten." Buchanan, J.M. (1981), S. 45f.

104 Dies ist die Kernthese der Hauptarbeiten von North, D.C. (1981/1988) und (1990/1992). So fuhrt Buchanan aus: "Die Institutionen, die uberleben und gedeihen, mussen nicht immer auch diejenigen sein, welche die menschlichen Möglichkeiten verbessern. Die Evolution kann gesellschaftliche Dilemmata ebenso wie ein gesellschaftliches Paradies zutage fordern." Buchanan, J.M. (1975/1984), S. 237.

105 Die Bedeutung der Konsenstheorie fur die Legitimation von Ordnungen wird von Eschenburg, $R$. (1977), S. 16ff. erortert. Siehe auch Homann, K. (1985). Vanberg betont die Vereinbarkeit der vertragstheoretischen und der evolutorischen Positionen. Siehe Vanberg, V. (1981).

106 Vgl. Buchanan, J.M. (1987a), S. 587 und (1990), S. 13ff. Siehe hierzu auch Pies, I. (1993), S. 130ff.

107 Vgl. Buchanan, J.M./Tullock, G. (1962), S. $110 \mathrm{ff}$. Frey, B.S. (1981a), S. 22ff.; (1981b), S. $367 \mathrm{ff}$. Buchanan spricht in diesem Zusammenhang von "choice among constraints" in Abgrenzung zu "choice within constraints". Buchanan, J.M. (1987a), S. 585. Vgl. auch Buchanan, J.M. (1977), S. 11.

108 Nach Wicksell kommt der Einstimmigkeitsregel die Eigenschaft zu, ausschließlich Pareto-superiore Ergebnisse hervorzubringen. Vgl. Wicksell, K. (1896). Den Beitrag Wicksells zur konstitutionellen Theorie würdigt Wagner, R.E. (1988a).

109 Siehe etwa Coleman, J.L. (1984), S. 146ff.

110 Siehe dazu die Ausfuhrungen im năchsten Abschnitt. 
Tendenz, fairen und allgemein akzeptablen Regelarrangements zuzustimmen. Daher erleichtert die langfristige Geltungsdauer das Zustandekommen einer einstimmigen Entscheidung. 111 Im theoretischen Grenzfall besitzt kein Individuum irgendwelche Informationen über die eigene Position im post-vertraglichen Stadium - eine Entscheidungskonstellation, für die von Rawls der Begriff "Schleier des Nichtwissens" ("veil of ignorance"112) geprägt wurde. 113

Freilich lassen sich solche Regeln praktisch nur auf dem Wege des Gedankenexperiments konstruieren. ${ }^{114}$ Die Relevanz des Konsenskriteriums liegt daher weniger in der Erklärung des Zustandekommens bestehender Institutionen, sondern in der Ableitung normativer Verbesserungsvorschläge für institutionelle Arrangements. ${ }^{115}$ Auf der Basis einer vergleichenden Analyse von Institutionen ermöglicht der vertragstheoretische Ansatz somit normative Empfehlungen für eine effizientere Ausgestaltung von Regeln. ${ }^{116}$ Damit wäre im nächsten Schritt zu klären, bei welchen Problemkonstellationen sich eigennützige Individuen auf ein Regelwerk einigen sollten, das ihre persönlichen Freiheiten beschränkt.

\section{Kooperationsprobleme als soziale Dilemmata}

\section{a. Die spieltheoretische Interpretation des Kooperationsproblems}

Um die allgemeine Vorteilhaftigkeit von Regelbindungen in abstrakter Form darzustellen, ist es hilfreich, sogenannte Kooperationsprobleme mit Hilfe der Spieltheorie zu analysieren. 117 Die Spieltheorie liefert ein formales Instrumentarium, das bei der Untersuchung strategischer Entscheidungssituationen verwendet werden kann, und ist in besonderer Weise geeignet, die Eigenschaften der in nachfolgenden Abschnitten konkreter erörterten Entscheidungsprobleme abzubilden.

Betrachtet sei die symmetrische Spielsituation zweier identischer Akteure 1 und 2. Beide Beteiligten verfügen über je zwei Handlungsoptionen, die mit $\mathrm{k}$ und $\mathrm{n}$ bezeichnet werden. Die Handlungsalternative $\mathrm{k}$ beschreibt ein kooperatives, die Option $\mathrm{n}$ dagegen nicht-kooperatives Verhalten. Die Akteure wählen unabhängig die Handlungsalternative, von der sie sich die größten individuellen Nutzen U erwarten. Die bei unterschiedlicher Strategiewahl jeweils erzielten Nutzen $U$ werden durch die Auszahlungsmatrix in Abbildung 2.1 dargestellt, wobei die in jeder Zelle links oben stehende Nutzenauszahlung die des Spielers 1 bezeichnet, die in der Zelle rechts unten stehende Auszahlung die des Spielers 2.

In Kooperationsspielen gelten für die Nutzenniveaus $U$ folgende Zusammenhänge: 118

- $\mathrm{U}(\mathrm{k}, \mathrm{k})>\mathrm{U}(\mathrm{n}, \mathrm{n})$ : Wenn beide Spieler kooperieren, stellen sich beide besser als in der Situation, in der beide nicht kooperieren.

- $\mathrm{U}(\mathrm{n}, \mathrm{k})>\mathrm{U}(\mathrm{n}, \mathrm{n})$ : Nicht-kooperierende Individuen ziehen aus der Kooperation des anderen Spielers Nutzen.

111 Vgl. Brennan, G./Buchanan, J.M. (1985/1993), S. 37ff.; Kirchgässner, G. (1994), S. 325f.

112 Rawls, J. (1971/1975), S. 29.

113 Vgl. Buchanan, J.M./Tullock, G. (1962), Kap. 7; Brennan, G./Buchanan, J.M. (1980/1988), S. 4.

114 Siehe auch Buchanan, J.M. (1987b), S. 248ff. Kritisch außert sich hierzu v.a. Schenk, K.-E. (1992), S. $347 \mathrm{ff}$.

115 Vgl. Buchanan, J.M. (1962), S. 318.

116 Vgl. Buchanan, J.M. (1987a), S. 585; Lowenberg, A.D./Yu, B.T. (1990), S. 52f.

117 Siehe hierzu die Einfuhrung bei Holler, M./llling, G. (1993).

$118 \mathrm{Vgl}$. Althammer, W./Buchholz, W. (1995), S. 96f. 
- $\mathrm{U}(\mathbf{k}, \mathbf{k})>\mathrm{U}(\mathbf{k}, \mathbf{n})$ : Die Kooperation des jeweils anderen Spielers führt auch bei eigenem kooperativen Verhalten zur individuellen Nutzenverbesserung.

- $\mathrm{U}(\mathrm{n}, \mathrm{k})>\mathrm{U}(\mathrm{k}, \mathrm{n})$ : Eigene Nicht-Kooperation bei gleichzeitiger Kooperation des anderen Individuums führt zu einem höheren individuellen Nutzenniveau als eigene Kooperation bei Nicht-Kooperation des anderen.

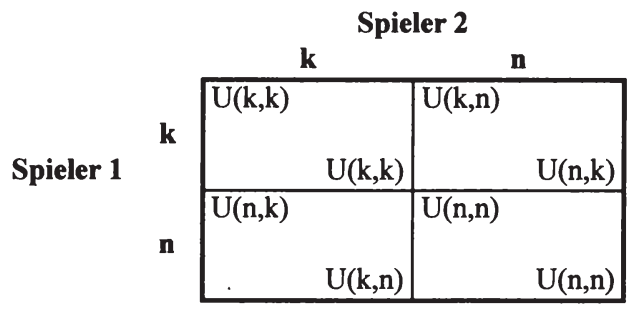

\section{Abbildung 2.1: Auszahlungsmatrix bei Kooperationsspielen}

Quelle: Althammer, W./Buchholz, W. (1995), S. 96.

Kooperationsspiele sind mithin dadurch gekennzeichnet, daß ein Individuum durch die Kooperation des anderen Spielers gegenüber dem Fall, daß dieser nicht kooperiert, stets besser gestellt wird. In dieser Ausgangssituation sind mehrere Spieltypen zu unterscheiden. Für die hier angestellten Überlegungen ist vor allem ein Spieltyp relevant, der in der Literatur unter dem Stichwort "prisoners' dilemma"119 diskutiert wird. Zwar ist das Gefangenendilemma ein sehr einfach strukturiertes Modell; es enthält aber alle für das Verständnis von

119 Siehe dazu grundlegend Luce, R.D./Raiffa, H. (1957), S. 94ff. Vgl. etwa auch Sandler, T. (1992), S. 40; Holler, M./Illing, G. (1993), S. Iff. Ein zweiter Spieltyp, das sog. "Game of Chicken" (Lipnowski, I./Maital, $S$. (1983)), wird durch folgende Annahme beschrieben: $\mathrm{U}(\mathrm{n}, \mathrm{k})>\mathrm{U}(\mathrm{k}, \mathrm{k})>\mathrm{U}(\mathrm{k}, \mathrm{n})>\mathrm{U}(\mathrm{n}, \mathrm{n})$. Je nach Wahl der Handlungsalternative des anderen Spielers fallt die individuell beste Antwort anders aus: Auf kooperatives Verhalten des Spielers 2 (Spielers 1) reagiert Spieler 1 (Spieler 2) am besten mit Nicht-Kooperation, auf Nicht-Kooperation von 2 (1) reagiert 1 (2) dagegen am besten mit Kooperation. Ein eindeutiges Gleichgewicht ist in diesem Falle nicht zu bestimmen, potentielle Gleichgewichte sind die Kombinationen $(\mathrm{n}, \mathrm{k})$ und $(\mathrm{k}, \mathrm{n})$. Wenn in dieser Situation ein Individuum, z.B. Spieler 1, dem Spieler 2 glaubhaft versichert, sich nicht-kooperativ zu verhalten, wird Spieler 2 kooperieren, denn dann kann er das fur ihn ungunstigste Ergebnis $(n, n)$ vermeiden. Dieses Gleichgewicht ist jedoch nur pareto-effizient, wenn nicht durch gemeinsame Kooperation ein insgesamt höheres Nutzenniveau beider Spieler erzielt werden kann. Wenn $2 \cdot \mathrm{U}(\mathrm{k}, \mathrm{k})>[\mathrm{U}(\mathrm{n}, \mathrm{k})+\mathrm{U}(\mathrm{k}, \mathrm{n})]$ gilt, kann durch wechselseitige Kooperation ein Spieler besser gestellt werden, ohne den anderen schlechter zu stellen. Vgl. Althammer, W./Buchholz, W. (1995), S. 99.

Ein dritter Spieltyp ist beschrieben durch: $U(k, k)>U(n, k)>U(n, n)>U(k, n)$. Tritt diese Konstellation auf, ist ein Spieler nur bereit zu kooperieren, wenn der andere Spieler ebenfalls kooperiert. Für den Fall der NichtKooperation ist die eigene Nicht-Kooperation die beste Antwort. Auch dieses Spiel besitzt zwei potentielle Gleichgewichte $(k, k)$ und $(n, n)$. Welches der beiden Gleichgewichte realisiert wird, hängt davon ab, ob der Spielpartner glaubhaft die Kooperationsbeteiligung zusichem kann oder nicht. Nur die Kombination $(\mathbf{k}, \mathbf{k})$ ist in diesem "Assurance game" (Gardner, M./Ostrom, E./Walker, J. (1990)) eine pareto-optimale Lösung. Schließlich existiert noch eine vierte Spielvariante, bei der $U(k, k)>U(n, k)>U(k, n)>U(n, n)$ gilt. Bei diesem Spieltyp, der als "Harmony Reigns" (Lipnowski, I./Maital, S. (1983)) bezeichnet wird, ist die Realisierung des pareto-optimalen Gleichgewichts $(k, k)$ sichergestellt, denn fur beide Beteiligten ist Kooperation stets die beste Antwort, unabhăngig davon, welche Strategie der andere Spieler wăhlt.

Alle vier Spieltypen können auch in unterschiedlichen Kombinationen auftreten, vgl. Althammer, W./Buchholz, W. (1995). 
Kooperationsproblemen zentralen Aspekte. ${ }^{120}$ Ein Gefangenendilemma liegt vor, wenn für die Beteiligten folgende Annahme über die jeweils erzielten Nutzenniveaus gilt:

$$
\mathrm{U}(\mathbf{n}, \mathrm{k})>\mathrm{U}(\mathrm{k}, \mathrm{k})>\mathrm{U}(\mathrm{n}, \mathrm{n})>\mathrm{U}(\mathbf{k}, \mathbf{n}) \text {. }
$$

Das Dilemma dieser Konstellation besteht darin, daß für beide Beteiligten Nicht-Kooperation $\mathrm{n}$ die dominierende Strategiewahl ist, unabhängig davon, ob der andere Spieler kooperiert oder nicht. Wählen aber beide Spieler individuell rational die Handlungsoption n, führt dies zum beiderseits unerwünschten Spielergebnis (n,n), da sie durch die Einigung auf eine gemeinsame Kooperation (k,k) besser gestellt werden könnten (Pareto-Verbesserung). Es kommt also durch unabhängiges, am Eigennutz orientiertes Verhalten zur "kollektiven Selbstschädigung durch Verfolgung des eigenen Vorteils." 121

Die Überwindung des Gefangenendilemmas erfordert beiderseitige Kooperation. Folgerichtig untersucht die Spieltheorie, unter welchen Bedingungen kooperatives Verhalten der Spieler zustande kommt. Als erster wichtiger Einflußfaktor für das Zustandekommen einer freiwilligen Kooperation der Beteiligten wird der Zeithorizont, der den individuellen Entscheidungen zugrundeliegt, identifiziert. Betrachtet wurde bisher nur ein Spiel, das nach einmaliger Aktion der Akteure beendet ist. Bei einer häufigen Wiederholung des Spiels steigt die Wahrscheinlichkeit einer allseitigen Kooperation, wenn die Individuen erkennen, daß nicht-kooperatives Verhalten zu unerwünschten Ergebnissen führt. Ist den Beteiligten die Zahl der Spielwiederholungen bekannt, läßt sich durch Rückwärtsinduktion der Teilspielergebnisse ableiten, daß eine Kooperation nicht erreicht wird. ${ }^{122}$ Rationale Individuen leisten freiwillige kooperative Beiträge nur bei unendlicher Spielwiederholung, man spricht dann von einem "Superspiel" 123 oder bei einer a priori unbekannten Zahl von Teilspielen. Die Wiederholung derselben Spielsituation eröffnet nämlich den Spielern die Möglichkeit, nicht-kooperatives Verhalten in der nächsten Spielrunde zu sanktionieren, und die Kosten langfristig wirkender Sanktionen können die kurzfristige Vorteilhaftigkeit der Nicht-Kooperation übersteigen. ${ }^{124}$

Doch selbst bei wiederholt auftretenden Spielsituationen ist eine freiwillige Kooperation nicht sichergestellt. Eine wesentliche Rolle spielt die Größe der Kooperationsgruppe. Da mit wachsender Zahl der Beteiligten die Fühlbarkeit individueller Kooperationsbeiträge fällt und die Chancen einer Wiedererkennung der Interaktionspartner sinken, sind die Anreize zur Kooperation der einzelnen geringer. ${ }^{125}$ Während somit in der kleinen Gruppe die Identifikation und Sanktionierung nicht-kooperierender Individuen durch die kooperierenden Beteiligten noch möglich erscheint, ist ein solches Vorgehen bei einer großen Zahl von Spielern immer weniger wahrscheinlich. Vor diesem Hintergrund muß davon ausgegangen werden, daß ein zwangfreies Zustandekommen kooperativer Arrangements nur unter ganz bestimmten, einschränkenden Bedingungen gewährleistet und selbst dann die Kooperation höchst instabil ist. Die Überwindung sozialer Dilemmata durch freiwillige Beachtung gemeinschaftlich festgelegter

$120 \mathrm{Vgl}$. Brennan, G./Buchanan, J.M. (1985/1993), S. 6.

121 Jöhr, W.A. (1976).

122 Vgl. Taylor, M. (1976), S. 28ff.; Holler, M./Illing, G. (1993), S. 139ff.

123 Vgl. Holler, M./Illing, G. (1993), S. 23.

124 Vgl. auch die Ausfuhrungen von Axelrod, $R$. (1988) zur 'tit-for-tat'-Strategie in wiederholten Spielen.

125 Grundlegend hierzu die Ausfuhrungen bei Olson, M. (1965/1992) und (1985/1991), Kap. 2. 
Kooperationsregeln wird oftmals daran scheitern, daß Regelverletzungen nicht adäquat sanktioniert werden.

\section{b. Die transaktionskostentheoretische Interpretation des Kooperationsproblems}

Die entscheidungslogisch fundierte Betrachtungsweise der Spieltheorie findet ihr Pendant im Transaktionskostenansatz. ${ }^{126}$ Um die Parallele aufzuzeigen, sei die obige Spielsituation des Gefangenendilemmas nochmals betrachtet. ${ }^{127}$ Bietet ein Spieler dem anderen eine Kooperation verbindlich an (Handlungsoption $\mathrm{k}$ ), so tätigt er eine Vorleistung, die als Investition im transaktionskostentheoretischen Sinne bezeichnet werden kann. Der Erfolg der Investition k ist nun aber wesentlich von der Reaktion des zweiten Spielers abhängig, und damit ist das typische Merkmal einer spezifischen Investition erfullt. Reagiert Spieler 2 ebenfalls mit k, erzielt die Investition des ersten Spielers die gewünschte Rendite U(k,k). Antwortet er jedoch auf das Kooperationsangebot mit Nicht-Kooperation n, wird die Investition für Spieler 1 zum Verlustgeschäft, denn $U(k, n)<U(n, n) .{ }^{128}$ Offenbar wird Spieler 1 die Investition k nur tätigen, wenn er sicher sein kann, daß Spieler 2 sich ebenfalls kooperativ verhält. Denn entscheidet sich der erste Spieler für k, kann sich der andere opportunistisch verhalten und die QuasiRente des Spielers 1 ausbeuten. Ohne eine beiderseitig bindende Verpflichtung, einen Vertrag, kommt die produktive Interaktion $(\mathrm{k}, \mathrm{k})$ nicht zustande, und die Individuen verharren in der Ausgangssituation (n,n).

Die Vertragsbeziehung selbst ist mit Transaktionsaufwendungen, namentlich Such-, Verhandlungs- und Kontrollkosten, verbunden. Nur wenn die individuellen Transaktionskosten geringer sind als die persönlich erzielbaren Nutzen aus der Kooperation, wird der Vertrag geschlossen. Damit kann mit Hilfe des Transaktionskostenkonzepts auch erklärt werden, weshalb es unter bestimmten Bedingungen zur Kooperation kommt.

In wiederholten Spielen stehen den kurzfristigen Vorteilen opportunistischen Verhaltens die langfristigen Nachteile der Nicht-Kooperation gegenüber. Rational kalkulierende Individuen vergleichen die abdiskontierten zukünftigen Nutzenverluste durch Nicht-Kooperation mit den Transaktionskosten eines Vertragsarrangements und verhalten sich kooperativ, wenn der Gegenwartswert der Nutzenverluste größer ist als die Transaktionskosten. Längerfristig kooperatives Verhalten führt zum Aufbau von Reputation ${ }^{129}$, und der Zugewinn an Sicherheit führt zu einer Verringerung der Transaktionskosten. Die Transaktionskosten können aber eventuell noch weiter verringert werden, wenn anstelle von Neuverhandlungen nach jeder Spielrunde eine längerfristig gültige Kooperationsvereinbarung getroffen wird.

Die Problematik der großen Gruppe wird bei Vorliegen von Transaktionskosten evident. Wenn nur zwei Spieler durch ein Kooperationsdilemma verbunden sind, genügt ein bilateraler Vertrag, um die wechselseitige Kooperation zu sichern. Die dabei anfallenden Vertragskosten können relativ gering sein. Bei einer großen Zahl von Beteiligten ist die Zahl der notwendigen zweiseitigen Vereinbarungen, und somit auch die Höhe der Transaktionskosten, beträchtlich. Folglich kann aus dem individuellen Kosten-Nutzen-Kalkül der Spieler abgeleitet werden, daß

126 Vgl. Leipold, H. (1989), S. 133. Vgl. auch Williamson, O.E. (1985/1990), S. 235.

127 Vgl. hierzu Pies, I. (1993), S. 244ff.

128 Zur Verdeutlichung der Abhangigkeit des Nutzenpotentials einer spezifischen Investition vom Verhalten der Vertragspartner wăhlt Pies anstelle des Begriffs Spezifităt die Bezeichnung "brisante Investition". Pies, l. (1993), S. 230ff.

129 Siehe etwa Kreps, D.M./Wilson, R. (1982). 
mit großer Wahrscheinlichkeit eine freiwillige, gemeinschaftliche Kooperation unterbleibt. ${ }^{130}$ Auch hier ist eine Reduktion der Transaktionskosten durch die Verringerung der Zahl erforderlicher Vertragsschlüsse möglich. Das kann im Rahmen einer hierarchisch aufgebauten Organisation erfolgen, in der die Vielzahl freiwilliger Austauschverträge durch ein Anweisungssystem ersetzt wird, bei dem einseitig angeordneter Kooperationszwang an die Stelle wechselseitiger Kooperationsversprechen tritt.

\section{c. Das Kooperationsproblem aus Sicht der konstitutionellen Ökonomik}

Die sich anschließende Frage muß deshalb lauten: Wenn freiwillige Kooperationsarrangements aufgrund der hohen Transaktionskosten nicht erreicht werden, wie kann es dann zur legitimen, d.h. konsensfähigen, Etablierung eines allseitigen Kooperationszwangs kommen? An dieser Stelle gewinnt die Unterscheidung zwischen konstitutioneller und post-konstitutioneller Entscheidungsebene zentrale Bedeutung. Hinter dem Schleier der Unwissenheit können die Individuen aufgrund der Unsicherheit über die eigene zukünftige Position nicht erkennen, ob sie persönlich von nicht-kooperativem Verhalten profitieren oder negativ betroffen sein werden. Für die Individuen ist in diesem Entscheidungsstadium lediglich absehbar, daß eine allgemeine Regelbefolgung auf Dauer für alle Beteiligten vorteilhaft ist. Anders als bei der Entscheidungssituation in der nach-vertraglichen Phase ist es deshalb denkbar, daß sich die Individuen im einmütigen Konsens auf die Einhaltung eines Kooperationszwangs einigen. Wird eine Institution etabliert, die Regelverletzungen in der post-konstitutionellen Phase sanktioniert, könnten eine wirksame Stabilisierung von Erwartungen über das Verhalten der Mitspieler erwirkt und dauerhaft Anreize zu kooperativem Verhalten gesetzt werden. Die Einhaltung der Kooperationsversprechen wird durch die auf konstitutioneller Ebene erfolgte Vereinbarung von Zwangsanwendung bei Regelverletzungen im post-konstitutionellen Stadium erreicht. 131

\section{Ressourcenzusammenlegung und Organisationsverfassung}

\section{a. Das grundlegende Dilemma der Organisation}

Doch damit ist nur ein Teil des Kooperationsproblems beschrieben. Durch die Etablierung einer Zwangsgewalt, einer Organisation, die regelwidriges Verhalten sanktioniert, ändern sich die Rahmenbedingungen von Interaktionsbeziehungen. Der freiwillige Tausch wird durch ein Anordnungssystem teilweise oder vollständig ersetzt. Diese Besonderheiten intra-organisatorischer Beziehungen werden im Modell der Ressourcenzusammenlegung von Coleman ${ }^{132}$ betont.

Nach Coleman ist das Hauptmerkmal korporativen Handelns, daß die Mitglieder der Organisation Ressourcen zur Verfügung stellen, die nicht mehr der unmittelbaren individuellen Dis-

130 Siehe dazu auch Eschenburg, R. (1977), S. 50ff.

131 "Deswegen kőnnen soziale Restriktionen ... neue Handlungsspielrăume eröffnen, und diese wiederum kőnnen so produktiv sein, daß alle Spieler von ihrem Verzicht auf Opportunismus profitieren und die mit einem solchen Verzicht verbundenen Nachteile durch jene Vorteile uberkompensieren, die durch einen solchen Verzicht uberhaupt erst realisiert werden können, mit entsprechenden Folgen fur die Konsensfahigkeit solcher Arrangements." Pies, I. (1993), S. 301, FN 106.

132 Siehe hierzu Coleman, J.S. (1979). 
position unterstehen. ${ }^{133} \mathrm{Da}$ eine individuelle Verfügungsgewalt nicht gegeben ist, müssen die Dispositionsrechte über die Ressourcen und die Verteilung der vom korporativen Akteur erwirtschafteten Erträge auf die Organisationsmitglieder geregelt werden. ${ }^{134}$ Die Festlegung dieser property rights erfolgt in einer Verfassung ${ }^{135}$, die die Rechte und Pflichten der Organisationsmitglieder regelt. 136

Dabei sind zwei idealtypische Grundmuster der Organisation korporativen Handelns zu unterscheiden. ${ }^{137}$ Beim monokratisch-hierarchischen Typ werden an einen der Beteiligten von den übrigen Ressourceneinbringern Verfügungsrechte über die eingebrachten Ressourcen abgetreten, und dieser tritt als zentraler Koordinationsagent auf. Nach der Auszahlung fester Erträge an die übrigen Mitglieder steht dem Zentralagenten das Restergebnis des Korporationsertrags zu. Genossenschaftlich-demokratische Typen korporativen Handelns sind demgegenüber dadurch charakterisiert, daß "... die Ressourceneinbringer in ihrer Gesamtheit, als Gruppe, das Verfügungsrecht über den Ressourcenpool innehaben"138 und der Korporationsertrag der Gruppe insgesamt zusteht. Dabei werden die Einbringer von Ressourcen nach Coleman bei der Ausgestaltung der Organisationsverfassung mit dem "grundlegenden Dilemma der Organisation" 139 konfrontiert:

\footnotetext{
"Um in den Genuß der Vorteile zu kommen, die Organisation bietet, müssen sie die Nutzung gewisser Rechte, Ressourcen oder Macht an die Korporation abtreten. Nur so kann der korporative Akteur die erforderliche Macht erhalten, um die Zwecke zu verfolgen, derentwegen er geschaffen wird. Dadurch jedoch, daß sie diese Rechte uberträgt, verliert jede Person weitgehend die Kontrolle uber sie. Denn der korporative Akteur kann durchaus in einer Weise handeln, die sie nicht billigt." 140
}

Die Etablierung einer Organisation erfolgt daher zur Erreichung eines (Organisations-)Ziels, gleichzeitig besteht aber die latente Gefahr der Ausbeutung der Mitglieder durch zentrale Koordinationsagenten oder andere Organisationsmitglieder. Die Festlegung von Regeln zur Durchsetzung von Kooperation verursacht damit das Folgeproblem, die Zentralgewalt durch geeignete Regelsysteme so zu begrenzen, daß ein hinreichender Schutz für die Organisationsmitglieder gegeben ist. Ein Schwerpunkt der konstitutionellen Ökonomik liegt deshalb in der Suche nach Begrenzungen der Koordinationsagenten.

\section{b. Abwanderung und Widerspruch}

Hierzu hat Hirschman in seiner Arbeit "Abwanderung und Widerspruch"141 grundlegende Vorarbeiten geleistet. Ausgangspunkt der Überlegungen Hirschmans ist ein absoluter oder

133 Daher ist es auch wichtig, zwischen organisierten Kollektiven mit korporativem Charakter und nicht-organisierten Kollektiven, die mittels einer rein statistischen Abgrenzung nach bestimmten Merkmalen definiert sind, zu unterscheiden. Vgl. Vanberg, V. (1992), S. 224.

134 Vgl. Vanberg, V. (1982), S. 16.

135 Vgl. Eschenburg, R. (1977), S. 7.

136 Nach diesem Ansatz ist die gemeinsame Basis der Mitglieder die gemeinsame Verfassung der Organisation. Das konstitutionelle Paradigma ist insoweit individualistisch ausgerichtet, berucksichtigt aber gleichzeitig den korporativen Charakter von Organisationen. Vgl. Vanberg, V. (1992), S. 242f.

137 Vgl. Vanberg, V. (1982), S. 18ff.

138 Vanberg, $V$. (1982), S. 168.

139 Coleman, J.S. (1979), S. 27.

140 Coleman, J.S. (1979), S. 25.

141 Hirschman, A.O. (1970/1974). 
relativer Rückgang der Leistungen einer Organisation. ${ }^{142}$ Der Abfall der Leistungsfähigkeit führt für die Betroffenen zu einem Informations- und Sanktionsproblem. ${ }^{143}$ Hirschman identifiziert zwei Wege, auf denen das Organisationsmanagement über die mangelhaften Leistungen informiert wird:

"(i) Eine Anzahl von Kunden hört auf, die Erzeugnisse der Firma zu kaufen, bzw. eine Anzahl von Mitgliedern tritt aus der Organisation aus: dies ist die Reaktionsweise Abwanderung. Daraufhin gehen die Einkunfte zuruck, die Mitgliederzahl sinkt, und die Unternehmensleitung wird dadurch veranlaßt, nach Mitteln und Wegen zur Korrektur der Fehler zu suchen, die zur Abwanderung gefuhrt haben. (ii) Die Kunden der Firma bzw. die Mitglieder der Organisation geben ihre Unzufriedenheit kund, und zwar auf direktem Wege durch Beschwerden bei der Unternehmens- bzw. Organisationsleitung oder einer anderen Stelle...: dies ist die Reaktionsweise Widerspruch. Daraufhin beginnt die Leitung wieder nach den Ursachen sowie den möglichen Abhilfen fur die Unzufriedenheit der Kunden bzw. Mitglieder zu suchen." 144

Die Wirksamkeit der Abwanderungsoption (exit) setzt die Verfügbarkeit realisierbarer Alternativen und damit von Wettbewerb auf gut funktionierenden Märkten voraus. ${ }^{145} \mathrm{Je}$ höher die Kosten der Abwanderung sind, desto stärker ist der empfundene Zwang der Kollektivmitgliedschaft. ${ }^{146}$ Diese Kosten sind selbst wiederum von organisationsinternen und -externen Faktoren bestimmt. ${ }^{147}$ Interne Austrittsbarrieren sind Kosten, die innerhalb des korporativen Akteurs z.B. durch die Einbehaltung bereits eingebrachter Ressourcen bis hin zu direkten Sanktionen 148 der Abwanderung entstehen. ${ }^{149}$ Die externe Marktstruktur bestimmt dagegen die alternativen Verwendungsmöglichkeiten. Dabei ist nicht entscheidend, daß von der Möglichkeit der Abwanderung auch tatsächlich Gebrauch gemacht wird; bereits die Androhung eines Austritts aus der Organisation kann einen "vorbeugenden Schutz"150 der Mitgliederinteressen bewirken.

Widerspruch (voice) bezeichnet dagegen den Versuch, die Praktiken, Grundsätze oder die Ausbringung der Organisation, der man angehört, zu ändern, anstatt ihnen auszuweichen. 151 Die Reaktionsweise Widerspruch beschreibt die Möglichkeit der Einflußnahme der Organisationsmitglieder auf Entscheidungen des korporativen Akteurs ${ }^{152}$, in den Worten Colemans: deren "Organisationsmacht"153. Nun sagt allein die Äußerung von Widerspruch nichts über dessen Erfolgsaussichten aus; es müssen für die Organisationsleitung auch Konsequenzen drohen. ${ }^{154}$ Der Zwangscharakter einer Organisation ist mithin abhängig von den Kosten und

142 Vgl. Hirschman, A.O. (1970/1974), S. 3f.; Birch, A.H. (1975), S. 73.

143 Vgl. Fehl, U. (1978), S. 402.

144 Hirschman, A.O. (1970/1974), S. 3f. (Hervorhebungen im Original).

145 Vgl. Hirschman, A.O. (1987), S. 219.

146 Vgl. Coleman, J.S. (1974), S. 11; Kirsch, G. (1993), S. 47f.

147 Vgl. Vanberg, V. (1982), S. $182 \mathrm{ff}$.

148 So verweist Hirschman darauf, daß gerade im politischen Bereich Abwanderung hăufig als verbrecherisch gebrandmarkt wurde. Hirschman, A.O. (1970/1974), S. 14f.

149 Interne Austrittsbarrieren bezeichnen damit die Spezifităt der getătigten Investitionen.

150 Vanberg, $V$. (1982), S. 181.

151 Vgl. Hirschman, A.O. (1970/1974), S. 25 und (1976), S. 388.

152 Vgl. Kirsch, G. (1993), S. 48.

153 Coleman, J.S. (1979), S. 65.

154 Vgl. Fehl, U. (1978), S. 408. Eine solche Konsequenz könnte auch im Verlust des Amtes aufgrund der Äußerung von Widerspruch durch die Organisationsmitglieder selbst liegen. Eschenburg unterscheidet daher auch explizit zwischen 'Widerspruch' und 'Abwahl'. Vgl. Eschenburg, R. (1977), S. $215 \mathrm{ff}$. 
den Veränderungschancen der voice-Option. ${ }^{155}$ Beide Faktoren werden bestimmt durch die Ausgestaltung der organisationsinternen Entscheidungsstrukturen.

Zwischen exit und voice steht nach Hirschman eine intervenierende Variable, die Loyalität. Hirschman versteht darunter eine besondere Anhänglichkeit der Mitglieder an die Organisation. ${ }^{156}$ Loyalität gegenüber einer Institution erhöht die exit-Kosten und schiebt die Wahrscheinlichkeit einer Abwanderung hinaus; andererseits setzt Loyalität das Vorliegen einer Abwanderungsalternative voraus. ${ }^{157}$

In seinen Darlegungen betont Hirschman, daß die Reaktionsweisen "Abwanderung und Widerspruch als Verkörperungen der Ökonomie und der Politologie"158 gelten, und daher in der jeweils anderen Disziplin nur geringe Beachtung gefunden haben, obwohl "... die Analyse dieses Wechselspiels zu einem vollständigeren Verständnis sozialer Prozesse führen wird, als es die ökonomische und politische Analyse isoliert voneinander bieten können." 159 Hauptanliegen Hirschmans ist es deshalb aufzuzeigen, daß Abwanderung und Widerspruch sowohl im politischen als auch im ökonomischen Bereich eine wichtige Rolle spielen (können). ${ }^{160}$ Insofern vermag das exit-voice-Konzept auch wichtige Erkenntnisse für die Ausgestaltung einer Organisationsverfassung im allgemeinen und einer foderativen Finanzverfassung im speziellen zu liefern.

Aus den bislang angestellten Überlegungen sind für das Design einer Organisationverfassung folgende Schlußfolgerungen zu ziehen. Es muß aufgezeigt werden, welche Faktoren für die Ressourcenzusammenlegung unter einer zentralen Koordinationsagentur sprechen. Aus dem Blickwinkel der Neuen Institutionenökonomik ist die Etablierung einer Organisation nur sinnvoll, wenn die Transaktionskosten infolge entgangener Kooperationsgewinne höher sind als die Kosten der intra-organisatorischen Koordination. Letztere beinhalten die Transaktionskosten zur Herstellung des Organisationsarrangements und die Kosten des Opportunismus der Koordinationsagenten, deren Höhe wiederum maßgeblich von den Regeln der (kollektiven) Beschlußfassung in der Organisation bestimmt ist. Die Ausgestaltung der Entscheidungsregeln muß daher einerseits die Erreichung der Organisationsziele garantieren, andererseits aber gleichzeitig Absicherungsmechanismen beinhalten, die die Organisationsmitglieder vor opportunistischem Verhalten der Koordinationsagenten schützen. Abwanderungs- und Widerspruchsoptionen können dabei die erforderliche Schutzfunktion bieten.

155 Vgl. Kirsch, G. (1993), S. 49.

156 Vgl. Hirschman, A.O. (1970/1974), S. 66.

157 Vgl. Hirschman, A.O. (1970/1974), S 66ff. Das Konzept der Loyalităt ist in der wissenschaftlichen Diskussion auf Kritik gestoßen. So fuhrt Barry aus, daß Loyalităt nur schwer okonomisch greifbar sei und daher eher der Nicht-Falsifizierbarkeit des exit-voice-Ansatzes dient, denn einer wirklichen Begrundung, weshalb Organisationsmitglieder trotz Unzufriedenheit mit den angebotenen Leistungen der Organisation nicht abwandern. Vgl. Barry, B. (1974), insbes. S. 93ff. Ähnlich hierzu Birch, A.H. (1975).

158 Hirschman, A.O. (1970/1974), S. 13. Widerspruch ist nach Hirschman "... politisches Handeln par excellence." Hirschman, A.O. (1970/1974), S. 13.

159 Hirschman, A.O. (1970/1974), S. 15.

160 Siehe hierzu die Einleitung in Hirschman, A.O. (1970/1974). 


\section{B. Die ökonomische Logik des Staates}

\section{Die Notwendigkeit der Existenz eines Staates}

\section{Vorbemerkungen}

Die Frage nach den Bestimmungsgründen der Existenz eines Staates bildet seit jeher einen zentralen Punkt des Erkenntnisinteresses verschiedener sozialwissenschaftlichen Ansätze, insbesondere der politischen Philosophie und der Ökonomie. Auch wenn zwischen beiden Forschungsrichtungen, wie noch zu zeigen ist, Überschneidungen vorliegen, soll im folgenden ausschließlich der Frage nachgegangen werden, weshalb ein Staatswesen aus spezifisch ökonomischer Sicht erforderlich ist. ${ }^{161}$

Dominierender Ansatz der ökonomischen Rechtfertigung des Staates ist die auf den Arbeiten von Pigou, Bator und Musgrave beruhende Theorie des Marktversagens ${ }^{162}$, nach der Staatstätigkeit allokationspolitisch im Falle des Vorliegens von öffentlichen Gütern, externen Effekten, natürlichen Monopolen und Informationsasymmetrien begründet wird. Darüber hinaus wird dem Staat häufig eine stabilisierungspolitische und eine verteilungspolitische Rolle zugedacht. ${ }^{163}$ Gemeinsame Grundaussage dieser Ansätze ist, daß der Markt bei der Lösung bestimmter Probleme zu versagen drohe und deshalb der Staat korrigierend eingreifen müsse. Indessen gibt es zwar "... Bereiche, bei denen marktliche Prozesse auf der Basis rein individueller Vertragsbeziehungen zwischen Anbietern und Nachfragern systematisch nicht zu effizienten Ergebnissen führen ...", freilich impliziert dies a priori nur einen "kollektiven Handlungsbedarf", jedoch nicht zwingend einen "staatlichen Regulierungsbedarf" 164 . Es geht also zunächst darum, gemeinschaftliche Handlungsbedarfe festzustellen, um dann in einem nächsten Schritt zu fragen, ob der Staat der geeignete Mechanismus ist, das anstehende Kooperationsproblem zu lösen.

\section{Der protektive Staat}

\section{a. Die staatslose Gesellschaft}

Die ökonomische Analyse geht in einem Gedankenexperiment von einer staatslosen Gesellschaft aus und untersucht, welche Aspekte die Individuen dazu bewegen können, sich kollektiv in einem Staat zu organisieren. In diesem fiktiven Urzustand, der als "Anarchie"165 oder "Naturzustand" 166 bezeichnet wird, existieren keine Regeln, die das menschliche Zusammen-

$161 \mathrm{Zu}$ einem Überblick uber die Ansătze der politischen Philosophie siehe Arnim, H.H. von (1984), S. 18ff.

162 Siehe Pigou, A.C. (1932); Bator, F. (1958); Musgrave, R.A. (1959/1969), S. 3ff. Zu einem aktuellen Überblick uber die Marktversagenstheorie siehe etwa Richter, W.F. /Wiegard, W. (1993).

163 So insbesondere bei Musgrave, R.A. (1959/1969), S. 26ff. und S. 353ff.

164 Alle Zitate Kruse, J. (1987), S. 93.

165 Buchanan, J.M. $(1975 / 1984)$, S. 80.

166 Buchanan, J.M. $(1975 / 1984)$, S. 78. 
leben in irgendeiner Weise ordnen. ${ }^{167}$ Es gibt keine Institutionen, die Rechte der Individuen garantieren; eine Rechtsordnung ist nicht vorhanden. 168

Da einer Aneignung der Früchte produktiver Tätigkeiten anderer keine Schranken gesetzt sind, existiert Eigentum nicht als eine legale Kategorie. ${ }^{169}$ Rational handelnde Individuen setzen nur einen Teil ihrer verfügbaren Ressourcen für die Produktion von Gütern ein, der andere Teil der Aktivitäten ist auf die gewaltsame Aneignung der produktiven Ergebnisse anderer und auf den Schutz der eigenen produktiven Ergebnisse vor einer Aneignung durch Dritte gerichtet. ${ }^{170}$ Das ökonomische Rationalkalkül impliziert, daß die Individuen ihre Ressourcen so einsetzen, daß alle drei Aktivitäten die gleichen Marginalerträge erbringen.

Als Resultat des Zusammenspiels individueller Produktionstätigkeit, wechselseitiger Gewaltanwendung bzw. -androhung und Abwehrbemühungen ergibt sich nach Buchanan eine "natürliche Verteilung"171 der physischen Güter. Die gesellschaftliche Produktivität ist gering, da nur die Gütererstellung, nicht jedoch die Schutz- und Eroberungsbemühungen sozial nutzenstiftend sind. ${ }^{172}$ Aus ökonomischer Perspektive wäre es deshalb vorteilhaft, wenn die Individuen auf die gegenseitige Gewaltanwendung verzichten würden und die freigewordenen Ressourcen einer produktiven Verwendung zuführen. Erst die Akzeptanz individueller property rights von allen anderen Akteuren verschafft den Wirtschaftssubjekten einen Freiheitsspielraum, der bei Nicht-Existenz eines solchen allgemein anerkannten Regelsystems durch den Einsatz von Ressourcen für Angriffs- und Verteidigungszwecke erkämpft werden muß. 173

Besitzsicherheit allein genügt nicht, um die Vorteile eines marktwirtschaftlichen Systems zu nutzen. Nur wenn keine Spezialisierungsvorteile existieren, die marktlichen Tausch sinnvoll machen, ist eine Selbstversorgerwirtschaft effizient. Die prosperierenden Wirkungen von Arbeitsteilung und marktlichem Tauschhandel können sich nur entfalten, wenn die abgeschlossenen Tauschverträge auch eingehalten werden. In der staatslosen Gesellschaft entstehen aufgrund der Unsicherheit über die Einhaltung von Abmachungen hohe Transaktionskosten. Da keine rechtliche Durchsetzbarkeit der Ansprüche aus Verträgen gegeben ist, sind in der Anarchie Vertragsschlüsse ausschließlich an gegenseitiges Vertrauen der Tauschpartner gebunden. ${ }^{174}$ Die Wirtschaftssubjekte müssen erhebliche Ressourcen in die Gewinnung von

167 Vgl. Buchanan, J.M. (1975/1984), Kap. 2. Siehe auch Lee, D.R./McKenzie, R.B. (1987), S. 18.

168 Buchanan nimmt als Ausgangspunkt den Hobbes'schen Naturzustand an, bei dem keinerlei ordnende Rechte der Individuen bestehen. Vgl. Buchanan, J.M. (1975/1984), S. 8, S. 34; Hobbes, T. (1651/1984). Alternativ könnte ein Urzustand im Locke'schen Sinne angenommen werden, bei dem Individuen uber bestimmte naturliche Rechte verfugen, aber gleichfalls durch eine fehlende Rechtsordnung charakterisiert ist. Der Naturzustand nach Locke, J. (1690/1977) bildet die Basis der Überlegungen von Nozick, $R$. $(1974 / 1976)$, S. $25 \mathrm{ff}$.

169 Vgl. Tullock, G. (1974), S. 9.

170 In der rechtslosen Gesellschaft ist ein Verzicht auf Angriffs- und Verteidigungsbemuhungen individuell irrational. Fur alle Individuen ist die dominante Verhaltensstrategie, alle ubrigen Gesellschaftsmitglieder anzugreifen und entsprechende Verteidigungsvorkehrungen zu treffen. Siehe Schotter, A. (1981), S. $45 \mathrm{ff}$.

171 Buchanan, J.M. (1975/1984), S. 33. Vgl. dazu auch Bush, W.C. (1972).

172 Vgl. Anderson, T.L./Hill, P.J. (1980), S. 5f. Siehe auch Frey, B.S. (1981a), S. 22.

$173 \mathrm{Vgl}$. Eschenburg, R. (1978), S. 14.

174 Vgl. Kronman, A.T. (1985), S. $11 \mathrm{ff}$. 
Informationen über die Glaubwürdigkeit der Tauschpartner investieren ${ }^{175}$, so daß viele Transaktionen aufgrund ihrer hohen Kosten unterbleiben.

Somit bleibt festzuhalten: In einem fiktiven Naturzustand, in dem das Zusammenleben der Individuen nicht durch Regeln geordnet ist, kann kein dauerhaft vorteilhafter Prozeß sozialer Interaktion entstehen. Die staatslose Gesellschaft ist durch Besitz- und Tauschunsicherheit geprägt. ${ }^{176}$ Erforderlich ist die Fixierung eines Regelsystems, welches den Individuen die Sicherheit gibt, daß Nutzungs- und Interaktionsrechte respektiert werden.

\section{b. Die Garantie von Besitz- und Tauschsicherheit durch den protektiven Staat}

Mit der Begründung eines sozialen Regelsystems sind aber die oben geschilderten Probleme sozialer Dilemmata verbunden: Alle Gesellschaftsmitglieder profitieren davon, wenn jeder die Verfügungsrechte der anderen respektiert, denn die erhöhte Sicherheit ermöglicht eine Verringerung der Verteidigungs- und Sicherungsbemühungen und eine Umwidmung der freigewordenen Ressourcen für produktive Verwendungen. Es liegen die typischen Merkmale eines Kooperationsspiels vor.

Die strategische Interdependenz der Individuen bei der gegenseitigen Anerkennung von Verfügungsrechten wird durch die Gefangenendilemmasituation adäquat beschrieben. ${ }^{177} \mathrm{Die}$ freiwillige Selbstbindung, die property rights aller anderen Gesellschaftsmitglieder zu respektieren und fortan auf die Anwendung oder Androhung von Gewalt zum Zwecke der Eroberung fremden Eigentums zu verzichten, stiftet dem sich selbst verpflichtenden Individuum keine Nutzen, sondern verursacht nur Kosten in Form einer Beschränkung des eigenen Handlungsspielraums. ${ }^{178}$ Eigene Verteidigungsbemühungen können dagegen nur reduziert werden, wenn gesicherte Erwartungen bestehen, daß die anderen Individuen auf Gewaltanwendung verzichten. Wenn aber alle Gesellschaftsmitglieder außer einem Individuum wechselseitig die Rechte aller anderen respektieren, wird der individuelle Vorteil einer Nicht-Beachtung von Verfügungsrechten besonders groß.

Jeder der Spieler stellt sich im Vergleich zur kooperativen Strategie besser, wenn er die Verfügungsrechte des anderen nicht respektiert, unabhängig davon, ob der jeweils andere Spieler sich regelkonform verhält oder nicht. Nicht-kooperatives Verhalten ist in jedem Falle die dominante Stategiewahl für alle Beteiligten. Selbst wenn eine Abmachung zu kooperativem Verhalten zwischen den Individuen getroffen wird, ist es für jeden einzelnen doch rational, sich in der Phase nach Vertragsschluß nicht an die getroffenen Vereinbarungen zu halten. ${ }^{179}$

Im Ergebnis kommt eine stabile Rechtsordnung nicht zustande, solange es keine externe Instanz gibt, die die Regeleinhaltung kontrolliert, Regelverletzungen sanktioniert und dadurch die Attraktivität eines regelkonformen Verhaltens erhöht. Ohne eine weisungs- und sanktionsbefugte Zwangsgewalt ist die Überwindung der sozialen Dilemmasituation, so Buchanan, nicht möglich, denn weil die Individuen von der Akzeptanz von Rechten anderer selbst nicht

175 Vgl. Tullock, G. (1974), S. 11.

176 Vgl. Kronman, A.T. (1985), S. 6.

177 Siehe hierzu unter vielen Buchanan, J.M. (1975/1984), S. 39.

178 Vgl. Buchanan, J.M. (1975/1984), S. 154.

179 Vgl. Taylor, M. (1976), S. 5; Miller, G.J. (1992), S. 25; Brennan, G./Buchanan, J.M. (1985/1993), S. 5 f. 
profitieren, ergibt sich aus dem ökonomischen Rationalkalkül, daß sich niemand regeltreu verhalten wird. ${ }^{180}$ Es entsteht eine potentielle Rolle für den Staat als Instanz zur Durchsetzung von Eigentums- und Vertragsrecht. 181

Freilich ist die Betreibung einer kollektiven Schutzorganisation nicht kostenlos, die Individuen müssen die Verfügungsgewalt über einen Teil ihrer Ressourcen aufgeben. ${ }^{182}$ Das ökonomische Kalkül liefert die Begründung für eine rechtsdurchsetzende Agentur, wenn die Kosten der Schaffung von Besitz- und Tauschsicherheit geringer sind als deren Nutzen. A priori kann keine definitive Aussage gemacht werden, ob eine kollektive Schutzorganisation kostengünstiger ist als individuelle Verteidigungsaufwendungen. Sofern jedoch die externe Instanz unerlaubte Handlungen effektiv sanktioniert, können die Beteiligten auf individuelle Abwehrmaßnahmen verzichten. ${ }^{183}$ Liegen für die "production of order" 184 ausreichend große Skalenerträge vor, ist die Übertragung des Gewaltmonopols auf den Staat ökonomisch geboten. ${ }^{185}$ Mit dieser Erkenntnis erscheint auf konstitutioneller Ebene eine Übereinkunft über die Etablierung eines Staates durch die beteiligten Individuen naheliegend.

Die Organisation, die Besitz- und Tauschsicherheit gewährleistet, bezeichnet Buchanan als "protektiven Staat" oder "Rechtsschutzstaat"186, der allein mit dem Schutz der Individuen vor Verletzungen ihrer grundlegenden Eigentumsrechte betraut ist; man kann deshalb von einem "Minimalstaat" 187 sprechen. Durch den protektiven Staat wird der Ordnungsrahmen durchgesetzt, der die Entfaltung der Individuen in einem marktlichen System frei von Beeinträchtigungen ihrer property rights gewährleistet. Seine ureigenste Aufgabe ist der Schutz der Gesellschaftsmitglieder gegen interne oder externe Bedrohung sowie die Bestrafung von Regelverletzungen.

Als rechtsschützende Institution fungiert der Staat, so Buchanan, wie ein außenstehender Schiedsrichter. ${ }^{188}$ Der protektive Staat definiert keine Rechte, sondern hat lediglich den Auftrag, das Faktum einer Rechtsverletzung festzustellen und den privat ausgehandelten Rechten Geltung zu verschaffen. Weder für die Feststellung von Eigentumsdelikten noch für den Befund von Vertragsverletzungen benötigt der protektive Staat deshalb gesetzgeberische Kompetenzen oder Auswahlmechanismen. Die Entscheidungen haben vielmehr den Charakter von "Wahrheitsurteilen"189.

$180 \mathrm{Vgl}$. Buchanan, J.M. (1975/1984), S. 154.

181 Vgl. Lee, D.R./McKenzie, R.B. (1987), S. 18. Ähnlich stellt bereits Eucken fest, daß "... ohne die ordnende Potenz eines Staates eine zureichende Wirtschaftsordnung nicht aufgebaut werden kann." Eucken, $W$. (1952), S. 332.

182 "Entry into a collective agreement to form a state necessariliy entails a restriction of ... freedom, for the individual's use of resources is now constrained by the property rules adopted by that state." Whynes, D.K./Bowles, R.A. (1981), S. 14. Zu den Kosten der Etablierung eines Eigentumsrechtssystems siehe Anderson, T.L./Hill, P.J. (1975); (1983).

183 Allein schon die glaubhafte Androhung negativer Sanktionen durch eine externe Instanz kann die Beteiligten zur Kooperation veranlassen, vgl. Tullock, G. (1974), S. 13f.

184 Auster, R.D./Silver, M. (1979), S. 5.

185 Vgl. Auster, R.D./Silver, M. (1979), insbes. Kap. 1 und S. 55ff. und Nozick, R. (1974/1976), S. 107ff.

186 Buchanan, J.M. (1975/1984), S. 97.

187 Nozick, R. (1974/1976), S. 38. Vgl. auch Brennan, G./Buchanan, J.M. (1981), S. 112.

188 Vgl. Buchanan, J.M. (1975/1984), S. 97.

189 Buchanan, J.M. (1975/1984), S. 136. 


\section{Der produktive Staat}

\section{a. Marktliche versus staatliche Koordination}

In einer Welt ohne Transaktionskosten führt der durch Wettbewerbspreise gesteuerte Transfer von property rights in Verbindung mit dem Nutzenmaximierungsstreben der Marktteilnehmer dazu, daß die knappen Faktoren stets ihrer sozial nützlichsten Verwendung zugeführt werden. Das Preissystem erfüllt eine Kommunikationsfunktion ${ }^{190}$, mittels der den Marktteilnehmern alle notwendigen Informationen über die effektiven Güter vermittelt werden. Der spontan koordinierte Prozeß der Marktinteraktionen bewirkt im Ergebnis eine Maximierung der gesellschaftlichen Wohlfahrt.

So ist auch in einer Modellwelt vollständiger Märkte Unsicherheit über die zukünftigen Umweltzustände allein kein einschneidendes Problem. Die Effizienz der freiwilligen marktlichen Koordination könnte durch Zukunfts- oder Versicherungsmärkte, auf denen bedingte Ansprüche gehandelt werden, gesichert werden. ${ }^{191}$ Ein zentrales Problem entsteht aber, weil die Individuen häufig keine Anreize haben, private Informationen korrekt zu offenbaren.

Marktliche Tauschhandlungen implizieren das Vorliegen von Spezialisierungsvorteilen und damit von Informationsasymmetrien. Rationale, eigennützige Individuen haben einen Anreiz, private Informationen nicht preiszugeben, sofern sie sich hieraus einen Vorteil in einer Tauschbeziehung erhoffen. In den Marktpreisen spiegeln sich dann nicht mehr alle relevanten Informationen über den Transaktionsgegenstand wider. Aufgrund der fehlenden Information darüber, wie sich ein potentieller Tauschpartner in der Transaktionsbeziehung tatsächlich verhält, kann der Koordinationsmechanismus Markt versagen, weil Eigenschaften von Leistung und Gegenleistung ex ante unbeobachtbar sind und dies auch solange bleiben, bis die Transaktion nicht mehr rückgängig gemacht werden kann. ${ }^{192}$ Der marktliche Tausch ist daher stets mit der latenten Gefahr opportunistischen Verhaltens verknüpft.

Asymmetrien der Informationsverteilung sind damit die Grundlage für das Entstehen sozialer Dilemmasituationen. Jeder Marktteilnehmer kann sich durch opportunistisches Verhalten kurzfristige Vorteile auf Kosten der Vertragspartner sichern. Längerfristig liefert dennoch ein funktionierender Wettbewerbsmarkt in den meisten Fällen die notwendige Sanktionierung nicht-kooperativen Verhaltens. Opportunistische Interaktionspartner würden Reputationsverluste erleiden, die schließlich dazu führen können, daß sie nicht mehr als Tauschpartner akzeptiert werden. 193

In manchen Fällen sind aber private Absicherungen zu kostspielig, bzw. die notwendigen Absicherungsmaßnahmen können aufgrund objektiver Tatbestände nicht getroffen werden, so daß potentiell wohlfahrtssteigernde Transaktionen unterbleiben. Es besteht zwar kollektiver Handlungsbedarf, der aber durch freiwillige Abmachungen nicht befriedigt werden kann. Ist dies der Fall, eröffnet sich eine denkbare Rolle für den Staat, durch entsprechende Maßnah-

190 Siehe Hayek, F.A. von (1945).

191 Siehe u.a. Debreu, G. (1959); Arrow, K.J./Hahn, E.F. (1971).

192 Vgl. Terberger, E. (1994), S. 61.

193 Vgl. Tullock, G. (1985); Pejovich, S. (1990), S. 40. Oftmals können sich die Individuen durch spezielle private Regelungen gegen Opportunismus der potentiellen Vertragspartner absichern, so daß Tauschvertrăge zustandekommen. Siehe etwa Spence, A.M. (1973); Jensen, M.C./Meckling, W.H. (1976); Holmström, B. (1979); Kreps, D.M. (1990). 
men eine Verbesserung der Ressourcenallokation zu erreichen. Staatliche Eingriffe, die über die minimalstaatlichen Funktionen hinausgehen, erscheinen gerechtfertigt, wenn der Steuerungsmechanismus Markt bestimmte Probleme nicht so gut lösen kann wie der Staat. 194

Trotz der formal (spieltheoretisch) identischen Problemstruktur besteht zwischen der protektiven Staatstätigkeit und den im folgenden erörterten potentiellen Begründungen für weitergehende staatliche Aktivitäten ein grundlegender Unterschied. ${ }^{195}$ Die Existenz einer schützenden Funktion ist notwendige Voraussetzung für privatwirtschaftliche, marktliche Koordination. Die nachfolgenden Betrachtungen beziehen sich dagegen auf potentielle Defekte im Markt, die das Zustandekommen von bestimmten Transaktionen behindern oder sogar gänzlich verhindern. Hier kann der Staat behilflich sein, Transaktionen abzuwickeln, die ohne sein Eingreifen nur in suboptimalem Umfang stattfinden. Während also ohne den schützenden Staat praktisch keine Transaktionen stattfinden können, tritt der Staat in den weiteren Fällen als alternativer Koordinationsmechanismus zum Markt auf, durch den die Individuen Güter und Dienste für sich selbst bereitstellen. Diese Staatsfunktion kennzeichet nach Buchanan den "produktiven Staat" oder "Leistungsstaat"196.

\section{b. Marktversagen als Konsequenz hoher Transaktionskosten}

\section{aa. Fehlende Ausschließbarkeit und das Problem der Externalitäten}

Eine zentrale These des property rights-Ansatzes besagt, daß die vollkommen spezifizierte Zuordnung der Rechte an einem Gut eine effiziente Verwendung der Ressourcen garantiert. Werden dagegen einzelne Teilrechte nicht privat zugeordnet, ergeben sich Ineffizienzen, weil bei individuellen Entscheidungen über die Ressourcenverwendung nur die persönlichen, nicht jedoch die sozialen Handlungskonsequenzen berücksichtigt werden ${ }^{197}$; bei der individuellen Inanspruchnahme entstehen Externalitäten ${ }^{198}$, als deren Folge marginale private und soziale Bewertungen differieren. 199

In der neoklassischen Modellwelt ohne Transaktionskosten ist die eindeutige Definition von Verfügungsrechten problemlos, so daß der freie Handel mit property rights eine perfekte Internalisierung der externen Effekte im Eigeninteresse der Beteiligten ermöglicht. ${ }^{200}$ Eine fundamentale Erkenntnis des sog. "Coase-Theorems"201 ist, daß bei Vernachlässigung von

194 Es ist jedoch zu beachten, daß auch die Entstehung der Institution private Unternehmung mit Hilfe der einzelnen Kategorien des Marktversagens begrundet werden kann. Vgl. Arrow, K.J. (1977), S. 79; Miller, G.J. (1992), S. 20.

$195 \mathrm{Vgl}$. auch Fritsch, M. (1982), S. 105ff.

196 Buchanan, J.M. (1975/1984), S. 97.

197 Siehe Gordon, H.S. (1954); Hardin, G. (1968); Cheung, N.S. (1970).

198 In der Definition von Baumol und Oates spricht man von Externalităten, "...whenever some individual's (say A's) utility or production relationships include real ... variables, whose values are chosen by others ... without particular attention to the effects on A's welfare." Baumol, W./Oates, W.E. (1988), S. 17.

199 Vgl. z.B. Buchanan, J.M./Stubblebine, W.C. (1962); Wegehenkel, L. (1980). Damit unterscheiden sich die hier angesprochenen technologischen Externalităten von pekuniären externen Effekten, die Konsequenz sich verändernder Knappheiten und damit allokativ irrelevant sind. In einem marktlichen System sind alle Handlungen der Wirtschaftssubjekte interdependent; Allokationsineffizienzen entstehen erst, wenn die Interdependenzen nicht uber den Preismechanismus koordiniert werden. Zur Abgrenzung von pekuniăren und technologischen Externalităten siehe Viner, J. (1931); Scitovsky, T. (1954); Meade, J.E. (1973), Kap. I.

200 Grundlegend dazu Coase, R.H. (1960).

201 Der Begriff "Coase-Theorem" geht zuruck auf Stigler, G.J. (1966), S. 113. 
Transaktionskosten und Einkommenseffekten durch freiwillige Verhandlungen eine effiziente Allokation erreicht wird, und dies unabhängig davon, welcher Marktseite die exklusiven Rechte zugeordnet werden. ${ }^{202}$ Insofern besteht keine Veranlassung für staatliche Eingriffe. ${ }^{203}$

Allerdings besteht der Anreiz, sich an Internalisierungsverhandlungen zu beteiligen, nur solange die individuell erzielbaren Nutzengewinne größer sind als die persönlichen Kosten. Aufgrund der Existenz positiver Transaktionskosten ist dies aber nicht immer der Fall. Erstens gibt es externe Effekte, deren Messung zu prohibitiv hohen Kosten führt und/oder die Informationen über die Auswirkungen der Externalität sind asymmetrisch verteilt. 204 Bei Verhandlungen haben die Nutzer des externen Effekts einen Anreiz, ihre Wertschätzungen zu untertreiben. Die Verursacher einer (positiven) Externalität neigen dazu, ihre Wertschätzungen überhöht anzugeben, Informationsasymmetrien behindern deshalb effiziente Verhandlungslösungen. ${ }^{205}$ Zweitens sind von bestimmten Externalitäten manchmal so viele Wirtschaftssubjekte (als Absender oder Empfänger) betroffen, daß selbst bei kostenloser Identifikation der Beteiligten Verhandlungen nicht zustande kommen, weil die Vertragskosten für jedes einzelne Individuum die möglichen Internalisierungsgewinne übersteigen. ${ }^{206}$

Dort, wo diese Bedingungen vorliegen, können keine exklusiven privaten Verfügungsrechte spezifiziert werden, man spricht von einer fehlenden Ausschließbarkeit von der Nutzung. 207 Damit bleiben potentielle Tauschvorteile unausgeschöpft. Die Bereitstellung eines positiven externen Effektes (wie auch die Beseitigung einer negativen Externalität) hat die Merkmale einer transaktionsspezifischen Investition und ist mit einem sozialen Kooperationsdilemma verbunden. Ist der Nutzungsausschluß unmöglich, profitiert jedes Individuum, das sich nicht am Bereitstellungsarrangement beteiligt, von kooperativem Verhalten anderer, ohne jedoch individuelle Kosten zu tragen. Die Einnahme einer nicht-kooperativen Trittbrettfahrerposition wird begünstigt. Es kann deshalb sinnvoll sein, Entscheidungen über die Bereitstellung von Gütern, bei denen die hohen Transaktionskosten bilateraler Vereinbarungen infolge fehlender Exklusivität der property rights eine rein marktliche Koordination erschweren, über den Staat abzuwickeln. Die staatliche Autorität, Finanzierungsbeteiligungen von den Individuen zu erzwingen oder ein bestimmtes Verhalten vorzuschreiben ${ }^{208}$, eröffnet Spielräume für Transaktionskostenersparnisse, die zu gesellschaftlichen Wohlfahrtsverbesserungen führen.

\section{bb. Steigende Skalenerträge und das Monopolproblem}

Als zweiter Standardfall von Marktversagen gilt die Existenz von Gütern, die durch "Unteilbarkeiten"209 gekennzeichnet sind. Fallen bei der Produktion so hohe Fixkosten an, daß im gesamten relevanten Nachfragebereich sinkende Durchschnittskosten vorliegen, kön-

202 Dies ist die extreme Variante des 'liability neutrality theorem', vgl. Veljanovsky, C.G. (1982), S. 54f.

203 Auch das Coase-Theorem kommt nicht ohne Staat aus, denn die Garantie von Handlungsrechten obliegt einer externen Sanktionsinstanz. Vgl. Richter, W.F./Wiegard, W. (1993), S. 194.

204 Vgl. North, D.C. (1990/1992), S. 34ff.; Richter, R. (1994), S. 14.

205 Vgl. Myerson, R.B./Satterthwaite, M.A. (1983); Farrell, J. (1987); Schweizer, U. (1988).

206 Siehe dazu auch Posner, R.A. (1977), S. 45.

207 Ausschlußarrangements sind eine wichtige Quelle von Transaktionskosten. Vgl. Arrow,K.J. (1977), S. 76f.

208 Einen Überblick uber staatliche Internalisierungsmechanismen für externe Effekte geben z.B. Boadway, R.W./Wildasin, D.E. (1984), Kap. 5.

209 Buchanan, J.M. (1968). Andere Autoren sprechen von "joint supply", so z.B. Head, J. (1962) oder Mueller, D.C. (1989), S. 11. 
nen kompetitive Anbieter diese Güter nicht verlustfrei am Wettbewerbsmarkt anbieten, obwohl exklusive private property rights spezifizierbar sind. In Konsequenz werde entweder kein privates Angebot zustandekommen oder es bilde sich ein natürliches Monopol, dessen Output unterhalb des sozial optimalen Versorgungsniveaus liegt. ${ }^{210}$

Arrow vertritt die Auffassung, hierbei handle es sich um ein technologisches Problem, das nicht von Interesse sei, wenn es um die Auswahl eines Koordinationsmechanismus geht. 211 Diese Interpretation ist aber fragwürdig, weil im Zusammenhang mit dem Vorliegen von Skalenvorteilen in der Produktion Probleme irreversibler Investitionen auftreten, die, wie Goldberg und Williamson zeigen, die Investoren in eine strategische Abhängigkeit von den potentiellen Vertragspartnern bringen würden. ${ }^{212}$ Potentielle Investoren sehen sich der Gefahr ausgesetzt, daß Nachfrager abwandern; potentielle Nachfrager wollen sich umgekehrt gegen die Risiken von Preis- und Qualitätsänderungen in der Versorgung absichern. ${ }^{213}$ Obwohl alle Beteiligten ein Interesse an einem Bereitstellungsarrangement haben, besteht für alle gleichermaßen das Risiko, daß sich die Interaktionspartner nach der Tätigung der Investition die Quasi-Rente aneignen. Das vor solchen Investitionsentscheidungen stehende Individuum antizipiert die Ausbeutungsgefahr, und das freiwillige Zustandekommen der Transaktion hängt davon $a b$, ob die Vertragspartner glaubhafte Zusicherungen nicht-opportunistischen Verhaltens machen können. ${ }^{214}$

Umgekehrt könnte man argumentieren, daß die Kunden einen Vertrag über die Bildung eines Kundenkollektivs schließen könnten. 215 Die Transaktionskonstellation eines bilateralen Monopols ermöglicht ihnen die Erreichung besserer vertraglicher Konditionen als individuelle Vertragsschlüsse mit dem Monopolisten. Indessen ist aber der Anreiz für den einzelnen Kunden, Transaktionskosten eines solchen Kooperationsarrangements zu tragen, aus oben erörterten Gründen geringer, je größer die Zahl der potentiellen Mitglieder ist. Auch hier entsteht ein Kooperationsdilemma. Rationale Individuen könnten deshalb auf konstitutioneller Ebene vereinbaren, daß Bereitstellungsarrangements durch staatliche Zwangsmaßnahmen (z.B. Kontrahierungszwang, Monopolregulierung etc.) unterstützt werden können. ${ }^{216}$

\section{cc. Öffentliche Güter}

Ein Sonderfall steigender Skalenerträge ist die Kategorie der öffentlichen Güter. ${ }^{217}$ Öffentliche Güter (public goods) liegen vor, wenn bei der Bereitstellung ausschließlich fixe Kosten anfallen, die Inanspruchnahme der Leistung durch einen weiteren Nutzer also keine weiteren

210 Ausfuhrlich dazu Kruse, J. (1985). Zu den Wohlfahrtsverlusten im Monopol siehe Harberger, A. (1954).

211 "Market failures ... are relative to the mode of economic organization, while increasing returns are essentially a technological phenomenon." Arrow, K.J. (1977), S. 68.

212 Vgl. Goldberg, V.P. (1976); Williamson, O.E. (1976). Siehe auch Kaufer, E. (1981), S. 152ff.; Gröner, H. (1983), S. 230f.; Kruse, J. (1987); Telser, L.G. (1988), S. 56f.

213 Vgl. Goldberg, V.P. (1976) insbes. S. 432ff.

214 Vgl. Williamson, O.E. (1985/1990), Kap. 7 und 8.

215 Siehe hierzu Demsetz, H. (1968) und (1980), S. 43ff.; Kaufer, E. (1981), S. 152; Kruse, J. (1987), S. 98ff.

$216 \mathrm{Zu}$ einem Überblick siehe etwa Musgrave, R.A./Musgrave, P.B./Kullmer, L. (1992), Kap. 32.

217 Die Begriffsverwendung 'offentliches Gut' für den im folgenden geschilderten Sachverhalt ist nicht einheitlich. Manche Autoren bezeichnen diese Guterkategorie auch als "Kollektivguter" (Kirsch, G. (1993), "social goods" (Musgrave, R.A. (1969a)) u.v.m. Bei der Verwendung des Terminus 'offentliches Gut' ("public good") folge ich Boadway, R.W./Wildasin, D.E. (1984), S. 57ff. und S. $85 \mathrm{ff}$. 
Produktionsaufwendungen verursacht. 218 Öffentliche Güter sind damit durch die gemeinsame Nutzbarkeit ("collective consumption"219, "indivisibility"220, Nicht-Rivalität"221) bereitgestellter Einheiten gekennzeichnet. Es entstehen Skalenerträge im Konsum²22, weil mit zunehmender Nutzerzahl die Bereitstellungskosten auf mehr Köpfe verteilt werden könnten. Das Zustandekommen eines freiwilligen Bereitstellungsarrangements stößt damit aufgrund hoher Transaktionskosten gemeinsamen Handelns in großen Gruppen auf potentielle Hindernisse.

Tritt zu der vollkommenen Unteilbarkeit noch die fehlende Exklusionsmöglichkeit von der Nutzung hinzu, erhält man den gedanklichen Extremfall reiner öffentlicher Güter ${ }^{223}$, der in der Literatur besondere Beachtung gefunden hat. ${ }^{224}$ Das simultane Vorliegen steigender Skalenerträge und von Nicht-Ausschließbarkeit vermindert zusätzlich die Wahrscheinlichkeit freiwilliger Kooperationsarrangements: "Jointness of supply is the carrot, making cooperativecollective decisions beneficial to all, absence of the exclusion principle the apple tempting indviduals into independent noncooperative behavior."225

\section{dd. Stabilisatorisches Marktversagen: Arbeitslosigkeit und Inflation 226}

Die bisherige Argumentation bezog sich auf eine in bestimmten Fällen mangelnde Koordinationseffizienz der Märkte auf der Mikroebene. Doch auch auf der Makroebene, d.h. für das private Marktsystem als ganzes, können hohe Transaktionskosten verhindern, daß Kooperationsvorteile ausgenutzt werden. Weder Mengen noch Preise sind so flexibel, daß alle Märkte stets geräumt werden. ${ }^{227}$ Rigiditäten, deren mögliche Begründungsmuster im einzelnen kaum überschaubar sind, führen zu kurz- und mittelfristigen Ungleichgewichten auf Güter- und Faktormärkten. 228 An dieser Stelle soll jedoch lediglich ein Begründungsansatz für eine dauerhafte Instabilität des Marktsystems aufgezeigt werden, denn nur langfristige Instabilitäten

218 Auf diesen Zusammenhang verweist insbesondere auch Olson: "Non-rivalness is simply an extreme form of market failure due to economies of scale or decreasing costs. In any type of production in which the marginal cost is less than average cost at the marginal cost-equals-price quantity of production, there is market failure for exactly the same reason there is market failure for pure nonrival public goods for which exclusion is possible." Olson, $M$. (1986), S. 121 (Hervorhebungen im Original).

219 Samuelson, P.A. (1954), S. 387.

220 Buchanan, J.M. (1968), S. 73.

221 Musgrave, R.A./Musgrave, P.B./Kullmer, L. (1994), S. 69.

222 Vgl. Boadway, R.W./Wildasin, D.E. (1984), S. 94.

223 Vgl. Samuelson, P.A. (1954); Buchanan, J.M. (1968), S. 49ff.; Musgrave, R.A. (1959/1969), S. 10ff.

224 Siehe den Überblick bei Blümel, W./Pethig, R./von dem Hagen, O. (1986).

225 Mueller, D.C. (1989), S. 11.

226 Probleme gesamtwirtschaftlicher Wachstumsdefizite werden in diesem Zusammenhang nicht erörtert, da die Beseitigung von Wachstumshemmnissen als Maßnahmen interpretiert werden können, die 'am dynamischen Allokationsziel' orientiert sind.

227 Die theoretische Attraktivităt des neoklassischen Gleichgewichtsmodells liegt gerade darin begrundet, daß der vom 'Walrasianischen Auktionator' zu bestimmende Preisvektor stets zu einer vollkommenen Răumung aller Markte fuhrt. Vgl. Whynes, D.K./Bowles, R.W. (1981), S. $90 \mathrm{f}$.

228 Azariadis, C./Stiglitz, J.E. (1983) u.v.a. begrunden reale Lohnrigidităten uber Informationsasymmetrien zwischen Arbeitgebern und Arbeitnehmern. Akerlof, G.A. (1982), Shapiro, C./Stiglitz, J.E. (1984) u.a. sehen in der Beziehung von Lohnzahlung und Produktivitat der Arbeitnehmer ('Effizienzlohn-Theorien') die Ursache nomineller Lohnstarrheiten. Guterpreisrigiditaten werden von Akerlof, G.A./Yellen, J.L. (1987) durch Transaktionskosten der Preisanpassung erklărt. Rationierungsansătze erklăren die Zusammenhănge von Lohn- und Preisstarrheiten und Ungleichgewichten. Siehe hierzu etwa Clower, R.W. (1965); Malinvaud, E. (1977). 
liefern notwendige und hinreichende Bedingungen für stabilisierungspolitische Staatseingriffe. $^{229}$

Ausgangspunkt sei ein auf kurz- oder mittelfristig bestehenden Lohn- oder Preisrigiditäten beruhendes Unterbeschäftigungsgleichgewicht. ${ }^{230}$ Die Unterbeschäftigung der Faktoren könnte durch einen Anstieg der marktlichen Nachfrage beseitigt werden. Dies setzt aber eine Steigerung der Pro-Kopf-Einkommen voraus, die endogen, also aus dem Marktsystem selbst, nur durch vermehrte Produktionsaktivitäten entstehen können. ${ }^{231}$ Die Entscheidungssituation ist erneut durch ein soziales Dilemma charakterisiert: Jeder einzelne Marktteilnehmer könnte durch Expansion des eigenen Angebotes zusätzliche Einkommen und damit vermehrte Nachfrage schaffen. Der aggregierte Nachfrageanstieg kommt freilich allen anderen Anbietern zugute. Solange aber die Nachfrage nach dem eigenen Güter- oder Faktorangebot nicht expandiert, sind verstärkte Produktionsanstrengungen mit dem Abweichen von der individuell optimalen Preis-Mengen-Kombination verbunden. Es liegt ein Fall positiver Externalitäten vor, und die Einnahme der nicht-kooperativen free rider-Position ist für den einzelnen Anbieter rational. Über ein kollektives Arrangement aller (oder zumindest der meisten) Anbieter, gemeinsam die Investitionen auszudehnen, wäre marktendogen der Ausweg aus dem Unterbeschäftigungsdilemma zu erreichen. Wie oben erläutert, stehen einem vertraglichen Arrangement aber möglicherweise hohe Transaktionskosten entgegen.

Während Veränderungen der Güter- und Faktorpreisrelationen wichtige Informationen über geänderte Knappheiten liefern und damit notwendige Voraussetzung für eine effiziente Ressourcenallokation sind, bedeuten inflatorische Prozesse eine Gefahr für die Funktion einer marktwirtschaftlichen Ordnung. Das Auftreten anhaltender Preisniveausteigerungen ist auf eine Vielzahl möglicher Ursachen zurückzuführen ${ }^{232}$, und ebenso komplex gestaltet sich die Analyse der Inflationswirkungen. 233 Wichtig ist hier lediglich, daß von inflationären (oder auch deflationären) Entwicklungen alle Wirtschaftssubjekte einer Volkswirtschaft negativ oder positiv betroffen sind. ${ }^{234}$ Infolgedessen wird auch kein von Inflation (negativ oder positiv) betroffenes Individuum einen freiwilligen Beitrag ${ }^{235}$ zur Inflationsbekämpfung (bzw. Deflationsbekämpfung) leisten, da die Kosten selbst getragen werden müßten, die Nutzen aber einer Vielzahl anderer Wirtschaftssubjekte zufließen. Mithin hat auch Preisniveaustabilität den Charakter eines Gutes, dessen Bereitstellung mit positiven Externalitäten verbunden ist. Anti-inflationäre Politik setzt daher kollektives Handeln voraus. Aufgrund transaktionskostenbedingter Hindernisse für freiwillige Übereinkünfte wird deshalb ein staatliches Geldausgabemonopol nahezu einheitlich befürwortet. Dennoch wird von einigen Autoren der Vorschlag eines Geldangebots freier Konkurrenzunternehmen gemacht. ${ }^{236}$ Ein Erhalt der Geld-

229 Vgl. Wagner, H. (1996), S. 20.

230 Siehe zum folgenden Weitzman, M. (1982).

231 Vgl. hierzu Hart, O. (1982), S. $110 \mathrm{ff}$. Siehe auch Wagner, H. (1996), S. $63 \mathrm{ff}$.

232 Zu einem Überblick uber die Inflationstheorien siehe etwa Brunner, K. (1979).

233 Siehe hierzu insbesondere Brunner, K./Meltzer, A.H. (1981).

234 Wenn hier von einem 'offentlichen Übel Inflation' gesprochen wird, so schließt dies nicht aus, daß inflatorische Prozesse durchaus (zumindest fur einen Teil der Gesellschaft) auch Vorteile bringen. Entscheidend ist, $\mathrm{da} ß$ der Konsum des Gutes (oder Übels) Preisniveaustabilităt nicht rivalisiert und daß auch niemand vom Konsum ausgeschlossen werden kann. Mit anderen Worten: der Konsum ist 'öffentlich', vgl. etwa Head, J. (1962); Olson, M. (1986).

235 Etwa durch die Zurlckstellung eigener Einkommensanspruche oder durch individuellen Konsumverzicht.

236 Siehe Hayek, F.A. von (1977); Vaubel, R. (1984). 
wertstabilität liege im Eigeninteresse der konkurrierenden Anbieter, da diese die Kosten der Wertverminderung ihres Geldes selbst zu tragen hätten. Im weiteren soll jedoch davon ausgegangen werden, daß die möglichen Vorteile eines privaten Geldangebots unter Wettbewerbsbedingungen durch die Nachteile erhöhter Kosten marktlicher Transaktionen ${ }^{237}$ überkompensiert werden und das Erfordernis eines Geldausgabemonopols bejaht. 238

\section{ee. Soziale Sicherung und Umverteilung}

Die Verteilungsergebnisse marktlicher Prozesse sind durch die originäre Ausstattung der Marktteilnehmer mit Verfügungsrechten bestimmt. Diese Ergebnisse bzw. deren Zustandekommen können aus verschiedenen Gründen als ungerecht oder sozial unerwünscht abgelehnt werden. Aus dieser traditionellen Sicht wird die Notwendigkeit von Umverteilung normativ abgeleitet. 239

Die Festlegung von Verteilungsnormen ist ein Problem der Bildung von Werturteilen und bleibt damit einer ausschließlich ökonomischen Analyse zu weiten Teilen unzugänglich. ${ }^{240}$ Die normative Bestimmung einer gerechten Verteilung setzt das Abwägen der Vor- und Nachteile einzelner Wirtschaftssubjekte in verschiedenen Verteilungssituationen für die Gesamtheit voraus. Ergebnisorientierte Gerechtigkeitsnormen suchen nach einer Antwort auf die Frage, wie das Sozialprodukt auf die Gesellschaftsmitglieder verteilt werden soll. ${ }^{241}$ Gerechtigkeit ist in diesem Sinne ein exogen definierter Begriff, und die Verteilungsnormen werden von einer außenstehenden moralischen Institution vorgegeben. 242

Der konstitutionelle Ansatz hat dagegen zum Ziel, Verteilungsnormen aus dem ökonomischen Denkansatz heraus endogen abzuleiten. ${ }^{243}$ Im Zentrum der Betrachtungen steht nicht der wertende Vergleich verschiedener Verteilungsergebnisse, sondern die Suche nach konsensfähigen Regelsystemen. ${ }^{244}$ Der Gerechtigkeitsbegriff erhält dadurch eine prozessuale Dimension: Verteilungsergebnisse werden als gerecht anerkannt, wenn sie regelgerecht innnerhalb einer auf konstitutioneller Ebene legitimierten Ordnung entstehen. ${ }^{245} \mathrm{Zu}$ klären ist deshalb, ob es plausible Argumente gibt, daß die Individuen in der Phase der konstitutionellen Beschlußfassung Umverteilungsregeln in der Verfassung verankert sehen wollen.246

Für die hier zu behandelnde Fragestellung liefert der Ansatz der Pareto-optimalen Redistribution einen zweckdienlichen Ausgangspunkt. 247 Wie andere Güter, so die These, stifte auch Redistribution Nutzen für die Individuen einer Volkswirtschaft. Unmittelbar einsichtig ist, daß

237 Grundsătzlich ist die Einfuhrung von Geld als indirektes Tauschmittel ohne die Existenz von Transaktionskosten ðkonomisch nicht erklärbar. Siehe hierzu Richter, R. (1990b), S. 186ff.

238 So auch Frey, B.S. (1981a), S. $248 \mathrm{f}$.

239 Vgl. z.B. Musgrave, R.A./Musgrave, P.B./Kullmer, L. (1994), S. $10 \mathrm{ff}$.

240 "The question of income distribution...is perhaps the most intractable normative problem with which the study of public finance has to deal." Boadway, R.W./Wildasin, D.E. (1984), S. 67.

241 Vgl. Brennan, G./Buchanan, J.M. (1985/1993), S. 150ff.

242 Anders ausgedruckt: Die Werturteile uber Verteilungsgerechtigkeit mussen bei anderen Wissenschaften ausgeborgt werden. Vgl. Blankart, C.B. (1994a), S. 79.

243 Ausfuhrlich dazu Brennan, G./Buchanan, J.M. (1985/1993), Kap. 7 und 8.

244 Siehe dazu Rawls, J. (1971/1974); Fritsch, M. (1985); Brennan, G./Buchanan, J.M. (1985/1993), S. 128ff.

245 Die besondere Problematik einer Einigung auf Umverteilungsnormen selbst auf konstitutioneller Ebene wird von Wessels, J. (1993) und Pasour, E.C. (1994) erortert.

$246 \mathrm{Zu}$ einem Überblich siehe Tullock, G. (1983).

247 Dieses Konzept beruht auf der Arbeit von Hochman, H.M./Rodgers, J.D. (1969). Kritisch dazu Musgrave, R.A. (1970). 
die durch Umverteilungsmaßnahmen Begünstigten (in der Regel: die 'Armen') eine Besserstellung in ihren Nutzenpositionen erfahren. Einkommenstransfers könnten aber für die relativ Wohlhabenden nutzenstiftend sein, wenn auch die Einkommenspositionen - oder besser Nutzenpositionen - anderer Individuen als Argumente in die eigene Nutzenfunktion eingehen.

Neben rein karitativen Motiven 248 der Umverteilung wird das Argument vorgebracht, eine höhere soziale Ausgeglichenheit reduziere innergesellschaftliche Konflikte und bewirke damit eine Reduktion armutsbedingter Kriminalität. ${ }^{249}$ Staatliche Umverteilungspolitik findet ihre Berechtigung darin, daß keine exklusiven Rechte am Gut Verteilungsgerechtigkeit definierbar sind; die gerechtere Verteilung hat den Charakter eines reinen öffentlichen Konsumgutes. ${ }^{250}$ $\mathrm{Da}$ die Transferleistungen eines reichen Individuums andere Wohlhabende ebenfalls besserstellen, wird kollektives Handeln notwendig, um ein Trittbrettfahrer-Verhalten zu überwinden. Es ist für die potentiellen Transfergeber individuell rational, die eigenen Präferenzen für Umverteilungsmaßnahmen nicht offenzulegen. Folglich wäre der Einsatz von Zwangsgewalt erforderlich, um die erforderlichen Maßnahmen durchzuführen.

Staatliche Umverteilung kann darüber hinaus durch ein Versicherungsmotiv begründet werden. 251 Ausgangspunkt ist die plausible Annahme, daß risikoaverse Individuen sich gegen plötzliche Verluste der Erwerbsquellen, wie z.B. durch Arbeitslosigkeit, Unfall oder Krankheit, versichern wollen. In der post-konstitutionellen Phase entstehen aber die für Versicherungsmärkte typischen agency-Probleme des moral hazard und der adverse selection. Zu einer adversen Selektion kommt es, wenn Anbieter von Versicherungsleistungen aufgrund ihrer relativen Informationsdefizite gegenüber den Versicherungsnehmern nicht zwischen guten (geringen) und schlechten (hohen) Risiken differenzieren können. Die Orientierung der Versicherungsprämien am durchschnittlichen Risiko führt zum Zusammenbruch der Versicherungsmärkte, da die guten Risiken zu diesem Preis keine freiwillige Versicherung einzugehen bereit sind und deshalb nur Nachfrager mit hohem individuellem Risiko übrigbleiben. ${ }^{252}$ Ähnliches gilt für den Fall, daß die Versicherungsnehmer nach Abschluß des Versicherungsvertrags ihren Sorgfaltspflichten nicht in genügendem Maße nachkommen, weil die Versicherungsanbieter opportunistisches Verhalten aufgrund der hohen Informationskosten kaum kontrollieren und sanktionieren können. Individuelles Rationalverhalten schädigt die Versicherungsgemeinschaft, so daß für solche Fälle, in denen der Mißbrauch nur schwer aufzudecken ist, überhaupt kein oder nur ein suboptimales privatwirtschaftliches Versicherungsangebot erfolgt. ${ }^{253}$ Infolgedessen ist die Annahme, daß die Individuen auf konstitutioneller Ebene z.B. einem Versicherungszwang oder anderen Maßnahmen zu Umverteilungszwecken zustimmen würden, durchaus plausibel. 254

248 Siehe z.B. Orr, L.L. (1976).

249 Siehe Thurow, L. (1971); Brennan, G. (1973); Pauly, M.V. (1973).

250 Vgl. Thurow, L. (1971), S. 328f.; Spahn, P.B./Kaiser, H. (1988), S. $201 \mathrm{ff}$.

251 Siehe Buchanan, J.M./Tullock, G. (1962), Kap. 13; Varian, H.R. (1980); Eisen, R. (1988). Den inneren Zusammenhang zwischen Pareto-optimaler Umverteilung und Versicherungsprinzip betont Sinn, H.-W. (1988).

252 Vgl. z.B. Rothschild, M./Stiglitz, J.E. (1976).

253 Vgl. etwa Pauly, M.V. (1974).

254 Wird eine Umverteilungsfunktion vom Staat wahrgenommen, spricht man manchmal auch vom "umverteilenden" Staat oder "Wohlfahrtsstaat", der aber nur eine besondere Erscheinungsform des produktiven Staates darstellt. Brennan, G./Buchanan, J.M. (1981), S. 113. 


\section{c. Der produktive Staat als potentiell transaktionskosteneinsparende Organisation}

Die vorangegangenen Erörterungen haben gezeigt, daß auf post-konstitutioneller Ebene das Auftreten sozialer Dilemmata eine freiwillige, marktliche Bereitstellung bestimmter Güter behindern kann, wenn die Transaktionskosten zur Überwindung der Dilemmasituation relativ hoch sind. Es wurde argumentiert, daß in diesen Fällen der Staat als alternativer Koordinationsmechanismus durch den Einsatz von Zwang Transaktionen begünstigen und so zur Mehrung der gesellschaftlichen Wohlfahrt beitragen könne. ${ }^{255}$ Die Wahl zwischen unterschiedlichen Mechanismen der Güterallokation (Markt, Unternehmen, Staat) orientiert sich nicht direkt an Gutseigenschaften, sondern an den mit diesen Eigenschaften verbundenen Transaktionskosten. 256

Unter diesem Aspekt ist der Staat als eine Organisation anzusehen, mittels derer sich die Individuen selbst mit Gütern versorgen. ${ }^{257}$ Der bilaterale marktliche Tausch wird durch hoheitlich organisierten Tausch ersetzt und die Zahl erforderlicher Verträge wird reduziert. Gleichwohl ist der produktive Staat keine 'Produktionseinheit'; seine Aufgabe ist die Bereitstellung und nicht die physische Produktion der Kollektivgüter:258

"These ... activities relate to the consumption (provision side) of service relationships and NOT to the production side. Thus, the key institutional problem to be solved in a public economy involving collective goods is the organization of consumption aspects. When citizens establish a governmental unit that can use sanctions against those who do not contribute resources toward the provision of a collective good, they are constituting a collective consumption unit." 259

Da mit Hilfe des Staates komplexe Tauschprozesse zwischen den Individuen realisiert werden sollen, ist der Leistungsstaat, im Gegensatz zum protektiven Staat, Bestandteil des Tauschsystems. ${ }^{260}$ Folglich muß auf konstitutioneller Ebene Konsens über die Regeln der gemeinsamen Beschlußfassung im produktiven Staat erzielt werden. Politische Verfügungsrechte legen fest, wann in der post-konstitutionellen Phase der zur Überwindung sozialer Dilemmata erforderliche Zwang ausgeübt werden darf. Die Vorteilhaftigkeit einer staatlich organisierten Bereitstellung ist im Sinne einer vergleichenden Institutionenanalyse nur dann gegeben, wenn die Kosten der Kollektiventscheidungen (Transaktionskosten) im Staat geringer sind als die Kosten der marktlichen Koordination. 261

255 Vgl. Inman, R.P. (1987), S. 663.

256 "Market failure has been presented as absolute, but in fact the situation is more complex than this. A more general formulation is that of transaction costs, which are attached to any market and indeed to any mode of resource allocation. Market failure is the particular case where transaction costs are so high that the existence of the market is no longer worthwhile." Arrow, K.J. (1977), S. 77. Vgl. auch Mueller, D.C. (1991), S. 472f.

257 Vgl. Fritsch, M. (1983), S. $118 \mathrm{f}$.

258 Der Begriff Kollektivgut soll hier und im folgenden für alle Fălle verwendet werden, in denen die Bereitstellung uber den Staat abgewickelt wird.

259 Ostrom, E. (1983), S. 83 (Hervorhebungen im Original).

260 Vgl. Buchanan, J.M. (1975/1984), S. 50ff.

261 Vgl. Buchanan, J.M./Tullock, G. (1962), S. 44 und S. 48. 


\section{Die Notwendigkeit und die Möglichkeiten einer Begrenzung des Staates}

\section{Beschränkungen des protektiven Staates: Das ungelöste konstitutionelle Dilemma}

Der protektive Staat ist eine Organisation, der von den Bürgern auf konstitutioneller Ebene das Gewaltmonopol übertragen wird, um private Verfügungsrechte durchzusetzen. Zu diesem Zweck erfolgt eine Ressourcenzusammenlegung unter zentraler Koordination. Die Festlegung der politischen Verfügungsrechte in der Staatsverfassung 262 erstreckt sich nach Auffassung von Buchanan ausschließlich auf den Tätigkeitsbereich des produktiven Staates, denn der Rechtsschutzstaat sei als eine idealerweise kollektivexterne Institution nicht mit irgendwelchen Wahlmechanismen ausgestattet. ${ }^{263}$ Der Befund von Regelverletzungen und die Durchsetzung der Regelbefolgung könne in einem quasi-automatischen Verfahren erfolgen, wobei kein Abwägen der Vor- und Nachteile, wie bei der Entscheidung über die Durchführung von Tauschgeschäften, erforderlich sei. Deshalb sei die Aufgabenerfüllung des schützenden Staates auch vollkommen losgelöst von persönlichen Bewertungen im Sinne eines Opportunitätskostenkalküls. ${ }^{264}$ Der protektive Staat könne daher auch undemokratisch organisiert sein. ${ }^{265}$ Buchanan behauptet natürlich nicht, daß die Regeldurchsetzung tatsächlich in der von ihm beschriebenen, idealen Weise funktioniert ${ }^{266}$, seine idealtypische Vorstellung vom Rechtsschutzsstaat dient lediglich der klaren Trennung von der produktiven Staatstätigkeit. ${ }^{267}$ Witt kritisiert deshalb:

\footnotetext{
"Unfortunately, however, with the creation of a protective agency a new problem emerges. Its capacity to threaten and police ... only works if the agency has sufficient power. If it enjoys a monopoly in the use of coercive means, it may turn out to be difficult to control and to prevent it from usurping the power in the private interest of its personnel. If this usurpation hazard is anticipated by the members of society, there is an obvious constitutional dilemma. Usurpation can deprive the members of the society, except those in the agency, of (almost all) the benefits from overcoming anarchy. Thus, the protective agency required for the credibility of post-constitutional freedom, peace, and cooperation may turn out to be a major threat to precisely these achievements at the post-constitutional level."268
}

262 Auch diese Fragestellung hat ihre Wurzeln in der politischen Philosophie. Im staatsphilosophischen Teil des "Leviathan" sieht Hobbes in der vollkommenen Unterwerfung der Menschen unter eine uneingeschränkte Staatsmacht den einzigen Weg zur Überwindung des Dilemmas der Anarchie. Nur ein starker Staat könne seine ordnungstiftende Funktion wahrnehmen, und jede Beschrănkung des Souveräns musse zu einer "Auflosung des Staates" fuhren. Hobbes lehnt deshalb insbesondere Beschrănkungen der staatlichen Zugriffsgewalt auf das Privatvermøgen und jegliche Form der Gewaltenteilung ab. Siehe Hobbes, $T$. (1651/1984), Kap. 29. Hobbes wird damit zum "Philosophen des (monarchischen) Absolutismus." Arnim, H.H. von (1984), S. 20.

263 Vgl. Buchanan, J.M. (1975/1984), S. 98.

264 Vgl. Buchanan, J.M. (1975/1984), S. 159f. und S. 163.

265 Vgl. Buchanan, J.M. (1975/1984), S. 99.

266 Vgl. Buchanan, J.M. (1975/1984), S. 150.

267 Vgl. Fritsch, M. (1983), S. 107.

268 Witt, U. (1992), S. 265. Inman beschreibt treffend das Problem: "Once we admit to the necessity of coercion we must confront an additional concern: how can we protect the citizenry from oppression, discrimination, or the violation of basic rights?" Inman, R.P. (1987), S. 673. Vgl. auch North, D.C. (1981/1988), S. 20. 
Im Rahmen der von ihm vorgebrachten Fundamentalkritik am vertragstheoretischen Ansatz $^{269}$ argumentiert Witt, daß weder die Schaffung kollektivinterner politischer Kontrollinstitutionen für den Rechtsschutzstaat noch die Etablierung einer weiteren externen Durchsetzungsinstanz, die den protektiven Staat in seine Schranken verweist, eine theoretische Lösung dieses Dilemmas sein kann. ${ }^{270}$ Auf konstitutioneller Ebene werde deshalb nach seiner Ansicht ein Konsens über die Errichtung einer protektiven Agentur niemals erreicht. 271 Die Begründung des Gewaltmonopols durch freiwillige Unterwerfung unter eine staatliche Zwangsgewalt unterbleibe, weil der schützende Staat sich bei Inkrafttreten des konstitutionellen Kontrakts quasi-automatisch in eine diktatorische Institution verwandelt und die Rechte verletzt, für deren Einhaltung er geschaffen wird. ${ }^{272}$ Aus dieser Sicht ist den Vertragstheoretikern um Buchanan ein Vertrauen in die Einhaltung der Verfassung eigen, das mit dem pessimistischen Menschenbild, das ihren weiteren Analysen zugrunde liegt, unvereinbar ist. Buchanan sieht diesen logischen Widerspruch, hält aber entgegen:

" Im Verlauf der Geschichte hat sich gezeigt, daß Regierungen tatsăchlich durch konstitutionelle Regeln unter Kontrolle gehalten worden sind. Die genauen Grunde fur diesen Tatbestand brauchen uns hier nicht zu interessieren. Aber unser gesamter Ansatz beruht auf dem Glauben oder Vertrauen, daß Verfassungen funktionieren können ..." 273

Es kann und soll an dieser Stelle auch nicht der Versuch unternommen werden, diese Lücke in der Theorie Buchanans zu schließen. Stattdessen muß angenommen werden, daß der soziale Grundkonsens der konstitutionellen Ebene, auf gegenseitige Gewaltanwendung zu verzichten, zur langfristigen Entwicklung eines Wertesystems führt, das auch in der post-konstitutionellen Phase zu einer tendenziell stabilen Rechtsordnung beiträgt. 274

\section{Die Logik konstitutioneller Beschränkungen des produktiven Staatshandelns}

\section{a. Der unbegrenzte Staat und die Notwendigkeit konstitutioneller Beschränkungen}

Gelingt die Begrenzung des protektiven Staates, ist in der Verfassungsdebatte zu klären, wie die politischen Verfügungsrechte im produktiven Staat zu organisieren sind, damit die Vorteile der Kollektivbildung maximiert werden. Deshalb muß in der Verfassung ein Entschei-

$269 "$ "... the constitutional dilemma appears to challenge the basic idea of the new contractarians: to legitimize the state by giving conditions under which a hypothetical unanimous agreement to a social contract enforced by the protective state could be reached." Witt, U. (1992), S. 265. (Hervorhebung H.P.)

270 "The first is rather a platonic notion as the problem is not so much one of design but one of enforcement ... The second takes this into account but induces an infinite regress - who prevents the external authority from defaulting or colluding?" Witt, U. (1992), S. 264. Ähnlich auch Olson, M. (1984), S. 92f.; North, D.C. (1990/1992), S. $70 \mathrm{ff}$.

271 Vgl. Witt, U. (1992), S. 264.

272 Nach Weingast ist dies das "fundamentale politische Dilemma eines 8konomischen Systems." Weingast, B. (1993), S. 287.

273 Brennan, G./Buchanan, J.M. (1980/1988), S. 12f.

274 Neben der Anwendung oder Androhung von Gewalt kommen auch die Entwicklung von Wertsystemen und Ideologien, Gewohnheit und Gewohnheitsrechten oder schließlich die Etablierung einer externen Sanktionsinstanz - den Staat - in Betracht. Vgl. Eggertsson, T. (1990), S. 284ff. Auf diese Aspekte verweist insbesondere North im Rahmen seiner Erörterungen zu 'formlosen Beschränkungen' als Mechanismen zur Schaffung von Ordnung in staatenlosen Gesellschaften. Siehe North, D.C. (1990/1992), Kap. 4. 
dungsmechanismus verankert werden, mit dessen Hilfe das Produktionsprogramm des Leistungsstaates bestimmt wird. 275

Die Argumentation der wohlfahrtsökonomischen Theorie umgeht das Problem der Kollektiventscheidungen, indem die Entscheidungsrechte implizit einem "wohlmeinenden Alleinherrscher"276 zugeteilt werden, dessen Ziel in der Maximierung einer ihm bekannten sozialen Wohlfahrtsfunktion besteht. ${ }^{277}$ Es ist offensichtlich, daß diese Verhaltensannahme keine argumentative Basis für konstitutionelle Beschränkungen des produktiven staatlichen Handelns bietet, denn jede Begrenzung behindert die staatlichen Agenten nur bei der Umsetzung definitionsgemäß wohlfahrtssteigernder Maßnahmen. 278

Die Sichtweise ändert sich radikal, wenn auch für die sozialen Entscheidungsträger die Verhaltensannahmen des "resourceful evaluating maximizing man (REMM)"279 gelten. Es kann nicht davon ausgegangen werden, daß die Agenten uneingeschränkt die Interessen der Prinzipale verfolgen. Im Gegenteil: Eröffnen sich opportunistische Handlungsspielräume, ist damit zu rechnen, daß eigennutzorientierte staatliche Akteure diese zu Lasten der Bürger ausnutzen werden. 280 Unter der Annahme opportunistischen Verhaltens der Regierung wurde insbesondere von Brennan und Buchanan das Staatsmodell eines "unbegrenzten Leviathan"281 entwickelt. Die Autoren nehmen an, daß Eigennutzmaximierung durch das Streben der staatlichen Akteure nach größtmöglichen monetären Überschüssen aus dem Staatshandeln zum Ausdruck kommt. ${ }^{282}$ Mithin versucht der Leviathan die Differenz zwischen Steuereinnahmen und Ausgaben für die Bereitstellung von Kollektivgütern zu maximieren.

Dieses Ziel impliziert keineswegs, daß vom Staat keine Kollektivgüter bereitgestellt werden. $\mathrm{Da}$ das Steueraufkommen insbesondere von der Höhe des Sozialprodukts abhängt, ist eine transaktionskostenminimierende und damit sozialproduktmaximierende Ausgestaltung der institutionellen Strukturen durchaus im Interesse der Leviathan-Regierung. ${ }^{283}$ Jedoch fallen in diesem Modell die residualen Überschüsse des staatlichen Handelns nur den Machthabern zu. Aus Sicht der Prinzipale wären die Netto-Vorteile der Kooperation im Staat gleich Null. Der Leviathan von Brennan und Buchanan bildet damit als 'worst case' den logischen Gegenpol zum 'best case' des benevolenten Diktators. Brennan und Buchanan unterstellen freilich nicht, daß sie mit ihrem Leviathan-Ansatz ein realistisches Bild des staatlichen Handelns entworfen haben. Sie leiten aber aus der potentiellen Bedrohung durch einen ausbeuterischen Leviathan die Notwendigkeit konstitutioneller Beschränkungen des Staatshandelns ab. 284

275 Vgl. Fritsch, M. (1983), S. 107.

276 Wicksell, K. (1896), S. 102.

277 Vgl. Eschenburg, R. (1977), S. 197.

278 Vgl. Brennan, G./Buchanan, J.M. (1980/1988), S. 5 f.

279 Meckling, W.H. (1976), S. 548. Siehe die Ausfuhrungen oben, S. 14.

280 Von der Existenz moralischer Restriktionen fur das Handeln der sozialen Entscheidungsträger, wie sie von einigen Autoren behandelt werden, soll im folgenden abstrahiert werden. Siehe dazu Brennan, G. (1981), S. 124; Anderson, T.L./Hill, P.J. (1986); North, D.C. (1990/1992).

281 Siehe Brennan, G./Buchanan, J.M. (1977); (1980/1988).

282 Vgl. Brennan, G./Buchanan, J.M. (1980/1988), S. 33f.

283 Siehe etwa auch Findlay, R./Wilson, J.D. (1987); Levi, M. (1988); North, D.C. (1981/1988), Kap. 3.

284 "Die Logik konstitutioneller Beschränkungen ist in der impliziten Vorhersage enthalten, daß jede dem Staat ubertragene Gewalt in bestimmten Bereichen und bei gewissen Gelegenheiten in einer Art und Weise ausgeubt werden kann, die im Widerspruch zu dem gewunschten Gebrauch dieser Gewalt steht, wie er von 
In der konstitutionellen Theorie werden deshalb verfassungsmäßige Beschränkungen des Staatshandelns diskutiert ${ }^{285}$, die nach Buchanan in prozedurale und quantitative Ansätze unterteilt sind. ${ }^{286}$ Prozedurale (verfahrensmäßige) Beschränkungen gestalten die Regeln der politischen Entscheidungsfindung, quantitative (ergebnisbezogenene) Restriktionen stellen dagegen auf ein bestimmtes erwünschtes Ergebnis der Prozesse ab. Für die Themenstellung dieser Arbeit sind insbesondere die Begrenzungen im Rahmen der demokratischen Widerspruchsoption und der Föderalisierung von Entscheidungskompetenzen von Bedeutung. Die Grundideen beider Ansätze sollen im folgenden kurz skizziert werden.

\section{b. Die demokratische Widerspruchsoption}

\section{aa. Das Interdependenzkostenkonzept von Buchanan und Tullock}

Angesichts der Ausbeutungsgefahr durch den Leviathan ist es wahrscheinlich, daß sich die Individuen in der konstitutionellen Beschlußphase auf die Etablierung einer Widerspruchsoption einigen. 287 Widerspruch bezeichnet die Einflußnahme der Mitglieder auf Kollektiventscheidungen. Im Prinzip bestehen vielfältige Möglichkeiten einer demokratischen Entscheidungsbeteiligung der Staatsbürger. ${ }^{288}$ An dieser Stelle sollen lediglich grundsätzliche Aspekte beleuchtet werden, die bei der Auswahl von Regeln, nach der die Entscheidungen im produktiven Staat verbindlich für alle Mitglieder der Organisation Staat getroffen werden, eine Rolle spielen. Das konstitutionelle Kalkül, das dieser Entscheidung zugrundeliegt, wurde von Buchanan und Tullock 1962 in "The Calculus of Consent" erörtert. 289

Buchanan und Tullock gehen davon aus, daß die Festlegung der Regeln für die kollektive Beschlußfassung über staatliche Eingriffe in der post-konstitutionellen Phase auf einem konstitutionellen Kosten-Nutzen-Kalkül beruht. Sie unterscheiden als relevante Kostenfaktoren erwartete Konsensfindungskosten ("expected decision-making costs"290) und die erwarteten externen Kosten ("expected external costs"291) der Kollektiventscheidungen in der nachkonstitutionellen Phase.

Der empfundene Zwang, einen gemeinschaftlichen Beschluß zu akzeptieren, läßt sich durch Anwendung der Einstimmigkeitsregel auf Null reduzieren. Da in diesem Fall jedes Individuum ein Vetorecht besitzt, könnten nur Projekte realisiert werden, die nach dem Pareto-Kriterium superior sind. Andererseits sind die Kosten der Verhandlungen, um zwischen allen Beteiligten einen Konsens zu erzielen, außerordentlich hoch, denn auf der operationalen Ebene sind die unmittelbaren Konsequenzen eines kollektiven Beschlusses für das beteiligte Individuum ersichtlich. Damit gewinnt strategisches Entscheidungsverhalten der Wirtschafts-

den Burgern hinter dem Schleier der Unwissenheit definiert ist." Brennan, G./Buchanan, J.M. (1980/1988), S. 6.

$285 \mathrm{Zu}$ einem Überblick siehe etwa Ladd, H.F./Tideman, N.C. (1979); Folkers, C. (1983), Kap. 2.

286 Siehe Buchanan, J.M. (1980a). Vgl. auch Brennan, G. (1984), S. 126f.; Hamlin, A.P. (1984).

287 Brennan und Buchanan gehen in ihrem Leviathan-Ansatz davon aus, daß demokratische Wahlverfahren im allgemeinen "keine wirksame Beschrankung fur die staatliche Machtausubung" sind. Brennan, G./Buchanan, J.M. (1980/1988), S. 9.

288 Frey nennt hier Wahlen, direkte Volksabstimmungen, Burgerinitiativen, Burgerforen und Vertretung von Interessen durch Anwaltsplanung. Siehe Frey, B.S. (1981a), S. 53ff. Siehe auch Breton, A. (1974), S. 74ff.

289 Vgl. Kapitel 6 "A Generalized Economic Theory of Constitutions" in Buchanan, J.M./Tullock, G. (1962). Siehe hierzu unter vielen auch Rae, D.W. (1969); Rowley, C.K. (1990).

290 Buchanan, J.M./Tullock, G. (1962), S. 68.

291 Buchanan, J.M./Tullock, G. (1962), S. 63. 
subjekte an Bedeutung. 292 Das Einstimmigkeitsprinzip ist deshalb mit dem Nachteil behaftet, daß gemeinschaftliche Beschlüsse nur unter hohen Kosten der Konsensfindung - und häufig sogar überhaupt nicht - zustandekommen. Mit einer Reduktion der beschlußnotwendigen Stimmenzahl werden die Verhandlungskosten sinken. Im Extrem der "any person rule"293, bei der jedes Individuum alleine für alle anderen Kollektivmitglieder verbindliche Beschlüsse treffen kann, fallen keine Konsensfindungskosten an, so daß die Funktion der Konsensfindungskosten D in Abhängigkeit von dem Zustimmungserfordernis wie in Abbildung 2.2 illustriert werden kann.

Die zweite relevante Kostenart, die erwarteten externen Kosten eines Beschlusses, sind die Nutzeneinbußen, die einem Individuum entstehen, wenn gegen seinen Willen entschieden wird. Je höher das Zustimmungserfordernis für einen allgemein verbindlichen Beschluß ist, desto geringer ist die Wahrscheinlichkeit, der (überstimmten) Minderheit anzugehören. Bei Gültigkeit der Einstimmigkeitsregel sind deshalb die erwarteten externen Kosten einer Entscheidung Null. In Abbildung 2.2 ist dieser Zusammenhang durch die Kurve C dargestellt.

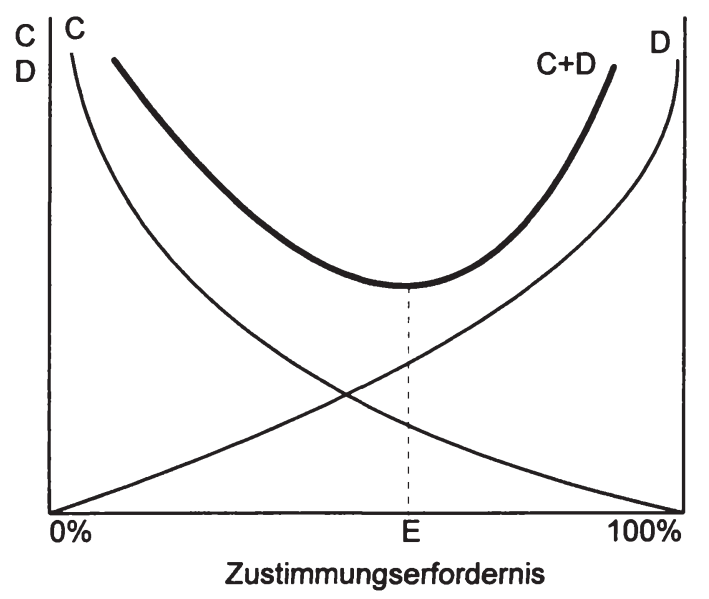

Abbildung 2.2: Das optimale Zustimmungserfordernis Quelle: in Anlehnung an Buchanan, J.M./Tullock, G. (1962), S. 71

Zur Bestimmung der optimalen Entscheidungsregel sind beide Kostenarten zu aggregieren. Erwartete externe Kosten $\mathrm{C}$ und Konsensfindungskosten D ergeben in der Summe die sog. Interdependenzkosten ("social interdependence costs"294) C+D. Das optimale Zustimmungserfordernis für Kollektivbeschlüsse in der nach-konstitutionellen Phase liegt im Minimum der Gesamtkosten bei E.

Nach Auffassung von Buchanan und Tullock werden die Individuen hinter dem Schleier der Unwissenheit unter bestimmten Voraussetzungen einstimmig der Einrichtung einer solchen

292 Vgl. Buchanan, J.M./Tullock, G. (1962), S. 69.

293 Buchanan, J.M./Tullock, G. (1962), S. 67.

294 Buchanan, J.M./Tullock, G. (1962), S. 49. 
Entscheidungsregel zustimmen können. 295 Die Ausübung von kollektivem (staatlichem) Zwang in der operationellen Phase ist legitimiert, wenn die erforderliche Mehrheit zur Durchführung der staatlichen Eingriffe erzielt wird. Die Legitimation der Zwangsausübung erfolgt durch die einstimmige Billigung der Abstimmungsregel $\mathrm{E}$ auf konstitutioneller Ebene. Zwei Aspekte sind hier hervorzuheben: Erstens werden die Kurven $C$ und D je nach betrachtetem Problemkreis unterschiedliche Verläufe annehmen. Somit ergeben sich für unterschiedliche Bereiche kollektiver Entscheidungen auch differierende optimale Mehrheiten. ${ }^{296}$ Zweitens genießt die einfache Mehrheitsregel eine Sonderstellung im Kontinuum aller möglichen Nicht-Einstimmigkeitsregeln. ${ }^{297}$ Eine Zustimmungserfordernis, die bei genau oder unter 50\% der beteiligten Individuen liegt, kann nämlich zu logisch widersprüchlichen Entscheidungen führen, so daß kollektive Entscheidungsprozesse trotz des Anfallens von Konsensfindungskosten keine umsetzbaren Ergebnisse hervorbringen. 298

\section{bb. Verringerung der Interdependenzkosten durch indirekte Demokratie}

Freilich sind die Interdependenzkosten nicht nur von der Zustimmungserfordernis und von der Art der betrachteten Problemklasse abhängig. Letztlich hat jede Veränderung der Entscheidungsstrukturen auch Konsequenzen für die Kostenarten C und D. Wenn sich hierdurch eine Verringerung der Interdependenzkosten erreichen läßt, erscheint eine einmütige Zustimmung zu diesen institutionellen Arrangements auf konstitutioneller Ebene möglich. Aus der Vielzahl möglicher Arrangements soll an dieser Stelle lediglich der Übergang zur indirekten Demokratie diskutiert werden. 299

Geringere Einigungskosten ergeben sich immer dann, wenn die Zahl der an der Entscheidungsfindung Beteiligten klein ist. 300 Eine Reduktion der Konsensfindungskosten läßt sich damit durch Delegation von Entscheidungskompetenzen an Entscheidungsgremien, die nur einen Teil der Gesellschaftsmitglieder umfassen, z.B. ein Parlament, erreichen. ${ }^{301}$ Die Konsensfindungskosten sind in der bisher betrachteten direkten Demokratie sehr hoch, da grundsätzlich alle Gesellschaftsmitglieder auch über alle anstehenden Fragen abstimmen. Bei einer geringeren Zahl von Entscheidungsbeteiligten ergibt sich eine drastische Verringerung der Einigungskosten schon allein deshalb, weil die Nicht-Beteiligten keine Ressourcen in persönliche Information und Verhandlungen investieren müssen.

Die Delegation von Verantwortlichkeiten auf Spezialisten, die verbindlich für das gesamte Kollektiv entscheiden, ermöglicht eine schnellere Entscheidungsfindung, birgt aber das Risiko hoher externer Kosten für die Gesellschaftsmitglieder. ${ }^{302}$ Damit liegen zwischen den Bürgern und den staatlichen Akteuren die Merkmale einer Vertretungs-Beziehung vor. Moderne

295 Siehe dazu Buchanan, J.M./Tullock, G. (1962), S. $78 \mathrm{f}$.

296 So ist anzunehmen, daß für Fragen der grundlegenden Rechte die erwarteten externen Kosten und damit die optimale Zustimmungserfordernis sehr hoch sein wird.

297 Vgl. etwa Eschenburg, R. (1977), S. 168ff.; Mueller, D.C. (1989), S. 55ff.; (1991), S. $315 \mathrm{ff}$.

298 Vgl. Eschenburg, R. (1977), S. 170f.; Mueller, D.C. (1989), S. 56f. Die Kurve der Konsensfindungskosten D weist daher bei einer 50\%-Zustimmungserfordernis eine Sprungstelle auf (in Abbildung 2.2 nicht eingezeichnet).

$299 \mathrm{Zu}$ den moglichen Effizienzvorteilen einer direkten Demokratie siehe Noam, E.M. (1980); Frey, B.S. (1994) und Bohnet, I./Frey, B.S. (1994).

300 Vgl. Buchanan, J.M./Tullock, G. (1962), S. $111 \mathrm{ff}$.

301 Vgl. Eschenburg, R. (1977), S. 85f., S. $193 \mathrm{ff}$.

302 Ähnlich auch Kirsch, G. (1993), S. $171 \mathrm{ff}$. 
Ansätze einer ökonomischen Theorie des Staates und der politischen Institutionen begreifen daher das Verhältnis der Bürger zur Regierung als Principal-Agent-Beziehung. ${ }^{303}$

Beim Übergang von der direkten zur indirekten Demokratie müssen auf konstitutioneller Ebene insbesondere folgende Fragen geklärt werden:304 (i) Nach welcher (Wahl-)Regel erfolgt die Bestimmung der Delegierten? (ii) Welche Entscheidungsregel gilt für die Entscheidungen der Repräsentanten selbst? (iii) Wie groß soll das Entscheidungsgremium sein? (iv) Auf welcher Basis erfolgt die Auswahl der Gremienmitglieder (funktional, geographisch etc.)? (v) Welche Kompetenzen sollen delegiert werden?305 Damit ist stets die Frage verbunden, durch welche Regelmechanismen die ausgewählten Agenten dazu angehalten werden können, die Interessen der Prinzipale zu berücksichtigen, mithin also die erwarteten externen Kosten der Entscheidungsfindung für die Bürger möglichst gering zu halten.

In der indirekten Demokratie ist die Wahl der Agenten hauptsächliche Quelle der Organisationsmacht der Gesellschaftsmitglieder. Die Steuerungswirkung der Agentenwahl beruht auf dem Interesse der Delegierten am Amtsverbleib. ${ }^{306}$ Dem liegt die Idee politischer Unternehmer zugrunde, die politische Programme anbieten, um die zur Erreichung des Amtes erforderliche Stimmenzahl der Bürger zu erhalten. Damit impliziert die Auswahl als Kontrollmechanismus die Notwendigkeit, daß sich die gewählten Vertreter in bestimmten Zeitabständen den Voten der Bürger stellen müssen. ${ }^{307}$

Somit kann folgendes Fazit gezogen werden: Zwar bietet die reine Einstimmigkeitsregel bei Kollektiventscheidungen maximalen Schutz der Staatsangehörigen vor einer Ausbeutung durch den Leviathan. Zur Aufrechterhaltung der Funktionsfähigkeit des Gemeinwesens ist sie jedoch, wie gezeigt, ungeeignet. Demgegenüber birgt die Abkehr vom Ideal der "government by consent"308 und der Übergang zur indirekten Demokratie die Gefahr opportunistischen Verhaltens der Delegierten gegenüber ihren Auftraggebern. Die Identifikation der Beziehung zwischen Bürgern und Delegierten in der indirekten Demokratie als Principal-Agent-Relation läßt vermuten, daß es zu besonderen Problemen bei der Vertragsumsetzung kommt. So betont etwa Moe:

"... while citizens are nominally the superiors in this hierarchy, it is the legislators who actually hold public office and have the right to make law. Their role, as agents, is to exercise public authority, backed by the police powers of the state, in telling their principals what to do." 309

Folglich ist denkbar, daß die Individuen bei der konstitutionellen Beschlußfassung über die demokratische Entscheidungsbeteiligung hinaus Restriktionen für die staatlichen Akteure

303 Vgl. Anderson, T.L./Hill, P.J. (1986); Merville, L.J./Osborne, D.K. (1990); Moe, T. (1990); Lowenberg, A.D./Yu, B.T. (1992); North, D.C. (1990/1992). Kruse spricht hier vom "Prinzip der kollektiven Delegation", in dem "die Prinzipal- und die Agenten-Rolle jeweils von einer Menge von Individuen eingenommen wird." Kruse, J. (1989), S. 243.

304 Siehe Buchanan, J.M./Tullock, G. (1962), S. $213 \mathrm{ff}$.

305 Zu diesem Punkt siehe Blankart, C.B. (1994b).

306 Vgl. Vanberg, V. (1982), S. 183f. Diese Überlegung ist auf Schumpeter, J.A. (1942/1950) zuruckzufuhren.

$307 \mathrm{Zu}$ den Einflußfaktoren der optimalen Dauer der Wahlperiode siehe Frey, B.S. (1981a), S. 53f.

308 Buchanan, J.M. (1975/1984), S. 214.

309 Moe, T. (1990), S. 232 
vereinbaren. ${ }^{310}$ Deshalb wird von Vertretern des konstitutionellen Ansatzes u.a. der Vorschlag eingebracht, durch die Dezentralisierung politischer Entscheidungskompetenzen in einem föderativen System weitergehende Begrenzungen einzurichten. ${ }^{311}$

\section{c. Beschränkungen des produktiven Staates durch Föderalismus?}

Die konstitutionelle Verankerung föderativer Strukturen ("constitutional federalism"312) in der Verfassung eines Staates dient nach Hamlin sowohl als indirekte ergebnisbezogenene Restriktion als auch als prozeduraler Kontrollmechanismus. ${ }^{313}$ Diese Unterscheidung kommt seiner Ansicht nach auch in den unterschiedlichen Ansätzen zum Ausdruck, die sich in der Ökonomik mit Fragen des Föderalismus beschäftigen:

"Fiscal federalism emphasises the interaction between the organisational structure and performance, with conduct assumed as given. The public choice approach discusses the link between the organisational aspect of structure and the behavioral aspect of conduct, with the motivational aspect of conduct fixed by hypothesis and with performance argued to be of secondary importance."314

Eine föderative Organisationsstruktur des Staates, so die These, verändert die Ergebnisse ("performance") und die Verhaltensanreize im politischen Entscheidungsprozeß ("behavioral aspects of conduct"). Erst durch die Analyse des Zusammenwirkens dieser Faktoren entsteht eine umfassende ökonomische Föderalismustheorie, denn veränderte Verhaltensanreize wirken natürlich auch wieder auf die Entscheidungsergebnisse. Eine polit-ökonomische Theorie des Föderalismus muß beide Aspekte integrieren. Die weitere Vorgehensweise kann dann in drei Schritten erfolgen, die wie folgt zu skizzieren sind:

- Es dürften nicht stets alle Individuen eines Gemeinwesens gleichermaßen von einem Marktversagen betroffen sein. Bei Berücksichtigung der territorialen Dimension des Marktversagens kann es sinnvoll sein, dezentrale Staatsstrukturen zu schaffen. Zur Analyse der Zusammenhänge bietet sich die Theorie des Fiskalföderalismus an (siehe 3. Kapitel).

- Mit zunehmender Dezentralisierung können möglicherweise organisationsinterne Opportunismusprobleme verringert werden, weil die Zahl der mittelbar Entscheidungsbeteiligten (bei Auswahl der Agenten) verringert wird. Die Public Choice-Theorie liefert hier fruchtbare Erkenntnisse bei der Analyse der politischen Widerspruchsoption (siehe 4. Kapitel).

- Zwar können die Bürger eines Staates nicht durch den Verkauf von Anteilswerten an der Organisation Staat 'abwandern'; denkbar wäre jedoch, den Staat so zu organisieren, daß den Mitgliedern ein Wechsel zu einer anderen Organisation ermöglicht wird. Kerngedanke der Schaffung von exit-Optionen ist die Beseitigung der Monopolstellung des produktiven Staates. Die veränderten Anreizstrukturen für politische Entscheidungsträger können wiederum mit Hilfe der Public Choice-Theorie untersucht werden (siehe 5. Kapitel).

310 Zum ahnlich gelagerten Problem der "separation of ownership and control" in Publikumsgesellschaften siehe etwa Jensen, M.C./Meckling, W.H. (1976); Fama, E.F./Jensen, M.C. (1983); Kallfass, H.H. (1992).

311 Stellvertretend fur viele seien genannt: Brennan, G./Buchanan, J.M. (1980/1988), Kap. 9; Breton, A. (1987); Bish, R.L. (1988); Aranson, P.H. (1990); Hamlin, A.P. (1991); Marlow, M.L. (1992).

312 Aranson, P.H. (1990), S. 19.

$313 \mathrm{Vgl}$. Hamlin, A.P. (1985), S. 193.

314 Hamlin, A.P. (1985), S. 193. Ähnlich auch Wiseman, J. (1990), S. $115 \mathrm{ff}$. 


\section{Zusammenfassende Thesen zum zweiten Kapitel}

1. Methodologische Grundbausteine der Neuen Institutionenökonomik sind die property rights-Theorie, das Vertragsdenken und die Transaktionskostentheorie. Mit Hilfe dieser Konzepte wird das Ziel der Ermittlung effizienter Koordinationsstrukturen zwischen den Gegenpolen Markt und Hierarchie verfolgt. Zentrales Problem der konstitutionellen Ökonomik ist die Gestaltung der Organisationsverfassung, in der die Rahmenbedingungen für das Handeln der Individuen in der Organisation festgelegt werden.

2. Bei der Ausgestaltung der Verfassung tritt das Dilemma der Organisation auf: Nur hierarchische Koordination ermöglicht kollektives Handeln großer Gruppen; die Etablierung der Koordinationsgewalt birgt aber die Gefahr opportunistischen Verhaltens der Agenten, auf das die Prinzipale mit Abwanderung oder Widerspruch reagieren können. Als Legitimationsgrundlage für individuelle Freiheitsbeschränkungen in hierarchischen Systemen wird der Konsens der Individuen auf konstitutioneller Ebene angesehen.

3. Die staatslose Gesellschaft ist aufgrund fehlender property rights durch Besitz- und Tauschunsicherheit gekennzeichnet. Da die gegenseitige Akzeptanz von Verfügungsrechten einem Gefangenendilemma gleicht, ist eine externe Sanktionsinstanz, der protektive Staat, erforderlich, um die wechselseitige Beachtung von Handlungs- und Interaktionsrechten zu garantieren. Bei der Erfüllung dieser Aufgabe benötigt der Staat keine gesetzgeberischen Kompetenzen oder Auswahlmechanismen, da Rechtsverletzungen lediglich objektiv festgestellt und sanktioniert werden müssen.

4. In einer Welt mit Transaktionskosten führt der durch Wettbewerbspreise gesteuerte Transfer von property rights am Markt nicht zu einer optimalen Allokation der Ressourcen, wenn private Absicherungen gegen opportunistisches Verhalten zu kostspielig sind. Eigennütziges Verhalten der Wirtschaftssubjekte verhindert eine wahrheitsgemäße Präferenzoffenlegung, und potentiell wohlfahrtssteigernde Transaktionen unterbleiben. Das Präferenzoffenbarungsproblem läßt sich für alle Fälle, in denen ein Versagen des marktlichen Koordinationsmechanismus konstatiert wird, gedanklich in soziale Dilemmata transformieren. Ursächlich für Marktversagen sind die prohibitiv hohen Transaktionskosten eines freiwilligen Bereitstellungsarrangements.

5. Die Herstellung solcher Arrangements könnte Aufgabe eines produktiven Staates sein. Im Gegensatz zum protektiven Staat taucht hier das Problem auf, daß unterschiedliche subjektive Bewertungen ein Abwägen der Vor- und Nachteile für einzelne Indidviduen erforderlich machen. Auf konstitutioneller Ebene müssen deshalb Auswahlmechanismen festgelegt werden, die allgemeine Akzeptanz finden.

6. Die Logik des Organisationsdilemmas impliziert, daß den staatlichen Agenten bei der Ausübung ihrer hoheitlichen Funktionen Beschränkungen auferlegt werden müssen, weil der Staat sonst aufgrund seines Gewaltmonopols zu einem ausbeuterischen Leviathan wird. Die Etablierung der Einstimmigkeitsregel für politische Kollektiventscheidungen in der post-konstitutionellen Phase als wirkungsvollste Begrenzung der staatlichen Macht scheitert an den hohen Kosten der Konsensfindung. Die Widerspruchsoption kann deshalb immer nur eine unvollkommene Beschränkung des Staatshandelns sein.

7. Ein Übergang zur indirekten Demokratie reduziert die Interdependenzkosten kollektiver Beschlüsse, eröffnet aber zusätzlichen Raum für Opportunismus der staatlichen Agenten. Hier könnte ein föderativer Staatsaufbau die Effizienz politischen Widerspruchs verbessern und den Staatsangehörigen Abwanderungsmöglichkeiten eröffnen. 


\section{Kapitel: Die Theorie des Fiskalföderalismus}

\section{A. Die Wesensmerkmale der Theorie des Fiskalfoderalismus}

Die bislang skizzierte ökonomische Theorie des Staates läßt noch keine Aussagen über den optimalen Staatsaufbau zu. Hierzu ist es erforderlich, Kriterien für die optimale interne Organisationsstruktur des Staates zu bestimmen. Die Überlegungen basieren auf der im angloamerikanischen Raum entwickelten Theorie des Fiskalföderalismus ("Fiscal Federalism"1). Der Fiscal Federalism-Ansatz versteht sich als Weiterentwicklung der Kollektivgütertheorie in ihrer neoklassischen Fundierung. ${ }^{2}$ Es wird das Ziel verfolgt, aus einem ökonomischen Kosten-Nutzen-Kalkül die optimale Gliederung des Staatswesens in mehr oder weniger selbständige, nebeneinander und übereinander existierende Teilkollektive abzuleiten. ${ }^{3}$ Die Mehrzahl der Publikationen ist der normativen Ökonomik zuzurechnen. ${ }^{4}$

Die neoklassische Sichtweise dieses Theorieansatzes impliziert die Ergebnisorientierung der Überlegungen und eine Vernachlässigung der prozessualen Dimension. ${ }^{5}$ Die staatlichen Entscheidungsabläufe selbst finden keine spezielle Beachtung, es wird lediglich der Zusammenhang zwischen der Organisationsstruktur des Staatsaufbaus und den durch diese Struktur erwarteten Entscheidungsergebnissen beleuchtet. Damit liefert der Fiscal Federalism-Ansatz zwar mögliche Argumente für föderative Staatsstrukturen ${ }^{6}$, vernachlässigt aber den zweiten Aspekt des Organisationsdilemmas, weil "... policymakers are assumed to be passive agents of the desires of taxpayers for a better allocation of resources."7

Den meisten Analysen ist außerdem gemeinsam, daß von einem vorkonstitutionellen Zustand ausgegangen wird, in dem bereits eine nationalstaatliche Einheit als Rahmen existiert, inner-

1 So der Titel der wohl meistzitierten Arbeit in diesem Forschungsbereich von Oates, W.E. (1972). In der langen Reihe von Vorlăufern sind v.a. die Arbeiten von Pennock, J. (1959); Buchanan, J.M. (1965); Tullock, G. (1969a) und Olson, M. (1969) hervorzuheben. Einen knappen Überblick uber den Forschungsstand dieses Theorieansatzes gibt Oates, W.E. (1990).

2 Vgl. Kirsch, G. (1977), S. 9f. und (1978), S. 10f. Da der Ansatz des Fiscal Federalism in unmittelbarer Verbindung zur Marktversagenstheorie steht, ist es auch nicht weiter verwunderlich, daß sich die Argumentationsmuster großtenteils ăhneln, mitunter sogar identisch sind.

3 Vgl. Kirsch, G. (1984), S. 118.

4 Eine bedeutende Ausnahme bildet der Ansatz von Breton, A./Scott, A. (1978). Siehe unten, FN 7.

5 Vgl. Thöni, E. (1986), S. 15f. oder Wiseman, J. (1990), S. $116 f$.

6 Anderer Ansicht sind Brennan und Buchanan, die dem traditionellen Fiscal Federalism-Ansatz jegliche normative Begrundungskraft fur foderative Staatsstrukturen absprechen. Vgl. Brennan, G./Buchanan, J.M. (1980/1988), S. 220. Im folgenden wird jedoch gezeigt, daß die Skepsis von Brennan/Buchanan bezlglich der Aussagekraft der Theorie des Fiskalfoderalismus nur zum Teil begrundet ist.

7 Marlow, M.L. (1992), S. 76. Ebenso Boadway und Wildasin: "In discussing the economic theory of fiscal federalism, it is generally presumed that the method of taking collective decisions is predetermined, and that it is relatively efficient. That is, governments, due to the incentives of vote-maximizing or whatever, tend to take resource allocation decisions according to the collective preferences of their constituents." Boadway, R.W./Wildasin, D.E. (1984), S. 499. Aus diesem Grund wird auch der Ansatz von Breton und Scott hier unter die Theorie des Fiskalfoderalismus subsumiert. Breton/Scott berucksichtigen zwar in ihrer positiv-theoretisch fundierten Studie explizit Eigeninteressen der politischen Entscheidungsträger, sind jedoch der Ansicht, daß der politische Prozeß hinreichend effizient ist, so daß zwischen einer foderativen Optimalløsung und der sich aus dem politischen Entscheidungsprozeß ergebenden Losung keine gravierenden Unterschiede bestehen. Siehe Breton, A./Scott, A. (1978), S. 101. Der gleichen Auffassung uber die Einordnung des Breton/Scott-Ansatzes sind Hamlin, A.P. (1985a), S. 189 und Wiseman, J. (1990), S. 117. 
halb dessen eine föderative Gliederung für die Funktionen des produktiven Staates abgeleitet wird. ${ }^{8}$ Historischen oder politischen Restriktionen für die Umgestaltung eines existierenden Staatswesens wird in der Regel nur Rechnung getragen, indem die äußeren Grenzen des Staates als gegeben betrachtet werden. Diese Vorgehensweise wird bei den folgenden Darlegungen beibehalten; in Erweiterung der traditionellen Theorie wird jedoch auch die nationalstaatliche Obergrenze der föderativen Gliederung hinterfragt.

\section{B. Regelungen für den protektiven Staat}

\section{Der Regelungsbedarf auf konstitutioneller Ebene}

Aufgabe des schützenden Staates ist die Schaffung von Besitz- und Tauschsicherheit bei marktlichen Transaktionen. Der protektive Staat regelt die privatrechtlichen Beziehungen zwischen den Gesellschaftsmitgliedern durch die Einrichtung einer Eigentumsordnung, eines Vertragsrechts und eines Strafrechts. ${ }^{9}$ Die Vorteilhaftigkeit einer Übereinkunft zur Errichtung des Rechtsschutzstaates wurde damit begründet, daß eine kollektive Organisation den Schutz der Verfügungsrechte kostengünstiger erreichen kann. Damit wird zwar die Notwendigkeit staatlichen Handelns aufgezeigt, der Ansatz liefert aber keinen unmittelbaren Hinweis auf die optimale Größe der kollektiven Schutzorganisation. So unterscheiden Auster und Silver die Staatsgröße nach ${ }^{10}$

- der Anzahl von Personen, welche die Dienste des Staates in Anspruch nehmen,

- der geographisch-territorialen Ausdehnung des staatlichen Hoheitsgebietes,

- dem Grad der Rechtssicherheit, den der Staat gewährt und

- nach der Inanspruchnahme der Ressourcen zur Erfüllung der staatlichen Aufgaben.

In der Tat besteht für alle vier Problemdimensionen in der staatslosen Gesellschaft ein Regelungsbedarf, und aufgrund ihrer Interdependenz wäre eine simultane Lösung erforderlich. Im Rahmen dieser Arbeit sind jedoch insbesondere die beiden erstgenannten Aspekte von Bedeutung. Es sind Faktoren zu ermitteln, die auf konstitutioneller Ebene eine Entscheidung über die optimale personelle und territoriale Größe des protektiven Staates ermöglichen.

\section{II. Überlegungen zu einer Theorie optimaler Rechtsräume}

\section{Die Nutzen und Kosten der Bildung des protektiven Staates}

\section{a. Die Nutzen der Rechtsvereinheitlichung}

Die Bestimmung der optimalen Mitgliederzahl des protektiven Staates erfordert Vorüberlegungen zu den Auswirkungen, die unterschiedliche personelle Gruppengrößen auf die Netto-Nutzenpositionen der Gesellschaftsmitglieder in der nachkonstitutionellen Phase

\footnotetext{
Vgl. z.B. Musgrave, R.A. (1969b).

Vgl. Bernholz, P./Faber, M. (1986), S. 38f.

Vgl. Auster, R.D./Silver, M. (1979), S. 27.
} 
haben. ${ }^{11}$ Die Nutzen der Gründung des Rechtsschutzstaates bemessen sich nach den hierdurch erschlossenen Transaktionsmöglichkeiten. Gesellschaftliche Arbeitsteilung und Spezialisierung schaffen neue Transaktionsspielräume, die um so größer sind, je mehr tatsächliche und potentielle Marktteilnehmer existieren. ${ }^{12}$ Dabei dürften mit fortschreitender Arbeitsteilung die Nutzenzuwächse, die aus dem Hinzutreten weiterer Marktteilnehmer erwachsen, dem Gesetz abnehmender Grenzerträge folgend, immer geringer ausfallen. ${ }^{13}$

Damit ist zu klären, ob es sinnvoll ist, potentielle Transaktionspartner als Mitglieder in einer protektiven Organisation zusammenzufassen und Tauschvorgänge unter einheitlichem Privatrecht abzuwickeln, oder ob es, im Gegenteil, sogar angebracht wäre, daß die Individuen verschiedenen Rechtsschutzstaaten mit differierenden Rechtsordnungen angehören. ${ }^{14}$ Bernholz und Faber ${ }^{15}$ argumentieren, daß eine einheitliche Rechtsordnung zur Sicherung der Freiheit der Individuen beitrage, da diese im privaten Bereich nur die für alle gleichermaßen geltenden Regeln zu beachten hätten. Außerdem würden durch einheitliche Regeln Rechtssicherheit und Kenntnis der Gesetze wachsen: "Die Entscheidungen der Gerichte können eher für ein Gebiet mit einheitlichem Recht vorausgesagt werden. Dagegen muß man sich bei unterschiedlichen Rechtsordnungen mit erheblichem Kostenaufwand in dem jeweils betreffenden Gliedstaat informieren." 16 Transaktionen zwischen Rechtsordnungsfremden (Außenhandel) erfordern dagegen Absicherungen der Vertragspartner, die im Binnenhandel nicht anfallen. ${ }^{17}$ Es dürfte deshalb unstrittig sein, daß eine Rechtsvereinheitlichung transaktionskostensparend wirken und ein einheitliches Privatrecht die Arbeitsteilung fördern kann. ${ }^{18}$

\section{b. Die Durchsetzungskosten des protektiven Staates}

Allerdings ist die Errichtung des Rechtsschutzstaates nicht kostenlos, so daß die Forderung nach einem einheitlichen 'Welt-Privatrecht' verfrüht erscheint. ${ }^{19}$ Die Sicherung der Rechtsordnung durch Gerichte, Polizei und Streitkräfte erfordert den Einsatz von Ressourcen, die als Durchsetzungskosten der Rechtsordnung $R$ bezeichnet werden sollen. $R$ ist naturgemäß um so höher, je höher der optimale Spezifikationsgrad $s^{*}$ der privaten Verfügungsrechte ist ${ }^{20}$ und je

11 Auf die Einbeziehung der Verhandlungskosten in der Phase der konstitutionellen Beschlußfassung wird hier wie auch im folgenden verzichtet.

12 Vgl. Auster, R.D./Silver, M. (1979), S. 16 oder Kliemt, H. (1992), S. 39.

13 Vgl. Schmidt-Trenz, H.-J. (1990), S. 207.

14 Der theoretisch denkbare Fall, daß innerhalb eines protektiven Staates unterschiedliche Rechtsordnungen gelten, sei hier ausgeklammert. Moglich ist auch, daß zwei protektive Agenturen die gleiche Rechtsordnung haben. Siehe hierzu die Ausfuhrungen unten, S. 77.

15 Siehe Bernholz, P./Faber, M. (1986), S. 41 .

16 Bernholz, P./Faber, M. (1986), S. 41.

17 Siehe z.B. Benson, B.L. (1989) oder Milgrom, P./North, D.C./Weingast, B. (1990)."Contracts whose parties operate under separate domestic legal systems ... face hazards not usually present in contracts subsumed under a single legal system." Yarbrough, B.V./Yarbrough, R.M. (1994), S. 244.

18 Die Bestrebungen der 'Commission on European Contract Law' zur Kodifikation allgemeiner Grundsătze eines europäischen Vertragsrechts gelten explizit der Erleichterung des grenzuberschreitenden Handels in Europa. Vgl. Zimmermann, R. (1995), S. 478.

19 "Unless something is said about tastes or technology of providing public services, it would seem that the optimal size of the 'protective state' is the world population." Moss, L.S. (1980), S. 25. Ähnlich auch Kliemt, H. (1992), S. 39, FN 18 sowie Alesina, A./Perotti, R./Spolaore, E. (1995), S. 754.

20 Vgl. hierzu grundlegend die Ausfuhrungen bei Ehrlich, I./Posner, R.A. (1974). 
intensiver Rechtsverletzungen verfolgt werden ${ }^{21}$, je höhere Werte also der optimale Durchsetzungsgrad $\mathrm{d}^{*}$ der Rechtsordnung annimmt. Für die Fragestellung dieser Arbeit ist vor allem der funktionale Zusammenhang zwischen Durchsetzungskosten R und der Anzahl der Rechtsordnungsangehörigen $\mathrm{n}$ relevant. Dieser Zusammenhang soll im folgenden durch einfache Plausibilitätsüberlegungen ermittelt werden.

Ausgangspunkt ist die Notwendigkeit einer protektiven Agentur, die aus der potentiellen Konfliktträchtigkeit sozialer Interaktionen im Hobbes'schen Naturzustand abgeleitet wurde. Mit zunehmender Zahl der Gesellschaftsmitglieder n vergrößert sich die Zahl möglicher Interaktionen zwischen den Wirtschaftssubjekten nach der Formel $n(n-1)$ überproportional. Nimmt man an, daß sich die Zahl der Rechtskonflikte proportional zur Zahl potentieller Interaktionen entwickelt, wäre bei wachsendem $\mathbf{n}$ folglich mit einem progressiven Anstieg der internen Durchsetzungskosten $\mathrm{R}_{\mathrm{int}}$ bei Rechtsstreitigkeiten zwischen Kollektivmitgliedern zu rechnen. 22

Darüber hinaus liegt die Aufgabe des protektiven Staates auch in der Verteidigung der Mitglieder gegen Bedrohungen ihrer Rechte von außen, mithin in der Gewährung von Schutz gegen Übergriffe von Rechtsordnungsfremden. Die Bildung zwischenstaatlicher militärischer Allianzen 23 zur Stärkung der Gefahrenabwehr nach außen dürfte die These stützen, daß größere Bevölkerungszahlen und weitere territoriale Ausdehnungen die äußere Sicherheit gegenüber Bündnisfremden stärken. ${ }^{24}$ Anzunehmen wäre daher, daß sich die externen Durchsetzungskosten $R_{\text {ext }}$ umgekehrt zu den internen Durchsetzungskosten verhalten, aber nicht von s bzw. d mitbestimmt sind. Je größer die Mitgliederzahl der schützenden Institution, um so höher sind die internen und um so geringer sind die externen Durchsetzungskosten. ${ }^{25}$

$\mathrm{Zu}$ berücksichtigen ist außerdem die territoriale Dimension des Staatswesens. ${ }^{26}$ Es ist zu vermuten, daß mit der räumlichen Ausweitung des Staatsgebietes die Kosten der territorialen Kontrolle überproportional ansteigen. ${ }^{27}$ Ursache hierfür sind gestiegene Transportkosten, aber auch spezielle geographische Faktoren könnten hier von Bedeutung sein. ${ }^{28}$ Aspekte der internen Rechtssicherheit im Hinblick auf das Verhältnis von Bevölkerungszahl und territorialer Ausdehnung des Hoheitsgebietes wurden von Brecht in seinem aus empirischen Beobachtungen abgeleiteten "Gesetz der progressiven Parallelität von Ausgaben und Bevölkerungsmassierung"29 erörtert. Zunehmende Bevölkerungsdichte führt nach Brecht zu einem

21 Siehe etwa Becker, G.S. (1968).

22 Vgl. Schmidtchen, D./Schmidt-Trenz, H.-J. (1994), S. 17.

23 Zur Theorie militărischer Allianzen siehe z.B. Conybeare, J.A.C./Murdoch, J.C./Sandler, T. (1994).

24 Vgl. auch Wittman, D. (1991), S. 126 und S. 129.

25 Für einen protektiven Staat, der die gesamte Weltbevőlkerung umfaßt, sind die externen Durchsetzungskosten naturlich definitionsgemäß gleich Null.

26 Explizit 0 konomische Betrachtungen der Staatsgrøße, die auf die territoriale Dimension abstellen, finden sich bei Friedman, D. (1979) und Blum, U./Dudley, L. (1991). Vgl. auch die Staatsdefinition von North, D.C. (1981/1988), S. 21. Das "Territorialitatsprinzip des Rechts" ist aus Kostengrunden gegenuber dem "Personenverbandsprinzip" als Organisationsform vorzuziehen. Vgl. Schmidt-Trenz, H.J. (1990), S. $210 \mathrm{ff}$.

27 "...jurisdictions expand by expanding the territorial area over which they claim domination. The logistics of enforcing hegemony over a large geographical area may explain why the costs of providing protection eventually rise at an accelerated rate..." Moss, L.S. (1980), S. 21. (Hervorhebung im Original). Vgl. auch Latzko, D.A. (1993); Artzrouni, M./Komlos, J. (1994).

28 Vgl. Blum, U./Dudley, L. (1991), S. 315.

29 Brecht, A. (1932). Vgl. Littmann, K. (1977), S. 360ff. 
verstärkten Bedarf an ordnungssichernden staatlichen Institutionen, der neben anderen Faktoren Ursache für öffentliches Ausgabenwachstum sei.

Insgesamt betrachtet kann deshalb davon ausgegangen werden, daß mit wachsender Zahl der Gesellschaftsmitglieder die internen Kosten der Rechtsdurchsetzung progressiv steigen, die externen Durchsetzungskosten hingegen überproportional sinken. Formal läßt sich die Argumentation wie folgt darstellen. Bezeichnet man die Gesamtpopulation bei der konstitutionellen Beschlußfassung 30 mit $\mathrm{N}$ und die Zahl der Rechtsordnungsfremden mit $\overline{\mathrm{n}}$, so gilt: $\mathrm{N}=\mathrm{n}+\overline{\mathrm{n}}$. Die totalen Durchsetzungskosten $\mathrm{R}$ setzen sich zusammen aus internen und externen Kosten der Rechtsdurchsetzung, $R=R_{\text {int }}+R_{\text {ext }}$. Die internen Durchsetzungskosten sind bestimmt durch Spezifikationsgrad und Durchsetzungsgrad der property rights sowie von der Zahl der Kollektivmitglieder, $R_{\text {int }}=R_{\text {int }}\left(n, s^{*}, d^{*}\right)$. Mit zunehmender Zahl von $n$ wachsen die internen Durchsetzungskosten annahmegemäß progressiv.

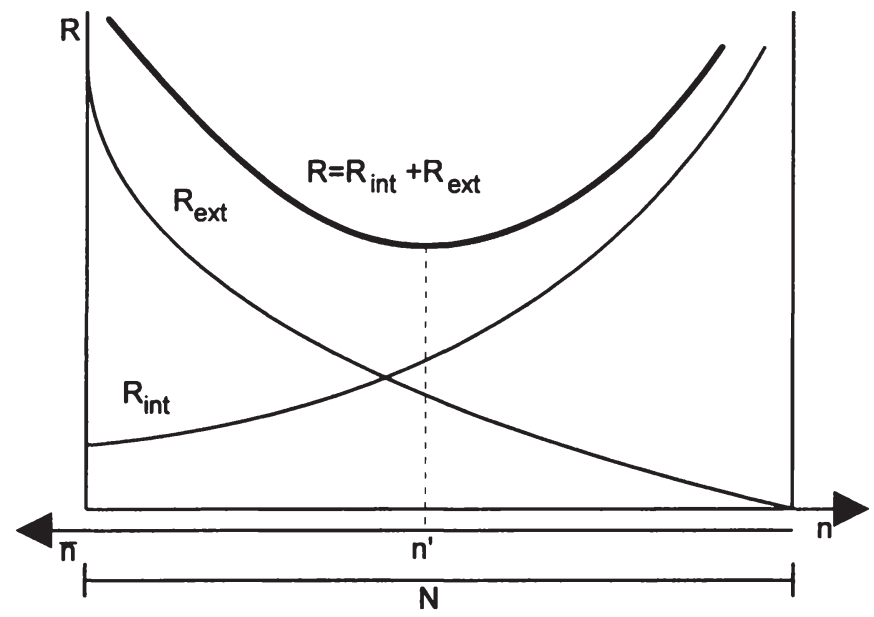

Abbildung 3.1: Die Durchsetzungskosten des protektiven Staates

Quelle: in Anlehnung an Schmidtchen, D./Schmidt-Trenz, H.-J. (1994), S. 18.

Analog ist zu vermuten, daß die Kosten des externen Schutzes gegenüber Rechtsordnungsfremden, $\mathbf{R}_{\text {ext }}=\mathbf{R}_{\text {ext }}(\overline{\mathbf{n}})$, mit steigender Zahl der Kollektivmitglieder $\mathbf{n}$ progressiv fallen. Abbildung 3.1 illustriert diesen Zusammenhang. Die Kurve der totalen Durchsetzungskosten $\mathbf{R}$ hat unter den gegebenen Annahmen einen u-förmigen Verlauf; das Gesamtkostenminimum ist bei einer Kollektivgröße n' erreicht.

\section{Die optimale personelle Größe des protektiven Staates: ein einfaches Modell}

Aus den bislang angestellten Überlegungen zu den Nutzen und Kosten der protektiven Agentur Staat lassen sich die Bedingungen für die optimale personelle Größe der Organisation

30 Die Bevઠlkerungsgroße $\mathrm{N}$ soll im folgenden als konstant angenommen werden. 
ableiten. ${ }^{31}$ Dabei kann die folgende theoretische Analyse kaum Anspruch auf vollständige Widerspiegelung aller für die Bestimmung einer optimalen Staatsgröße relevanten Faktoren erheben. Da historischen Gegebenheiten und daraus resultierenden institutionellen Rigiditäten keine Beachtung geschenkt wird, haben die Ausführungen eher den Charakter von Plausibilitätsüberlegungen. 32

Ausgangspunkt der Betrachtungen, die auf einem clubtheoretischen Ansatz ${ }^{33}$ beruhen, sei das Kosten-Nutzen-Kalkül eines repräsentativen Individuums auf konstitutioneller Ebene. Bezeichnet man die aus der Sicherung des Eigentums- und Tauschsystems entstehenden Bruttoeinkommen des repräsentativen Individuums mit vorgegebener Ressourcenausstattung mit $Y$, ist dessen Nutzenfunktion $U=U(Y)$ mit $(d U / d Y)>0$ beschrieben. Neben der Zahl der Marktteilnehmer $\mathrm{n}$ sind die in der postkonstitutionellen Phase realisierbaren Bruttoeinkommen vom Spezifikationsgrad s der property rights und vom Durchsetzungsgrad d der Rechtsordnung bestimmt. Da diese bereits annahmegemäß die Optimalwerte $\mathrm{s}^{*}$ bzw. $\mathrm{d}^{*}$ haben, ergibt sich aus den obigen Ausführungen der Funktionszusammenhang $\mathrm{Y}=\mathrm{Y}\left(\mathrm{n}, \mathrm{s}^{*}, \mathrm{~d}^{*}\right)$ mit $(\partial \mathrm{Y} / \partial \mathrm{n})>0$ und $\left(\partial^{2} \mathrm{Y} / \partial \mathrm{n}^{2}\right)<0$. Im Kalkül des Individuums finden die von ihm anteilig zu tragenden Durchsetzungskosten Berücksichtigung. Wird vereinfachend unterstellt, daß die Durchsetzungskosten $\mathrm{R}$ von allen Mitgliedern $\mathbf{n}$ der Kooperationsgruppe zu gleichen Anteilen zu tragen sind, lautet das Optimierungskalkül: ${ }^{34}$

Maximiere: $\quad \mathrm{Y}\left(\mathrm{n}, \mathrm{s}^{*}, \mathrm{~d}^{*}\right)-\frac{\mathrm{R}\left(\mathrm{n}, \mathrm{s}^{*}, \mathrm{~d}^{*}\right)}{\mathrm{n}}$

über die Wahl der Kontrollvariable n. Als Maximierungsbedingung erhält man:

$$
\frac{\partial Y}{\partial n}=\frac{1}{n}\left(\frac{\partial R}{\partial n}-\frac{R}{n}\right) .
$$

Nach (3.B.II.1) ist die optimale personelle Größe der Kooperationsgruppe im schützenden Staat erreicht, wenn die marginalen Einkommenszuwächse durch Aufnahme eines weiteren Mitglieds gleich den marginalen Kostenbelastungen je Gruppenmitglied sind. Aus Abbildung 3.1 läßt sich ableiten, daß die Durchsetzungskosten je Mitglied ebenfalls einen u-förmigen Verlauf annehmen. Bis zu einer Kollektivgröße n' sinken die totalen Kosten R, und es verringern sich die von jedem Kollektivmitglied zu tragenden Durchsetzungskosten, weil die Zahl der Mitglieder ansteigt. Letzterer Entlastungseffekt $(-R / n)$ bleibt mit wachsender Zahl der Mitglieder weiter bestehen. $\mathrm{Da}$ aber ab der Kollektivgröße n' die totalen Durchsetzungskosten $\mathrm{R}$ ansteigen, resultiert $\mathrm{ab} \mathrm{n}^{\prime}$ aus dem Beitritt weiterer Individuen zur Rechtsschutzkoalition eine marginale Belastung der ursprünglichen Mitglieder. ${ }^{35}$ Bis zur Gruppengröße n" (Abbildung 3.2) wird dieser Belastungseffekt durch den Entlastungseffekt dominiert; für

31 Siehe Schmidt-Trenz, H.J. (1990), S. 203ff.; Schmidtchen, D./Schmidt-Trenz, H.-J. (1994).

32 Siehe aber die Ausfuhrungen von Wittman, D. (1991) und Yarbrough, B.V./Yarbrough, R.M. (1994), die ahnlichen Überlegungen bei empirischen Analysen freiwilliger und gewaltsamer Staatszusammenschlusse und -trennungen einen hohen Erklärungswert beimessen.

33 Grundlegend Buchanan, J.M. (1965). Siehe hierzu auch Abschnitt C.II des Kapitels, S. 82ff.

34 Da infolge $N=n+\bar{n}$ jede Grßße von $n$ automatisch bei gegebenem $N$ auch $\bar{n}$ determiniert, kann $R$ als einfache Funktion von $\mathrm{n}$ dargestellt werden.

$35 \mathrm{Vgl}$. Schmidtchen, D./Schmidt-Trenz, H.-J. (1994), S. 17. 
Gruppengrössen über $n$ " überwiegt dagegen der Belastungseffekt, und die Durchsetzungskosten je Mitglied steigen an. ${ }^{36}$

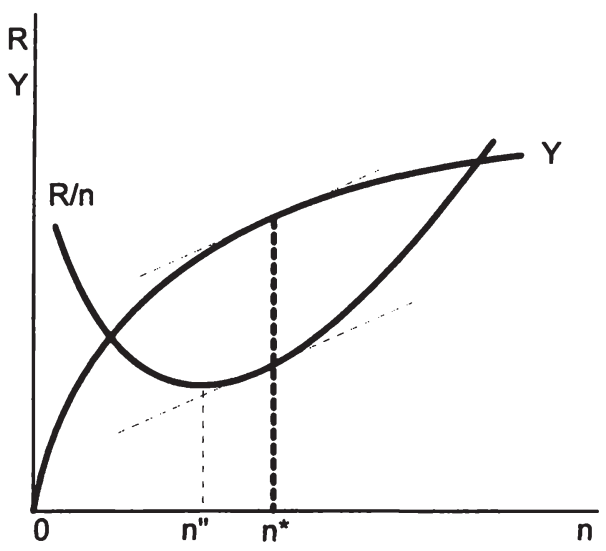

Abbildung 3.2: Die optimale personelle Größe des protektiven Staates

Quelle: in Anlehnung an Schmidtchen, D./Schmidt-Trenz, H.-J. (1994), S. 17.

Die optimale personelle Größe n* des protektiven Staates liegt dort, wo die Differenz zwischen dem postkonstitutionellen Bruttoeinkommen des repräsentativen Individuums $\mathrm{Y}(\mathrm{n})$ und den Durchsetzungskosten je Gruppenmitglied $(R(n) / n)$ maximal ist. Die Gruppengröße $n *$ beschreibt einen optimalen Rechtsraum, der durch die Einheitlichkeit der Regelung privatautonomer Beziehungen gekennzeichnet ist. ${ }^{37}$ Entgegen der Auffassung von Buchanan, daß der protektive Staat die Grundgesamtheit $\mathrm{N}$ umfassen müsse ${ }^{38}$, ist der 'Weltstaat' lediglich optimal, wenn $\mathrm{N} \leq \mathrm{n}^{*}$. Die optimalen einheitlichen Rechtsräume sind um so größer, je höher die Durchsetzungskosten gegenüber Rechtsordnungsfremden und je geringer die Kosten einer internen Konfliktbewältigung sind. 39

36 Einen u-formigen Verlauf unterstellen auch Auster und Silver: "Holding the level of state-produced order constant, the average total cost curve with respect to the size of the population can be expected to have the traditional u-shape. An initial range of decreasing average costs, resulting from indivisibilities, the finer division of labor, or perhaps from the very nature of the technology of the good is necessarily offset in the limit by increased transportation costs, increased coordination problems, and by the increased importance of the 'shirking problem'." Auster, R.D./Silver, M. (1979), S. 28f. Ebenso Holcombe, R.G./Sobel, R.S. (1995), S. 47 und S. 55.

37 Vgl. Schmidtchen, D./Schmidt-Trenz, H.-J. (1994), S. 7f.

38 "Der Prozeß vertraglicher Internalisierung kann sich bei großer werdenden Subgruppen so lange fortsetzen, bis ein abschließender Verhandlungsprozeß erreicht ist, der alle Angehörigen des Gemeinwesens in einen einzigen Verfassungsvertrag zusammenschließt." Buchanan, J.M. (1975/1984), S. 45. (Hervorhebungen H.P.)

39 Technologische Veränderungen bedingen daher auch Änderungen in der personellen Optimalgroße des Rechtsschutzstaates. Siehe Bean, R. (1973). Vgl. die Studie von Rokkan, S. (1975) zur Staatsbildung in Europa. 


\section{Die Implikationen für die föderative Aufgabenverteilung}

Der Rechtsschutzstaat liefert nicht nur den Rahmen für die privatwirtschaftlichen Aktivitäten der Staatsbürger. Seine Zwangsgewalt ist darüber hinaus auch für die Durchsetzung der Kollektiventscheidungen im produktiven Staat erforderlich. Angesichts dessen bildet die Größe des protektiven Staates gleichzeitig die natürliche Obergrenze für den Leistungsstaat. 40 Diese Auffassung entspricht im übrigen auch der Definition von North, der den Staat sieht als

"... eine mit dem komparativen Vorteil der Gewaltanwendung ausgestattete Organisation, die sich uber ein Gebiet der Erdoberflache erstreckt, dessen Grenzen durch ihre Steuerhoheit bestimmt sind."41

Das Modell impliziert indes nicht, daß jeglicher Außenhandel unterbleibt. Tauschbeziehungen zwischen Rechtsordnungsfremden sind aber mit höheren Transaktionskosten als im innerstaatlichen Wirtschaftsverkehr verbunden. Rechtsunsicherheiten im Außenhandel wären gleichwohl erst dann durch Ausweitung des protektiven Staates zu beseitigen, wenn private Absicherungen kostenintensiver sind als staatliche Aktivitäten.

Allerdings wäre kritisch einzuwenden, daß die Garantie äußerer Sicherheit z.B. durch militärische Allianzen erfolgen kann. Die bei der Bildung der Bündnisse auftretenden free rider- und Lastverteilungsprobleme ${ }^{42}$ stellen zwar eine latente Gefahr für die Stabilität der Zusammenschlüsse dar. Sie sind aber mit dem Vorteil verbunden, daß die Übertragung hoheitlicher Befugnisse auf internationale Organisationen zur Gewähr äußerer Sicherheit den Mitgliedsstaaten intern unterschiedliche Regelungen der Rechtsordnungen ermöglicht. Äußere und innere Sicherheit sind, entgegen den Modellannahmen, nicht untrennbar miteinander verbunden. In der vorliegenden Form vermag die Theorie auch nur identische Rechtsordnungen zu begründen. ${ }^{43}$ So sind in der Realität beobachtete Differenzen historisch gewachsen. ${ }^{44}$ Hier wäre zu prüfen, ob die Unterschiede auf heterogene Präferenzen zurückzuführen $\operatorname{sind}^{45}$ oder auf dem nicht notwendigerweise effizienten Zusammenwirken der Kräfte des institutionellen Wandels beruhen. 46

Die Modellierung des Rechtsschutzstaates als neutrale Durchsetzungsinstanz für die property rights der Staatsmitglieder vernachlässigt überdies, daß in der Realität weder die Eigentumsnoch die Wettbewerbsordnung im institutionenfreien Raum des konstitutionellen Konvents spezifiziert wird. Es ist zu erwarten, daß dann auch die Durchsetzungsautorität über Freiräume bei der Interpretation der Rechtsregeln verfügt. Hieraus könnten sich Änderungen im dargelegten Optimierungskalkül ergeben.

40 "Die Schutzfunktionen werden nahezu zwangsläufig der staatlichen Einheit, die in Fläche und Einwohnerschaft mit dem Gebiet der potentiellen ökonomischen Interdependenz ubereinstimmt, ubertragen." Brennan, G./Buchanan, J.M. (1980/1988), S. 221.

41 North, D.C. (1981/1988), S. 21.

42 Grundlegend: Olson, M./Zeckhauser, R.J. (1966).

43 Siehe den Kommentar zu Schmidtchen, D./Schmidt-Trenz, H.-J. (1994) von Emons, W. (1994), S. 30.

44 Vgl. Schmidt-Trenz, H.-J. (1990), S. 222ff.

45 So zumindest Broder, J.M./Schmid, A.A. (1983), S. 9.

46 Bolton, P./Roland, G./Spolaore, E. (1996), S. 701 vermuten, daß "... too many nations may emerge as democracy spreads." 
Die Analyse hat gezeigt, daß für die schützende Funktion des Staates die personelle und territoriale Staatsgröße entscheidende Bedeutung haben. Der optimale protektive Staat umfaßt nicht zwingend die gesamte Weltbevölkerung. Es ist aufgrund von Kosten-Nutzen-Überlegungen eher davon auszugehen, daß eine Vielfalt von Staaten, auch mit voneinander verschiedenen Rechtsordnungen, einer konstitutionellen Optimallösung näher kommt.

Von ausschlaggebender Bedeutung für die Ableitung dieser Ergebnisse ist die Annahme des u-förmigen Verlaufs der Durchsetzungskosten der Rechtsordnung. ${ }^{47}$ Eine empirische Überprüfung dieser Annahme wäre erforderlich, Plausibilitätsüberlegungen lassen jedoch die Vermutung zu, daß dieser Kostenverlauf keineswegs realitätsfern ist.

Im weiteren Verlauf der Arbeit wird die theoretisch ermittelte Größe des protektiven Staates als Obergrenze aller anderen Staatsaktivitäten aufgefaßt. Von den Außenbeziehungen der Organisation Staat selbst als auch von denen der Bürger wird abstrahiert. Es soll dann der Frage nachgegangen werden, wie die Aufteilung der Funktionen des produktiven Staates zu organisieren ist.

\section{Regelungen für den produktiven Staat}

\section{Der Regelungsbedarf auf konstitutioneller Ebene}

\section{Bereitstellungszuständigkeit und Durchführungszuständigkeit}

Zentrale Funktion des produktiven Staates ist die Organisation eines nicht-marktlichen Tauschmechanismus. Die staatliche Autorität, Transaktionen zu erzwingen, dient dem Zweck, durch eine für die Gesellschaftsmitglieder verbindliche Kollektiventscheidung die Vielzahl erforderlicher Tauschverträge zu ersetzen und die Finanzierungsbeteiligungen der Kollektivmitglieder festzulegen. $\mathrm{Zu}$ regeln sind auf konstitutioneller Ebene insbesondere zwei Aspekte:

(i) Die Aufgabenkompetenz ${ }^{48}$ umfaßt die Befugnis zur Entscheidung über Qualität und Quantität einer staatlichen Aufgabe. ${ }^{49}$ Sie umschließt das Recht, darüber zu entscheiden, ob und wie eine Maßnahme durchgeführt wird und welche finanziellen Mittel dafür aufgewendet werden (Ausgabenkompetenz). Die Zuordnung der Aufgaben- (und Ausgaben-) kompetenzen auf staatliche Entscheidungsträger bezeichnet man auch als "passiven Finanzausgleich"50. Aufgaben- und Ausgabenverantwortung sollten nach der Theorie der Verfügungsrechte grundsätzlich bei einem Entscheidungsträger vereinigt sein. 51

47 Schmidtchen, D./Schmidt-Trenz, H.J. (1990), S. 60.

48 Hansmeyer, K.-H./Kops, M. (1984), S. 128 bezeichnen diese Kompetenzen als "Entscheidungskompetenz". Diese Begriffswahl erscheint jedoch etwas unglucklich, da Entscheidungen auf allen Stufen der Leistungserstellung erfolgen.

49 Vgl. Hansmeyer, K.-H./Kops, M. (1984), S. 128.

50 Peffekoven, R. (1980), S. 608.

51 Dies gilt selbst dann, wenn die Aufgabenerfullung durch wenig ausgabenintensive Ge- und Verbote oder ausschließlich uber die budgetăre Einnahmenseite erfolgt. Vgl. Peffekoven, $R$. (1980), S. 617. 
(ii) $\mathrm{Zu}$ regeln ist auch das Recht, $\mathrm{zu}$ entscheiden, ob und wie eine Finanzierungsquelle (Steuern, Verschuldung) beansprucht wird (Objekt- und Gestaltungshoheit) und in welcher Höhe die Quellen ausgeschöpft werden. Da die Einnahmenerzielung des Staates kein Selbstzweck sein kann, sondern immer im Zusammenhang mit der Aufgabenerfullung steht, ist unstrittig, daß die Zuordnung der Finanzierungskompetenzen, der "aktive Finanzausgleich"52, der Zuweisung der Aufgabenkompetenzen folgen muß.53

Aufgaben- und Finanzierungsverantwortlichkeit bilden nach Musgrave/Musgrave/Kullmer 54 die Bereitstellungskompetenz. Die Bereitstellung öffentlicher Leistungen umfaßt also Kollektiventscheidungen über die Realisierung von Aufgaben und über deren Finanzierung. Bereitstellungskompetenzen sind spezielle property rights (politische Verfügungsrechte). Dem institutionenökonomischen Ansatz folgend sollten sie so zugeordnet werden, daß die Kosten des Bereitstellungsarrangements, also die Transaktionskosten der 'Organisation produktiver Staat', minimiert werden. 55

Von der Bereitstellungskompetenz ist die Durchführungskompetenz abzugrenzen. ${ }^{56}$ Sie beinhaltet das Recht bzw. die Pflicht, "... eine öffentliche Aufgabe unter Beachtung der vom entscheidungsbefugten Aufgabenträger erlassenen Vorgaben durchzuführen." 57 Die Durchführungskompetenzen sollten so gestaltet sein, daß die Produktion der Kollektivgüter zu minimalen Durchschnittskosten erfolgt. Die Entscheidung, wie der Produktionsprozeß der Kollektivgüter vonstatten gehen soll, hat folglich mit dem für die normative Begründung staatlicher Aktivitäten ursächlichen Marktversagen nichts zu tun. ${ }^{58}$ Für die Ermittlung der optimalen "collective consumption units" 59 ist die Durchfuhrungskompetenz allenfalls von sekundärer Bedeutung. ${ }^{60}$ Es spricht grundsätzlich nichts dagegen, Produktionseinheiten - sei es nun eine staatliche Bürokratie oder eine private Unternehmung - von Entscheidungseinheiten zu trennen. Ein Hersteller von Kollektivgütern kann zur Realisierung von Skalenerträgen in der Produktion im Auftrag vieler kollektiver Entscheidungsträger arbeiten, und umgekehrt kann eine Bereitstellungseinheit bei Vorliegen von diseconomies of scale die Produktion auf mehrere Produktionseinheiten delegieren.61 Die weiteren Betrachtungen werden daher auf die Aufgaben- und Finanzierungskompetenzen beschränkt. Hierzu sollen im nächsten Abschnitt die prinzipiell denkbaren organisatorischen Ausgestaltungen von property rights-Regelungen skizziert werden.

52 Peffekoven, R. (1980), S. 608.

53 Vgl. z.B. Musgrave, R.A. (1983), S. 2.

54 Vgl. Musgrave, R.A./Musgrave, P.B./Kullmer, L. (1994), S. 9.

55 So auch Buchanan, J.M./Tullock, G. (1962), S. 44 oder Wagner, R.E. (1983), S. 454.

56 "The primary reason for using a form of collective organization is to solve problems of provision. But once a collective consumption unit is established, how production is organized is an entirely separate question." Ostrom, E. (1983), S. 84 (Hervorhebung im Original).

57 Hansmeyer, K.-H./Kops, M. (1984), S. 129.

58 Die Durchfuhrungskompetenz ist insofern den Bereitstellungsverantwortlichkeiten nachgelagert; letztere beinhalten auch das Recht, daruber zu entscheiden, wie die Produktion zu erfolgen hat.

59 Ostrom, E. (1983), S. 83.

60 Anders zunächst Tiebout, C.M. (1961), der jedoch diese Ansicht spăter revidierte, vgl. Tiebout, C.M./Houston, D.B. (1962). Siehe hierzu auch Tullock, G. (1969a); Olson, M. (1970); Oates, W.E. (1972), S. 45; Theiler, J. (1977), S. 65ff.; Blankart, C.B. (1978); King, D.N. (1984), S. 66ff. und Fisher, R.C. (1988), S. 83ff.

61 Vgl. Teutemann, M. (1992), S. 182; Stehn, J. (1993), S. 39. 


\section{Alternative Organisationsformen der Zuordnung von Bereitstellungskompetenzen}

Aus institutionenökonomischer Perspektive ist die Organisationsstruktur des Staates durch die Zuordnung politischer Verfügungsrechte auf die Staatsmitglieder bestimmt. Ausgehend von der These der property rights-Theorie, daß die inhaltliche Ausgestaltung der Verfügungsrechte die Allokationsergebnisse in einer "specific" und "predictable"62 Weise beeinflußt, untersucht die Theorie des Fiskalföderalismus, wie eine vertikale Aufteilung politischer Entscheidungsrechte auf territorial definierte Subgruppen die Ergebnisse verändert. Das normative Erkenntnisinteresse der ökonomischen Föderalismustheorie bezieht sich deshalb auf die Frage, wie für die Funktionen des Leistungsstaates ${ }^{63}$ populationsmäßige Größen von Zuständigkeitsbereichen (Jurisdiktionen ${ }^{64}$ ), die Entscheidungen über die Bereitstellung von Kollektivgütern zu treffen haben, festzulegen sind. In einem durch die Extrema Zentralismus und Dezentralismus abgegrenzten Spektrum wird versucht, durch Gegenüberstellung der Kosten und Nutzen einer Zentralisierung einzelner Staatsaufgaben die optimale personelle Größe der Gebietskörperschaften zu ermitteln. ${ }^{65}$ Mit René Frey lassen sich die beiden 'reinen' Varianten beschreiben als

- "die rein föderative Lösung: Sämtliche Kompetenzen liegen in den Händen der Gliedstaaten; sie kommen auch für die Finanzierung der betreffenden Aufgaben auf. Jegliche dauernde und formalisierte Kooperation unter ihnen beziehungsweise zwischen ihnen und dem Bund ist ausgeschlossen;

- die rein zentralistische Lösung: Alle wichtigen Kompetenzen für eine öffentliche Aufgabe liegen beim Bund." 66

Föderative Strukturen ergeben sich dann aus der Zuordnung von Bereitstellungskompetenzen für verschiedene Staatsaufgaben auf unterschiedliche Ebenen im Staat. ${ }^{67}$ In der Realität zu beobachtende Organisationsstrukturen zeichnen sich freilich durch ein weit höheres Maß an Komplexität aus, als es von diesem Schema beschrieben wird. Die Politikwissenschaft untersucht seit geraumer Zeit das Phänomen der institutionalisierten Politikverflechtung im föderativen Staat ${ }^{68}$, verstanden als die "... gemeinsame Aufgabenplanung und -finanzierung der gebietskörperschaftlichen Ebenen."69 So lehnt Scharpf das einfache Dezentralisierungs-Zen-

62 Furubotn, E.G./Pejovich, S. (1972), S. 1139. Siehe auch FN 43 im 2. Kapitel.

63 Streng von diesen Funktionen sind dagegen einzelne Politiken zu trennen. Letztere umfassen die konkreten Maßnahmen, also die quantitative und qualitative Ausgestaltung der Staatsaktivităten im Hinblick auf die Erreichung der im Entscheidungsprozeß ermittelten Zielvorgaben. Vgl. Breton, A./Scott, A. (1978), S. 11.

64 Nicht als Jurisdiktionen im hier verwendeten Sinn sollen rein weisungsgebundene administrative Korperschaften gelten. Konstituierendes Merkmal einer Jurisdiktion ist die Autonomie bei der Entscheidung uber Zielbestimmung und Maßnahmeneinsatz. Vgl. hierzu auch die Definition von Breton, A./Scott, A. (1978), S. 19f. Im Hinblick auf den direkten Zusammenhang zwischen populationsmäßiger und territorialer Grøße von Jurisdiktionen wird im folgenden auch synonym von 'Gebietskorperschaften' oder auch 'regionalen Subgruppen' gesprochen.

65 Vgl. etwa Theiler, J. (1977), S. 33 oder Frey, R.L. (1977), S. $40 \mathrm{ff}$.

66 Frey, R.L. (1977), S. 43f.

67 Die Wahl des Begriffs 'rein foderative Løsung' macht deshalb auch nur Sinn, wenn zumindest eine Staatsfunktion auf der ubergeordneten (Zentral-)Ebene angesiedelt ist, da ansonsten das bundesstaatliche Element der Ordnung fehlt. Man könnte insofern treffender von einer 'rein dezentralen Lősung' sprechen.

69 Hesse, J.J. (1978), S. 9. 
tralisierungs-Schema als unzureichend $a b$, da es der unvermeidlichen Mehrdimensionalität staatlicher Aufgaben nicht gerecht werde. ${ }^{70}$ Die normative Politikverflechtungsuntersuchung verfolgt dagegen das Ziel einer "... Zuordnung notwendiger Steuerungsprogramme zu den ... Typen von Dezentralisierungsproblemen"71, für die eine Entscheidungszentralisierung keine geeignete Lösung sei. Mithin wird betont, daß Bereitstellungsverantwortlichkeiten zwischen den Ebenen und zwischen den dezentralen Einheiten derselben Ebene aufgeteilt werden können; Problemlösungsdefizite einer rein föderativen Lösung implizierten nicht zwingend die völlige Kompetenzverlagerung auf die nächsthöhere Ebene. $\mathrm{Zu}$ unterscheiden sind mehrere Strukturtypen, die durch eine differierende Aufteilung der Kompetenzen für die Formulierung und Beschlußfassung der Restriktionen rein dezentralen Handelns charakterisiert sind: ${ }^{72}$

- Horizontale Verflechtungssysteme, bei denen nur die dezentralen Entscheidungseinheiten selbst an der Interaktion beteiligt werden,

- Hierarchische Verflechtungssysteme, deren Merkmal es ist, daß Zentraleinheiten Restriktionen für die Untereinheiten bei deren Entscheidungen festlegen können und

- Verbundsysteme, die durch konsensuale Beziehungen zwischen der Zentralinstanz und den Untereinheiten bei der Entwicklung der Steuerungsprogramme definiert sind.

Zweifelsohne ermöglicht diese Systematik, die Realität föderativer Organisationsstrukturen genauer zu erfassen, als es das einfache ökonomische Schema kann. Zwar bleibt auch die Taxonomie von Scharpf noch stark vereinfachend. Gleichwohl stellt er explizit den von der traditionellen ökonomischen Theorie vernachlässigten Aspekt der interkollektiven Beziehungen zwischen den gliedstaatlichen Einheiten in horizontaler Sicht einerseits und zwischen den Gliedstaaten und der Zentralebene in vertikaler Sicht andererseits in den Vordergrund der Betrachtungen. Somit ist die Organisationsstruktur nicht allein durch die Zahl der gebietskörperschaftlichen Ebenen (vertikale Fragmentierung) und die Anzahl der selbständigen, nach territorialen Aspekten gegliederten Entscheidungseinheiten auf jeder Ebene (horizontale Fragmentierung) beschrieben ${ }^{73}$, wie das einfache Zentralisierungs-Dezentralisierungsschema suggeriert. Die sich daraus ergebende organisatorische Vielfalt beläßt den Individuen bei der konstitutionellen Beschlußfassung über die optimale Staatsstruktur differenzierte Gestaltungsmöglichkeiten.

\section{Die Zuordnung der Allokationsfunktion}

\section{Fiskalische Äquivalenz und Informationskosten}

\section{a. Kollektivgüter, räumliche Nutzengrenzen und das Prinzip fiskalischer Äquivalenz}

Ausgangspunkt der Aufgabenverteilungsdebatte des Fiscal Federalism ist die Theorie der Kollektivgüter, erweitert durch die Berücksichtigung unterschiedlicher räumlicher Nutzer-

70 Scharpf, F.W. (1976), S. 28.

71 Scharpf, F.W. (1978), S. 25. Dezentralisierungsprobleme resultierten aus einer "Inkongruenz zwischen Entscheidungsstruktur und Problemstruktur", die "... durch den Einsatz geeigneter Steuerungsprogramme (sanktionsbewehrte Instrumente, durch die Restriktionen fur die Entscheidungsautonomie der dezentralen Einheiten gesetzt werden)" gelost werden könten. Scharpf, F.W. (1978), S. 24 und S. 25.

72 Siehe Scharpf, F.W. (1976), S. 34f. Ähnlich auch Frey, R.L. (1977), S. $43 \mathrm{ff}$.

73 Vgl. Boyne, G.A. (1992), S. 334f. 
kreise $^{74}$ ("benefit areas"75). Nicht alle bereitgestellten Kollektivgüter stehen nämlich der Gesamtbevölkerung zur Verfügung, die Gruppe der gemeinschaftlichen Konsumenten ist unterschiedlich groß. ${ }^{76}$ Technologisch bedingte räumliche Effekte in der Nutzung von Kollektivgütern können vereinfachend in drei Kategorien eingeteilt werden. ${ }^{77}$

- Reine lokale öffentliche Güter sind durch Nicht-Rivalität und Nicht-Ausschließbarkeit innerhalb einer Region gekennzeichnet. Die räumliche Ausdehnung des Nutzerkreises ist exogen vorgegeben, der Konsum ist somit zwischen den Regionen quasi-rivalisierend. ${ }^{78}$

- Abhängig von der räumlichen Distanz vom Bereitstellungsort bestehen Nutzungsoptionen für die Konsumenten. ${ }^{79} \mathrm{Ab}$ einer bestimmten Entfernung ist die Nutzung des Gutes aber infolge wachsender Kosten der Raumüberwindung nicht mehr sinnvoll.

- Die Nutzen, die die Konsumenten aus dem Kollektivgut erhalten, können mit zunehmender Distanz vom Bereitstellungsort abnehmen. 80

Den drei Fällen ist gemeinsam, daß der Konsum der Kollektivgüter partiell rivalisiert. ${ }^{81}$ Zwischen dem Zuständigkeitsbereich eines Entscheidungsträgers, einer Regierung, und der Wirkungsreichweite eines Kollektivgutes existieren nun nach Olson drei logisch denkbare Relationen, die für die Organisation des Staatswesens weitreichende Konsequenzen haben:82

(i) Der Nutzen des Gutes streut über die räumlichen Grenzen der Regierungszuständigkeit hinaus (positiver spillover-Effekt). Das Kollektivgut stiftet auch Individuen Nutzen, die nicht an der Entscheidung über die Bereitstellung beteiligt werden. Entsprechend können sie auch nicht zur zwangsweisen (Mit-)Finanzierung von Produktion und Bereitstellung des Gutes herangezogen werden, da sie außerhalb des Zuständigkeitsbereiches der bereitstellenden Regierung wohnen. Es liegen positive Externalitäten vor, die ohne korrigierende Eingriffe zu einer suboptimalen Versorgung führen können.

(ii) Die populationsmäßigen Zuständigkeitsgrenzen des Entscheidungsträgers überschreiten die Nutzengrenzen des Kollektivgutes. Dieser von Olson als "internality" 83 bezeichnete Fall führt zu einem suboptimalen Versorgungsniveau, wenn Kollektivmitglieder, die keinen Nutzen aus dem Konsum des Gutes erhalten, trotzdem zwangsweise an den Kosten

74 "The spatial characteristics of market failures are at the heart of the fiscal federalism issues." Mueller, D.C. (1971), S. 569.

75 Musgrave, R.A. (1969b), S. 296.

76 Dabei werden răumliche Nutzenkreise nicht territorial, sondern uber die Zahl der Nutzer definiert. Vgl. King, D.N. (1984), S. 50. Nach abnehmender Zahl der (potentiellen) Nutzer sind demgemäß internationale, kontinentale, nationale, regionale, provinziale, metropolitane, städtische und lokale Kollektivguter zu unterscheiden. Vgl. Breton, A. (1965).

77 Vgl. hierzu insbesondere Bennett, R.J. (1980), S. $220 \mathrm{ff}$.

78 Vgl. z.B. Olson, M. (1986).

79 Siehe z.B. Oakland, W.H. (1972); Oates, W.E. (1977a), S. 6.

80 Siehe etwa Kirsch, G. (1978) oder Tiebout, C.M. (1961).

81 Daher kann auch die Unterscheidung in reine offentliche Guter, reine private Guter und nicht-private Guter mit divergierenden Öffentlichkeitsgraden vorgenommen werden; siehe Breton, A. (1965). Bennett unterscheidet diesbezuglich zwischen răumlichen und nicht-răumlichen Rivalităten im Konsum; Bennett, R.J. (1980), S. 220ff.

82 Siehe hierzu Olson, M. (1969) und (1986).

83 Olson, M. (1969), S. 482. 
beteiligt werden. Sie werden bei der Entscheidungsfindung stets gegen eine Bereitstellung votieren. 84

(iii) Der Streubereich der Nutzen aus dem Kollektivgut entspricht dem Zuständigkeitsbereich des Entscheidungsträgers. Es können alle Nutzer zur Finanzierung herangezogen werden und alle Bewertungen der Mitglieder des Gemeinwesens in die Entscheidungsfindung einfließen. In diesem Falle gibt es keine Externalitäten, und die Voraussetzungen für eine effiziente Bereitstellungsentscheidung sind gegeben. Diese Struktur wird in der Literatur als "perfect mapping"85, "perfect correspondence"86 oder "priniciple of fiscal equivalence" 87 bezeichnet.

Das Prinzip der fiskalischen Äquivalenz besagt, daß die Zuordnung der property rights so zu erfolgen habe, daß alle Entscheidungsfolgen bei den Entscheidungsträgern internalisiert sind; insbesondere dürften Aufgaben- und Finanzierungskompetenzen nicht getrennt werden. Folglich sollte für jedes Kollektivgut eine separate Bereitstellungseinheit (Gebietskörperschaft) gebildet werden, deren Größe sich nach dem Umfang der benefit area bemißt. ${ }^{88}$ Entscheidungen über die Bereitstellung von lokalen öffentlichen Gütern sollten auf lokaler Ebene erfolgen, und über Güter mit regionalen Reichweiten wäre auf regionaler Ebene zu entscheiden. Zentralisierte Kompetenzen sind dagegen nur für Leistungen erforderlich, deren Nutzenreichweite das gesamte Staatsgebiet umfaßt. Der strukturelle Aufbau des Staates wird damit von den Eigenschaften der vom öffentlichen Sektor bereitzustellenden Güter bestimmt. ${ }^{89}$

\section{b. Fiskalische Clubs und lokale öffentliche Güter}

Ein Mangel des Prinzips fiskalischer Äquivalenz liegt darin, daß es in der bisher dargestellten Form noch keine Aussagen über die personelle Größe des Bereitstellungskollektivs zuläßt. Der Vorteil des gemeinschaftlichen Konsums der Kollektivgüter besteht aber darin, daß die Kosten von den Mitgliedern des Nutzerkollektivs gemeinsam getragen werden. Mit zunehmender Zahl der Finanzierungsbeteiligten sinken die individuellen Kostenanteile ${ }^{90}$, und durch die Erweiterung des Bereitstellungskollektivs werden positive Externalitäten internalisiert, denn jedes weitere Kollektivmitglied reduziert die Belastungen für alle übrigen Mitglieder. Andererseits treten bei den meisten kollektiv nutzbaren Gütern ab dem Erreichen einer bestimmten Nutzerzahl zumindest partielle Nutzungsrivalitäten auf. Bei gegebener Bereitstellungsmenge des Kollektivgutes nehmen die Nutzen jedes Mitglieds aus dem Konsum mit zunehmender Mitgliederzahl ab, man spricht von Überfüllungseffekten. ${ }^{91}$ Das konstitutionelle Kalkül, das sich aus der Berücksichtigung der beiden gegenläufigen Effekte für die Bestim-

84 Siehe dazu ausfuhrlich Theiler, J. (1977), S. 50ff.

85 Breton, A. (1965), S. 180.

86 Oates, W.E. (1972), S. 34.

87 Olson, M. (1969) und (1986).

88 Vgl. etwa auch die Ausfuhrungen bei Wust, H.F. (1981), S. $31 \mathrm{ff}$.

89 Vgl. Breton, A. (1965).

90 Die Einsparungen fallen um so geringer aus, je großer die ursprüngliche Nutzerzahl ist. Vgl. Litvack, J.M./Oates, W.E. (1970), S. 43ff. Man beachte, daß es hier um Skalenvorteile in der Nutzung und nicht in der Produktion der Kollektivgüter geht.

91 Siehe hierzu die empirischen Befunde von Borcherding, T.E./Deacon, R.T. (1972); Bergstrom, T.C./ Goodman, R.P. (1973) und Oates, W.E. (1988a). 
mung der optimalen Mitgliederzahl des Nutzerkollektivs ergibt, beruht auf Buchanans "Economic Theory of Clubs"92.

Indessen modelliert die Clubtheorie nicht die räumlichen Effekte des gemeinschaftlichen Konsums. Regionale Ballung ist mit einer Vielzahl spezifischer Vor- und Nachteile verbunden, die hier nicht im einzelnen erörtert werden sollen. ${ }^{93}$ Ein Vorteil der räumlichen Ballung ergibt sich z.B. durch größere lokale Absatz- und Arbeitsmärkte, die sich in einer Steigerung des lokalen Produktionspotentials niederschlagen. Agglomerationsnachteile entstehen, wenn mit steigender Einwohnerzahl eines Gemeinwesens infolge der Verknappung immobiler Faktoren die Grenzproduktivität mobiler Faktoren sinkt. ${ }^{94}$ Die modelltheoretischen Überlegungen hierzu basieren auf Stiglitz' "Theory of Local Public Goods"95. Die Ermittlung der optimalen personellen Größe von Bereitstellungskollektiven sollte alle diese Einflußfaktoren in das konstitutionelle Kalkül einbeziehen.

Die grundlegenden Überlegungen können in einem einfachen Modell formalisiert werden. Betrachtet sei hierzu eine lokale Einheit in der das Sozialprodukt Q produziert wird. Q ist abhängig vom Arbeitseinsatz $\mathrm{n}$ und vom Einsatz des unvermehrbaren Faktors Boden $\overline{\mathrm{L}}$ in der Gemeinde. Jeder Bewohner biete unelastisch genau eine Einheit des homogenen Faktors Arbeit an, dessen Grenzproduktivität positiv und abnehmend sei. Die linear homogene lokale Produktionsfunktion ist beschrieben durch $Q=Q(n, \bar{L})$ mit $(\partial Q / \partial n)>0$ und $\left(\partial^{2} Q / \partial n^{2}\right)<0$. Das lokale Sozialprodukt $Q$ setzt sich zusammen aus einem privaten Gut, dessen Pro-KopfKonsum mit $\mathrm{X}$ bezeichnet wird, und einem lokalen Kollektivgut $\mathrm{G}$, das von den $\mathbf{n}$ Gemeindemitgliedern gemeinschaftlich genutzt wird. Zur Vereinfachung sei angenommen, daß die Opportunitätskosten der Produktion einer zusätzlichen Mengeneinheit von X konstant sind und einer Einheit von $\mathrm{G}$ entsprechen; die marginale Transformationsrate beträgt Eins.

Die Bewohner des Gemeinwesens seien in allen relevanten Merkmalen identisch. Der Nutzen $\mathrm{U}$ eines repräsentativen Individuums werde bestimmt durch den Konsum des privaten Gutes $\mathrm{X}$ und des lokalen Kollektivgutes $\mathrm{G}$, so daß dessen Nutzenfunktion beschrieben werden kann durch $U=U(X, G)$ mit den üblichen Annahmen abnehmender Grenznutzen in $X$ und $G$. Die Gesamtkosten $\mathrm{C}$ des Kollektivgutes, ausgedrückt in Einheiten des Privatgutes $\mathrm{X}$, können formal dargestellt werden durch $\mathrm{C}=\mathrm{C}(\mathrm{n}, \mathrm{G})$, mit $(\partial \mathrm{C} / \partial \mathrm{n}) \geq 0$ und $(\partial \mathrm{C} / \partial \mathrm{G})>0 .{ }^{96}$ Eine effiziente Allokation ist charakterisiert durch die Lösung des Optimierungsproblems

92 Buchanan, J.M. (1965). Aus der kaum noch uberschaubaren Literatur zur Theorie der fiskalischen Clubs seien exemplarisch genannt: Pauly, M.V. (1967); Allen, L./Amacher, R./Tollison, R.D. (1974); Berglas, E. (1976); Sandler, T./Tschirhart, J. (1980); Cornes, R./Sandler, T. (1986).

93 Ausfuhrlich hierzu: Isard, W. (1956) und Richardson, H.W. (1977).

94 Vgl. Flatters, F./Henderson, V./Mieszkowski, P. (1974); Mieszkowski, P./Zodrow, G.R. (1989), S. 1133. Zur Betrachtung von Land als Konsumgut siehe Evans, A.W. (1973).

95 Stiglitz, J.E. (1977). Siehe hierzu auch unter vielen: Flatters, F./Henderson, V./Mieszkowski, P. (1974); Arnott, R.J./Stiglitz, J.E. (1979); Boadway, R.W./Flatters, F. (1982); Stiglitz, J.E. (1983); Wildasin, D.E. (1986) und (1987); Rubinfield, D. (1987); Mieszkowski, P./Zodrow, G.R. (1989).

96 Durch die partielle Ableitung von $\mathrm{C}$ nach n kommt der Überfullungseffekt zum Ausdruck: Existieren im relevanten Bereich keine Nutzungsrivalitaten, ist $(\partial \mathrm{C} / \partial \mathrm{n})=0$, treten dagegen Rivalităten auf, ist dieser Wert positiv. Vgl. Wildasin, D.E. (1987), S. 1135. Siehe auch Henderson, V. (1979), S. 236 und Rubinfield, D. (1987), S. 580. Alternativ könnte man die Nutzungsrivalităten auch direkt in die Nutzenfunktion des repräsentativen Konsumenten einbeziehen (so etwa bei Berglas, E./Pines, D. (1981); Pestieau, P. (1983)) oder als Verringerung der bereitgestellten Menge G (vgl. etwa Foldvary, F. (1994), S. 65ff.) interpretieren. Es andert sich dann die formale Darstellung, nicht jedoch der Aussagegehalt. 
Maximiere: $\quad U(X, G)+\lambda[Q(n, \bar{L})-n X-C(n, G)]$.

Daraus ergibt sich die notwendige Bedingung für eine effiziente Mitgliederzahl $n^{*}$ der Jurisdiktion:

$$
\frac{\partial Q}{\partial \mathrm{n}}-\mathrm{X}-\frac{\partial \mathrm{C}}{\partial \mathrm{n}}=0
$$

Die Interpretation der Effizienzbedingung wird erleichtert, wenn vereinfachend angenommen wird, daß alle Kollektivmitglieder den gleichen pro-Kopf-Anteil $\mathrm{C} / \mathrm{n}$ an den Kosten tragen und auch der pro-Kopf-Konsum des privaten Gutes X für alle Bewohner identisch ist. Man erhält dann die Bedingung für die optimale Mitgliederzahl $\mathrm{n}^{*} .97$

$$
\frac{\partial Q}{\partial n}+\frac{C(n, \bar{G})}{n}=\frac{\partial C}{\partial n}+\frac{Q(n, \bar{L})}{n} \text {. }
$$

Die linke Seite von (3.C.II.2) beschreibt die marginalen Vorteile, die dem repräsentativen Individuum durch Ausweitung der Mitgliederzahl erwachsen. Durch die Aufnahme eines zusätzlichen Mitglieds wächst das lokale Arbeitsangebot, und das Sozialprodukt steigt entsprechend der Produktivität des marginalen Arbeitsanbieters. Ein weiterer Ballungsvorteil, die Verringerung der pro-Kopf-Bereitstellungskosten von G, kommt durch den zweiten Term der linken Seite von (3.C.II.2) zum Ausdruck.

Die Grenzkosten der Agglomeration werden durch die rechte Seite von (3.C.II.2) dargestellt. Sie setzen sich zusammen aus der Überfüllungsexternalität $(\partial C / \partial n)$ und der Verknappung des privaten Gutes bei zunehmender Einwohnerzahl $n$. Die optimale personelle Größe n* der lokalen Jurisdiktion ist dort erreicht, wo Grenznutzen und Grenzkosten der Aufnahme eines weiteren Gemeindemitglieds gleich groß sind. ${ }^{98}$ Das Ergebnis beinhaltet zum einen die aus der Clubtheorie bekannte Mitgliedschaftsbedingung 99 und zum anderen die Bedingung für die optimale Mitgliederzahl einer lokalen Gebietskörperschaft der Theorie lokaler öffentlichen Güter. In der Clubtheorie wird von den spezifisch răumlichen Agglomerationseffekten abstrahiert, und die Bedingung für die optimale Kollektivgröße ${ }^{100}$ reduziert sich auf

$$
(\partial \mathrm{C} / \partial \mathrm{n})=\mathrm{C} / \mathrm{n}
$$

Die optimale Mitgliederzahl eines fiskalischen Clubs ist erreicht, wenn die marginalen Überfullungskosten die reduzierten Mitgliedsbeiträge gerade ausgleichen. Vernachlässigt man hin-

97 Vgl. Wildasin, D.E. (1987), S. 1144. Theoretisch ist auch denkbar, daß mehrere Gruppengroßen $n^{*}$ die in (3.C.II.2) abgeleitete Optimalbedingung erfullen. Vgl. Stiglitz, J.E. (1977), S. 277ff. Fur die weiteren Erorterungen soll dagegen davon ausgegangen werden, daß nur eine effiziente Mitgliederzahl $n^{*}$ existiert.

98 Eine Randlosung ergibt sich, wenn die marginalen Vorteile des gemeinsamen Konsums auch bei einer Mitgliederzahl, die der Grundgesamtheit aller Staatsangehorigen N entspricht oder großer ist, deren marginalen Nachteile ubersteigen. Die optimale Jurisdiktionsgrøße entspricht dann der Gesamtzahl der Individuen im Staatsgebiet, was eine vollstăndige Zentralisierung der Zustandigkeiten impliziert.

99 "Membership condition"; Sandler, T./Tschirhart, J. (1980), S. 1484.

$100 \mathrm{Vgl}$. auch Henderson, V. (1979), S. 237. Sofern positive Ballungskosten existieren, liegt bei Identităt von Grenz- und Durchschnittskosten gleichzeitig auch die durchschnittskostenminimale Mitgliederzahl vor. 
gegen die gegenseitigen Nutzenbeeinträchtigungen beim kollektiven Konsum von G, gilt die Optimalbedingung 101

$$
(\partial Q / \partial n)=[Q-C(n, \bar{G})] / n=X
$$

d.h., es werden solange zusätzliche Mitglieder aufgenommen, bis deren produktive Beiträge mit der lokalen Durchschnittsproduktivität des Faktors Arbeit übereinstimmen.

Ist die Bevölkerung des gesamten Staatsgebietes völlig homogen, ergibt sich die optimale Zahl der Einheiten durch eine Aufteilung der Bevölkerung, die für alle Bewohner einer Jurisdiktion die Erfullung der Optimalbedingungen garantiert. 102 Bei identischen Individuen im Staatsgebiet ist keine Pareto-Verbesserung möglich, wenn alle Bewohner in allen Jurisdiktionen die gleichen Netto-Nutzen aus der Bereitstellung des Kollektivgutes ziehen. Auch bei homogener Bevölkerungsstruktur im Staat wäre somit dezentrale Bereitstellung in mehreren politischen Einheiten gegenüber einer Zentralisierung vorzuziehen. ${ }^{103}$ Während das Prinzip fiskalischer Äquivalenz die Erfordernis der Übereinstimmung von Bereitstellungskompetenzen und Nutzengrenzen betont, liefert dieser Ansatz die Bedingungen für die optimale personelle Größe der Jurisdiktionen. Im folgenden soll überprüft werden, ob diese Prinzipien eine zwingende Begründung für lokale Bereitstellungsautonomie liefern.

\section{c. Das Dezentralisierungstheorem}

\section{aa. Das Modell von Oates}

Einen möglichen Begründungsansatz für lokale Entscheidungsautonomie liefert Oates 104 unter Zuhilfenahme eines einfachen Modells. Hierzu werden die unterschiedlichen Ergebnisse der Bereitstellung eines Kollektivgutes $G$ durch eine zentrale Einheit $Z$ oder durch lokale Entscheidungseinheiten A bzw. B betrachtet. Weiter wird angenommen:

- Erfolgt die Bereitstellung des Kollektivgutes durch die zentrale Einheit, kann diese nur ein einheitliches, standardisiertes Versorgungsniveau im gesamten Staatsgebiet realisie-

101 Vgl. Rubinfield, D. (1987), S. 578.

102 Siehe Pauly, M.V. (1967). Vgl. auch Wildasin, D.E. (1987), S. 1142ff.

103 Es kann sein, daß die gesamte Bevolkerung nicht in Subgruppen aufgeteilt werden kann, die einer optimalen Kollektivgröße entsprechen. Das hat zur Folge, daß entweder die optimale Clubgroße nicht realisiert werden kann, oder daß einige Büger das bereitgestellte Gut nicht nutzen könnten. Eine Maximierung der durchschnittlichen Netto-Nutzen der Mitglieder fuhrt nicht zu einem Wohlfahrtsmaximum, da die Mitgliedschaftsbedingung aus einer clubinternen Perspektive abgeleitet wurde, in der gesamtgesellschaftliche Aspekte außer acht gelassen werden. Aus Sicht der gesamten Volkswirtschaft ist es nämlich solange wohlfahrtssteigernd, zusătzliche Mitglieder in das Kollektiv aufzunehmen, wie die neuen Mitglieder noch positive Netto-Nutzen aus dem Konsum des Club-Gutes erhalten und diese Nutzengewinne größer sind als die Summe der marginalen Netto-Nutzeneinbuße aller ursprunglichen Mitglieder. Dieses Ganzzahligkeitsproblem wird erortert bei $\mathrm{Ng}$, Y.-K. (1973); Sandler, T./Tschirhart, J.T. (1980), S. 1493 und Cornes, R./ Sandler, T. (1986), S. 175ff. Je kleiner die optimale Mitgliederzahl eines fiskalischen Clubs in Relation zur Gesamtpopulation ist, desto höher ist die Wahrscheinlichkeit, daß die clubinterne Perspektive auch zu einem gesamtgesellschaftlichen Optimum fuhrt. Vgl. Henderson, V. (1979), S. 238.

104 Siehe Oates, W.E. (1972), S. $9 \mathrm{ff}$. Vgl. hierzu auch Boadway, R.W./Wildasin, D.E. (1984), S. 499ff. oder King, D.N. (1984), S. $20 \mathrm{ff}$. 
ren. 105 Dezentralisierung impliziert dagegen selbständige, jeweils für eine Region zuständige Entscheidungseinheiten, die autonom über den Output entscheiden.

- Die Präferenzen der Bewohner von A und B differieren interregional; intraregional besteht jedoch vollkommene Homogenität. $\mathrm{D}_{\mathrm{A}}$ und $\mathrm{D}_{\mathrm{B}}$ bezeichnen in Abbildung 3.3 die interregional unterschiedlichen Nachfragekurven nach dem Kollektivgut.

- Die Nutzen aus der Bereitstellung sind auf die räumliche Ausdehnung der jeweiligen Jurisdiktion beschränkt; es existieren keine spillovers. Die Bereitstellungskosten sind auf subnationaler und nationaler Ebene identisch, die Grenzkosten MC konstant und gleich den Durchschnittskosten. Zentraliserte Bereitstellung führt nicht zu Kostenersparnissen; es können also keine Skalenerträge realisiert werden. ${ }^{106}$

- Zwischen den Subgruppen kommt es zu keinen Wanderungen. Die Bewohner von A und $\mathrm{B}$ sind interregional immobil.

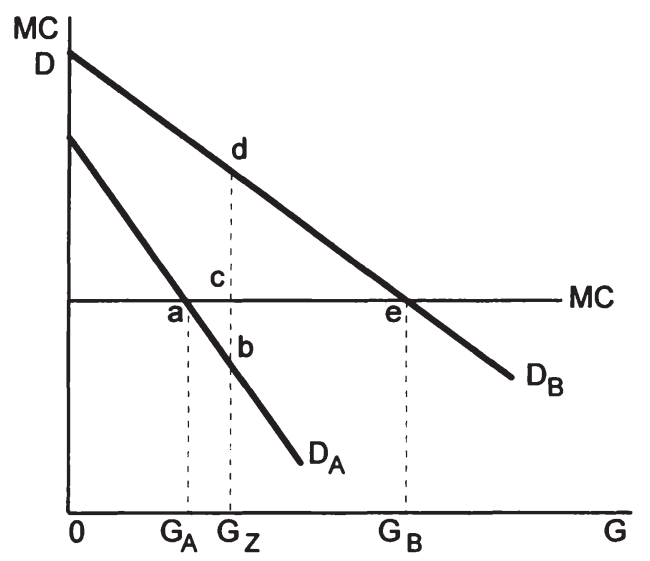

Abbildung 3.3: Das Dezentralisierungstheorem Quelle: Oates, W.E. (1977a), S. 10

Eine fiskalisch äquivalente Zuordnung liegt vor, wenn die Bereitstellungskompetenzen auf lokaler Ebene angesiedelt sind. Die Regierungen in A und B könnten ihr Angebot der lokalen Nachfrage entsprechend gestalten und $G_{A}$ bzw. $G_{B}$ realisieren. Die Zentralregierung muß dagegen ein einheitliches Versorgungsniveau festlegen; denkbar wäre hier eine Kompromißlösung $G_{Z}$, die zwischen den lokal präferierten Mengen $G_{A}$ und $G_{B}$ liegt. ${ }^{107}$ Bei einem einheitlichen Versorgungsniveau $G_{Z}$ entstehen Wohlfahrtsverluste ("frustration costs"108) in Höhe von abc+cde, da in keiner der regionalen Subgruppen das jeweils präferierte Angebot

105 Vgl. Oates, W.E. (1972), S. 11 und S. 36; (1977a), S. 6.

106 Siehe Oates, W.E. (1972), S. 56.

107 Fur die weitere Argumentation spielt es keine Rolle, ob diese Menge zwischen den lokalen Optima liegt oder etwa mit $G_{A}$ bzw. $G_{B}$ identisch ist. Entscheidend ist, daß bei Bereitstellung durch die zentrale Einheit ein im gesamten Staatsgebiet einheitliches Outputniveau realisert wird.

108 Pennock, J. (1959), S. 150ff. In der Terminologie von Buchanan/Tullock: "erwartete externe Kosten". 
zustande kommt. Durch dezentrale Bereitstellung können Frustrationskosten verringert werden, weil Präferenzunterschieden zwischen den Subgruppen entsprochen werden kann. ${ }^{109}$

Unter diesen Annahmen ist dezentrale Bereitstellung stets effizienter als zentrale Bereitstellung. Je stärker die Präferenzen der Bürger beider Regionen voneinander abweichen, je größer die interregionalen Einkommensunterschiede und je unelastischer die Nachfragefunktionen $D_{A}$ und $D_{B}$ sind, desto größer sind die Wohlfahrtsverluste einer Zentralisierung. ${ }^{110}$ Lokale Autonomie wäre auch zu präferieren, wenn keine interregionalen Präferenz- und Einkommensunterschiede existieren, denn die Standardisierung des Angebots bei zentraler Verantwortlichkeit ist eine zusätzliche Restriktion für die Entscheidungsfindung der Regierung. 111 Diesen Sachverhalt bezeichnet Oates als "Dezentralisierungstheorem" 112.

\section{bb. Eine informationsökonomische Begründung}

Als zwingende Begründung für lokale Autonomie vermag das Dezentralisierungstheorem freilich nur unter den restriktiven Annahmen des Modells zu dienen. ${ }^{113}$ Oates unterstellt, daß die zentrale Entscheidungseinheit an die Restriktion gebunden ist, ein im gesamten Staatsgebiet einheitliches Versorgungsniveau zu realisieren. A priori spricht jedoch nichts dagegen, daß auch die Zentralregierung die regional differierenden Outputs $G_{A}$ und $G_{B}$ bereitstellen könnte ${ }^{14}$; das Dezentralisierungstheorem allein liefert somit kein wirklich überzeugendes Argument für lokale Bereitstellungsautonomie. 115

Eine Begründung könnte vorliegen, wenn lokale Regierungen besser als zentrale Einheiten über die Mitgliederpräferenzen informiert sind. So wird behauptet, daß der Informationsfluß von den Bürgern zu einer zentralen Regierung allein durch die größere räumliche Distanz beeinträchtigt werde. ${ }^{116}$ Daher hätten zentrale Einheiten die Bereitstellungsentscheidungen unter größerer Unsicherheit über die Bürgerpräferenzen als subnationale Regierungen zu treffen. ${ }^{117} \mathrm{Je}$ heterogener die Kollektive sind, desto schwerer werde es, die Präferenzen korrekt zu ermitteln. Es bestehe daher die Gefahr, "... daß sich überregionale Behörden eher an Durchschnittswerten orientieren und ... regionale Differenzierungen nicht in genügender Weise vornehmen." 118 Vorausgesetzt, die interregional heterogene Gesellschaft besteht aus regional homogenen Gruppen, könne für die Suchkosten politischer Entscheidungsträger

109 Zur empirischen Quantifizierung der Wohlfahrtsverluste siehe Bradford, D.F./Oates, W.E. (1974).

110 Vgl. Oates, W.E. (1977a), S. 10.

111 Vgl. Tresch, R. (1981), S. 570.

112 Oates, W.E. (1972), S. 35.

113 Wie Oates selbst betont, hat das Theorem strenggenommen nur für den Fall rein privater Guter uneingeschrănkte Gultigkeit. Siehe Oates, W.E. (1972), S. 42 und S. 54 ff.

114 Im Sinne einer rein fiskalischen Definition wăre auch dies eine foderative Lösung, vgl. Oates, W.E. (1972), S. 37.

115 "In principle it would be preferable for the uniformity constraint itself to be deduced from some aspects of political decision-making that require governments to behave in this way." Walsh, C. (1993), S. 30.

116 Siehe etwa Hirsch, W.Z. (1964), S. 333f. Kritisch äuert sich hierzu Bös, D. (1983), S. 46.

$117 \mathrm{Vgl}$. Tresch, R. (1981), S. $574 \mathrm{ff}$.

118 Frey, R.L. (1977), S. 37. Siehe auch Stiglitz, J.E. (1977), S. 304ff.; Tresch, R. (1981), S. 576ff. oder Rubinfield, D.L. (1987), S. 582. 
("search costs"119) angenommen werden, daß sie mit zunehmender Zentralisierung der Kompetenzen ansteigen. 120

$\mathrm{Zu}$ berücksichtigen seien dabei auch die Kosten der Kollektivmitglieder zur Übermittlung von Informationen an die politischen Agenten ("signalling costs"121). Für die dabei anfallenden Informations- und Partizipationskosten der Bürger ${ }^{122}$ wird üblicherweise angenommen, daß sie bei hoher intrakollektiver Homogenität geringer sind. Entsprechend folgert Kirsch: "Unter dem Aspekt der Beherrschbarkeit der Kollektive durch ihre Mitglieder ist es wünschenswert, kleine und homogene Kollektive zu haben." 123

Akzeptiert man diese Argumentation, liegt eine informationsökonomische Begründung für das Dezentralisierungstheorem und eine Rechtfertigung lokaler Entscheidungsautonomie vor. $\mathrm{Ob}$ diese Hypothese zutrifft, wird im vierten Kapitel bei der Analyse politischer Entscheidungsprozesse in unitarischen und föderativen Systemen untersucht. Einstweilen soll davon ausgegangen werden, daß zentrale Einheiten nur zu höheren Kosten über die Informationen verfügen, um geographische Subgruppen mit differenzierten Leistungen zu versorgen oder deren Finanzierung durch räumlich differenzierte Besteuerung zu sichern.

\section{d. Die Implikationen für die Zuordnung der Bereitstellungskompetenzen}

Zusammenfassend betrachtet ergeben sich für die Zuordnung der Bereitstellungskompetenzen folgende Konsequenzen: Nach der Theorie des Fiskalföderalismus sind in lokalen Einheiten die Informationskosten der Präferenzermittlung und -offenbarung geringer als in größeren Einheiten, z.B. auf zentraler Ebene. Aus dieser Perspektive sind dezentrale Lösungen, also die Zuweisung politischer Verfügungsrechte über die Bereitstellung von Kollektivgütern an eine Vielzahl unabhängiger fiskalischer Clubs, gegenüber der zentralen Lösung, bei der nur eine Einheit im Leistungsstaat über das Versorgungsniveau entscheidet, zu präferieren.

Allerdings sind die Vorteile der Dezentralisierung limitiert. Der prinzipiellen Überlegenheit dezentraler Bereitstellung steht der Nachteil gegenüber, daß in kleinen Einheiten Skalenvorteile im Konsum nicht ausgeschöpft werden oder die von Olson beschriebenen externalities auftreten. Zwischen der Realisierung von Vorteilen des gemeinsamen Konsums und internalisierter spillover-Effekte auf der einen Seite und den informationsökonomisch bedingten Nachteilen der Kollektivgröße auf der anderen Seite besteht offenbar ein Zielkonflikt. ${ }^{124}$ Diesem Aspekt wird im folgenden Abschnitt näher nachgegangen.

119 Breton, A./Scott, A. (1977), S. 353. Diese entsprechen den "Planungskosten" bei Frey, R.L. (1977), S. 39.

120 So etwa Pennock, J. (1959), S. 147ff. oder Kirsch, G. (1980), S. 166ff. Ebenso Rothenberg, J. (1970); Frey, R.L. (1977), S. 39 und Hansmeyer, K.-H./Kops, M. (1984), S. 129, die von "internen Entscheidungskosten" sprechen.

121 Breton, A./Scott, A. (1978), S. 7.

122 Die Bürger offenbaren ihre Praferenzen fur Kollektivguter durch die Teilnahme an Wahlen, ihr Engagement in Interessenverbanden, Burgerinitiativen usw. Siehe Breton, A. (1974), Kap. 5.

123 Kirsch, G. (1978), S. 15. Weniger eindeutig dagegen Breton, A./Scott, A. (1978), S. 56f. Hierauf wird noch zuruckzukommen sein.

124 So bereits Buchanan, J.M./Tullock, G. (1962), S. 114. Siehe auch Barzel, Y. (1969); Tullock, G. (1969b) und Oates, W.E. (1972), S. 38ff. und S. $46 \mathrm{f}$. 


\section{Spillover-Effekte, Skalenvorteile im Konsum und Koordinationskosten}

\section{a. Die Wohlfahrtsverluste bei nicht-kooperativem Verhalten der subzentralen Einheiten}

Bislang wurde argumentiert, daß die Zuordnung von Bereitstellungskompetenzen nach dem Prinzip fiskalischer Äquivalenz Voraussetzung effizienter Entscheidungen ist, da nur dann alle Entscheidungsfolgen bei den Entscheidungsträgern internalisiert sind. Einer Ausweitung des Bereitstellungskollektivs stehen aber interne Informationsprobleme gegenüber. Damit stellt sich die Frage, welche Faktoren unter Berücksichtigung dieses Zielkonfliktes die optimale Kollektivgröße bestimmen. Zur Ermittlung der Bestimmungsfaktoren wird nun der zum vorangegangenen Abschnitt umgekehrte Weg gewählt. Am Beispiel eines positiven spilloverEffekts sollen die Wirkungen einer nicht fiskalisch äquivalenten Zuordnung von Verantwortlichkeiten untersucht werden. 125 Folgende Annahmen seien getroffen:

- In zwei subnationalen Kollektiven A und B wird ein rein privates Gut X und ein rein öffentliches Gut G produziert und konsumiert. Die Produktion von X und G erfolgt in A und B zu konstanten, identischen Grenzkosten.

- Die Nutzenreichweite von $G$ erstreckt sich auf beide subnationalen Kollektive. Die in Gliedstaat $i$ bereitgestellte Menge des Kollektivgutes $G_{i}$ steht in gleicher Menge auch den Bewohnern von $\mathrm{j}(\mathrm{i}, \mathrm{j}=\mathrm{A}, \mathrm{B})$ zur Verfügung. Wenn das Kollektivgut in $\mathrm{i}$ bereitgestellt wird, kommen die Bürger von $\mathrm{j}$ daher zu Opportunitätskosten von Null in den Genuß der öffentlichen Leistung.

- Die Bevölkerung von A und B ist intern völlig homogen, zwischen den Kollektiven bestehen jedoch Präferenzunterschiede. Die Nutzen der Bürger in A und B sind durch die konsumierten Mengen der privaten Güter $X_{i}$ sowie des Kollektivgutes $G$ bestimmt. Ihre Nutzenfunktionen sind $U_{i}=U_{i}\left(X_{i}, G_{i}, G_{j}\right)$.

- Die Entscheidung über die Bereitstellung von G obliegt den Regierungen der Gliedstaaten. Die Angebotsmengen des jeweils anderen Gliedstaates werden als gegeben betrachtet, Rückwirkungen des eigenen Angebotsverhaltens auf Entscheidungen der anderen Jurisdiktion werden dagegen ignoriert (Cournot-Nash-Verhalten). ${ }^{126}$

Betrachtet sei das Entscheidungsverhalten der Regierung in A. Die $\mathrm{T}_{1} \mathrm{~T}_{1}$-Linie in Abbildung 3.4 bezeichne die Transformationsfunktion zwischen privaten Gütern $\mathrm{X}_{\mathrm{A}}$ und dem Kollektivgut $G_{A}$. Der Nutzen eines repräsentativen Mitglieds von $A$ ist maximiert bei der Kombination von $X_{A}$ und $G_{A}$ gemäß Punkt I auf der Indifferenzkurve $u_{1}$.

Unterstellt sei nun, daß in der Nachbarjurisdiktion $B$ ein Kollektivgutangebot $G_{B}$ in der Höhe $\mathrm{T}_{1} \mathrm{~T}_{2}$ erfolge. Dadurch verschiebt sich die Konsummöglichkeitenkurve in A parallel nach rechts. ${ }^{127}$ Das neue lokale Nutzenmaximum liegt in Punkt II auf der Indifferenzkurve $u_{2}$, bei höherer Menge $X_{A}$ und und gesunkener Menge $G_{A}\left(G_{2}\right)$. Die Verbindungslinie I-II-III-IV der sich bei wachsendem $G_{B}$ ergebenden Gleichgewichtspunkte beschreibt den Expansionspfad.

125 Siehe Breton, A. (1970). Vgl. auch Olson, M./Zeckhauser, R.J. (1966); Williams, A. (1966); Pauly, M.V. (1970) und Arnold, V. (1992), Kap. 6. Die Analyse könnte ebenso am Beispiel unausgeschøpfter Skalenvorteile im Konsum erfolgen; in ihrer Natur unterscheiden sich beide Problemstellungen nicht. Vgl. auch Breton, A. /Scott, A. (1978), S. 149f.

126 Vgl. z.B. Varian, H. (1985), S. $103 \mathrm{f}$.

127 Also $T_{3} T_{3}$ fur $G_{B}=T_{1} T_{3}$ bzw. IVT $T_{4}$ fur $G_{B}=T_{1} T_{4}$. Die Überlegungen gelten analog fur Jurisdiktion $B$. 
Wie in Schaubild 3.4 zu erkennen ist, reagiert A auf jeden Anstieg von $\mathrm{G}_{\mathrm{B}}$ mit einer Verringerung des eigenen Angebots $\mathrm{G}_{\mathrm{A}}$.

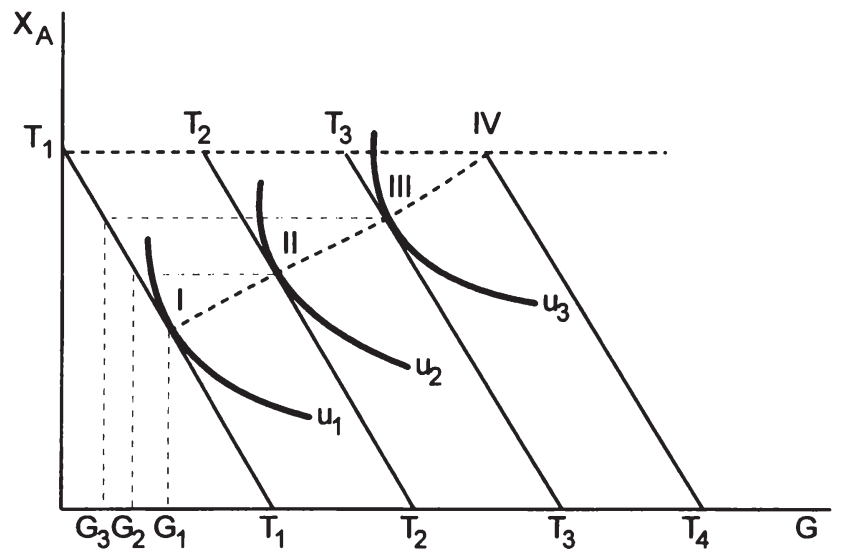

Abbildung 3.4: Allokationswirkungen räumlicher spillover-Effekte Quelle: in Anlehnung an Arnold, V. (1992), S. 313.

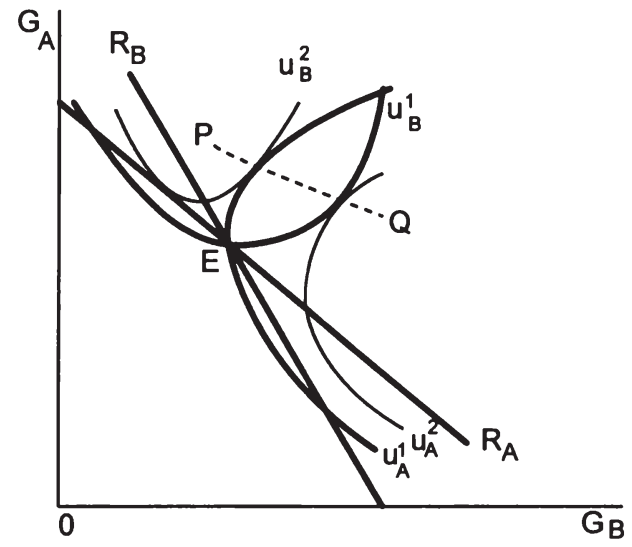

Abbildung 3.5: Pareto-Inferiorität nicht-kooperativer Strategien Quelle: in Anlehnung an Arnold, V. (1992), S. 316.

Für die Entscheidungsträger $\mathrm{A}$ und $\mathrm{B}$ lassen sich nun Reaktionsfunktionen ${ }^{128}$ ableiten, die angeben, wie sich die von einer Einheit angebotenen Mengen von $\mathrm{G}$ bei alternativen Bereit-

128 Breton, A. (1970) verwendet dagegen die Bezeichnung "Output-Konsum-Kurve". 
stellungsmengen der anderen Jurisdiktion verändern. Unter den getroffenen Annahmen haben die Reaktionskurven der Entscheidungsträger ${ }^{129}$ in $A\left(R_{A}\right)$ und $B\left(R_{B}\right)$ negative Steigungen. Ein Cournot-Nash-Gleichgewicht liegt vor, wenn die Angebotspläne der Einheiten übereinstimmen und für keinen der Beteiligten Veranlassung besteht, seine Outputentscheidungen zu ändern. Dies ist offensichtlich im "independent adjustment equilibrium"130 Punkt E (Abbildung 3.5) der Fall. ${ }^{131}$

Überträgt man Indifferenzkurven repräsentativer Individuen aus A und B in Abbildung 3.5, so ist zu erkennen, daß das Gleichgewicht $\mathrm{E}$ ineffizient ist. ${ }^{132}$ In $\mathrm{E}$ schneiden sich die Indifferenzkurven $\left(u_{A}^{l}, u_{B}^{l}\right)$. Der durch diese Indifferenzlinien abgegrenzte Kern kennzeichnet den Raum möglicher Pareto-Verbesserungen, die Verbindungslinie PQ aller Tangentialpunkte der Indifferenzkurven von A und B beschreibt alle Pareto-effizienten Allokationen. Aus gesellschaftlicher Sicht liegt eine Unterversorgung mit G vor, da jede Regierung bei ihren Bereitstellungsentscheidungen nur die Präferenzen ihrer eigenen Bürger berücksichtigt. Dagegen finden Nutzenzuwächse, die den Einwohnern anderer Jurisdiktionen erwachsen, im Optimierungskalkül keinen Niederschlag. Die Situation gleicht damit dem oben erörterten Gefangenendilemma. ${ }^{133}$ Potentielle Kooperationsgewinne bleiben bei nicht-kooperativem Verhalten unausgeschöpft.

\section{b. Potentielle Wohlfahrtsgewinne bei kooperativem Verhalten der subzentralen Einheiten}

\section{aa. Horizontale Verflechtungen}

Die Inferiorität des nicht-kooperativen Gleichgewichts impliziert, daß durch Verhandlungen der beteiligten Jurisdiktionen Effizienz-Verbesserungen erreicht werden können. ${ }^{134}$ Während bei kurzfristiger Betrachtung ein free rider-Verhalten der involvierten Gliedstaaten rational ist, entsteht im wiederholten Spiel möglicherweise eine explizite Kooperationsbereitschaft im Sinne einer horizontalen Verflechtung. ${ }^{135}$

Der Vorteil einer Internalisierung räumlicher spillovers durch Verhandlungen gegenüber der Zentralisierungslösung, wie sie aus der Anwendung des Prinzips fiskalischer Äquivalenz abgeleitet würde, besteht in der Möglichkeit, räumliche Differenzierungen vorzunehmen. Unterschiedlichen Präferenzintensitäten und/oder Nutzungsoptionen der Bürger in den beteiligten Gliedstaaten kann bei dezentralen Verhandlungslösungen vermutlich besser entsprochen werden als bei zentralisierter Bereitstellungsverantwortung. Dies gilt insbesondere auf der Finanzierungsseite. Angenommen sei z.B., daß auf lokaler Ebene ein Projekt durchgeführt wird, das durch erhebliche Unteilbarkeiten gekennzeichnet ist, dessen Nutzen überlokal streuen und mit wachsender Distanz vom Ort der physischen Leistungserstellung abnehmen. Wird auf der

129 Vereinfachend soll von linearen Reaktionsfunktionen ausgegangen werden.

130 Buchanan, J.M. (1967a), S. 111.

131 Zur Existenz und Eindeutigkeit des Cournot-Nash-Gleichgewichts siehe etwa Cornes, R. (1980); Sandmo, A. (1980); Holler, M.J./Illing, G. (1993), S. 66ff.

132 Zu dieser Technik siehe Oakland, W.H. (1987), S. 511f. oder Arnold, V. (1992), S. $315 \mathrm{f}$.

133 Alternativ wäre etwa denkbar, daß Entscheidungsträger B die Strategie des A erkennt und in seine Planuberlegungen einbezieht, das Verhalten von B entspricht der eines Fuhrers in der Stackelberg'schen Oligopolløsung. Zur graphischen Lðsung bei Stackelbergfuhrer-Verhalten eines der Beteiligten siehe Breit, W. (1968), S. 163.

134 Vgl. Ng, Y.K. (1971) oder Oates, W.E. (1972), S. 67f.

$135 \mathrm{Vgl}$. oben, S. 22ff. Bei Guttman, M. (1987) wird die Verhandlungslosung unter der Annahme vollkommener Information modelliert. 
übergeordneten Ebene über die Bereitstellung des Gutes entschieden, muß man davon ausgegehen, daß aufgrund der mangelnden Information über die räumliche Nutzenverteilung alle Bürger gleichermaßen zur Finanzierung herangezogen werden, ungeachtet der faktischen Unterschiede in der Nutzung des Gutes. Hier könnten interkollektive Verhandlungen effizientere Ergebnisse hervorbringen, indem die differierenden Nutzungsoptionen auf lokaler Ebene festgestellt und in der Festlegung der Beitragsschlüssel der lokalen Einheiten an der Finanzierung des Gesamtprojekts berücksichtigt werden. ${ }^{136}$

Jede Einheit wäre dann für die Erbringung des von ihr ausgehandelten Finanzbeitrags zur Erstellung des Kollektivgutes alleinverantwortlich. Hieraus ergibt sich ein weiterer Vorteil der dezentralen Verhandlungslösung. Die analoge Übertragung des für die Ausgabenseite abgeleiteten Dezentralisierungstheorems von Oates auf die Einnahmenseite des Budgets legt den Schluß nahe, daß auch hinsichtlich der Art der Finanzierung öffentlicher Leistungen regionale Präferenzunterschiede bestehen dürften. ${ }^{137}$

Natürlich sind kooperative Lösungen mit Trittbrettfahrer-Problemen behaftet. Ausschlaggebend für die Erfolgsaussichten der freiwilligen Kooperation ist wiederum die Höhe der anfallenden Transaktionskosten. Rationalverhalten der Beteiligten vorausgesetzt, kommen Verhandlungen nur zustande, wenn die erzielbaren Gewinne größer sind als die Kosten der Kooperation. ${ }^{138}$ Damit wird die Zahl der involvierten Jurisdiktionen fur die Erfolgsaussichten horizontaler Verflechtungen zu einer bestimmenden Größe.

Mit zunehmender Zahl betroffener Einheiten wachsen nämlich die Koordinationskosten ("coordination costs"139) gemeinschaftlicher Bereitstellungsarrangements progressiv. Je größer die Gruppe der Betroffenen ist, desto geringer fallen umgekehrt die möglichen Netto-Vorteile kooperativen Verhaltens aus. Die Anreize für kooperatives Handeln sinken bei steigender Gruppengröße schon allein deshalb, weil die Einnahme der free-rider-Haltung durch eine kleine Einheit nur geringen Einfluß auf das Gesamtangebot hat. Wenn zudem eine Jurisdiktion ein überragendes Interesse an der Bereitstellung hat, begünstigt dies ein TrittbrettfahrerVerhalten anderer Entscheidungsträger. ${ }^{140}$ Kirsch verweist schließlich darauf, daß mit größerer intrakollektiver Homogenität die interkollektive Kompromißbildung erschwert wird. ${ }^{141}$

Für die Höhe der Koordinationskosten ist auch die Zahl der Verhandlungsgegenstände von Bedeutung. Unterschiede der Gliedstaaten in Technologie, Faktorausstattung usw. führen zu komparativen Kostenunterschieden in der Bereitstellung. Trotz eines suboptimalen Outputs würden in der nicht-kooperativen Ausgangssituation möglicherweise sogar zu viele Ressourcen in der Produktion des Kollektivgutes eingesetzt. ${ }^{142}$ Folglich besteht weiterer Einigungs-

136 Dieses Argument wird graphisch im Anhang verdeutlicht.

137 So sieht Cnossen, $S$. (1990) im Hinblick auf die zukunftige EU-Finanzierung prinzipielle Vorteile dezentraler Besteuerung gegenuber einer zentralen EU-Steuer. Vgl. auch Spahn, P.B. (1993), S. 101.

138 Die grundlegenden Gedanken entsprechen der Arbeit von Coase, R.H. (1960).

139 Breton, A./Scott, A. (1978), S. 7. Vgl. auch Spahn, P.B. (1993), S. 84ff.

$140 \mathrm{Vgl}$. Olson, M. (1965/1993). Weiter gibt es eine Vielzahl moglicher Optima, die sich in ihren Verteilungsergebnissen unterscheiden. So kann einer der Verhandlungspartner im Kampf um distributive Vorteile durch eine Blockierungsstrategie die Entwicklung zum Allokationsoptimum behindern. Vgl. Arnold, $V$. (1984).

141 Siehe ausfuhrlich Kirsch, G. (1978), S. $20 \mathrm{ff}$.

142 Vgl. z.B. Olson, M./Zeckhauser, R.J. (1970); Baumol, W.J./Oates, W.E. (1988), S. 98f. 
bedarf darüber, in welcher Jurisdiktion das Kollektivgut produziert werden soll, damit Kostenvorteile ausgenützt werden. ${ }^{143}$

Es kann deshalb folgendes vorläufiges Fazit gezogen werden: Mit zunehmender Zahl der Beteiligten wird es infolge der steigenden Koordinationskosten immer unwahrscheinlicher, daß die subzentralen Jurisdiktionen auf freiwilligem Wege eine sozial optimale Bereitstellung von Kollektivgütern mit überlokaler Nutzenreichweite erreichen. ${ }^{144}$ Die Einschaltung einer höheren Instanz mit der Aufgabe, Verhandlungen zu lenken und einen Ausgleich zu schaffen, erscheint sinnvoll. ${ }^{145}$

\section{bb. Vertikale Verflechtungen: Kooperativer Föderalismus}

Sind die Hemmnisse für eine freiwillige Kooperation zu groß, wird von der traditionellen Theorie der Einsatz des auf die Gedanken von Pigou ${ }^{146}$ zurückgehenden Instruments der vertikalen Finanztransfers empfohlen. ${ }^{147}$ Durch Finanzzuweisungen einer höheren Ebene an die Gebietskörperschaften der unteren Ebene werden im Idealfall Anreize für subnationale Entscheidungsträger gesetzt, externe Nutzen in ihre Entscheidungen einzubeziehen.

Die Internalisierung könnte durch an Eigenbeteiligung geknüpfte zweckgebundene Subventionen erreicht werden, deren optimale Höhe durch die marginalen Nutzen bestimmt wird, die die Bereitstellung des Kollektivgutes den Nicht-Mitgliedern der Einheit stiften. ${ }^{148}$ Die Subventionierung senkt die Grenzkosten der Bereitstellung und induziert einen Anreiz zur Ausweitung der Aktivitäten. Dagegen würde durch eine ungebundene Finanzzuweisung ohne Eigenbeteiligung zwar ein Einkommenseffekt bei der Empfängerregion erzeugt, der mit einem Nachfrageanstieg nach dem betreffenden Kollektivgut verbunden ist. Da aber hierdurch die relativen Preise unverändert bleiben, kann das sozial optimale Angebot nur durch ein vergleichsweise höheres Zuweisungsvolumen erreicht werden. 149

Reziproke Externalitäten machen eine Subventionierung beider Einheiten erforderlich, da die Abhängigkeiten in der Bereitstellung auch Interdependenzen bei der Transfergestaltung implizieren. ${ }^{150}$ Erhält lediglich einer der involvierten Gliedstaaten den Finanztransfer, resultiert nämlich aus der Ausgabenerhöhung ein höherer spillover-Effekt, der die anderen Jurisdiktionen zu Verringerungen der eigenen Bereitstellungsmengen veranlassen würde. ${ }^{151}$

143 Vgl. Buchanan, J.M./Kafoglis, M. (1963). Zu speziellen Problemen solcher Produktionsarrangements siehe Theiler, J. (1977), S. 66f.

144 Vgl. Hamlin, A.P. (1991), S. $195 \mathrm{f}$.

145 Vgl. Tullock, G. (1969a); Oates, W.E. (1972), S. 69 oder Spahn, P.B. (1993), S. 9.

146 Siehe Pigou, A.C. (1932), S. $172 \mathrm{ff}$.

$147 "$ "... where joint planning and decision-making by the concerned governments promise to resolve inefficiencies, these processes should be encouraged by higher-level public authorities in lieu of any program of unit subsidies and taxes to the individual units. However, where it is evident that such coordination will not be forthcoming, I believe a real case for Pigovian grants remains." Oates, W.E. (1972), S. $73 \mathrm{f}$.

148 Aus der umfangreichen Literatur zu den innerstaatlichen Finanzzuweisungen seien genannt: Wilde, $J$. (1968); Oates, W.E. (1972), S. 75ff.; Break, G.F. (1980); Tresch, R. (1981), S. 605ff.; King, D.N. (1984), S. $122 \mathrm{ff}$.

149 Vgl. Oates, W.E. (1972), S. 75 ff. oder auch Boadway, R.W./Wildasin, D.E. (1984), S. $519 f f$.

150 Vgl. Oates, W.E. (1972), S. $95 \mathrm{ff}$.

151 Ausfuhrlich hierzu: Wust, H.F. (1981), S. $111 \mathrm{ff}$. Siehe auch King, D.N. (1984), S. $127 \mathrm{ff}$. 
Indessen erscheint der Optimismus, der von Vertretern des kooperativen Föderalismus ${ }^{152}$ in bezug auf die Effizienz vertikaler Koordination und des Finanztransfersystems geäußert wird, wenig gerechtfertigt. Zwei Argumente sind hier einschlägig. Erstens erfolgt durch das Zuweisungssystem die Internalisierung der externen Effekte nur beim Emittenten. ${ }^{153} \mathrm{Um}$ gesamtwirtschaftlich optimale Ergebnisse zu erhalten, müßten die Empfänger der spillovers im Umfang der erhaltenen marginalen Nutzen eine Leistung an den Oberverband abführen. Es spricht freilich wenig dafür, daß die Empfängerregionen ihre Präferenzen für die erhaltenen Leistungen wahrheitsgemäß offenbaren. Voraussichtlich entsteht eine neue Externalität, weil Jurisdiktionen, deren Bürger keine Nutzen aus dem Kollektivgut empfangen, zur Finanzierung beitragen müßten. ${ }^{154}$

Die Eleganz des Finanztransferansatzes verdeckt zweitens die Informationsprobleme, die eine zentrale Einheit bei der Bestimmung der Zuweisungen hat, denn zwischen der Zentrale und den subzentralen Einheiten besteht eine Informationsasymmetrie. ${ }^{155}$ Die Regierungen der lokalen Jurisdiktionen haben Anreize, die für die Ausgestaltung der Transfers relevanten Informationen (z.B. über die Kosten der Leistungen) verzerrt an die Zentrale weiterzugeben ${ }^{156}$ oder die Finanzzuweisungen nicht in der vom Zuweisungsgeber erhofften Weise zu verwenden. ${ }^{157}$ Auch der Prozeß des Aushandelns von Finanzzuweisungen ist auf Seiten der beteiligten Einheiten mit Koordinations- und Informationskosten verbunden. Vertikale Verflechtungssysteme könnten aufgrund des höheren Zentralisierungsgrades der Verantwortlichkeiten zwar externe Koordinationskosten einsparen ${ }^{158}$, sie sind jedoch mit Ineffizienzen verbunden, die nur durch höhere Investitionen in Informationsgewinnung verringert werden können.

\section{c. Die Implikationen für die Zuordnung der Bereitstellungskompetenzen}

Bisher konnte gezeigt werden, daß die Internalisierung räumlicher spillovers (und analog die Ausschöpfung von Skalenerträgen im Konsum) durch drei Organisationsarrangements erreicht werden kann, nämlich durch Verhandlungen zwischen den betroffenen lokalen Einheiten, durch vertikale Verflechtungssysteme und durch Zentralisierung der Kompetenzen. Die Erreichung fiskalischer Äquivalenz von Kollektivgutnutzern, Entscheidern und Kosten-

152 Siehe dazu etwa Oates, W.E. (1972), S. $237 \mathrm{ff}$.

153 Vgl. Peffekoven, R. (1980), S. 626.

154 Vgl. auch Musgrave, R.A. (1969b), S. 525; Breton, A./Scott, A. (1978), S. 150.

155 Zwischen Zentralregierung und den Regierungen der subnationalen Transferempfanger entsteht ein typisches agency-Verhăltnis. Siehe Ferris, J.M./Winkler, D.R. (1990); Levaggi, R. (1991) und Rey, M. (1991). Weitere Nachteile der Mischfinanzierung erörtern beispielsweise Caesar, R. /Kops, M. (1983).

156 "The subnational government can act opportunistically. It can provide artificially high cost estimates in an attempt to increase central government financing. Any excess of grant over cost is perfectly fungible, and can be used to pursue subnational government objectives." Ferris, J.M./Winkler, D.R. (1990), S. 159. Levaggi, R./Smith, P. (1994) modellieren die intergovernmentalen Beziehungen bei der Vergabe von Finanztransfers in einem spieltheoretischen Ansatz. Vgl. auch Barrow, M.M. (1986); (1988) und Singh, N./ Thomas, R. (1989).

157 Vgl. Peffekoven, R. (1980), S. 623f. Empirische Untersuchungen uber die Praxis der Finanzzuweisungen in foderativen Staaten bestătigen die Existenz solcher Probleme. Zu einem Überblick siehe Gramlich, E.M. (1977).

158 Peffekoven spricht in diesem Zusammenhang von "technisch-administrativen Vorteilen vertikaler Zuweisungen", Peffekoven, R. (1980), S. 627. 
trägern ist nicht an die Zusammenfassung zu einem einzigen Bereitstellungskollektiv gebunden.

Es wurde weiter argumentiert, daß stärker zentralisierte Lösungen mit einer Verringerung der externen Koordinationskosten, aber auch mit einem Anstieg der (kollektivinternen) Kosten der Präferenzermittlung verbunden sind. Vernachlässigt man Informationsaspekte und Kosten der Koordination, führen die drei Organisationsformen zu identischen allokativen Ergebnissen; man befände sich dann in einer transaktionskostenfreien Welt, in der naturgemäß auch kein Organisationsproblem auftritt. Berücksichtigt man hingegen diese Kosten, lassen sich Vor- und Nachteile unterschiedlicher Strukturen bestimmen.

Horizontale Verflechtungen, also institutionalisierte Kooperationen gliedstaatlicher Einheiten derselben Ebene, bieten den Vorteil, daß divergierenden Präferenzen der Bürger in den kooperationsbeteiligten Jurisdiktionen besser entsprochen werden kann. Andererseits ist die gemeinschaftliche Bereitstellung mit erhöhtem externen Koordinationsaufwand verbunden. $\mathrm{Zu}$ klären wäre damit die Frage, wie die institutionalisierte Kooperation erfolgen sollte und nach welcher Regel Entscheidungen in den Gemeinschaftsinstitutionen getroffen werden. Hier könnte das von Buchanan und Tullock entwickelte Interdependenzkostenkalkül fruchtbare Anwendung finden. ${ }^{159}$ Daraus wäre abzuleiten, daß für alle Gliedstaaten verbindliche Entscheidungen der Gemeinschaftsinstitutionen mindestens mit einfacher Mehrheit zu erfolgen hätten; mit wachsender Bedeutung der Fragestellung und zunehmender Gefahr hoher erwarteter externer Kosten für die Bürger der beteiligten Einheiten wären qualifizierte Mehrheiten, gegebenenfalls eine Konsensregel, in den gemeinschaftlichen Gremien erforderlich.

Vertikale Verflechtungen sind zwar gegenüber der horizontalen Kooperation wahrscheinlich mit Einsparungen an Koordinationskosten verbunden, gleichwohl steigt die Gefahr von Bereitstellungsentscheidungen, die nicht den regional differierenden Präferenzen entsprechen. Die Argumentation, zentrale Einheiten könnten durch Finanztransfers eine Internalisierung externer Entscheidungsfolgen bei den lokalen Entscheidungsträgern erreichen, basiert auf der Annahme besserer Information der übergeordneten Ebene. Hieraus ergeben sich aus finanztheoretischer Sicht zwei gewichtige Argumente gegen Mischfinanzierungen. Erstens kann es den subzentralen Einheiten gelingen, Teile der Kosten einer Bereitstellung zu externalisieren. Zweitens wäre - und zwar auch aus rein wohlfahrtstheoretischer Sicht (!) - mit einem ressourcenverschwendenden Verteilungskampf der potentiellen Transferempfängerregionen um Subventionen der Zentralebene zu rechnen. 160

Die Identität der Problemstrukturen bei Vorliegen von Marktversagen infolge Nicht-Rivalität und Nicht-Ausschließbarkeit und dem hier betrachteten Problem räumlicher, kollektivexterner Effekte führt zu Lösungsvorschlägen, die sich im Grunde nicht von der Theorie des Marktversagens unterscheiden. Immer wenn die Schwierigkeiten einer kollektiven Übereinkunft auf-

159 Siehe dazu auch die Ausfuhrungen im 2. Kapitel, S. $63 \mathrm{ff}$.

160 Vgl. hierzu Tullock, G. (1975a). Das Streben nach moglichst hohen Finanzzuweisungen ist somit nicht unbedingt Ausdruck eines politischen Rentenstrebens, sondern vielmehr eines Strebens der lokalen Regierungen nach maximaler Wohlfahrt der Jurisdiktionsmitglieder. Es uberrascht deshalb ein wenig, daB die Theorie des Fiskalfoderalismus zwar die Möglichkeit suboptimaler Entscheidungen bei Vorliegen răumlicher spillovers auf lokale Egoismen der Entscheidungsträger zuruckfuhrt, dieselben Gedanken jedoch in der Theorie der Finanzzuweisungen höchst selten aufnimmt, bzw. nur mit burokratischem Interesse an Budgetmaximierung begrundet. Siehe hierzu McGuire, M.C. (1973) und (1979). 
grund der großen Zahl der Beteiligten steigen, wird die Einrichtung einer übergeordneten Hierarchiestufe empfohlen. Hier wie dort ist es die Höhe der Transaktionskosten, die bestimmen, ob eine dezentrale oder zentrale Lösung vorteilhafter ist. Die Zentralisierung der Verantwortlichkeiten wäre also in Betracht zu ziehen, wenn koordinationskostenbedingte Hindernisse für interkollektive Verhandlungen prohibitiv wirken und die sozialen Kosten der Zentralisierung infolge der Standardisierung des staatlichen Leistungsangebots die Wohlfahrtsgewinne der Internalisierung von spillovers nicht übersteigen. ${ }^{161}$

Allerdings wurde bislang ein wesentliches Element föderativer Strukturen, die Möglichkeit der Präferenzoffenbarung durch interkollektive Wanderungen, nicht angesprochen. Wăhrend bei den bisherigen Betrachtungen die räumliche Verteilung der Bürgerpräferenzen modellexogen vorgegeben war, betont die Theorie des Fiskalföderalismus, daß sich durch Wanderungsbewegungen der Bürger zwischen subnationalen Einheiten eine intrakollektive Präferenzhomogenität herausbilden könnte. Infolgedessen könnten Heterogenitätsprobleme der Ermittlung von Bürgerpräferenzen verringert werden. Im folgenden Abschnitt wird die Annahme räumlicher Immobilität fallengelassen und überprüft, welche Konsequenzen sich aus Sicht des Fiscal Federalism für die Zuordnung von Bereitstellungsverantwortlichkeiten ergeben.

\section{Die Präferenzoffenbarung durch Wanderungen: Das Tiebout-Modell}

\section{a. Die Grundgedanken von Tiebout und die herkömmliche Kritik am Tiebout-Modell}

In seinem vielzitierten Beitrag "A Pure Theory of Local Expenditures"162 argumentiert Tiebout, daß Migrationen der Individuen zwischen lokalen Jurisdiktionen ein Substitut für Abstimmungen und andere politischen Entscheidungsverfahren sein könnten, denn durch die Wahl ihres Wohnsitzes offenbaren die Bürger ihre Präferenzen für lokale öffentliche Güter. Der Grundgedanke des Tiebout-Mechanismus ist einfach: Sind die Individuen mit den Leistungen ihrer Gemeinde und deren Finanzierung unzufrieden, können sie in eine Kommune ziehen, deren Leistungsangebot ihren Präferenzen besser entspricht ("Abstimmung mit den Füßen"163). ${ }^{164}$ Existiert eine ausreichend große Anzahl verschiedener lokaler Clubs, findet jeder Bürger ein Steuer-Leistungspaket, das seinen Wünschen völlig gerecht wird. 165 Jeder Haushalt wählt aus der Vielzahl unterschiedlicher Gemeinden diejenige aus, in der die Differenz zwischen persönlichen Nutzen und Kosten der angebotenen öffentlichen Leistungen, das "fiskalische Residuum"166, maximal ist.

161 Ähnlich auch Wust, H.F. (1981), S. $117 \mathrm{ff}$.

162 Tiebout, C.M. (1956). Dowding, K./John, P./Biggs, S. (1994) zăhlen allein seit 1970 uber 1000 Zitate.

163 Wellisch, D. (1995), S. 9. Dieser oftmals mit Tiebout in Zusammenhang gebrachte Terminus findet sich allerdings in seiner Arbeit von 1956 nicht.

164 In den Worten Hirschmans: Sie nehmen eine exit option wahr.

165 Die Bedingungen fur ein Funktionieren des Mechanismus wurden im einzelnen nicht alle von Tiebout genannt, sondern erst in der weiterfuhrenden Literatur herausgearbeitet, siehe z.B. Pestieau, P. (1977); Bewley, T.F. (1981) oder Rubinfield, D. (1987). Im weiteren Verlauf dieses Abschnitts werden sie im einzelnen konkretisiert.

166 Buchanan, J.M. (1950), S. 588. 
Auf diese Weise biete, so Tiebout, der Wettbewerb lokaler Jurisdiktionen um Bürger/Steuerzahler eine Lösung des Präferenzoffenbarungsproblems. Individuen mit starken Präferenzen für lokale öffentliche Güter wohnen in Jurisdiktionen mit einem großen Angebot an Kollektivgütern und einer entsprechend hohen Steuerbelastung; Bürger mit weniger starken Präferenzen für öffentliche Güter wandern dagegen in Gemeinden mit geringerem Kollektivgüterangebot und niedrigeren Finanzierungsbeiträgen. ${ }^{167}$ Die "Abstimmung mit den Füßen" führe daher zu einer optimalen räumlichen Aufteilung der Bevölkerung und einer effizienten Bereitstellung lokaler Kollektivgüter. Die Parallelen zum traditionellen Marktmodell sind offensichtlich und von Tiebout in einem prominenten Zitat betont worden:

\footnotetext{
"Just as the consumer may be visualized as walking to a private market place to buy his goods, the prices of which are set, we place him in the position of walking to a community where the prices (taxes) of community services are set. ... Spatial mobility provides the local public goods counterpart to the private market's shopping trip." 168
}

Tiebout liefert mit seinem Denkansatz ein gewichtiges Argument für die Dezentralisierung der Bereitstellungskompetenzen. Die wissenschaftliche Diskussion über das Tiebout-Modell wurde in der Folgezeit allerdings sehr kontrovers geführt. Nachdem der Beitrag über eine Dekade nur verhältnismäßig geringe Beachtung gefunden hat, befaßten sich seit Beginn der siebziger Jahre zahlreiche Ökonomen mit dessen zentralen Aussagen. Dabei sind vier Hauptströmungen einer Kritik des Tiebout-Modells auszumachen, die eng miteinander in Verbindung stehen. ${ }^{169}$

1. Realistischerweise müsse man annehmen, daß die Menschen, gleichzeitig Konsumenten der lokalen Kollektivgüter und Anbieter der Faktoren Arbeit und Kapital, interregional eher immobil seien, so daß der postulierte Mechanismus wenig praktikabel sei. ${ }^{170}$

2. Doch selbst bei vollkommener Mobilität könne durch freie Wanderungsbewegungen eine effiziente räumliche Allokation nicht realisiert werden. Weil sich die Bürger bei ihren Migrationsentscheidungen nur von individuellen Vorteilhaftigkeitsüberlegungen leiten ließen, berücksichtigten sie nicht die sozialen Kosten und Nutzen von Wanderungen in Herkunfts- und Zielregion. Fiskalische Externalitäten der Migrationsbewegungen würden deshalb Ineffizienzen in der räumlichen Ressourcenallokation erzeugen. ${ }^{171}$

$167 \mathrm{Da}$ die Nachfrage nach Kollektivgutern von der individuellen Einkommenshöhe abhăngt, bewirkt der Tiebout-Mechanismus eine Segregation nach Einkommensgruppen, vgl. Bradford, D.F./Oates, W.E. (1974).

168 Tiebout, C.M. (1956), S. 422.

169 Eine ausgezeichnete Diskussion der hier angefuhrten Kritikpunkte ist bei Gordon, R.H. (1983) zu finden.

170 Siehe z.B. Bös, D. (1983), S. 46, der anfuhrt, die Bedeutung der räumlichen Mobilităt sei in den Ansătzen des Fiskalfoderalismus "overstressed".

171 Externe Kosten entstehen in der Herkunftsgemeinde durch die Verringerung des Produktionspotentials und den Anstieg der Steuerbelastung verbleibender Mitglieder bei gegebenem Output lokaler Kollektivguter. Dem stehen in der Zieljurisdiktion externe Nutzen der Zuwanderung gegenuber. Dort treten allerdings zunehmend Ballungsexternalităten auf. Für die Burger der Gemeinde, aus der abgewandert wird, ergeben sich umgekehrt verringerte Nutzungsrivalitatten und damit externe Nutzen der Abwanderung. Vgl. Buchanan, J.M./Wagner, R.E. (1970); Buchanan, J.M./Goetz, C.J. (1972); Flatters, F./Henderson, V./ Mieszkowski, P. (1974); Boadway, R.W./Flatters, F. (1982); Hercowitz, Z./Pines, D. (1991). 
3. Der Wettbewerb lokaler Einheiten um interjurisdiktionell mobile Faktoren führe außerdem zu einer ruinösen Konkurrenz. Die subzentralen Gebietskörperschaften würden versuchen, durch attraktive Ausgabenprogramme und Steuersenkungen mobiles Kapital zu attrahieren. Deshalb müsse davon ausgegangen werden, daß Fiskalwettbewerb zur Unterversorgung mit lokalen Kollektivgütern, die den räumlich weniger mobilen Faktoren zugute kommen, und zu einer übermäßigen steuerlichen Belastung der immobilen Faktoren führe. ${ }^{172}$

4. Schließlich wird argumentiert, positive spillovers bei der Bereitstellung der Kollektivgüter verhinderten eine effiziente Allokation durch interjurisdiktionelle Wanderungen, denn die Individuen könnten durch Abwanderung aus der bereitstellenden lokalen Einheit ohne Finanzierungsbelastung in den Genuß der angebotenen Leistung kommen. Es sei daher mit einer suboptimalen Versorgung der Bevölkerung mit Kollektivgütern zu rechnen. ${ }^{173}$ Umgekehrt könne nicht sichergestellt werden, daß nur Gemeindemitglieder die Kosten der Kollektivgüterbereitstellung tragen. Es würden Teile der Belastungen auf Nichtmitglieder überwälzt, so daß bei dezentralen Entscheidungen aufgrund des Steuerexports tendenziell eine Überversorgung zu erwarten sei. ${ }^{174}$

Letztlich, so Bewley in einer Gesamtschau der geübten Kritik, sei die postulierte Effizienz der interjurisdiktionellen Migrationen überhaupt nur $\mathrm{zu}$ erwarten, wenn von Migrationskosten abstrahiert würde und die Kommunen rein private Güter anbieten. Damit sei der Ansatz aber zur Lösung der Präferenzoffenbarungsprobleme bei Kollektivgütern ungeeignet. 175

Beim vierten Kritikpunkt handelt es sich nicht um eine explizite Ablehnung des Tiebout'schen Modellansatz, sondern um Aspekte des Zuordnungsproblems, wie sie bereits bei den Erörterungen in den vorangegangenen Abschnitten dieses Kapitels behandelt wurden. ${ }^{176}$ Tiebout selbst weist darauf hin, daß sein Modell im Falle des Vorliegens räumlicher Externalitäten nur eingeschränkte Gültigkeit besitzt, und daß "... in cases in which the external economies and diseconomies are of sufficient importance, some form of integration may be indicated." 177 Diesem Aspekt soll daher auch im folgenden nicht näher nachgegangen werden. Demgegenüber sind die Kritikpunkte 1-3 auf ihre Relevanz zu prüfen.

172 Vgl. Break, G.F. (1967), S. 23; Oates, W.E. (1972), S. 142f.; Gordon, R.H. (1983); Boadway, R.W./ Wildasin, D.E. (1984), S. 504; Wilson, J.D. (1986); Zodrow, G.R./Mieszkowski, P. (1986); Wildasin, D.E. (1989).

173 Vgl. die Ausfuhrungen oben in Abschnitt C.II.2 dieses Kapitels, S. 89ff.

174 Vgl. z.B. McLure, C.E. (1967) und (1969); Oates, W.E. (1972), S. 140ff.; Hogan, T.D./Shelton, R.B. (1973); Ladd, H.F. (1975); Zimmerman, D. (1983); Mieszkowski, P. (1983). Allgemein spricht man von Steuerexport, wenn das Steueraufkommen einer Region deren eigene Steuerleistung ubersteigt, also ein Teil des Steueraufkommens der Region nicht von deren Bewohnern selbst getragen wird. Vgl. ausfuhrlich Peffekoven, R. (1975).

175 "Tiebout considers a different allocation problem and suggests a different mechanism. But when one considers his idea critically, one finds that in order to solve his problem in the way he suggests, one is obliged to strip the problem of all its distinguishing characteristics and to reduce it to the problem already solved in general equilibrium theory." Bewley, T.F. (1981), S. 736.

176 Aus wohlfahrtsøkonomischer Sicht handelt es sich beim Steuerexport um einen negativen spillover-Effekt. Siehe etwa Sandler, T./Shelton, T. (1972).

177 Tiebout, C.M. (1956), S. 423. 


\section{b. Zur räumlichen Mobilität von Arbeit und Kapital}

\section{aa. Migrationstheorie und räumliche Mobilität des Faktors Arbeit}

Bis heute gibt es keine umfassende Migrationstheorie. Die Ermittlung der Migrationsursachen und deren Wirkungen ist Gegenstand mehrerer Wissenschaftsdisziplinen, die sich auch in den gewählten Forschungsmethoden stark unterscheiden; selbst eine einheitliche Definition des Migrationsbegriffs fehlt bislang. $178 \mathrm{Im}$ folgenden sei unter Migration die "... relativ dauerhafte freiwillige Änderung des hauptsächlichen Wohnorts von einem politischen Raum ... in einen anderen" 179 verstanden.

Aus ökonomischer Perspektive sind persönliche Wanderungsentscheidungen Ergebnis eines Suchprozesses, bei dem das Individuum die Kosten und Nutzen einer Wanderung unter dem Gesichtspunkt individueller Nutzenmaximierung gegenüberstellt. Eine Abwanderung von A nach B erfolgt, wenn der Gegenwartswert der erwarteten Nettonutzen in B abzüglich der Wanderungskosten den Gegenwartswert des Nettonutzens in A übersteigt. 180

Wanderungskosten bestehen aus monetären und nicht-monetären Komponenten ${ }^{181}$, denn neben Raumüberwindungs- und Suchkosten fallen insbesondere auch Kosten der Trennung von sozialen Bezugsgruppen und der Integration in neue soziale Systeme an. ${ }^{182}$ Psychische und kulturelle Bindungen haben weitgehend Fixkostencharakter, sie stellen somit spezifische Investitionen in das Humankapital dar. ${ }^{183}$ Je höher die versunkenen Kosten, um so stärker sind die Verharrungstendenzen des Individuums. ${ }^{184}$ Es ist deshalb plausibel anzunehmen, daß mit wachsender räumlicher Distanz zwischen Herkunfts- und Zieljurisdiktion die individuelle Migrationsbereitschaft abnimmt, denn mit zunehmender Entfernung dürften die Unterschiede in den sozio-ökonomischen Systemen wachsen, und die psychischen Kosten der Lösung von den sozialen Herkunftsgruppen sind um so bedeutender. Zudem fallen mit steigender Entfernung Informationeffekte geringer aus. ${ }^{185}$

Migrationsentscheidungen werden zweitens von den erzielbaren Nutzen der Wanderung bestimmt. Die Differenz der Gegenwartswerte der Nettonutzen in den Jurisdiktionen B und A wird als Lagerente ("locational surplus"186) bezeichnet; interjurisdiktionelle Wanderungen erfolgen nur, wenn positive Lagerenten realisiert werden. Freilich setzen sich Lagerenten aus einer Vielzahl von Komponenten, wie lokalen Verdienstmöglichkeiten, Wohnraumangebot,

178 Überblick bei Delbrück, C./Raffelhüschen, B. (1993) und Fischer, P.A./Straubhaar, T. (1994), S. 75ff.

179 Fischer, P.A./Straubhaar, T. (1994), S. 75. Dabei wird davon ausgegangen, daß das Arbeitsangebot nur in der Jurisdiktion erfolgt, in der der betreffende Haushalt wohnt.

180 Vgl. Siebert, H. (1993), S. 229ff. Grundlegend hierzu Sjaastad, L.A. (1962). Wanderungsentscheidungen sind Investitionsentscheidungen unter Unsicherheit, so daß fur die individuelle Migrationsentscheidung die persönliche Risikoneigung einerseits als auch der Zustrom von Informationen, insbesondere aus der Zielregion, andererseits von Bedeutung sind. Vgl. Siebert, H. (1967), S. 59f.

181 Vgl. hierzu insbesondere Sjaastad, L.A. (1962), S. 83ff.

182 Vgl. z.B. auch Vanhove, N./Klaassen, L.H. (1980), S. 357f. oder Tuchtfeld, E./Straubhaar, T. (1985), S. 99.

$183 \mathrm{Vgl}$. Siebert, H. (1993), S. $230 \mathrm{f}$.

184 Nach der Optionstheorie fuhrt die Verschiebung der Migrationsentscheidung zu einer Verringerung der relativen Unsicherheit und ein Zuwarten ist mit einem positiven Optionswert verbunden. Vgl. Burda, M./Wyplosz, C. (1992); Siebert, H. (1993), S. $231 \mathrm{ff}$. Vgl. auch Quigley, M. (1980).

$185 \mathrm{Vgl}$. hierzu Siebert, H. (1967), S. 63f. Aufgrund der Existenz von Migrationskosten in nicht unerheblichem Ausmaß wird auch oftmals nach Einkommensgruppen differenziert. So wird angenommen, daß Wohlhabende und gut ausgebildete Arbeitskrăfte eine deutlich hőhere interregionale Mobilităt haben als Geringerverdienende. Vgl. etwa Sinn, H.-W. (1995).

186 Grewal, B.S. (1988). 
klimatischen Bedingungen etc. zusammen ${ }^{187}$, so daß das erzielbare fiskalische Residuum lediglich einen (möglicherweise untergeordneten) Einflußfaktor der Wohnortwahl darstellt. Ausschlaggebend für Migrationsentscheidungen ist die Summe der Lagerentenkomponenten; negative Werte einzelner Bestandteile können durch positive Werte anderer Komponenten kompensiert werden. Doch selbst wenn positive Lagerenten infolge fiskalischer Aktivitäten der subzentralen Einheiten erzielt werden könnten, finden Migrationen nur statt, wenn die erzielbaren Lagerenten die Wanderungskosten übersteigen. ${ }^{188}$

Die Idealbedingungen der Tiebout'schen Modellwelt vollkommener Mobilität des Faktors Arbeit sind daher nur bei kleinräumiger Betrachtung, und auch dann allenfalls annähernd, anzutreffen. Signifikante Einflüsse fiskalischer Variablen auf die Wanderungsbewegungen der Haushalte sind vorwiegend im Stadt-Umland-Verhältnis zu erwarten, was auch in einer Vielzahl empirischer Untersuchungen bestätigt wurde. 189 Je größer die zu überwindenden räumlichen Distanzen sind, um so höher dürfte die Bedeutung der nicht-fiskalischen Lagerentenkomponenten für die individuellen Migrationsentscheidungen sein.

\section{bb. Räumliche Mobilität des Faktors Kapital}

Obwohl von Tiebout nicht explizit in die Überlegungen einbezogen, hat sich die weitere Diskussion seiner "Pure Theory of Local Expenditures" in vielen Beiträgen von der Analyse der Mobilität der Bürger auf die Mobilitätswirkungen des Faktors Kapital verlagert. Beim Faktor Kapital unterscheidet man Geldkapital und reale Kapitalmittel, die wiederum in die Stromgröße Investitionen und die Bestandsgröße Sachkapital unterteilt werden. ${ }^{190}$ Es wird angenommen, daß Kapital in die Regionen fließt, in denen die höchste Netto-Rendite erzielt wird. 191

Die an einem Standort erzielbare Netto-Rendite des Kapitals wird von mehreren Faktoren bestimmt. Bökemann 192 unterscheidet faktor- und güterartenbezogene Eigenschaften des Standorts, wie natürliche Eigenschaften des Bodens und die Versorgung mit Infrastruktur, sowie lage- und kapazitätsbezogene Eigenschaften des potentiellen Standorts; darunter fällt auch das lokale Arbeitsangebot. Somit können lokale oder regionale Regierungen zwar die Höhe der Lagerenten des Faktors Kapital beeinflussen, bestimmte Umweltbedingungen müssen sie aber als unveränderliche Restriktionen akzeptieren.

Ein wichtiger Unterschied zum Faktor Arbeit liegt darin, daß die interregionale Allokation von Kapital nicht an eine physische Wanderung der Kapitaleigner gebunden ist. ${ }^{193}$ Daher

187 "Locational surplus [is] the algebraic sum of the benefits which a citizen perceives as accruing to him, in the course of his consumption, production or employment activities, as well as his fiscal transactions with governments, by choosing to remain in his present jurisdiction in preference to other jurisdictions." Grewal, B.S. (1988), S. 167.

$188 \mathrm{Vgl}$. Grewal, B.S. (1988), S. 170.

189 Siehe etwa Cebula, R.J. (1973); Kohn, R.M./Vedder, R.K./Cebula, R.J. (1973); Greenwood, M.J./Anderson, E.J. (1974); Kau, J.B./Sirmans, C.F. (1976); Ziegler, J.A. (1976); Koven, S.G./Shelley, M.C. (1989); Day, K.M. (1992). Die Vielzahl moglicher Beweggrunde fur Migrationen erschwert allerdings die empirische Testbarkeit der Tiebout-Hypothese. Zu den methodischen Problemen empirischer Tests der Tiebout-Hypothese siehe Pommerehne, W.W. (1987), S. 90ff.

190 Damit wird der Einteilung von Siebert, H. (1967), S. 67 gefolgt.

191 Vgl. z.B. Siebert, H. (1967), S. 68f. oder Ruffin, R.J. (1984), S. 284.

192 Vgl. hierzu Bökemann, D. (1982), S. 155.

193 Vgl. auch Musgrave, P.B./Musgrave, R.A. (1990), S. 67. 
spielen psychische Mobilitätshemmnisse für die interregionale Mobilität von Kapital nur eine geringe Rolle. Während Geldkapital als nahezu vollkommen mobil angesehen werden kann, ist die kurzfristige interregionale Mobilität von realen Kapitalmitteln begrenzt, denn bereits getätigte spezifische Investitionen sind kurz- und mittelfristig ein Mobilitätshemmnis. ${ }^{194}$ Diese Mobilitätsbeschränkungen gelten allerdings in geringerem Maße für Ersatz- und Neuinvestitionen. Auf lange Sicht kann von hoher interregionaler Kapitalmobilität ausgegangen werden, v.a. dürfte nur eine geringe Abhängigkeit der Kapitalmobilität von der räumlichen Entfernung vorliegen. ${ }^{195}$ Entsprechend ist eine deutlich höhere Reagibilität von Kapitalbewegungen auf finanzpolitische Maßnahmen subnationaler Einheiten zu erwarten.

\section{c. Zum Problem der Migrationsexternalitäten}

\section{aa. Die effiziente räumliche Allokation von Arbeit und Kapital}

Ein zweites Argument gegen die Funktionsfähigkeit des Tiebout-Mechanismus wird in der Existenz fiskalischer Externalitäten der Migrationsbewegungen gesehen. Zur Überprüfung dieser These sollen die mehr intuitiven Aussagen von Tiebout in einem neoklassischen Modellansatz formalisiert werden. In Erweiterung der Gedanken von Tiebout wird allerdings räumliche Mobilität des Kapitals ebenso einbezogen wie die Bereitstellung produktiver öffentlicher Vorleistungen. ${ }^{196}$ Folgende Annahmen seien getroffen:

- Ein Bundesstaat bestehe aus zwei Jurisdiktionen $\mathrm{i}(\mathrm{i}=\mathrm{A}, \mathrm{B})$ in denen das Sozialprodukt $\mathrm{Q}_{\mathrm{i}}=\mathrm{Q}_{\mathrm{i}}\left(\mathrm{L}_{\mathrm{i}}, \mathrm{n}_{\mathrm{i}}, \mathrm{k}_{\mathrm{i}}, \mathrm{H}_{\mathrm{i}}\right)$ produziert wird. $\mathrm{L}_{\mathrm{i}}$ bezeichnet das fixe Bodenangebot, $\mathrm{n}_{\mathrm{i}}$ die Bevölkerungszahl in i. Jeder Haushalt bietet unelastisch eine Einheit des Faktors Arbeit an. Der Kapitaleinsatz in der Region $\mathrm{i}$ beträgt $\mathrm{k}_{\mathrm{i}}$. Die Grenzproduktivität des Kapitaleinsatzes wird bestimmt von einem Effizienzfaktor $e$ und ist abhängig von einer lokalen öffentlichen Vorleistung ${ }^{197} \mathrm{H}_{\mathrm{i}}$ mit $\left(\partial \mathrm{e}_{\mathrm{i}} / \partial \mathrm{H}_{\mathrm{i}}\right)>0,\left(\partial^{2} \mathrm{e}_{\mathrm{i}} / \partial \mathrm{H}_{\mathrm{i}}^{2}\right)<0$, und $\mathrm{e}_{\mathrm{i}}=1$ für $\mathrm{H}_{\mathrm{i}}=0$. Für die Faktorerträge gelten die üblichen Annahmen abnehmender Grenzproduktivitäten.

- In der Föderation existieren ein fixer Kapitalbestand $198 \overline{\mathrm{K}}$ und eine fixe Zahl homogener Haushalte $\overline{\mathrm{N}}$, die sich auf die Regionen aufteilen. ${ }^{199}$ Arbeit und Kapital sind vollkommen mobil. Die Haushalte in $\mathrm{i}$ ziehen Nutzen aus dem Konsum eines privaten Gutes $\mathrm{X}_{\mathrm{i}}$ und

194 So etwa Siebert, $H$. (1967), S. 67ff.

195 Eine solche Abhăngigkeit kann nur konstruiert werden, wenn "... mit zunehmender Entfernung die Information uber regionale Profitraten abnimmt ... Die Abhăngigkeit von der Information scheint für das Kapital aber nicht die entscheidende Bedeutung zu haben wie fur das Arbeitsangebot, da Kapitalanleger in der Regel uber ein breiter gestreutes Kommunikationssystem formeller und informeller Art verfugen ..." Siebert, H. (1967), S. 69.

196 Die folgenden Ausfuhrungen beruhen auf den Arbeiten von Wildasin, D.E. (1986), S. 5ff. und (1987), S. $1134 \mathrm{ff}$. und Wellisch, D. (1995), S. 19ff.

197 Vgl. z.B. Aschauer, D.A. (1989); Lynde, C./Richmond, J. (1992).

198 Damit wird implizit unterstellt, das gesamtwirtschaftliche Kapitalangebot reagiere nicht auf Zinsanderungen. Zu empirischen Untersuchungen uber die Zinsreagibilităt der Ersparnis siehe den Überblick bei Boadway, R.W./Wildasin, D.E. (1984), S. 312ff. und die dort angegebene Literatur. In dieser Arbeit sollen Effekte der Zuordnungen von Bereitstellungskompetenzen erörtert werden und nicht Besteuerungswirkungen auf das Kapital- und Arbeitsangebot. Unter diesem Aspekt erfullt die Annahme die sinnvolle Funktion, die Aufmerksamkeit auf die fur die Allokation von Kompetenzen wesentlichen Faktoren zu lenken. Vgl. auch Wildasin, D.E. (1989), S. 210.

199 Randlosungen, in denen der gesamte Kapitalbestand oder die Gesamtzahl der Haushalte nur in einer Jurisdiktion alloziiert sind, sollen ausgeschlossen bleiben. Siehe hierzu die Ausfuhrungen bei Stiglitz, J.E. (1977) und (1983). 
eines lokal begrenzten Kollektivgutes $G_{i}$, nicht jedoch aus der Vorleistung $H_{i}$. Ihre Nutzenfunktion ist $\mathrm{U}=\mathrm{U}\left(\mathrm{X}_{\mathrm{i}}, \mathrm{G}_{\mathrm{i}}\right)$, mit fallenden Grenznutzen in $\mathrm{X}$ und $\mathrm{G}$.

- Die Bereitstellung des lokalen Kollektivgutes in i führt zu Kosten, ausgedrückt in Einheiten des privaten Gutes $X$, von $C_{i}=C_{i}\left(n_{i}, G_{i}\right)$. Die Kosten der Bereitstellung des öffentlichen Produktionsfaktors sind bestimmt durch $\mathrm{D}_{\mathrm{i}}=\mathrm{D}_{\mathrm{i}}\left(\mathrm{k}_{\mathrm{i}}, \mathrm{H}_{\mathrm{i}}\right)$ mit $\left(\partial \mathrm{D}_{\mathrm{i}} / \partial \mathrm{H}_{\mathrm{i}}\right)>0$. Stellt ein lokales Gemeinwesen Infrastrukturleistungen bereit, entstehen bei der Nutzung durch die Unternehmen Überfüllungskosten, die durch $\left(\partial \mathrm{D}_{\mathrm{i}} / \partial \mathrm{k}_{\mathrm{i}}\right) \geq 0$ beschrieben sind. Vollkommene Rivalität (quasi-private Vorleistungen) liegt vor bei $\left(\partial \mathrm{D}_{\mathrm{i}} / \partial \mathrm{k}_{\mathrm{i}}\right)=\left(\mathrm{D}_{\mathrm{i}} / \mathrm{k}_{\mathrm{i}}\right)$. Bei einer reinen öffentlichen Vorleistung gilt $\left(\partial \mathrm{D}_{\mathrm{i}} / \partial \mathrm{k}_{\mathrm{i}}\right)=0$.

Bei kostenloser Mobilität der Individuen und der Unternehmen kann eine gleichgewichtige und stabile Allokation der Bevölkerung auf die Gemeinden der Volkswirtschaft nur vorliegen, wenn die Netto-Nutzenpositionen für alle Haushalte in den Gemeinwesen A, B gleich hoch sind. ${ }^{200}$ Eine effiziente Allokation ist durch die Lösung des Optimierungsproblems ${ }^{201}$

$$
\text { Maximiere: } \begin{aligned}
\mathrm{U}\left(\mathrm{X}_{\mathrm{A}}, \mathrm{G}_{\mathrm{A}}\right) & +\lambda_{1}\left[\mathrm{U}\left(\mathrm{X}_{\mathrm{A}}, \mathrm{G}_{\mathrm{A}}\right)-\mathrm{U}\left(\mathrm{X}_{\mathrm{B}}, \mathrm{G}_{\mathrm{B}}\right)\right] \\
& +\lambda_{2}\left[\sum_{\mathrm{i}=\mathrm{A}, \mathrm{B}}\left[\mathrm{Q}_{\mathrm{i}}\left(\mathrm{L}_{\mathrm{i}}, \mathrm{n}_{\mathrm{i}}, \mathrm{k}_{\mathrm{i}}, \mathrm{H}_{\mathrm{i}}\right)\right]-\mathrm{n}_{\mathrm{i}} \mathrm{X}_{\mathrm{i}}-\mathrm{C}_{\mathrm{i}}\left(\mathrm{n}_{\mathrm{i}}, \mathrm{G}_{\mathrm{i}}\right)-\mathrm{D}_{\mathrm{i}}\left(\mathrm{k}_{\mathrm{i}}, \mathrm{H}_{\mathrm{i}}\right)\right] \\
& +\lambda_{3}\left[\overline{\mathrm{K}}-\mathrm{k}_{\mathrm{A}}-\mathrm{k}_{\mathrm{B}}\right] \\
& +\lambda_{4}\left[\overline{\mathrm{N}}-\mathrm{n}_{\mathrm{A}}-\mathrm{n}_{\mathrm{B}}\right] .
\end{aligned}
$$

beschrieben. Durch partielle Differentiation nach den entsprechenden Kontrollvariablen erhält man die Bedingungen erster Ordnung:

$$
\begin{aligned}
& \frac{\partial \mathrm{Q}_{\mathrm{A}}}{\partial \mathrm{n}_{\mathrm{A}}}-\mathrm{X}_{\mathrm{A}}-\frac{\partial \mathrm{C}_{\mathrm{A}}}{\partial \mathrm{n}_{\mathrm{A}}}=\frac{\partial \mathrm{Q}_{\mathrm{B}}}{\partial \mathrm{n}_{\mathrm{B}}}-\mathrm{X}_{\mathrm{B}}-\frac{\partial \mathrm{C}_{\mathrm{B}}}{\partial \mathrm{n}_{\mathrm{B}}} \\
& \frac{\partial \mathrm{Q}_{\mathrm{A}}}{\partial \mathrm{k}_{\mathrm{A}}} \cdot \mathrm{e}_{\mathrm{A}}-\frac{\partial \mathrm{D}_{\mathrm{A}}}{\partial \mathrm{k}_{\mathrm{A}}}=\frac{\partial \mathrm{Q}_{\mathrm{B}}}{\partial \mathrm{k}_{\mathrm{B}}} \cdot \mathrm{e}_{\mathrm{B}}-\frac{\partial \mathrm{D}_{\mathrm{B}}}{\partial \mathrm{k}_{\mathrm{B}}} \\
& \mathrm{n}_{\mathrm{i}} \frac{\partial \mathrm{U} / \partial \mathrm{G}_{\mathrm{i}}}{\partial \mathrm{U} / \partial \mathrm{X}_{\mathrm{i}}}=\frac{\partial \mathrm{C}_{\mathrm{i}}}{\partial \mathrm{G}_{\mathrm{i}}} \quad \mathrm{i}=\mathrm{A}, \mathrm{B} \\
& \mathrm{k}_{\mathrm{i}} \frac{\partial \mathrm{Q}_{\mathrm{i}}}{\partial \mathrm{k}_{\mathrm{i}} \partial \mathrm{e}_{\mathrm{i}}} \cdot \frac{\partial \mathrm{e}_{\mathrm{i}}}{\partial \mathrm{H}_{\mathrm{i}}}=\frac{\partial \mathrm{D}_{\mathrm{i}}}{\partial \mathrm{H}_{\mathrm{i}}} \quad \mathrm{i}=\mathrm{A}, \mathrm{B} .
\end{aligned}
$$

(3.C.II.3) beschreibt die Bedingung für eine effiziente räumliche Allokation der Bevölkerung auf die lokalen Gebietskörperschaften eines Staates. Die sozialen Nettonutzen der Ansiedlung eines zusätzlichen Haushalts in einem der Gliedstaaten sind auszugleichen. Man beachte, daß in (3.C.II.3) die lokalen Bereitstellungsmengen $G_{i}$ keinen direkten Eingang finden. Die üblichen Annahmen über die individuelle Nutzenfunktion implizieren jedoch, daß für ein gegebenes Nutzenniveau $\overline{\mathrm{U}}(\mathrm{X}, \mathrm{G})$ eines Haushalts der Mehrkonsum des privaten Gutes X 
durch geringeren Konsum des Kollektivgutes $G$ ausgeglichen wird, et vice versa. Die Nutzen aus dem Konsum des Kollektivgutes finden somit implizit Berücksichtigung. 202

Die Bedingung für eine effiziente räumliche Kapitalallokation wird durch (3.C.II.4) beschrieben. Danach sind im Optimum die marginalen sozialen Nettoerträge einer Kapitalansiedlung in allen Jurisdiktionen identisch. Die Nettoerträge bestehen aus den Produktionssteigerungen abzüglich den durch die Kapitalansiedlung entstehenden Kosten für öffentliche Vorleistungen. Werden keine Infrastrukturleistungen erbracht, ist die räumlich effiziente Kapitalallokation durch den interregionalen Ausgleich der Grenzproduktivitäten charakterisiert.

(3.C.II.5) und (3.C.II.6) sind Effizienzbedingungen für die Bereitstellung der Kollektivgüter G und H. Nach der Samuelson-Regel (3.C.II.5) muß in beiden Gemeinwesen die Summe der Grenzbewertungen des Konsums aller Jurisdiktionsmitglieder zwischen dem Kollektivgut G und dem privaten Gut X den Grenzkosten der Produktion des Kollektivgutes entsprechen. Für die Bereitstellung der produktiven öffentlichen Vorleistung sind solange zusätzliche Einheiten von $\mathrm{H}$ bereitzustellen, bis in beiden Einheiten deren Grenzkosten die zusätzlichen Produktionserträge durch den effizienteren Einsatz des Faktors Kapital gerade ausgleichen.

\section{bb. Dezentrale Bereitstellungskompetenzen und effiziente räumliche Allokation}

Im folgenden wird überprüft, ob dezentrale Bereitstellungskompetenzen eine effiziente räumliche Allokation ermöglichen. Dazu wird angenommen, jeder Haushalt in einer Gemeinde i beziehe Faktoreinkommen aus Arbeit $\mathbf{n}$ zum Bruttolohnsatz $\mathbf{w}_{\mathbf{i}}$, die Haushalte erhalten zusätzlich Bodenrenten $p_{i}$ sowie Kapitalerträge $r_{i}$. Die Faktoren werden nach ihren Grenzproduktivitäten entlohnt, so daß $w_{i}=\partial Q_{i} / \partial n_{i}, p_{i}=\partial Q_{i} / \partial L_{i}$ und $r_{i}=\left(\partial Q_{i} / \partial K_{i}\right) e_{i}$. Ferner wird angenommen, daß jede Jurisdiktion i zur Finanzierung der Bereitstellung des kollektiven Konsumgutes $G_{i}$ und der öffentlichen Vorleistung $H_{i}$ über eine Kopfsteuer mit dem Satz $\tau_{i}^{n}$ sowie über eine Steuer auf den Faktor Boden $\tau_{\dot{i}}^{L}$ und eine Kapitalsteuer $\tau_{i}^{k}$ verfügt, die nach dem Quellenprinzip erhoben werden. Die Budgetbeschränkung eines repräsentativen Haushalts im Gemeinwesen $i$ lautet dann:

$$
X_{i}=w_{i}-\tau_{i}^{n}+I,
$$

wobei I die Summe der nicht aus Arbeit fließenden Faktoreinkommen des Haushalts bezeichne. Die Budgetausgleichsbedingung für Jurisdiktion i ist ${ }^{203}$

$$
\tau_{i}^{n} n_{i}+\tau_{i}^{L} L_{i}+\tau_{i}^{k} k_{i}=C_{i}\left(n_{i}, G_{i}\right)+D_{i}\left(k_{i}, H_{i}\right) .
$$

Da die Besteuerung der Landrenten und der Kapitalerträge unabhängig von der Wohnsitzwahl erfolgt, ergibt sich aus der Bedingung eines interregionalen Nutzenausgleichs unter der Berücksichtigung der individuellen Budgetbeschränkung (3.C.II.7) unmittelbar

$$
w_{A}-\tau_{A}^{n}-X_{A}=w_{B}-\tau_{B}^{n}-X_{B}
$$


Vergleicht man (3.C.II.9) mit der Effizienzbedingung (3.C.II.3), wird deutlich, daß ein stabiles Gleichgewicht nur dann auch effizient ist, wenn für die Besteuerung der Haushalte

$$
\frac{\partial C_{A}}{\partial n_{A}}-\frac{\partial C_{B}}{\partial n_{B}}=\tau_{A}^{n}-\tau_{B}^{n}
$$

gilt. ${ }^{204}$ Nach (3.C.II.10) verlangt die effiziente Besteuerung mobiler Haushalte, daß die Differenz der marginalen Agglomerationskosten der Differenz der Kopfsteuersätze 205 entspricht. Dies ist insbesondere dann der Fall, wenn jede Gemeinde ihre Steuersätze so wählt, daß sie den Grenz-Überfüllungskosten, und damit einer 'lokalen Ballungssteuer', entsprechen.

Indessen muß dann natürlich die Frage gestellt werden, wie bei einer Bereitstellung reiner lokaler öffentlicher Konsumgüter, bei denen keine Überfüllungseffekte auftreten, zu verfahren wäre. Sollen reine lokale öffentliche Güter angeboten werden, folgt aus (3.C.II.10), daß für eine effiziente Allokation der Haushalte $\tau_{A}^{n}=\tau_{B}^{n}=0$ gelten muß und die Finanzierung des Kollektivgutangebotes über Kopfsteuern damit ausscheidet. ${ }^{206}$ Mittels einer Kopfsteuer als Alleinsteuer kann die effiziente Allokation einer heterogenen Bevölkerung auf die Gemeinden einer Volkswirtschaft nicht erreicht werden, da bei Präferenzunterschieden bezüglich des Konsums der Kollektivgüter, und daher unterschiedlichen Mengen $G_{i}$, auch die individuellen Belastungen $\tau_{i}^{n}$ zwischen den Kommunen differieren müßten. Im Gegensatz zur Besteuerung auf nationaler Ebene ist eine Kopfsteuer auf lokaler Ebene deshalb im Regelfall nicht allokationsneutral.

Sieht man von einer Kapitalbesteuerung zunächst ab, muß geklärt werden, ob das aus der Bodensteuer resultierende Aufkommen ausreichend groß ist, um eine effiziente Bereitstellung zu sichern. Für die lokale Produktionsfunktion gilt nach dem Euler'schen Satz ${ }^{207}$

$$
\mathrm{Q}=\mathrm{n} \frac{\partial \mathrm{Q}}{\partial \mathrm{n}}+\mathrm{L} \frac{\partial \mathrm{Q}}{\partial \mathrm{L}}
$$

und durch Einsetzen in die interne Optimierungsbedingung (3.C.II.2b) erhält man

$$
\mathrm{L} \frac{\partial \mathrm{Q}}{\partial \mathrm{L}}=\mathrm{C}\left(\mathrm{n}^{*}, \overline{\mathrm{G}}\right) \text {. }
$$

Zusammen mit der gemeindlichen Budgetbeschränkung (3.C.II.8) ist zu erkennen, daß durch eine konfiskatorische Besteuerung $\left(\tau_{i}^{L}=p_{i}\right)$ der aggregierten Bodenrenten die Gesamtkosten

204 Vgl. Wildasin, D.E. (1987), S. 1140.

205 Man beachte, daß die Annahme der Kopfsteuer nicht so rigide ist, wie sie auf den ersten Blick erscheinen mag. Im hier betrachteten Modell ist sie gleichzusetzen mit einer Steuer auf Arbeitseinkommen, bei im relevanten Bereich unelastischem Arbeitsangebot.

206 Stellen die lokalen Jurisdiktionen unterschiedliche Mengen von G bereit, so ist bei Nicht-Vorliegen von Rivalităten die linke Seite von (3.C.II.10) gleich Null und die rechte Seite ungleich Null. Allein fur das unrealistische Extrem, daß alle Kommunen im Optimum personell gleich groß sind und die lokalen Kollektivguter in gleicher Menge bereitstellen, kann eine effiziente raumliche Aufteilung der Burger die Erfullung von (3.C.II.10) und die Finanzierung des Angebots gewăhrleisten.

$207 \mathrm{Vgl}$. Schwarze, J. (1986), S. 71. 
des lokalen Kollektivgüterangebots gedeckt sind. 208 "Land rents are created through the advantages of collective consumption, and efficiency requires that such land rents finance the source of benefits."209 Die Abschöpfung der Landrenten ist damit der Ausdruck einer Äquivalenzbesteuerung. Dahinter steht die Überlegung, daß erst durch die Nutzung des räumlich immobilen Faktors Boden durch mobile Faktoren auch Bodeneinkommen entstehen. Die ökonomische Rente des Bodens ergibt sich als Differenz zwischen lokalem Sozialprodukt $\mathrm{Q}$ und den Einkommen aller mobilen Faktoren. Landrenten sind im neoklassischen Modell "locational co-operation rents." 210 Liegen negative Überfüllungsexternalitäten vor, könnten die Bereitstellungskosten $\mathrm{C}$ nicht mehr nur über eine Bodensteuer aufgebracht werden. 211 Hier würde die Haushaltssteuer als 'Ballungs'- oder 'Immigrationssteuer' gemäß (3.C.II.10) die Internalisierung der Migrationsexternalitäten garantieren. ${ }^{212}$

Wildasin weist darauf hin, daß die Regierungen der lokalen Gemeinwesen bei perfekter Mobilität der Haushalte deren Nutzenposition im interjurisdiktionellen Wettbewerb nicht beeinflussen können. Deshalb erscheine die Annahme plausibel, die Gemeinden verfolgen das Ziel einer Maximierung der Netto-Bodeneinkommen, die erreicht ist, wenn die angeführten Effizienzbedingungen realisiert werden. ${ }^{213}$ Offenbar würde aus diesem Blickwinkel perfekter Wettbewerb subzentraler Einheiten um mobile Haushalte eine effiziente Allokation garantieren.

Schließlich sei kurz auf einen weiteren Aspekt der Migrationsexternalitäten eingegangen. Die Abwanderung von Haushalten führt in der Herkunftsgemeinde ebenfalls zu externen Effekten, da negative Ballungseffekte verringert werden (positive Externalität) und/oder die Pro-KopfKosten der Kollektivgutbereitstellung wachsen (negative Externalität). Die Logik dieses Modells impliziert, daß die Gemeinwesen die entstehenden externen Effekte ebenfalls durch eine Subventionierung und/oder eine Besteuerung der Abwanderung ('Emigrationssubvention' bzw. 'Emigrationssteuer') internalisieren.

Die Überlegungen können analog auf die Besteuerung des mobilen Faktors Kapital übertragen werden. Aufgrund der interregionalen Kapitalarbitrage liegt ein Gleichgewicht nur bei Identität der Nettorenditen in allen Jurisdiktionen des Bundesstaates vor. Daraus erhält man:

$$
\mathrm{r}_{\mathrm{A}}-\tau_{\mathrm{A}}^{\mathrm{k}}=\mathrm{r}_{\mathrm{B}}-\tau_{\mathrm{B}}^{\mathrm{k}}
$$

Setzt man die Bedingung für eine effiziente räumliche Kapitalallokation (3.C.II.4) unter Berücksichtigung von $\mathbf{r}_{i}=\left(\partial Q_{i} / \partial \mathrm{k}_{i}\right) \mathrm{e}_{\mathrm{i}}$ in (3.C.II.13) ein, ergibt sich

208 Den Vorschlag einer Alleinsteuer auf den Faktor Boden formulierte erstmals der Journalist und Ökonom Henry George in seinem Werk "Progress and Poverty" (1879). Nach Stiglitz, J.E. (1977) wird die oben abgeleitete Besteuerungsregel daher als Henry George-Theorem bezeichnet. Siehe hierzu auch Wildasin, D.E. (1986), S. 22ff., Mieszkowski, P./Zodrow, G.R. (1989), S. 1135ff. und Althammer, W. (1995).

209 Mieszkowski, P./Zodrow, G.R. (1989), S. 1135. Die Nutzen der Kollektivgutbereitstellung werden in den Landrenten 'kapitalisiert'. Năheres dazu unten.

210 Welter, P. (1995), S. 135.

211 Vgl. etwa Bucovetsky, S. (1981).

212 Vgl. Wildasin, D.E. (1987), S. 1141.

213 Vgl. Wildasin, D.E. (1986), S. 85. Das setzt naturlich voraus, daß keine Bodenrenten an Gebietsfremde, deren Nutzen (Wahlerstimmen) nicht in die Entscheidungen der lokalen Regierungen eingehen, 'abfließen'. Siehe dazu ausfuhrlich Wellisch, D. (1995), S. 64ff. 


$$
\frac{\partial \mathrm{D}_{\mathrm{A}}}{\partial \mathrm{k}_{\mathrm{A}}}-\frac{\partial \mathrm{D}_{\mathrm{B}}}{\partial \mathrm{k}_{\mathrm{B}}}=\tau_{\mathrm{A}}^{\mathrm{k}}-\tau_{\mathrm{B}}^{\mathrm{k}}
$$

Effiziente Kapitalbesteuerung erfordert, daß die Differenz der marginalen Kapitalsteuersätze gleich der Differenz der marginalen Überfüllungskosten durch die Kapitalagglomeration in den Jurisdiktionen ist. (3.C.II.14) ist erfüllt, wenn die öffentlichen Vorleistungen quasiprivater Natur sind, die Kapitalsteuer hätte den Charakter einer Gebühr der ortsansässigen Unternehmen für die Inanspruchnahme der lokalen Vorleistung $\mathrm{H}_{\mathrm{i}}$.

Handelt es sich bei der Vorleistung um einen reinen öffentlichen Produktionsfaktor, scheidet die Finanzierung über eine Kapitalsteuer aus, da im Optimum die Kapitalsteuersätze gleich Null sein müßten. Wie im Fall eines reinen öffentlichen Konsumgutes bietet sich die Finanzierung über eine Bodensteuer an. Da die Gemeinwesen nur die Nutzen der Eigentümer immobiler Faktoren beeinflussen können, sind ihre Aktivitäten auf die Maximierung der Netto-Renten immobiler Faktoren gerichtet. Das impliziert, daß die Zuwanderung von Kapital durch Infrastrukturpolitik solange gefördert wird, bis die Sozialproduktzuwächse infolge des größeren lokalen Kapitalstocks den sozialen Grenzkosten der Kapitalansiedlung entsprechen.

Es bleibt festzuhalten: Fiskalische Externalitäten der Wanderungsbewegungen von Arbeit und Kapital können durch eine Haushaltssteuer bzw. eine Kapitalsteuer internalisiert werden; die Besteuerung des Faktors Boden sichert die Finanzierung der kollektiv bereitgestellten Güter und ermöglicht lokal unterschiedliche Bereitstellungsniveaus. Der Wettbewerb um mobile Haushalte und mobiles Kapital zwingt die lokalen Einheiten, ihr steuerpolitisches Instrumentarium so einzusetzen, daß die Faktoren nach dem Äquivalenzprinzip besteuert werden.

\section{cc. Kapitalisierung und Ausschluß als Voraussetzung für Tiebout-Effizienz}

Die bislang vorgetragene Argumentation stützt sich wesentlich auf die Annahme vollkommer Immobilität des Faktors Boden. Zwar gilt generell, daß Land interregional immobil ist, andererseits kann nicht davon ausgegangen werden, daß die Bodeneigentümer selbst räumlich immobil sind. Um einer konfiskatorischen Besteuerung der Bodenrenten zu entgehen, könnten sie ihre Anteile verkaufen und in andere Jurisdiktionen abwandern. Folglich könnten Landrenten nicht abgeschöpft werden; die potentielle Effizienz des Tiebout-Mechanismus wäre gestört, weil die Finanzierung reiner lokaler Kollektivgüter gefährdet wäre. ${ }^{214}$

Von herausragender Bedeutung für das Funktionieren des Tiebout-Mechanismus ist damit, ob eine Kapitalisierung fiskalischer Variablen in den Marktwerten der besteuerten Faktoren erfolgt. ${ }^{215}$ Werden die Eigentümer der immobilen Faktoren durch die bereitgestellten Leistungen für die steuerliche Belastung kompensiert, unterbleibt eine Abwanderung. Dabei wäre es unerheblich, ob die Faktoreigner selbst unmittelbar von den öffentlichen Aktivitäten profitieren. Stellen nämlich lokale Gemeinwesen attraktive Steuer-Leistungspakete bereit und erfahren sie eine Zuwanderung mobiler Haushalte (analog natürlich mobilen Kapitals), dann

\footnotetext{
214 Diese Argumentation hat zu einer intensiven theoretischen Diskussion uber die Effizienz- und Verteilungswirkungen einer local property tax gefuhrt, deren Ergebnisse hier nicht im einzelnen erörtert werden können. Unter vielen seien genannt: Oates, W.E. (1969); Edel, M./Sclar, E. (1974); Rosen, H.S./Fullerton, D.J. (1977); Sonstelie, J./Portney, P. (1980); Yinger, J. (1982); Hamilton, B.W. (1983). Siehe auch die Surveys von Mieszkowski, P./Zodrow, G.R. (1989) oder Wildasin, D.E. (1986), S. 64ff.
}

215 Diese Idee geht auf Marshall, A. (1948), zuruck. Vgl. Chaudry-Shah, A. (1988), S. 211 f. 
ergibt sich daraus eine zunehmende Verknappung des Faktors Boden. In der Folge steigen die Bodenpreise an, und aus den gestiegenen Bodeneinkommen ist die Steuerbelastung finanzierbar.

Die Bedeutung des Kapitalisierungsmechanismus für die Effizienz der Tiebout-Wanderungen wird deutlich, wenn man etwa annimmt, daß zwei Bevölkerungsgruppen existieren, die sich in ihren Präferenzen für Wohnraum unterscheiden. Unterstellt sei, daß wohlhabende Haushalte 'große' und ärmere Haushalte 'kleine Häuser' nachfragen, deren Wert die Bemessungsgrundlage der lokalen Steuer sei. Freie Migrationen würden ohne Kapitalisierung zu Ineffizienzen führen, da über die Wahl des Gebäudewerts die Gemeindemitglieder die individuelle Steuerschuld und damit die fiskalischen Restwerte aus der Wohnortwahl beeinflussen könnten. ${ }^{216}$ In Gemeinwesen mit hohem Bereitstellungsniveau von $G$ würden Zuwanderer durch den Kauf eines 'kleinen' Hauses, d.h. eines Grundstücks mit unterdurchschnittlichem Wert - und damit geringerer Steuerbelastung je Outputeinheit von G als die der übrigen Gemeindemitglieder -, höhere Netto-Nutzen realisieren können als in Kommunen mit geringem Niveau von G. 217 Folglich bestünde ein Zuwanderungsanreiz, der für die originären Jurisdiktionsmitglieder mit negativen fiskalischen Externalitäten verbunden wäre. 218

Die induzierten Wanderungsbewegungen ziehen, so die These, in der Zuwanderungsregion eine Verknappung bei kleinen Häusern nach sich, so daß deren Preis im Vergleich zu äquivalentem Wohnraum in der Herkunftsjurisdiktion, wo die Nachfrage nach kleinen Häusern sinkt, ansteigt. Der Preisanstieg für kleine Häuser in der reicheren Jurisdiktion resultiert in einem Anstieg der Steuerpreise je Einheit von G. ${ }^{219}$ Bei perfekter Kapitalisierung ist die Summe aus Anschaffungspreisen und dem Barwert der daraus resultierenden Steuerzahlungen für alle Nachfrager gleicher öffentlicher Leistungen identisch, und in Kommunen mit gleichem Kollektivgüterangebot wären für alle Mitglieder die "total residence

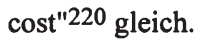

Allerdings erscheint fraglich, ob eine Kapitalisierung der Nutzen und Kosten öffentlicher Einrichtungen in der beschriebenen idealen Weise erfolgen kann. ${ }^{221}$ Wie in der Theorie der property rights betont, ist der Wert eines Eigentumsrechts eben davon bestimmt, ob NichtVerfügungsberechtigte von der Nutzung ausgeschlossen werden können. Übertragen auf das Kapitalisierungsargument bedeutet dies, daß sich die Nutzen aus dem Kollektivgutangebot nur dann in den immobilen Werten widerspiegeln, wenn es den Einwohnern der Gemeinde gelingt, Auswärtige von der Nutzung auszuschließen. In der Tat haben die oben abgeleiteten optimalen Haushalts- und Kapitalsteuern die Funktion eines Ausschlußmechanismus.

Problematisch erscheint ferner die Annahme, die lokalen Gemeinwesen verfügten über die Informationen, um die Haushalte (bzw. den Faktor Kapital) so zu besteuern, daß sie in ihren Wanderungsentscheidungen die verursachten Ballungseffekte berücksichtigen. Faktisch wird es den Regierungen zwar kaum gelingen, die 'wahren' Überfüllungskosten, die durch die

216 Vgl. Buchanan, J.M./Goetz, C.J. (1972); Henderson, V. (1979) und Rubinfield, D. (1987), S. 587ff.

217 Vgl. Fisher, R.C. (1988), S. 72.

218 Vgl. Hamilton, B.W. (1975). Dieselben Implikationen ergeben sich, wenn statt einer 'property tax' z.B. eine Einkommensteuer zur Finanzierung von $G$ herangezogen würde. Einkommensschwache Bürger hătten einen Anreiz, sich in reichen Kommunen mit höherem Kollektivgutangebot niederzulassen.

219 Man beachte, daß die Steuersätze unverändert bleiben.

220 Fisher, R.C. (1988), S. 77.

221 Skeptisch åußert sich hierzu insbesondere Buchanan, J.M. (1969). 
Ansiedlung von Unternehmen oder Haushalten entstehen, festzustellen. ${ }^{222}$ Gleichwohl darf vermutet werden, daß die subzentralen Einheiten in einem Lemprozeß zumindest annähernd optimale Ballungssteuern erheben könnten.

Im einschlägigen Schrifttum wird auch die Einrichtung fiskalischer Zuzugsbeschränkungen ("fiscal zoning"223) intensiv dikutiert. So könnten sich die Gemeindebewohner durch Zuwanderungsvorschriften, die an die Einkommenssituation der potentiellen Zuwanderer geknüpft sind, oder aber auch indirekt als Mindestanforderungen an Grundstücksgrößen, Bauvorschriften, persönliche Qualifikationen o.ä. ausgestaltet werden, die Zuwanderungen regulieren. Wird durch fiscal zoning eine in jeder Hinsicht (Präferenzen bezüglich besteuerten privaten und öffentlichen Gütern, Einkommen etc.) homogene Bevölkerungsstruktur erreicht, so kann jede Steuer wie eine Äquivalenzsteuer wirken

Als Konsequenz wäre $\mathrm{zu}$ folgern, daß die lokalen Gemeinwesen als Clubs mit einer Ausschlußberechtigung zu organisieren sind. Damit wird jedoch das Recht der freien binnenstaatlichen Wanderung faktisch beschränkt. Offenkundig stehen hier zwei liberale Grundrechte in einer konfliktären Zielbeziehung. ${ }^{224}$ Es sei zunächst nur darauf hingewiesen, daß daraus v.a. polit-ökonomische Probleme resultieren. Darauf wird im fünften Kapitel noch zurückzukommen sein.

Vor dem Hintergrund dieser Darlegungen muß deshalb die Beantwortung der Frage, ob der Tiebout-Wettbewerb zwingend zu nicht-internalisierten Migrationsexternalitäten führt, offen bleiben. Für die weiteren Überlegungen sei davon ausgegangen, daß der Ausschluß durch Steuern, die eine Quasi-Preisfunktion haben, möglich und gestattet ist. Im folgenden Abschnitt soll der weitergehenden Frage nachgegangen werden, welche Implikationen sich ergeben, wenn die institutionelle Ausgestaltung der Einnahmekompetenzen den lokalen Einheiten die Besteuerung immobiler Faktoren untersagt und die Gemeinwesen zur Finanzierung öffentlicher Leistungen auf die Besteuerung mobiler Faktoren angewiesen sind.

\section{d. Zum Problem des Fiskalwettbewerbs}

\section{aa. Unterversorgung mit konsumtiven Kollektivgütern?}

Als weiteres Hindernis für dezentrale Bereitstellungskompetenzen wird angeführt, fiskalischer Wettbewerb um mobile Faktoren führe zu einer volkswirtschaftlich ineffizienten "beggar-thyneighbour policy among governments"225. Es sei deshalb erforderlich, Kompetenzen auf übergeordnete föderative Ebenen zu verlagern, da dort mit den negativen Konsequenzen des Fiskalwettbewerbs nicht zu rechnen sei. Zwar kann Wettbewerb um mobile Faktoren sowohl durch den Einsatz finanzpolitischer Instrumente der Einnahmen- als auch der Ausgabenseite des Budgets erfolgen; dennoch beschränken sich die Betrachtungen meist auf Aspekte des Steuerwettbewerbs. Dem soll auch hier gefolgt werden. Die Beweisfuhrung gilt analog, wenn lokale Ausgaben zur Attrahierung mobiler Faktoren eingesetzt werden; man spricht dann von fiskalischem Ausgabenwettbewerb. 226

222 Vgl. ebenso Fuest, C. (1995), S. 154.

223 Siehe etwa Mills, E.S./Oates, W.E. (1975); Fischel, W.A. (1975); Hamilton, B.W. (1976); Mieszkowski, P. (1976); Epple, D./Zelenitz, A./Visscher, M. (1978).

224 Siehe insbesondere Buchanan, J.M. (1969).

225 Boadway, R.W. (1992), S. 27.

226 Vgl. Wildasin, D.E. (1988) und auch Taylor, L. (1992). 
Das Begründungsmuster kann wie folgt skizziert werden: Müßten die lokalen Gemeinwesen versuchen, die konsumtiven Kollektivgüter durch die Belastung räumlich mobiler Faktoren zu finanzieren, führt der Wettbewerb der Einheiten um die mobile Bemessungsgrundlage für die lokalen Steuern dazu, daß Steuersätze 'nach unten konkurriert' werden. Weil mit den gesunkenen Steuereinnahmen die Bereitstellung nicht sichergestellt werden kann, kommt es zur Unterversorgung der Jurisdiktionsmitglieder. Man spricht daher auch von der "race-to-the bottom"227- oder "zero regulation-These"228. Entsprechend wird gefolgert, der Konkurrenzdruck des Steuerwettbewerbs mache eine Harmonisierung ${ }^{229}$ oder gegebenenfalls eine Zentralisierung der Besteuerung mobiler Faktoren in der Föderation erforderlich. ${ }^{230}$

Im folgenden soll untersucht werden, ob dieser These gefolgt werden kann. Vereinfachend wird hierzu angenommen, Kapital sei interregional völlig mobil, Arbeit dagegen (wie Boden) immobil. Weiter sei angenommen, die Bevölkerung im Bundesstaat sei vollkommen homogen und alle Gliedstaaten der Föderation würden daher gleiche Kapitalsteuersätze zur Finanzierung identischer Bereitstellungsniveaus lokaler öffentlicher Konsumgüter wählen; die Bedingung (3.C.II.14) für eine effiziente räumliche Kapitalallokation wäre also erfüllt.

Betrachtet wird die Entscheidungssituation einer lokalen Einheit, die versucht, mittels einer Kapitalsteuer als Alleinsteuer das Angebot von konsumtiven lokalen öffentlichen Gütern zu finanzieren. Wollen die lokalen Entscheidungsträger das Kollektivgutangebot ausdehnen und den Steuersatz auf Kapital anheben, müssen sie mit einer Kapitalflucht aus dem Gemeinwesen rechnen. Fließt infolge der Steuererhöhung Kapital aus einer Jurisdiktion in andere Einheiten ab, so könnten diese unter Beibehaltung ihrer Steuersätze aufgrund der höheren Besteuerungsbasis mehr Kollektivgüter bereitstellen. Die Entscheidung einer lokalen Einheit, den Kapitalsteuersatz anzuheben, erzeugt somit positive fiskalische Externalitäten in den anderen Jurisdiktionen. 231

Der Nutzenzuwachs bei den auswärtigen Bürgern findet aber in der Entscheidung der betrachteten Einheit keine Berücksichtigung. Dort werden nämlich nur die den Mitgliedern entstehenden Nutzen und Kosten kalkuliert. Die Kosten der Kollektivgutbereitstellung setzen sich aus Sicht der lokalen Einheit aus zwei Komponenten zusammen. ${ }^{232}$ Erstens werden dem privaten Sektor Ressourcen entzogen, die nicht mehr für die Produktion privater Güter zur Verfügung stehen. Zweitens führt die Steuererhöhung zu einer Abwanderung von Kapital in andere Regionen. Diese zweite Kostenkomponente ist freilich aus bundesstaatlicher Sicht ein rein pekuniärer Effekt, denn das gesamtstaatliche Kapitalangebot bleibt - im Gegensatz zum subnationalen Kapitalangebot - unverändert. ${ }^{233}$ Die wahren Kosten der Bereitstellung öffent-

227 Streit, M./Mussler, W. (1995), S. 98.

228 Siebert, H. (1991), S. 20.

$229 \mathrm{Zu}$ unterschiedlichen Interpretationsmoglichkeiten des Harmonisierungsbegriffs siehe etwa Peffekoven, $R$. (1983), S. 258ff. Hier soll unter Harmonisierung die Angleichung der Bemessungsgrundlagen und der Steuersătze der Jurisdiktionen verstanden werden, so daß interregionale Kapitalbewegungen nicht durch steuerpolitische Entscheidungen beeinflußt werden. Vgl. auch Tanzi, V./Bovenberg, A.L. (1990), S. 172.

230 Vgl. Musgrave, P.B./Musgrave, R.A. (1990); Keen, M. (1989); Razin, A./Sadka, E. (1991).

231 Vgl. Wildasin, D.E. (1989), S. 194.

232 Vgl. Hoyt, W.H. (1991); Wellisch, D. (1995), S. 79ff.

233 Daher argumentieren auch einige Autoren, der Steuerwettbewerb um mobiles Kapital fuhre zu rein pekuniăren Externalităten, also lediglich zu Umverteilungen zwischen den Jurisdiktionen. Folglich könnten hieraus keine ineffizienten Entscheidungen resultieren. Vgl. z.B. Sinn, S. (1992), S. 191. Tatsăchlich kann aber von pekuniăren externen Effekten nur dann gesprochen, wenn die Anpassungsvorgănge uber einen Markt erfolgen. Genau dies ist aber hier nicht der Fall: Leistung (Bereitstellung von konsumtiven Kollek- 
licher Leistungen kommen deshalb nur in der ersten Kostenkomponente zum Ausdruck. Die Bereitstellungskosten werden auf subzentraler Ebene zu hoch kalkuliert, was zu einer suboptimalen Bereitstellung lokaler öffentlicher Konsumgüter führt.

Das Problem kann auch graphisch veranschaulicht werden. ${ }^{234}$ In Abbildung 3.6 illustriert die $\mathrm{T}_{1} \mathrm{~T}_{1}$-Linie die lokale Transformationskurve zwischen dem privaten Gut $\mathrm{X}$ und dem Kollektivgut G. $T_{1} T_{1}$ beschreibt die Ressourcenkosten der Produktion von $G$ im subnationalen Kollektiv. Eine effiziente Allokation wäre in Punkt I erreicht, wo $T_{1} T_{1}$ zur Tangente an die Indifferenzkurve $u_{1}$ eines repräsentativen Kollektivmitglieds wird.

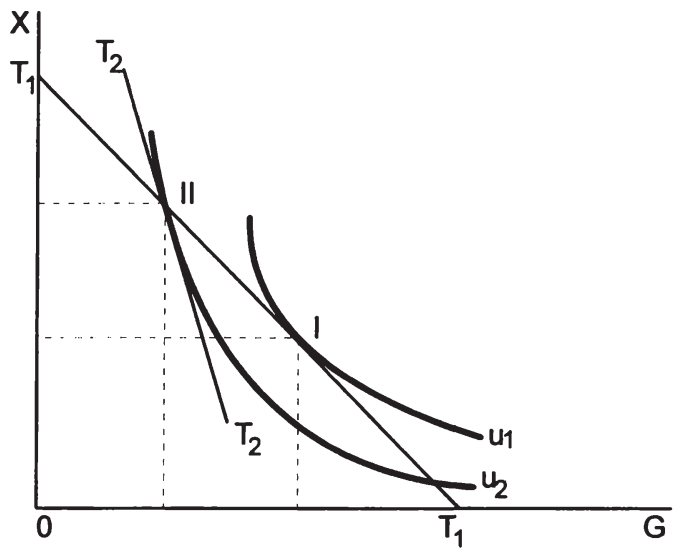

\section{Abbildung 3.6: Suboptimale Bereitstellung von Kollektivgütern bei Steuerwettbewerb \\ Quelle: in Anlehnung an Zodrow, G.R./Mieszkowski, P. (1986), S. 362.}

Aus Sicht der lokalen Einheit sind die Kosten der Kollektivgutbereitstellung aber um die Kostenkomponente Kapitalflucht größer. Die für die lokale Entscheidung relevante Transformationslinie $T_{2} T_{2}$ hat daher einen steileren Verlauf, und die Entscheidungsträger wählen eine Aufteilung der Ressourcen gemäß Punkt II. Da alle identischen Einheiten gleichermaßen kalkulieren, muß II auf der $\mathrm{T}_{1} \mathrm{~T}_{1}$-Kurve liegen. ${ }^{235}$

tivgutern) und Gegenleistung (Steuer auf Kapital) sind unverbunden. Andererseits handelt es sich auch nicht um eine technologische Externalităt in dem Sinne, daß die Entscheidungen von $\mathbf{A}$ in der direkten Nutzenfunktion von B Eingang finden. Der Begriff der fiskalischen Externalität umschreibt diesen besonderen Zusammenhang. Wenn allerdings ein direkter, quasi-marktlicher Zusammenhang zwischen Leistung und Gegenleistung besteht, wie es der Fall ist, wenn die Kapitalsteuer zur Finanzierung von Vorleistungen mit Privatgutcharakter verwendet wird, kann man von pekuniären externen Effekten sprechen. Dann, und nur dann, ergeben sich von den Ausgaben- und Einnahmenentscheidungen der Jurisdiktionen nur interregionale Umverteilungseffekte, jedoch keine allokativen Ineffizienzen. Kurz gesagt: Der Begriff der pekuniären Externalităt ist in diesem Zusammenhang unbrauchbar.

234 Vgl. Zodrow, G.R./Mieszkowski, P. (1986), S. 362 oder Wellisch, D. (1995), S. 80.

235 Je geringer der im Vergleich zu den anderen Jurisdiktionen gewăhlte Kapitalsteuersatz ist, desto geringer ist bei gegebenem Kapitalbestand das Steueraufkommen, und desto weniger Kollektivguter können bereitgestellt werden. Andererseits fließt der Region Kapital zu und der Kapitalstock steigt an. Damit erhöht sich das lokale Produktionspotential, das fur die Produktion von privaten und offentlichen Gutern genutzt wer- 
Die Allokation in II ist offensichtlich suboptimal, und das Kollektivgutangebot ist im Vergleich zu I geringer. Wie Hoyt nachweist, fallen die lokalen Bereitstellungsmengen um so kleiner aus, je mehr Jurisdiktionen die Föderation bilden, d.h. je intensiver der interjurisdiktionelle Wettbewerb um den mobilen Faktor Kapital ist. 236

Die Situation ähnelt offenbar einem Gefangenendilemma. Alle lokalen Jurisdiktionen werden versuchen, durch die Wahl niedriger Kapitalsteuersätze mobiles Kapital zu attrahieren. Im Ergebnis wird, da alle Beteiligten so handeln, die räumliche Kapitalallokation nicht beeinflußt, und die Aufkommen aus der Kapitalbesteuerung sind sehr gering. Könnte eine kollektive Übereinkunft der subzentralen Einheiten erzielt werden, die Kapitalsteuersätze zu erhöhen, würden die Konsequenzen des Steuerwettbewerbs vermieden. Eine Einigung ist jedoch um so weniger zu erwarten, je kleiner die Gemeinwesen sind und je größer damit die Zahl der Beteiligten ist, weil mit zunehmendem Dezentralisierungsgrad die Einnahme der free rider-Position begünstigt wird.

Besteht beispielsweise ein Bundesstaat aus einer großen Zahl von M Jurisdiktionen und einigen sich (M-1) Einheiten auf eine gemeinsame Steuererhöhung, so können die kooperierenden Jurisdiktionen die Kostenkomponente Kapitalabwanderung ignorieren. Zwar fließt bei einer gemeinschaftlichen Steuererhöhung Kapital in die nicht-kooperierende Einheit $\mathrm{i}$ ab; dort sinkt jedoch die Kapitalgrenzproduktivität, und die Kapitalwanderung kommt schnell wieder zum Stillstand. Ist das Gemeinwesen i sehr klein, verändert sich durch die Steuererhöhung in den (M-1) Einheiten die Netto-Kapitalrendite genau entsprechend der Steuererhöhung, der Einfluß der Einheit i auf die Nettorendite des Faktors Kapital im Bundesstaat ist jedoch unter den gemachten Annahmen verschwindend gering. Die für die kooperierenden Einheiten relevante Transformationskurve ist deshalb mit der gesamtgesellschaftlichen Transformationslinie $T_{1} T_{1}$ identisch. Die Jurisdiktionen des Steuerkartells würden die effiziente Lösung I auf $\mathbf{u}_{1}$ wählen. 237

In i muß dagegen bei einer Kapitalsteuererhöhung mit der Abwanderung von Kapital kalkuliert werden. Die Außenseiterposition birgt aber einen Vorteil, den sich i, wie Abbildung 3.7 zeigt, zunutze machen kann. Die Entscheidungsträger in i können nämlich durch die Wahl eines Steuersatzes, der unterhalb des von der Gemeinschaft der anderen Jurisdiktionen gewählten liegt, zusätzliches Kapital von dort attrahieren. Dieses Kapital kann für die Produktion privater Konsumgüter eingesetzt werden. Daher verläuft die in i relevante Transformationskurve $\mathrm{T}_{2} \mathrm{~T}_{2}$ steiler als die Transformationslinie $\mathrm{T}_{1} \mathrm{~T}_{1}$, aber im Vergleich zu Schaubild 3.6 weiter rechts. Ist der Marktanteil von i so klein, daß von der dortigen Steuerpolitik keine Einflüsse auf das nationale Netto-Zinsniveau ausgehen, schneidet die in i relevante Transformationskurve $T_{2} T_{2}$ in I. Region i könnte zwar die kooperative Lösung I wählen, stellt ihre

den kann. Die Auswirkung auf die lokale Allokation der Produktionsfaktoren hinsichtlich der Bereitstellung privater und offentlicher Guter ist insofern unbestimmt. Hier wird angenommen, daß der erstgenannte Steuersatzeffekt den zweiten Bemessungsgrundlageneffekt dominiert. Dies bedeutet, daß durch den Kapitalzufluß als Folge einer Steuersenkung zwar mehr private Guter, jedoch weniger Kollektivguter in der Region hergestellt werden kőnnen. Infolgedessen ist die relevante lokale Transformationskurve stets steiler als die Transformationskurve, welche die tatsăchlichen Opportunitatskosten widerspiegelt. Wăhlen die identischen Jurisdiktionen den gleichen Steuersatz, schneiden sich die beiden Transformationskurven.

236 Siehe Hoyt, W.H. (1991). Auch bei der Besteuerung von Konsumgütern würden die Jurisdiktionen zu geringe Steuersătze wăhlen; vgl. hierzu Mintz, J./Tulkens, H. (1986). Entsprechend wird auch die Forderung nach einer Harmonisierung der Konsumbesteuerung abgeleitetet. Siehe z.B. Hamlin, A.P./Ulph, A. (1991).

237 Siehe dazu ausfuhrlich Wellisch, D. (1995), S. $90 \mathrm{ff}$. 
Bürger aber durch eine relative Unterversorgung mit dem Kollektivgut in II auf $\mathrm{u}_{2}$ besser. Da aber jede lokale Einheit diese Überlegungen anstellt, fehlt der Anreiz zur Kooperation; eine freiwillige Harmonisierung der Kapitalsteuern ist deshalb nicht zu erwarten. 238

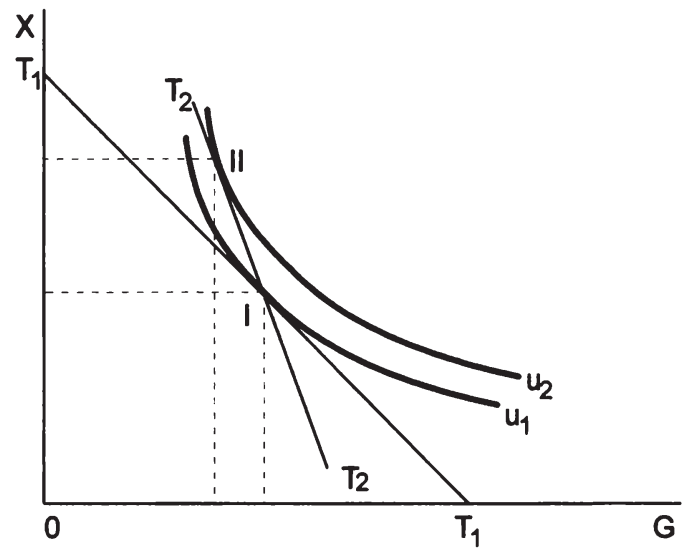

\section{Abbildung 3.7: Fehlender Kooperationsanreiz lokaler Einheiten bei Steuerwettbewerb Quelle: Wellisch, D. (1995), S. 92}

Zur Lösung des Problems findet man in der Literatur eine Reihe von Vorschlägen vertikaler Verflechtungen. ${ }^{239}$ Wird eine Kapitalsteuerharmonisierung auf freiwilligem Wege nicht erreicht, wird erstens empfohlen, eine zentrale Einheit solle durch Finanzzuweisungen den Preis für das lokale Kollektivgutangebot senken. ${ }^{240}$ Eine vollständige Internalisierung erfordert, daß die Subventionierung des lokalen Kapitaleinsatzes genau in der Höhe erfolgt, in der die potentielle Kapitalabwanderung die lokal relevanten Bereitstellungskosten erhöht.

Zweitens wird auch die Trennung von Aufgaben- und Finanzierungskompetenzen in Betracht gezogen. Zentrale Einheiten könnten die Probleme der Besteuerung mobiler Faktoren auf subzentraler Ebene vermeiden, da sie der Gefahr einer Kapitalflucht (annahmegemäß) nicht ausgesetzt sind. Auf lokaler Ebene würde dann über die Bereitstellungsmengen der Kollektivgüter entschieden; die Finanzierung sollte durch Zuweisungen der Zentralebene erfolgen. ${ }^{241}$

238 Ebenso Bucovetsky, S. (1991), S. 178ff. Wie Wildasin zeigt, fuhrt fiskalischer Ausgabenwettbewerb zu identischen Ergebnissen, wenn die Jurisdiktionen so klein sind, daß von ihrer Politik keine Kapitalmarktwirkungen ausgehen. Ausgabenwettbewerb zwischen großeren Regionen erzeuge dagegen großere Ineffizienzen als Steuerwettbewerb, wenn Kapitalmarktwirkungen zu erwarten sind. Zur Finanzierung steigender Ausgaben fur Kollektivguter muß eine regionale Einheit den Kapitalsteuersatz erhø̈en. In den Jurisdiktionen, die infolgedessen eine Kapitalzuwanderung erfahren, könten identische Bereitstellungsniveaus nunmehr mit verringerten Kapitalsteuersătzen finanziert werden. Diese Steuersenkung fuhre zu einer erneuten Zuwanderung von Kapital aus der ersten Region, ein Effekt, der bei Steuerwettbewerb nicht auftritt. Siehe Wildasin, D.E. (1988).

$239 \mathrm{Vgl}$. insbesondere Gordon, R.H. (1983), S. $581 \mathrm{ff}$.

240 Vgl. Wildasin, D.E. (1989), S. 196ff.

241 In der anglo-amerikanischen Literatur wird von der fiskalischen Aufkommenslucke (fiscal gap) gesprochen, die durch das oben beschriebene Zuweisungssystem des revenue sharing geschlossen werden kann. Vgl. Boadway, R.W. (1992), S. 49. Zum revenue sharing siehe ausfuhrlich Stolz, O.G. (1974). 
Die mit der Zuweisungsvergabe verbundenen Informations- und Anreizprobleme schmälern jedoch die Vorteilhaftigkeit beider Finanztransferlösungen nicht unerheblich. ${ }^{242}$

Schließlich impliziert die Analyse von Hoyt, die Bereitstellungsverantwortlichkeiten größeren Jurisdiktionen zu übertragen, da sich der Wettbewerbsdruck bei einer geringeren Zahl von Beteiligten verringert. ${ }^{243}$ Zentralisierung sei aber nur bei Vernachlässigung von Informationsaspekten 244 und homogener Bevölkerungsstruktur im Bundesstaat ${ }^{245}$ sinnvoll.

\section{bb. Unterversorgung mit produktiven Kollektivgütern?}

Es überrascht kaum, daß Steuerwettbewerb unter den gegebenen Annahmen zu Ineffizienzen führt. Es wird nämlich unterstellt, daß von den Gemeinwesen Güter bereitgestellt werden, deren Vorteile nur den Haushalten, nicht aber dem Faktor Kapital zufließen. ${ }^{246}$ Wird hingegen die Kapitalsteuer zur Finanzierung öffentlicher Vorleistungen in Form des lokalen Produktionsfaktors $\mathrm{H}$ herangezogen, wäre es möglich, die Kapitalsteuersätze anzuheben, ohne daß mit einer Abwanderung gerechnet werden muß, weil durch die öffentlichen Vorleistungen die Kapitalproduktivität ansteigt. Je stärker die Privatgutskomponente von $\mathrm{H}$, desto stärker ausgeprägt wäre dabei der Gebührencharakter der Kapitalsteuer. ${ }^{247}$

Man könnte allerdings die Auffassung vertreten, daß eine Steuerbelastung des Kapitals, das der Effizienzbedingung lokaler Besteuerung 248 entspricht, den subzentralen Einheiten nicht die Deckung der Gesamtkosten der Bereitstellung von $\mathrm{H}$ ermöglicht, sofern das Infrastrukturangebot mit fallenden Durchschnittskosten produziert wird. So argumentiert Sinn:

"Bei Gutern, die unter fallenden Durchschnittskosten produziert werden, gibt es nicht nur auf privaten Mărkten ein ernsthaftes Problem. Auch der Wettbewerb zwischen unabhangigen Staaten steht vor einem Dilemma. Reine Äquivalenzsteuern, deren Sătze gerade den Grenzkosten der Nutzung des offentlichen Gutes entsprechen, ermöglichen es dem Staat nicht, seine Gesamtkosten zu decken, und verursachen ein Staatsdefizit. Zur Vermeidung des Defizits wäre ein hðherer Steuersatz nð̋tig, doch bei einem Steuersatz, der uber den Grenzkosten liegt, besteht stets ein Anreiz, die Konkurrenten durch Steuersenkungen zu unterbieten, weil dies zusătzliche 'Konsumenten' anlockt ... Der Versuch, zusătzliche Steuerzahler anzulocken, wird im Ergebnis nur zu Einnahmeverlusten aller Staaten fuhren. Überall gibt es ein fiskalisches Defizit aus der Bereitstellung offentlicher Infrastruktur, das entweder durch Steuern auf die immobilen Faktoren finanziert wird oder eine Unterversorgung mit offentlicher Infrastruktur impliziert."249

Offenbar geht Sinn davon aus, daß Wettbewerb um mobiles Kapital lokale Budgetdefizite mit sich bringe, die nur über die Besteuerung immobiler Faktoren gedeckt werden könnten, und daß die Belastung der immobilen Faktoren nicht nur (verteilungs-)politisch inakzeptabel sei, sondern zu einer dauerhaft ruinösen Konkurrenz führt. Bei näherer Betrachtung kann aber aus beiden Argumenten keine zentralisierte Bereitstellungsverantwortung abgeleitet werden:250

$242 \mathrm{Vgl}$. die Ausfuhrungen oben in Abschnitt C.II.2. des Kapitels, S. 93ff.

243 So etwa Boadway, R.W. (1992), S. 27.

244 Ähnlich auch Gordon, R.H. (1983), S. 582.

245 "The gains from consolidating jurisdictions by reducing tax competition must be balanced against the reduced ability of residents to sort according to tastes for public services." Hoyt, W.H. (1991), S. 124.

246 Vgl. Wildasin, D.E. (1988), S. 237.

247 Vgl. insbesondere McLure, C.E. (1986), S. 342f.; Oates, W.E./Schwab, R.M. (1991); Wellisch, D. (1995), S. $83 \mathrm{ff}$.

248 Siehe Bedingung (3.C.II.14) auf S. 106.

249 Sinn, H. $-W$. (1994), S. 30f.

250 Ausfuhrlich hierzu auch Fuest, C. (1995), S. $93 \mathrm{ff}$. 
Zunächst ist zu prüfen, unter welchen Bedingungen die Grenzkostenbesteuerung des Faktors Kapital zu lokalen Defiziten führt. Hierzu ist es zweckmäßig, nochmals auf die Kostenfunktion für produktive öffentliche Vorleistungen einzugehen. Gemäß $D=D(k, H)$ können steigende Skalenerträge in der Produktion und in der Nutzung der lokalen Infrastruktur vorliegen. Solange die Durchschnittskosten in der Produktion fallen, decken die marginalen Outputzuwächse infolge der Kapitalansiedlung nie die Kosten der öffentlichen Vorleistung. In der Tat entstehen hier Verluste, die zu Lasten der immobilen Faktoren gehen.

Allerdings spielen Skalenvorteile in der Produktion nur bei der Zuordnung von Durchführungskompetenzen, nicht jedoch für die Bereitstellungskompetenzen eine Rolle. Es ist deshalb für unsere Fragestellung unerheblich, ob mit zunehmendem Output des Kollektivgutes die Kosten je produzierter Mengeneinheit fallen oder ansteigen. Für die föderative Aufgabenzuweisung wäre die Argumentation von Sinn nur relevant, wenn Skalenerträge in der Nutzung der öffentlichen Infrastruktur zu den von ihm geschilderten Problemen führen.

$\mathrm{Zu}$ untersuchen ist deshalb der zweite Fall, der in Abbildung 3.8 dargestellt ist. Es wird angenommen, das Grenzprodukt des Kapitals nach Bereitstellung der öffentlichen Vorleistung im Gemeinwesen i verlaufe gemäß der eingezeichneten MPK-Linie. Die bundesstaatlich einheitliche Nettoverzinsung des Kapitals sei durch $r$ gegeben. Sofern die Zuwanderung von Kapital keine Ballungskosten erzeugt, ist die Allokation $\mathrm{k}_{1}$, bei der die marginale Kapitalproduktivität und der Nettozins identisch sind, effizient.

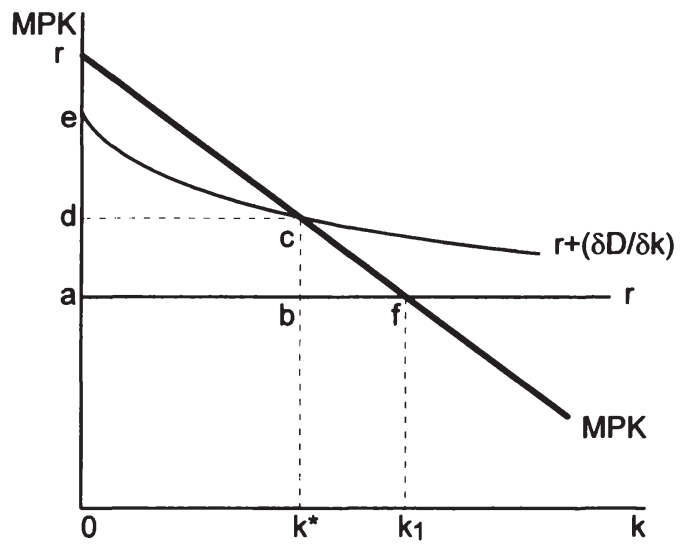

Abbildung 3.8: Ruinöse Konkurrenz bei Bereitstellung lokaler öffentlicher Vorleistungen? Quelle: Sinn, H.W. (1994), S. 32.

Angenommen sei nun, die Nutzung des Produktionsfaktors $\mathrm{H}$ verursache konstante marginale Überfüllungskosten in Höhe $\mathrm{ad}=\mathrm{bc}$. Ohne Internalisierungssteuer treten soziale Verluste in Höhe der Fläche bfc auf. Gemäß (3.C.II.14) ist mobiles Kapital so zu besteuern, daß der Kapitalsteuersatz $\tau^{\mathbf{k}}$ den marginalen Überfüllungskosten der Kapitalansiedlung entspricht. Das hieraus resultierende Steueraufkommen abcd entspricht genau der Höhe der Ballungskosten, die sozialen Kosten der Kapitalansiedlung sind voll internalisiert, und die Allokation $\mathbf{k}^{*}$ ist effizient. Obwohl der Faktor Kapital formal die Zahllast der Besteuerung trägt, liegt die 
ökonomische Last der Besteuerung bei den immobilen Faktoren, denn Kapital wandert aus der betrachteten Jurisdiktion ab, bis die Grenzproduktivität des Faktoreinsatzes in der lokalen Einheit so weit ansteigt, daß das Kapital die bundesweite Nettoverzinsung erbringt. Die Vorteilhaftigkeit der Kapitalbesteuerung für die immobilen Faktoren in i liegt darin, daß die Verringerung der Überfüllungskosten die Nutzeneinbuße durch den Sozialproduktrückgang in i übersteigt. 251

Das von Sinn angedeutete Problem ruinöser Konkurrenz tritt auf, wenn die marginalen Ballungskosten der Nutzung öffentlicher Infrastruktur durch den Faktor Kapital zwar positiv, jedoch abnehmend sind. Ein solcher Verlauf ist in Schaubild 3.8 eingezeichnet. ${ }^{252}$ Auch hier stellt $\mathbf{k}^{*}$ das allokative Optimum dar, und $\tau^{\mathbf{k}}=\mathrm{bc}$ bezeichnet den optimalen Kapitalsteuersatz. Das Steueraufkommen reicht aber nicht aus, um die Ballungskosten zu decken. Es verbleibt ein Verlust in Höhe von edc, der zu Lasten der immobilen Faktoren geht. Insgesamt gesehen scheint es sich aber bei dem hier betrachteten Fall um einen empirisch wenig relevanten Sonderfall zu handeln, denn es ist eher unwahrscheinlich, daß die marginalen Ballungskosten mit steigender Zahl von Unternehmensansiedlungen abnehmen.

Als Fazit kann deshalb festgehalten werden: Ursächlich für die postulierten Ineffizienzen des Steuerwettbewerbs ist regelmäßig die mangelnde Verknüpfung von Steuerbelastung und bereitgestellten Leistungen. ${ }^{253}$ Dezentrale Entscheidungen führen $\mathrm{zu}$ einer ineffizienten Faktorallokation, wenn die Gliedstaaten der Föderation über kein adäquates steuerpolitisches Instrumentarium verfügen. 254

\section{cc. Exkurs: Besteuerung nach dem Wohnsitzprinzip als Ersatz für Steuerharmonisierung?}

Manchmal wird auch der Vorschlag gemacht, Wettbewerb um mobiles Kapital durch den Übergang von der Quellenbesteuerung zur Besteuerung nach dem Wohnsitzprinzip zu unterbinden. ${ }^{255}$ Sind die Haushalte als Kapitaleigner immobil, können sie ihr Kapital im gesamten Bundesstaat investieren, einer Besteuerung in der Heimatjurisdiktion aber nicht ausweichen. Kapital fließt stets in jene Region, in der die höchsten Brutto-Renditen erzielt werden ${ }^{256}$, die räumliche Kapitalallokation ist effizient und der Steuerwettbewerb entfällt. ${ }^{257}$

Dagegen ist einzuwenden, daß zwar bei einer Besteuerung nach dem Wohnsitzprinzip Steuersatzdifferenzen keine Kapitalreallokation erzeugen, daß aber unterschiedliche

251 Es sei unterstellt, das Steueraufkommen abcd werde in Form eines Pauschaltransfers an die immobilen Faktoren weitergeleitet.

252 Sinn, H.-W. (1994) interpretiert die in Abbildung 3.8 (dort Abb. 2 auf S. 32) eingezeichnete, abwärts geneigte Kurve als Summe aus Kapitalzins und den so von ihm bezeichneten "Grenzkosten der Infrastruktur".

253 McLure, C.M. (1986), S. 342 fordert daher: "Taxes levied by state and local governments could - and should - reflect more closely benefits received by taxpayers.". Vgl. auch Teutemann, M. (1992), S. 51.

254 Vgl. Wellisch, D. (1995), S. 73.

255 Siehe z.B. Giovannini, A. (1989); Musgrave, P.B./Musgrave, R.A. (1990), S. 74. Wahrend beim Quellenprinzip die Faktoreinkommen ohne Berucksichtigung des Wohnsitzes der Einkommensempfanger in der Jurisdiktion besteuert werden, in der die Faktoreinkommen entstehen, werden die Faktorertrăge beim Wohnsitzprinzip grundsătzlich der Steuer unterworfen, die in der Wohnjurisdiktion gilt, unabhăngig davon, ob die Ertrăge innnerhalb oder außerhalb des Gemeinwesens erzielt werden. Man spricht beim Wohnsitzprinzip daher auch vom Universalprinzip. Vgl. Peffekoven, $R$. (1983), S. $241 \mathrm{ff}$.

256 Vgl. Sinn, H.W. (1990), S. 497f.; Razin, A./Sadka, E. (1991), S. 75.

257 Musgrave und Musgrave weisen allerdings darauf hin, daß bei Haushaltsmobilităt die oben erörterten Probleme wieder auftauchen. Musgrave, P.B./Musgrave, R.A. (1990), S. 75. 
Abschreibungssätze die Besteuerungsbasis und damit die Kapitalrendite beeinflussen. 258 Folglich ist das Wohnsitzprinzip nur allokationsneutral, wenn alle anderen steuerlichen Aktionsparameter völlig anreizneutral ausgestaltet sind.259 Damit erfordert das Wohnsitzprinzip die Harmonisierung der Bemessungsgrundlagen. 260

Damit ist allerdings der Mangel verbunden, daß bei einer Abkehr vom Quellenprinzip keine Äquivalenz von Kapitalbesteuerung und produktiven Infrastrukturleistungen hergestellt werden kann. Öffentliche Vorleistungen werden auch von Kapitaleigentümern finanziert, die selbst nicht die Vorteile der lokalen Infrastruktur nutzen, da sie ihr Kapital in einer fremden Jurisdiktion investiert haben. Die subzentralen Einheiten haben geringere Anreize, öffentliche Vorleistungen bereitzustellen, denn die Kapitalerträge fließen unversteuert in andere Jurisdiktionen.

Zwar könnte man dem aus dem Weg gehen, wenn die Kapitalerträge in der Quellenregion besteuert werden und die Steuer in der Heimatjurisdiktion angerechnet wird. 261 Aber dies hätte wiederum strategisches Verhalten der Jurisdiktionen zur Folge: Sie könnten nämlich durch hohe Kapitalsteuersätze die Steuerlast auf die Regionen überwälzen, in denen die Kapitaleigentümer ihren Wohnsitz haben. Man spricht von "Steuerexport durch Offset"262, der den lokalen Einheiten eine Ausweitung des Kollektivgüterangebots ermöglicht, ohne die eigenen Bürger zu belasten. Würden die subzentralen Einheiten hingegen davon ausgehen, $\mathrm{da} ß$ die in ihrem Hoheitsgebiet erwirtschafteten Kapitalerträge am Wohnsitz des Kapitaleigners unversteuert bleiben ${ }^{263}$, bestünde der Anreiz, die Kapitalsteuersätze zu senken, um mobiles Kapital zu attrahieren. De facto käme es zur Rückkehr zum Quellenprinzip. ${ }^{264}$ Zusammenfassend betrachtet scheint daher der Übergang zum Wohnsitzprinzip keine adäquate Lösung für die konstatierten Probleme zu bieten.

\section{e. Die Implikationen für die Zuordnung der Bereitstellungskompetenzen}

Zwar mögen die Tiebout'schen Modellannahmen äußerst restriktiv erscheinen: für den kleinräumigen Zusammenhang ist ihnen Plausibilität nicht abzusprechen. Voraussetzung für die Effizienz des Tiebout-Mechanismus ist, daß die lokalen Einheiten mit einem geeigneten steuerlichen Instrumentarium ausgestattet sind.265 Dezentrale Bereitstellungskompetenzen für lokale Kollektivgüter führen dann bei Mobilität von Arbeit und Kapital tendenziell zu einer Äquivalenzbesteuerung. Ineffizienzen wie die räumliche Fehlallokation mobiler Ressourcen

258 Siehe hierzu grundlegend: Jorgenson, D.W. (1963); Boadway, R.W./Bruce, N. (1979).

259 Vgl. Sinn, H.-W. (1990), S. 497f. oder Fuest, C. (1995), S. 68ff.

260 Vgl. Sinn, H.W. (1990), S. 500.

261 Vgl. Peffekoven, R. (1975), S. 17ff.

262 Peffekoven, R. (1975), S. 17. Siehe auch Slemrod, J. (1990), S. $25 f$.

263 Z.B., weil die in der fremden Gebietskorperschaft erzielten Kapitalerträge in der Wohnsitzgemeinde nicht deklariert werden.

$264 \mathrm{Vgl}$. auch Genser, B./Haufler, A. (1990), S. 318. Der Übergang zu einem funktionsfahigen Wohnsitzprinzip ist folglich mit einer Ausweitung der Finanzverwaltungsaktivităten verbunden. Ein weiterer Aspekt, der gegen das Wohnsitzprinzip spricht, sind daher die erheblichen Verwaltungsmehraufwendungen. Vgl. Sinn, H.W. (1990), S. 499; Razin, A./Sadka, E. (1990), S. 163. Gleiches gilt auch für den Übergang von der Ursprungslandbesteuerung zum Bestimmungslandprinzip bei der Guterbesteuerung. Neben den administrativen Hindernissen, die solchen Regelungen entgegenstehen, kønnten durch legale Steuerumgehungsmøglichkeiten die beabsichtigten Wirkungen des Bestimmungslandprinzips unterlaufen werden. Vgl. etwa Sinn, H. $-W$. (1990), S. 432.

265 Vgl. Wellisch, D. (1995), S. 66ff. 
oder die suboptimale Bereitstellung lokaler Kollektivgüter bei Steuerwettbewerb treten auf, wenn kein Zusammenhang von Nutzen aus bereitgestellter Leistung und Finanzierungslast besteht. 266

Wanderungen von Arbeit und Kapital zwischen den lokalen Jurisdiktionen können somit ein wichtiges Instrument der Präferenzoffenbarung sein. Geht man davon aus, daß Kapital im gesamten Bundesstaat völlig mobil ist, die Mobilitätsbereitschaft der Bürger aber mit zunehmender Entfernung abnimmt, ist für die Präferenzoffenbarung durch Migrationen der räumliche Aspekt des Staatsaufbaus wichtig. Je stärker dezentralisiert das Staatswesen organisiert ist, um so geringer sind die Mobilitätskosten und um so besser können die Haushalte durch Wanderungen ihre Präferenzen für lokale öffentliche Güter zum Ausdruck bringen. ${ }^{267}$ Zwar dürfte der Mechanismus interregionaler Wanderungen nicht perfekt sein, aber, wie Tiebout anmerkt,

"... those who compare the reality described by this model with the reality of the competitive model ... may find that local government represents a sector where the allocation of public goods (as a reflection of the preferences of the population) need not take a back seat to the private sector." 268

\section{Ein Zwischenfazit}

Ausgangspunkt der Diskussion um die Zuordnung allokativer Bereitstellungskompetenzen ist die Feststellung, daß Kollektivgüter unterschiedliche territoriale Nutzenstreuungen aufweisen, so daß durch die Bereitstellung verschieden große personale Nutzerkreise betroffen sind. Es wird argumentiert, daß effiziente Allokationsentscheidungen die Übereinstimmung von Nutzern, Kostenträgern und Entscheidern voraussetzen (Prinzip fiskalischer Äquivalenz).

Indessen stellt sich insbesondere bei Gütern mit großen Nutzerkreisen das Problem, daß aufgrund wachsender intrakollektiver Heterogenität der Bevölkerung die Zuordnung der Kompetenzen an eine zentrale Bereitstellungseinheit mit steigenden Frustrationskosten verbunden ist. Daraus wird abgeleitet, daß die höheren Kosten der Präferenzoffenbarung und -erkundung in personell großen Einheiten die Vorteile einer Zentralisierung nicht unerheblich schmälern.

In diesem Zusammenhang ist auf die Vorteile horizontaler Verflechtungen zu verweisen. Durch interjurisdiktionelle Kooperation kann fiskalische Äquivalenz auch ohne die Nachteile einer Zentralisierung auf dem Wege interkollektiver Verhandlungen erreicht werden. Die dabei anfallenden externen Koordinationskosten limitieren allerdings die Vorteile der Dezentralisierung. Vertikale Verflechtungen, also die Beteiligung übergeordneter Einheiten an den Internalisierungsverhandlungen, können zwar zu einer Verringerung externer Koordinationskoten führen, sie sind jedoch mit einem Anstieg der Informations- bzw. Frustrationskosten verbunden.

266 Hier soll nicht behauptet werden, auf lokaler Ebene sei eine vollige Umsetzung des Äquivalenzprinzips moglich. Aber in lokalen Gemeinwesen dürten die Voraussetzungen fur eine Besteuerung nach dem Äquivalenzgedanken aufgrund bestehender Informationsvorteile eher vorliegen als auf der zentralen Ebene.

$267 \mathrm{Vgl}$. Breton, A./Scott, A. (1978), S. 56.

268 Tiebout, C.M. (1956), S. 424. (Hervorhebung im Original). 
Schließlich wird ein weiterer Vorteil dezentraler Kompetenzen darin gesehen, daß die Bürger durch Wanderungen ihre Präferenzen für die Kollektivgutangebote der lokalen Gemeinwesen offenbaren. Während ältere Arbeiten der Finanztheorie den Wanderungsmechanismus eher skeptisch beurteilen, da sie in Migrationen die Quelle von Ineffizienzen sehen, betonen neuere Ansätze, daß die postulierten Mängel des Tiebout-Mechanismus in erster Linie auf die unzureichende Finanzautonomie der lokalen Gemeinwesen zurückzuführen sind. Wird den subzentralen Einheiten ein adäquates einnahmenpolitisches Instrumentarium zugestanden, so die These, können Wanderungen zwischen den lokalen Gebietskörperschaften die Effizienz dezentraler Bereitstellungskompetenzen für lokal begrenzte Kollektivgüter verbessern. Da die Mobilitätskosten mit zunehmender räumlicher Distanz wachsen, würde jede Zuweisung von Bereitstellungskompetenzen an höhere Ebenen die möglichen Vorteile der "Abstimmung mit den Füßen" beschränken.

Mit Hilfe dieser Elemente wird in Abschnitt VI dieses Kapitels ein Modell der 'optimalen' föderativen Aufgabenverteilung entwickelt. Zuvor soll jedoch in den Abschnitten III und IV gezeigt werden, daß aus der Perspektive der Theorie des Fiskalföderalismus auch die Zuordnung stabilisierungs- und redistributionspolitischer Kompetenzen prinzipiell denselben Kriterien folgt. In Abschnitt $\mathrm{V}$ werden sodann die Implikationen für das jeweilige adäquate einnahmenpolitische Instrumentarium diskutiert.

\section{Die Zuordnung der Stabilisierungsfunktion}

\section{Die geldpolitischen Zuständigkeiten}

Ebenso wie allokationspolitisch motivierte Staatstätigkeiten lassen sich stabilisierungspolitische Eingriffe des Staates mit der Notwendigkeit hoheitlichen Zwangs zur Überwindung sozialer Dilemmata begründen. Wohl kaum eine Frage wird in der Wirtschaftswissenschaft so kontrovers diskutiert wie die nach dem geeigneten geld- und/oder finanzpolitischen Ansatzpunkt zur Korrektur wirtschaftlicher Fehlentwicklungen. Obwohl es fast durchweg Übereinstimmung hinsichtlich der Interpretation und der Operationalisierung der makropolitischen Hauptziele Vollbeschäftigung und Preisniveaustabilität ${ }^{269}$ gibt, herrscht ebenso weitgehende Uneinigkeit über die zur Erreichung dieser Ziele geeigneten Strategien. ${ }^{270}$ Für die hier zu

$269 \mathrm{Da}$ internationale Aspekte und damit auch Zielvorstellungen bezuglich des außenwirtschaftlichen Gleichgewichts ausgeklammert bleiben, werden nur die Ziele Vollbeschăftigung und Preisniveaustabilităt betrachtet. Das im StabWG angefuhrte Ziel des stetigen und angemessenen Wirtschaftswachstums wird hier als dynamisches Allokationsziel interpretiert. Vgl. Musgrave, R.A. (1959/1969), S. 354ff.

270 Stark vereinfachend lassen sich der angebotsorientierte und der nachfrageorientierte Ansatz unterscheiden. Angebotsorientierte Politik ist vor allem eine ordnungspolitische Strategie, die grundsătzlich langfristig und auf die Stărkung der Marktkrăfte ausgerichtet ist. Basis dieser Konzeption ist die Vorstellung von der prinzipiell inhärenten Stabilităt des marktwirtschaftlichen Systems. Dementsprechend wird der Geldpolitik die Aufgabe zugewiesen, durch eine Politik der Verstetigung die Rahmenbedingungen fur ein störungsfreies Wachstum der Volkswirtschaft zu schaffen. Angebotsorientierte Finanzpolitik ist vor allem Konsolidierungspolitik mit der Zielsetzung, negative Anreize auf den privatwirtschaftlichen Sektor zu verringern und dort Wachstumskrafte freizusetzen.

Der nachfrageorientierte Ansatz beruht dagegen auf der Keynes'schen These, daß das marktwirtschaftliche System instabil sei. Angesichts auftretender Ungleichgewichte zwischen gesamtwirtschaftlicher Nachfrage und Angebot sei es Aufgabe des Staates, konjunkturbedingten Schwankungen durch eine aktive nachfrageorientierte Geld- und Fiskalpolitik entgegenzusteuern. Kurze Überblicke uber die unterschiedlichen Konzeptionen findet man bei Ramser, H.J. (1981) und Landmann, O. (1982). 
beantwortende Frage nach der optimalen Trägerebene für stabilisierungspolitische Zuständigkeiten ist diese Diskussion jedoch nicht maßgeblich ${ }^{271}$, sie soll deshalb auch nicht vertieft werden.

Üblicherweise wird in der Theorie des Fiscal Federalism von der Prämisse eines einheitlichen Währungsraums (mit einem einheitlichen Geld als gesetzlichem Zahlungsmittel) ausgegangen. ${ }^{272}$ Aufgrund dieser Annahme ist die Zentralisierung der geldpolitischen Zuständigkeiten zwingend erforderlich. Betrachtet sei z.B. ein Bundesstaat Z, bestehend aus zwei Gliedstaaten A und B. Z bilde einen einheitlichen Währungsraum, geldpolitische Kompetenzen seien aber dezentral angesiedelt. Eine solche Konstellation ermöglicht es beiden Jurisdiktionen, Geld in Umlauf zu bringen, das zu Käufen in der jeweils anderen Gebietskörperschaft verwendet wird, was unkontrollierbare inflationäre Prozesse in der gesamten Volkswirtschaft $\mathrm{Z}$ zur Folge hätte. 273

Gleichwohl vermag diese Argumentation nur dann zu überzeugen, wenn die Prämisse des einheitlichen Währungsgebiets akzeptiert wird. Nun zeigt aber gerade die Theorie optimaler Währungsräume ${ }^{274}$, daß der Geltungsbereich einer Einheitswährung keineswegs zwingend mit dem Raum der ökonomischen Interdependenz, also dem in Abschnitt B dieses Kapitels bestimmten optimalen Rechtsraum, identisch ist. So wird vielfach die Vermutung geäußert, daß optimaler Währungsraum und optimaler Allokationsraum nicht notwendigerweise kongruent sein müssen. ${ }^{275}$ Zwar ist die Zentralisierung der Geldpolitik logische Konsequenz des einheitlichen Währungsgebiets; es spricht aber grundsätzlich nichts dagegen, daß sich der einheitliche Rechtsraum aus mehreren Währungsräumen zusammensetzt, für die entsprechend eigene geldpolitische Verantwortlichkeiten existieren.

Hierbei handelt es sich jedoch nicht um ein Problem der finanzpolitischen Kompetenzverteilung, dieser Frage soll deshalb im folgenden nicht weiter nachgangen werden. Stattdessen sei angenommen, die unstrittigen Transaktionskostenvorteile einer einheitlichen Währung würden die ebenso unstrittigen Vorteile eines dezentralisierten Systems mit flexiblen Wechselkursen überkompensieren. Für die Zuordnung finanzpolitischer Zuständigkeiten im Dienste des Stabilisierungsziels sind damit drei institutionelle Restriktionen vorgegeben. Die Zentralisierung geldpolitischer Verantwortlichkeiten 276 impliziert,

- daß die Verfolgung des Preisniveaustabilitätsziels primär zur Aufgabe der Zentralebene wird und lokale Stabilisierungspolitik v.a. der Erreichung beschäftigungspolitischer Ziele dient,

- daß subzentrale Einheiten bei der Verfolgung von Beschäftigungszielen einen optimalen 'policy mix' von Geld- und Finanzpolitik weder anstreben noch realisieren können und

271 In die Entscheidungskompetenzen einer staatlichen Einheit fallt auch die Kompetenz, uber die 'richtige' Stabilisierungskonzeption zu befinden. So auch Caesar, R. (1990), S. 323.

272 Vgl. etwa Oates, W.E. (1977b), S. 298.

273 Vgl. Oates, W.E. (1972), S. 4 und (1968), S. 38.

$274 \mathrm{Zu}$ den Theorien optimaler Wahrungsräume siehe etwa den Überblick bei Menkhoff, L./Sell, F.L. (1991).

275 Vgl. Luckenbach, H. (1991), S. 422 und Vosgerau, H.-J. (1987), S. 134.

276 Die weitergehende Frage, ob die geldpolitischen Kompetenzen einer autonomen Fachinstitution oder einer von der allgemeinen Politik abhăngigen Institution ubertragen werden sollten, soll hier nicht weiter erörtert werden, weil das kein Problem der vertikalen, sondern der horizontalen Gewaltenteilung ist. Siehe dazu etwa Caesar, $R$. (1980). 
- daß ihnen auch das stabilisierungspolitische Instrument der Wechselkurspolitik nicht zur Verfügung steht.

Vor diesem Hintergrund soll überprüft werden, welche Argumente für und gegen eine Zentralisierung der finanzpolitischen Stabilisierungskompetenzen sprechen.

\section{Zentrale oder dezentrale finanzpolitische Stabilisierungskompetenzen?}

\section{a. Argumente für dezentrale finanzpolitische Stabilisierungskompetenzen}

Ein erstes Argument für dezentrale Kompetenzen ist in einer gedanklichen Übertragung des Dezentralisierungstheorems zu finden. A priori besteht nämlich kein Grund zur Annahme, daß die Präferenzen der Bewohner verschiedener Regionen hinsichtlich der Erreichung von Stabilisierungszielen gleich sind. Bürger einer Jurisdiktion können starke Präferenzen für beschäftigungspolitische Ziele haben, die in anderen Regionen weniger präferiert werden. Unterstellt man die Gültigkeit des Phillips-Kurven-Zusammenhangs ${ }^{277}$, so ist anzunehmen, daß die Bewohner der Gliedstaaten unterschiedliche Kombinationen von Inflationsrate und Arbeitslosenquote realisiert sehen wollen. 278 Des weiteren wird für dezentrale Kompetenzen vorgebracht, in Analogie zum Tiebout-Ansatz könnten die Individuen durch Wanderungen ihre Präferenzen für unterschiedliche Stabilisierungspolitiken offenbaren, bzw. erfolglose Aktivitäten lokaler Einheiten durch Abwanderung sanktionieren. 279

Als Hauptargument gegen zentrale Stabilisierungspolitik und für lokale oder regionale Kompetenzen wird angeführt, daß makroökonomische Fehlentwicklungen sich in der Regel nicht symmetrisch auf alle volkswirtschaftlichen Regionen verteilen. Aufgrund struktureller Unterschiede sind einige Regionen krisenanfälliger als andere. Externe Schocks lösen deshalb häufig asymmetrische Wirkungen aus, die für eine Region positiv wirken und für andere Regionen negativ. Gramlich formuliert das dabei entstehende Problem wie folgt: "In the presence of such 'zero sum' shocks, it is hard to know what a national stabilization authority would do, increase or decrease fiscal stimulus?"280 Unterschiede in den wirtschaftlichen Bedingungen der Regionen einer Volkswirtschaft machen deshalb auch regionsspezifische Stabilisierungsmaßnahmen notwendig. ${ }^{281}$

Diesen Überlegungen zufolge existiert auch bei der Stabilisierungspolitik ein Vorteil der Dezentralisierung von Entscheidungskompetenzen. ${ }^{282}$ Stabilisierungspolitik wäre - zumindest partiell - als ein lokales öffentliches Gut anzusehen, das nach dem Prinzip fiskalischer Äquivalenz auf lokaler Ebene anzubieten wäre.

277 Siehe hierzu insbesondere Gordon, R.J. (1982) und (1985).

278 Vgl. Breton, A./Scott, A. (1978), S. 138f.; King, D.N. (1984), S. 37.

279 Vgl. Breton, A. (1978), S. 50f.; Breton, A.Scott, A. (1978), S. $138 \mathrm{f}$.

280 Gramlich, E.M. (1987), S. 310.

281 Vgl. Oates, W.E. (1977b), S. 303.

282 "In this way, it could be hoped that variations in tastes regarding stabilisation might be met, at least in some degree, in the same way that subcentral authorities can seek to cater for variations in tastes for local public goods ..." King, D.N. (1984), S. 37. Vgl. auch Lang, E. (1992), S. 9. 


\section{b. Argumente für zentrale finanzpolitische Stabilisierungskompetenzen}

Traditionell wird dennoch die Verantwortlichkeit für eine an makroökonomischen Stabilisierungszielen orientierte Finanzpolitik der Zentralebene zugewiesen. ${ }^{283}$ Zentralisierte Lösungen seien erforderlich, so wird vorgebracht, weil das Erfordernis des zentralen Geldangebotsmonopols die monetäre Alimentierung finanzpolitischer Aktivitäten auf lokaler Ebene erschwere und weil aufgrund der Offenheit subzentraler Jurisdiktionen spillover-Effekte lokaler Stabilitätspolitik vorliegen, die eine optimale Bereitstellung des Gutes wirtschaftliche Stabilităt verhindern würden. ${ }^{284}$

Lokale Jurisdiktionen sind offene Volkswirtschaften; Güter- und Faktorströme zwischen den lokalen Einheiten bedingen eine hohe ökonomische Interdependenz der Einheiten. ${ }^{285}$ Die engen Verflechtungen haben zur Folge, daß die Wirtschaftspolitik einer Jurisdiktion verstärkt überlokale Wirkungen entfaltet. Infolge der ökonomischen Verflechtung der subnationalen Einheiten haben die lokalen Ausgabenmultiplikatoren niedrige Werte. Je höher die marginalen Importneigungen der Bürger einer Jurisdiktion sind, desto geringer fallen aufgrund von Versickerungseffekten die intrajurisdiktionellen Wirkungen einer antizyklisch konzipierten lokalen Fiskalpolitik aus. 286 Gleichzeitig kommen Anstrengungen zur Überwindung einer Rezession durch eine lokale Gebietskörperschaft $\mathrm{zu}$ großen Teilen den anderen Jurisdiktionen zugute; es werden positive spillover-Effekte produziert.

Daher wird gefolgert, daß die subnationalen Einheiten nur geringe Anreize hätten, eigene Beiträge zur Stabilisierung der wirtschaftlichen Entwicklung der Volkswirtschaft zu leisten. ${ }^{287}$ Die Einnahme von Trittbrettfahrer-Haltungen sei auf kurze Sicht die dominante Strategie der Entscheidungsträger. Aus gesamtgesellschaftlicher Sicht werde deshalb durch die lokalen Entscheidungsträger zu wenig Stabilisierungspolitik angeboten. ${ }^{288}$

Überdies wird nicht nur die Gefahr gesehen, daß subzentrale Zuständigkeiten bei symmetrischen Schocks $\mathrm{zu}$ stabilisierungspolitischem Freifahrerverhalten führen, sondern es wird betont, daß sich mit steigender Größe eines Gemeinwesens prinzipiell die Chancen einer erfolgreichen, eigenständigen Konjunkturpolitik verbessern. ${ }^{289}$ Damit verstärkt sich die gegenseitige Abhängigkeit der Politikwirkungen bei der Verfolgung konjunkturpolitischer Ziele. ${ }^{290}$ Nicht-koordinierte Strategien subzentraler Regierungen könnten folglich unerwünschte Resultate zeitigen. ${ }^{291}$

283 Siehe etwa Oates, W.E. (1968), S. 44; King, D.N. (1984), S. 37ff.

284 Vgl. etwa Oates, W.E. (1990), S. 43f.

285 Zur Unterscheidung von "Offenheit" und "Interdependenz" siehe Cooper, R.N. (1985), S. 1198f.

286 Umgekehrt sind in Boomphasen zur Dämpfung der Nachfrage kontraktive fiskalpolitische Maßnahmen erforderlich, die ebenfalls externe Nutzen stiften. Allerdings können Versickerungseffekte durch gezieite Vergabe staatlicher Aufträge an Kollektivmitglieder zumindest begrenzt werden. Vgl. Oates, W.E. (1968), S. $41 \mathrm{f}$.

287 Siehe in diesem Zusammenhang auch Hansmeyer, K.-H./Mackscheidt, K. (1973), S. 136f.; Kromphardt, J./ Brückmann, F. (1977), S. 135; Hanusch, H. (1978), S. 103.

$288 \mathrm{Vgl}$. Head, J.G. (1962). Siehe auch Kock, H. (1975), S. 56ff. und Huppertz, P.H. (1977), S. 150ff.

289 Vgl. Thöni, E. (1986), S. 55.

290 Siehe dazu fur den internationalen Zusammenhang etwa den Überblick bei Cooper, R.N. (1985), S. 1198ff. Die Interdependenzen sind im interregionalen Kontext eher noch verstärkt.

291 Vgl. King, D.N. (1984), S. 39f. 
Negative externe Effekte treten z.B. auf, wenn defizitfinanzierte Ausgabenerhöhungen eines Gliedstaates zu einem Zinsanstieg führen, der sich bei hoher Kapitalmobilität auf die anderen Gliedstaaten überträgt. Dort kann es zu einem unerwünschten Nachfragerückgang kommen, der die expansiven Wirkungen des spillover-Effektes überkompensiert. ${ }^{292}$ In verschiedenen modelltheoretischen Analysen durch Cooper, Hamada und anderen wurde gezeigt, daß ohne eine Koordination der finanzpolitischen Aktivitäten weder bei positiven noch bei negativen spillovers eine wohlfahrtsoptimale subzentrale Fiskalpolitik erwartet werden kann. ${ }^{293}$

Verschiedentlich wird zwar argumentiert, daß makroökonomische spillover-Effekte der Konjunkturpolitik subzentraler Einheiten über die Märkte entstehen und deshalb als pekuniäre Externalitäten anzusehen seien. Dies hätte zur Konsequenz, daß sie für die assignment-Diskussion irrelevant sind. 294 Dagegen ist aber einzuwenden, daß es für Güter wie Vollbeschäftigung und Preisniveaustabilität keine Märkte gibt, so daß die Unterscheidung von pekuniären und technologischen Externalitäten in diesem Zusammenhang wenig sinnvoll ist. ${ }^{295}$ Entscheidend ist, daß von den Aktivitäten regionaler Einheiten unerwünschte Nebeneffekte auf andere Jurisdiktionen ausgehen können. Der hier verwendete Externalitätenbegriff ist insofern eher pragmatischer Art und entspricht vielmehr den im Zusammenhang mit dem Steuerwettbewerb dargestellten fiskalischen Externalitäten. ${ }^{296}$

Als weiteres Argument gegen dezentrale Verantwortlichkeiten wird angeführt, den lokalen Einheiten könne eine Stabilisierung der Einkommensentwicklung selbst dann nicht gelingen, wenn es sich bei den Fehlentwicklungen nicht um symmetrische, sondern um asymmetrische Schocks handle, die nur die einzelnen Regionen selbst betreffen. Probleme entstehen für lokale Einheiten z.B. bei der Defizitfinanzierung konjunkturpolitischer Programme, denn je kleiner eine Jurisdiktion sei, desto geringer sei ihre Kreditwürdigkeit. ${ }^{297}$ Außerdem sind lokale Defizite - im Gegensatz zur nationalen Verschuldung - überwiegend als externe Verschuldung zu qualifizieren. 298 Daher finden bei der Rückzahlung der Kredite Realtransfers an Gebietsfremde statt, die Last der stabilisierungspolitischen Maßnahmen verbleibt bei den Bürgern der stabilisierungspolitisch aktiven Region auf subzentraler Ebene. ${ }^{299}$ Folglich ergibt sich ein geringerer Anreiz zu konjunkturgerechtem Verhalten der lokalen Entscheidungsträger.

Hinzu kommt, daß eine Jurisdiktion, die kontraktive Maßnahmen zur Stabilisierung der Konjunktur ergreift, für die privaten Wirtschaftssubjekte weniger attraktiv ist. Es müsse daher damit gerechnet werden, daß mobile Arbeit, und in noch größerem Maße der Faktor Kapital, gemäß dem neoricardianischen Äquivalenztheorem ${ }^{300}$ die zukünftigen Steuerbelastungen antizipiert und deshalb abwandert. Damit wäre die Gefahr verbunden, daß sich die ungünstige

292 Vgl. z.B. Reszat, B. (1986), S. 269.

293 Vgl. Cooper, R.N. (1985), S. 1217; Hamada, K. (1985); Reszat, B. (1986); Herrmann, A. u.a. (1992).

294 Siehe Vaubel, $R$. (1980), S. 14ff.

295 Vgl. Caesar, R. (1990), S. 326f.

296 Vgl. Caesar, R. (1990), S. 329.

297 Vgl. Inman, R.P./Rubinfield, D.L. (1992), S. 655; Walsh, C. (1993), S. 46. Zu weiteren okonomischen Grenzen lokaler Verschuldung siehe Carlberg, M. (1990).

$298 \mathrm{Vgl}$. Nowotny, E. (1979), S. 165ff. Angesichts der zunehmenden Internationalisierung der Kapitalmärkte ist allerdings diese These sicher nicht mehr uneingeschränkt gultig, vgl. Gramlich, E.M. (1987), S. 310.

299 Vgl. Oates, W.E. (1968), S. 43.

300 Siehe dazu Barro, R.J. (1974). 
regionale wirtschaftliche Entwicklung weiter verschärft. ${ }^{301}$ Auf zentraler Ebene verteilen sich hingegen die künftigen Belastungen auf alle Gliedstaaten der Föderation, so daß gezielte finanzpolitische Fördermaßnahmen für eine Region nicht von einer drohenden Abwanderung konterkariert werden.

Allerdings ist die Gültigkeit des neoricardianischen Äquivalenztheorems an die Bedingungen vollkommener Information und Ultra-Rationalität der Wirtschaftssubjekte gebunden. Berthold zieht deshalb diese Argumentation für zentralisierte Zuständigkeiten in Zweifel, denn wenn das Äquivalenztheorem weder auf subzentraler noch auf zentraler Ebene gilt, ist es nicht erforderlich, die stabilitätspolitischen Aktivitäten auf die Zentralebene zu verlagern. ${ }^{302}$

\section{Die Implikationen für die Zuordnung der Bereitstellungskompetenzen}

Spezifisch regionale Eigenheiten und Präferenzunterschiede lassen Vorteile dezentraler Entscheidungskompetenzen vermuten. Hier kommt einerseits die informationsökonomische Begründung zum Tragen ${ }^{303}$, andererseits erhöhen sich mit steigendem Zentralisierungsgrad auch die Wanderungskosten der Individuen zur Offenbarung ihrer stabilisierungspolitischen Präferenzen.

Dem stehen die mangelnden Anreize und Möglichkeiten subzentraler Einheiten für eigene stabilisierungspolitische Aktivitäten gegenüber. Die Nutzenreichweite des Gutes 'ökonomische Stabilität' erstreckt sich meist auf größere Regionen, wenn nicht auf den ganzen Bundesstaat. Folglich entspricht die optimale personelle Größe stabilisierungspolitischer Clubs wohl der gesamten Staatsbevölkerung. Nach dem Prinzip fiskalischer Äquivalenz spricht dies für eine stärker zentralisierte Aufgabenzuweisung. 304

Marktliche Transmissionsmechanismen können bewirken, daß für einen Gliedstaat positive $\mathrm{Maßnahmen} \mathrm{sich} \mathrm{auf} \mathrm{die} \mathrm{Zielerreichung} \mathrm{anderer} \mathrm{Jurisdiktionen} \mathrm{negativ} \mathrm{auswirken.} \mathrm{Erfolgt}$ keine Koordination der subzentralen Finanzpolitiken, kann es zu einem nicht nur den eigenen, sondern auch den gemeinsamen Interessen zuwiderlaufenden Maßnahmeneinsatz kommen. Eine Abstimmung der stabilisierungspolitischen Aktivitäten ist dann unabdingbar.

Analog zur Allokationsfunktion können die anfallenden Koordinationskosten ein Hindernis für das Zustandekommen aufeinander abgestimmter Maßnahmen sein. Berücksichtigt man, daß chancenreiche Stabilisierungspolitik nur größeren Einheiten möglich ist ${ }^{305}$, darf vermutet werden, daß die Kooperationshemmnisse infolge externer Koordinationskosten tendenziell nicht so stark ins Gewicht fallen. Eine Koordinationslösung hätte gegenüber einer rein zentralen Verantwortlichkeit auch den Vorteil, daß bei den interkollektiven Verhandlungen Präferenzunterschiede stärker berücksichtigt werden können.

Die Einschaltung einer zentralen Einheit wird erst erforderlich, wenn eine Kooperation nicht zustande kommt. Doch selbst dann ist ein zentrales Stabilisierungsbudget nicht zwingend

301 Vgl. King, D.N. (1984), S. 38 oder Berthold, N. (1993), S. $163 f$.

302 Vgl. Berthold, N. (1993), S. 163f.

303 Vgl. auch Walsh, C. (1993), S. 47.

304 Oates zieht daher den Schluß, "... that the primary responsibility for the exercise of countercyclical policy must rest with the central government." Oates, W.E. (1990), S. 43.

305 Es macht schließlich keinen Sinn, einer lokalen Einheit, die aufgrund ihrer beschrankten Ressourcen uberhaupt nicht in der Lage ist, Konjunkturpolitik zu betreiben, konjunkturpolitische Kompetenzen zuzuweisen. Koordinationswilligkeit setzt Koordinationsfähigkeit voraus; vgl. Lang, E. (1992), S. 12. 
erforderlich. 306 Die Bündelung finanzpolitischer Stabilisierungsaktivitäten der subnationalen Ebenen kann über bindende Budgetvorschriften, deren Einhaltung durch die Zentrale kontrolliert wird, erreicht werden. Darüber hinaus kann eine übergeordnete Jurisdiktion durch Stabilisierungszuweisungen ${ }^{307}$ eine Internalisierung der externen Effekte vornehmen. Auch für die Stabilisierungsfunktion gilt also, daß eine Zentralisierung der Aufgabenkompetenzen lediglich notwendig ist, wenn auf dem Wege der Kooperation der Jurisdiktionen keine akzeptablen Ergebnisse zustandekommen und die Wohlfahrtsverluste dezentraler Bereitstellung die externen Koordinationskosten übersteigen.

\section{Die Zuordnung der Redistributionsfunktion}

\section{Interpersonale und interregionale Umverteilungsziele}

In der finanzwissenschaftlichen Literatur zur Zuordnung verteilungspolitischer Zuständigkeiten im Staat werden Ausgleichsziele von zwei verschiedenen Standpunkten aus diskutiert. 308 Zum einen geht es um das Problem, die für die Aufgabe der interpersonalen Umverteilung geeignete Organisationsstruktur des Staates zu bestimmen, mithin also um die Frage, welcher Ebene im föderativen Staat das Ziel der vertikalen Einkommensumverteilung zugeordnet werden sollte. Wenn im weiteren von 'Redistributionspolitik' die Rede ist, dann steht dieser Aspekt des interpersonellen Ausgleichs im engeren Sinne im Vordergrund.

In föderativ gegliederten Staatswesen taucht allerdings ein zweiter Ausgleichsaspekt auf, der sich nicht direkt auf interpersonelle Ungleichheiten, sondern auf interregionale Disparitäten bezieht. Hier ist zu prüfen, ob und $\mathrm{zu}$ welchem Grad divergierende Einkommens- und Versorgungsniveaus der Bürger in den subzentralen Einheiten durch geeignete Maßnahmen auszugleichen sind. Freilich stehen hinter den Forderungen nach einem interregionalen Ausgleich der Einkommenserzielungsmöglichkeiten und der Versorgung mit öffentlichen Leistungen nicht nur distributive Erwägungen, sie sind vielmehr auch allokationspolitisch motiviert. ${ }^{309}$ Regionale Ausgleichsziele sollen deshalb getrennt von personalen Verteilungszielen (s.u. IV.3) diskutiert werden.

\section{Zentrale oder dezentrale redistributionspolitische Kompetenzen?}

\section{a. Argumente für dezentrale redistributionspolitische Kompetenzen}

Als Hauptargument für dezentrale Kompetenzen bei der Umverteilungspolitik werden erneut die Informationsvorteile lokaler Entscheidungsträger angeführt. ${ }^{310}$ Prominenter Vertreter dieser These ist Pauly, der in einem formalen Ansatz die unter bestimmten Bedingungen bestehende Überlegenheit dezentraler Entscheidungskompetenzen ableitet. ${ }^{311}$ Hierzu wird angenommen:

306 Vgl. Caesar, R. (1990), S. 335.

307 Siehe hierzu Schwarting, G. (1979); Vaughan, R.J. (1979) und Fischer, H. (1988), S. 119ff. Freilich sind auch Stabilisierungszuweisungen mit oben geschilderten Informationsproblemen behaftet.

308 Vgl. etwa Zimmermann, H. (1983), S. 24ff.; Musgrave, P.B./Musgrave, R.A. (1990), S.72ff.

309 Siehe hierzu ausfuhrlich Zimmermann, H. (1987).

$310 \mathrm{Vgl}$. etwa Zimmermann, H. (1983), S. $25 f$.

311 Siehe Pauly, M.V. (1973). Siehe auch Buchanan, J.M. (1974). 
- Es existieren zwei selbständige Jurisdiktionen $\mathrm{i}=\mathrm{A}, \mathrm{B}$, die den Bundesstaat $\mathrm{Z}$ bilden.

- In jeder der beiden Regionen lebt eine bestimmte Anzahl von Armen Pi und Reichen $\mathrm{R}^{\mathrm{i}}$, deren Bruttoeinkommen vor Durchfuhrung von Redistributionsmaßnahmen $y_{p}^{i}$ bzw. $y_{r}^{i}$ sei. Innerhalb der beiden Einkommensgruppen bestehen keine Einkommensunterschiede, die Bevölkerung ist interregional immobil.

- Es wird davon ausgegangen, daß die Reichen von einer Besserstellung der Armen in ihrer eigenen Jurisdiktion profitieren. Die Nutzenfunktionen der Reichen in jeder Jurisdiktion lauten daher $U_{r}^{i}=U_{r}^{i}\left(Y_{r}^{i}, Y_{p}^{i}\right)$ mit $Y_{r}^{i}$ bzw. $Y_{p}^{i}$ als verfügbaren Nettoeinkommen der Reichen bzw. der Armen nach Durchfuhrung von Redistributionsmaßnahmen.

- Die Umverteilung erfolgt durch ein kombiniertes Steuer-Transfer-System. ${ }^{312}$ Die Steuerzahlungen eines repräsentativen reichen Individuums sind dann $y_{r}^{i}-Y_{r}^{i}$. Die Summe der Steuerzahlungen entspricht der Summe der Transfers. Es wird lediglich Paretooptimale Redistribution vorgenommen.

Jeder Transferrempfänger dẹ Region i erhălt unter den gegebenen Annahmen eine Zahlung in Höhe von $\mathrm{R}^{\mathrm{i}}\left(\mathrm{y}_{\mathrm{r}}^{\mathrm{i}}-\mathrm{Y}_{\mathrm{r}}^{1}\right) / \mathrm{P}^{\mathrm{i}}$. Das Optimalniveau der Redistribution bestimmt sich durch ${ }^{313}$

Maximiere: $\quad U_{r}^{i}\left(Y_{r}^{i}, Y_{p}^{i}\right)+\lambda\left[y_{p}^{i}+\frac{R^{i}}{P^{i}}\left(y_{r}^{i}-Y_{r}^{i}\right)-Y_{p}^{i}\right]$,

und man erhält die Optimalbedingung

$$
\frac{\left(\partial U_{r}^{i} / \partial Y_{p}^{i}\right)}{\left(\partial U_{r}^{i} / \partial Y_{r}^{i}\right)}=\frac{P^{i}}{R^{i}} \quad i=A, B
$$

Die individuelle Grenzrate der Substitution eines reichen Bewohners von i entspricht im Optimum den Kosten der Redistributionstätigkeit, die bestimmt sind durch die Relation von Armen zu Reichen Pi/ $\mathrm{R}^{\mathrm{i}}$ in der Gemeinde i. ${ }^{314}$ Die lokalen Regierungen könnten so das intrajurisdiktionell optimale Redistributionsvolumen bestimmen, wobei "... those poor fortunate enough to be in jurisdictions where they constitute a relatively small fraction of the population will receive relatively large transfers as compared to their counterparts in localities where the poor are a larger proportion of the residents." 315

Verfügt die Zentralebene über die gleichen Informationen wie die unteren Ebenen und unterliegt sie keinem Verbot der geographischen Diskriminierung, könnte sie dasselbe Resultat

312 Dabei sei angenommen, daß alle Steuern und Transfers nur zu Einkommenseffekten fuhren. Zur Berucksichtigung von Substitutionseffekten bei Arbeit-Freizeit-Entscheidungen und den Konsequenzen fur die Aufgabenverteilungsdiskussion siehe Johnson, W.R. (1988) und (1991).

313 Vgl. Brown, C.C./Oates, W.E. (1987), S. 310.

314 Fur $\mathrm{R}$ identische Reiche in i ergibt sich die Samuelson-Bedingung fur eine effiziente Bereitstellung reiner offentlicher Konsumguter. Vgl. Pauly, M.V. (1973), S. 41.

315 Brown, C.C./Oates, W.E. (1987), S. 311. Allerdings bleibt zu bedenken, daß dieses Ergebnis bestimmten Gerechtigkeitsvorstellungen widerspricht, da "...the proper amount of redistribution, even if rich and poor were chained to their communities, could not depend upon the accidents of income composition of a particular community.“ Stigler, G.J. (1962), S. 173. 
erzielen. Muß die Zentrale jedoch identische Individuen unabhängig von deren Wohnsitz gleich behandeln, so würde sie das Redistributionsvolumen wählen, das der Bedingung 316

$$
R^{A} \frac{\left(\partial U_{r}^{A} / \partial Y_{p}^{A}\right)}{\left(\partial U_{r}^{A} / \partial Y_{r}^{A}\right)}+R^{B} \frac{\left(\partial U_{r}^{B} / \partial Y_{p}^{B}\right)}{\left(\partial U_{r}^{B} / \partial Y_{r}^{B}\right)}=P^{A}+P^{B}
$$

entspricht. Nach (3.C.IV.2) orientiert sich die Zentralregierung bei der Festlegung des Redistributionsvolumens an Durchschnittswerten. Ein optimales Umverteilungsvolumen wäre in diesem Fall in beiden Jurisdiktionen nur erreichbar, wenn in A und B identische Präferenzen vorliegen. Anderenfalls konsumieren die Bewohner der einen Jurisdiktion 'zu viel' und die der anderen Jurisdiktion 'zu wenig' Einkommensumverteilung. ${ }^{317}$ Dieses Ergebnis entspricht offensichtlich dem oben erörterten Dezentralisierungstheorem: lokale Umverteilung ist unter diesen Bedingungen zu präferieren.

\section{b. Argumente für zentrale redistributionspolitische Kompetenzen}

\section{aa. Spillover-Effekte dezentraler Redistributionspolitik}

Pauly berücksichtigt jedoch auch, daß die Netto-Einkommen der Armen in der jeweils anderen Gebietskörperschaft ebenfalls ein Argument der Nutzenfunktion der Reichen sein können. Die Nutzenfunktion eines repräsentativen reichen Wirtschaftssubjekts in A kann dann formuliert werden als $U_{r}^{A}=U_{r}^{A}\left(Y_{r}^{A}, Y_{p}^{A}, Y_{p}^{B}\right)$. Redistributionsmaßnahmen in $B$ verbessern daher die Nutzenpositionen der Wohlhabenden in A und umgekehrt, es existieren reziproke Nutzen-spillover-Effekte. Da lokale Entscheidungsträger nicht die positiven externen Effekte durch die in der eigenen Jurisdiktion vorgenommenen Einkommenstransfers berücksichtigen, resultiert autonome Umverteilungspolitik der Gliedstaaten A und B in einem suboptimalen Redistributionsniveau. Je stärker die Einkommenspositionen der Armen in anderen Regionen in die Nutzenfunktionen der Reichen eingehen, desto größer fallen die Wohlfahrtsverluste einer nicht-koordinierten, dezentralen Umverteilungspolitik aus.

Nach gängiger Auffassung wäre eine Internalisierung der Externalitäten erreichbar durch koordiniertes Verhalten der Entscheidungsträger A und B oder durch Finanzzuweisungen einer übergeordneten Einheit, "... which transfers represent the interests of taxpayers in all communities in the nation." 318 Eine Zentralisierung der Entscheidungskompetenzen führt hingegen nur zu einer Optimallösung, wenn räumlich diskriminierende Besteuerung der Wirtschaftssubjekte in A und B erlaubt ist und die hierfür erforderlichen Informationen über die Präferenzen bekannt wären, da die Maximierung der Wohlfahrt in der Regel bei Präferenzunterschieden in beiden Gliedstaaten unterschiedliche verfügbare Netto-Einkommen der Armen erfordert. 319 


\section{bb. Redistributionspolitik bei räumlicher Mobilität von Arbeit und Kapital}

In einem nächsten Schritt unterstellt Pauly, daß die Bevölkerung zwischen den Jurisdiktionen $A$ und $B$ vollkommen mobil sei, und daß die Nutzenfunktionen der Reichen in A und B vom Typ $U_{r}^{i}=U_{r}^{i}\left(Y_{r}^{i}, Y_{p}^{i}\right)$ sind. Im Vergleich zum Gliedstaat B existiere in A eine stärkere Präferenz für redistributive Maßnahmen.

Während bei Immobilität der Bevölkerung unterschiedliche Redistributionspolitiken in A und $\mathrm{B}$ unter diesen Bedingungen durchführbar sind und zu effizienten Ergebnissen führen, gilt dies bei mobiler Bevölkerung nicht mehr. Verstärkte Umverteilungsmaßnahmen in A bergen die Gefahr, daß Arme aus der Jurisdiktion B zuwandern. Ein Zuzug von Armen ist aber aus der Sicht des Gemeinwesens A unerwünscht, denn dies führt zu einem Anstieg der Kosten der Redistributionsmaßnahmen $\left(\mathrm{P}^{\mathrm{A}} / \mathrm{R}^{\mathrm{A}}\right)$. Um durch Transfers dasselbe Einkommensniveau der Armen in A zu erreichen wie vor Migration, wäre eine höhere Steuerbelastung der Reichen in A notwendig. Umgekehrt ist mit gleichem Steueraufkommen in A nurmehr ein geringeres Redistributionsvolumen zu erreichen. ${ }^{320}$ Allein die potentielle Mobilität der Armen reduziert die Transfers in A. ${ }^{321}$ Je höher die Migrationsbereitschaft des ärmeren Bevölkerungsteils also ist, desto geringer sind die Umverteilungsaktivitäten in A.

Gleiches gilt für $B$, denn auch hier muß bei verstärkten Umverteilungsbemühungen mit einer Zuwanderung von Armen gerechnet werden. Kann allerdings in B von einer Netto-Abwanderung der ärmeren Bewohner ausgegangen werden, so bleibt der Gesamteffekt auf die dortige Umverteilung unbestimmt. Einerseits bedeutet eine hohe Mobilität verringerte Umverteilungsanreize, andererseits profitieren die Reichen in B von einer Abwanderung der Armen, da sich die Relation $\mathrm{P}^{\mathrm{B}} / \mathrm{R}^{\mathrm{B}}$ verbessert. 322 Werden in A Umverteilungsmaßnahmen beschlossen, so erfolgt dies gemäß den Präferenzen der wohlhabenden Bewohner von A. Keine Berücksichtigung finden dagegen die positiven Externalitäten, die die Maßnahmen für die Wohlhabenden in B haben. Da jede Einheit als Folge verstärkter Redistributionstätigkeit mit einer Zuwanderung von Armen rechnen muß, ist das gesellschaftliche Umverteilungsvolumen ineffizient gering.

Die Problematik einer dezentralen Umverteilungspolitik bei mobiler Bevölkerung wird noch verschärft, wenn Wanderungen der Reichen berücksichtigt werden. Selbst wenn die reichere Bevölkerungsschicht in A starke Präferenzen für Umverteilung hat, ist es für sie trotzdem rational, die Jurisdiktion A zu verlassen, um der Steuerbelastung zu entgehen. ${ }^{323}$ Es kommt zur Nivellierung der intrajurisdiktionellen Einkommen, die mit hohen interjurisdiktionellen Einkommensdifferenzen einher geht.324. In Gliedstaaten mit überwiegend ärmerer Bevölkerung wäre eine Umverteilung aufgrund der Erosion der steuerlichen Basis, aus der Redistributionsmaßnahmen finanziert werden, überhaupt nicht mehr durchführbar. ${ }^{325}$

Umverteilungsbemühungen lokaler Gebietskörperschaften werden zusätzlich durch Faktormarktreaktionen konterkariert. ${ }^{326}$ So nimmt Wildasin an, daß Wohlhabende und Arme hete-

320 Vgl. Brown, C.C./Oates, W.E. (1987), S. 311.

321 Vgl. Boadway, R.W./Wildasin, D.E. (1984), S. 510 und King, D.N. (1992), S. $25 \mathrm{ff}$.

322 Vgl. Brown, C.C./Oates, W.E. (1987), S. 314ff. Vgl. auch King, D.N. (1984), S. 33.

323 Vgl. Stigler, G.J. (1962), Oates, W.E. (1972), S. 7f. und King, D.N. (1984), S. 35.

324 Vgl. z.B. Musgrave, R.A. (1969b), S. 310.

325 Vgl. Stigler, G.J. (1962), S. 169ff.

326 Vgl. hierzu Wildasin, D.E. (1991) und (1992). 
rogene Produktionsfaktoren anbieten. ${ }^{327}$ Eine Abwanderung der Reichen (Zuwanderung der Armen) als Reaktion auf Redistributionsmaßnahmen in einem Gliedstaat A fuhrt zu einer relativen Verknappung (Vermehrung) des Faktorangebots der Wohlhabenden (Armen) in der Jurisdiktion. Innerhalb von A vergrößert sich damit die Differenz der Bruttoentlohnung der Faktoren. Entsprechend existiert verstärkter Bedarf an intraregionaler Umverteilung. Die Wanderungsbewegungen kommen erst zum Stillstand, wenn die Netto-Einkommen der Reichen bzw. der Armen in allen Gliedstaaten zum Ausgleich kommen. Immer dann, wenn die Budgets lokaler Einheiten redistributive Wirkungen haben, ergeben sich Anreize für die Bürger, sich in reicheren Regionen niederzulassen. ${ }^{328}$ Diesen Überlegungen zufolge wäre also eine zentrale Verantwortlichkeit für redistributionspolitische Aktivitäten erforderlich, denn Migrationen stellen dort keine Beschränkung dar. 329

Die gleichen Probleme stellen sich aus Sicht der Politiker auf subzentraler Ebene bei der Besteuerung mobilen Kapitals zu Umverteilungszwecken. Die Diskussion des TieboutModells und die vorangegangenen Erörterungen haben verdeutlicht, daß die subzentralen Jurisdiktionen perfekt mobile Faktoren nur in der Höhe steuerlich belasten können, wie ihnen auch äquivalente Leistungen zukommen. Daraus kann der Schluß gezogen werden, daß eine Umverteilung zu Lasten mobiler und zugunsten immobiler Faktoren auf dezentraler Ebene nicht möglich ist, so daß eine Umverteilungspolitik, die durch die Besteuerung von Kapital finanziert werden soll, im Regelfall nur auf nationaler Ebene erfolgreich sein kann. ${ }^{330}$ Allerdings ist die Möglichkeit in Betracht zu ziehen, daß auch die Eigentümer des Faktors Kapital von einer höheren sozialen Ausgeglichenheit profitieren. In diesem Fall erscheint es möglich, daß selbst mobiles Kapital bereit ist, einen Beitrag zur sozialen Stabilität einer lokalen Jurisdiktion $\mathrm{zu}$ leisten. 331

\section{Regionale Ausgleichsziele}

Während die bisherige Argumentation auf die interpersonale Umverteilung gerichtet war, sind in der theoretischen Diskussion um regionale Ausgleichsziele allokative und distributive Motive gleichermaßen relevant. ${ }^{332}$ Dabei sind mit Zimmermann zwei Politikvarianten zu unterscheiden, die auf mögliche Einkommensdisparitäten der Bürger verschiedener Regionen einer Volkswirtschaft korrigierend einwirken sollen:333

327 Z.B. hochqualifizierte Arbeit durch die Reichen, weniger qualifizierte Arbeit durch die Armen.

328 Vgl. Peffekoven, R. (1980), S. 624; Boadway, R.W./Flatters, F. (1982).

329 "Since redistribution is intrinsically a national policy, it should not be restricted to a community level." Stigler, G.J. (1962), S. 173.

330 Vgl. z.B. Sinn, H.-W. (1995), S. 245 f.

331 "Even in the financing of the social security system, there are opportunity costs of reducing regulation. Admittedly, the link between the user and payer may be weak from the firm's point of view, but it still exists. Improved social security can lower the riskiness of investment and increase labour productivity because of fewer sick-leaves or better motivation of the labour force. Since these factors increase the return on capital, firms are willing to pay contributions to the system of social security. These payments can be interpreted as user charges for the factor of social stability." Siebert, H. (1991), S. $22 \mathrm{f}$.

332 Die Begrundung interregionaler Ausgleichsmaßnahmen ist allerdings in der politischen Realităt uberwiegend distributiver Art, vgl. Zimmermann, H. (1987), S. 57.

$333 \mathrm{Vgl}$. Zimmermann, H. (1983), S. $28 \mathrm{ff}$. 
- Horizontale Finanzausgleichsmaßnahmen, die lediglich indirekt durch Finanztransfers zwischen lokalen Einheiten auf die interpersonale Nivellierung hinwirken, und

- regionalpolitische Eingriffe, die als Raumordnungs- oder regionale Entwicklungspolitik gegebenenfalls neben Wachstumszielen auch Ausgleichsziele verfolgen. Sie sollen jedoch im folgenden nicht gesondert behandelt werden, da sie im Bereich der bereits oben behandelten Allokationspolitik anzusiedeln sind.

Gemeinsamer Ausgangspunkt der allokativen wie auch der distributiven Begründung horizontaler Ausgleichszuweisungen ist die Feststellung, daß in einem Staat in der Regel regionale Unterschiede in den strukturellen Bedingungen bestehen, die beispielsweise auf einer ungleichen Verteilung natürlicher Ressourcen im Raum beruhen können. ${ }^{334}$ Es wird deshalb vermutet, daß Ungleichheiten der subzentralen Einheiten in den "fiscal capacities" 335 zu "regional differences in standards of public services and/or burdens of taxation"336 fuhren. Reichere Gemeinwesen könnten die gleichen öffentlichen Leistungen mit geringeren Pro-Kopf-Beiträgen realisieren oder mit gleichen Finanzierungsbeiträgen je Einwohner ein quantitativ oder qualitativ besseres Angebot bereitstellen, als dies ärmeren Einheiten möglich ist, so daß die Versorgungssituation der Bevölkerung unterschiedlicher Regionen differiert. 337

Bei räumlicher Immobilität resultieren damit selbst bei identischer Umverteilungspolitik aller Gliedstaaten differierende fiskalische Residuen für ansonsten identische Individuen. Das ist, so Buchanan, ein Verstoß gegen das Postulat horizontaler Gleichbehandlung. ${ }^{338}$ Selbst wenn also die von Pauly formulierten Idealbedingungen für eine dezentrale Umverteilungspolitik vorliegen würden, erscheint es aus dieser Perspektive fraglich, ob die Individuen auf konstitutioneller Ebene eine rein dezentrale Verantwortlichkeit für Redistributionsmaßnahmen befürworten würden.

Indessen ist die auch im Grundgesetz der Bundesrepublik Deutschland in Art. 72 erhobene Forderung nach einer gewissen Einheitlichkeit der Lebensverhältnisse in den föderativen Untereinheiten zwar durchaus, wie Zimmermann betont, als "... Unterfall des Ziels der personalen Redistribution [aufzufassen, H.P.], weil letztlich die regionale Bevölkerung und damit personale Verteilungsaspekte, wenngleich auf den Durchschnitt der Region bezogen, hinter diesen Zielen stehen." 339 Gleichwohl rechtfertigt dieses Argument keine personenbezogene Umverteilungsaktivität der Zentralebene, denn im Vordergrund der Argumentation steht die Schaffung interrregionaler Chancengleichheit, die durch ein System interjurisdiktioneller Transfers zu erreichen wäre. ${ }^{340}$ Mittels horizontaler Zuweisungen wäre ein Ausgleich zwischen dem lokalen Finanzbedarf und der Finanzkraft anzustreben, der den Gebietskörperschaften eine zumindest annähernd gleiche Versorgung ihrer Bürger im gesamten Bundesstaat ermöglicht. ${ }^{341}$ Allerdings kommt es auch hier wieder zu Informationsproblemen, denn es ist zu bestimmen, welche Indikatoren für die Leistungsfähigkeit der subzentralen Einheiten fest-

334 Siehe etwa Hansmeyer, K.-H. (1968) oder Schneider, H.K. (1968).

335 Buchanan, J.M. (1950), S. 584.

336 Buchanan, J.M. (1950), S. 585.

337 Vgl. Oates, W.E. (1968), S. 46.

338 Vgl. Buchanan, J.M. (1950), S. 587. Siehe auch Oates, W.E. (1977a), S. 13 und Hamlin, A.P. (1985b).

339 Zimmermann, H. (1987), S. 57.

340 Siehe etwa Buchanan, J.M. (1950), S. 588ff.

341 Siehe dazu etwa Zimmermann, H./Henke, K.D. (1994), S. $192 \mathrm{ff}$. 
zusetzen sind und zu welchem Grad der Ausgleich von Finanzkraft und Finanzbedarf erfolgen soll. ${ }^{342}$

Demgegenüber stellt die allokative Rechtfertigung horizontaler Ausgleichsleistungen auf die Annahme einer mangelnden Fähigkeit lokaler Einheiten zur Internalisierung räumlicher Ballungseffekte bei Mobilität der Individuen ab. ${ }^{343}$ Nimmt man beispielsweise an, daß die Region A im Vergleich zu Region B verhältnismäßig reich an Boden und anderen natürlichen Ressourcen ist, erreicht der mobile Faktor Arbeit in Region A eine höhere marginale und durchschnittliche Produktivität. Stellen die Einheiten keine Kollektivgüter bereit, wäre die sich durch die Wanderungen ergebende asymmetrische interregionale Verteilung bei einem Ausgleich der Grenzproduktivitäten der Arbeit effizient. Werden hingegen Kollektivgüter angeboten, die partielle Nutzungsrivalitäten aufweisen, kann Gemeinwesen A identischen Individuen bei gleicher Bevölkerungszahl wie B stets ein höheres fiskalisches Residuum $\mathrm{u}_{\mathrm{A}}>\mathrm{u}_{\mathrm{B}}$ anbieten.

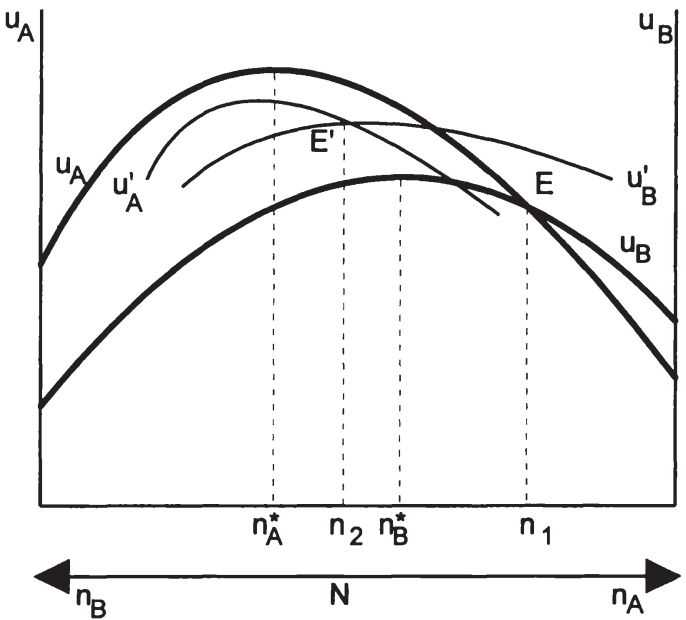

Abbildung 3.9: Regionale Ausgleichszahlungen zur Verbesserung der räumlichen Allokation Quelle: in Anlehnung an Arnold, V. (1992), S. 294.

In Abbildung 3.9 ist dieser Zusammenhang graphisch verdeutlicht. Werden Migrationsexternalitäten nicht internalisiert, ist die Aufteilung der Gesamtbevölkerung $\mathrm{N}$ auf die Einheiten $\mathrm{A}$ und $B$ gemäß $n_{1}$ im Gleichgewichtspunkt $E$, bei dem die Bürger identische fiskalische Restwerte $u_{i}$ realisieren, ineffizient. ${ }^{344}$ In der an immobilen Faktoren reichen Einheit $A$ ist das

342 Musgrave, R.A. (1961) unterscheidet dabei allein sechs mogliche Definitionen von regionalem Ausgleich und analysiert dann die Notwendigkeit unterschiedlicher Finanzzuweisungssysteme. Siehe hierzu auch Zimmermann, H. (1983), S. 47ff.

343 Grundlegend hierzu Buchanan, J.M./Wagner, R.E. (1970) und Boadway, R.W./Flatters, F. (1982).

344 Hier sieht man, daß das Problem der horizontalen Ungleichbehandlung nur bei Immobilitat der Burger auftauchen kann. Bei perfekter Mobilităt kommt es stets zu einem Ausgleich der fiskalischen Restwerte fur identische Individuen. 
Agglomerationsoptimum $\mathrm{n}_{\mathrm{A}}^{*}$ überschritten. Gemeinwesen $\mathrm{B}$ leidet dagegen an Ausdünnung, befindet sich also unterhalb des internen Ballungsoptimums $\mathrm{n}_{\mathrm{B}}^{*}$. Bei einer Bevölkerungsverteilung, in der B mehr und A weniger Einwohner hätte, könnten die Pro-Kopf-Nutzen aller Staatsbewohner gesteigert werden.

Anreize zur effizienzsteigerndern Reallokation der Bevölkerung können durch ein System interregionaler Finanzausgleichszahlungen gesetzt werden. Transferzahlungen vom reichen Gemeinwesen A an B verändern die maximal erreichbaren Netto-Nutzen in beiden Einheiten, da sie in der leistenden Einheit die privaten Konsummöglichkeiten verringern und in der empfangenden Einheit erhöhen. In A sind daher für alle Gemeindegrößen $n_{A}$ die pro-KopfNutzen geringer als in der Ausgangssituation; in B sind sie dagegen angestiegen. Die neuen Netto-Nutzen-Kurven $u_{A}^{\prime}$ und $u_{B}^{\prime}$ haben ihren Schnittpunkt E' links oberhalb von E. Die Allokation $\mathrm{n}_{2}$ ist eine eindeutige Pareto-Verbesserung gegenüber der Ausgangsposition, denn alle Individuen in beiden Gemeinwesen erhalten höhere Netto-Nutzen.

$\mathrm{Ob}$ solche interkommunalen Finanztransfers auf freiwilliger Basis zustandekommen, hängt wesentlich von der Zahl der betroffenen Gemeinwesen ab. Im einfachen Beispiel mit nur zwei Kommunen A und B dürften Verhandlungen der politischen Entscheidungsträger über Transfers von A nach B hohe Erfolgsaussichten haben. Die Situation ist anders, wenn viele reiche, überbevölkerte Gemeinden in der betrachteten Volkswirtschaft existieren. Von jeder Transferleistung einer Einheit, die das Ballungsoptimum bereits überschritten hat, an eine unterbevölkerte Einheit profitieren auch alle anderen reichen Einheiten. Nach der Logik kollektiven Handelns wird keines der reichen Gemeinwesen freiwillige Ausgleichszahlungen an ärmere Gemeinden leisten. Mit der Organisation und Durchführung der erforderlichen Finanztransfers müßte eine höhere Ebene im föderativen Staat beauftragt werden.

\section{Die Implikationen für die Zuordnung der Bereitstellungskompetenzen}

Für die Zuordnung der Redistributionsfunktion auf die Staatsebenen werden deshalb in der Theorie des Fiskalföderalismus folgende Schlußfolgerungen gezogen. Auf der einen Seite werden die Vorteile einer Dezentralisierung der Redistributionsaufgaben betont, die in der besseren Anpassung an lokale Präferenzen begründet liegen. ${ }^{345}$ Eine "active local participation"346 sollte daher, so Oates, Element staatlicher Umverteilungspolitik sein. Die Informationsvorteile subzentraler Einheiten kommen gerade bei der Identifikation Bedürftiger zum Tragen.

Gleichwohl ist völlige Autonomie der unteren Einheiten bei der Bestimmung ihres Redistributionsvolumens nicht einmal bei räumlicher Immobilität der Bevölkerung und lokal begrenzten Nutzenreichweiten der Umverteilungsmaßnahmen zu empfehlen. Erstens führen interregionale Differenzen der fiskalischen Restwerte zu einem Verstoß gegen das Postulat horizontaler Gleichbehandlung. Ihr Ausgleich ist deshalb aus verteilungspolitischen Gründen durch Finanztransfers zwischen den unterschiedlich ausgestatteten Einheiten anzustreben.

Zweitens beschränkt die interjurisdiktionelle Mobilität der Individuen die Effizienz lokaler Umverteilungspolitik. Redistributionsaktivitäten dezentraler Entscheidungsträger führen bei Mobilität zu einer Art adverser Selektion, da infolge der $\mathrm{Zu}$ - und Abwanderungen nur die

345 Vor allem besteht kein Grund zur Annahme, daß Werturteile uber erwunschte Verteilungsergebnisse auf der Zentralebene denen auf subzentralen Ebenen uberlegen seien. Vgl. Boadway, R.W. (1992), S. 34.

346 Oates, W.E. (1990), S. 45. Ähnlich auch Tresch, R. (1981), S. 576ff. 
potentiellen Transferempfänger, nicht aber die Wohlhabenden als potentielle Transfergeber in der Region verbleiben. ${ }^{347}$ Dennoch ist daraus nicht zwingend die Forderung nach einer uneingeschränkten Zentralisierung der Redistributionskompetenzen ${ }^{348}$ abzuleiten. Vielmehr könnten kombinierte Maßnahmen in einem vertikalen Verbund lokaler und zentraler Gemeinwesen geeignet erscheinen, die Vor- und Nachteile einer Zentralisierung bzw. Dezentralisierung auszugleichen. Diese Arrangements könnten so gestaltet sein, daß etwa den subzentralen Einheiten primäre Entscheidungskompetenz für die interpersonale Redistribution, den zentralen Ebenen dagegen die Verantwortlichkeiten für den interregionalen Ausgleich zugeordnet werden. 349

Bei der Zuordnung der Redistributionsfunktion sollten daher die Informationsvorteile dezentraler Einheiten ebenso einbezogen werden, wie die Koordinationskosten einer abgestimmten Umverteilungspolitik. ${ }^{350}$ Schwierigkeiten bereitet in diesem Zusammenhang die Mobilität der Individuen. Einerseits ist sie die Ausdrucksmöglichkeit für unterschiedliche Präferenzen für redistributive Maßnahmen, andererseits ist sie die Quelle von Ineffizienzen dezentraler Umverteilung. Gerade weil Redistribution die bewußte Abkehr vom allokativen Ideal der Äquivalenzbesteuerung erfordert, droht durch Migrationen "the death of the insurance state"351. Allerdings bedeutet die Mobilität der Haushalte voraussichtlich nur auf kommunaler Ebene eine signifikante Beschränkung der subzentralen Umverteilungspolitik. Aus diesem Grund erscheint eine Zuordnung der Kompetenzen auf die mittleren Ebenen im Staat durchaus gangbar.

\section{Die Zuordnung der Finanzierungskompetenzen}

\section{Die Zuordnung der Finanzierungskompetenzen als Teilproblem der Zuordnung von Bereitstellungskompetenzen}

\section{a. Die institutionelle Symmetrie von Aufgaben- und Finanzierungskompetenzen}

Neben der Regelung der Aufgabenkompetenzen wird in der Theorie des Fiskalföderalismus auch untersucht, welche föderative Ebene mit welchen Finanzierungsverantwortlichkeiten ausgestattet werden soll. Die Zuordnung der Einnahmequellen auf gebietskörperschaftliche Einheiten wird unter dem Stichwort "primärer vertikaler Einnahmenausgleich"352 diskutiert. Im Vordergrund stehen die Probleme, wie die Objekthoheiten, also die Zugriffsmöglichkeiten

347 Vgl. Sinn, H.-W. (1994), S. 22ff.

348 So z.B. Stigler, G.J. (1962), S. 173; Oates, W.E. (1972), S. 6ff.; Wildasin, D.E. (1991).

349 Vgl. insbesondere Tresch, R. (1981), S. 596ff. und King, D.N. (1984), S. 36.

$350 \mathrm{Vgl}$. Breton, A./Scott, A. (1978), S. $111 \mathrm{ff}$.

351 Sinn, H.-W. (1990), S. 50. Zur Überwindung dieses Problems macht $H .-W$. Sinn den Vorschlag, redistributive Clubs einzurichten, uber deren Zugehörigkeit die Individuen im Stadium relativ hoher persönlicher Unsicherheit uber die zukunftigen Lebensverhalttnisse definitiv zu entscheiden haben. Da Wettbewerb zwischen diesen Parafisci nur ex ante, also vor Eintreten möglicher Versicherungsleistungen, besteht, ex post aber "nicht durch den Fiskalwettbewerb unterminiert werden kann" (Sinn, H.-W. (1994), S. 29.), wäre einer Aushøhlung des Wohlfahrtsstaates durch dezentrale Verantwortlichkeiten Einhalt geboten. Die funktionale Organisation der Umverteilung im Staat konnte nach Sinn das Auftreten der Mobilitătsproblematik verhindern.

352 Peffekoven, R. (1980), S. 618. 
auf unterschiedliche Finanzierungsquellen, und die Ertragshoheiten, also die Frage, welcher föderativen Einheit die Einnahmen zufließen sollen, geregelt sind. 353

Wie oben angemerkt, ist die Finanzierungskompetenz Teil der Bereitstellungskompetenz. Die Regelung der Finanzierungskompetenzen kann deshalb nicht unabhängig von der Zuordnung der Aufgaben auf die gebietskörperschaftlichen Einheiten erfolgen. Dennoch finden die Bedingungen "institutioneller Symmetrie" 354 von Aufgaben- und Finanzierungskompetenzen oftmals nur wenig Beachtung. So befindet beispielsweise Boadway im Hinblick auf die Steuerkompetenzen, daß "... the assignment of taxes can be determined independently of the assignment of expenditures." 355 Und Thöni reduziert das Problem der Verteilung der Einnahmequellen auf die Fragestellung: "Wie sollten die von verschiedenen föderalistischen Einheiten bereitgestellten Güter finanziert werden?"356

Bei dieser Betrachtungsweise wird übersehen, daß sich institutionelle Symmetrie zwar auch auf die Übereinstimmung von Ausgabenbelastung und Einnahmenpotential bezieht, dies jedoch nur ein Teilaspekt verschiedener Zielsetzungen des aktiven Finanzausgleichs ist. So verlangt die "... Autonomie bei der Ausgabenentscheidung ... nach weitgehend akzeptierter Auffassung (zumindest in gewißen Grenzen) autonome Einnahmenbeschaffung." 357 Es geht also darum zu bestimmen, zu welchem Grad die gebietskörperschaftlichen Ebenen eigenständig auf bestimmte Finanzierungsquellen zugreifen können. Überdies bedeutet institutionelle Symmetrie, daß durch die Verteilung der Einnahmekompetenzen "... die einzelnen Körperschaften bei der Verfolgung der ihnen zugewiesenen ökonomischen Ziele, unterstützt werden müssen." 358 Daraus folgt, daß die allgemeinen Kriterien zur Zuordnung der Bereitstellungskompetenzen auch für die Zuordnung spezieller Finanzierungskompetenzen eine Rolle spielen.

\section{b. Alternative Organisationsformen der Zuordnung von Finanzierungskompetenzen}

Zur Finanzierung öffentlicher Ausgaben stehen im wesentlichen die Alternativen Steuern und Kreditaufnahme zur Verfügung. Im Hinblick auf die mögliche organisatorische Ausgestaltung der Besteuerungskompetenzen kann nach fallender Autonomie nachgeordneter Ebenen unterschieden werden in 359

- das Zuweisungssystem mit Umlagen (Beiträgen), bei dem Objekt- und Ertragshoheit nur auf subzentraler Ebene liegen und die übrigen Ebenen durch Zuweisungen alimentiert werden,

353 Wie bei der Erörterung der Aufgabenzustăndigkeiten sollen Aspekte der Durchfuhrungshoheit keine Berlicksichtigung finden. Für jede Einnahmeart sollte eine Verwaltungseinheit verantwortlich sein, die die Minimierung administrativer Erhebungskosten und privater Erfullungskosten ermøglicht. Vgl. z.B. Oates, W.E. (1972), S. 125f.; Netzer, D. (1974), S. 394ff.; Zimmermann, H. (1983), S. 39; Kops, M. (1984), S. 291 und Spahn, P.B. (1993), S. 21 f.

354 Blankart, C.B. (1994a), S. 514.

355 Boadway, R.W. (1992), S. 43.

356 Thöni, E. (1986), S. 56.

357 Peffekoven, R. (1980), S. 618.

358 Peffekoven, R. (1980), S. 618.

359 Siehe Peffekoven, R. (1980), S. 618ff. 
- das freie Trennsystem (Konkurrenzsystem), nach dem sich jede gebietskörperschaftliche Ebene die für die Erfüllung ihrer Aufgaben erforderlichen Steuereinnahmen autonom beschaffen kann,

- das gebundene Trennsystem, bei dem einzelne Ebenen die Objekthoheit für ganz bestimmte Steuerquellen erhalten, die damit dem Zugriff der anderen Ebenen vorenthalten bleiben,

- Zuschlagssysteme, deren Kennzeichen es ist, daß den unteren Ebenen prozentuale Zuschläge auf die von höhereren Ebenen erhobenen Steuern möglich sind,

- Verbundsysteme, bei denen einzelne oder alle Steuern von nur einer staatlichen Einheit (meist: Zentralebene) erhoben werden und die übrigen Ebenen nach ex ante festgelegten Quoten am Ertrag der Steuern partizipieren,

- Zuweisungssysteme mit Überweisungen, in denen die nachgeordneten Einheiten durch Finanztransfers der Zentralebene (Dotationen) alimentiert werden.

Im Hinblick auf die Verschuldungskompetenzen geht es lediglich darum aufzuzeigen, ob den gebietskörperschaftlichen Einheiten unbegrenzte, begrenzte oder eventuell überhaupt keine Verschuldungsrechte eingeräumt werden sollten.

\section{c. Die Kriterien für eine optimale Zuordnung der Finanzierungskompetenzen}

In einem weiteren Schritt ist zu klären, wie die einzelnen Einnahmearten auf die unterschiedlichen gebietskörperschaftlichen Ebenen zuzuweisen sind. Folgt man Spahn, so lassen sich für die vertikale Verteilung der Besteuerungskompetenzen vier relevante Entscheidungskriterien bestimmen: 360

- Effiziente Bereitstellungsentscheidungen setzen voraus, daß die property rights in einem räumlichen Verbund von Nutzern, Entscheidern und Kostenträgern zugeordnet sind. Aufgaben- und Finanzierungskompetenzen sollten daher so aufgeteilt sein, daß eine möglichst weitgehende Kongruenz von Nutzenempfängern aus der Bereitstellung eines Kollektivgutes und den Trägern der Finanzierungslasten hergestellt wird. ${ }^{361}$ Folglich spielt für die Zuordnung der Besteuerungskompetenzen die regionale Inzidenz der Lastverteilung eine wichtige Rolle ("benefit-pricing argument").

- Die meisten Steuern haben nach heutiger Auffassung auch instrumentalen Charakter zur Erreichung wirtschaftspolitischer Ziele. ${ }^{362}$ Die Zuordnung von Steuerhoheiten sollte nach dem "instrumental approach argument" an diejenige Ebene erfolgen, die für die Erfüllung dieser Aufgaben als hauptverantwortlich zeichnet. 363

- Nach dem "tax competition argument" muß durch die Zuordnung von Besteuerungskompetenzen dafür Sorge getragen werden, daß die möglichen Ineffizienzen eines Steuerwettbewerbs subzentraler Einheiten vermieden werden.

360 Siehe Spahn, P.B. (1993), S. 15ff.

361 Vgl. z.B. Oates, W.E. (1972), S. 124; Brennan, G. (1983), S. 22f.; Spahn, P.B. (1993), S. 15. Damit wird bewußt von der Auffassung abgewichen, die Zuordnung der Finanzierungskompetenzen kőnne unabhăngig von der Aufgabenverteilung erfolgen.

$362 \mathrm{Zu}$ einem Überblick siehe Schmölders, G./Hansmeyer, K.-H. (1980), § 10.

363 Vgl. Musgrave, R.A. (1983), S. 11 ff.; Spahn, P.B. (1993), S. 17f. 
- Den Entscheidungseinheiten müssen Finanzierungsquellen zugestanden werden, die ihnen die Erfüllung ihrer Ausgabenverpflichtungen ermöglichen. ${ }^{364}$ Diese Aspekte werden in der einschlägigen Literatur unter dem Stichwort der Angleichung von Finanzbedarf und Finanzkraft der Gebietskörperschaften behandelt. ${ }^{365}$ Damit angesprochen ist auch die mögliche Gefahr einer regionalen Ungleichverteilung der Steueraufkommen, die bereits durch die Festlegung der Steuerquellen vermieden werden könnte ("regional arbitrariness argument").

Ein ähnliches Schema findet sich bei Caesar, der die Systematik von Spahn für die vertikale Zuordnung von Besteuerungskompetenzen auf die Verschuldungskompetenzen überträgt. ${ }^{366}$ Danach sind für die Zuweisung von Verschuldungsrechten zu untersuchen:

- Eine mögliche Äquivalenz von Kosten und Nutzen öffentlicher Verschuldung,

- der instrumentelle Charakter der öffentlichen Verschuldung,

- Effekte des Wettbewerbs subzentraler Einheiten für die öffentliche Verschuldung sowie

- unterschiedliche Zugangsmöglichkeiten verschiedener Körperschaften zum Kapitalmarkt.

Ausgehend von dieser Systematik soll im nächsten Abschnitt versucht werden, die einzelnen Einnahmearten im Hinblick auf ihre Eignung zur Erfüllung der ökonomischen Ziele der Einnahmenverteilung zu überprüfen.

\section{Die Grundprobleme der Zuordnung von Finanzierungskompetenzen}

\section{a. Zur Zuordnung der Besteuerungskompetenzen im föderativen Staat}

\section{aa. Zur Übereinstimmung von Nutzern und Kostenträgern}

Unter dem Gesichtspunkt der lokalen Äquivalenz der Steuerlasten geht es darum, für subzentrale Einheiten potentielle Steuerquellen zu ermitteln, deren Inzidenz regional begrenzt ist. Die Streuung der Steuerlasten über das Hoheitsgebiet eines Entscheidungsträgers hinaus ist vorwiegend auf die räumliche Mobilität von Gütern und Faktoren zurückzuführen. Auf lokaler Ebene sollten daher, so das Argument, immobile Bemessungsgrundlagen gewählt werden. ${ }^{367}$ Eine Steuer auf die Erträge von Grund und Boden bietet sich auf kommunaler Ebene an, größere Einheiten könnten darüber hinaus auch den Faktor Arbeit steuerlich belasten. Verbrauchsteuern sind für Jurisdiktionen der unteren Ebenen für solche Güter zu befürworten, die z.B. aufgrund hoher Transportkosten nur intraregional produziert und konsumiert werden, so daß ein Export der Steuerlasten erschwert wird. Dagegen wären unter dem Aspekt der regionalen Steuerinzidenz Steuern auf natürliche Ressourcen, die von Gebietsfremden genutzt werden, auf subzentraler Ebene abzulehnen.

Erfolgt die Bereitstellung von Kollektivgütern im vertikalen Verbund, können Effizienzvorteile erzielt werden, wenn die Steuerkompetenzen dezentral verbleiben. Zentraleinheiten könnten durch Transfers 'von unten nach oben' alimentiert werden, die Mitverantwortung für

364 Vgl. z.B. McLure, C.E. (1983a), S. xiv; Zimmermann, H. (1983), S. 47 und S. $50 \mathrm{ff}$.

365 Hierzu unter vielen: Peffekoven, R. (1980), S. 618.

366 Siehe Caesar, $R$. (1996), S. 159ff.

367 So z.B. Musgrave, R.A. (1983), S. 11f.; Oates, W.E. (1977), S. 15; (1990), S. 47. 
die Bereitstellung von Kollektivgütern mit großem Nutzenradius impliziert nicht zwingend ein eigenes Besteuerungsrecht. ${ }^{368}$

\section{bb. Zum instrumentalen Charakter von Steuern}

Aus allokativer Perspektive wäre es erforderlich, daß die Finanzierung öffentlich bereitgestellter Leistungen über Nutzensteuern erfolgt. Das gilt grundsätzlich für alle gebietskörperschaftlichen Ebenen, selbst wenn dafür auf lokaler Ebene bessere Voraussetzungen vorliegen sollten. ${ }^{369}$ Wenn produktive öffentliche Vorleistungen dem Faktor Kapital zufließen, ist es daher sinnvoll, diese auch auf kommunaler Ebene mittels einer Kapitalsteuer zu finanzieren. 370

Gleichzeitig gilt z.B. die progressive Einkommensteuer als geeignetes Instrument der Konjunkturstabilisierung und der Umverteilungspolitik. ${ }^{371}$ Finanzierungshoheiten sollten folglich den für diese Aufgaben zuständigen Einheiten zugewiesen werden. ${ }^{372}$

\section{cc. Zum Steuerwettbewerbsargument}

Vorzüge und Gefahren des Steuerwettbewerbs zwischen subzentralen Einheiten wurden bei der Diskussion des Tiebout-Modells erörtert. Da die Ursache fiskalischen Wettbewerbs in der interregionalen Mobilität der Steuerbemessungsgrundlagen zu finden ist, wird aus dem tax competition argument von den Autoren, die v.a. die möglichen Ineffizienzen des Steuerwettbewerbs betonen, die Besteuerung mobiler Güter und Faktoren auf subzentraler Ebene abgelehnt. ${ }^{373}$ Zumindest sei die Besteuerung mobiler Faktoren durch horizontale Arrangements oder gegebenenfalls vertikale Intervention zu harmonisieren. ${ }^{374}$

Diejenigen Autoren, die in der Tradition von Tiebout die positiven Aspekte fiskalischer Konkurrenz hervorheben, sehen dagegen in der Harmonisierung eine Schwächung der Präferenzoffenbarungsmöglichkeiten für die Bürger. Sie verweisen auf den wettbewerblichen Druck, der lokale Einheiten zur präferenzadäquaten Bereitstellung lokaler Kollektivgüter zwinge. Mit steigendem Äquivalenzcharakter der Kapitalbesteuerung würden damit auch die Gefahren eines ruinösen Steuer- und Ausgabenwettbewerbs eingedämmt. 375

Insgesamt betrachtet kann deshalb aus dem Steuerwettbewerbsargument, zumindest aus wohlfahrtstheoretischer Perspektive, kein eindeutiger Schluß für die Zuordnung von Besteuerungskompetenzen gezogen werden.

\section{dd. Zur regionalen Streuung der Bemessungsgrundlagen}

Die möglichen Steuererträge jeder Gebietskörperschaft müssen so hoch sein, daß sie den aus der Verteilung der Aufgabenzuständigkeiten resultierenden Ausgaben entsprechen. Sind viele lokale Einheiten derselben gebietskörperschaftlichen Ebene mit denselben Aufgaben betraut,

368 Vgl. Spahn, P.B. (1988), S. 169f. und (1993), S. 17.

369 Vgl. Musgrave, R.A. (1983), S. 9 und S. 13 sowie Bird, R.M. (1993), S. 212f. Gebuhren und Beiträge kommen den benefit taxes zwar recht nahe, setzen jedoch Ausschließbarkeit und zumindest annahernd individuelle Zurechenbarkeit offentlicher Leistungen voraus. Vgl. etwa Zeitel, W. (1981), S. 384.

$370 \mathrm{Vgl}$. die Ausfuhrungen oben in Abschnitt C.II.3. dieses Kapitels, S. 105ff.

371 Vgl. z.B. die Arbeit von Lieb, R. (1992).

372 Goodspeed zeigt in einer Analyse lokaler Einkommensteuern, daß auch auf subzentraler Ebene in eingeschranktem Maße selbst bei vollkommener Mobilitat der Haushalte gewunschte Umverteilungseffekte erzielt werden konnen. Siehe Goodspeed, T.J. (1989).

373 So insbesondere Musgrave, R.A. (1983).

374 Vgl. dazu auch Spahn, P.B. (1993), S. 18f.

375 Siehe insbesondere McLure, C.E. (1986). 
so sollte die gemeinsame Besteuerungsbasis nicht regional ungleich streuen ${ }^{376}$, denn die ungleiche räumliche Verteilung der Steuerbemessungsgrundlagen ermöglicht fiskalisch reicheren Regionen die Realisierung höherer fiskalischer Restwerte. Neben allokativ ineffizienten Wanderungsanreizen und der Möglichkeit des Steuerexports 377 ergibt sich bei Immobilität der Bevölkerung auch eine distributiv unerwünschte Ungleichbehandlung von Individuen gleicher ökonomischer Position. Daraus wird die Notwendigkeit zentraler Entscheidungshoheiten abgeleitet. 378

\section{b. Zur Zuordnung der Verschuldungskompetenzen im föderativen Staat}

\section{aa. Zur Übereinstimmung von Nutzern und Kostenträgern}

Die Übertragung des Kriteriums räumlicher Übereinstimmung von Nutzern und Kostenträgern bei der Zuordnung der Steuerkompetenzen führt bezüglich der öffentlichen Kreditaufnahme zur Fragestellung, wie die Lasten der Kreditaufnahme in räumlicher Sicht auf die Bürger verteilt werden. ${ }^{379} \mathrm{Im}$ Kern ist die Frage der Zuordnung von Verschuldungskompetenzen im föderativen Staat nach diesem Kriterium daher ein Aspekt der Wirkungsanalyse öffentlicher Verschuldung. ${ }^{380}$

Freilich liefert schon die theoretische Diskussion um die personale Inzidenz der staatlichen Kreditaufnahme keine eindeutigen Ergebnisse. Noch problematischer dürften daher Aussagen über die regionalen Verteilungswirkungen sein. Legt man die einfache, 'zahlungstechnische' Argumentation zeitlicher Lastverschiebung zugrunde, ist fur die Ermittlung der Belastungswirkungen die Inzidenz der zur Finanzierung von Zins- und Tilgungszahlungen herangezogenen Steuern maßgeblich. ${ }^{381}$ Schließt man sich der Behauptung des neoricardianischen Äquivalenztheorems an, Steuerfinanzierung und Staatsverschuldung seien letztlich äquivalent, käme es für die regionalen Verteilungswirkungen ebenfalls nicht auf die Kreditaufnahme selbst, sondern auf die Art der zukünftigen Steuerbelastung an.

\section{bb. Zum instrumentalen Charakter öffentlicher Verschuldung}

Zur Rechtfertigung der Staatsverschuldung werden sowohl allokations- wie auch konjunkturpolitische Argumente angeführt. ${ }^{382}$ Die jüngere stabilisierungspolitische Rechtfertigung sieht öffentliche Verschuldung v.a. als Instrument der antizyklischen Fiskalpolitik. Nach dem instrumental approach sollten daher stabilisierungspolitische Verschuldungskompetenzen den höheren Ebenen zugesprochen werden.

Kern der älteren allokationstheoretischen Begründung ist die These, daß mit Hilfe der öffentlichen Verschuldung eine zeitliche Verschiebung der aus den staatlichen Aktivitäten resultierenden Lasten erreicht werden könne. Da die Nutzen vieler öffentlicher Investitionen auch künttigen Generationen zukommen, sei es aus Gründen der allokativen Effizienz und der intergenerativen Gerechtigkeit sinnvoll, diese Investitionen über Kredite zu finanzieren ("payas-you-use-Prinzip"383). Während die Debatte über die zeitliche Verschiebung der Lasten

376 Vgl. etwa Matthews, R. (1983); Musgrave, R.A. (1983), S. 13; Spahn, P.B. (1993), S. $19 \mathrm{ff}$.

377 Vgl. Groenewegen, P. (1990), S. 104.

378 Vgl. Musgrave, R.A. (1983), S. $11 \mathrm{ff}$.

379 Vgl. Caesar, R. (1996), S. 160.

$380 \mathrm{Zu}$ einem Überblick siehe etwa Gandenberger, $O$. (1981).

$381 \mathrm{Vgl}$. Caesar, R. (1996), S. 160.

382 Siehe etwa Gandenberger, O. (1981) oder Caesar, R. (1993).

$383 \mathrm{Vgl}$. Musgrave, R.A./Musgrave, P.B./Kullmer, L. (1992), S. 146ff. 
interner Verschuldung zu keinem eindeutigen Ergebnis führt ${ }^{384}$, sei, so die These, die Außenverschuldung stets mit einem zukünftigen realen Ressourcentransfer an Gebietsfremde verbunden 385 , und eine zeitliche Lastverschiebung werde erreicht. 386 Oates folgert deshalb: "By virtue of its external character, bond finance at decentralized levels of government would thus appear to provide a means to an equitable allocation of the costs of capital projects among those who will share the benefits of the programs." 387 Dieser Effekt wird abgeschwächt, wenn eine Kapitalisierung der Steuerbelastung erfolgt, jedoch wiederum verstärkt, wenn ebenso die zukünftigen Nutzen aus lokalen Investitionsprojekten kapitalisiert werden. ${ }^{388}$ Verschuldungsrechte lokaler Einheiten könnten daher v.a. allokationspolitisch begründet werden.

\section{cc. Zum Argument der externen Effekte des Wettbewerbs subzentraler Einheiten}

Auch die Diskussion, ob die um mobile Faktoren konkurrierenden Gliedstaaten Anreize zu einer überoptimalen Verschuldung haben, wird kontrovers geführt. ${ }^{389}$ Einerseits wird vorgebracht, daß den lokalen Gebietskörperschaften teilweise eine Externalisierung der ökonomischen Konsequenzen der Staatsverschuldung möglich sei. Fiskalischer Wettbewerb würde dann dazu führen, daß sich die lokalen Gemeinwesen zur Attrahierung mobiler Faktoren übermäßig verschulden. Wird von den Bewohnern Gegenwartskonsum relativ hoch bewertet, kann sich die Neigung zu exzessiver lokaler Verschuldung verstärken. Das gilt v.a. dann, wenn mobile Steuerzahler der zukünftigen Belastung durch Abwanderung ausweichen können. 390 Allerdings ließe sich mit demselben Argument die Möglichkeit einer suboptimalen Verschuldung begründen. Wenn nämlich die Nutzen der durch Verschuldung finanzierten Projekte subzentraler Einheiten bei den mobilen Bewohnern nicht kapitalisiert werden, besteht die Gefahr einer Abwanderung der Bürger aufgrund der zukünftigen Zins- und Tilgungsverpflichtungen. Wird diese mögliche Reaktion antizipiert, unterbleibt auf dezentraler Ebene möglicherweise eine ökonomisch sinnvolle Finanzierung durch Kreditaufnahme. Bei Mobilität der Individuen ist damit für die Wirksamkeit einer marktlich erzwungenen Etatdisziplin insbesondere relevant, ob künftige Verbindlichkeiten in den Werten der immobilen Faktoren einer Jurisdiktion kapitalisiert werden. ${ }^{391}$ Damit wären interkollektiv abgestimmte oder zentral vorgegebene Verschuldungsregeln nur dann erforderlich, wenn die marktlichen Sanktionsmechanismen versagen. 392

Zusammenfassend betrachtet haben die Argumente, mit denen versucht wird, die Ineffizienz subzentraler Finanzierungsentscheidungen bei Steuerwettbewerb zu begründen, bei der lokalen Verschuldung allenfalls eingeschränkte Gültigkeit. Gerade bei der Kreditaufnahme würde ein funktionierender Zinsmechanismus die Entscheidungsträger zu einer Äquivalenzfinanzierung der Ausgaben veranlassen. Die Tendenz zu mangelnder Budgetdisziplin der föderativen Gliedstaaten ist allerdings um so größer, je stärker die marktlichen Sanktionseffekte einer übermäßigen Verschuldung durch eine Solidarhaftung der übrigen Einheiten ausgehebelt wer-

384 Vgl. Caesar, R. (1993), S.142f.

385 Vgl. King, D.N. (1984), S. 274; Musgrave, R.A./Musgrave, P.B./Kullmer, L. (1992), S. $157 \mathrm{ff}$.

386 Dies setzt natürlich voraus, daß nicht Teile der Steuerlasten auf Gebietsfremde exportiert werden.

387 Oates, W.E. (1972), S. 154. Vgl. auch Nowotny, E. (1979), S. 163ff.; Ziffer, S. (1980), S. 160ff.; Akai, N. (1994).

388 Vgl. Daly, G.G. (1969) und Oates, W.E. (1972), S. 155ff. Kritisch hierzu King, D.N. (1984), S. 274ff.

389 Einen Überblick geben Scheide, J./Trapp, B. (1991) und Caesar, R. (1994a). Zur Frage des optimalen Verschuldungsgrades lokaler Jurisdiktionen siehe etwa Breton, A. (1977).

390 Vgl. Wagner, R.E. (1970) und (1971), Aronson, J.R. (1971), King, D.N. (1984), S. $277 \mathrm{ff}$.

391 Vgl. Aronson, J.R. (1971), S. 108; King, D.N. (1984), S. $281 \mathrm{ff}$.

392 Vgl. Caesar, R. (1994a), S. $243 \mathrm{ff}$. 
den. Verschuldungsfreundliche Einheiten erleiden nur dann einen Zinsmalus, wenn auf konstitutioneller Ebene glaubwürdig eine no bail-out Klausel vereinbart wird, wonach die übrigen Gliedstaaten oder die Zentralregierung im Falle gravierender Verschuldungsprobleme einer Teileinheit nicht unterstützend einspringen. ${ }^{393}$

\section{dd. Zum Argument der unterschiedlichen Zugangsmöglichkeit zum Kapitalmarkt}

Das Funktionieren marktlicher Sanktionsmechanismen ist schließlich auch zentrales Argument gegen zentralstaatliche Interventionen aufgrund der vermeintlich geringeren Kreditwürdigkeit kleiner gebietskörperschaftlicher Einheiten. Sofern der Zinsmechanismus nämlich nicht durch Solidarhaftungsklauseln aufgeweicht wird, besteht kein Grund zu der Annahme, daß die Gliedstaaten einer Föderation allein aufgrund ihrer unterschiedlichen Größe differierende Zugangsmöglichkeiten zum Kapitalmarkt hätten. Entscheidend für ihre Kreditwürdigkeit wäre allein ihre Bonität, die jedoch vornehmlich davon abhängt, ob es sich um finanzpolitisch solide Schuldner handelt. Die Nivellierung der Konditionen durch eine zentralstaatliche anstelle einer autonomen subzentralen Verschuldungskompetenz wäre damit allokativ sogar eher schädlich. ${ }^{394}$

\section{Die Implikationen für die Zuordnung der Finanzierungskompetenzen}

Als Ergebnis kann festgehalten werden, daß allen Ebenen umfassende Freiheiten in der Gestaltung ihrer Ausgabenfinanzierung zugestanden werden sollten, denn effiziente Bereitstellungsentscheidungen einer Gebietskörperschaft implizieren eine volle Verantwortlichkeit für Ausgaben- wie Einnahmenentscheidungen. Aus dieser Sicht erscheint ein freies Trennsystem bei den Besteuerungskompetenzen besonders vorteilhaft. ${ }^{395}$

Es spricht auch aus diesem Blickwinkel nichts dagegen, daß mehrere jurisdiktionelle Ebenen Zugriff auf dieselbe steuerliche Bemessungsgrundlage haben. Einer Mehrfachbesteuerung könnte durch ein vertikal koordiniertes Steuerverrechnungssystem, sogenannte "offsets"396, entgegengewirkt werden. ${ }^{397}$ Allerdings könnte strategisches Verhalten der Einheiten zu einem teilweisen Export der Steuerlasten führen. ${ }^{398}$ Diese Nachteile würden durch den Übergang zu einem gebundenen Trennsystem vermieden.

Beschränkungen der Entscheidungsautonomie auf konstitutioneller Ebene erscheinen sinnvoll, wenn durch die Zuordnung der Objekthoheit für ein Finanzierungsinstrument ineffiziente Entscheidungen zu erwarten sind. Dies könnte der Fall sein, wenn subzentrale Einheiten interregional mobile Güter und Faktoren besteuern; bei der Verschuldung könnten externe Effekte über bundesstaatliche Zinssteigerungen entstehen.

Allerdings begründen diese Externalitäten bei näherer Betrachtung kaum ein Verbot bestimmter Finanzierungsformen für Gebietskörperschaften der unteren Ebenen. Erstens würden Ineffizienzen durch die äquivalente Zuordnung von Ausgaben und steuerlichen Instrumenten

393 Siehe hierzu fur den Fall der EG insbesondere von Hagen, J./Fratianni, M. (1991), S. 242.

394 Vgl. Caesar, R. (1996), S. 162.

395 Ähnlich Peffekoven, R. (1980), S. 619.

396 Peffekoven, R. (1980), S. 619.

397 Musgrave verweist darauf, daß die Ablehnung einer Doppelbesteuerung weniger auf ökonomischen Überlegungen als auf reinem "Ordnungssinn" beruhe. Musgrave, R.A. (1983), S. 14.

398 Siehe dazu ausfuhrlich Peffekoven, $R$. (1975), S. 17ff. 
verringert. Zweitens könnten die Ergebnisse aus der Perspektive des Fiskalföderalismus auch durch interkollektive Kooperation ${ }^{399}$ verbessert werden. Drittens spricht gegen Begrenzungen, daß Wanderungen mobiler Faktoren Ausdruck unterschiedlicher Präferenzen für Finanzierungssysteme sein können. Viertens ermöglichen vertikale und horizontale Finanzzuweisungen zumindest theoretisch Effizienzverbesserungen, ohne die Kompetenzen der subnationalen Einheiten radikal zu beschrănken. Diese Überlegungen gelten sinngemäß für die Verschuldung, zumal wenn die marktliche Sanktionierung exzessiver Kreditaufnahme wirksam ist.

Es ist deshalb anzunehmen, daß die Individuen auf konstitutioneller Ebene weitgehenden Beschränkungen der subzentralen Entscheidungsautonomie bezüglich der Finanzierung der bereitzustellenden Kollektivgüter nicht zustimmen würden.

\section{Der organisationskostenminimierende Staatsaufbau}

\section{Das Organisationskostenkonzept von Breton und Scott}

Obwohl der Grundgedanke, daß die optimale Organisationsstruktur des Staates von den Kosten der kollektiven Entscheidungsfindung bestimmt ist, in der Literatur von verschiedenen Autoren ansatzweise diskutiert wird ${ }^{400}$, wurde erst von den kanadischen Ökonomen Breton und Scott der Versuch unternommen, die Entscheidungsfindungskosten zum Ausgangspunkt einer ökonomischen Föderalismustheorie zu machen. Ihre Hauptarbeiten "The Assignment Problem in Federal Structures" (1977), "The Economic Constitution of Federal States" (1978) und "The Design of Federations" (1980) können deshalb als Pionierarbeiten einer institutionenökonomischen Theorie des Föderalismus verstanden werden. Breton/Scott begründen den von ihnen konstatierten Reformbedarf der "konventionellen Theorie"401 in der angeblichen empirischen Leere des Ansatzes ${ }^{402}$, die sich insbesondere darin äußere, daß "... in equilibrium, the number of government levels can be as large as the number of public goods supplied by the public sector." 403

Nach Auffassung von Breton und Scott begründet sich die mangelnde Aussagekraft des konventionellen Ansatzes darin, daß 404

- die verwendeten Kategorien von Nutzen und Kosten eines föderativen Systems in verschiedenen Dimensionen gemessen würden und daher nicht gegeneinander aufrechenbar seien,

- sich die Analyse bestenfalls separat auf eine Funktion beschränken könne,

- die Betrachtungen häufig nicht auf Funktionen des Staates, sondern auf Einzelmaßnahmen innerhalb staatlicher Funktionen abstellen. Die technologische Sichtweise der Theorie

399 So v.a. Oates, W.E. (1972), S. 148f.; Break, G.F. (1980), Kap. 2; Musgrave, R.A. (1983), S. 6 ff.

400 Namentlich Tullock, G. (1969a); Oates, W.E. (1972), Kap. 2; Theiler, J. (1977); Frey, R.L. (1977), S. $31 \mathrm{ff}$. und Kirsch, G. (1978), die kollektivinternen Entscheidungsfindungskosten und interkollektiven Verhandlungskosten fur die Gestaltung des Staatsaufbaus hohe Bedeutung beimessen.

401 Breton, A.Scott, A. (1980), S. 22. Alternativ bezeichnen die Autoren diesen Ansatz auch als "traditional" oder "orthodox". Breton, A./Scott, A. (1977), S. 344 und (1978), S. 34.

402 Breton, A./Scott, A. (1977), S. 345.

403 Breton, A./Scott, A. (1977), S. 345.

$404 \mathrm{Vgl}$. Breton, A./Scott, A. (1980), S. $22 \mathrm{f}$. 
impliziere dabei, daß post-konstitutionelle Bereitstellungsentscheidungen einer Jurisdiktion das Nutzen-Kosten-Kalkül des Staatsaufbaus beeinflussen würden und deshalb wiederum zu Änderungen der optimalen föderativen Struktur führen müßten. ${ }^{405}$

Damit würden die wirklichen Bestimmungsfaktoren des Staatsaufbaus, als welche Breton und Scott die sogenannten "Organisationskosten" 406 des öffentlichen Sektors identifizieren, keine oder allenfalls unzureichende Beachtung finden. Ihre Ablehnung der konventionellen Theorie beruht auf derselben Erkenntnis wie die Feststellung von Coase, daß der neoklassische Ansatz ungeeignet ist, das Entstehen von Unternehmen im marktlichen System zu erklären. ${ }^{407} \mathrm{Sie}$ folgern, daß die Begründung für einen dezentral oder zentral organisierten Staat nicht unmittelbar über die Eigenschaften von staatlich bereitgestellten Gütern erfolgen könne. Breton und Scott richten folglich das Hauptaugenmerk ihrer Diskussion auf die "organizational activities"408 der Bürger und der staatlichen Agenten. Nach ihrer Auffassung begründen allein die Kosten dieser Aktivitäten, welche Organisationsform wünschenswert ist:

\footnotetext{
"We conclude that in a world of zero organizational costs, the search for a theory of the structure of the public sector or of federalism is fruitless. The basic question of such a theory - that of the assignment of functions - does not even arise!"409
}

Im Verlauf des dritten Kapitels wurde festgestellt, daß den Ansätzen der konventionellen Theorie meist nicht explizit formulierte Annahmen zugrunde liegen 410 , ohne die die dort abgeleiteten Resultate nicht begründbar wären. In der oben diskutierten Literatur wurde gezeigt,

- daß das Dezentralisierungstheorem auf der Annahme beruht, in subzentralen Einheiten sei die korrekte Erfassung von Bürgerpräferenzen kostengünstiger als auf zentraler Ebene,

- daß die Frage, wie die Internalisierung räumlicher spillover-Effekte und die Ausschöpfung von Skalenvorteilen im Konsum erfolgen soll, von den anfallenden Koordinationskosten bestimmt ist, und

- daß die Vorteile der Präferenzoffenbarung durch interjurisdiktionelle Wanderungen von den Mobilitätskosten der Bürger abhängig sind.

Diese Thesen werden von Breton und Scott aufgegriffen und explizit zur Basis ihrer Überlegungen gemacht. In Analogie zum Transaktionskostenansatz argumentieren sie, daß allein die unvollständige Information Ansatzpunkt für eine Theorie des Entstehens und der Struktur von Organisationen sein könne. ${ }^{411}$ Im einzelnen identifizieren sie vier Komponenten von

405 Vgl. dazu insbesondere Breton, A./Scott, A. (1977), S. 346f.

406 Breton, A./Scott, A. (1978), S. 35.

407 Breton und Scott berufen sich auch ausdrucklich auf die Erorterungen von Coase zur "Nature of the firm".Siehe Breton, A./Scott, A. (1977), S. 346 und (1978), S. 7. Vgl. auch Brennan, G. (1979), S. 1051.

408 Breton, A./Scott, A. (1978), S. 31.

409 Breton, A./Scott, A. (1978), S. 41.

410 Vgl. Breton, A./Scott, A. (1978), S. 35.

411 "It is only when we drop the idea that utility functions are known and that benefit taxes can be levied, but still hold to the notion that public goods generating spill-overs and that production processes with economies of scale that cannot be exploited costlessly also exist, that the full package of organizational costs appears and provides us with a rationale for a public sector structure." Breton, A./Scott, A. (1978), S. 47. 
Organisationskosten des öffentlichen Sektors. ${ }^{412}$ Die erste Kategorie bezeichnet die Kosten, die bei der Bereitstellung öffentlicher Aktivitäten durch Politiker und Bürokraten entstehen. Darunter fallen

- Verwaltungskosten ("administration costs"), unter denen die "... costs of setting up and the operation of governmental units"413 ebenso wie die Kosten der Entscheidungsfindung der Regierung verstanden werden. Breton und Scott verstehen unter den Verwaltungskosten die Kosten der internen Koordination jeder Regierungseinheit, sie umfassen insbesondere die oben diskutierten Suchkosten einer Ermittlung der Bürgerpräferenzen.414 Nicht zu den Verwaltungskosten zählen die Produktionskosten der angebotenen Leistungen.

- Externe Koordinationskosten ("co-ordination costs") der interjurisdiktionellen Kooperation der Regierungen, die bei Verhandlungen über die Internalisierung räumlicher externer Effekte entstehen.

In der Summe bilden die Elemente der Verwaltungskosten und der Koordinationskosten die Organisationskosten der Regierung $\left(\mathrm{O}^{\mathrm{R}}\right)$. Hinzu kommen die Kosten, die die Bürger zahlen, um im öffentlichen Sektor mitzubestimmen. Nach Breton und Scott bestehen die Organisationskosten der Bürger $\left(\mathrm{O}^{\mathrm{B}}\right)$ aus den

- "signalling costs" der Präferenzoffenbarung durch die diversen Instrumente der voiceOption und den

- Mobilitätskosten ("mobility costs") der Präferenzbekundung durch Wanderungen zwischen den Jurisdiktionen, d.h. durch die exit-Option.

Wenngleich die Verwaltungs- und die Koordinationskosten formal auf der Anbieterseite der öffentlichen Leistungen anfallen, so sind es doch stets die Bürger des Staates, die die Kosten der organisatorischen Aktivitäten zu tragen haben. Für die Bestimmung des optimalen Zentralisierungsgrades einer Staatsaufgabe macht es daher, so die These, keinen Unterschied, auf welcher Seite der Organisation (Regierung oder Bürger) die Kosten entstehen. ${ }^{415}$

Aufgabe sei es nun, den Zentralisierungsgrad zu finden, welcher die Erledigung der dem Staat übertragenen Funktionen zu minimalen Organisationskosten ermögliche. ${ }^{416}$ Breton und Scott analysieren, wie eine verfassunggebende Versammlung die Zuordnung der Funktionen regeln würde und betrachten vermutete Ergebnisse der Aufgabenverteilung in Abhängigkeit von der Größe und der Besetzung der konstitutionellen Konferenz. ${ }^{417}$ Sie unterscheiden zwischen Versammlungen, die nur aus eigennutzorientierten Politikern und Bürokraten bestehen, und einem Konvent, der sich aus den Staatsbürgern zusammensetzt. Für unsere Überlegungen ist ausschließlich die reine Bürgerversammlung von Bedeutung, denn nur hier können die Ergebnisse gewonnen werden, die im Rahmen des konstitutionellen Denkansatzes eine nor-

412 Siehe Breton, A./Scott, A. (1977), S. 351 ff.; (1978), S. 7 ff. und S. $31 \mathrm{ff}$. sowie (1980), S. $23 \mathrm{ff}$. Ähnlich auch Hansmeyer, K.-H./Kops, M. (1984), S. $129 \mathrm{f}$.

413 Breton, A./Scott, A. (1978), S. 59. Siehe auch Breton, A. (1978), S. 47.

414 Vgl. Breton, A./Scott, A. (1978), S. 32.

415 Vgl. Breton, A./Scott, A. (1978), S. 101.

416 Siehe Breton, A.Scott, A. (1978), Kap. 7 und 8 sowie (1980), S. 23ff. und Kap. 3.

417 Siehe Breton, A./Scott, A. (1978), S. 62ff. sowie (1980), Kap. 3. 
mative Rechtfertigung finden. Die Betrachtungen beschränken sich daher auf das "least cost model" 418 von Breton und Scott.

\section{Die organisationskostenminimale Staatsstruktur}

Ausgangspunkt der weiteren Überlegungen von Breton und Scott ist das Investitionskalkül der politischen Agenten und der Bürger hinsichtlich der von ihnen im politischen Prozeß - beim 'organisatorischen Handeln' - eingesetzten Ressourcen. Zur Ermittlung kostenminimaler Staatsstrukturen leiten Breton und Scott funktionale Zusammenhänge zwischen den vier Komponenten der Organisationskosten und dem Zentralisierungsgrad $\gamma$ des öffentlichen Sektors ab. Der Zentralisierungsgrad $\gamma$ wird dabei als kontinuierliche Variable zwischen Null (völlige Dezentralisierung) und Eins (völlige Zentralisierung) interpretiert. ${ }^{419}$

Die Autoren nehmen an, daß die Individuen über eine fixe Kapitalausstattung verfügen und bestimmen für einen gegebenen Zinssatz, der die Opportunitätskosten organisatorischer Aktivitäten reflektiert, wieviele Ressourcen von den Politikern/Bürokraten in interne und externe Koordination, bzw. von den Bürgern in voice und exit, bei variierendem Zentralisierungsgrad $\gamma$ investiert werden. ${ }^{420}$ Der organisationskostenminimale Staatsaufbau ist erreicht, wenn die zur Realisierung gegebener, unvermeidlicher Frustrationskosten erforderlichen politischen Investitionsausgaben minimiert sind. ${ }^{421}$

Auf der Seite der staatlichen Agenten gehen Breton und Scott davon aus, daß lokale Einheiten über Kostenvorteile bei der Ermittlung der Bürgerpräferenzen verfügen. Dieser Effekt werde jedoch durch höhere Kosten einer Vielzahl von Verwaltungseinheiten in stark dezentralisierten Systemen aufgehoben, so daß für die Beziehung von administrativen Kosten A und Zentralisierungsgrad $\gamma$ gelte 422
(3.C.VI.1)
$(\partial \mathrm{A} / \partial \gamma)=0$

Die externen Koordinationskosten $\mathrm{K}$ zur Internalisierung räumlicher spillover-Effekte sinken dagegen mit geringerer Zahl der Gemeinwesen, und man erhält ${ }^{423}$

418 Breton, A./Scott, A. (1978), S. 68.

419 Vgl. Breton, A./Scott, A. (1978), S. $22 \mathrm{ff}$.

420 Siehe Breton, A./Scott, A. (1978), S. 52ff. und S. $58 \mathrm{ff}$.

421 Diese Annahme wird von Breton und Scott nicht explizit getroffen, weil ihre Ausfuhrungen positiv-theoretisch fundiert sind. Die normative Interpretation des Organisationskostenmodells ist zurlickzufuhren auf Breton, A. (1978), S. 49, wo explizit die Annahme getroffen wird, daß die verfassunggebende Versammlung "... sich davon leiten laßt, die Organisationskosten des offentlichen Sektors zu minimieren."

$422 \mathrm{Vgl}$. Breton, A./Scott, A. (1977), S. 353 und (1978), S. 60f. Ähnlich auch Hansmeyer, K.-H./Kops, M. (1984), S. 129. Wust fuhrt in diesem Zusammenhang aus: "Da die Ausgaben fur Verwaltung recht unterschiedliche Komponenten umfassen, kann man nicht eindeutig angeben, wie sie sich verăndern, wenn der Zentralisationsgrad $(\gamma)$ etwa steigt. Einerseits fallen mit sinkender Anzahl selbstăndiger Gemeinwesen etwa diejenigen Ausgaben, die fur den Unterhalt der lokalen Regierungen notwendig wären. Andererseits sind aus dem Blickwinkel der ubergeordneten 'Ebene' die Praferenzen der Bürger fur nicht-nationale Einheiten heterogen. Für eine unitarische oder bürgerferne Regierung ist es aber vergleichsweise teuer, die Wunsche ihrer Bürger zu enthullen und das Angebot răumlich danach zu differenzieren. Wust, H.F. (1981), S. 196. (Hervorhebungen im Original).

423 Vgl. dazu v.a. Kirsch, G. (1978), S. 20ff. und (1980), S. 168ff. 


$$
(\partial \mathrm{K} / \partial \gamma)<0
$$

Die Aktivitäten der Bürger erfolgen mit dem Ziel, Bereitstellungsentscheidungen so zu beeinflussen, daß das Kollektivgüterangebot den eigenen Präferenzen besser entspricht, der Frustrationsgrad also reduziert wird. ${ }^{424}$ Hierzu verfügen sie über die Optionen voice und exit. Die Annahmen von Breton und Scott bezüglich der Präferenzoffenbarungskosten durch voice (signalling costs S) sind in ihren verschiedenen Arbeiten nicht eindeutig. Folgt man der Annahme aus ihrer Arbeit "The Design of Federations"425, so sind die Kosten einer Veränderung des politischen Outputs um so größer, je größer der Zentralisierungsgrad $\gamma$ ist. Zur Reduzierung der Frustrationskosten seien im unitarischen System daher größere Investitionen in signalling erforderlich als bei dezentralen Bereitstellungskompetenzen:

$$
(\partial \mathrm{S} / \partial \gamma)>0
$$

Eindeutig fallen demgegenüber die Aussagen von Breton und Scott hinsichtlich der Kosten M einer Präferenzoffenbarung durch räumliche Migration aus. Bei gegebenen Migrationskosten sinken die möglichen Erträge einer Abwanderung mit steigendem Zentralisierungsgrad $\gamma$, weil sich für die potentiellen Migranten die möglichen Alternativen verringern. Bei unitarischen Bereitstellungskompetenzen existiert keine Möglichkeit, durch Abwanderung die Präferenzen zu bekunden; $M$ ist dann unendlich hoch. ${ }^{426}$ Daher gilt

$$
(\partial \mathrm{M} / \partial \gamma)>0
$$

Zur Ermittlung der optimalen Organisationsstruktur des Staates genügt es nach Breton und Scott allerdings nicht, die Kostenkomponenten zu summieren, denn Wechselbeziehungen zwischen den Elementen der Organisationskosten müßten einbezogen werden. ${ }^{427}$ Die Autoren nehmen an, daß Abwanderungen und intensiver politischer Widerspruch der Bürger wachsende Koordinationsbemühungen der Regierungen 428 und unveränderte administrative Kosten $^{429}$ zur Folge haben. Umgekehrt würden intensive organisatorische Aktivitäten der

424 "Citizens invest time and money in political participation ... because the use of resources in these activities reduces the amount of frustration they have to endure." Breton, A./Scott, A. (1978), S. 54.

425 Dort nehmen Breton/Scott an, es sei "... less costly for citizens to signal their preferences to governments that are smaller and closer geographically because the smaller the territory the more homogenous are the citizens' preferences." Breton, A./Scott, A. (1980), S. xvi. Auch in ihrer Vorarbeit aus dem Jahre 1977 gehen sie davon aus, daß die signalling costs mit fortschreitender Zentralisierung ansteigen. Vgl. Breton, A./Scott, A. (1978), S. 354. In der "Economic Constitution of Federal States" nehmen sie an, daß keine klare Aussage uber die Abhăngigkeit der signalling-Aktivităten vom Zentralisierungsgrad getroffen werden könne. Vgl. Breton, A./Scott, A. (1978), S. 56f. In einer Einzelveroffentlichung unterstellt Breton, "... daß sich die Kosten der Präferenzłußerung bei einer Änderung des Zentralisierungsgrades nicht andern." Breton, A. (1978), S. 48.

$426 \mathrm{Vgl}$. Breton, A./Scott, A. (1978), S. 57.

427 Ausfuhrlich hierzu Breton, A./Scott, A. (1978), S. $70 \mathrm{ff}$.

$428 \mathrm{Vgl}$. Breton, A./Scott, A. (1978), S. 71. Ursăchlich hierfur sei, daß die Unzufriedenheit der Burger von den Regierungen zum Anlaß genommen werde, nach Kooperationsmoglichkeiten zu suchen, um eine suboptimale Versorgung zu beseitigen.

429 Einerseits bedeute intensive politische Aktiviăt der Burger, daß die Regierungen weniger Ressourcen in die Erforschung der Bürgerprăferenzen investieren maßten, andererseits stiegen die Aufwendungen fur die Suche nach praferenzadăquaten Politiken. Breton und Scott nehmen an, daß sich die beiden Effekte ungefahr ausgleichen. Siehe Breton, A./Scott, A. (1978), S. 71. 
Politiker zu geringeren Abwanderungs- und Widerspruchsaktivitäten der Bürger führen. Aus Sicht der Bürger seien Aktivitäten der Regierungen Substitute für eigene Anstrengungen. Dabei nehmen Breton und Scott an, daß die verstärkten Aktivitäten der politischen Agenten eine Verringerung der Frustrationskosten für die Bürger mit sich bringen und diese deshalb weniger in eigenes politisches Engagement investieren würden. ${ }^{430}$

Auf Basis dieser Überlegungen leiten Breton/Scott Reaktionsfunktionen für die Bürger (Regierungen) ab, die die Investitionen der Bürger (Regierungen) bei steigenden Aktivitäten der staatlichen Akteure (Bürger) für einen gegebenen Zentralisierungsgrad $\gamma$ abbilden. In Abbildung 3.10 ist der Zusammenhang dargestellt. Unter den gegebenen Annahmen hat die Reaktionskurve $\mathbf{R}(\gamma)$ der Regierung einen steigenden Verlauf, die Reaktionskurve $\mathbf{B}(\gamma)$ der Bürger verläuft fallend. Bei einem Zentralisierungsgrad $\gamma_{0}$ ergeben sich die zugehörigen Reaktionsfunktionen $R_{0}$ und $B_{0}$. Unter den gemachten Annahmen werden Bürger und Regierungen ihre "organizational activities" 431 solange verändern, bis ein organisatorisches Gleichgewicht im Schnittpunkt $\mathrm{E}_{0}$ erreicht ist. Die Organisationskosten auf Bürgerseite betragen $0 \mathrm{~F}$, auf Regierungsseite $0 \mathrm{~A}$.

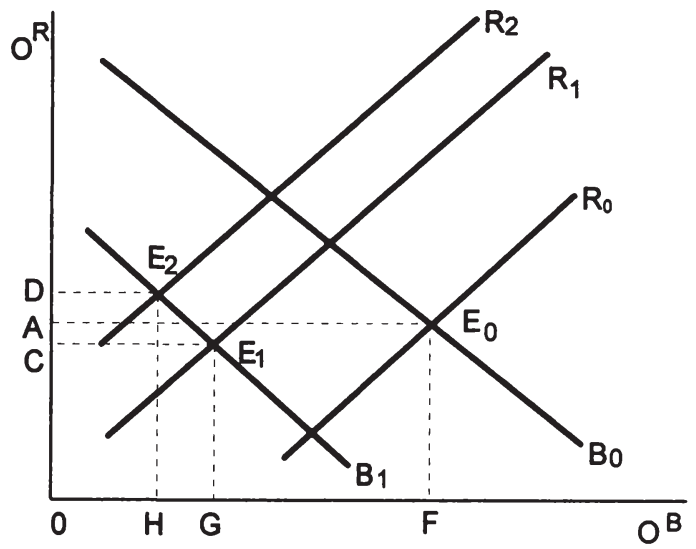

Abbildung 3.10: Organisatorische Aktivitäten und Zentralisierungsgrad

Quelle: in Anlehung an Breton, A./Scott, A. (1978), S. 73.

Verringert man gedanklich den Zentralisierungsgrad auf $\gamma_{1}$, verschiebt sich die Reaktionskurve der Bürger aufgrund der Zusammenhänge (3.C.VI.3-4) nach unten auf $B_{1}$. Die Reaktionskurve der Regierung verschiebt sich bei Gultigkeit der Funktionszusammenhänge (3.C.VI.1-2) nach oben. Fällt die Verschiebung gering aus, z.B. auf $R_{1}$, erhält man ein neues Gleichgewicht in $\mathrm{E}_{1}$, bei dem die gesamten Organisationskosten $0 \mathrm{C}+0 \mathrm{G}$ betragen und damit eindeutig geringer sind als bei $\gamma_{0}$. In diesem Fall sind die Organisationskosten auf beiden Seiten gefallen: die organisatorischen Aktivitäten von Regierung und Bürgern sind komple-

430 Siehe Breton, A./Scott, A. (1978), S. 71.

431 Breton, A./Scott, A. (1978), S. 31. 
mentär. Gilt der komplementäre Zusammenhang für alle Zentralisierungsgrade $\gamma$, wäre das logische Ergebnis, daß bei perfekter Dezentralisierung, also für $\gamma=0$, die Summe der Organisationskosten minimal ist.

Fällt dagegen die Linksverschiebung der R-Kurve stärker aus, wie z.B. auf $R_{2}$, ist zwar die Summe der Organisationskosten im Gleichgewicht $\mathrm{E}_{2}$ gesunken, denn $0 \mathrm{D}+0 \mathrm{H}<0 \mathrm{~A}+0 \mathrm{~F}$. Der Verringerung der Organisationsaktivitäten auf Bürgerseite steht aber ein Anstieg der organisatorischen Aktivitäten der Regierungen gegenüber. Bei höherem $\gamma$ investieren die Bürger mehr in Abwanderung und Widerspruch, allein aus dem Grund, weil die Regierung ihre organisatorischen Aktivitäten einschränkt. Offenkundig liegt hier ein substitutiver Zusammenhang vor: Mit zunehmender Dezentralisierung fallen die Organisationskosten der Bürger und die der Regierung steigen an.

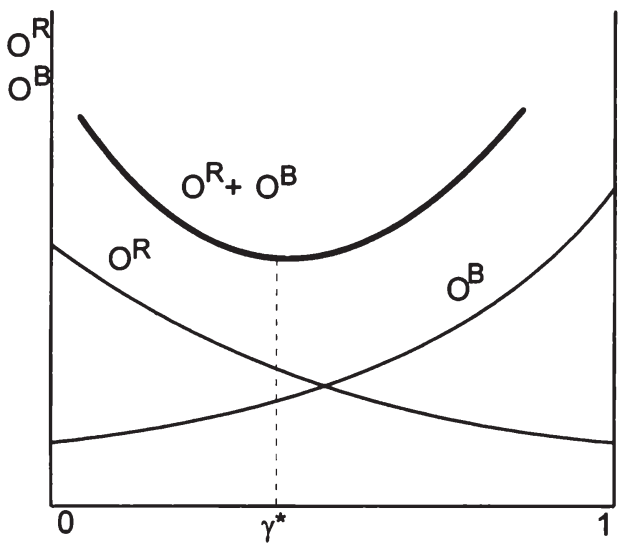

\section{Abbildung 3.11: Organisationskostenminimum und Zentralisierungsgrad \\ Quelle: in Anlehnung an Breton, A./Scott, A. (1978), S. 75.}

Für die Fälle substitutiver Beziehungen läßt sich eine funktionale Abhängigkeit der organisatorischen Aktivitäten vom Zentralisierungsgrad $\gamma$ konstruieren, wie sie in Abbildung 3.11 illustriert ist. Dort wird angenommen, daß mit zunehmender Zentralisierung der Verantwortlichkeiten die Investitionen der Bürger in politische Partizipation (voice und exit) ansteigen, die der Regierungen hingegen fallen. Das Organisationskostenminimum liegt dort, wo die Aggregation der Kurven $\mathrm{O}^{\mathrm{R}}$ und $\mathrm{O}^{\mathrm{B}}$ ein Minimum hat $\left(\gamma^{*}\right)$. Ein optimaler Zentralisierungsgrad $0<\gamma^{*}<1$ existiert nur, wenn $\mathrm{O}^{\mathrm{R}}$ und $\mathrm{O}^{\mathrm{B}}$ substitutiv verbunden sind. ${ }^{432}$

Das Konzept von Breton und Scott ermöglicht also unter bestimmten Bedingungen die Ableitung einer organisationskostenminimierenden Staatsstruktur. Entscheidende Faktoren sind die organisatorischen Aktivitäten der Bürger und Regierungen, die bei der Bereitstellung von Kollektivgütern erforderlich sind. Das Aufgabenzuweisungsmodell von Breton und Scott liefert allgemeine Kriterien, nach denen die Zuordnung der Kompetenzen erfolgen kann. Sie versuchen nicht, ein optimales Aufgabenverteilungsmodell vorzulegen. 433 


\section{Die Reduzierung der Organisationskosten durch multifunktionale Einheiten}

Fruchtbare Anwendung findet das Organisationskostenkonzept vor allem bei der Frage, ob für einzelne Politikbereiche selbständige Bereitstellungseinheiten gebildet werden sollten, oder ob vielmehr durch die Zusammenlegung von Funktionen Einsparungen von Organisationskosten erreicht werden. Bislang wurde implizit davon ausgegangen, daß Entscheidungseinheiten jeweils für nur eine staatliche Funktion oder öffentliche Leistung verantwortlich sind, die Kompetenzen der Jurisdiktionen sind monofunktional. Hieraus ergeben sich zwei Probleme, die zu einem Anstieg der Organisationskosten des öffentlichen Sektors führen.

Erstens sind alle Bürger gleichzeitig Mitglieder vieler verschiedener Kollektive, da für jede Bereitstellungsentscheidung nur eine separate Einheit verantwortlich ist. Bei der großen Zahl von Gütern, die durch den Staat bereitgestellt werden, so die These, sind die Kosten der politischen Partizipation und die administrativen Kosten vieler monofunktionaler Einheiten außerordentlich hoch. ${ }^{434}$ Durch die Zusammenlegung mehrerer Funktionen bei einer Entscheidungseinheit kann daher eine Reduktion der Organisationskosten erreicht werden. So ist die Existenz von Organisationskosten Ursache dafür, daß nicht für jede öffentliche Leistung eine eigene Entscheidungseinheit gebildet werden kann, sondern daß vielmehr Leistungen bei einer einzigen Einheit zusammengefaßt werden sollten, die dann für die Bereitstellung mehrerer Kollektivgüter gleichzeitig verantwortlich ist ("clustering"435). Prinzipiell bietet sich an, die Kompetenzen für die Bereitstellung öffentlicher Güter, deren benefit areas annähernd identisch sind, bei einer Einheit zu konzentrieren. 436

Die Zuordnung der Verantwortlichkeiten an monofunktionale Kollektive ist außerdem mit dem Problem verbunden, daß die Politikbereiche nicht unabhängig voneinander sind. Bereits bei der Zuweisung von allokativen, redistributiven und stabilisierungspolitischen Kompetenzen an eine Ebene entstehen Zielkonflikte ${ }^{437}$, die durch eine nur im politischen Prozeß mögliche Gewichtung der Zielvorstellungen gelöst werden können. $\mathrm{Zu}$ vermuten ist deshalb, daß die Zuweisung von Entscheidungskompetenzen an verschiedene Ebenen im föderativen Staat noch konfliktträchtiger ist. 438 Deshalb wäre eine intensive externe Koordination verschiedener Entscheidungsträger erforderlich. 439

So ist zu beachten, daß z.B. die Zentralisierung distributionspolitischer Zuständigkeiten auch den Mitteleinsatz weitgehend determiniert. Damit müßte in Kauf genommen werden, daß lokale Kompetenzen im allokativen Bereich durch Entscheidungen der Zentralebene ausgehöhlt werden, zumal die Entscheidung über Umfang und Struktur des öffentlichen Leistungsangebots häufig auch verteilungspolitisch motiviert ist. ${ }^{440}$ Desgleichen sind viele allokative Ausgaben aufgrund ihres investiven Charakters ein bedeutendes Instrument der kurzfristigen Stabilitätspolitik, so daß Spannungen zwischen zentralen und lokalen Entscheidungsträgern

434 Siehe z.B. Tullock, G. (1969a); Oates, W.E. (1972), S. 49; Bulutoglu, K. (1976), S. 20; Fisher, R.C. (1988), S. 86f.; Biehl, D. (1991), S. 367. Kritisch dazu Teutemann, M. (1992), S.187ff.

435 Oates, W.E. (1972), S. 49. Siehe auch Tullock, G. (1969a), S. 28.

436 Vgl. Fisher, R.C. (1988), S. 85f. oder Biehl, D. (1991), S. 367.

437 Siehe Musgrave, R.A. (1959/1969), S. 44ff.

438 Vgl. insbesondere Dafflon, B. (1977), S. 180ff. und Hanusch, H. (1979).

439 Abstimmungsprobleme im 'kooperativen Föderalismus' werden z.B. erörtert bei Haller, H. (1968); Füchsel, W.-D. (1985), S. 182ff. und Wiseman, J. (1989), insbes. S. $106 \mathrm{ff}$.

440 Vgl. Netzer, D. (1974), S. 375; King, D.N. (1984); Kap. 9 oder Thöni, E. (1986), S. 51. 
auftreten können. ${ }^{441}$ Auch hier könnte es sinnvoll sein, mehr als eine Funktion bei einer Jurisdiktion anzusiedeln, wenn dadurch externe Koordinationskosten verringert werden und der Ausgleich widerstreitender Zielvorstellungen kollektivintern besser erfolgen kann. ${ }^{442}$ Zwar könnten durch multifunktionale Entscheidungskollektive Organisationskosten eingespart werden; es sind aber auch Organisationskosten, die der Konzentration von Zuständigkeiten bei einer Einheit entgegenstehen. Insbesondere wäre zu bedenken, daß durch die Zusammenlegung von Funktionen Organisationskosten für die Bürger und Regierungen wachsen könnten. ${ }^{443}$ Abweichungen von der optimalen monofunktionalen Jurisdiktionsgröße implizieren Wohlfahrtsverluste, die nur durch verstärkte organisatorische Aktivitäten - und damit verbundene höhere Kosten - beseitigt werden können.

\section{Eine kritische Würdigung des Organisationskostenkonzepts von Breton und Scott}

Breton und Scott zeigen, daß die Interdependenz der Organisationskosten des Staates ein bestimmender Faktor der ökonomisch optimalen Staatsstruktur ist. Sie betonen, daß die Transaktionskosten, die aus spezifischen Eigenschaften der vom öffentlichen Sektor bereitgestellten Güter resultieren, die optimale Zuordnung von Verantwortlichkeiten nicht vollständig determinieren. Der organisationskostenminimierende Staatsaufbau kann erst ermittelt werden, wenn neben der direkten funktionalen Abhängigkeit der Kosten vom Zentralisierungsgrad die Wechselwirkungen zwischen den Kostenkomponenten bekannt sind.

Natürlich wird damit die Bestimmung des optimalen Zentralisierungsgrades zu einem sehr komplexen Problem. Vernachlässigt man hingegen Kosteninterdependenzen, liefert das hier dargestellte transaktionskostentheoretische Modell gegenüber den traditionellen wohlfahrtsökonomischen Ansätzen nur wenig neue Erkenntnisse. Der Wert des Aufgabenverteilungsmodells von Breton und Scott zeigt sich vor allem bei zwei Problemaspekten:

Erstens hebt die Analyse mit den Organisationskosten die Bestimmungsfaktoren für die Gestaltung des Staatsaufbaus hervor. Das optimale Design der Staatsstruktur wird nicht von technischen Faktoren bestimmt, sondern von organisatorischen Aktivitäten. Die Existenz von Organisationskosten limitiert die Größe von Jurisdiktionen nach unten (vorwiegend durch die Existenz externer Koordinationskosten) und nach oben (durch Informations- und Mobilitätskosten). ${ }^{444}$ Sie liefert damit auch eine rationale Erklärung dafür, daß nicht alle kollektivexternen Effekte durch die Ausweitung der Bereitstellungskompetenzen internalisiert werden sollten. ${ }^{445}$ Mit Hilfe des Organisationskostenkonzepts finden zudem Abweichungen von einer einfachen Organisationsstruktur, bei der jeweils nur eine Ebene des föderativen Staates für eine Funktion alleinverantwortlich ist, eine ökonomische Begründung, denn durch vertikale Koordination verschiedener Regierungsebenen bei der Wahrnehmung einer oder mehrerer Funktionen sind möglicherweise bessere Ergebnisse zu erzielen als durch Aufgabenzuordnung

441 Vgl. Hanusch, H. (1979), S. 368.

442 Externe Koordinationskosten fallen also nicht nur bei horizontaler, sondern auch bei vertikaler Koordination an. Vgl. Breton, A./Scott, A. (1978), S. 33.

443 So etwa Biehl, D. (1991), S. 369f.

444 Vgl. auch Wagner, R.E. (1983), S. 454f. Es wird daher explizit der These von Brennan und Buchanan widersprochen, die Theorie des Fiskalfoderalismus biete "... keine Grundlage fur die Ableitung einer großenmaßigen Obergrenze der politischen Körperschaften." Brennan, G./Buchanan, J.M. (1980/1988), S. 220 (Hervorhebung im Original).

445 Vgl. Tullock, G. (1969a). 
auf nur eine Ebene. Erst in der Welt mit Organisationskosten können Vor- und Nachteile unterschiedlicher Organisationsformen aufgezeigt werden. 446 Schließlich erlaubt es das Konzept, spezielle Fragestellungen der Allokations-, Distributions und Stabilisierungsfunktionen mit Hilfe des gleichen Instrumentariums zu erörtern.

Zweitens ist es das Verdienst von Breton und Scott, daß die den einzelnen Modellen der traditionellen Theorie des Fiskalföderalismus inhärente einseitige Fixierung auf angebots- oder nachfrageseitige Betrachtungen aufgehoben wird. 447 Erst bei simultaner Betrachtung von Kostenaspekten der Staatsorganisation auf Seiten der Regierung und der Bürger ist die Suche nach einer wohlfahrtsmaximierenden Staatsstruktur fruchtbar.

Kritik ist aus zweierlei Perspektiven zu üben: Erstens sind die Mutmaßungen über die Abhängigkeit der Organisationskosten vom Zentralisierungsgrad der Kompetenzen eher spekulative ad hoc-Annahmen als empirisch oder positiv-theoretisch fundierte Fakten. ${ }^{448}$ Mit diesen Vermutungen steht und fällt aber die gesamte Analyse. Dies gilt besonders für die Erörterungen zu den Informationskosten im politischen Prozeß. Wie die nähere Betrachtung im nächsten Kapitel zeigen wird, kann nicht a priori davon ausgegangen werden, daß die Zusammenhänge in der postulierten Weise existieren.

Zweitens unterstellen Breton und Scott, daß die politischen Mechanismen so wirksam sind, daß die Regierungen aller Ebenen immer das Ziel der Wohlfahrtsmaximierung ihrer Bürger verfolgen müßten. So kritisiert Brennan:

"Once the possibility that governments may be substantially imperfect is taken seriously, however, the whole objective of minimizing transaction costs between levels of government becomes questionable..."449

Damit haben die beiden Autoren zwar aus institutionenökonomischem Blickwinkel einen Schritt in die richtige Richtung getan, ihr Organisationskostenkonzept schöpft aber nicht die ganze Fülle des neoinstitutionalistischen Denkansatzes aus. ${ }^{450}$ Die von Brennan vorgetragene Kritik ist um so schwerwiegender, weil die Überlegungen von Breton und Scott damit eine fundamental neue Bewertung erfahren müssen. Die Notwendigkeit verfassungsmäßiger Beschränkungen des Staatshandelns wird bei Breton und Scott aufgrund der Annahmen über die Effizienz politischer Entscheidungsprozesse nicht beachtet. Die Autoren vernachlässigen die Rolle der Abwanderung als Instrument der politischen Disziplinierung der Regierungen ebenso wie die Möglichkeit, daß die Koordination der finanzpolitischen Aktivitäten lokaler Regierungen der Ausbeutung der Bürger dienen kann. ${ }^{451}$ In den folgenden beiden Kapiteln wird deshalb die hier geäußerte Kritik an Breton und Scott zum Anlaß genommen, eine Modifizierung ihrer Analyse vorzunehmen und den zweiten Aspekt des grundlegenden Organisationsdilemmas in die Theorie zu integrieren.

446 Vgl. Breton, A./Scott, A. (1978), S. 47.

447 Vgl. Brennan, G. (1979), S. 1052.

448 Vgl. auch Thöni, E. (1986), S. 103.

449 Brennan, G. (1979), S. 1052. Ebenso Thöni, E. (1986), S. 103f.

450 Wie Brennan feststellt, "My complaint is that they have not gone far enough." Brennan, G. (1979), S. 1052.

451 Vgl. Brennan, G. (1979), S. 1052. 


\section{Zusammenfassende Thesen zum dritten Kapitel}

1. Die Theorie des Fiskalföderalismus ermittelt, wie die Individuen auf konstitutioneller Ebene die Verteilung der Entscheidungsrechte im Staat vornehmen würden, wenn sie davon ausgehen, die politischen Entscheidungsmechanismen sind effizient und opportunistisches Verhalten der staatlichen Akteure daher nicht zu erwarten.

2. Eine einheitliche Privatrechtsordnung ist die Grundlage für marktliche Arbeitsteilung, da unterschiedliche Rechtssysteme zu höheren Transaktionskosten führen. Die Schaffung eines uniformen 'Welt-Privatrechts' ist jedoch nicht optimal, weil die Durchsetzungskosten des protektiven Staates mit zunehmender Mitgliederzahl progressiv steigen.

3. Im produktiven Staat sind Regeln über die Zuordnung von Bereitstellungskompetenzen (Aufgaben- und Finanzierungskompetenzen) zu treffen. Dabei sind vielfältige Koordinationsformen zwischen völliger Dezentralisierung und reiner Zentralisierung zu unterscheiden.

4. Ausgangspunkte der Überlegungen zur Zuordnung der Allokationsfunktion sind das Prinzip fiskalischer Äquivalenz und die Theorie der Clubgüter. Danach ergeben sich aus Kosten-Nutzen-Erwägungen optimale personelle Größen für Kollektive. Das Dezentralisierungstheorem liefert die informationsökonomisch fundierte Begründung dafür, daß allokative Bereitstellungskompetenzen prinzipiell dezentral angesiedelt sein sollten.

5. Dezentrale Entscheidungen führen zu Wohlfahrtsverlusten bei der Bereitstellung von Kollektivgütern mit größerer räumlicher Nutzenstreuung. Theoretisch können diese Externalitäten durch Verhandlungen lokaler Einheiten und Finanzzuweisungen zentraler Jurisdiktionen internalisiert werden, ohne die Bereitstellungskompetenzen auf eine zentrale Ebene im Staat zu verlagern. Während aber die Verhandlungslösung mit externen Koordinationskosten verbunden ist, führt die Finanztransferlösung zu einem Anstieg der Informationskosten.

6. Das Informationsproblem kann verringert werden, wenn Individuen durch interkollektive Wanderungen ihre Präferenzen für Kollektivgüter offenlegen. Präferenzoffenbarung durch räumliche Mobilität setzt dezentrale Verantwortlichkeiten voraus. Jedoch nur bei einer adäquaten Ausstattung der subzentralen Einheiten mit steuerpolitischen Instrumenten können die Wanderungsbewegungen mobiler Faktoren zu effizienten Ergebnissen führen.

7. Bei der Zuordnung der stabilisierungs- und distributionspolitischen Kompetenzen sind dieselben Zielkonflikte auszumachen wie bei der Allokationsaufgabe. Einerseits liegen Informations- und Migrationskostenvorteile dezentraler Bereitstellungskompetenzen vor; andererseits müssen diese Vorteile mit den erhöhten Koordinationskosten bei dezentralen Entscheidungen abgewogen werden.

8. Die Zuweisung der Finanzierungskompetenzen richtet sich nach der Verteilung der Aufgabenverantwortlichkeiten. Wesentliche Zuordnungskriterien sind die Sicherung der Finanzautonomie der staatlichen Einheiten, die regionale Inzidenz der Lastverteilung, die instrumentale Eignung der Einnahmearten und der Ausgleich von Finanzbedarf und Finanzkraft.

9. Informations-, Mobilitäts- und Koordinationskosten sind Transaktionskosten, die als Organisationskosten des Staatsaufbaus bezeichnet werden. Der Zentralisierungsgrad der Zuständigkeiten ist ein Bestimmungsfaktor der Kosten organisatorischer Aktivitäten. Föderative Strukturen führen zu Verringerungen der Organisationskosten. 


\section{Kapitel: Eine Public Choice-Analyse politischer Entscheidungsprozesse im föderativen System}

\section{A. Die Wesensmerkmale der Public Choice-Theorie}

Das vierte Kapitel dient der Untersuchung der Frage, ob die bisher verwendeten Hypothesen über die angeblichen Vorteile einer präferenzadäquate(re)n Bereitstellung durch dezentrale Kompetenzen Allgemeingültigkeit beanspruchen können oder ob sie gegebenenfalls zugunsten anderer Annahmen modifiziert oder revidiert werden müssen. In der Theorie des Fiscal Federalism werden die Regierungen als wohlwollende Agenten modelliert, deren Entscheidungen das Ziel einer Maximierung der Vorteile für die Bürger ihrer Jurisdiktionen zugrunde liegt. Dieses Bild ist kennzeichnend für die ursprüngliche Sicht einer politischen Vertretertheorie. ${ }^{1}$ Die Sichtweise ist jedoch stark simplifizierend und versperrt den Blick für das Dilemma der Organisation im Staat. Vertritt das Management nicht uneigennützig die Ziele der Mitglieder, sind die Opportunismusgefahren bei der Delegation von Kompetenzen Faktoren, die bei der Festlegung der Organisationsstruktur des Staates Berücksichtigung finden müssen. Die Public Choice-Theorie (Neue Politische Ökonomie, Ökonomische Theorie der Politik ${ }^{2}$ ) liefert das analytische Instrumentarium zur Analyse dieser Fragestellungen.

Gemeinsames Thema aller Vertreter der Public Choice-Schule ist die Überzeugung, daß sich die Menschen auch im politischen Raum rational und eigennützig verhalten. Eigennutzstreben im politischen Prozeß unterscheidet sich aus dem Public Choice-Blickwinkel nicht prinzipiell vom Nutzenmaximierungsstreben im privaten Sektor, allerdings differieren die institutionellen Rahmenbedingungen des Handelns: ${ }^{3}$ "The relevant difference between markets and politics does not lie in the kinds of values/interests that persons pursue, but in the conditions under which they pursue their interests." 4 Die institutionenökonomische Politikanalyse untersucht deshalb, welche "systemimmanenten Handlungsmaximen"5 sich für die handelnden Akteure aus dem institutionellen Rahmen der politischen Prozesse ergeben.

Das individualistische Prinzip der Analyse legt es nahe, politische Entscheidungsvorgänge als Tauschprozesse zu interpretieren. ${ }^{6}$ Analog zur Tauschtheorie des Marktes treten Individuen in Interaktion, wenn sie sich aus einer (politischen) Transaktion individuelle Vorteile erwarten. Die Neue Politische Ökonomie untersucht mithin den Tauschprozeß "politischer Güter"7 im produktiven Staat. Durch die Wahl des Begriffs "politische Güter" soll dokumentiert werden, daß es sich um Güter handelt, über deren Bereitstellung im politischen Prozeß entschieden wird. Die Public Choice-Theorie trägt dem Umstand Rechnung, daß für normative Analysen die Unterscheidung allokations-, stabilisierungs- und distributionspolitischer Aktivitäten ein

1 Vgl. dazu Schumpeter, J.A. (1942/1950), S. 397ff.; Herder-Dorneich, P./Groser, M. (1977), S. 60ff.

2 Als fruhe Hauptwerke sind Downs, A. (1957/1968); Harding, F.O. (1959); Buchanan, J.M./Tullock, G. (1962); Olson, M. (1965/1992); Niskanen, W.A. (1971) einzustufen. Als deren Vorlăufer dürfen Wicksell, $K$. (1896) und Schumpeter, J.A. (1942/1950) gelten. Einen aktuellen Überblick uber die Public ChoiceTheorie gibt Mueller, D.C. (1989).

3 Vgl. Downs, A. (1957/1968), S. 278; Mc Cormick, R.E./Tollison, R.D. (1981), S. 5ff.

4 Buchanan, J.M. (1987b), S. 246.

5 Herder-Dorneich, P./Groser, M. (1977), S. 33f.

6 Vgl. insbesondere Buchanan, J.M. (1987b), S. 246; Herder-Dorneich, P./Groser, M. (1977), S. 42ff. und S. 58.

$7 \quad$ Herder-Dorneich, P./Groser, M. (1977), S. 55. 
theoretisch fruchtbares Konzept sein kann, daß aber dieser Differenzierung im politischen Prozeß eher geringe Bedeutung zukommt.

Das Abwägen der Vorteilhaftigkeit von Transaktionen beschränkt sich freilich nicht nur auf die Verwirklichung materieller Ziele wie die Steigerung von persönlichem Einkommen oder Vermögen. Gerade im politischen Sektor sind viele Entscheidungen von nicht-monetären, ideologischen Erwägungen geleitet. ${ }^{8}$ Die Anwendung eines ökonomischen Modells auf die Entscheidungsprozesse im öffentlichen Sektor, häufig kritisiert als Ausdruck eines "ökonomischen Imperialismus"9, impliziert daher nicht, daß z.B. altruistische Elemente in politischen Entscheidungen keinen Platz finden.

\section{B. Die neoinstitutionalistische Perspektive politischer Entscheidungs- prozesse}

\section{Das Interaktionsgeflecht politischer Akteure im Überblick}

Die Analyse politischer Entscheidungsmechanismen setzt die Identifikation der "treibenden Kräfte der finanzpolitischen Meinungs- und Willensbildung" 10 voraus. Als Akteure stehen in Modellen der indirekten Demokratie auf der Nachfrageseite politischer Güter die Bürger. Sie offenbaren ihre Nachfrage als Wähler und als Mitglieder organisierter Interessengruppen. Die Anbieterseite wird zum einen von den Politikern in Parlament, Parteien und Regierung, zum anderen durch die staatliche Bürokratie repräsentiert. ${ }^{11}$ Auch bei der Betrachtung der Organisationen des politischen Handelns, wie den Parteien, den Verbänden oder der Bürokratie, findet das Postulat des methodologischen Individualismus grundsätzlich Anwendung. ${ }^{12}$ Allerdings werden in den Fällen, in denen dies zweckmäßig ist, die Organisationen selbst als handelnde korporative Akteure modelliert.

Politische Entscheidungen sind das Ergebnis der Interaktionen aller Akteure. Die Interdependenzen der Beteiligten können in einem einfachen Schema politischer Entscheidungsabläufe in der indirekten Demokratie dargestellt werden. Die durchgezogenen Linien in Abbildung 4.1 bezeichnen die direkten Wirkungen, die von einer Gruppierung auf andere Akteure ausgehen, bzw. die direkten Auswirkungen des staatlichen Outputs auf die relevanten Gruppen. Unterbrochene Linien sind als indirekte Einflüsse (durch politische Werbung, Informationspolitik etc.) $\mathrm{zu}$ interpretieren.

8 Vgl. die Erörterungen von Rowley, C.K. (1992), Kap. 12. Siehe auch Kirsch, G. (1993), S. $5 \mathrm{ff}$.

9 Siehe hierzu etwa Hirshleifer, J. (1985); Frey, B.S. (1990), S. $18 f$.

10 Schmölders, G. (1970), S. 94.

11 Die strikte Trennung von legislativer Gewalt (Parlament) und exekutiver Gewalt (Regierung und Burokratie) ist in dieser Form in der politischen Realităt nicht vorzufinden. Tatsächlich liegt in vielen parlamentarischen Systemen die gesetzgeberische Entscheidungsgewalt faktisch bei der Regierung. Siehe dazu Steffani, $W$. (1969), S. $331 \mathrm{ff}$. Deshalb wird hier und im folgenden die Regierung vereinfachend als (Teil der) Legislative modelliert. Auf die Betrachtung der Rolle der Judikative wird hier verzichtet.

12 Vgl. z.B. Moe, T. (1980), S. $73 \mathrm{ff}$. 


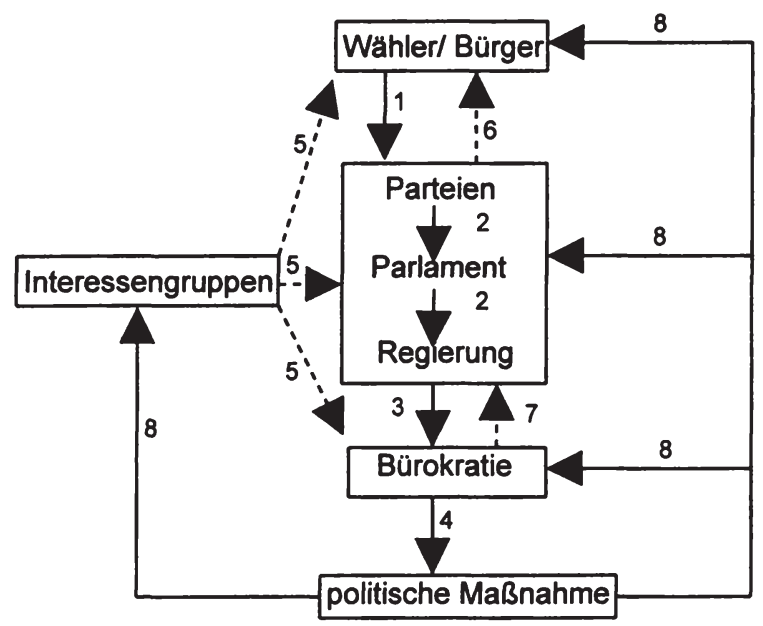

1 Die Wahler bestimmen die Zusammensetzung des Parlaments

2 Die Politiker (Parteien, Parlament und Regierung) entscheiden uber die durchzufuhrenden Maßnahmen

3 Die Regierung beauftragt die Burokratie mit der Produktion der Leistungen und kontrolliert die Verwaltung

4 Die Bürokratie fuhrt die Produktion der Leistungen durch

5 Interessengruppen wirken auf Entscheidungen der Wahler, Politiker und Burokraten ein 13

6 Politiker bieten den Wahlem politische Programme an

7 Burokraten beeinflussen uber ihre Informationspolitik die Politiker

8 Staatliche Outputs wirken auf die Nutzenpositionen aller Beteiligten

\section{Abbildung 4.1: Das Interaktionsgeflecht politischer Entscheidungen}

Quelle: in Anlehnung an Atkinson, A.B./Stiglitz, J.E. (1980), S. 296

\section{Die ökonomische Theorie des politischen Wettbewerbs um Wählerstimmen}

\section{Die Ziele der Wähler, der Politiker und der Parteien}

Die Organisationsmacht der Staatsbürger ist in der indirekten Demokratie auf der Wahl der entscheidungsbevollmächtigten Politiker begründet. ${ }^{14}$ In ihrer Rolle als Wähler entscheiden die Mitglieder eines Staatswesens darüber, wer die Regierungsverantwortung übernehmen soll. ${ }^{15}$ Rationalverhalten bei der Wahlentscheidung impliziert nach Downs, daß die Wähler ihre Stimme dem Kandidaten geben, von dem sie sich die größten Netto-Nutzen aus der

13 Es ist naturlich nicht ausgeschlossen, daß zwischen Politikern, Burokraten und Mitgliedern von Interessengruppen personelle Überschneidungen bestehen. Insbesondere sind in der Regel Verbandsmitglieder und offentliche Bedienstete auch Wahlberechtigte.

14 Es wird angenommen, daß die politischen Entscheidungen durch Mehrheitswahl getroffen werden. Von der Existenz einer Abwanderungsoption wird in diesem Kapitel noch abstrahiert.

15 Vgl. Downs, A. (1957/1968), S. 23. Gleichzeitig ist die Wahl eine "Signalvorrichtung", da sie einen Urteilsspruch uber die Leistungen der Regierung darstellt. Downs, A. (1957/1968), S. 40. 
Regierungstätigkeit erwarten. ${ }^{16}$ Das Wahlverhalten der Bürger ist überdies von ideologischen Faktoren und Loyalitätsbeziehungen zu einzelnen Politikern und/oder Parteien beeinflußt. ${ }^{17}$

Auch das persönliche Nutzenstreben der Politiker ist auf die Verwirklichung materieller (z.B. Einkommen) und immaterieller (Prestige, weltanschauliche Überzeugung) Zielvorstellungen gerichtet. ${ }^{18}$ Sie können diese Ziele durch die Wahrnehmung von Ämtern in politischen Organisationen erreichen. Gleichwohl hängt der Erfolg von Politikern letztlich davon ab, daß sie in die Regierungsverantwortung gewählt werden. Die ökonomische Theorie der Politik geht daher davon aus, daß die Handlungen der Politiker darauf abzielen, Wahlen zu gewinnen ${ }^{19}$, denn die Ausübung von Regierungsämtern ermöglicht ihnen die Erlangung finanzieller Vorteile und die Umsetzung ideologischer Vorstellungen. ${ }^{20}$

Um gewählt zu werden, müssen die Kandidaten bei Gültigkeit der Mehrheitswahl ihre politischen Programmangebote an die Wähler so gestalten, daß sie mindestens $50 \%$ plus eine Stimme der abgegebenen Voten erreichen. Als konkrete Handlungsmaxime kann für die Politiker daher die Erreichung einer ausreichenden Mehrheit zur Ämterübernahme angenommen werden. ${ }^{21}$ Opportunistisches Politikerverhalten impliziert, daß Ressourcen, die nicht zur Gewinnung von Wählerstimmen eingesetzt werden müssen, von den Regierenden zur Realisierung persönlicher Vorteile eingesetzt werden. 22 Üblicherweise wird angenommen, daß intensive Konkurrenz um Wählerstimmen den Druck auf die Politiker vergrößert, ihre Programme so zu formulieren, daß die erwartete Stimmenzahl maximiert wird. Mangelnder oder fehlender Wettbewerb verringert nach gängiger Ansicht den Stimmenmaximierungsanreiz. ${ }^{23}$ Die Integration von Parteien in die Analysen verändert zwar nicht die Zielfunktion der Politiker. In ihren Aktivitäten müssen sie aber beachten, daß sie, um als Kandidaten nominiert zu werden, parteiinterne Mehrheiten erreichen müssen. Die Programmangebote sind damit schon allein deshalb nicht zwingend mit wählerstimmenmaximierenden Offerten identisch. ${ }^{24}$

\section{Die These von der Effizienz des politischen Wettbewerbs um Wählerstimmen}

Ausgangspunkt der ökonomischen Analyse von Wettbewerbsprozessen in repräsentativen Demokratien ist die fundamentale Arbeit von Downs ${ }^{25}$ aus dem Jahre 1957, die ihrerseits auf Vorarbeiten von Hotelling, Smithies und Schumpeter beruht. ${ }^{26}$ Downs behandelt in seinem

16 Vgl. Downs, A. (1957/1968), S. 7; Herder-Dorneich, P./Groser, M. (1977), S. 104.

17 Vgl. z.B. Bernholz, P./Breyer, F. (1994), S.110ff.

18 Vgl. z.B. Black, G. (1972), S. 144.

19 Vgl. etwa Downs, A. (1957/1968), S. 30; Mayhew, D.R. (1987), S. $18 \mathrm{ff}$.

20 Als finanzielle Vorteile kommen die direkte Entlohnung der Tătigkeit oder die Beteiligung an Sondervergünstigungen spezieller Interessen in Frage. Vgl. dazu Margolis, J. (1974), S. 302ff. Ideologische Aspekte werden behandelt bei Hansson, I./Stuart, C. (1984) und Wittman, D. (1990).

21 Vgl. Frey, B.S./Lau, L. (1968), S. 358; van Winden, F. (1983), S. 155.

22 Vgl. etwa Brennan, G./Buchanan, J.M. (1980/1988); Bernholz, P./Breyer, F. (1994), S. $109 \mathrm{f}$.

23 Vgl. Black, G. (1972), S. 145f.; Herder-Dorneich, P./Groser, M. (1977), S. 91 f.

24 Vgl. Coleman, J.S. (1971). Für uberwiegenden Teil der Arbeit sei allerdings angenommen, daß Parteien wie Einzelpersonen zu behandeln sind. Vgl. Downs, A. (1957/1968), S. 25.

25 Siehe Downs, $A$. (1957/1968).

26 Siehe Hotelling, H. (1929); Smithies, A. (1941); Schumpeter, J.A. (1942/1950), insbes. Kap. 22. 
Werk "Ökonomische Theorie der Demokratie" die Konkurrenz der Parteien um Wählerstimmen in einem räumlichen Demokratiemodell. 27

Kern der Überlegungen von Downs ist die Übertragung marktlicher Wettbewerbsgedanken auf den Bereich politischer Entscheidungen. Eigennützige Politiker streben politische Ämter durch Wahl an; eigennützige Wähler geben der Partei ihre Stimme, von der sie sich bei Regierungsübernahme die größten Nutzen versprechen. Die Bereitstellung öffentlicher Leistungen ist insofern nur das Nebenprodukt des Ämterstrebens der Politiker. ${ }^{28}$

In der "Gewißheitswelt"29, d.h. bei Vorliegen vollkommener Information auf Seiten der Wähler und Politiker, führt der Wettbewerb zweier Kandidaten um Wählerstimmen zu einem effizienten öffentlichen Leistungsangebot. ${ }^{30}$ Die politischen Programme konvergieren unter diesen Bedingungen zur Position des Medianwählers im Spektrum der Wählerpräferenzen. ${ }^{31}$ Es taucht kein agency-Problem auf, denn jede Abweichung vom effizienten Programmangebot durch eine Partei führt zum Verlust der Wahl. Der Wettbewerbsdruck eliminiert opportunistisches Verhalten und zwingt die Politiker zu einem Angebot politischer Güter, das den Wählerpräferenzen entspricht. Analog zum mikroökonomischen Ideal der vollkommenen Konkurrenz und der vollständigen Kontrakte, in dem es keinen Raum für Opportunismus gibt, existieren im Grundmodell von Downs keine Handlungsspielräume für die Politiker zur Verfolgung von Interessen, die denen der Wähler entgegenstehen. 32

Dieses Nirwana-Ergebnis ist die Konsequenz der restriktiven Modellprämissen. ${ }^{33}$ Eine nähere Betrachtung des institutionellen Rahmens und die Berücksichtigung von Transaktionskosten führt zu einem differenzierteren und weit weniger optimistischen Bild über die Ergebnisse des politischen Wettbewerbs. Wie im folgenden zu zeigen ist, eröffnen die institutionellen Rahmenbedingungen des politischen Wettbewerbs den Politikern Handlungsspielräume, die sie opportunistisch zu Lasten der Wähler ausnützen können.

\section{Die Unvollkommenheiten des Wettbewerbs um Wählerstimmen}

\section{a. Intransitive Ergebnisse und Stimmentausch}

Die behauptete Effizienz der Parteienkonkurrenz beruht auf der Annahme, daß vollkommener Wettbewerb zwischen den rivalisierenden Kandidaten eindeutige Abstimmungsergebnisse generiert. Freilich ist bereits seit langem die mangelnde Eindeutigkeit der Ergebnisse einer Mehrheitsabstimmung als "Condorcet-Paradoxon"34 bekannt. Kollektiventscheidungen über mehr als zwei Alternativen führen unter der Annahme mehrgipfliger Präferenzordnungen der

27 Siehe insbesondere Kapitel 8 bei Downs, A. (1957/1968). Der Begriff 'răumliches Modell' bezieht sich auf die Verteilung der Wahlerprăferenzen in einem 'răumlichen' Links-Rechts-Kontinuum. Zu neueren Entwicklungen răumlicher Wahlmodelle siehe etwa Enelow, J.L./Hinich, M.J. (1990). Vgl. Downs, A. (1957/1968), S. 27ff.

29 Downs, A. (1957/1968), S. 32.

30 Vgl. etwa Shubik, M. (1968), S. 341 ff. oder van den Doel, H. (1979), S. 114; S. 117.

31 Vgl. z.B. Herder-Dorneich, P./Groser, M. (1977), S. $121 \mathrm{ff}$,; Bernholz, P./Breyer, F. (1994), S. $101 \mathrm{ff}$.

32 Vgl. Demsetz, H. (1982), S. 69.

33 Vgl. z.B. van den Doel, H. (1979), S. $110 \mathrm{ff}$; Rowley, C.K. (1984), S. $105 \mathrm{f}$.

34 Bernholz, P./Breyer, F. (1994), S. 54. 
Abstimmungsbeteiligten häufig zu intransitiven Gruppenentscheidungen. ${ }^{35}$ Damit läßt sich bei einfacher Mehrheitswahl ein Wahlsieger nicht zweifelsfrei bestimmen. ${ }^{36}$ Je größer die Zahl der Entscheidungsbeteiligten und je größer die Zahl der zur Wahl stehenden alternativen Programme oder Kandidaten ${ }^{37}$ ist, desto wahrscheinlicher wird das Auftreten instabiler zyklischer Majoritäten. ${ }^{38}$ Insbesondere reine Umverteilungsfragen führen theoretisch zu ständig wechselnden Wahlgewinnern. 39

Auch kann die Mehrparteien-Konkurrenz die Wähler veranlassen, aus strategischen Gründen ihre Stimme nicht der eigentlich präferierten Partei zu geben. ${ }^{40}$ Strategische Stimmabgabe verwässert den Informationsgehalt der Wahlentscheidung für die Politiker, und für die Wähler steigt die Unsicherheit über das zu erwartende Regierungsprogramm. ${ }^{41}$ Darüber hinaus sind die Parteien nicht gezwungen, sich auf stimmenmaximale Positionen festzulegen, denn die Bildung der kleinsten Gewinnkoalition ${ }^{42}$ ermöglicht auch eine Regierungsbeteiligung bei geringerer Stimmenzahl. ${ }^{43}$ In gleicher Weise führt die faktisch gegebene Mehrdimensionalität der zur Wahl stehenden Programme; von wenig realistischen Ausnahmen abgesehen ${ }^{44}$, zu zyklischen Mehrheiten, die sich bereits im Zwei-Parteien-System in einer permanenten Abwahl der Regierung äußern würden. 45

Die theoretisch ermittelte Instabilität der Mehrheitsentscheidungen ist jedoch in der politischen Realität so nicht zu beobachten. Ursächlich für dieses Mißverhältnis von Theorie und Empirie ist die in den Modellen der Wahltheorie fehlende Berücksichtigung institutioneller Faktoren, die die Stabilität der Ergebnisse sichern. ${ }^{46}$ Gerade aufgrund der Mehrstufigkeit der Wahlprozesse in der indirekten Demokratie existieren Mechanismen, die das Auftreten von Zyklen verhindern, gleichzeitig aber den Politikern Spielräume für opportunistisches Verhalten eröffnen.

Die Aufstellung von Parteiprogrammen vor den eigentlichen Wahlen bietet den ersten Ansatzpunkt. Da die Abstimmung der Bürger nicht über einzelne Sachfragen, sondern über ein ganzes Bündel politischer Güter erfolgt, haben die Kandidaten die Möglichkeit, in ihren Programmangeboten auch von den Wählern nicht gewünschte Güter unterzubringen. ${ }^{47}$ Das Zustandekommen der Programmpakete erfolgt in einem Stimmentausch-Prozeß (log rolling ${ }^{48}$, und es kann a priori nicht gesagt werden, ob dessen Ergebnisse per saldo wohl-

35 Siehe grundlegend Black, D. (1948). Das Condorcet-Paradoxon ist Ausdruck des grundlegenden Problems der Aggregation individueller Praferenzen zu einer konsistenten gesellschaftlichen Wohlfahrtsfunktion. Siehe hierzu Arrow, K.J. (1963b).

$36 \mathrm{Vgl}$ unter vielen Mueller, D.C. (1989), S. 62ff.

37 Vgl. Riker, W.H. (1962); Schofield, N. (1981).

38 Vgl. etwa Plott, C.R. (1967); Niemi, R.G. (1969); Riker, W.H./Ordeshook, P. (1973).

39 Vgl. z.B. die Darstellungen bei Knappe, E. (1985), S. 99ff.; Bernholz, P./Breyer, F. (1994), S. 59ff.;

40 Siehe etwa Riker, W.H./Ordeshook, P. (1973) oder Bernholz, P./Breyer, F. (1994), S. $126 \mathrm{f}$.

$41 \mathrm{Vgl}$. Bernholz, P./Breyer, F. (1994), S. 126.

42 Siehe Riker, W.H. (1962), S. 32. Siehe auch Herder-Dorneich, P./Groser, M. (1977), S. 184ff.

$43 \mathrm{Vgl}$. Rowley, C.K. (1984), S. 118.

44 Vgl. die Ausfuhrungen bei Bernholz, P./Breyer, F. (1994), S. 62ff.

45 Vgl. Downs, A. (1957/1968), S. 54ff.; Plott, C.R. (1967); McKelvey, R.D. (1976).

$46 \mathrm{Vgl}$. Shepsle, K./Weingast, B. (1981), die in diesem Zusammenhang von "strukturinduzierten Gleichgewichten" sprechen. Siehe dazu insbesondere auch Tullock, G. (1981a); Hill, J.S. (1985).

47 Vgl. Mackay, R.J./Weaver, C.L. (1981); Rowley, C.K. (1992), S. 81. Breton bezeichnet diesen Sachverhalt auch als "full-line supply". Breton, $A$. (1974), S. 50.

$48 \mathrm{Vgl}$. Breton, A. (1974), S. 126ff. Siehe auch Knappe, E. (1985), S. $102 \mathrm{f}$. 
fahrtsmindernd oder -erhöhend sind. ${ }^{49}$ Die Bündelung unterschiedlicher Sachfragen in einem Parteiprogramm (packaging) beschränkt allerdings in jedem Fall die Wahlalternativen und ist mit dem Verlust an Auswahlmöglichkeiten für die Bürger verbunden. ${ }^{50}$

Wie von Schmölders beschrieben, sind für die Vorlage der im Parlament zur Abstimmung stehenden Programme meist entscheidungsvorbereitende Ausschüsse ausschlaggebend, die überwiegend mit Spezialisten in den zu entscheidenden Sachfragen besetzt sind. ${ }^{51}$ In ihrer Rolle als gatekeeper reduzieren die Ausschußmitglieder die Bedeutung von Zyklen durch ihre Einflußmöglichkeiten auf die politische Agenda. ${ }^{52}$ Durch strategische Festlegung der zur Abstimmung gelangenden Alternativenmenge und der Abstimmungsreihenfolge können die Ausschußmitglieder die Entscheidungsergebnisse im Eigeninteresse manipulieren - dieser Aspekt gewinnt vor allem bei der Betrachtung des Verbandseinflusses zusätzlich an Bedeutung.

\section{b. Mangelnder politischer Wettbewerb}

Die Gültigkeit der Effizienzhypothese setzt vollkommene Beweglichkeit der Parteien im Spektrum der Wählerpräferenzen voraus. Diese Mobilität kann nicht angenommen werden, wenn Parteiideologien eine Bewegung zur Mitte abbremsen ${ }^{53}$ oder wenn die längerfristige politische Glaubwürdigkeit der Bewerber durch häufig wechselnde Positionen beeinträchtigt wird. ${ }^{54}$ Zudem müssen die Kandidaten bei ihren Programmangeboten berücksichtigen, daß sie sich durch die Annäherung an die Medianposition von den politischen Extremen immer weiter entfernen. Dies kann Wahlabstinenz durch Entfremdung zur Folge haben; Bürger, deren politische Vorstellungen durch die existierenden Parteien nicht mehr ausreichend repräsentiert werden, enthalten sich der Stimme ${ }^{55}$, oder politische Unternehmer werden die Entfremdung der Wähler von den Parteien zur Gründung neuer Parteien nützen. ${ }^{56}$ Das Problem der Wahlabstinenz ist deshalb evident, weil die Wahlbeteiligung zwischen unterschiedlichen gesellschaftlichen Gruppen oftmals erheblich differiert und daher die abgegebenen Stimmen die Präferenzen der Gesamtbevölkerung nur unzureichend widerspiegeln. ${ }^{57}$

49 Ausfuhrlich dazu Tullock, G. (1959); Buchanan, J.M./Tullock, G. (1962), Kap. 10; Bernholz, P. (1973); Riker, W.H./Brams, S.J. (1973). Vgl. auch den Überblick bei Mueller, D.C. (1989), S. 82ff.

50 Vgl. z.B. Hinich, M.J. (1978); Rowley, C.K. (1984), S. 113ff. Dies erklärt auch die Konzentration von Wahlkămpfen auf sehr wenige, hăufig sogar nur ein oder zwei, politische Zielbereiche. Vgl. Koford, B.K. (1982), S. 11f.; Knappe, E. (1985), S. 103f. In den Modellen zu mehrdimensionalen Entscheidungen wird daher unterstellt, bei ihrer Wahlentscheidung geben die Wăhler den Kandidaten ihre Stimme, deren Programmangebote zu den geringsten eigenen Verlusten (Abweichungen von der individuell am höchsten praferierten Kombination) fuhrt. Siehe etwa Davis, O./Hinich, M.J./Ordeshook, P. (1970), S. 429ff.

51 Siehe Schmölders, G. (1970), S. 100ff.

52 Vgl. Shepsle, K. (1979).

53 Vgl. Downs, $A$. (1957/1968), S. 106ff.

54 Vgl. etwa Enelow, J.L./Hinich, M.J. (1984); Rowley, C.K. (1992), S. 80; Kirsch, G. (1993), S. 238f.

55 Ausfuhrlich dazu Hinich, M.J./Ordeshook, P. (1969); Herder-Dorneich, P./Groser, M. (1977), S. 128ff. Bei unimodal-symmetrischer Verteilung der Wählerpraferenzen uber das gesamte politische Spektrum spielt Wahlabstinenz aufgrund von Indifferenz oder Entfremdung fur das Medianergebnis keine Rolle. Siehe Hinich, M.J./Ordeshook, P. (1969). Dies gilt nicht bei asymmetrischen und/oder multimodalen Verteilungen: hier erfolgt die Annăherung an die Modalwerte, vgl. Davis, O./Hinich, M.J./Ordeshook,P. (1970); Comanor, W.S. (1976).

56 Vgl. z.B. Hinich, M.J./Ordeshook, P. (1970), S. 786.

57 Vgl. Aranson, P.H. (1989), S. 103f. Insbesondere ist anzunehmen, daß vor allem ärmere Bevölkerungsschichten sich der Stimme enthalten. Siehe dazu Frey, B.S. (1971); Barzel, Y./Silberberg, E. (1973). 
Effizienz der Ergebnisse demokratischen Konkurrenz ist außerdem nur gewährleistet, wenn die Wahlvorgänge permanent erfolgen, denn die Kontrolle der Politiker durch die Bürger erfolgt erst durch die nächstfolgende Wahl. ${ }^{58}$ Längere Legislaturperioden bedeuten dagegen, daß die Konkurrenz um die Regierungsverantwortung über einen gewissen Zeitraum hinweg nur potentiellen Charakter hat. Die Regierung unterliegt keiner laufenden Kontrolle durch die Wähler, was zu einer temporären Monopolstellung der Regierenden führt. 59 Vor allem nach einer Wahl werden damit der Regierung diskretionäre Spielräume eröffnet. Sieht man von gewaltsamen, revolutionären Umstürzen ab, bleibt die Regierungsmacht für die Dauer einer Legislaturperiode erhalten. ${ }^{60}$ Inwieweit diese Freiräume zur Durchsetzung von Maßnahmen genutzt werden können, die den Wählerpräferenzen entgegenstehen, ist auch davon abhängig, ob die Regierenden der Wiederwahlrestriktion unterworfen sind 61 und ob die Reputation der Amtsinhaber durch opportunistisches Verhalten gefährdet ist. ${ }^{62}$ Hier könnten die Parteien als Überwachungsinstanzen im Principal-Agent-Verhältnis der Wähler zu den gewählten Repräsentanten agieren. Im Gegensatz zum einzelnen Kandidaten mit möglicherweise begrenztem Zeithorizont, der die kurzfristigen Vorteile der Regierungsübernahme maximieren will, sind langfristig bestehende Parteiorganisationen am Aufbau von Reputation zum Schutz ihrer Markennamen tendenziell stärker interessiert. 63

Die Möglichkeit einer Ausbeutung der Bürger durch die Politiker steigt in dem Maße, wie die Wähler Vergessenseffekten unterliegen. So sieht Nordhaus in der Nichtberücksichtigung von Ereignissen, die lange Zeit vor dem Wahltermin stattfinden, und in der Höhergewichtung von aktuellen Entwicklungen bei Wahlentscheidungen einen Grund für das Entstehen politischer Konjunkturzyklen. ${ }^{64}$ Ist dies der Fall, sind die Regierenden auch gezwungen, unmittelbar vor der Wahl durch Wahlgeschenke die eigenen Wiederwahlchancen zu erhöhen.65 Dies wirft Licht auf ein weiteres Problem der Dauer der Wahlperiode. Dient das Handeln der Politiker dem Wiederwahlziel, ist es auf den Wahltermin ausgerichtet. Damit sind politische Entscheidungen systembedingt eher kurzfristig als langfristig orientiert. 66

Überdies ist auf die Asymmetrie in den Ausgangspositionen von Amtsinhabern und politischen Konkurrenten einzugehen. Es kann angenommen werden, daß die Amtsinhaber, die sich einer Wiederwahl stellen, Wettbewerbsvorteile gegenüber ihren Herausforderern haben. ${ }^{67}$ Ein Vorteil der Amtsinhaber besteht z.B. darin, daß sie zur Informationsbeschaffung auf öffentliche Budgetmittel zurückgreifen können, sie unterliegen also tendenziell einer schwächeren Budgetrestriktion als die Opposition. ${ }^{68} \mathrm{Da}$ die Regierung, wie noch zu zeigen ist, die Ziel-

58 Ausfuhrlich hierzu Kirsch, G. (1993), S. 266ff.

59 Siehe z.B. Breton, A. (1974), S. 48f.

60 Breton, A. (1974), S. 49 betont, daß in dieser Zeit die Wahlkosten für die Bürger quasi 'unendlich hoch' sind.

61 In einer empirischen Studie kommt Zupan zum Ergebnis, daß Politiker in ihrer letzten Amtsperiode bevor sie in Ruhestand treten, tendenziell stärker zu 'ideological shirking' neigen. Siehe Zupan, M.A. (1990).

62 Vgl. Wittman, D. (1989), S. 1388.

63 Siehe Galeotti, G./Breton, A (1986); Wittman, D. (1989), S. 1398; Holcombe, R.G./Gwartney, J.D. (1989); Kruse, J. (1989), S. 246.

64 Vgl. Nordhaus, W.D. (1975); (1989). Siehe hierzu auch Kirchgässner, G. (1984); Harrington, J.E. (1993).

65 Vgl. Schmölders, G. (1970), S. 204f.

66 Vgl. Breton, A. (1974), S. 132ff.

67 Vgl. Samuelson, L. (1984); Bernhardt, M.D./Ingberman, D.E. (1985); Anderson, S.P./Glomm, G. (1992).

68 Vgl. Anderson, S.P./Glomm, G. (1992), S. 207. 
scheibe von Lobbying-Aktivitäten spezieller Interessengruppen ist, werden die Amtsinhaber ständig mit Informationen versorgt, zwischen Lobbyisten und Regierungsmitgliedern entstehen längerfristige Geschäftsbeziehungen. ${ }^{69}$ Es kann daher angenommen werden, daß Amtsinhaber über Informationen verfügen, die der Opposition nicht zur Verfügung gestellt werden. Im Gegensatz zum oppositionellen Herausforderer können die Amtsinhaber auch aktiv den gesetzlichen Rahmen ihrer Tätigkeit bestimmen und insbesondere selbst politische Renten schaffen. ${ }^{70}$ Die Opposition ist dagegen darauf angewiesen, Vorschläge einzubringen, die nur bei einem Wahlgewinn umgesetzt werden.

Zusammenfassend betrachtet muß man davon ausgehen, daß die amtierende Regierung weder völlig uninformiert über die Wählerpräferenzen ist noch einem starkem Wettbewerbsdruck der Opposition ausgesetzt ist. Es ist vielmehr von beschränktem Wettbewerb auszugehen, der den Regierenden diskretionäre Spielräume zur Verfolgung eigener materieller oder ideologischer Interessen beläßt. Damit wäre aus Sicht der Regierung die Gewinnung von Wählerstimmen lediglich eine Restriktion, nicht aber der Maximand der Zielfunktion.

\section{c. Rationale Unwissenheit der Wähler}

Ein funktionierender Wettbewerb im Sinne des oben skizzierten Grundmodells setzt voraus, daß die Wähler über die politischen Programme, die Politiker über die Präferenzen der Bürger voll informiert sind. Weder vom einen noch vom anderen kann ausgegangen werden, wenn der Prozeß der Informationsgewinnung und -verarbeitung nicht kostenlos ist. ${ }^{71}$ Rationale Individuen akquirieren Informationen, bis deren Grenzkosten und Grenznutzen gleich sind. 72 Im öffentlichen Sektor sind die Informationskosten für die Prinzipale im Vergleich zum privaten Sektor relativ hoch: ${ }^{73}$ Erstens gibt es keinen Preismechanismus mit einer dem Markt entsprechenden Informationsfunktion. Zweitens impliziert die temporäre Monopolstellung der Regierung, daß eine unmittelbare Kontrolle der Agenten durch tatsächlichen Wettbewerb fehlt. ${ }^{74}$

Während bei Kaufentscheidungen am Markt der Konsument unmittelbar persönlich die Kosten einer Fehlentscheidung trägt, ist der Anreiz, sich zu informieren, bei Kollektiventscheidungen gering, da sich die Kosten einer individuell fehlerhaften Wahlentscheidung auf die Gesamtheit der Wähler verteilen. ${ }^{75}$ Da eine abgegebene Stimme bei einer großen Zahl von Wählern nur verschwindend geringen Einfluß auf den Wahlausgang hat, stehen den Informationskosten nur geringe Nutzen der Informationsgewinnung und einer Wahlteilnahme gegenüber. ${ }^{76}$ Formal läßt sich die Nutzenauszahlung $P$ eines Individuums durch die Teilnahme an einer Wahl darstellen als 77

69 Vgl. Weingast, B. (1981), S. 159ff.

70 Siehe McChesney, F.S. (1987); Anderson, G.M./Tollison, R.D. (1988), S. 533.

71 Die Bedeutung der Informationskosten wurde erstmals von Downs, A. (1957/1968) und Tullock, G. (1967a) betont.

72 Vgl. Downs, A. (1957/1968), S. 209f.; Herder-Dorneich, P./Groser, M. (1977), S. $154 \mathrm{ff}$.

73 So auch Kirsch, G. (1993), S. 204f.

74 Siehe etwa Anderson, T.L. /Hill, P.J. (1986), S. 326.

75 Kirchgässner und Pommerehne bezeichnen diesen Sachverhalt als "low cost decisions". Kirchgässner, G./Pommerehne, W.W. (1993). Tullock, G. (1971a) charakterisiert Wahlentscheidungen daher als reine offentliche Guter. Vgl. auch Herder-Dorneich, P./Groser, M. (1977), S. 154ff. So bereits Downs, A. (1957/1968), Kap. 11-14.

77 Vgl. Tullock, G. (1967a), S. 110ff.; Riker, W.H./Ordeshook, P. (1968). 


$$
P=\pi b+d-c,
$$

wobei $\pi$ die Wahrscheinlichkeit bezeichnet, da $\beta$ die abgegebenen Stimme den Wahlausgang entscheidet, $b$ die Nutzeneinkommens-Differenz zwischen den alternativ zur Wahl stehenden Kandidatenprogrammen (das "Parteidifferential"78) beschreibt und c für die in Geld- oder Nutzeneinheiten gemessenen Kosten des Wählens steht. ${ }^{79}$ Der Faktor $d$ bezeichnet schließlich Zusatznutzen, die der Bürger aus der Teilnahme an der Wahl selbst erhält. 80

(4.B.II.1) zeigt, daß bei großer Zahl von Wahlberechtigten der "Stimmenwert"81 $\pi \mathrm{b}$ des einzelnen sehr klein ist und für gegebene Wahlkosten c der Anreiz, überhaupt wählen zu gehen, nahezu verschwindet. ${ }^{82}$ Geben sie dennoch eine Stimme ab ${ }^{83}$, tun dies die Wähler rational uninformiert. ${ }^{84}$ Es kann gefolgert werden, daß der Informationsstand der Bürger über die konkreten Auswirkungen der politischen Programmalternativen bei der Stimmabgabe sehr gering ist. 85

Wie Brennan/Buchanan zeigen, ist die individuelle Wahlentscheidung aufgrund des Informationsproblems von einer Vielzahl von Faktoren bestimmt, die mit der eigentlichen politischen Wahl nur wenig zu tun haben, und es bleibt letztlich unklar, worüber die Wähler überhaupt abstimmen. ${ }^{86}$ Damit eröffnet sich Raum für die Kandidaten, knappe Ressourcen nicht in die Gewinnung von Informationen, sondern in die Formung von Wählerpräferenzen zu investieren und durch selektive Informationspolitik das Wählerverhalten im eigenen Interesse zu beeinflussen ${ }^{87}$ Hierzu gehören die bewußte Manipulation von Daten ${ }^{88}$ und die Verschleierung von Belastungswirkungen ${ }^{89}$ für die Bürger durch die bewußte Erzeugung einer Fiskalillusion. ${ }^{90}$ Aus diesem Blickwinkel ist insbesondere das Finanzierungsinstrument der öffentlichen Verschuldung kritisch zu beurteilen. ${ }^{91}$

78 Downs, A. (1957/1968), S. 38.

79 Vgl. z.B. Downs, A. (1957/1968), S. $255 \mathrm{ff}$.

80 Eine ausfuhrliche Diskussion moglicher Einflußfaktoren findet sich bei Kirsch, G. (1993), S. $214 \mathrm{ff}$.

81 Downs, A. (1957/1968), S. 261.

82 Aus (4.B.II.1) laß sich auch formal ableiten, daß bei vollkommener Information (und $d=c=0$ ) im DownsGrundmodell völlige Wahlenthaltung bestehen muß, denn das Parteidifferential $b$ ist bei Identităt der Parteiprogramme im Medianpunkt gleich Null.

83 Zum "paradox of voting" siehe Mueller, D.C. (1987) und (1989), S. 348ff. sowie Crain, W.M./Shugart, W.F./Tollison, R.D. (1988).

84 Vgl. insbesondere Downs, A. (1957/1968), S. 234ff.

85 Hierzu etwa Barzel, Y./Silberberg, E. (1973). Wie auch schon Schumpeter anmerkt, "fallt der typische Burger auf eine tiefere Stufe der gedanklichen Leistung, sobald er das politische Gebiet betritt." Schumpeter, J.A. (1942/1950), S. 416. Mit der Ansicht, "... one would be hard put to find nonpolitical markets that process information better than the voting market", steht Peltzman jedenfalls eher allein. Peltzman, $S$. (1990), S. 63. Wittman, D. (1989), S. 1400f. behauptet, die Informationsmöglichkeiten seien nicht prinzipiell schlechter als am Markt und folgert, der Informationsstand der Wahhler sei fur effiziente Wahlentscheidungen ausreichend. Wittman ubersieht jedoch die mangelnden Anreize zur Informationsgewinnung auf der Wahlerseite. Siehe auch Rowley, C.K./Vachris, M. (1993), S. 577.

86 Vgl. Brennan, G./Buchanan, J.M. (1984).

87 Vgl. Bartlett, R. (1973), S. 60ff. oder Mackscheidt, K./Steinhausen, H.-J. (1977), S. 55. Zum Einsatz von Wahlwerbung siehe etwa Kau, J.B./Keenan, D./Rubin, P.H. (1982); Chapman, R.G./Palda, K.S. (1984).

88 Vgl. dazu die Untersuchung von Pommerehne, W.W./Feld, L.P. (1994).

89 Auch etwa durch Neben- und Schattenhaushalte. Siehe Bennett, J.T./DiLorenzo, T.J. (1983).

90 Zu einem Überblick siehe Twight, C. (1988). Vgl. auch Buchanan, J.M. (1967b), S. 128ff.; West, E.G./ Winer, S.L. (1980); Oates, W.E. (1988b).

91 Siehe insbesondere Buchanan, J.M./Wagner, R.E. (1977). 
Die Ungewißheit der Kandidaten über die Wählerpräferenzen veranlaßt sie zu Aufwendungen in Informationsgewinnung, die prinzipiell demselben Marginalkalkül folgen.92 Politiker stehen allerdings dem Problem gegenüber, daß die Wähler keine Anreize zur korrekten Präferenzoffenbarung haben. ${ }^{93}$ Es besteht deshalb eine Tendenz der Politiker, solche Gruppen, die spezielle Informationen über Wählerpräferenzen anbieten, in ihren Programmen zu bevorzugen; darauf wird noch zurückzukommen sein.

Zusammenfassend bleibt festzuhalten: Der politische Wettbewerb um Wählerstimmen in einer Mehrheitsdemokratie ist nur bedingt geeignet, opportunistisches Verhalten der Mandatsträger in ausreichendem Maße zu verhindern. ${ }^{94}$ Vielmehr ist davon auszugehen, daß die gewählten Repräsentanten über diskretionäre Handlungsspielräume zur Realisierung eigener materieller Vorteile oder zur Durchsetzung persönlicher ideologischer Vorstellungen verfügen. 95

\section{Die Rolle spezieller Interessengruppen}

\section{Die Ziele spezieller Interessengruppen}

In einer Demokratie ist die Möglichkeit politischen Engagements für die Bürger nicht auf die Teilnahme an Wahlen beschränkt, die Koalitionsfreiheit ist integraler Bestandteil einer freiheitlichen Ordnung. ${ }^{96}$ Die Individuen können sich in Verbänden ${ }^{97}$ zusammenschließen, die auf politische Entscheidungsprozesse einwirken. Interessenverbände sind organisierte Gruppen von Individuen, die gemeinsame Ziele verfolgen und diese im politischen Prozeß zu verwirklichen suchen, die aber im Unterschied zu den Parteien nicht das Ziel eines Wahlgewinns oder der Regierungsübernahme verfolgen. ${ }^{98}$ Durch ihre Einflußnahme können Verbände spezielle Vorteile für ihre Mitglieder erwirken. ${ }^{99}$ Ihre Einflußmöglichkeiten erstrecken sich grundsätzlich auf alle an der staatlichen Bereitstellung und Produktion Beteiligten, also auf Wähler, Politiker und Bürokratie.

Die Tauschtheorie politischer Prozesse impliziert, daß die Verbände im Gegenzug bestimmte Leistungen anbieten müssen. Als Determinanten ihres politischen Einflusses identifiziert Bernholz 100 die Verfügbarkeit spezieller Informationen 101 und finanzieller Ressourcen ${ }^{102}$ sowie durch Verbandsaktivitäten mobilisierbare Wählerstimmen ${ }^{103}$, die sie politischen Tauschpartnern als Gegenleistung für gewährte Vergünstigungen an die Verbandsmitglieder anbieten. 104

92 Vgl. Lindblom, C.E. (1965), S. 66; Rose-Ackerman, S. (1978), S. 43ff.

93 Vgl. van den Doel, H. (1979), S. 118.

94 Vgl. Breton, A. (1974), S. 43; Kalt, J.P. (1981), S. 251; Rowley, C.K. (1992), S. 82.

95 Vgl. Nelson, D./Silberberg, E. (1987); Kalt, J.P./Zupan, M. (1990); Kau, J.B./Rubin, P.H. (1993).

96 Die Koalitionsfreiheit ist eines der wesentlichen wirtschaftlichen Grundrechte im deutschen Recht. Siehe dazu etwa Stein, E. (1993), S. 367ff.

97 Als Synonyme werden die Begriffe 'Lobby', 'Interessengruppe' oder 'pressure group' verwendet.

98 Vgl. Schmölders, G. (1970), S. 125; Berry, J.M. (1984), S. 5; Vieler, M. (1986), S. 8ff.

99 Siehe z.B. Schmidt, K. (1976).

100 Vgl. Bernholz, P. (1969); Bernholz, P./Breyer, F. (1994), S. 169ff. Vgl. auch Kollewe, W. (1979), S. $19 \mathrm{ff}$.

101 Siehe u.a. Vieler, $A$. (1986), S. 135.

102 Vgl. etwa Wittmann, W. (1976); Ippolito, D.S./Walker, T.G. (1980), S. 348ff.; Jacobson, G.C. (1985).

103 Dies betriftt einerseits die Voten der Verbandsmitglieder selbst und andererseits auch mobilisierbare Stimmen von Nicht-Mitgliedern. Vgl. z.B. Tullock, G. (1984), insbes. S. 95; Becker, G. (1985), S. 342.

104 Siehe insbesondere Frohlich, N./Oppenheimer, J.A./Young, O.R. (1971), S. 106. 


\section{Die These von der Effizienz des Wettbewerbs spezieller Interessengruppen}

\section{a. Pluralismustheorie und countervailing powers}

Die traditionelle politische Wissenschaft hat sich überwiegend mit der Rolle von Interessengruppen als Mittler zwischen Bürgern und Regierung beschäftigt. ${ }^{105}$ Die Pluralismustheorie geht davon aus, daß sich in einer freiheitlichen Gesellschaft für alle politischen Anliegen Interessenverbände organisieren können, deren Wettbewerb zur Bildung von Kompromissen widerstreitender Gruppeninteressen und zu sozial erwünschten Ergebnissen führt. ${ }^{106}$ In ihrer intermediären Funktion erfüllen Verbände wichtige soziale Aufgaben wie die Aggregation und Artikulation der Präferenzen ihrer Mitglieder ${ }^{107}$ und die kostengünstige Versorgung politischer Entscheidungsträger mit politisch relevanten Informationen. 108

Zentrale Bedeutung für die von der Pluralismustheorie hervorgehobenen effizienzfördernden Wirkungen des Interessengruppenwettbewerbs hat das "countervailing powers"109-Argument. Nach Galbraith ${ }^{110}$ erzeugt die Etablierung einer einflußreichen pressure group, die über den Weg der politischen Einflußnahme Partikularvorteile für ihre Mitglieder zu Lasten anderer gesellschaftlicher Gruppen erzielen will, automatisch Gegendruck der negativ betroffenen Gruppierungen. Die Pluralismustheorie überträgt somit die Gedanken von der Effizienz einer unsichtbaren Hand des Marktprozesses auf die Beziehungen zwischen den gesellschaftlichen Gruppen. ${ }^{111}$

\section{b. Der Ansatz von Becker}

Das Zusammenspiel von politischem Druck und Gegendruck konkurrierender Interessen wurde von Becker in zwei Aufsätzen formal analysiert. ${ }^{112}$ Becker geht dabei von zwei homogenen pressure groups, Steuerzahlern $t$ und Subventionsempfängern s, aus. ${ }^{113}$ Beide Gruppen machen politischen Einfluß geltend, um Vorteile im politischen Prozeß durchzusetzen, die für die Mitglieder von $\mathrm{t}$ in der Reduktion der Steuerbelastungen, für die Mitglieder von $\mathbf{s}$ in der Erhöhung der Subventionszahlungen bestehen.

Becker unterstellt, daß die Gruppenmitglieder politischen Einfluß ausüben, wenn ihnen durch staatliche Aktivitäten Nutzeneinbuße drohen ${ }^{114}$, die zum einen aus Umverteilungsverlusten und zum anderen aus Mehrbelastungen infolge marktlicher Anpassungsreaktionen an geän-

105 Siehe etwa Bentley, A.F. (1908/1967); Truman, D.B. (1951); Latham, E. (1952). Zu einem Überblick siehe Dunleavy, $P$. (1991), S. 24ff. und Vieler, A. (1986), S. 16.

$106 \mathrm{Vgl}$. Vieler, A. (1986), S. 16. "Because one center of power is set against another, power itself will be tamed... Because even minorities are provided with opportunities to veto solutions they strongly object to, the consent of all will be won in the long run." Dahl, R. (1967), S. 24.

107 Vgl. Vieler, A. (1986), S. 159f.

108 Vgl. Bernholz, P./Breyer, F. (1994), S. 169.

109 Galbraith, K. (1952).

110 Vgl. Galbraith, K. (1952). Siehe hierzu auch Herder-Dorneich, P. (1973), S. 65ff.

111 Vgl. Mitchell, W.C.Simmons, R.T. (1994), S. 26.

112 Siehe Becker, G. (1983); (1985). Vgl. auch Märtz, T. (1990), S. 89ff. Becker bezieht sich in seinen Ausfuhrungen konkret auf Bentley. Vgl. Becker, G. (1983), S. 372 und (1985), S. $329 f$.

113 Vgl. Becker, G. (1983), S. 374.

114 Dies entspricht der Annahme von Breton, A. (1974), S. 63f., daß Individuen zur Reduktion ihrer Frustrationskosten politisch aktiv werden. 
derte Steuern und/oder Subventionen resultieren. 115 Der von einer pressure group erzeugte Einfluß I steigt mit den in die Erzeugung von politischem Druck p investierten Ressourcen $\mathrm{m}$ und der jeweiligen Mitgliederzahl n. Der Einfluß einer Gruppe wird von entgegengerichteten Aktivitäten der konkurrierenden Gruppe verringert, und die politische Einflußnahmefunktion einer Gruppe i kann somit dargestellt werden als 116

$$
I^{i}=I^{i}\left[p^{i}\left(m^{i}, n^{i}\right), p^{j}\left(m^{j}, n^{j}\right)\right], \text { mit } i, j=s, t \text { und } i \neq j \text {, }
$$

wobei $\left(\partial \mathrm{I}^{\mathrm{i}} / \partial \mathrm{p}^{\mathrm{i}}\right)>0 ;\left(\partial \mathrm{I}^{\mathrm{i}} / \partial \mathrm{p}^{\mathrm{j}}\right)<0$, sowie $\left(\partial \mathrm{p}^{\mathrm{i}} / \partial \mathrm{m}^{\mathrm{i}}\right)>0$.

Erhöht z.B. die Gruppe s ihren politischen Druck, erwirkt sie einen Anstieg der Subventionen, die nur durch eine höhere Besteuerung finanziert werden können. Die damit verbundenen Nutzenverluste der t-Mitglieder verstärken deren Anreiz zur Ausübung von politischem Gegendruck. Der Prozeß kommt nach Becker in einem Gleichgewicht zum Stillstand, wenn keine der Gruppen einen Anreiz zur Veränderung der Aktivitäten hat.

Becker nimmt an, daß die Höhe der an jede Gruppe gewährten Vergünstigung von der Fähigkeit abhängt, politischen Einfluß zu produzieren. ${ }^{117}$ Je größer der Druck der s-Gruppe ist, desto höher fallen die an die Mitglieder von s gewährten Subventionen aus. Aufgrund der staatlichen Budgetrestriktion entspricht die Summe der Transfers auch der Höhe des Steueraufkommens. Da infolge des Auftretens marktlicher Substitutionseffekte bei der Besteuerung Wohlfahrtsverluste entstehen, übersteigen selbst bei effizienter Subventionsgewährung die Verluste der Besteuerten die Gewinne der Begünstigten. 118

Weil allokative Ineffizienzen der staatlichen Einnahmen- und Ausgabenpolitik das maximale Umverteilungsvolumen schmälern, werden die Wohlfahrtsverluste zum zentralen Punkt der Argumentation. Mit zunehmender Ineffizienz der staatlichen Maßnahmen besteht nach Becker ein "intrinsic advantage of taxpayers" 119: Je größer die marginale Zusatzlast einer steuerlichen Maßnahme ist, so die These, um so mehr profitieren die Mitglieder der Steuerzahlergruppe $t$ von einer Verringerung des Steueraufkommens. Die Erzeugung von politischem Druck werde daher für die Gruppe der Steuerzahler lohnender. ${ }^{120}$ Beide Gruppen würden folglich eine effiziente Besteuerung favorisieren - die Steuerzahler, weil sie ihre Belastung reduziert, die Transferempfänger, weil sie das potentielle Subventionsvolumen erhöht. Während aber der Widerstand der Steuerzahler gegen jede Form der Umverteilung mit zunehmender Belastung wächst, verringern Ineffizienzen in der Subventionierung den Druck der Empfänger zur Erhöhung der Begünstigungen, da zur Erreichung gleicher Vorteile immer größere Aufwendungen notwendig sind.

115 Erfolgt die Besteuerung bzw. Subventionsgewăhrung allokationsneutral, sind die Zusatzlasten gleich Null.

116 Vgl. Becker, G. (1983), S. 375ff.

117 Vgl. Becker, G. (1983), S. 376.

118 Vgl. Mitchell, W.C./Munger, M.C. (1991), S. 534.

119 Becker, G. (1983), S. 382.

120 Siehe auch Coe, R.D./Wilber, C.K. (1985), S. 43; Märtz, T. (1990), S. 123. 
Die Darlegungen von Becker implizieren, daß intensiver Wettbewerb der Interessengruppen um Verteilungsvorteile effiziente staatliche Maßnahmen hervorbringt; ${ }^{121}$ seine Ergebnisse stehen insoweit in der Tradition der Pluralismus-Ansătze. ${ }^{122} \mathrm{Je}$ ineffizienter dagegen die staatlichen Aktivitäten, desto größer wird der politische Druck der Belasteten zur Revision des Staatshandelns.

Insbesondere von Vertretern der Interessengruppentheorie des Staates ("interest group theory of government" ${ }^{123}$ ) wird Becker vorgeworfen, daß die Bedingungen, unter denen Interessengruppenkonkurrenz effiziente Ergebnisse hervorbringt, restriktiv und unrealistisch sind. $124 \mathrm{Im}$ folgenden wird anhand der an Becker geübten Kritik gezeigt, daß seine positive Sicht im Rahmen einer generellen Analyse politischer Entscheidungsprozesse nicht aufrechterhalten werden kann.

\section{Die Interessengruppentheorie des Staates}

\section{a. Die Organisation spezieller Interessen}

Becker betont in seinen Modellen den Einfluß der Mitgliederzahl eines Verbandes für die Produktion von politischem Einfluß.125 Einerseits liefern die Verbandsmitglieder Ressourcen zur Ausübung von politischem Druck ${ }^{126}$, andererseits ist nach seiner Ansicht die personelle Stärke des Interessenverbandes selbst ein Einflußfaktor. Da aber die durch politischen Druck erlangten Verteilungsvorteile allen Gruppenmitgliedern zukommen, und zwar unabhängig davon, ob sie an der Produktion des Gruppeneinflusses beteiligt waren oder nicht, hat die Einflußnahme Kollektivgutcharakter. ${ }^{127}$

Die Fähigkeit einer Gruppe, gemeinschaftliches Handeln zu organisieren, ist von mehreren Faktoren abhängig ${ }^{128}$, die bereits mehrfach angesprochen wurden. Nach der "Logik kollektiven Handelns" ist die zwangfreie Bildung eines Verbandes um so einfacher,

- je kleiner die Zahl der potentiellen Verbandsmitglieder ist ${ }^{129}$,

- je homogener die Mitgliederinteressen sind ${ }^{130}$ und

- je eher durch die Bereitstellung privater Güter als by-product selektive Anreize zum Gruppenbeitritt geschaffen werden können. ${ }^{131}$

121 Vgl. Becker, G. (1983), S. 384 und (1985), S. 344. Siehe auch Peltzman, S. (1989), S. $11 \mathrm{ff}$.

122 Vgl. Dunleavy, P. (1991), S. 24ff.; Mitchell, W.C./Simmons, R.T. (1994), S. 26.

123 McCormick, R.E./Tollison, R.D. (1981).

124 So etwa Mitchell, W.C./Munger, M.C. (1991), S. 534, die dem Becker-Modell den Erkenntniswert des Coase-Theorems ohne Transaktionskosten beimessen.

125 Vgl. Becker, G. (1983), S. 377. Siehe auch den Funktionszusammenhang (4.B.III.1).

126 Die Ressourcen werden benotigt fur "campaign contributions, political advertising, and ... other ways that exert political pressure." Becker, G. (1983), S. 372.

127 Vgl. Becker, G. (1985), S. 332. Vgl. auch Olson, M. (1982/1991), S. $22 \mathrm{ff}$

128 Grundlegend Olson, M. (1965/1992) und (1982/1991), Kap. 2.

129 Vgl. Moe, T. (1980), S. 27; Olson, M. (1982/1991), S. $28 \mathrm{ff}$.

130 Vgl. Olson, M. (1982/1991), S. 29ff.

131 Kritisch hierzu Frohlich, N./Oppenheimer, J.A./Young, O,R. (1971), S. 18; Stigler, G.J. (1974), S. 360 und Magee, S.P./Brock, W.A./Young, L. (1989), S. 92, die argumentieren, daß Konkurrenzanbieter teilbare Nebenprodukte günstiger erstellen könnten, da sie mit den Mitgliedsbeiträgen keine Kollektivgutbereitstellung finanzieren mußten. 
Aus dem Zusammenspiel dieser Faktoren folgt, daß es für große und heterogene Gruppen, wie z.B. die der Konsumenten oder der Steuerzahler, schwer ist, ein gemeinsames Handeln zu organisieren. ${ }^{132}$ In einer Kleingruppe, in der die Mitgliederinteressen auf nur wenige spezielle Anliegen ausgerichtet sind, ist dagegen die Möglichkeit der Organisation eher gegeben. Die Überwindung der Latenz ist mit Transaktionskosten verbunden, die mit steigender Gruppengröße und steigender Heterogenität überproportional ansteigen.

Becker berücksichtigt zwar die Kosten, die in Gruppen zur Überwindung des free riderVerhaltens anfallen ${ }^{133}$, und er kommt zum Schluß, daß "... the political efficiency of a group is mainly determined not by its absolute efficiency - e.g. its absolute skill at controlling free riding - but by its efficiency relative to the efficiency of other groups." $134 \mathrm{Er}$ vernachlässigt aber, daß für viele Anliegen die Grundbedingungen einer Organisation kollektiven Handelns nahezu gänzlich fehlen. Die symmetrische Organisation der Gruppen, Voraussetzung für die postulierte Effizienz des Interessengruppenwettbewerbs, ist nicht gegeben. ${ }^{135}$

\section{b. Die Bedeutung der Informationsasymmetrien}

Allein die Existenz von Interessenverbänden ist kein Beweis für deren politischen Einfluß, denn in einer perfekt funktionierenden Demokratie mit vollkommener Information spielen Interessengruppen keine Rolle. ${ }^{136}$ Die Möglichkeit politischer Einflußnahme organisierter Interessen setzt voraus, daß Wähler, Politiker und Bürokraten ihre Entscheidungen unter Unsicherheit treffen. Becker ignoriert dagegen die Rolle der Wähler und Politiker im politischen Willensbildungsprozeß. 137

Interessenverbände können als Spezialisten zu relativ geringen Kosten Informationen über die Wirkungen politischer Maßnahmen beschaffen. Dies eröffnet die Chance zur selektiven Informationsversorgung, indem die Informationen der Entscheidungsträger subventioniert werden. 138 Interessengruppen können daher Sondervergünstigungen durchsetzen, die sie Politikern und Wählern als Regelungen im Allgemeininteresse verkaufen. 139

Verbände verfügen außerdem über ein Wählerstimmenpotential, das sie den Politikern als Gegenleistung für gewährte Privilegien anbieten können. Aus Sicht der Kandidaten ist die Gewährung von Vergünstigungen für eine gesellschaftliche Gruppe um so lohnender, je mehr Wählerstimmen sie durch die Begünstigung gewinnen können. 140 Wie Coughlin/Mueller/ Murrell zeigen ${ }^{141}$, steigt der Einfluß einer Gruppierung jedoch nicht proportional zu ihrer Mitgliederzahl, denn die Verbände können nicht versichern, daß alle potentiellen Stimmen der Gruppenmitglieder auch den Kandidaten zufließen. ${ }^{142}$ Eine Interessengruppe ist vielmehr um

132 Vgl. Olson, M. (1982/1991), S. 221.

133 "Free riding raises the cost of producing pressure." Becker, G. (1983), S. 377. Vgl. auch McCormick, R.E./ Tollison, R.D. (1981), S. $42 \mathrm{ff}$.

134 Becker, G. (1983), S. 380 (Hervorhebung H.P).

$135 \mathrm{Vgl}$. Olson, M. (1982/1991), S. 48.

136 Vgl. Wagner, R.E. (1966), insbes. S. 166.

137 "Government is not even a 'black box'; it does not exist." Mitchell. W.C./Munger, M.C. (1991), S. 536. Becker klammert diese Aspekte bewußt aus: "Politicians, political parties, and voters ... are assumed mainly to transmit the pressure of active groups." Becker, G. (1983), S. 372.

138 Siehe hierzu etwa Bartlett, R. (1973), Kap. 2; Herder-Dorneich, P./Groser, M. (1977), S. $156 \mathrm{ff}$.

139 Vgl. Rose-Ackerman, S. (1978), S. 40ff.

140 Vgl. Stigler, G.J. (1971), S. 3; Peltzman, S. (1976), S. 214.

141 Siehe Coughlin, P./Mueller, D.C./Murrell, P. (1990a); (1990b). Vgl. auch Mueller, D.C. (1989), S. $203 \mathrm{ff}$.

142 Vgl. Ippolito, D.S./Walker, T.G. (1980), S. 360; Magee, S.P./Brock, W.A./Young, L. (1989), S. 88. 
so stärker, je homogener ihr Wahlverhalten ist, d.h. je sicherer die Kandidaten mit den angebotenen Wählerstimmen rechnen können. ${ }^{143}$ Damit ergibt sich ein prinzipieller Vorteil kleinerer und homogener pressure groups.

Rationale Unwissenheit der Wähler impliziert, daß Wahlkampagnen der konkurrierenden Kandidaten erfolgreich sind. ${ }^{144}$ Durch Werbung können die Politiker den Bürgern ihre Programme näherbringen und so ihre Wahlchancen erhöhen. ${ }^{145}$ Die Beeinflussung der Bürger ist dabei um so erfolgversprechender, je weniger informiert die Wähler sind. ${ }^{146}$ Zur Durchführung von Wahlkampagnen benötigte Ressourcen können aus Parteimitteln stammen und von speziellen Interessengruppen bereitgestellt werden. Ein weiterer Einfußfaktor der Interessenverbände liegt daher in der Finanzierung von Parteien oder Wahlkampagnen durch Spenden begründet. Die Höhe der Unterstützungen an Politiker oder Parteien ist, so die These, von den erwarteten Nutzen der Gruppenmitglieder abhängig, die wiederum von den Parteiprogrammen der Kandidaten und deren Wahlchancen bestimmt sind. ${ }^{147}$ Auch können die Interessengruppen die Ausrichtung der Programme durch Wahlkampfspenden 'quid pro quo' direkt beeinflussen. ${ }^{148}$

Es liegt der Schluß nahe, daß der Einfluß spezieller Interessengruppen um so größer ist, je unsicherer die Politiker über die Wählerpräferenzen sind und je weniger die Wähler über die politischen Programme und deren mögliche Wirkungen informiert sind. Die rationale Uninformiertheit der Wähler und die unterschiedliche Organisationsfähigkeit der Interessen führt dann zu einem "perversen Anreizmechanismus"149 für die Politiker. Im Hinblick auf die Erreichung des Wahlziels stehen die Kandidaten organisierten und über spezielle Aspekte gut informierten pressure groups sowie nicht-organisierten, uninformierten Wählern gegenüber. Bei ihren Entscheidungen über die angebotenen politischen Güter und deren Finanzierung können die Politiker daher zwischen mehreren Alternativen wählen: 150

(i) Maßnahmen, deren Gewinner und Verlierer leicht identifizierbar sind,

(ii) Maßnahmen, bei denen weder Gewinner noch Verlierer zu bestimmen sind,

(iii) Regelungen, deren Gewinner leicht und deren Verlierer schwer identifizierbar sind und

(iv) Maßnahmen, bei denen die Verlierer leicht, die Gewinner schwer zu ermitteln sind.

Offensichtlich bietet Konstellation (iii) für die Politiker einen geeigneten Ansatzpunkt zur Erhöhung ihrer Wahlchancen. Die Interessengruppentheorie des Staates betont, daß die Bereitstellung von Vorteilen für spezielle, gut organisierte Interessen politische Unterstützung erwarten läßt, wohingegen eine Belastung der nicht-organisierten Interessen deshalb nicht zu

143 Vgl. Coughlin, P./Mueller, D.C./Murrell, P. (1990a), S. 682.

144 "Wenn alle Bürger alle einschlägige Information erlangt und verarbeitet hătten, konnten sie nicht durch Werbung oder eine andere Form der Überredung beeinflußt werden. Bei vollkommen informierten Bürgern kőnnten die gewăhlten Volksvertreter nicht den Künsten der Lobbyisten erliegen..." Olson, M. (1982/1991), S. 32.

145 Vgl. den Überblick bei Mueller, D.C. (1989), S. 209ff. und die dort angegebene Literatur.

146 Vgl. Denzau, A./Munger, M.C. (1986), S. 99.

147 Vgl. Kau, J.B./Rubin, P.H. (1981); Hinich, M.J./Munger, M.C. (1989), S. 56ff.

148 Vgl. Frohlich, N./Oppenheimer, J.A./Young, O,R. (1971), S. 106; Mueller, D.C. (1989), S. $208 \mathrm{f}$.

149 Merville, L.J./Osborne, D.K. (1990), S. 37.

150 Vgl. McCormick, R.E./Tollison, R.D. (1981), S. 17; Tollison, R.D. (1982), S. 589f. 
nennenswertem Widerstand führt, weil bei einer Vielzahl von Betroffenen die Belastung des einzelnen kaum spürbar und womöglich von diesem überhaupt nicht identifizierbar ist. ${ }^{151}$ Diese Strategie ist um so erfolgversprechender, je weniger transparent die Regelungen sind. 152

Der politische Prozeß ist aus dieser Sicht ein Quasi-Markt, auf dem organisierte Interessen Vermögenstransfers nachfragen und nicht-organisierte Individuen Vermögenstransfers anbieten, da sie sich aufgrund der hohen Organisationskosten nicht adäquat gegen staatliche Eingriffe in ihre property rights verteidigen können. ${ }^{153}$ Politiker spielen die Rolle von "political brokers" 154 , die im Eigeninteresse diesen Umverteilungsprozeß fördern; die Bereitstellung öffentlicher Güter ist nur ein Nebenprodukt der "transfer society"155. Zentrale These der Interessengruppentheorie ist daher: "It is narrow private objectives instead of broad community concerns that motivate political action." 156 Damit ist ein "politisch effizientes"157, d.h. wählerstimmenmaximierendes Programmangebot nicht der Ausdruck eines wohlfahrtsoptimalen Budgets. Es reflektiert vielmehr die ungleichen Durchsetzungschancen der diversen Interessen im politischen Prozeß.

\section{c. Ressourcenverschwendung im Kampf um Distributionsvorteile: Die Theorie des rent seeking}

Der Wettbewerb der Interessengruppen um staatlich garantierte Vorteile erfordert den Einsatz von Ressourcen, die produktiven Verwendungen entzogen werden. ${ }^{158}$ Damit führen die im politischen Prozeß erwirkten Vermögenstransfers zu zusätzlichen sozialen Kosten. Die dabei entstehenden Wohlfahrtsverluste stehen im Mittelpunkt der Analysen der Theorie des rent seeking.

Die grundlegende Argumentation des rent seeking-Ansatzes soll anhand von Abbildung 4.2, zurückgehend auf Tullock ${ }^{159}$, skizziert werden. Betrachtet sei der Markt für das private Gut $\mathrm{X}$, bei dem zum Wettbewerbspreis $\mathrm{p}^{*}$ die Menge $\mathrm{X}^{*}$ produziert wird. Gelingt es den Anbietern des Gutes X, durch Beeinflussung der Regierung eine Regulierungsmaßnahme, z.B. eine Zugangsbarriere für potentielle Konkurrenten durch restriktive Qualitätsregulierung, zu errei-

151 Vgl. Weingast, B./Shepsle, K./Johnsen,C. (1981); Gwartney, J.D./Wagner, R.E (1988), S. 19.

152 Vgl. Crew, M.A./Rowley, C.K. (1988); Crew, M.A./Twight, C. (1990).

153 Vgl. Benson, B.L. (1984); Epstein, R. (1988).

154 McCormick, R.E./Tollison, R.D. (1981), S. 17.

155 Anderson, T.L./Hill, P.J. (1980). Werden in diesem Umverteilungsprozess gleichzeitig offentliche Guter produziert, begunstigt dies die Erfolgschancen der jeweiligen Interessengruppe. Vgl. Anderson, G.M./ Tollison, R.D. (1988), S. 531 oder Pommerehne, W.W./Kirchgässner, G. (1988), S. $229 \mathrm{f}$.

156 Lee, D.R./McKenzie, R.B. (1988), S. 390.

157 Magee, S.P./Brock, W.A./Young, L. (1989), S. 259.

158 Grundlegend Tullock, G. (1967b); Krueger, A.O. (1974); Posner, R.A. (1975). Siehe auch die surveys von Tollison, R.D. (1982) und Tullock, G. (1993). Auch Becker verweist darauf, daß im politischen Gleichgewicht aus wohlfahrtsokonomischer Sicht zu viele Ressourcen im Kampf um Verteilungsvorteile eingesetzt werden. Vgl. Becker, G. (1983), S. 387f. Allerdings resultiert der Ressourceneinsatz bei Becker in effizienten Ergebnissen, ist also insofern zumindest kein Negativsummenspiel. Vgl. Tullock, G. (1980a), S. 21.

159 Siehe Tullock, G. (1967b), S. 225. Vgl. auch Ekelund, R.B./Tollison, R.D. (1981), S. 22. 
chen, sind sie einem geringeren Wettbewerbsdruck ausgesetzt und können den Preis $\mathrm{p}_{1}$ festlegen; der Output geht auf $\mathrm{X}_{1}$ zurück. ${ }^{160}$

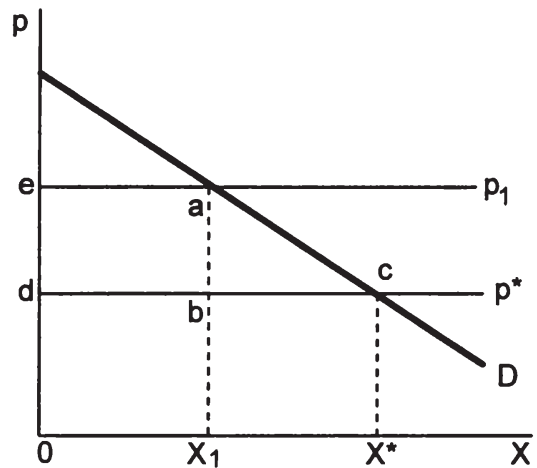

\section{Abbildung 4.2: Wohlfahrtsverluste durch rent seeking Quelle: Tullock, G. (1967b), S. 225.}

Die traditionelle Wohlfahrtstheorie sieht in der Fehlallokation der Ressourcen einen Wohlfahrtsverlust, der in der Grafik durch das Dreieck abc beschrieben wird. ${ }^{161}$ Die Fläche aedb wird dagegen als reine Umverteilung von Konsumenten zu Produzenten interpretiert.

Die staatlich verfügte Monopolisierung des Marktes für X verschafft den Anbietern Zusatzgewinne. Ein Interessent wird deshalb Ressourcen in Lobbying zur Gewinnung des Monopolrechts investieren, bis der erwartete Gegenwartswert der zusätzlichen Gewinne den marginalen Lobbying-Kosten entspricht. ${ }^{162}$ Unter der Annahme risikoneutraler Anbieter und vollkommener Konkurrenz um die Monopolrenten ist die Summe der Lobbying-Aufwendungen aller Interessenten am Monopolrecht gleich den durch das Regierungshandeln geschaffenen Renten aedb. 163 Tullock folgert, daß soziale Verluste einer Monopolisierung der Märkte im wohlfahrtstheoretischen Ansatz unterschätzt werden. ${ }^{164}$

In einer Vielzahl von Beiträgen verschiedener Autoren zum "efficient rent seeking" 165 wurde untersucht, zu welchem Anteil die künstlichen Monopolrenten im Konkurrenzkampf aufgezehrt werden. Wichtigste Bestimmungsfaktoren des Grades der "rent dissipation"166 sind die Risikoneigung der Interessenten und die Intensität des Wettbewerbs um die Monopolrenten.

160 Im Gegensatz zur freiwilligen Kartellbildung, bei dem free rider-Probleme die Stabilităt des Kartells gefahrden, wird das Kartell hier durch die staatliche Regulierungsmaßnahme gefestigt. Vgl. Buchanan, J.M. (1980), S. 7f. Zu anderen Erscheinungsformen des rent seeking siehe den Überblick bei Mueller, D.C. (1989), S. 135ff.

161 Vgl. Harberger, A.C. (1954).

162 Vgl. Tullock, G. (1980b), S. $100 \mathrm{f}$.

163 Vgl. Ekelund, R.B./Tollison, R.D. (1981), S. 23; Mueller, D.C. (1989), S. $231 \mathrm{f}$.

164 Vgl. Tullock, G. (1967b), S. 225.

165 Tullock, G. (1980b). Siehe unter vielen Rogerson, W.P. (1982); Hillman, A.L./Katz, E. (1984); Tullock, G. (1988).

166 Higgins, R.S./Shugart, W.F./Tollison, R.D. (1988), S. 131. 
Durch das "Tullock-Viereck"167 aedb lassen sich aber nicht alle potentiellen Wohlfahrtsverluste durch rent seeking illustrieren. So sprechen einige Faktoren dafür, daß die wahren sozialen Kosten sogar noch höher sind. Exemplarisch seien einige Argumente herausgegriffen:

- Die Erlangung der Monopolrenten geht häufig mit Korruption bei der Privilegienvergabe einher. ${ }^{168}$ Während die Bestechung selbst eine reine Umverteilung darstellt, sind die mit dem Streben nach Positionen, in denen man in den Genuß der Gelder kommt, verbundenen Kosten als Folgekosten des rent seeking zu interpretieren. 169

- Verzerrungen auf den monopolisierten Märkten führen zu weiteren Anpassungsreaktionen der Konsumenten und Faktoranbieter, die ebenfalls als Wohlfahrtsverluste zu qualifizieren sind. 170

- Die Schaffung von Monopolprivilegien führt dazu, daß andere Gruppierungen, wie von Becker angenommen, gegen die Einrichtung der Privilegien opponieren. Die hierfür eingesetzten Ressourcen sind eine weitere Quelle sozialer Verluste. ${ }^{171}$

- Soziale Verluste entstehen schließlich, wenn infolge der Dynamik marktlicher Anpassungsprozesse die durch Lobbying erworbenen Monopolrechte ihren Wert für die Anbieter verlieren. Die im rent seeking-Prozeß investierten Ressourcen sind für die Monopolanbieter versunkene Kosten, so daß die Zurücknahme der Privilegien für sie mit Verlusten verbunden ist, zu deren Vermeidung erneut Aufwendungen getätigt werden. ${ }^{172}$

Olson kommt deshalb zu dem Schluß, daß Interessengruppen die Effizienz und das Gesamteinkommen der Gesellschaften, in denen sie wirken, verringern. ${ }^{173}$

\section{Die Rolle der staatlichen Bürokratie}

\section{Die Ziele der Bürokraten}

Die staatliche Bürokratie ist eine nicht-gewinnorientierte, monopolistische Organisation ${ }^{174}$, die sich nicht durch marktliche Umsatzerlöse, sondern durch Zuweisungen aus den öffentlichen Haushalten finanziert. ${ }^{175} \mathrm{Da}$ an den Residualergebnissen der bürokratischen Tätigkeit keine property rights definierbar sind 176 und Gewinnmaximierungsstreben der Bürokraten damit ausgeschlossen werden kann, lassen sich unterschiedliche bürokratische

167 Tullock, G. (1993), S. 10.

168 Ausfuhrlich hierzu Rose-Ackerman, S. (1978).

169 Vgl. Buchanan, J.M. (1980b), S. 8ff.

170 Vgl. Buchanan, J.M. (1980b), S. $8 \mathrm{ff}$.

171 "The problem is that the possibility of a transfer leads people to invest resources in either obtaining the transfer or preventing it. People who hope to receive the transfer will invest resources until the return in probability of receiving the transfer on the last dollar is worth one dollar. Those against whom the transfer would work will invest similarly. One side or the other will win, but from the social standpoint the resources invested in the conflict are entirely wasted." Tullock, G. (1971b), S. 640. Siehe auch Rowley, C.K./Tollison, R.D. (1986); Tollison, R.D. (1987), S. 151.

172 Vgl. Tullock, G. (1975b) und (1993), S. 66ff.

173 Vgl. Olson, M. (1982/1991), S. 61.

174 Vgl. Roppel, U. (1979), S. 83ff.

175 Vgl. Niskanen, W.A. (1971), S. 15; Wagner, R.E. (1983), S. 108.

176 Vgl. Wagner, R.E. (1983), S. 111; Rowley, C.K./Elgin, R. (1988), S. 287. 
Handlungsmaximen vermuten. ${ }^{177}$ Niskanen geht davon aus, daß "Chef-Bürokraten"178 Informationsvorteile ${ }^{179}$ über den Produktionsprozeß der öffentlichen Leistungen gegenüber den politischen Auftraggebern mit dem Ziel einer Maximierung der zur Verfügung gestellten Budgets ausnutzen, da die meisten pekuniären und nicht-pekuniären Elemente ihrer Nutzenfunktion positiv mit der Budgetgröße korrelieren. ${ }^{180}$ Andere Autoren ${ }^{181}$ betonen die Bedeutung diskretionärer Handlungsspielräume für die Nutzen der Bürokraten, die ihnen die Produktion der Leistungen mit verschwenderischem Mitteleinsatz (bureaucratic waste) ermöglichen. Verwaltungsspitzen könnten insbesondere eine Ausweitung der Mitarbeiterzahl ${ }^{182}$ oder kapitalintensive Produktionsverfahren ${ }^{183}$ präferieren.

\section{Die These von der Dominanz der Legislative über die staatliche Bürokratie}

\section{a. Die Bürokratie in sozialwissenschaftlichen Hierarchiemodellen}

In älteren soziologischen und politologischen Ansätzen wird die hierarchisch aufgebaute Bürokratie als ideale Organisationsform für rationales und effizientes Verwaltungshandeln gesehen. Effizienz werde erreicht durch "... a corps of civil servants prepared by a special schooling and drilled ... into a perfect organization, with appropriate hierarchy and characteristic discipline ..."184 Ähnlich argumentiert Weber: "Der entscheidende Grund für das Vordringen der bürokratischen Organisation war von jeher ihre rein technische Überlegenheit über jede andere Form." 185 Ursache für die Dominanz des Hierarchieprinzips sei die systematische Arbeitsteilung, die exakte Kompetenzfestlegung und die Etablierung fester Aufsichtsbehörden für jedes Büro. 186

Dieser These liegt die Annahme zugrunde, daß von der Politik exakt formulierte Vorgaben an die Bürokratie ergehen, politische Kontrollbehörden das Verhalten der Bürokraten und deren produktive Aktivitäten effizient überwachen und infolge eines hierarchisch organisierten Systems Fehlverhalten wirksam sanktionieren könnten. ${ }^{187} \mathrm{Da}$ die Kontrolle der Administration effizient erfolge, sei keine "... weitgehende Abweichung bürokratischer Leistungserstellung vom Willen der politischen Auftraggeber"188 zu erwarten. Diese Sichtweise staatlichen Verwaltungshandelns beherrschte bis in die 60er Jahre auch die ökonomische Theorie. ${ }^{189}$

177 Zu einem ausfuhrlichen Überblick siehe etwa Peirce, W.S. (1981), S. 37ff.; Dunleavy, P. (1991), S. 148ff.

178 Blankart, C.B. (1975), S. 167.

179 Vgl. dazu Schmölders, G. (1970), S. 113.

180 Vgl. Niskanen, W.A. (1971), S. 38. Siehe auch Roppel, U. (1979), S. 86ff.

181 Vgl. etwa Migué, J.L./Bélanger, G. (1974); Peacock, A.T. (1983); Wyckoff, P.G. (1990a); (1990b).

182 Vgl. Williamson, O.E. (1964); Tullock, G. (1965b), S. 134ff.; Orzechowski, W. (1977), S. $242 \mathrm{ff}$.

183 Vgl. De Alessi, L. (1969); Niskanen, W.A. (1975), S. 639.

184 Wilson, W. (1887/1992), S. 21. Vgl. hierzu auch Ostrom, V. (1973), S. 28.

185 Weber, M. (1922), S. 668.

186 Vgl. Weber, M. (1922), S. 125. Siehe hierzu auch Jackson, P.M. (1982), S. 5.

187 Vgl. Roppel, U. (1979), S. 23ff.; (1982), S. 192.

188 Roppel, U. (1982), S. 191.

189 Vgl. Ostrom, V./Ostrom, E. (1971), S. 204; Conybeare, J.A.C. (1984), S. 480; Rowley, C.K./Elgin, R. (1988), S. 267. 


\section{b. Principal-Agent Modelle der legislativen Dominanz über die Bürokratie}

Mit der Entwicklung der Theorie der Firma wurde der Grundstein für ein neues Verständnis von Beziehungen zwischen Auftraggebern und Beauftragten im Produktionsprozeß gelegt. In den meisten der Beiträge sieht man im Hierarchie- und Anweisungssystem die prinzipiell beste Möglichkeit, opportunistisches Verhalten der Beauftragten zu reduzieren. Diese Überlegungen wurden von zahlreichen Autoren ${ }^{190}$ aufgegriffen und auf das Verhältnis von Legislative und staatlicher Bürokratie angewendet. Ausgangspunkt ist die Feststellung, daß zwischen Politikern und der staatlichen Bürokratie eine agency-Beziehung besteht. ${ }^{191}$ Unter der Annahme, daß Politiker am Wiederwahlziel orientiert sind, streben sie nach Positionen in parlamentarischen Ausschüssen, in denen sie als agenda-setter bestimmen können, welche politischen Vorschläge im Parlament zur Abstimmung kommen. ${ }^{192}$ Das Wahlziel impliziert, daß sie die Mitgliedschaft in parlamentarischen Komitees anstreben, deren Aufgabengebiete für die Wählerklientel der Ausschußmitglieder besonders von Bedeutung sind. 193

In diesen Ausschüssen sind sie Spezialisten, die ihre Positionen dazu verwenden, bürokratisches Verhalten zu beeinflussen, um besondere Vorteile für ihre Wählerschaft zu erlangen. Durch ihre gesetzgeberische Tätigkeit bestimmen sie den Rahmen für das bürokratische Handeln. So stellt Fiorina mit Blick auf das System in den USA fest: "The Congress controls the bureaucracy, and the Congress gives us the kind of bureaucracy it wants." 194 Daher wird angenommen, die Legislative verfüge über ein effizientes Machtinstrument zur Vermeidung opportunistischen Verhaltens der Administration. 195

Der fundamentale Unterschied zu den sozialwissenschaftlichen Hierachiemodellen besteht darin, daß der von den Politikern gesteckte Rahmen für die Bürokratie im Hinblick auf Wahlziele instrumentalisiert wird; dies impliziert, daß nicht ein wie auch immer definiertes Gemeinwohl bei der Ausgestaltung der institutionellen Restriktionen für bürokratisches Handeln im Vordergrund steht, sondern deren politische Effizienz. Daher kann angenommen werden, daß die Kontrollinstitutionen mit Politikern besetzt sind, deren Nachfrage nach den von der bürokratischen Einheit erstellten Leistungen relativ groß ist. 196

Dieser Ansatz ist allerdings auf Kritik gestoßen, weil aufgrund der einseitigen Fixierung auf die Legislative Probleme der Kontrolle bürokratischen Handelns nur unzureichend berücksichtigt werden. ${ }^{197}$ Diesem Aspekt soll im folgenden Abschnitt nachgegangen werden.

190 Siehe u.a. Weingast, B. (1981) und (1984); Moran, M.J./Weingast, B. (1982); Weingast, B./Moran, M.J. (1983); McCubbins, M./Schwartz, T. (1984); McCubbins, M. (1985); McCubbins, M./Noll, R./Weingast, B. (1987).

191 Vgl. etwa Moe, T. (1984), S. 740ff.; Rowley, C.K./Elgin, R. (1988); Pethig, R. (1988).

192 Siehe z.B. Shepsle, K./Weingast, B. (1981), S. 514.

193 Dies kommt besonders zum Tragen, wenn die Abgeordneten nach geographischen Gesichtspunkten bestimmt werden. Ist z.B. im Wahlkreis eines Politikers der Steinkohlebergbau besonders bedeutend, wird der Politiker einen Platz in einem fur Fragen des Bergbaus relevanten Ausschuß (z.B. für Energiepolitik) einnehmen wollen. Entsprechend streben Abgeordnete aus ländlichen Wahlkreisen eher nach Sitzen in Komitees, die sich mit landwirtschaftlichen Aspekten befaßen.

194 Fiorina, M. (1981), S. 333. Siehe auch Weingast, B. (1984), S. $154 \mathrm{ff}$.

195 Vgl. insbesondere Calvert, R.L./Moran, M.J./Weingast, B.R. (1987), S. 499ff.

196 Vgl. Niskanen, W.A. (1971), S. 40; (1975), S. 624ff.

197 So fuhrt Moe aus: "The proponents of congressional dominance often use principal-agent language to frame their theoretical discussion, but their assertions about congressional control are neither based on a systematic investigation of these analytical dimensions nor logically derived from a principal-agent 


\section{Die These von der Dominanz der Exekutive über die Legislative}

Ausgangspunkt ist hier die Erkenntnis, daß Informationsasymmetrien zwischen Prinzipalen und Agenten in Organisationen bestehen, weil Überwachungsaktivitäten nie kostenlos sind und in hierarchischen Beziehungen den Beauftragten Handlungsspielräume bei der Durchführung ihrer Tätigkeiten belassen. ${ }^{198}$ Die verursachten Effizienzeinbuße wirken sich naturgemäß im Verwaltungshandeln des Staates ebenso aus wie bei der privaten Unternehmung. ${ }^{199}$ Im Sinne einer vergleichenden Institutionenanalyse kann aber erst von besonderen Ineffizienzen der staatlichen Bürokratie gesprochen werden, wenn institutionelle Gegebenheiten hier zu Ergebnissen führen, die systematisch negativ von den Resultaten im privaten Sektor abweichen. 200

Eine wirksame Kontrolle der Bürokratie setzt voraus, daß die politischen Aufsichtsbehörden über Überwachungsmöglichkeiten und Kontrollanreize verfügen. Es zeigt sich, daß die Überwachung der staatlichen Administration aus mehreren Gründen problematisch ist, denn bei Kollektivgütern existieren signifikante Meßprobleme. Erstens ist eine wirksame Bürokratiekontrolle schon allein aufgrund der "Überlegenheit ihres sachkundigen Fachwissens"201 problematisch. Zweitens führt die Art der bereitgestellten Leistungen schon auf der Ebene der Zielvorgaben für die Bürokratie zu einem "Outputdefinitionsproblem"202. Sind aber bereits die politischen Anweisungen unpräzise, kann die Kontrolle ihrer Einhaltung nur unvollständig sein. Die Überwachung der bürokratischen Leistungserstellung erstreckt sich daher meist nur auf Inputgrößen, eine echte Wirtschaftlichkeitskontrolle entfällt fast zwangsläufig. ${ }^{203}$ Die Kontrolle der Bürokratie wird drittens erschwert, wenn die personelle Größe der Organisation und die Zahl der Hierarchiestufen steigt, denn "... the larger an organization becomes the weaker is the control over its actions exercised by those at the top." 204 Dies gilt v.a. deshalb, weil der Informationsfluß in der hierarchischen Ordnung Verzerrungen unterliegt. ${ }^{205}$ Überdies gibt es oft keine Möglichkeit, durch Leistungsvergleiche Abweichungen von kostenminimalen Produktionsverfahren festzustellen, da die Bürokratie in der Regel eine Monopolstellung in der Produktion der politischen Güter besitzt. 206 Daher wird davon ausgegangen, daß die Kontrollmöglichkeiten in staatlichen Bürokratien im Vergleich zu privatwirtschaftlichen Verwaltungen geringer und damit die Kontrollkosten tendenziell größer sind.

model." Moe, T. (1987), S. 481 und "The most rigorous aspects of the theory have nothing to do with control ... Yet it is the control relationship that the [principal-agent, H.P.] theory is ultimately interested in explaining, and the assertion that control is unproblematic does not make it so." Moe, T. (1987), S. 480.

198 Vgl. Williamson, O.E. (1964) und (1967); Tullock, G. (1965b); Downs, A. (1967); Jensen, M.C./Meckling, W.H. (1976).

199 Die Betrachtungen von Downs sind beispielsweise nicht nur auf die staatliche Burrokratie zugeschnitten, sondern auch z.T. auf privatwirtschaftliche bürokratische Systeme gemunzt. Vgl. Downs, A. (1967), S. 24.

200 Ähnlich auch Blankart, C.B. (1975), S. 175.

201 Schmölders, G. (1970), S. 113.

202 Roppel, U. (1982), S. 193.

203 Vgl. Peirce, W.S. (1981), S. 24; Roppel, U. (1982), S. 193f.; Rowley, C.K./Elgin, R. (1988), S. 286.

204 Downs, A. (1967), S. 143.

205 Vgl. Tullock, G. (1965b), insbes. S. 137ff.; Peirce, W.S. (1981), S. 27ff.; Tirole, J. (1986), S. 185ff.

206 Niskanen, W.A. (1971), S. 24. 
Bei gegebenen Kontrollkosten bestimmt sich das optimale Überwachungsniveau nach den Nutzen der politischen Kontrolleure. ${ }^{207}$ Anreize zur Überwachung der Bürokratie ergeben sich für die Politiker aufgrund ihres Wiederwahlziels. ${ }^{208}$ Eine ineffiziente Produktion öffentlicher Leistungen führt zu höheren Steuerbelastungen der Bürger, die sich in schlechteren Wahlchancen für die Mandatsträger äußern; umgekehrt kann eine effizient arbeitende Bürokratie die Wiederwahlchancen der amtierenden Regierung verbessern. ${ }^{209}$ Außerdem besteht ein Interesse der Politiker an Bürokratiekontrolle, weil dabei erzielte Überschüsse zur Verwirklichung ideologischer Ziele eingesetzt werden können. ${ }^{210}$ Die Abgeordneten haben folglich ein vitales Eigeninteresse an der Kontrolle der bürokratischen Leistungserstellung.

Aus Sicht des gesamten Parlaments ist aber die Ausübung der Kontrollfunktion ein reines öffentliches Gut. ${ }^{211}$ Abgeordnete, die knappe zeitliche und finanzielle Ressourcen für Bürokratiekontrolle einsetzen und durch die Androhung von Sanktionen 212 ein effizientes Verwaltungshandeln erzwingen, verbessern sowohl ihre eigenen Wiederwahlchancen als auch die von Repräsentanten, die keinen Beitrag zur Kontrolle leisten. Insofern, so die These, ist es für den einzelnen Politiker rational, wenig in die Überwachung der Verwaltung zu investieren. 213 Daher ist anzunehmen, daß die staatliche Bürokratie aufgrund ihrer Informationsvorteile über die Produktionsbedingungen des öffentlichen Leistungsangebots gegenüber der Legislative über monopolistische Spielräume verfügt; Schmölders spricht von einem "Übergewicht der Exekutive"214. Die Bürokratiemodelle von Niskanen und deren Weiterentwicklungen 215 basieren auf der Annahme, daß den Politikern eine wirksame Kontrolle der Verwaltung nicht möglich ist. Die Administration ist in der Lage, in bilateralen Budgetverhandlungen mit den Politikern die Rolle monopolistischer Optionsfixierer ${ }^{216}$ einzunehmen und ihre Interessen nahezu vollständig durchzusetzen. Politiker werden als passive Sponsoren modelliert ${ }^{217}$, die der Verhandlungs(über)macht der Bürokratie nichts entgegensetzen können.

Die modelltheoretischen Ergebnisse, die auf dieser Annahme beruhen, können wie folgt zusammengefaßt werden: Durch den signifikanten Informationsvorsprung, den die staatliche Bürokratie gegenüber den Politikern als Nachfrager administrativer Leistungen hat, können die Beschäftigten der Verwaltung Budgets in Höhe der gesamten Zahlungsbereitschaft der Legislative durchsetzen. Erfolgt in einzelnen Teilbereichen der bürokratischen Aktivitäten eine verstärkte Kontrolle, vermögen die Bürokraten mittels Quersubventionierung die Renten

207 Vgl. Moe, T. (1987), S. 481.

208 Vgl. Breton, A./Wintrobe, R. (1975), S. 199ff.; Niskanen, W.A. (1975), S. 623f.; Margolis, J. (1975), S. $652 \mathrm{ff}$.

209 Vgl. Breton, A./Wintrobe, R. (1975), S. 198.

$210 \mathrm{Vgl}$. insbesondere Wintrobe, $R$. (1987a), S. 438f., der betont, daß deshalb fehlender Wettbewerb um Wahlerstimmen keineswegs zwingend mangelnde Kontrolle der Verwaltung impliziert.

211 Vgl. Niskanen, W.A. (1975), S. 626ff.

212 Hierbei ist insbesondere die Stellenbesetzung der Chefbürokraten zu nennen. Siehe Weingast, B./Moran, M.J. (1983), S. 769.

213 Dieser Effekt wird allerdings verringert, wenn die Parteiorganisation "... maintains some internal rewards and sanctions to induce more monitoring by individual legislators ..." Niskanen, W.A. (1975), S. 628.

214 Schmölders, G. (1970), S. 108ff. Vgl. z.B. auch Rowley, C.K. (1992), S. 85.

215 Niskanen, W.A. (1971); (1974); (1975); Migué, J.L./Bélanger, G. (1974); Orzechowski, W. (1977); Mackay, R.J./Weaver, C.L. (1981); Roppel, U. (1982); Thürmer, L. (1984), S. 93ff.; Moene, K. (1986).

216 Vgl. Niskanen, W.A. (1971), S. 25; Conybeare, J.A.C. (1984), S. 486ff.

217 Vgl. Niskanen, W.A. (1971), S. 24ff. 
der Politiker abzuschöpfen. 218 Während in den reinen Budgetmaximierungsmodellen von Niskanen stets allokative Ineffizienzen durch überoptimale Produktion auftreten ${ }^{219}$, spielt technische Ineffizienz - also Abweichungen von der kostenminimalen Produktionsweise - nur eine Rolle bei der nachfragebeschränkten Gleichgewichtslösung. ${ }^{220}$ Die Ergänzung der bürokatischen Nutzenfunktion um das Argument des diskretionären Budgets erklärt dagegen das simultane Auftreten von allokativer und X-Ineffizienz ${ }^{221}$ auch bei budgetbeschränkten Lösungen. 222

Demgegenüber ist kritisch anzumerken, daß angesichts der Wahlrestriktion der politisch Verantwortlichen kaum von einer völlig unkontrollierten Bürokratie ausgegangen werden kann. ${ }^{223}$ Die Niskanen-Modelle der Bürokratie überzeichnen die Machtposition der Administration gegenüber den Politikern. 224 Ein realistisches Modell der Bürokratie sollte davon ausgehen, daß diskretionäre Handlungsspielräume der Verwaltung zwar bestehen, aber nicht uneingeschränkt zu Lasten der Politiker genutzt werden können. Insbesondere ist eine Integration der Theorien des Wahlwettbewerbs und der Verbände in die Untersuchung der Beziehungen zwischen Legislative und Administration erforderlich. ${ }^{225}$ In der Analyse muß Berücksichtigung finden, daß ein mehrstufiges Principal-Agent-Verhältnis vorliegt, in dem die Politiker als Agenten der Wähler und gleichzeitig als Prinzipale der Bürokratie handeln. 226

\section{Die Bürokratie in der Interessengruppentheorie des Staates}

Diese Sonderstellung der staatlichen Bürokratie wird im Modell der Interessengruppentheorie des Staates betont. Auf der Angebotsseite des politischen Prozesses handeln die Bürokraten als Agenten der Politiker und Wähler; gleichzeitig agieren sie aber wie eine Interessengruppe als Nachfrager nach Vermögenstransfers. In dieser Rolle unterliegen sie aber nicht dem für die Gruppenbildung fundamentalen free rider-Problem, da die Organisation durch hoheitlichen Zwang erfolgt. 227

Die Interessengruppentheorie betont die Asymmetrie bei den stimmenmaximierenden Strategien der Politiker hinsichtlich der Bestimmung von Ausgaben und Steuern. Während die Ausgaben speziellen, gut organisierten gesellschaftlichen Gruppen zufließen, werden die daraus resultierenden Belastungen weit gestreut. Für die Politiker sind nur Fehlentwicklungen

$218 \mathrm{Vgl}$. Roppel, $U$. (1979), S. 125ff.

219 Siehe Niskanen, W.A. (1971), S. 52; Roppel, U. (1979), S. $114 \mathrm{ff}$.

220 Vgl. Niskanen, W.A. (1971), S. 58.

221 Siehe hierzu Leibenstein, H. (1966); Crew, M.A./Jones-Lee, M.W./Rowley, C.K. (1971). Kritisch zum Konzept der X-Effizienz äußert sich Stigler, G.J. (1976).

222 Vgl. Migué, J.L./Bélanger, G. (1974), S. 33.

223 Vgl. Thompson, E.A. (1973), S. 951; Roppel, U. (1979), S. 170ff.; Jackson, P.M. (1982), S. $132 \mathrm{ff}$.

224 Dies kommt auch darin zum Ausdruck, daß bei Niskanen das formal bestehende Subordinationsverhaltnis zugunsten der Modellierung einer bilateralen Monopolbeziehung aufgegeben wird. Siehe Niskanen, W.A. (1971), S. 24.

225 Vgl. Thürmer, L. (1984), S. 120f.; Moe, T. (1987), S. 477.

226 "The whole of politics is ... structured by a chain of principal-agent relationships, from citizen to politician to bureaucratic superior to bureaucratic subordinate..." Moe, T. (1984), S. $765 f$.

227 Vgl. Crew, M.A./Rowley, C.K. (1986), S. 55; Rowley, C.K. (1992), S. 85. 
relevant, die unmittelbare Auswirkungen für ihre Wahlchancen haben. ${ }^{228}$ Folglich erstrecken sich Überwachungstätigkeiten der Abgeordneten weniger auf die Verringerung von X-Ineffizienzen und auf die Reduktion der Produktionskosten für politische Programmangebote, weil dadurch nur in geringem Umfang Wählerstimmen gewonnen werden können. 229 "The effect of distributive policies on the behavior of both the legislative review committee and the bureaucrat is to promote output production rather than cost reduction."230

Staatliche Behörden haben aus dieser Sicht Anreize, die Nachfrage ihrer politischen Auftraggeber durch Budgetausweitungen zu befriedigen. ${ }^{231}$ Eigennutzmaximierende Bürokraten werden die politische Nachfrage nach den von ihnen angebotenen Leistungen nicht durch eine Verringerung der Produktionskosten zu steigern suchen, sondern durch politische Werbung ${ }^{232}$, die als soziale Verschwendung einzustufen ist. ${ }^{233}$ Die Beziehung von Legislative und Bürokratie ist deshalb nicht nur von einer Interessenantinomie gekennzeichnet. Im Bestreben, Sondervergünstigungen für spezielle Interessen durchzusetzen, begründet die staatliche Bürokratie durch die eigene Nachfrage nach Ausweitung der Staatsaktivität eine dauerhafte Verfestigung staatlicher Programme, die sowohl im Interesse der Verbände als auch der Bürokratie selbst ist. ${ }^{234}$ Insofern kann man eher von der Kollusion von Legislative und Exekutive als von einer Gewaltentrennung sprechen. ${ }^{235}$ Auch kann angenommen werden, daß Bürokraten als Wähler Maßnahmen präferieren, die ein Wachstum der staatlichen Bürokratie zur Folge haben. Die Stärke dieser Wählergruppe in Verbindung mit der üblicherweise überdurchschnittlich hohen Wahlbeteiligung 236 läßt den staatlichen Bediensteten im politischen Programmkalkül hohes Gewicht beikommen. 237

Zusammenfassend betrachtet kann deshalb folgendes Fazit gezogen werden: Zwar sind die Bürokraten als Produzenten der Staatsleistungen nicht unmittelbar an der demokratischen Willensbildung beteiligt, sie beeinflussen aber deren Ergebnisse, weil sie die Nachfrage von Sonderinteressen verstärken und als eigenständige Nachfragergruppe im politischen Prozeß auftreten, deren Interesse vorwiegend in einer Ausweitung der öffentlichen Budgets besteht. Es kann deshalb angenommen werden, daß öffentliche Verwaltungen dazu tendieren, "... die Nachfrage nach den von ihnen bereitgestellten Gütern und Dienstleistungen zu übertreiben, die Kosten hingegen zu untertreiben." 238 Gleichzeitig ist eine staatliche Bürokratie mit diskretionären Spielräumen Ansatzpunkt für die Aktivitäten von Interessenverbänden. Deren Nachfrage nach den von ihnen bereitgestellten Gütern und Dienstleistungen zu übertreiben,

228 Vgl. Moe, T. (1987), S. 485ff.

229 Vgl. Carroll, K.A. (1990), S. 26.

230 Carroll, K.A. (1990), S. 26.

231 Vgl. Wagner, R.E. (1983), S. 115f. und S. 119. Siehe auch Rowley, C.K. (1992), S. 103.

232 Vgl. etwa Amacher, R./Tollison, R.D./Willett, T. (1976); Roppel, U. (1979), S. 128.

233 Vgl. Faith, R. (1980), S. 335ff.

234 Vgl. Crain, W.M./Tollison, R.D. (1979), S. 558ff.; Wagner, R.E. (1983), S. $120 \mathrm{ff}$.

235 Vgl. Crain, W.M./Tollison, R.D. (1979), S. 561. Dieser Ansatz liefert damit auch eine Erklärung, weshalb die Legislative trotz der vielfaltigen Kontrollprobleme eine staatlich-bürokratische Produktion politischer Guter der privaten Produktion vorzieht. Vgl. Wagner, R.E. (1983), S. 120.

$236 \mathrm{Vgl}$. etwa die empirischen Untersuchungen von Bush, W.C./Denzau, A.T (1977); Frey, B.S./Pommerehne, W.W. (1982); Bennett, J./Orzechowski, W. (1983). Jaarsma, B./Schram, A./van Winden, F. (1986) bezweifeln die Relevanz dieses Einflußfaktors.

237 Vgl. Borcherding, T.M./Bush, W.C./Spann, R.M. (1977), S. $216 \mathrm{ff}$.

238 Frey, B.S./Kirchgässner, G. (1994), S. 187. 
die Kosten hingegen $\mathrm{zu}$ untertreiben."239 Gleichzeitig ist eine staatliche Bürokratie mit diskretionären Spielräumen Ansatzpunkt für die Aktivitäten von Interessenverbänden. Deren Erfolgsaussichten beim Lobbying gegenüber der Verwaltung sind deshalb besonders groß, weil die Bürokraten keiner Wahlrestriktion unterliegen. 240

Eine politische Kontrolle der Bürokratie erfolgt, weil die Verwaltung das Wahlziel der Politiker gefährden kann und residuale Überschüsse die Handlungsfreiräume der Mandatsträger bei der Umsetzung ideologischer Ziele vergrößern. In beiden Fällen ist aber nicht garantiert, daß die Bürokratiekontrolle zur Besserstellung der Wähler führt. Politische Wahlziele implizieren, daß vorwiegend spezielle Interessen bedient werden müssen, und ideologische Freiräume dienen nicht zwingend einer Umsetzung wohlfahrtssteigernder Maßnahmen. ${ }^{241}$ Aus Sicht der Wähler geht es bei der Bürokratiekontrolle in erster Linie um die Umverteilung von Renten zwischen Legislative und Exekutive.

\section{Ein Totalmodell politischer Entscheidungsprozesse: Der 'beschränkte Leviathan- Staat'}

\section{Die Modellgrundlagen}

Während bisher die Interaktionen der Politiker mit Wählern, organisierten Interessengruppen und der staatlichen Bürokratie weitgehend isoliert betrachtet wurden, ist es zur Formulierung eines Totalmodells erforderlich, die wechselseitigen Abhängigkeiten in den Handlungen aller politischen Akteure darzustellen. In diesem Modell, das in Anlehnung an Denzau und Munger 242 entwickelt wird, werden als Akteure Politiker, unorganisierte Wähler, organisierte Interessengruppen und die Bürokratie 243 betrachtet, die im gegenseitigen Verteilungskampf um die Vorteile aus dem staatlich organisierten Tauschprozeß stehen.

Als Ausgangspunkt der Überlegungen dient das Wahlziel der Politiker. Die Kandidaten formulieren ihr Programm $P$, das sich aus unterschiedlichen Einzelregelungen $\left(P_{i}, P_{u}, P_{B}\right)$ und den hierfür erforderlichen Ausgaben $\left(E_{i}, E_{u}, E_{B}\right)$ zusammensetzt. Der Suffix $(j=i, u, B)$ kennzeichnet die Begünstigten der jeweils angebotenen politischen Güter, wobei i die Interessenverbände, $\mathrm{B}$ die Bürokratie und $\mathrm{u}$ die unorganisierten Wähler symbolisiert. Zur Durchführung der Maßnahmen stehe ein Steueraufkommen T zur Verfügung. Da keine Budgetdefizite gestattet seien, gilt die staatliche Budgetrestriktion

$$
\mathrm{E}_{\mathrm{i}}+\mathrm{E}_{\mathrm{u}}+\mathrm{E}_{\mathrm{B}}=\overline{\mathrm{T}}
$$

Es sei angenommen, daß die Steuerbelastung $T$ ausschließlich von den nicht organisierten Wählern getragen wird. Zum Wahlsieg ist die Gewinnung von Wählerstimmen V erforderlich, die von den unorganisierten Wählern $\left(V_{u}\right)$ und den in der Bürokratie Beschäftigten $\left(V_{B}\right)$ ange-

239 Frey, B.S./Kirchgässner, G. (1994), S. 187.

240 Vgl. etwa Messerlin, P. (1982).

241 Siehe dazu die Ausfuhrungen von Breton, A./Wintrobe, $R$. (1986).

242 Denzau, A.T./Munger, M.C. (1986). Siehe auch Eggertsson, T. (1990), S. $350 \mathrm{ff}$.

243 Denzau und Munger berlucksichtigen bei ihren Betrachtungen die Rolle der Burokratie nicht. 
boten werden. Die organisierten Verbände sind so klein, daß sie keine Wählerstimmen direkt anbieten $\left(V_{i}=0\right) \cdot 244$

$$
\mathrm{V}=\mathrm{V}_{\mathrm{u}}+\mathrm{V}_{\mathrm{B}}
$$

Die Interessengruppen offerieren im Tausch für Partikularvorteile $P_{i}$ nach dem 'quid pro quoPrinzip' Ressourcen $\mathbf{R}_{\mathbf{i}}$ (Informationen, Wahlkampfspenden usw.), die von den Kandidaten zur Wahlwerbung und Beeinflussung der Wähler eingesetzt werden, so daß

$$
\mathrm{R}_{\mathrm{i}}^{\prime} \equiv \frac{\partial \mathrm{R}_{\mathrm{i}}}{\partial \mathrm{P}_{\mathrm{i}}}>0
$$

Dabei wird unterstellt, daß die von den Kandidaten akquirierten Ressourcen R optimal (z.B. stimmenmaximierend) eingesetzt werden. Da die unorganisierten Wähler nicht vollständig über die Konsequenzen der Programme auf ihre individuellen Nutzenpositionen informiert sind, reagieren sie auf eine intensivere Wahlwerbung der Kandidaten mit einem veränderten Abstimmungsverhalten 245

$$
\mathrm{V}_{\mathrm{R}}^{\prime} \equiv \frac{\partial \mathrm{V}_{\mathrm{u}}}{\partial \mathrm{R}_{\mathrm{i}}}>0
$$

Wenn die unorganisierten Wähler auf politische Werbung eines Verbandes mit einer Stimmabgabe reagieren, die zur Begünstigung der werbenden pressure group führt, ist dies nicht gleichzusetzen mit der Annahme, daß die Wähler auch von der Maßnahme profitieren. Vielmehr beruht ihr Votum auf der Vermutung, das politische Programm fuhre zu einer individuellen Besserstellung. ${ }^{246}$ Die von öffentlich Bediensteten angebotenen Stimmen seien ausschließlich auf die Ausweitung der Staatsaktivitäten gerichtet und nicht durch Wahlwerbung beeinflußbar. Unter Zugrundelegung dieser Zusammenhänge werden nun die Ergebnisse des Zusammenspiels der (ungleichen) Kräfte im politischen Prozeß dargestellt.

\section{Die Modellergebnisse}

\section{a. Stimmenmaximierende Kandidaten}

Bei Stimmenmaximierung lautet die Zielfunktion der Politiker 247

Maximiere: $V=V_{u}\left[P_{u}\left(E_{u}\right), P_{i}\left(E_{i}\right), R\right]+V_{B}\left[P_{B}\left(E_{B}\right), E_{u}, E_{i}\right]+\lambda\left(\bar{T}-E_{u}-E_{i}-E_{B}\right)$.

Nach dem ersten Term der rechten Seite sind die Voten der unorganisierten Wähler abhängig von den Vorteilen, die ihnen direkt zukommen (public interest), den Vorteilen, die speziellen

246 Es soll jedoch nicht ausgeschlossen werden, daß einige Wahler zumindest teilweise aus der Maßnahme Vorteile ziehen. Vgl. Denzau, A.T./Munger, M.C. (1986), S. 93.

247 Vgl. Denzau, A.T./Munger, M.C. (1986), S. 93; Eggertsson, T. (1990), S. 352. 
Interessengruppen zukommen, und der Wahlwerbung. Die Bürokraten, so sei angenommen, votieren für eigene spezielle Vorteile $\left(\mathrm{P}_{\mathrm{B}}\right)$ sowie für generelle Budgetausweitungen $\left(\mathrm{E}_{\mathrm{u}}\right.$ und $\mathrm{E}_{\mathrm{i}}$ ), dies kommt durch den zweiten Term der rechten Seite zum Ausdruck. Der LagrangeMultiplikator $\lambda=(\partial \mathrm{V} / \partial \mathrm{T})$ bezeichnet den Schattenpreis des Steueraufkommens T. Die stimmenmaximierende Lösung ergibt sich durch Ableitung nach den Ausgabenkategorien $\mathrm{E}_{\mathrm{i}}$

$$
\lambda=V_{\mathrm{u}}^{\prime} \cdot \mathrm{P}_{\mathrm{u}}^{\prime}+\mathrm{V}_{\mathrm{Bu}}^{\prime}=\left(\mathrm{V}_{\mathrm{R}}^{\prime} \cdot \mathrm{R}_{\mathrm{i}}^{\prime}+\mathrm{V}_{\mathrm{i}}^{\prime}\right) \cdot \mathrm{P}_{\mathrm{i}}^{\prime}+\mathrm{V}_{\mathrm{Bi}}^{\prime}=\mathrm{V}_{\mathrm{B}}^{\prime} \cdot \mathrm{P}_{\mathrm{B}}^{\prime}
$$

(4.B.V.5) beschreibt das Ergebnis des politischen Verteilungskampfs um das Budget. Das verfügbare Steueraufkommen $\mathrm{T}$ wird für die verschiedenen Maßnahmen so eingesetzt, daß die zum Schattenpreis $\lambda$ zuletzt ausgegebene Geldeinheit von $E$ für alle Aktivitäten $P$ den gleichen marginalen Effekt auf die erreichte Stimmenzahl hat. Die einzelnen Terme sind wie folgt $\mathrm{zu}$ interpretieren:

$\mathrm{V}_{\mathrm{u}}^{\prime} \equiv\left(\partial \mathrm{V}_{\mathrm{u}} / \partial \mathrm{P}_{\mathrm{u}}\right)$ bezeichnet die marginalen Stimmengewinne als Reaktion unorganisierter Wähler auf eine (angekündigte) marginale Änderung der Regelung $\mathrm{P}_{\mathrm{u}}$. In analoger Weise ist $\mathrm{V}_{\mathrm{i}}^{\prime} \equiv\left(\partial \mathrm{V}_{\mathrm{u}} / \partial \mathrm{P}_{\mathrm{i}}\right) \mathrm{zu}$ interpretieren. Unorganisierte Wähler, die von der Bereitstellung von Partikularvorteilen profitieren, werden dieser Regelung zustimmen. Andererseits wird $\mathrm{V}_{i}^{\prime}$ negative Werte annehmen, wenn die nichtorganisierten Wähler erkennen, daß die Begünstigung spezieller Interessen zu ihrem Nachteil erfolgt. Diese Reaktionen implizieren, daß die Wähler um die persönlichen Konsequenzen politischer Maßnahmen auf ihre Nutzenposition wissen. Sind alle Wähler völlig uninformiert, reagieren sie nicht auf Veränderungen der Politikvariablen, und folglich ist $\mathrm{V}_{\mathrm{u}}^{\prime}=\mathrm{V}_{\mathrm{i}}^{\prime}=0$.

Die Grenzproduktivität des staatlichen Ressourceneinsatzes für eine bestimmte Aktivität kommt durch $P_{j}^{\prime} \equiv\left(\partial P_{j} / \partial E_{j}\right)$ mit $(j=u, i, B)$ zum Ausdruck. Die Grenzproduktivität beschreibt die Höhe der marginalen Vorteile, die jeder gesellschaftlichen Gruppe durch den marginalen Einsatz von Steuermitteln zukommen.

$\mathrm{V}_{\mathrm{R}}^{\prime} \equiv\left(\partial \mathrm{V}_{\mathrm{u}} / \partial \mathrm{R}_{\mathrm{i}}\right)$ beschreibt die Reaktion der Wähler auf veränderte Ausgaben für politische Werbung, die von den speziellen Interessengruppen finanziert wird. Diese Größe ist für alle Ausgaben für politische Werbung gleich groß, unabhängig davon, welches spezielle Interesse damit unterstützt werden soll, denn stimmenmaximierendes Verhalten impliziert einen Ausgleich der Grenzstimmenproduktivitäten der Wahlkampfunterstützungen.

$\mathrm{R}_{\mathrm{i}}^{\prime} \equiv\left(\partial \mathrm{R}_{\mathrm{i}} / \partial \mathrm{P}_{\mathrm{i}}\right)$ bezeichnet die marginale Änderung der Unterstützung der Politiker durch die organisierten Interessen zur Finanzierung der Wahlkampagnen als Gegenleistung für die Bereitstellung von Partikularvorteilen. Damit spiegelt $\mathbf{R}_{\mathbf{i}}^{\prime}$ den Preis wider, den die pressure groups für die Erlangung von Sondervorteilen an die Kandidaten entrichten.

Mit $V_{\mathrm{Bu}}^{\prime} \equiv\left(\partial \mathrm{V}_{\mathrm{B}} / \partial \mathrm{E}_{\mathrm{u}}\right)$ sind die Stimmengewinne beschrieben, die die Politiker durch die Ausweitung des Budgets für public interest-Güter im Wählerkreis der Bürokraten erzielen. Analog gilt für die Bereitstellung von Partikularvorteilen für organisierte Interessengruppen, daß sie damit Wählerstimmen der Bürokratie gewinnen können: $V_{B i}^{\prime} \equiv\left(\partial V_{B} / \partial E_{i}\right)$. Die Bereitstellung von Sondervorteilen für die Bürokratie führt ebenfalls zu Stimmengewinnen, die durch $\mathrm{V}_{\mathrm{B}}^{\prime} \equiv\left(\partial \mathrm{V}_{\mathrm{B}} / \partial \mathrm{P}_{\mathrm{B}}\right)$ umschrieben werden. 
Vernachlässigt man zunächst die Rolle der öffentlichen Bediensteten als Wähler, so sind die Modellergebnisse vom Informationsstand der unorganisierten Wähler bestimmt. ${ }^{248}$ Je geringer die Wählerinformation ist, um so stärker erfolgt die Ausrichtung der politischen Schwerpunkte auf organisierte Interessen. Bei vollkommener Uninformiertheit wird das Ziel einer Stimmenmaximierung übereinstimmend mit dem Ziel der Maximierung der Wahlkampfunterstützung durch organisierte Verbände. ${ }^{249} \mathrm{Da}$ für die public interest-Aktivitäten keine Lobby existiert, erfolgt in diesem Extremfall auch keine Bereitstellung politischer Güter $\mathrm{P}_{\mathrm{u}}$. Die Politiker erhalten auch Stimmen, wenn sie sich nur für Partikularinteressen engagieren, denn einerseits gibt es immer Wähler, denen Transfers an spezielle Interessengruppen als Nebenprodukt Nutzen stiften. Andererseits kann durch Wahlwerbung ein öffentliches Interesse an der Durchführung bestimmter Programme suggeriert und ein erwünschtes Abstimmungsverhalten erreicht werden. Unterstellt man im anderen Extrem perfekte Information der Wähler, so sinkt die Grenzstimmenproduktivität der Wahlwerbung $V_{R}^{\prime}$ und der Einfluß der Interessengruppen auf Null. 250 Wenn trotzdem Privilegien für spezielle Interessen angeboten werden, ist dies auf den positiven Nutzen zurückzuführen, den informierte Wähler aus solchen Maßnahmen ziehen.

Die besondere Rolle der Bürokratie in der Interessengruppentheorie des Staates kommt durch ihre Bedeutung als Nachfrager steigender öffentlicher Budgets zum Ausdruck. Die Politiker können mithin allein durch die Zusage, Leistungen auszuweiten, Wählerstimmen der öffentlich Bediensteten gewinnen.

Durch Umformen von (4.B.V.5) erhält man auch:251

$$
\mathrm{R}_{\mathrm{i}}^{\prime}=\frac{\lambda-\mathrm{V}_{\mathrm{Bi}}^{\prime}}{\mathrm{V}_{\mathrm{R}}^{\prime} \cdot \mathrm{P}_{\mathrm{i}}^{\prime}}-\frac{\mathrm{V}_{\mathrm{i}}^{\prime}}{\mathrm{V}_{\mathrm{R}}^{\prime}}
$$

Der erste Term auf der rechten Seite von (4.B.V.6) erlaubt folgende Interpretation. Für einen gegebenen Schattenpreis $\lambda$ und eine gegebene Wählerstimmenproduktivität der Wahlwerbung $\mathrm{V}_{\mathrm{R}}^{\prime}$ ist der Preis für die Erlangung von Partikularvorteilen durch organisierte Interessengruppen um so höher, je geringer die Produktivität des Ressourceneinsatzes bei der Bereitstellung von Sondervergünstigungen und je geringer der Wählerstimmeneinfluß der bürokratischen Bediensteten ist. Durch den zweiten Term auf der rechten Seite von (4.B.V.6) kommt die Macht der Wähler zum Ausdruck. Erkennen die Wähler, daß die Begünstigung einer pressure group zu ihrem Nachteil erfolgt, so ist $V_{i}^{\prime}$ negativ, und der Preis für die Erlangung spezieller Vergünstigungen steigt. ${ }^{252}$ Dieser Effekt wird verringert, wenn die Wähler wenig informiert sind und daher die Stimmenproduktivität der Wahlwerbung groß ist.

Unter realistischen Bedingungen werden die Kandidaten daher schon aus Eigeninteresse die unorganisierten Wähler bei ihren Programmentscheidungen nicht völlig mißachten: Das Mehrheitswahlrecht ist zwar nur eine unvollkommene Beschränkung für opportunistisches Verhalten der Regierung; die Ausrichtung des politischen Handelns auf das Wiederwahlziel

248 Vgl. Denzau, A.T./Munger, M.C. (1986), S. 99ff.

249 Siehe Denzau, A.T./Munger, M.C. (1986), S. 99f.

250 Vgl. Eggertsson, T. (1990), S. 353.

251 Vgl. Denzau, A.T./Munger, M.C. (1986), S. 97, jedoch ohne Berucksichtigung der Burokratie.

252 Vgl. auch Mitchell, W.C./Munger, M.C. (1991), S. 537ff. 
erfordert aber in jedem Fall ein Mindestmaß an Bereitstellung öffentlicher Leistungen entsprechend den Wählerwünschen. ${ }^{253}$

Es ist deshalb zu erwarten, daß politische Programme eine Mixtur aus dem Angebot öffentlicher Güter zum Nutzen der Wähler und aus Maßnahmen, deren Nutzen sich auf spezielle organisierte Interessen konzentriert, sind. ${ }^{254}$ Im Extremfall völliger Uninformiertheit der Wähler agiert der Staat ausschließlich als Redistributionsagentur, über die konkurrierende organisierte Interessen, einschließlich der staatlichen Bürokratie, ihre Verteilungskämpfe abwickeln. ${ }^{255}$ Es kommt zum Rückfall in die Hobbes'sche Anarchie. ${ }^{256}$

\section{b. Satisfizierende Regierung}

Geht man hingegen davon aus, die Regierung könne sich aufgrund mangelnden politischen Wettbewerbs mit einer befriedigenden Mehrheit begnügen, wird in der Zielfunktion das Streben nach maximalen Wählervoten durch ein Streben nach maximalen fiskalischen Überschüssen ersetzt. Die Überschüsse Z, die sich die Regierungspolitiker aus der Amtstätigkeit aneignen können, fallen um so höher aus, je größer der Überschuß der Steuereinnahmen über die zur Gewinnung von Wählerstimmen notwendigen Ausgaben ist. 257 Daraus ergibt sich die Zielfunktion der Amtsinhaber

$\operatorname{Max} .: Z=\left(\bar{T}-E_{u}-E_{i}-E_{B}\right)+\lambda\left\{V_{u}\left[P_{u}\left(E_{u}\right), P_{i}\left(E_{i}\right), R\right]+V_{B}\left[P_{B}\left(E_{B}\right), E_{u}, E_{i}\right]-\bar{V}\right\}$

wobei $\bar{V}$ die zum Wahlgewinn ausreichende Stimmenmehrheit bezeichnet. Unter Annahme eines fix vorgegebenen Steueraufkommens sollen die Ausgaben für die Bereitstellung öffentlicher Güter und Partikularvorteile minimiert werden. Als Lösung ergibt sich:

$$
(1 / \lambda)=V_{u}^{\prime} \cdot P_{u}^{\prime}+V_{B u}^{\prime}=\left(V_{R}^{\prime} \cdot R_{i}^{\prime}+V_{i}^{\prime}\right) \cdot P_{i}^{\prime}+V_{B i}^{\prime}=V_{B}^{\prime} \cdot P_{B}^{\prime}
$$

Auch Überschußmaximierung impliziert, daß die zuletzt ausgegebene Geldeinheit des Steueraufkommens für alle Verwendungen die gleichen marginalen Stimmenerträge erbringen soll. Besteht intensiver Wettbewerb, zwingt der Konkurrenzdruck die Kandidaten zum ressourcensparenden Einsatz der Mittel zur Stimmengewinnung; bei fehlendem Wettbewerb liegt dieser Anreiz in der möglichen Aneignung der verbleibenden Überschüsse begründet.

Der Unterschied zwischen den Lösungen besteht nicht bei den Marginalbedingungen, sondern beim absoluten Ausgabenniveau. Wenn eine ausreichende Mehrheit angestrebt wird, ist es nicht notwendig, das gesamte Einnahmenvolumen $\mathrm{zu}$ verausgaben. Die oben abgeleiteten Marginalbedingungen sind dann kein Muß für die Politiker; eine modifizierte Zielfunktion unter Einbeziehung ideologischer Absichten ermöglicht Abweichungen von der Handlungsmaxime. 
Die Verletzung der Marginalbedingungen reduziert zwar die diskretionären Überschüsse, ermöglicht aber trotzdem noch die Erreichung des angestrebten Wahlziels. Damit kann auch der Schluß gezogen werden, daß bei weniger intensivem Wettbewerb um Wählerstimmen die relative Machtposition der Politiker gegenüber den organisierten Interessen gestärkt ist. Je geringer der politische Konkurrenzdruck ist, desto kleiner ist auch der Einfluß der Interessengruppen auf den politischen Output. 258 Die These vom "powerless politician"259 hat nur Gültigkeit bei Stimmenmaximierung.

\section{Die graphische Darstellung des Modells}

Die Überlegungen können mit Hilfe von Abbildung 4.3 weiter verdeutlicht werden. Quadrant 3 veranschaulicht die Budgetlinie der staatlichen Akteure, die Linie ee bezeichnet die staatliche Budgetrestriktion bei maximalem Steueraufkommen ( $T=0 e)$, das für Ausgaben für öffentliche Güter $\left(E_{u}\right)$ und Ausgaben für Partikularvorteile spezieller Interessengruppen $\left(E_{i}\right)$ verwendet werden kann. Quadrant 2 zeigt die Produktionsfunktion OF für die Bereitstellung öffentlicher Güter $\left(\mathrm{P}_{\mathrm{u}}\right)$, und in Quadrant 4 ist die Produktionsfunktion $0 \mathrm{G}$ für öffentliche Güter $\left(E_{u}\right)$ und Ausgaben für Partikularvorteile spezieller Interessengruppen $\left(E_{i}\right)$ verwendet werden kann. Quadrant 2 zeigt die Produktionsfunktion OF für die Bereitstellung öffentlicher Güter $\left(\mathrm{P}_{\mathrm{u}}\right)$, und in Quadrant 4 ist die Produktionsfunktion $0 \mathrm{G}$ für gruppenspezifische Partikularvorteile $\left(\mathrm{P}_{\mathrm{i}}\right)$ abgebildet. Zur Vereinfachung der graphischen Darstellung wird davon ausgegangen, daß lediglich eine Interessengruppe i existiert. 260

Der Verlauf der 0G-Kurve ist bestimmt von der Grenzproduktivităt der Staatsausgaben für die Bereitstellung von Partikularvorteilen. Es wird die Gültigkeit des Gesetzes fallender Marginalerträge angenommen. Der Verlauf der OF-Funktion zeigt die Netto-Vorteile, die der Allgemeinheit der Wähler aus der staatlichen Aktivität zufließen. Die Kurve 0F beschreibt sowohl die Produktivität von Ausgaben für öffentliche Konsumgüter als auch von Ausgaben für staatliche Vorleistungen, die beide annahmegemäß das Nutzenniveau der Wähler erhöhen. Im Maximum von OF sind die Renten der Bürger/Steuerzahler maximiert. ${ }^{261} \mathrm{Nimmt}$ man vereinfachend an, daß die Besteuerung keine verzerrenden Wirkungen erzeugt, bezeichnet das hierfür aufzuwendende Steueraufkommen 0e gleichzeitig die Maximaleinnahmen des Staates. Jede Ausweitung des öffentlichen Budgets über 0e hinaus verringert die Produktivität der Ausgabenkategorie $E_{u}$, die Netto-Vorteile der Bürger $P_{u}$ und die Steuereinnahmen $T$. Der Maximalpunkt von OF korrespondiert damit mit dem Maximalpunkt der Laffer-Kurve. Mit diesen Produktionsfunktionen kann die politische Transformationskurve TT im 1. Quadranten konstruiert werden. TT beschreibt den Möglichkeitsraum zur Bereitstellung von $P_{u}$ und $P_{i}$ bei gegebenem Budget $\overline{\mathrm{E}}$.

In Quadrant 1 ist außerdem eine Iso-Stimmenfunktion VV eingezeichnet. VV beschreibt die Kombinationen von $\mathrm{P}_{\mathrm{u}}$ und $\mathrm{P}_{\mathrm{i}}$, die den Politikern die gleiche Stimmenzahl einbringen. ${ }^{262} \mathrm{Je}$

$258 \mathrm{Vgl}$. Anderson, G.M./Tollison, R.D. (1988), S. 534f.

259 Magee, S.P./Brock, W.A./Young, L. (1989), S. 58.

260 Interessengruppe i kann als Summe der organisierten Interessen einschließlich der Burokratie interpretiert werden.

261 Ähnlich auch die Darstellung bei Findlay, R./Wilson, J.D. (1987), S. $291 \mathrm{ff}$.

262 Siehe Salmon, P. (1991), S. 172. Vgl. auch Sinn, S. (1992), S. 181. Im Gegensatz zu Salmon und Sinn sind hier jedoch die Iso-Stimmenfunktionen abhăngig von der absoluten Hơhe der Ausgaben fur unorganisierte und organisierte gesellschaftliche Gruppen und nicht von der relativen Hohe. 
weiter entfernt die Iso-Stimmenkurve vom Ursprung verläuft, desto mehr Stimmen erhalten die Politiker für die jeweiligen Politikkombinationen. Die Steigung wird von den marginalen Stimmengewinnen bestimmt, die die Kandidaten durch Veränderungen ihrer Angebote erzielen. Bei geringer Information der Wähler erhält die Iso-Stimmenkurve eine stark negative Krümmung, da bereits eine marginale Verringerung der Partikularvorteile $P_{i}$ zu großen Stimmenverlusten führt, die nur durch eine starke Ausweitung von $P_{u}$ kompensiert werden können. Im Extremfall völliger Uninformiertheit der Wähler würde die Iso-Stimmenkurve senkrecht verlaufen, einen waagerechten Verlauf erhält sie bei perfekter Wählerinformation.

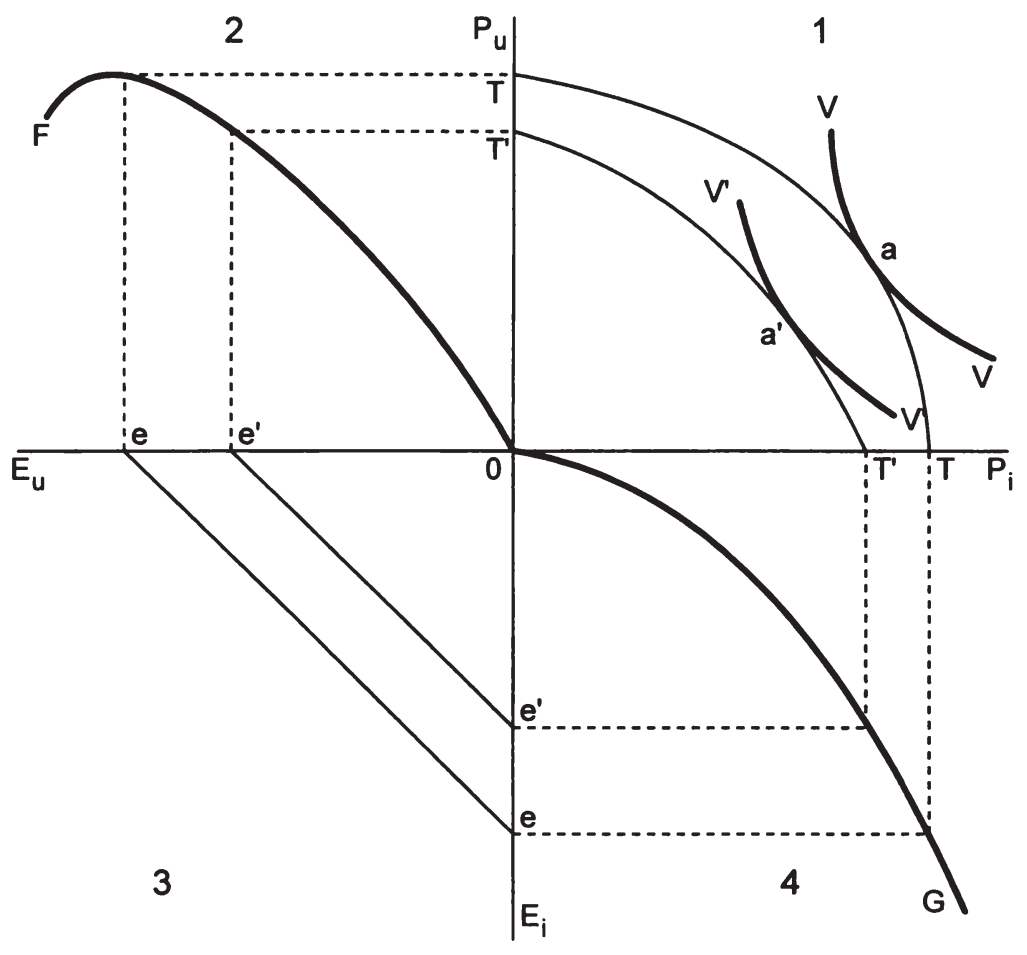

Abbildung 4.3: Ein Totalmodell politischer Entscheidungsprozesse Quelle: in Anlehnung an Salmon, P. (1991), S. 172.

Bei intensivem Wettbewerb der Kandidaten um Wählerstimmen liegt das erreichbare Stimmenmaximum in Punkt a auf TT. Das gesamte Budget $\bar{E}$ wird zur Bereitstellung von $P_{u}$ und $P_{i}$ verwendet; den Regierenden verbleibt kein diskretionäres Budget zur Verwirklichung eigener Interessen. Aufgrund des hohen Gewichts der speziellen Interessen in der Zielfunktion der Kandidaten ist der Anteil der Ausgaben für öffentliche Güter $E_{u}$ an den Gesamtausgaben $\bar{E}$ relativ gering.

Strebt die Regierung dagegen eine ausreichende Mehrheit $\bar{V}$ an, orientiert sie sich in ihren Programmentscheidungen nicht an VV, sondern an der niedriger liegenden Iso-Stimmenkurve 
$V^{\prime} V^{\prime}$. Dies bedeutet, daß bereits geringere $E_{u}$ und $E_{i}$ zur Erreichung des Wahlziels genügen, so daß kein Anreiz besteht, einen Punkt auf TT zu realisieren. Zur Maximierung des diskretionären Überschusses wählen die Politiker die Kombination $\left(\mathrm{P}_{u}, \mathrm{P}_{\mathrm{i}}\right)$ gemäß Punkt a' auf $\mathrm{T}^{\prime} \mathrm{T}^{\prime}$, die zum Wahlerfolg gerade vonnöten ist. T'T' korrespondiert mit der Budgetlinie e'e', und der diskretionäre Überschuß beläuft sich auf ee'. Stuft man sowohl die Ausgaben für Partikularinteressen als auch die diskretionären Überschüsse als social waste und lediglich $P_{u}$ als sozial nutzenstiftend ein, liegt das unter dieser institutionellen Struktur erreichbare gesellschaftliche Optimum im Schnittpunkt der TT-Kurve mit der $\mathrm{P}_{\mathrm{u}}$-Achse. Dort wird das erzielte Steueraufkommen $\mathrm{T}$ vollständig zur Bereitstellung von Gütern im Interesse der Bürger/Steuerzahler verausgabt.

Freilich spiegelt dieses Schaubild nicht die längerfristigen Aspekte der politischen und ökonomischen Prozesse wider. Aufgrund der Ineffizienz der Ausgabenkombinationen a bzw. a' werden die Wachstumskräfte der betrachteten Volkswirtschaft geschwächt, so daß die Kurve OF in den folgenden Wahlperioden immer weiter nach unten verlagert wird. Die maximal erzielbaren Steuereinnahmen sinken, es kommt zu dem von Olson beschriebenen "Decline of Nations"263. Allerdings spielen diese Gesichtspunkte aus der dem politischen Prozeß inhärenten kurzfristigen Sicht nur eine eher untergeordnete Rolle.

Offensichtlich liefert die indirekte Demokratie nur bei perfektem politischen Wettbewerb und vollkommener Information wohlfahrtsmaximierende Ergebnisse. Es ist aber auch nicht zu erwarten, daß das parlamentarisch-demokratische System keine Beschränkung für die Organisationsmanager darstellt, wie Brennan/Buchanan vermuten. ${ }^{264}$ Ein realistisches Bild des Staates muß deshalb von einem "beschränkten Leviathan"265 ausgehen, der zwar über Handlungsfreiräume verfügt, die entgegen den Interessen der Bürger eingesetzt werden können, aber nicht über quasi-diktatorische Vollmachten.

\section{Ein Zwischenfazit}

Aus Sicht der neoinstitutionalistischen Theorie sind politische Entscheidungsprozesse durch einen Verteilungskampf zwischen Wählern, Politikern, Bürokraten und Interessengruppen um staatlich bereitgestellte (politische) Güter charakterisiert. Das Ergebnis der "battle over the budget" 266 wird dabei von den Kräfteverhältnissen der Beteiligten bestimmt.

Das Informationsproblem im politischen Sektor ist für die Bürger-Prinzipale im Vergleich zum Markt von extremer Bedeutung. Folglich unterliegen die Bürger stets der Gefahr opportunistischen Verhaltens der Regierung. Es ist deshalb anzunehmen, daß viele Vorteile der Kooperation im Staat nicht den eigentlichen Ressourceneinbringern der Organisation zu Gute kommen, sondern daß sich andere politische Akteure, namentlich die Politiker, die staatliche Bürokratie und die organisierten Interessengruppen, diese Renten aneignen.

263 Siehe Olson, M. (1982/1991).

264 Siehe Brennan, G./Buchanan, J.M. (1980/1988), S. 9.

265 Sinn, S. (1993), S. 32.

266 Rowley, C.K. (1992), S. 163. 
Die Regierung agiert in der indirekten Demokratie als Organisationsmanagement. Die Regierungsmitglieder treffen für alle Staatsbürger verbindliche Entscheidungen unter dem Gesichtspunkt einer Wiederwahl. Je zwingender die Wahlrestriktion für die Politiker wirkt, um so weniger können sie Überschüsse der staatlichen Einnahmen über die Ausgaben für politische Güter für eigene Zwecke zurückbehalten. Ist der politische Konkurrenzdruck so stark, daß sie sich als Stimmenmaximierer verhalten müssen, ist ihre Rolle auf die passiver Transfermakler beschränkt.

Die Bürokraten als Produzenten der öffentlichen Leistungen verfügen gegenüber der Regierung über diskretionäre Handlungsfreiräume, die sie opportunistisch zu Lasten ihrer Auftraggeber ausnützen können. Je intensiver die Kontrolle politischer Aufsichtsgremien ist, desto weniger können sie sich residuale Überschüsse aneignen. Gleichzeitig ist die Bürokratie auch als organisierte Nachfragegruppe nach politischen Gütern aktiv.

Die Macht organisierter Verbände liegt in Informationsvorteilen begründet. Je schlechter die Bürger über die Auswirkungen von Sondervergünstigungen für pressure groups informiert sind, um so größer ist der Einfluß der Interessengruppen auf politische Entscheidungen.

\section{Die politischen Entscheidungsprozesse in föderativen Staaten}

\section{Der Vergleich unitarischer und föderativer Strukturen als komparative Institutionenanalyse}

Ausgangspunkt der nachfolgenden Analyse der demokratischen Willensbildung in föderativen Staaten sind die in Abschnitt B gewonnenen Erkenntnisse. Da weiterhin die Gültigkeit des einfachen Mehrheitswahlrechts in einer indirekten Demokratie unterstellt wird, ist anzunehmen, daß sich an der Grundstruktur der Entscheidungsfindung nichts ändert. Die Dezentralisierung eines Teils der staatlichen Kompetenzen und die Abkehr vom unitarischen System setzt allerdings einen neuen institutionellen Rahmen für das Handeln der politischen Akteure.

Während die individuellen Ziele der beteiligten Handlungseinheiten sich nicht von denen im unitarisch aufgebauten Staat unterscheiden, werden durch einen föderativen Aufbau des Staates neue Restriktionen geschaffen, die das eigennutzorientierte Handeln in andere Richtungen lenken (können). $\mathrm{Zu}$ untersuchen ist, wie föderative Strukturen das Anreizsystem für die politische Akteure verändern und wie das Kräfteverhältnis in der politischen Willensbildung beeinflußt wird. Es sei daran erinnert, daß die im dritten Kapitel dargestellte traditionelle Theorie stets von der Annahme ausgeht, daß bei fortschreitender Dezentralisierung politische Entscheidungen besser den Präferenzen der Bürger entsprechen.

Um diese These zu überprüfen, soll hier davon ausgegangen werden, daß zwischen den betrachteten Subeinheiten des Staates keine Außenbeziehungen (spillovers) bestehen und daß folglich auch externe Koordinationskosten für die Aufgabenverteilung im Staat keine Rolle spielen. Daher muß auch angenommen werden, daß alle Güter und Faktoren räumlich immobil sind. In Abschnitt $\mathrm{C}$ wird lediglich diskutiert, welche Konsequenzen ein föderativer Staatsaufbau im Vergleich zu einer unitarischen Struktur für das Verhalten der Beteiligten und die Ergebnisse der politischen Interaktionen hat (komparative Institutionenanalyse). 


\section{Die Konsequenzen der Föderalisierung für den Wettbewerb um Wählerstimmen}

\section{Die Implikationen für die diskretionären Handlungsspielräume der Politiker}

Die Existenz diskretionärer Handlungsfreiräume der Politiker im demokratischen System ist eine der Hauptursachen für die vermutete Ineffizienz politischer Entscheidungen. Sind die Entscheidungsverantwortlichkeiten über die Vielzahl der Politikbereiche nicht unitarisch auf einer einzigen Ebene im Staat angesiedelt, sondern auf mehrere Staatsebenen verteilt, wird auf den einzelnen politischen Entscheidungsebenen über weniger Sachfragen entschieden. Legt man das Prinzip räumlicher Äquivalenz als Aufteilungskriterium zugrunde, wird auf lokaler Ebene nur über die Bereitstellung lokaler Kollektivgüter abgestimmt, auf nationaler Ebene dagegen über Güter mit gesamtstaatlichen Nutzenreichweiten.

Theiler vermutet, ganz traditionell argumentierend, daß die Zusammenlegung von Funktionen in Mehrzweckkollektiven die Konsensbildung und den Konfliktausgleich durch log-rolling erleichtern könne, mithin zu Kosteneinsparungen bei der Entscheidungsfindung führe. ${ }^{267}$ Bei dieser Argumentation wird allerdings übersehen, daß packaging keineswegs nur zum Vorteil der Bürger gereicht, sondern vielmehr als opportunistische Strategie der politischen Agenten dienen kann. Jede Verringerung sachlicher Zuständigkeiten begrenzt damit die Handlungsspielräume der Politiker. ${ }^{268}$ Föderative Strukturen mit strikter ebenenspezifischer Funktionentrennung reduzieren die Chancen der Regierungen, unterschiedliche Politiken zu Programmen zu bündeln und den Bürgern unliebsame Programmpunkte im Paket aufzuzwingen.269 Implizite und explizite log-rolling-Prozesse setzen voraus, daß verschiedene politische Projekte zur Debatte stehen. ${ }^{270}$ Je geringer folglich die Zahl der Programmpunkte ist, die miteinander verknüpft werden können, um so weniger bestehen Möglichkeiten zum Stimmentausch. Differenzierter argumentieren Bish und Warren aus Sicht der Wähler:

"The more numerous the political units, the more accurately a citizen may indicate his preferences, but the more costly it will be in terms of his own participation. Conversely, the fewer the political units, the more costly it will be to express preferences on any single good or service, but the less costly will be his own participation ... This choice problem is often called the 'menu problem'."271

Die These, eine Zusammenlegung von Funktionen reduziere die Entscheidungskosten ${ }^{272}$ ist deshalb nach Bish und Warren zu einseitig. Bei näherer Betrachtung vermag freilich auch dieses Argument noch nicht voll zu überzeugen. Hinter dem konstatierten "menu problem" steht die Annahme, daß mit dem Übergang zu multifunktionalen Kollektiven die Kosten der politischen Partizipation sinken würden. Dies mag allenfalls auf die Kosten für den Gang zur Wahl zutreffen, obwohl auch hier kein stichhaltiges Argument gegen die föderative Aufteilung von Kompetenzen vorliegt, da Wahlen auf mehreren jurisdiktionellen Ebenen jederzeit gleichzeitig abgehalten werden könnten. Die Kosten der Information über die anstehenden politischen Entscheidungen werden aber von der Anzahl der Themenkomplexe bestimmt, die

267 Vgl. Theiler, J. (1977), S. 83.

268 Vgl. Wagner, R.E./Weber, W.E. (1975), S. $671 \mathrm{ff}$.

269 Vgl. Breton, A. (1974), S. 51, S. 114f.; Aranson, P.H. (1989), S. 130; Boyne, G.A. (1992), S. 338.

270 Vgl. Tullock, G. (1976), S. 45ff.

271 Bish, R./Warren, R. (1972), S. 105.

272 Vgl. Oates, W.E. (1972), S. 48f. Siehe auch die Ausfuhrungen im 3. Kapitel, Abschnitt C.VI.3, S. 143ff. 
sich jedoch nicht durch die Zusammenfassung auf einer Ebene verringern lassen. ${ }^{273}$ Das Argument angeblicher Verbundvorteile einer Konzentration von Bereitstellungskompetenzen steht daher auf schwachen Füßen.

Eine zweites zentrales Element der traditionellen ökonomischen Föderalismustheorie ist die These von der höheren intrakollektiven Homogenität der Bevölkerungsstrukturen auf dezentraler Ebene im Vergleich zu größeren Einheiten. Geht man von der Gültigkeit dieser Annahme aus, so erzwingt der höhere Grad an Präferenzübereinstimmung der Bürger einer lokalen Jurisdiktion von den Politikern eine stärkere Ausrichtung ihrer angebotenen Programme an den Bürgerpräferenzen. Wenn die Präferenzen der Bürger sich nur in geringem Maße von denen des Medianwählers unterscheiden, wird auch der Spielraum der Politiker bei der Programmerstellung geringer. Dies gilt insbesondere, weil es Minderheitenparteien in homogeneren Subkollektiven besser gelingen kann, die politischen Marktzutrittsschranken zu überwinden. 274

Galeotti $^{275}$ betont die veränderte Rolle der Parteiideologien in dezentralisierten Systemen. Nach seiner Auffassung erfolgt die Herausbildung von Ideologien als Konsequenz der mit steigender Zahl von Politikbereichen verbundenen Informationsdefizite der Wähler. ${ }^{276}$ Mit geringerer Zahl von Verantwortlichkeiten, um die die Parteien konkurrieren, so die These, verlieren ideologische Bindungen der Wähler an die Parteien an Bedeutung. 277 Damit wird die Beweglichkeit der Parteien im Wählerspektrum erhöht ${ }^{278}$, und gleichzeitig steigen die Risiken der Politiker, sich entgegen der parteipolitischen Linie zu verhalten. Dezentralisierung begünstigt damit die institutionelle Funktion der Parteien, opportunistisches Verhalten der aus ihren Reihen gewählten Vertreter zu verhindern. 279

Die Föderalisierung von Kompetenzen wirkt ebenfalls auf den innerparteilichen Wettbewerb um Positionen. Nach gängiger Auffassung wird der Erfolg von Parteimanagern auf zentraler Ebene auch durch Wahlergebnisse in den subnationalen Kollektiven bestimmt. Damit stellen sich die Politiker aber praktisch permanent zur Wahl. Die Kontrolle politischer Prozesse durch die Wähler erfolgt dann nicht mehr nur durch die Abstimmung in der jeweiligen Jurisdiktion, und die Wahlperioden verkürzen sich quasi auf indirektem Weg. ${ }^{280}$ Dieser Effekt kann in beide Richtungen der vertikalen föderativen Beziehungen wirken. Mißmanagement auf nationaler Ebene reduziert die Wahlchancen der parteipolitischen Vertreter auf subzentraler Ebene $^{281}$, und Fehlleistungen der lokalen oder regionalen Mandatsträger verringern die Aus-

273 Ähnlich auch Teutemann, M. (1992), S. 186f.

274 Vgl. Chandler, W.M./Chandler, M.A. (1987), S. 91.

275 Vgl. Galeotti, G. (1987) und (1992).

276 Wie Downs betont, dienen Parteiideologien zur Reduktion der Informationskosten. Siehe Downs, A. (1957/1968), S. 95ff. Vgl. auch Herder-Dorneich, P./Groser, M. (1977), S. 173ff.

277 Vgl. Galeotti, G. (1987), S. 125; (1992), S. 8f.

278 Auf lokaler Ebene ist pragmatische Realpolitik eher zu beobachten als ideologisch geprägte Fundamentalpolitik.

279 Ähnlich Galeotti, G. (1987), S. $118 \mathrm{f}$.

280 Man spricht von der "electoral interdependence hypothesis", Simon, D.M./Ostrom, C.W./Marra, F. (1991), S. 1184 oder vom "coattail effect", Levernier, W. (1992), S. 182.

281 Vgl. Peltzman, S. (1987); Simon, D.M./Ostrom, C.W./Marra, F. (1991). 
sichten der Parteikandidaten der zentralen Ebene. ${ }^{282}$ Ein 'splitting' der abgegebenen Stimmen, hier verstanden im Sinne des Votums für eine Partei A bei Wahlen zum nationalen Parlament und für eine Partei B bei subzentralen Abstimmungen, vergrößert zugleich die Möglichkeiten der Wähler, opportunistisches Verhalten der Regierenden zu begrenzen. ${ }^{283}$

Andererseits verwischen die Verantwortlichkeiten der Regierungen verschiedener Ebenen im föderativen Staat. Wenn die Zentralebene für makroökonomische Stabilisierung zuständig und wenig erfolgreich ist, könnte die Konsequenz lauten, daß auf subzentraler Ebene erfolgreiche Allokationspolitik einer Regierung derselben parteipolitischen Couleur von den Wählern nicht honoriert wird. 284 Ebenso könnte erfolgreiche nationale Politik einer Regierungspartei Opportunismus der parteiangehörigen Regierungsmitglieder in den lokalen Kollektiven verdekken. 285 Insgesamt erscheint daher nur eine Mischung aus innerparteilichem Wettbewerbsdruck und deutlichem Bewußtsein der Wähler, welche politische Ebene für welche Aufgabenerfüllung verantwortlich ist, verstärkten intrajurisdiktionellen Wettbewerb der Parteien um Wählerstimmen zu garantieren. Während der erstgenannte Aspekt von der Binnenstruktur der Parteien bestimmt wird ${ }^{286}$, ist der zweite Gesichtspunkt von den Informationsmöglichkeiten und -anreizen der Bürger abhängig. ${ }^{287}$ Im nächsten Unterabschnitt werden Argumente aufgezeigt, die darauf schließen lassen, daß gerade dieser Aspekt durch föderative Strukturen positiv beeinflußt wird.

Insgesamt scheint die Aufteilung der Entscheidungsverantwortlichkeiten auf mehrere Staatsebenen die Möglichkeiten der Wähler, opportunistisches Verhalten der Politiker zu sanktionieren, zu verbessern. Damit verringern sich die Handlungsfreiräume der Politiker auf allen Ebenen. Der Wettbewerb der Kandidaten um Wählerstimmen kann deshalb bei föderativem Staatsaufbau an Intensität gewinnen.

\section{Die Implikationen für den Informationsstand der Wähler}

Als zweite Ursache für die mangelnde Effizienz der politischen Widerspruchsoption in repräsentativen Demokratien wurde die unzureichende Informiertheit der Wähler identifiziert. Erstens sind die Kosten der Informationsgewinnung für die Prinzipale hoch, und zweitens sind die Anreize zur Information aufgrund des Kollektivgutcharakters demokratischer Entscheidungen für die Wähler gering. Beide Komponenten werden durch den Übergang zu föderativen Strukturen beeinflußt.

282 Vgl. Dinkel, R. (1980a), S. 74f. oder speziell fur die Prăsidentschaftswahlen in den USA im Jahre 1992 Abrams, B.A./Butkiewicz, J.L. (1995). Allerdings können "... untergeordnete Wahlen in der Legislaturperiode ... eine solche Funktion nicht ubernehmen, solange dabei der Bestand der ubergeordneten Regierung nicht gefahrdet ist." Dinkel, $R$. (1980b), S. 142.

283 Vgl. Chandler, W.M./Chandler, M.A. (1987), S. 99.

284 Vgl. dazu etwa Stein, R.M. (1990). Grundsătzlich zu den Beziehungen zwischen makroøkonomischen Daten und Wahlverhalten der Bevőlkerung: Stigler, G.J. (1973).

$285 \mathrm{Vgl}$. Abrams, J.D./Kenny, L.W. (1989).

286 Die durch Art. 21 Abs. I des Grundgesetzes der Bundesrepublik Deutschland vorgeschriebene demokratische innere Ordnung der Parteien kann dem nur insoweit Rechnung tragen, wie ein demokratisches Wahlsystem selbst den Bügerpraferenzen entspricht. Zu Besonderheiten des innerparteilichen Wettbewerbs siehe auch Herder-Dorneich, P./Groser, M. (1977), S. $191 \mathrm{ff}$.

287 Levernier vermutet, daß die Wahler relativ genau wissen, welche staatliche Ebene fur welche Aufgabenerfullung zustăndig ist. Siehe Levernier, $W$. (1992), S. 188f. 
Die Anreize, Informationen über die angebotenen politischen Programme der Kandidaten und deren Konsequenzen für die individuellen Nutzenpositionen zu gewinnen, steigen durch eine räumliche Dezentralisierung. Je geringer die Zahl der Wähler ist, desto größer ist ceteris paribus der Einfluß des einzelnen Bürgers auf die Wahlentscheidung, und der Stimmenwert des einzelnen Wahlberechtigten steigt. $288 \mathrm{Da}$ Wahlentscheidungen Kollektivgutcharakter haben, wächst bei einer kleineren Gruppe die Spürbarkeit des eigenen Beitrags zur Bereitstellung dieses Gutes. ${ }^{289}$ Zwar bleibt auch auf lokaler Ebene der Kollektivgutcharakter von Wahlentscheidungen erhalten, aber die Betroffenheit der Bürger von den Entscheidungen der Regierung nimmt zu. Damit wird auch die für den einzelnen Wahlbürger häufig anzutreffende Irrelevanz der zur Entscheidung anstehenden Probleme verringert, und es werden zusätzliche Informationsanreize geschaffen. ${ }^{290}$ Allerdings darf dieser Einflußfaktor nicht überbewertet werden, da selbst bei deutlich geringerer Wählerzahl auf lokaler Ebene oder bei niedriger Wahlbeteiligung der Stimmenwert in Relation zu den Kosten des Wählens klein bleibt. 291

Dezentralisierung berührt auch die soziologische Komponente der Wahlbeteiligung. So wird vermutet, daß auf lokaler Ebene die Identifikation von Trittbrettfahrern aufgrund der engeren sozialen Kontakte erleichtert ist und die Gefahr einer negativen Sanktionierung durch Gruppenmitglieder bei Wahlabstinenz die persönlichen Nutzen aus dem Gang zur Wahl erhöht. 292 Der persönliche Gewinn aus einer Wahlbeteiligung steigt auch, wenn die Identifikation der Bürger mit der lokalen oder regionalen Einheit groß ist, weil damit 'Wählen als Bürgerpflicht' an Bedeutung gewinnt. 293 Überdies ist die Höhe der Informationskosten unter anderem bestimmt durch die intra- und interregionalen Kommunikationsstrukturen. ${ }^{294}$ Gerade in kleinräumigen Einheiten haben aber informelle Kontakte verstärkte Bedeutung. Informelle Kontakte sind eine verhältnismäßig kostengünstige Informationsquelle für die Bürger, da sie häufig ein Nebenprodukt der interpersonellen Kommunikation darstellen. 295 Dieser Informationsaustausch unter den Bürgern ("horizontal voice"296) einer kleinen Jurisdiktion unterliegt nicht dem free rider-Problem der Formulierung von politischem Widerspruch gegen die Regierung, ist aber nach Hirschman "... a necessary precondition for the mobilization of vertical voice" 297 .

Als weiteres Argument für dezentrale Strukturen wird angeführt, daß das Problem einer mangelnden Verfügbarkeit von Informationen über das Handeln der Agenten durch die Föderalisierung der Entscheidungskompetenzen verringert wird. Die parallele Existenz mehrerer Einheiten, denen dieselben Aufgaben zugeordnet sind, eröffnet den Bürgern der lokalen/regionalen Einheiten eine neue Informationsquelle. Zur Bewertung der Leistungen der eigenen Regierung können sie, wie bereits von Tiebout - in einer wenig beachteten Fußnote -

288 Vgl. Downs, A. (1957/1968), S. 239; Romer. T./Rosenthal, H. (1983), S. 178; Eichenberger, R. (1994), S. 411.

289 Vgl. Hansen, S./Palfrey, T.R./Rosenthal, H. (1987), S. 18.

290 Vgl. Aranson, P.H. (1989), S. 130.

291 Vgl. Tullock, G. (1993), S. 40.

292 Vgl. z.B. Opp, K.-D. (1994), S. 397. Siehe auch Hansen, S./Palfrey, T.R./Rosenthal, H. (1987), S. 18, die allerdings diesem Erklarungsansatz nur geringe Bedeutung beimessen.

293 Vgl. dazu Pennock, G. (1989), S. 26f.

294 Vgl. Siebert, H. (1967), S. 61.

295 Vgl. Breton, A. (1974), S. 111. Ähnlich auch bereits Downs, A. (1957/1968), S. 219.

296 Hirschman, A.O. (1987), S. 220.

297 Hirschman, A.O. (1987), S. 220. 
angemerkt, die Ergebnisse des Regierungshandelns der benachbarten Jurisdiktionen als Vergleichsmaßstab heranziehen. 298

Folglich dürften durch die Föderalisierung der Strukturen für die Wähler die Nutzen der Informationsgewinnung steigen und die Kosten der Informationsgewinnung sinken, so daß von insgesamt besser informierten Wählern auf subzentraler Ebene ausgegangen werden kann.

\section{Das Konzept des interjurisdiktionellen Rangordnungswettbewerbs}

\section{a. Rangordnungswettbewerb und Wettbewerb um Wählerstimmen}

Die Möglichkeit interjurisdiktioneller Vergleiche reduziert nicht nur die Informationskosten der Bürger, sie erzeugt auch einen intensiveren intrakollektiven Wettbewerb der politischen Kandidaten, der zu einer Verringerung der diskretionären Freiräume der Politiker führt. Die grundlegenden theoretischen Überlegungen hierzu stammen von Salmon ${ }^{299}$, der das aus der Arbeitsökonomik entliehene Konzept der tournaments (Rangordnungswettbewerbe) ${ }^{300}$ auf das Informationsproblem in demokratischen Systemen anwendet.

In einem unitarischen Staat können sich die Wähler durch die Gegenüberstellung von fiktiven Angeboten der Opposition mit dem tatsächlich erbrachten Output der amtierenden Regierung oder durch den intertemporalen Vergleich der eigenen Nutzenposition bei Amtsantritt der Regierung und zum Wahlzeitpunkt Informationen über die Leistungen der Regierung zu verschaffen. Während im ersten Fall ein außerordentlich hohes Maß an Ungewißheit über die Vergleichbarkeit der Alternativen herrscht, ist der retrospektive Vergleich problematisch, weil sich die ökonomischen Rahmenbedingungen zwischen den Wahlzeitpunkten stark verändern können. In beiden Fällen liegt der Gegenüberstellung eine unterschiedliche Ausgangsbasis zugrunde, was die Aussagekraft der Informationen für den Wähler stark einschränkt.

In dezentralisierten Systemen können sich dagegen die Bürger, so die These, mit relativ geringem Aufwand Kenntnisse von dem in anderen Jurisdiktionen existierenden Güterangebot beschaffen, das gerade bei unmittelbar benachbarten Einheiten unter ähnlichen ökonomischen Rahmenbedingungen erstellt wird. ${ }^{301}$ Zwar verfügen die Wähler damit nicht über absolute Informationen über die Leistungen der eigenen Regierung, sie vermögen jedoch die relative Qualität der bereitgestellten Güter einzuschätzen und können diese zu einem maßgeblichen Einflußfaktor ihrer Wahlentscheidung machen.

Verschlechtert sich z.B. das öffentliche Leistungsangebot in Jurisdiktion A relativ zu dem im Gemeinwesen B, werden die Wähler der eigenen Regierung in A schlechte Leistungen attestieren und tendenziell für die politische Opposition in A votieren. ${ }^{302}$ Diese Tatsache erzeugt eine Konkurrenzbeziehung zwischen den Regierungen gleicher Ebenen, die als 'Quasi-Wettbewerb' bezeichnet werden kann. Im Bemühen um eine bessere Rangordnungs-

298 Vgl. Tiebout, C.M. (1956), S. 422, FN 18; Bish, R./Warren, R. (1972), S. 110; Salmon, P. (1987b), S. 71ff.; Case, A. (1993).

299 Siehe Salmon, P. (1987a); (1987b). Vgl. auch Besley, T./Case, A. (1995).

300 Grundlegend etwa Lazear, E.P./Rosen, S. (1981); Nalebuff, B.J./Stiglitz, J.E. (1983).

301 Siehe etwa Case, A. (1993), S. 137.

302 Vgl. Breton, A. (1991), S. 40; Besley, T./Case, A. (1995), S. 30f.; Staley, S.R./Blair, J.P. (1995), S. 24. 
position in der Bewertungsskala der Wähler müßten die Politiker ihre Regierungspolitik den Präferenzen ihrer Bürger besser anpassen, diskretionäre Spielräume werden dadurch verringert. 303 "Thus ... we discover a rather strange situation: the possibility of competition without a market on which it could take place." 304

Die Argumentation behält nach Salmon auch Gültigkeit, wenn die Wähler lediglich einzelne Teilpolitiken zum Vergleich heranziehen oder fehlerhafte Informationen über das Regierungshandeln in den Gliedstaaten besitzen. ${ }^{305}$ Selbst dann, wenn aufgrund regionsspezifischer Merkmale zwischen den Gebietskörperschaften Unterschiede in den Produktions- und Kostenfunktionen bei der Bereitstellung öffentlicher Leistungen bestehen, geben Veränderungen der Rangordnungspositionen im Zeitablauf Aufschluß über Opportunismus der Amtsinhaber. ${ }^{306}$

Bislang beschränkte sich die Analyse auf horizontale Beziehungen in einem dezentralisierten System. In einem föderativen System spielen aber auch die vertikalen Interdependenzen eine Rolle. Es eröffnen sich daher Perspektiven für einen vertikalen Rangordnungswettbewerb der Jurisdiktionen verschiedener Ebenen. Eine trennscharfe Definition von Zuständigkeiten der Ebenen im föderativen Staat scheint oftmals gar nicht möglich, weil von allen staatlichen Aktivitäten zur Realisierung eines (finanzpolitischen) Ziels immer Nebenwirkungen auf die anderen Ziele ausgehen und gleiche öffentliche Aufgaben mit unterschiedlichem Instrumenteneinsatz angegangen werden können. ${ }^{307}$ In der traditionellen ökonomischen Föderalismusdiskussion wird deshalb die Notwendigkeit vertikaler Koordination und gemeinschaftlicher Aufgabenwahrnehmung zur Vermeidung von Ressourcenverschwendung betont. ${ }^{308}$ Aus politökonomischer Perspektive können konkurrierenden Zuständigkeiten dagegen positive Aspekte abgewonnen werden, da die Anreiz- und Informationswirkungen ein den Bürgerpräferenzen adäquateres Verhalten der Regierungen erzeugen können. 309

Bieten mehrere staatliche Ebenen ähnliche Staatsleistungen an, könnten die Bürger EffizienzVergleiche anstellen. Rangordnungswettbewerb setzt nicht voraus, daß die von den Jurisdiktionsregierungen der verschiedenen Ebenen angebotenen Leistungen perfekte Substitute sind. 310 So erleichtert bereits eine hohe Substitutionalität der Güter die Gegenüberstellung und reduziert die Informationskosten der Wähler. Darüber hinaus begrenzt horizontaler Wettbewerb der Regierungen unterer Ebenen bei Substitutionalität der angebotenen Güter die Monopolmacht der übergeordneten Ebene. Liegt allerdings zwischen den Gütern eine Komplementaritätsbeziehung vor, liefert vertikaler Wettbewerb keine Beschränkung für die Regierung höherer Ebenen. ${ }^{311}$

303 "The good incumbent inflicts an externality on the bad one, reducing the latter's reelection chances." Besley, T./Case, A. (1995), S. 31 f.

304 Salmon, P. (1987a), S. 31. Besley, T./Case, A. (1995) bezeichnen die Quasi-Konkurrenz als "yardstick competition".

305 Vgl. Salmon, P. (1987a), S. 32f.

306 Vgl. Salmon, P. (1987a), S. 33f.

307 Vgl. Bish, R. (1988), S. $361 \mathrm{ff}$. und Spahn, P.B. (1993), S. 5 f.

308 Siehe die Ausfuhrungen im 3. Kapitel, S. 143ff.

309 Vgl. Salmon, P. (1987a), S. 35f.

310 Vgl. Bish, R./Ostrom, V. (1979), S. 30f.; Bish, R. (1988), S. 363.

311 Vgl. Turnbull, G.K./Djoundourian, S.S. (1993), S. $243 f$. 


\section{b. Rangordnungswettbewerb als Entdeckungsverfahren}

In der traditionellen Föderalismustheorie wird oftmals der Gedanke formuliert, daß die lokalen Einheiten als Experimentierstätten für Innovationen fungieren, die in einem trial-anderror-Prozeß auf längere Sicht neue Wege zur besseren und kostengünstigeren Produktion von (Kollektiv-)Gütern hervorbringen. ${ }^{312}$ Die Grundgedanken des Innovationswettbewerbs gehen auf das Schumpeter'sche Ideal des dynamischen Pionierunternehmers und auf Hayeks Idee vom Wettbewerb als Entdeckungsverfahren zurück. 313 Unternehmerischer Wettbewerb erzeugt danach Anreize zur Schaffung neuer Produkte oder Technologien und ist damit Motor der gesellschaftlichen Entwicklung. Voraussetzung für die Wirksamkeit der Konkurrenz ist, daß innovative Unternehmer die Vorteile aus der Erlangung temporärer Monopolstellungen internalisieren können. Der träge Unternehmer muß imitieren oder verschwindet vom Markt. Es wird deshalb vorgebracht, daß Rangordnungswettbewerb in föderativen Systemen ein kompetitives Element schaffe, das indirekt ähnliche innovatorische Wirkungen entfalten kann. Entsprechend äußert Oates die Vermutung:

"With a large number of independent producers of a good, one might expect a variety of approaches (for example, varying techniques of instruction in local public schools) that, in the long run, promises greater technical progress in modes of providing these goods and services." 314

Stehen die Regierungen subzentraler Einheiten im Quasi-Wettbewerb mit den Entscheidungsträgern anderer Jurisdiktionen, müssen die Amtsinhaber, um im Vergleich mit anderen Einheiten nicht zurückzufallen, nach neuen politischen Konzepten suchen. ${ }^{315}$ Liegen dagegen keine indirekten Konkurrenzbeziehungen der Jurisdiktionen vor, ist der Anreiz für die Politiker, innovative Konzepte zur Lösung politischer Probleme zu suchen, geringer. Folglich wäre bei unitarischem Staatsaufbau weniger mit Neuerungen zu rechnen als in föderativen Systemen. 316

Die Problematik einer Übertragung dieses Konzepts auf politische Märkte wird bei näherer Betrachtung evident. ${ }^{317}$ Weder existieren 'Gewinnansprüche' der Bürger als formale Eigentümer der Organisation Staat, noch scheidet eine Staatsorganisation vom Markt aus. ${ }^{318}$ Kerber und Vanberg geben auch zu bedenken, daß

"... the advantages and disadvantages of advancing or falling back in competition among jurisdictions may be both widely dissipated and presumably unevenly distributed among the citizens of jurisdictions. Compared to the clearcut role of entrepreneurs in ordinary markets, the incentives for political entrepreneurs to search for institutional innovations ... may be rather weak." 319

312 Siehe Oates, W.E. (1972), S. 12 und (1990), S. 52; Frey, R.L. (1977), S. 39f. Allerdings ist die Behandlung des Innovationswettbewerbs in der traditionellen Theorie im Grunde systemfremd, da die lokalen Regierungen annahmegemäß ohnehin die bestmögliche Versorgung ihrer Büger anstreben. Ähnlich Hauser, $H$. (1993), S. 466.

313 Schumpeter, J.A. (1964); Hayek, F.A. von (1968).

314 Oates, W.E. (1972), S. 12.

315 Vgl. Vihanto, M. (1992); Vanberg, V./Kerber, W. (1994); Staley, S.R./Blair, J.P. (1995).

316 Vgl. Vanberg, V,/Kerber, W. (1994), S. 206.

317 Zur Sicht politischer Prozesse aus evolutionstheoretischer Perspektive siehe Wohlgemuth, M. (1995).

318 Vgl. Vanberg, V./Kerber, W. (1994), S. $205 f$.

319 Kerber, W./Vanberg, V. (1995), S. 46. 
Ebenso könne die Imitation von erfolgreichen Einzelregelungen, die in einer lokalen Einheit Anwendung finden, in den imitierenden subzentralen Gebietskörperschaften aufgrund der unterschiedlichen Rahmenbedingungen sogar $\mathrm{zu}$ einer Verschlechterung führen. ${ }^{320}$ Kritisch ist weiter einzuwenden, daß innovative Verbesserungen mit langfristigen Wirkungen auch bei Rangordnungswettbewerb nur bedingt zu erwarten sind und fehlender Patentschutz Innovationen im öffentlichen Sektor zu einem Kollektivgut macht. ${ }^{321} \mathrm{Da}$ die positiven Konsequenzen der Portfolioentscheidungen zwischen risikoreichen und risikoarmen öffentlichen Investitionen über alle Jurisdiktionen streuen, die Kosten von Fehlinvestitionen aber nur von den Jurisdiktionsmitgliedern getragen werden, wird die Position der Innovatoren geschwächt. Deshalb liegt, so Rose-Ackerman, auf lokaler Ebene eine systematische Verzerrung zu risikoarmen Projekten vor. ${ }^{322}$

Wenn daher auch nicht zu erwarten ist, daß Rangordnungswettbewerb im öffentlichen Sektor dieselben Innovationswirkungen entfaltet wie unternehmerischer Wettbewerb, so ist allein aufgrund des fehlenden Wettbewerbsdrucks im unitarischen Staat im dezentralisierten System eher mit der Erfüllung innovatorischer Funktionen zu rechnen. ${ }^{323}$

\section{Die Konsequenzen der Föderalisierung für den Einfluß spezieller Interessengruppen}

\section{Die Organisation spezieller Interessen im foderativen System}

\section{a. Konsequenzen für die Organisierbarkeit spezieller Interessen}

Der Einfluß spezieller Interessengruppen auf politische Entscheidungen in der Demokratie ist von mehreren Faktoren abhängig. Dies sind vor allem die Organisationsfähigkeit der latenten Gruppen, der Informationsstand der Wähler und Politiker und die Intensität der politischen Konkurrenz um Wählerstimmen. Je nachdem, welcher Aspekt in der Diskussion stärker betont wird, ergeben sich unterschiedliche Konsequenzen für die Erfolgschancen spezieller Interessen. Entsprechend kontrovers sind die in der theoretischen und empirischen Literatur abgeleiteten Auswirkungen einer föderativen Staatsstruktur für den Verbandseinfluß. Im folgenden sollen diese Faktoren näher untersucht werden, um konkrete Aussagen über den Interessengruppeneinfluß im föderativen Staat zu gewinnen.

Höhere Homogenität der Interessen und eine geringere Zahl der Gruppenmitglieder begünstigen nach Olson die Organisationsfähigkeit latenter Interessen, da die Transaktionskosten der Verbandsbildung sinken. ${ }^{324}$ Akzeptiert man die These, daß innerhalb einer lokalen Gebietskörperschaft von einer homogeneren Präferenzstruktur ausgegangen werden kann, begünstigt damit eine räumliche Dezentralisierung die Entstehung spezialisierter, subnationaler Interessenverbände. ${ }^{325}$ Interessen, die auf nationaler Ebene nicht oder nur schwer organisierbar sind, könnten auf subnationaler Ebene politischen Druck ausüben. 326

320 Siehe Kerber, W./Vanberg, $V$. (1995), S. 47.

321 Zur Diffusion von Neuerungen uber die lokalen und regionalen Jurisidiktionen siehe Walker, J.L. (1969)

322 Ausfuhrlich hierzu Rose-Ackerman, S. (1980).

323 Vgl. Vihanto, M. (1992), S. 415.

324 Vgl. Olson, M. (1982/1991), S. 29ff.

325 Vgl. Breton, A. (1974), S. 115f.; Murrell, P. (1984), S. 155 und Olson, M. (1982/1991), S. 42 f. und S. 166.

326 Siehe auch Hettich, W./Winer, S.L. (1987), S. $45 \mathrm{ff}$. 
Der Einfluß föderativer Strukturen auf die Organisierbarkeit von Interessen wird in einer formalen Analyse von Magee, Brock und Young untersucht. ${ }^{327}$ Vereinfachend wird von den Autoren die Annahme getroffen, daß zwei gesellschaftliche Gruppen $i$ (mit $n_{i}$ potentiellen Mitgliedern) und $\mathrm{j}$ (mit $\mathrm{n}_{\mathrm{j}}$ potentiellen Mitgliedern) existieren, deren Binnenstrukturen vollkommen homogen sind. Beide Gruppen konkurrieren um Partikularvorteile $P_{i}$ bzw. $P_{j}$. Weiter wird angenommen, daß alle organisierten Mitglieder die gleichen individuellen Beiträge $a_{i}$ (bzw. $a_{j}$ ) zu den Lobbyaktivităten ihres Verbandes leisten. Der Beitrag eines Mitglieds des Verbandes i beträgt

$$
a_{i}=P_{i}\left(\alpha_{i} / n_{i}+\beta_{i}\right)
$$

bzw. für ein Mitglied der Organisation j:

$$
a_{j}=P_{j}\left(\alpha_{j} / n_{j}+\beta_{j}\right)
$$

$P_{i}\left(P_{j}\right)$ gibt die Größe des persönlichen Vorteils aus der Bereitstellung gruppenspezifischer Güter für i (bzw. j) an. Die Variable $\alpha_{i}\left(\right.$ bzw. $\alpha_{j}$ ) bezeichnet die Fühlbarkeit einer individuellen Beteiligung an den Lobbyaktivitäten. Je größer $\alpha_{i}$ (bzw. $\alpha_{j}$ ), desto größer sind die positiven externen Effekte des Ressourceneinsatzes für Lobbying und um so stärkere Anreize für individuelles Trittbrettfahrerverhalten bestehen.

Die Effektivität des persönlichen Beitrags kommt durch den Faktor $\beta_{i}$ (bzw. $\beta_{j}$ ) zum Ausdruck. $\beta$ beschreibt die Auswirkungen eines erhöhten individuellen Mitgliedsbeitrags auf die erreichten individuellen Vorteile $P_{i}\left(P_{j}\right)$. Da ein rationales Individuum maximal so viel Ressourcen in die lobbying-Aktivitäten seines Verbandes investiert, wie die Höhe des erreichbaren Vorteils ist, gilt $\left(\alpha_{i}+\beta_{i}\right) \leq 1$ für Gruppe $i$ und $\left(\alpha_{j}+\beta_{j}\right) \leq 1$ für Gruppe $j$. Nimmt $\alpha_{i}$ den Wert 1 an (und damit $\beta_{i}=0$ ), verhalten sich die Mitglieder von $i$ als völlige Trittbrettfahrer. Für die totalen Lobby-Aufwendungen der beiden Gruppen gilt dann:

$$
\begin{aligned}
& m_{i} \equiv n_{i} a_{i}=P_{i}\left(\alpha_{i}+n_{i} \beta_{i}\right) \\
& m_{j} \equiv n_{j} a_{j}=P_{j}\left(\alpha_{j}+n_{j} \beta_{j}\right) .
\end{aligned}
$$

Solange $\alpha_{i}<1$, ergeben sich trotz fallender individueller Mitgliedsbeiträge durch einen Anstieg der organisierten Mitgliederzahl $n_{i}$ steigende Gesamtlobbyausgaben $m_{i}$. Wenn $\alpha_{i}=1$, reduziert ein repräsentatives Mitglied den eigenen Beitrag genau um den Betrag, den das neue Mitglied erbringt, und die gesamten Lobbyaufwendungen des Interessenverbandes i bleiben konstant. Gleiches gilt analog für den Interessenverband j. Der relative Einfluß der Gruppen sei durch

$$
\theta=\frac{m_{i}}{m_{j}}
$$

beschrieben. Nimmt $\theta$ den Wert Eins an, sind die Lobbying-Aufwendungen der beiden Gruppen gleich groß. Es wird unterstellt, daß dann auch deren politischer Einfluß identisch 
ist. Für Werte von $\theta$ größer als Eins überwiegt der Einfluß des Verbandes i, für Werte von $\theta$ kleiner als Eins ist die Gruppe j relativ stärker.

Die Auswirkungen der Jurisdiktionsgröße für den relativen Verbandseinfluß können nun abgeleitet werden. Es wird angenommen, daß es zwei identische Gebietskörperschaften gibt, in denen jeweils $n_{i}$ Gewinner und $n_{j}$ Verlierer einer Regulierungsvorschrift existieren. Durch Zusammenlegung der Jurisdiktionen zu einer einzigen Körperschaft verändern sich die individuellen Mitgliedsbeiträge zu

$$
\begin{aligned}
& a_{i}^{z}=P_{i}\left(\alpha_{i} / 2 n_{i}+\beta_{i}\right) \\
& a_{j}^{z}=P_{j}\left(\alpha_{j} / 2 n_{j}+\beta_{j}\right),
\end{aligned}
$$

und die Gesamtlobbyaufwendungen der beiden Gruppen können beschrieben werden als

$$
\begin{aligned}
& m_{i}^{z}=2 n_{i} a_{i}^{z}=P_{i}\left(\alpha_{i}+2 n_{i} \beta_{i}\right) \\
& m_{j}^{z}=2 n_{j} a_{j}^{z}=P_{j}\left(\alpha_{j}+2 n_{j} \beta_{j}\right) .
\end{aligned}
$$

Magee, Brock und Young nehmen an, daß die Mitglieder von j einen großen Anreiz zu free rider-Verhalten haben, so da $\beta \alpha_{\mathrm{j}}=1$ und $\beta_{\mathrm{j}}=0$. In diesem Fall führt die Konsolidierung der beiden territorialen Einheiten zu einem Rückgang der individuellen Mitgliedsbeiträge in genau der Höhe, die die totalen Lobbyingaufwendungen $m_{j}^{z}=m_{j}$ unverändert beläßt. Anders wird dagegen für die Gruppe i angenommen, daß Trittbrettfahrerverhalten eine weniger bedeutende Rolle spielt. Durch die Zusammenlegung und damit Verdopplung der Zahl der Gruppenmitglieder werden zwar die individuellen Lobbying-Aufwendungen $a_{i}$ sinken, die gesamten Ausgaben jedoch ansteigen. Für $\alpha_{i}=\beta_{i}=0,5$ ergibt sich z.B. für die Lobbying-Ausgaben von $i$ bei Konsolidierung $m_{i}^{z}=P_{i}\left(n_{i}+0,5\right)$, während ohne die Zusammenlegung der Gebietskörperschaften in jeder lokalen Einheit $m_{i}=P_{i}\left(0,5 n_{i}+0,5\right)$ gilt. Für den relativen Einfluß der beiden Gruppen heißt dies:

$$
\theta^{z}=\frac{m_{i}^{z}}{m_{j}^{z}}>\frac{m_{i}}{m_{j}}=\theta
$$

Die relative Position von gesellschaftlichen Gruppen, die schlecht organisierbar sind, wird offenbar durch eine Zentralisierung der Zuständigkeiten geschwächt. ${ }^{328}$

\section{b. Relative Organisationskosten und staatliche Umverteilungstätigkeit}

Daran schließt sich die Frage an, ob durch die bessere Organisierbarkeit vieler Interessen auf subzentraler Ebene auch politischer Widerspruch gegen die Transfertätigkeit der Regierungen

328 "Thus, general interests can lose their relative clout as we move to larger jurisidctions." Magee, S.P./Brock, W.A./Young, L. (1989), S. 290. Siehe auch Brock, W.A./Magee, S.P. (1978), S. 247f. 
erfolgversprechender ist als im zentralen System. Das ist nicht zwingend der Fall, denn je stärker die Dezentralisierung, um so mehr und um so kleinere Interessengruppen werden sich bilden. ${ }^{329}$ Bei dezentraler Organisation von Staat und Parteien haben daher auch Verbände Aussicht auf Erfolg, die spezielle, örtliche oder regional konzentrierte Interessen vertreten. 330 Andererseits verbessern sich auch die Organisationsbedingungen der potentiell belasteten gesellschaftlichen Gruppen.

Allein die Zahl der Interessenverbände ist allerdings kein Indikator für deren politischen Einfluß. ${ }^{331}$ Damit kann a priori nicht eindeutig festgestellt werden, welche Ergebnisse der politische Verteilungskampf auf lokaler oder regionaler Ebene hervorbringt. Der bestehende Dissens wird dokumentiert in den unterschiedlichen Ansichten von Olson einerseits und Ekelund/Tollison andererseits über die Auswirkungen der Zentralisierung für den Einfluß der Zünfte im merkantilistischen System. Olson vertritt die Auffassung:

\begin{abstract}
"Selbst wenn [eine] Stadt nur wenige tausend Einwohner hat, ist es unwahrscheinlich, daß die Bevollkerung als Ganze sich organisieren könnte, um solchen Zusammenschlussen zu begegnen, obwohl die Bevolkerung in winzigen Orten dafur klein genug wäre ... Viele Züfte beeinflußten oder kontrollierten tatsăchlich ihre Städte." "Hoheitliche Integration bedeutet ..., daß die politischen Entscheidungen ... an einem recht weit entfernten Ort getroffen werden. Hinzukommt, daß das Ausmaß politischen Einflusses, das notwendig ist, um die Politik der integrierten Hoheitsgewalt zu andern, erheblich großer sein wird als das Ausmaß, das in dem vorhergehenden, relativ eng begrenzten Hoheitsgebiet notwendig war ... [Daher] verloren die Zunfte ... politischen Einfluß, wenn wirtschaftlich integrierte, die Nation umfassende Hoheitsgewalten lokale Hoheitsgewalten ersetzten." 332
\end{abstract}

Ekelund und Tollison schreiben dagegen:

329 Vgl. Salisbury, R.H. (1975), S. 200. Diese These findet in der empirischen Untersuchung von Murrell uber die Bestimmungsgrunde der Bildung von Interessengruppen in OECD-Lăndern Bestătigung. Vgl. Murrell, P. (1984), S. 166.

330 Vgl. Bernholz, P./Breyer, F. (1984), S. 365f. North, D.C./Wallis, J.J. (1982) fuhren das zunehmende Entstehen von Interessengruppen auf den steigenden Spezialisierungsgrad in der Marktwirtschaft zuruck. Siehe auch Murrell, P. (1984), S. 154. Übertragt man dieses Argument auf das hier zu erörternde Problem, so ist in kleinrdumigen Einheiten, die spezielle Standortvorteile fur bestimmte Branchen vorweisen, ebenfalls mit einer größeren Zahl von besser organisierten Interessengruppen zu rechnen.

331 Vgl. Salmon, P. (1987b), S. 79. Siehe auch Vaubel, R. (1992), S. 38, FN 14. Ebensowenig kann deshalb ohne weiteres davon ausgegangen werden, daß sich bei einer größeren Zahl aktiver pressure groups der Anteil der Staatsausgaben am Sozialprodukt zunimmt. So bewirken beispielsweise spezielle Steuervergunstigungen, die politisch sehr effizient sind, weil ihre Transparenz relativ gering ist, eine tendenziell sinkende Staatsquote. Vgl. auch Mueller, D.C./Murrell, P. (1986), S. 126, die nichtsdestotrotz in ihrer empirischen Untersuchung uber den Zusammenhang von Interessengruppenaktivităt und Staatsanteil davon ausgehen, "that on average the factors sought by interest groups from government require an expansion of tax revenues and expenditures." Diese Annahme widerspricht auch einer von Schmölders herausgegebenen Erhebung uber "Das Selbstbild der Verbande". Danach streben die organisierten Verbände danach, "... mogliche Interessengegensătze nicht oder nicht so stark zur Auswirkung kommen zu lassen..." Schmölders, $G$. (1965), S. 121. Das hieße aber, daß auf dezentraler Ebene im Vergleich zur Zentralebene insbesondere die Bedeutung von Ge- und Verboten sowie anderen, das knappe Budget weniger belastenden Regulierungsmaßnahmen, zunimmt. Vgl. Bernholz, P./Breyer, F. (1984), S. 363.

332 Olson, M. (1982/1991), S. 166 und S. 168. 
"Prior to the centralization of authority, rent seekers had to deal with a multitude of feudal rulers, which caused the costs of negotiating and enforcing exclusive rights to be relatively higher. The correlated rise of mercantilism and central monarchies was thus the result of changed cost conditions ..."333

Beide Positionen sind theoretisch plausibel. Die verschiedenen Auffassungen verdeutlichen aber, daß ein monokausaler Erklärungsansatz keine eindeutigen Aussagen über die Erfolgschancen der Interessengruppenaktivitäten zuläßt. ${ }^{334}$ Im folgenden soll der Versuch unternommen werden, einen theoretischen Ansatz zu entwickeln, der beiden Erklärungsversuchen Rechnung trägt.

Dazu wird auf ein Modell von McCormick und Tollison zurückgegriffen. ${ }^{335}$ Auf der Abszisse der Abbildung 4.4 sind alle gesellschaftlichen Gruppen, geordnet nach ihrer Organisationsfähigkeit, abgetragen. Ausgehend von Punkt 0 steigen bei einer Bewegung nach rechts die Organisationskosten jeder Gruppierung, so daß am äußersten rechten Punkt die gesellschaftliche Gruppe steht, deren Organisationskosten (Lobbying-Kosten) am größten sind (z.B. die Steuerzahler). Alle Gruppen sind potentielle Nachfrager nach Vermögenstransfers in Höhe einer Geldeinheit (GE), die über den Staat abgewickelt werden.

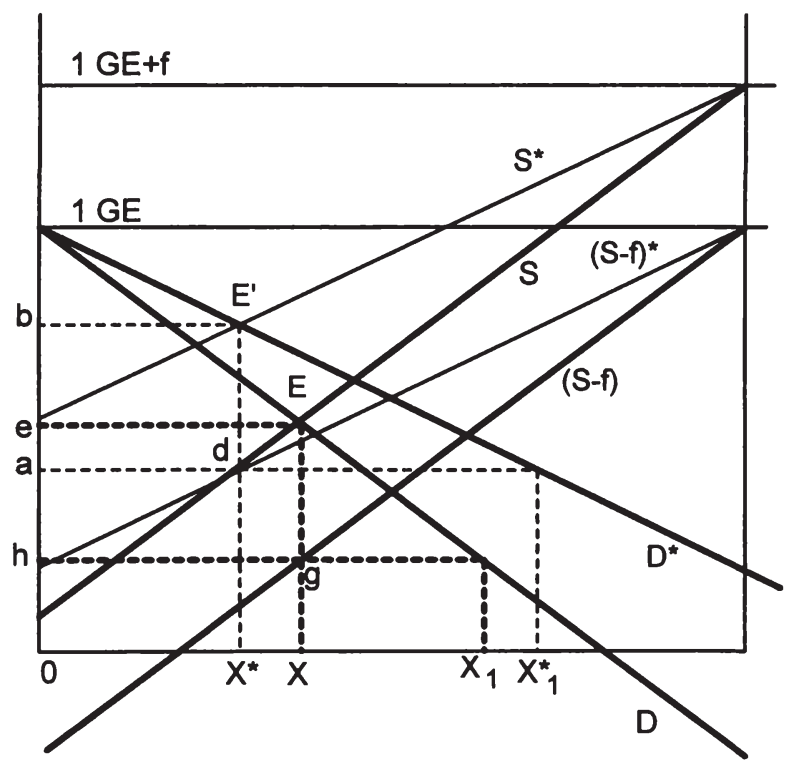

Abbildung 4.4: Intrajurisdiktionelle Homogenität und staatliche Transfertätigkeit

Quelle: Eigene Darstellung in Anlehnung an McCormick, R.E./Tollison, R.D. (1981), S. 18.

333 Ekelund, R.B./Tollison, R.D. (1981), S. 26. Siehe auch S. 86f.

334 Breton, A. (1974), S. 114, erwähnt zwar diesen Konflikt, mißt dem Argument von Ekelund und Tollison aber offensichtlich nur untergeordnete Bedeutung bei.

335 Siehe McCormick, R.E./Tollison, R.D. (1981), S. $18 \mathrm{ff}$. 
Der Nettowert der Transfers an eine Gruppe i ergibt sich aus der Differenz von Transfersumme und den Lobbying-Kosten. Die 'Nachfragefunktion' nach staatlichen Transfers jeder Gruppe wird dann durch die Gerade D dargestellt. D verläuft fallend, da von links nach rechts die Lobbying-Kosten wachsen. Die Organisationskosten jeder Gruppe ergeben sich aus der vertikalen Differenz der (1 GE)-Linie und der D-Linie. Da jede Gruppe auch potentieller 'Anbieter' von Transfers ist - alle Gruppierungen unterliegen ja der Gefahr, besteuert zu werden - kann man spiegelbildlich zur D-Kurve die Linie der 'Transferangebote' (S-f) konstruieren. 336

Die Interpretation der Linie (S-f) ist einfach, wenn man z.B. die Gruppe betrachtet, deren Lobbying-Kosten am höchsten sind. Um 1 GE Transfers zu erhalten, müßte die Gruppe mehr als 1 GE Organisationskosten aufwenden. Es wäre daher irrational, sich um den Erhalt dieses Transfers zu bemühen. Folglich ist es auch nicht rational, sich zu organisieren, wenn ihr $1 \mathrm{GE}$ durch Besteuerung entzogen wird, da die Organisation politischen Widerstandes gegen die Besteuerung mit höheren Kosten verbunden ist als die möglichen Verluste der erzwungenen Umverteilung zu ihren Lasten. ${ }^{337}$

Die Durchführung der Transaktionen am Quasi-Markt für Vermögenstransfers durch die Politiker als Transfermakler erfordert den Einsatz von Ressourcen $f$, die annahmegemäß nur durch Besteuerung der Gesellschaftsmitglieder aufgebracht werden können. Unter der Prämisse konstanter marginaler Transaktionskosten der Transfertätigkeit verschiebt sich die Transferangebotskurve um den Betrag $f$ nach oben. Die relevante Angebotslinie ist daher $S=(S-f)+f$. Die Größe f bezeichnet damit den marginalen Wert der Ressourcen, die von den staatlichen Akteuren (Politikern und Bürokraten) zur Produktion von Umverteilung eingesetzt werden.

Ein politisches Gleichgewicht ist im Schnittpunkt der S-Kurve und der D-Kurve in Punkt E gegeben. Der Grenzpreis für Vermögenstransfers beträgt dann 0e. Alle Gruppierungen, deren Organisationskosten geringer als (1 GE-0e) sind, werden von den Transfers begünstigt, also die Gruppen im Bereich 0 bis X. Gruppen, deren 'Nachfragepreis' kleiner als $0 \mathrm{~h}(=\mathrm{Xg})$ ist, werden dagegen nicht gegen erzwungene Transfers opponieren, da ihre Organisationskosten zu hoch sind. Daher sind alle Gruppen rechts von $\mathrm{X}_{1}$ durch Umverteilung belastet. ${ }^{338}$ Die Gruppen, die zwischen $\mathrm{X}$ und $\mathrm{X}_{1}$ liegen, werden weder benachteiligt nach bevorzugt. Die von den Politikern und Bürokraten in diesem Umverteilungsprozeß erhaltene "brokerage fee"339 beträgt heEg. 340

Sinken durch eine Dezentralisierung die Lobbying-Kosten der schlechter organisierbaren Gruppen, dann dreht sich die D-Kurve entgegen dem Uhrzeigersinn auf $D^{*} .341 D^{*}$ ist so gezeichnet, daß es sich für diese Gruppen lohnt, politischen Widerstand gegen erzwungene Transfers zu leisten, denn die Organisationskosten sind geringer als die Nutzenverluste durch die steuerliche Belastung. Spiegelbildlich dazu ergibt sich die Kurve (S-f)*. Unter der

336 Vgl. McCormick, R.E./Tollison, R.D. (1981), S. 19ff.; Tollison, R.D. (1988), S. 343.

337 "The supply of legislation is, therefore, grounded in the unorganized or relatively less-organized members of society." Tollison, R.D. (1988), S. 343.

338 In der Abbildung wird der Punkt $X_{1}$ dadurch ermittelt, daß vom Gleichgewichtspunkt $f$ auf der S-Linie die marginalen Ressourcenkosten $f$ abgezogen werden. Man erhält dann den korrespondierenden Punkt $g$ auf der (S-f)-Linie. Von dort aus geht man soweit nach rechts, bis die D-Linie geschnitten wird.

339 McCormick, R.E./Tollison, R.D. (1981), S. 19.

$340 \mathrm{Vgl}$. McCormick, R.E./Tollison, R.D. (1981), S. 21.

341 Vgl. McCormick, R.E./Tollison, R.D. (1981), S. 25 f. 
Annahme unveränderter marginaler Kosten $f$ resultiert die relevante Angebotskurve $S^{*}$. Das neue politische Gleichgewicht liegt in Punkt E' bei einem Transferpreis von 0b. Die bei dieser Konstellation begünstigten Gruppen liegen zwischen 0 und $\mathrm{X}^{*}$, die benachteiligten Gruppen befinden sich rechts von $\mathrm{X}_{1}^{*}$. Die von den Politikern im Umverteilungsprozeß absorbierten Ressourcen betragen abE'd, das Umverteilungsvolumen sinkt infolge der höheren Homogenität der Bevölkerung.

Diese Argumentation stärkt prima facie die Position von Ekelund und Tollison. Auch Aranson verweist darauf, daß bei dezentralen Entscheidungszuständigkeiten die Ausgangsbedingungen für die Aktivitäten organisierter Lobbies schlechter sind. Im unitaristischen System können die Regierungen eine breite Streuung der Kosten bereitgestellter Partikularvorteile erreichen. Ist dagegen die Möglichkeit einer Belastung nicht-organisierter Wähler auf die Bewohner der lokalen Jurisdiktion beschränkt, steigen die Fühlbarkeit der Benachteiligung und damit der Anreiz, politischen Gegendruck zu entwickeln. ${ }^{342}$

Weingast, Shepsle und Johnsen zeigen, daß unter bestimmten institutionellen Gegebenheiten regional konzentrierte Interessengruppen größere Durchsetzungschancen bei zentralen $\mathrm{Zu}$ ständigkeiten haben. ${ }^{343}$ Erfolgt nämlich die Auswahl der politischen Repräsentanten auf der Basis regional gegliederter Wahlkreise, können die Politiker auf der Zentralebene spezielle Begünstigungen für ihren Wahlkreis durchsetzen, die Belastungen aber auf die gesamte Bevölkerung des Staates verteilen.

Ähnlich argumentiert Vaubel in einer theoretischen Analyse der "Politischen Ökonomie der wirtschaftspolitischen Zentralisierung in der Europäischen Gemeinschaft" ${ }^{444}$, daß eine Verlagerung von Entscheidungskompetenzen auf EG-Ebene die Begünstigung europaweit agierender, homogener Interessengruppen erleichtere. Er führt an, daß die Zentralisierung höhere Informationskosten und geringere Kontrollanreize der Wähler mit sich bringe und gleichzeitig die Lobbyingkosten homogener Verbände sinken. ${ }^{345}$

\section{Die Konsequenzen verstärkten politischen Wettbewerbs um Wählerstimmen}

Der politische Preis für Umverteilung wird bestimmt durch die Möglichkeiten der Politiker, Umverteilungsprozesse zu forcieren. In der Betrachtung von McCormick und Tollison wurde angenommen, daß eine Maklergebühr $f$ festgelegt ist, die für alle Umverteilungstransaktionen gültig ist und nicht durch Veränderungen im Homogenitätsgrad der Bevölkerungsstruktur beeinflußt wird.

Die Höhe von $\mathrm{f}$ wird nach Ansicht von McCormick/Tollison bestimmt durch "the marginal cost of the real resources used in transacting in the brokerage house"346. Der Anreiz der Transfermakler, durch die Variation von $\mathrm{f}$ ihre eigenen Renten $\mathrm{zu}$ maximieren, wird von den Autoren in diesem Grundmodell des Umverteilungsstaates nicht einbezogen. Die Kosten, zu denen die Transfers stattfinden, sind bestimmt von den Rahmenbedingungen des politischen Wettbewerbs. 347 Der Quasi-Markt von McCormick und Tollison ist ein kompetitiver Markt,

342 Vgl. Aranson, P.H. (1989), S. 131. Ebenso Giertz, F. (1981), S. 121.

343 Siehe Weingast, B./Shepsle, K./Johnsen, C. (1981).

344 Vaubel, R. (1992).

345 Vgl. Vaubel, R. (1992), S. 38. Siehe auch Vaubel, R. (1986), S. 51; Lee, D.R./McKenzie, R.B. (1987), S. 80.

346 McCormick, R.E./Tollison, R.D. (1981), S. 19.

347 Vgl. Crain, W.M. (1979); Tollison, R.D. (1988), S. 344. 
monopolistische Anbieter werden aber versuchen, durch Preissetzungspolitik ihre Renten zu maximieren. 348

McChesney kritisiert deshalb, "the role of politicians has not been integrated satisfactorily into the model"349. Er betont die aktive Rolle der Politiker bei der Abschöpfung von Renten ("rent extraction" ${ }^{350}$ ) von den Transfernachfragern. Es ist anzunehmen, daß eine schwache Beschränkung durch den Wettbewerb um Wählerstimmen es den Mandatsträgern eher ermöglicht, in gewissem Ausmaß politisches Einkommen zu erzielen. Folglich werden auch die Ergebnisse des Umverteilungsprozesses mit der Intensität des Wettbewerbs um Wählerstimmen variieren, wie durch Abbildung 4.5 verdeutlicht wird.

Ausgangspunkt ist die Situation mit einer Transfernachfrage D. Die marginalen Ressourcenkosten der Transfertätigkeit sind durch $\mathrm{f}$ beschrieben. Bei kompetitiver Preissetzung beträgt der Umverteilungsoutput $0 \mathrm{X}^{*}$, die Maklergebühren sind $\mathrm{abEd}$.

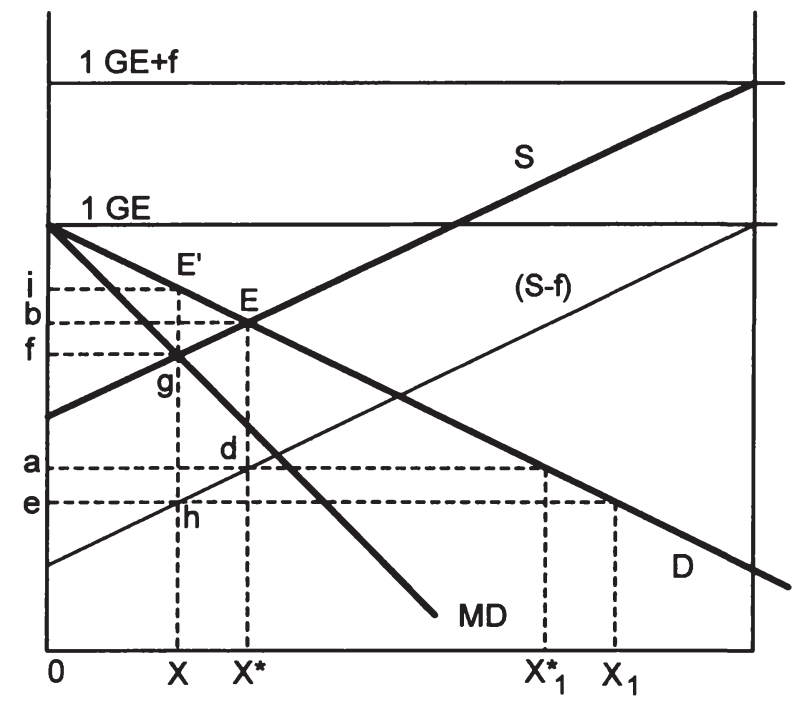

Abbildung 4.5: Politischer Wettbewerb und staatliche Transfertätigkeit Quelle: eigene Darstellung

Sind die Politiker keiner Konkurrenz ausgesetzt, verfügen sie über Preissetzungsspielräume, die sie zur Maximierung ihrer Renten aus den Transferaktivitäten ausnützen. 351 Analog zur monopolistischen Preisbildung maximieren sie ihre Überschüsse über die Ressourcenkosten

$348 \mathrm{Vgl}$. Anderson, G.M./Tollison, R.D. (1988), insbesondere S. $533 \mathrm{ff}$.

349 McChesney, F.S. (1987), S. 102.

350 McChesney, F.S. (1987).

351 "Since in this theory politicians are brokers between winners and losers in the wealth-transfer process, the degree of competition in the legislative process will affect their brokerage fee." McCormick, R.E./Tollison, R.D. (1981), S. 33. 
durch Festlegung des Cournot-Preises 0i, bei dem ein Output 0X realisiert wird. 352 Beim Transferoutput $0 \mathrm{X}$ betragen die von den Politikern absorbierten Renten eiE'h, die Fläche fiE'g stellt die Überschüsse über die Ressourcenkosten efgh dar.

Die abgeschöpften Renten belasten alle Mitglieder des Staatswesens. Insgesamt gehören weniger gesellschaftliche Gruppen zu den Nettogewinnern und weniger Gruppen zu den Nettoverlierern der staatlichen Maßnahmen. Die traditionelle Argumentation von den positiven Wirkungen politischen Wettbewerbs um Wählerstimmen wird damit auf den Kopf gestellt. ${ }^{353}$ Die Maklerprovision der staatlichen Agenten ist um so höher, je weniger intensiv der Wettbewerb um die verantwortlichen Regierungsämter ist:

"Government is like criminal activity in that it coercively transfers wealth - specifically, from consumers and taxpayers in general to organized interest groups. As entry barriers confronting potential competitors in the public sector rise, the output of government (i.e., wealth transfers to interest groups) should fall, ceteris paribus." 354

Wenn durch die Dezentralisierung von Kompetenzen tatsächlich der Wettbewerb um Wählerstimmen intensiviert wird, stellt sich deshalb auch ein Effekt ein, der zur Begünstigung spezieller Interessen führt. Verstärkte Kontrolle der Regierung durch besser informierte Wähler und Rangordnungswettbewerb auf subzentraler Ebene verringern monopolistische Spielräume der Politiker. Aber nicht nur die Wähler, sondern auch die Verbände üben Druck auf die Regierung aus. Damit ist die Machtposition der Politiker gegenüber beiden Nachfragergruppen öffentlicher Leistungen geschwächt. 355 Wird ein ineffizientes öffentliches Leistungsangebot auf lokaler Ebene stärker sanktioniert, werden die Politiker durch den Wettbewerb gezwungen, auch auf spezielle Interessen einzugehen. Hierin spiegelt sich die Olson'sche Argumentationslinie wider. Da der Erfolg von pressure groups durch die relative Verhandlungsstärke der Regierung bestimmt ist, bedeutet jede Stärkung der Regierungsposition auch eine Reduktion des Interessengruppeneinflusses. ${ }^{356}$

Augenscheinlich wird der Einfluß organisierter Verbände auf die politische Willensbildung durch eine Dezentralisierung des öffentlichen Sektors zumindest auf kurze Sicht nicht eindeutig in eine bestimmte Richtung verändert. Die höhere intrakollektive Homogenität auf lokaler Ebene stärkt tendenziell die Position der unorganisierten Gruppen, wohingegen der größere Wettbewerbsdruck für die Politiker in subzentralen Einheiten das Gewicht der pressure groups erhöht.

352 Sie orientieren sich dabei an der 'Grenzerloskurve' MD.

353 Vgl. Anderson, G.M./Tollison, R.D. (1988), S. 534f.

354 Anderson, G.M./Tollison, R.D. (1988), S. 530 (Hervorhebung im Original).

355 Bernholz und Breyer argumentieren, daß bei foderativen Strukturen die Informationskosten fur regionale Parteiorganisationen und Politiker regelmaßig höher seien als im unitaristisch aufgebauten Staat, "...denn unter diesen Bedingungen werden von vielen Stellen hăufig gleiche oder ăhnliche Informationen benøtigt, die wegen ihrer kleineren Große naturgemäß nur uber geringere Mittel verfugen. Trifft das aber zu, so wird bei dezentraler Organisation der Parteien und bei foderalistischem Staatsaufbau eine Tendenz bestehen, sich in stärkerem Maße der Informationen von Interessenverbănden als bei zentraler Organisation zu bedienen und ihnen dafur weitreichende Zugestandnisse zu machen." Bernholz, P./Breyer, F. (1984), S. 367.

356 Vgl. Olson,M. (1983), S. 23. Siehe auch Spahn, P.B. (1993), S. 10. 


\section{Die Konsequenzen der Föderalisierung für den Einfluß der staatlichen Bürokratie}

\section{Bürokraten als Anbieter von Leistungen: Die Kontrolle der Bürokratie}

Das agency-Verhältnis zwischen der Regierung und der staatlichen Bürokratie wird durch eine Dezentralisierung der politischen Zuständigkeiten verändert. Bürokratische Macht liegt vor allem in den Informationsvorteilen der bürokratischen Akteure über die Produktions- und Kostenbedingungen begründet. ${ }^{357} \mathrm{Zu}$ erörtern ist damit die Frage, welche Auswirkungen auf die Informationsasymmetrien zwischen den gewählten politischen Repräsentanten und der Verwaltung zu erwarten sind. Deshalb werden zunächst die Veränderungen von Kosten und Nutzen der politischen Kontrolle durch eine föderative Staatsstruktur untersucht.

Die Binnenstruktur der Bürokratie dürfte durch eine Verlagerung der Kompetenzen auf untere Ebenen im föderativen System verändert werden. Dezentralisierung geht einher mit der Verringerung der bürokratischen Hierarchiestufen, die die Informationen auf dem Weg zur Kontrollbehörde zu durchlaufen haben. Tullock charakterisiert den Kommunikationsprozeß in Büros als eine lange Kette von Informationsträgern, die, bewußt oder unbewußt, bei der Weitergabe und Kondensierung Informationen verfälschen. 358 Systematische Verzerrungen der Informationen durch die Verwaltungsakteure können nicht mehr so groß sein; die Kontrollverluste verringern sich. Downs argumentiert daher: "Having only a few levels in the hierarchy reduces the number of screenings and thus keeps the degree of distortion low." $359 \mathrm{Je}$ kleiner die bürokratische Einheit, desto kostengünstiger ist damit auch die Kontrolle der Bürokraten. 360

Downs schlägt als weiteres Verfahren der Bürokratiekontrolle die Nutzung externer Informationsquellen vor. ${ }^{361}$ Solange die Administration das absolute Informationsmonopol über die Produktionsbedingungen innehat, ist die Beschaffung von Informationen über die Qualităt der angebotenen bürokratischen Leistungen mit hohen Kosten verbunden. Die oben für die Wăhler dargestellte Option des interjurisdiktionellen Vergleichs politischer Outputs im fóderativen Staat eröffnet aber auch den Regierenden eine zusätzliche Informationsquelle. Politiker können die Ergebnisse des administrativen Handelns in anderen Subsystemen zur Beurteilung der Aktivitäten des eigenen Verwaltungsapparates heranziehen. ${ }^{362}$ Auch aus dieser Perspektive ergibt sich durch die größere Zahl von Informationsquellen eine Verringerung der Informationskosten für die politischen Kontrollbehörden.

Wie ausgefuhrt ${ }^{363}$, setzt sich der Nutzen einer Bürokratiekontrolle für die Politiker prinzipiell aus zwei Komponenten zusammensetzen: Eine Kontrolle der Verwaltung durch die Mandats-

357 Dies ist der 'gemeinsame Nenner' der bürokratietheoretischen Überlegungen von Tullock, G. (1965b); Downs, A. (1967) und Niskanen, W.A. (1971).

358 Vgl. Tullock, G. (1965b), S. 137ff. und Downs, A. (1967), S. 117.

359 Downs, A. (1967), S. 124. Vgl. auch van den Doel, H. (1979), S. $123 \mathrm{f}$.

$360 \mathrm{Vgl}$. Wintrobe, $R$. (1987b), S. $17 \mathrm{ff}$.

361 Vgl. Downs, A. (1967), S. 119.

362 Vgl. Tullock, G. (1976), S. 36f.; McGuire, T.G./Coiner, M./Spancake, L. (1979), S. 352; Spencer, B. (1980), S. $231 \mathrm{ff}$; Wintrobe, R. (1987b), S. 17ff. Tullock betont, daß daruberhinaus ein Vergleich der burokratischen Leistungserstellung mit privaten Anbietern, die ähnliche Leistungen erbringen, die Kontrollkosten verringert. Tullock, G. (1976), S. 37.

363 Vgl. oben, S. $172 f$. 
träger erfolgt einmal deshalb, weil sie den Politikern direkt zugute kommt, wenn freigewordene Mittel zur Umsetzung ideologischer Ziele eingesetzt werden können. Dieser Aspekt ändert sich durch eine Dezentralisierung des Staatsaufbaus nicht. Es können aber auch die Anreize zur Überwachung der Verwaltungsakteure variieren, wenn sich durch eine Dezentralisierung die Rahmenbedingungen der politischen Konkurrenz um Wählerstimmen verändern.

Wie gesehen, führt eine Dezentralisierung zu einer Intensivierung des Wettbewerbs um Wählerstimmen. Die Bürger verfügen über zusätzliche Informationsinstrumente, die es im unitarischen System nicht gibt. Der Konkurrenzkampf um die Regierungsposition zwingt die Politiker zu einem höheren Leistungsangebot an die Wähler und an spezielle Interessen. Im Umkehrschluß bedeutet das, daß bei gegebenem öffentlichen Einnahmevolumen die Politiker aus eigenem Interesse dafür Sorge tragen müssen, Ineffizienzen des bürokratischen Verhaltens einzudämmen. Gelingt ihnen dies nicht, gefährden sie ihr Wiederwahlziel. Die wachsende Intensität der politischen Konkurrenz erhöht somit die Kontrollanreize auf indirektem Weg. 364

Somit dürften durch eine Dezentralisierung der Aufgaben die Kontrollkosten für die politischen Überwachungsinstanzen sinken und die Kontrollnutzen im Vergleich zur unitarischen Lösung steigen. Ceteris paribus verschlechtern sich damit die Bedingungen für bürokratisches Rentenstreben im föderativen Staat. 365

\section{Bürokraten als Nachfrager von Leistungen}

Bürokraten sind als spezielle Interessengruppe gleichzeitig auf der Nachfragerseite der öffentlichen Budgets aktiv. Aufgrund ihrer relativ höheren Wahlbeteiligung erhalten sie in der politischen Entscheidungsfunktion bereits automatisch ein größeres Gewicht. Für die Bestimmung des Gewichtes der Bürokratie im föderativen System ist es deshalb erforderlich, Annahmen über die Anteile der öffentlichen Bediensteten an der gesamten Wahlbevölkerung zu treffen. Ein Ausgangspunkt könnte die Annahme steigender Skalenerträge bei der Produktion von Kollektivgütern sein. Liegen solche Skalenvorteile vor, dann wäre auf subzentraler Ebene der Anteil der in der öffentlichen Verwaltung Beschäftigten an der Gesamtbevölkerung relativ größer als bei einer Produktion auf Zentralebene.

Bush/Denzau 366 sowie Borcherding/Bush/Spann 367 versuchen, anhand einer einfachen "Machtfunktion"368 unter Zugrundelegung empirischer Ergebnisse über das Wahlverhalten der öffentlichen Bediensteten den veränderten Einfluß bei einer wachsenden Zahl von Beschäftigten im öffentlichen Dienst aufzuzeigen. Sie kommen u.a. zu dem Ergebnis, daß aufgrund der höheren Wahlbeteiligung der öffentlichen Bediensteten der Wählerstimmeneinfluß der Bürokratie überproportional groß ist. Nimmt infolge einer Dezentralisierung der

364 Vgl. Breton, A./Wintrobe, R. (1975).

365 "Since bureaucrats have less power under a federal system of government, it follows that they are also more efficient under that system than under a unitary system." Wintrobe, R. (1987b), S. 20.

366 Siehe Bush, W.C./Denzau, A.T. (1977), S. 97f.

367 Siehe Borcherding, T.E./Bush, W.C./Spann, R.M. (1977), S. $218 \mathrm{ff}$.

368 "Power function", Bush, W.C./Denzau, A.T. (1977), S. 97. 
Anteil der Staatsbediensteten an der Gesamtbevölkerung zu, wächst auch der politische Einfluß der Bürokratie. 369

Insgesamt betrachtet kann deshalb angenommen werden, daß durch die Dezentralisierung von Entscheidungskompetenzen die relative Macht der staatlichen Bürokratie als Nachfrager von Staatsleistungen eher zu- als abnimmt. Diese Vermutung wird in der empirischen Untersuchung von Joulfaian und Marlow bestätigt, die u.a. das Fazit ziehen: "The more decentralized the government workforce, ceteris paribus, the larger government employment and expenditures tend to be." 370

Damit bleibt jedoch die Gesamtwirkung einer Föderalisierung auf den Einfluß der staatlichen Bürokratie unbestimmt. Einerseits kann davon ausgegangen werden, daß die relative Stärkung der Nachfragemacht öffentlicher Bediensteter in föderativen Systemen zu tendenziell größeren Budgets führt als im unitarischen Staat. Andererseits ist auch ein gegenläufiger Effekt zu verzeichnen, denn die Politiker verfügen auf subzentraler Ebene über verbesserte Kontrollmöglichkeiten und größere Kontrollanreize.

\section{Ein Totalmodell politischer Entscheidungsprozesse im foderativen Staat}

\section{Die Modellergebnisse}

Zur Bestimmung der Konsequenzen einer Föderalisierung für die Gesamtergebnisse der politischen Prozesse wird auf die oben in Abschnitt B.V. abgeleiteten Modellergebnisse zurückgegriffen. Weil die grundlegenden Zusammenhänge des Zustandekommens politischer Entscheidungen unverändert bleiben, gelten die Optimierungsbedingungen (4.B.V.1.-5.) analog. Es wird unterstellt, daß der betrachtete Bundesstaat aus zwei identischen Jurisdiktionen besteht, so daß die dort gewonnenen Erkenntnisse hier übernommen werden können.

Ausgangspunkt der Überlegungen sind die Marginalbedingungen (4.B.V.5) für einen stimmenmaximierenden Einsatz der Ausgabeninstrumente E. Die unter den Elementen der Gleichung angegebenen Vorzeichen zeigen, wie sich durch eine Dezentralisierung von Kompetenzen die ursprünglich für einen unitarischen Staat abgeleiteten Werte vermutlich verändern.

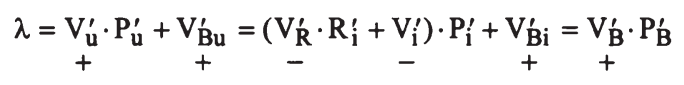

Es wurde festgestellt, daß durch eine Dezentralisierung der Verantwortlichkeiten der Informationsstand der nicht organisierten Wähler verbessert wird. Damit ist eine höhere Reagibilität der Wählerstimmen auf Veränderungen aller Politikvariablen anzunehmen. Je stärker dezentral die Kompetenzen angesiedelt sind,

369 Bei einer Wahlbeteiligung der Bürokratie, die bei ca. 88\% liegt, und einer Wahlbeteiligung der ubrigen Bevolkerung von ca. $50 \%$ fuhrt ein Anstieg des Anteils der Beschăftigten von $5 \%$ auf $10 \%$ der Gesamtbevolkerung zu einem Einfluß der Bürokratie auf offentliche Budgets, der einem Anteil an der Bevőlkerung von $8 \%$ bzw. $16 \%$. entspricht.

370 Joulfaian, D./Marlow, M.L. (1991), S. 231. 
- desto eher dürfte die Bereitstellung von public interest-Gütern durch die Politiker mit Stimmengewinnen honoriert werden,

- um so mehr dürfte die Gewährung von Partikularvorteilen an spezielle Interessengruppen mit Stimmenverlusten einhergehen und

- um so weniger werden die Wăhler auf Wahlwerbung ansprechen.

Da der Einfluß der Bürokratie als Wählergruppe im dezentral organisierten Staat vermutlich steigt, wirken die entsprechenden Wählerreaktionen der öffentlichen Bediensteten stets als Verstärker.

Der relative Einfluß der organisierten Interessen wird hingegen durch die Dezentralisierung sinken. Betrachtet man hierzu erneut die Gleichung

$$
R_{i}^{\prime}=\frac{\lambda-V_{B_{i}}^{\prime}}{V_{R}^{\prime} \cdot P_{i}^{\prime}}-\frac{V_{i}^{\prime}}{V_{R}^{\prime}}
$$

wird dieser Effekt deutlich. Da die Wähler annahmegemäß auf subzentraler Ebene die Begünstigung organisierter Interessen besser erkennen, nimmt $V_{i}^{\prime}$ immer größere negative Werte an. Gemeinsam mit der fallenden Produktivität der Wahlwerbung wird deshalb in (4.B.V.6) der erste Term der rechten Seite immer größer, der zweite Term erhält wachsende negative Werte, so daß der Preis für die Erlangung von Sondervorteilen weiter ansteigt.

Infolgedessen dürfte das relative Gewicht der unorganisierten Wähler an den politischen Entscheidungen auf subzentraler Ebene tendenziell zunehmen und das der organisierten Interessen tendenziell abnehmen. Zur Gewinnung derselben Stimmenzahl mit demselben Ressourceneinsatz müssen die Kandidaten für politische Ämter deshalb den unorganisierten Gruppierungen relativ mehr politische Güter anbieten. Das politische Kräfteverhältnis zwischen organisierten und nicht-organisierten gesellschaftlichen Gruppen verschiebt sich durch eine Dezentralisierung zugunsten der unorganisierten Wähler.

Eine organisierte Gruppierung, die spezifisch lokale Interessen vertritt, könnte beim Lobbying auf Zentralebene deshalb größere Durchsetzungschancen haben, weil die Belastungen auf eine größere Zahl von unorganisierten Wählern verteilt werden können. Auf lokaler Ebene sind die zusätzlichen Lasten hingegen für die Bürger stärker fühlbar, so daß mit einem größeren Widerstand gegen die Gewährung der Partikularvorteile zu rechnen ist. Doch selbst wenn die Gruppenmitglieder geographisch über mehrere Jurisdiktionen gestreut ansässig sind, würde die Bereitstellungsverantwortung auf Zentralebene die Erfolgschancen der pressure group allein aufgrund der rationalen Unwissenheit der Wähler verbessern. ${ }^{371}$

Allerdings können Gruppen, die auf zentraler Ebene schlechter organisierbar sind, auf lokaler Ebene relativ mehr Wählerstimmen zur Durchsetzung spezieller Vorteile mobilisieren. Betrachtet sei dazu eine Gruppe, die ortsgebundene Interessen vertritt und das Ziel verfolgt, in ihrer Region ein öffentliches Projekt durchzusetzen. Ihre Lobbying-Anstrengungen können auf zentraler Ebene deshalb erfolgreich sein, weil sich die budgetären Belastungen auf die Bürger des gesamten Staates verteilen. Aus Sicht eines Politikers auf der Zentralebene ist aber der Effekt auf die damit gewonnenen Wählerstimmen möglicherweise relativ unbedeutend. Es

371 So auch Lee, D.R. (1985), S. 280. 
ist deshalb unklar, ob die Einflußnahme auf der Zentralebene zum Erfolg führt. Auf lokaler Ebene wären dann die Erfolgsaussichten der Lobbyisten sogar größer.

Dieser Effekt läßt sich nur durch einen auf der Zentralebene fehlenden Zwang zur Stimmenmaximierung erklären. Während im zentralisierten System die Regierung eine stärkere Verhandlungsposition innehat, darf für das dezentrale System angenommen werden, daß die bargaining-Position spezieller Interessen aufgrund des höheren politischen Wettbewerbsdrucks verbessert wird. Ebenso steigt der Wählereinfluß auf die politischen Entscheidungen. Das Kräfteverhältnis zwischen den staatlichen Agenten und den Nachfragern nach Staatsleistungen wird, wie in Abschnitt C.III.2 dargelegt, durch Dezentralisierung zugunsten aller Nachfrager öffentlicher Leistungen (Wähler, Interessengruppen und Bürokratie) verschoben. Die Politiker auf regionaler oder lokaler Ebene verfügen über geringere diskretionăre Spielräume.

\section{Die graphische Darstellung des Modells}

In der graphischen Darstellung wirken sich die unterschiedlichen Effekte der Föderalisierung wie folgt aus. Da zur Erreichung derselben Stimmenzahl im dezentralen System nunmehr die nicht organisierten Wähler gegenüber den organisierten Verbänden stärker berücksichtigt werden müssen, erhält die Iso-Stimmenfunktion, also die Kombinationen von $P_{u}$ und $P_{i}$, die den Kandidaten dieselbe Stimmenzahl erbringen, einen flacheren Verlauf als im zentralen System. Jede Reduktion der $\mathrm{P}_{\mathrm{u}}$ muß mit einer großen Ausdehnung der $\mathrm{P}_{\mathrm{i}}$ durch die Politiker erkauft werden.

Die Lage der Iso-Stimmenkurven wird bestimmt durch das absolute Niveau der Bereitstellung von gruppenspezifischen Gütern und von reinen Kollektivgütern. Weil die Konsumenten der Staatsleistungen die relativen Outputs der subzentralen Einheiten besser beobachten können, ist $\mathrm{zu}$ vermuten, daß die angebotenen öffentlichen Leistungen relativ umfangreicher sein müssen, um die Wiederwahl zu sichern. Aus Sicht der Politiker als Anbieter der Staatsleistungen bedeutet dies einen Rückgang der Handlungsfreiräume für ideologisches Verhalten. Die maximal erzielbaren Überschüsse $Z$ werden verringert, selbst wenn der politische Wettbewerb nicht so intensiv ist, daß die Maximierung der erwarteten Stimmenzahl zur Handlungsmaxime wird.

Zur Vereinfachung sei in Abbildung 4.6 unterstellt, daß die Föderation $\mathrm{Z}$ aus zwei völlig identischen Gliedstaaten A und B bestehe, Effekte der Präferenzunterschiede zwischen den Bewohnern der Jurisdiktionen, die für die traditionelle Theorie maßgeblich sind, werden ausgeklammert. Betrachtet wird die Situation in einem der beiden Gliedstaaten bei dezentraler und bei zentraler Bereitstellungsverantwortung. Bei unitarischer Aufgabenzuordnung verlaufen die relevanten Iso-Stimmenkurven VV und V'V' sehr steil. Die Entscheidungsergebnisse sind a bzw. $a^{\prime}$, je nachdem, ob intensiver oder mangelnder politischer Wettbewerb angenommen wird.

Im dezentralen System sind die neuen, flacher verlaufenden, Iso-Stimmenkurven mit WW bzw. W'W' bezeichnet. 'W'W' würde der subzentralen Regierung dieselben diskretionären Budgetüberschüsse wie im unitarischen System belassen, die jedoch mit einer anderen Kombination von $\mathrm{P}_{\mathrm{u}}$ und $\mathrm{P}_{\mathrm{i}}$ (gemäß Punkt $\mathrm{b}^{\prime}$ ) erreicht würden. Die relativen Anteile der public interest-Güter am Gesamtbudget würden im Vergleich zur zentralen Bereitstellung ansteigen. 


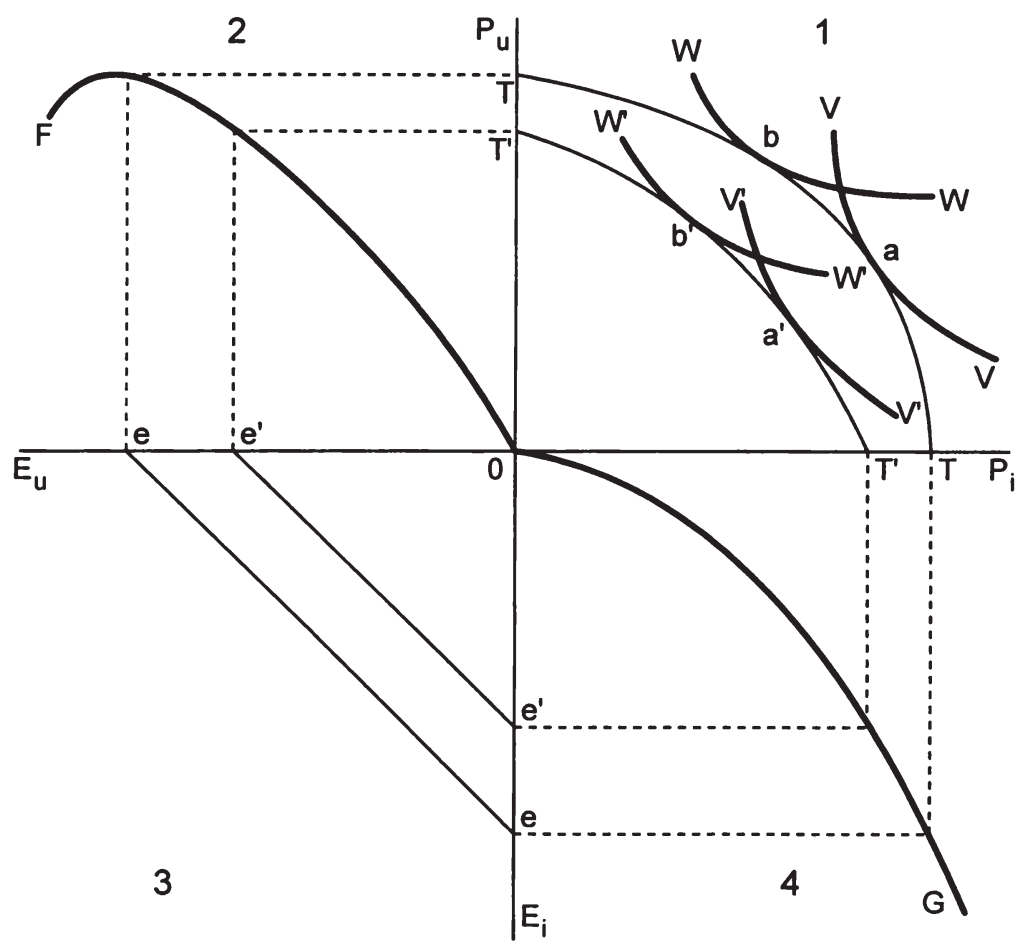

Abbildung 4.6: Ein Totalmodell politischer Entscheidungsprozesse im föderativen System Quelle: eigene Darstellung

$\mathrm{Da}$ aber aufgrund des intensiveren politischen Wettbewerbs die Politiker immer stärker in die Rolle der Preis-Nehmer gedrängt werden, kann W' $W$ ' nicht mehr auf Dauer die Iso-Stimmenfunktion sein, die eine ausreichende Mehrheit sichert. Die Verschiebung der relevanten IsoStimmenfunktion nach außen ist die Konsequenz des intensiveren intrakollektiven Wettbewerbs. Ist die politische Konkurrenz so scharf, daß die Kandidaten nach Stimmenmaximierung streben, reduziert sich das diskretionäre Budget auf Null: Die relevante Iso-Stimmenfunktion wird nun durch die WW-Kurve dargestellt, das realisierte politische Gleichgewicht ist $b$.

Insgesamt erweist sich diejenige institutionelle Struktur als beste verfügbare Alternative, die unter den gegebenen Annahmen zu einer Maximierung der Bereitstellung von $P_{u}$ führt, weil Ausgaben für $P_{i}$ durch den Interessengruppenwettbewerb aufgezehrt und die Renten der Politiker und Bürokraten ebenfalls zu Lasten der Bevölkerung erzielt werden. In der graphischen Darstellung könnte dies durch horizontal verlaufende "Meta-Indifferenzkurven" 372 dargestellt werden. Das Ergebnis in Punkt $b$ ist für die Bürger das unter der gegebenen institutionellen 
Struktur bestmögliche, denn eine horizontal verlaufende Meta-Indifferenzlinie erreicht hier ihre höchstmögliche Lage. Das Maximum im Schnittpunkt von TT mit der Ordinate kann nur erreicht werden, wenn die Bürger vollkommen informiert sind.

Zum Vergleich der institutionellen Strukturen sind die Punkte a' und b heranzuziehen. Punkt a' beschreibt den Output, der bei zentraler Bereitstellung und geringem politischen Wettbewerb realisiert wird, wohingegen Punkt $b$ die Ergebnisse in einem dezentralisierten System charakterisiert. Auf den ersten Blick erscheint die Wahl zwischen den Institutionen eines unitarischen und eines föderativen Staates eindeutig, denn b liegt auf einer höheren gesellschaftlichen Indifferenzlinie (in Abbildung 4.6 nicht eingezeichnet). Die Wohlfahrtsgewinne einer Dezentralisierung dominieren in Falle eindeutig. Dieser Fall liegt implizit stets der Argumentation in der Theorie des Fiskalföderalismus zugrunde.

Dieses Ergebnis ist jedoch nicht zwingend, wie in Abbildung 4.7 demonstriert wird. Hier ist lediglich der Quadrant 1 aus Abbildung 4.6 abgebildet. Dabei wird angenommen, daß die politischen Produktionsfunktionen eine andere Gestalt haben und sich auch die Transformationsfunktionen TT und T'T' entsprechend verändern. ${ }^{373}$ Unter diesen Bedingungen ergibt sich durch die Dezentralisierung von Kompetenzen eine Verschlechterung des Gesamtergebnisses; eine Zentralisierung ist effizienzsteigernd, denn a' liegt auf einer höheren Meta-Indifferenzkurve als Punkt $b$. Man beachte, daß die WW-Kurve in $b$ aufgrund des Informationseffektes der Dezentralisierung flacher verläuft als die V'V'-Kurve in Punkt a'.

Intensiver politischer Wettbewerb um Wählerstimmen im dezentralisierten System führt zu einer Aufzehrung der Politikerrenten. Die Politiker sind gezwungen, sowohl die unorganisierten Wähler als auch die speziellen Interessengruppen, einschließlich der staalichen Bürokratie, zu bedienen. Verlierer im Umverteilungskampf sind hier die Regierungspolitiker, ihre Position hat sich relativ zu den anderen Beteiligten verschlechtert. Auch wenn die Regierung keine Steuerzahlerrenten für eigene Zwecke abschöpfen kann, könnte daher die gesellschaftliche Wohlfahrtsposition im föderativen System geringer sein, wenn die Renten nicht den Wählern, sondern speziellen Interessen zukommen.

373 Den Verlauf der Transformationskurven TT und TT in Abbildung 3.7 kann man dadurch erklären, daß furr die Bereitstellung von public interest-Gutern die Grenzertrăge im relevanten Bereich relativ schwăcher sinken. Zur Erklärung ist es sinnvoll, für einen kurzen Moment vollstăndig von der Wahlrestriktion zu abstrahieren. Will die Regierung beispielsweise einen Überschuß e'e' realisieren, so kann sie lediglich $0 \mathrm{e}^{\prime}$ als Budgetsumme verausgaben. In diesem Falle ergibt sich die Transformationskurve TT. Je mehr Ressourcen E die Regierungsverantwortlichen von ihrem eigenen Überschuß zur Bereitstellung von politischen Gutern verausgaben, desto mehr nahert man sich der Transformationskurve TT an. Auch TT ist für beide Aktivităten durch abnehmende (oder zumindest nicht zunehmende) Grenzerträge gekennzeichnet. Aber der flachere Verlauf impliziert, daß die Grenzertrăge der Produktion von $\mathbf{P}_{i}$ nicht so stark sinken wie die Grenzertrăge einer Bereitstellung von $\mathrm{P}_{\mathrm{u}}$. Der geringe Abstand zwischen $\mathrm{T}$ und $\mathrm{T}$ auf der Ordinate zeigt, daß eine zusătzlicher Ressourcenverwendung $E_{u}$ nur noch einen geringen Outputzuwachs von Kollektivgutern $P_{u}$ erzeugt, wahrend der relativ große Abstand zwischen $T$ und $T$ auf der Abszisse hohe marginale Zuwăchse an gruppenspezifischen Gutern darstellt. Wenn daher die Grenzertrăge der Produktion von $P_{u}$ relativ zu den Grenzertrăgen der Produktion von $P_{i}$ sinken, sind die eingezeichneten Verläufe von TT und TT denkbar. 


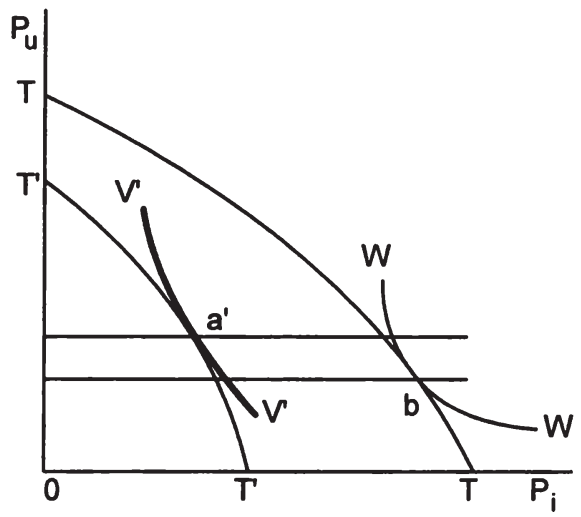

Abbildung 4.7: Wohlfahrtseinbuße durch intensiven politischen Wettbewerb im föderativen Staat

Quelle: eigene Darstellung

Es kann daher nicht ausgeschlossen werden, daß eine Dezentralisierung von Entscheidungsverantwortlichkeiten zu einer Verschlechterung des Gesamtergebnisses führt. Nur bei vollkommener Information der Wähler und Politiker auf subzentraler Ebene, die Iso-Stimmenkurven sind dann mit den horizontal verlaufenden Meta-Indifferenzkurven deckungsgleich, gelten die Annahmen des Dezentralisierungstheorems uneingeschränkt.

Dem könnte entgegengehalten werden, daß, wie die Analyse von McCormick und Tollison gezeigt hat, in völlig homogenen Gemeinwesen keine Transfers zwischen organisierten und nicht-organisierten Gesellschaftsmitgliedern stattfinden können. Dieser Fall erscheint zwar als theoretisch interessant, aber praktisch irrelevant, weil nur für sehr kleine Gruppen zutreffend. Die Notwendigkeit staatlich organisierter Bereitstellung von Kollektivgütern entsteht ja gerade erst in größeren, und damit zumindest bedingt heterogenen Gruppen.

\section{Die Implikationen für die föderative Aufgabenverteilungsdiskussion}

Die positive Analyse politischer Entscheidungsverfahren hat für das unitarische System gezeigt, daß der Sanktionsmechanismus Widerspruch in der Mehrheitsdemokratie mit Defiziten behaftet ist. Die scheinbar auf Gleichbehandlung hinauslaufende Regel one-man-one-vote führt in der Realität der repräsentativen Demokratie zu unterschiedlichen Durchsetzungschancen im politischen Prozeß. Betrachtet man die Wirkungen einer Föderalisierung von Entscheidungsverantwortlichkeiten auf die Effizienz des politischen Widerspruchs, bleiben jedoch die Konsequenzen unklar.

Die These, daß bei dezentralen Kompetenzen den Präferenzen der Bürger besser entsprochen wird, kann keine generelle Gültigkeit beanspruchen. Dieses Ergebnis steht allerdings nicht im Widerspruch zu dem des Fiscal Federalism-Ansatzes. In der traditionellen Theorie wird jedoch nur die Relation Bürger-Regierung betrachtet. Hier wie dort wird die Vermutung 
geäußert, daß die politischen Mandatsträger in subzentralen Einheiten geringere Handlungsfreiräume haben als auf der Zentralebene.

Der fundamentale Unterschied der beiden Ansätze besteht darin, daß in der polit-ökonomischen Analyse die Rolle der organisierten Interessengruppen und der Bürokratie aus anderer Perspektive betrachtet wird. Vertreter des Fiscal Federalism unterstellen nämlich, daß die verbesserten Organisationsbedingungen für pressure groups in kleineren Jurisdiktionen die politischen Widerspruchskosten verringern. ${ }^{374}$ Interessengruppenaktivitäten sind aber häufig eine Quelle von Wohlfahrtsverlusten. Sie führen nicht zu einer Besserstellung der Bürger, sondern zur Benachteiligung nicht-organisierter gesellschaftlicher Gruppen. Die Theorie des rent seeking hat gezeigt, daß damit nicht nur Verteilungsprobleme verbunden sind, sondern daß ein ökonomisches Negativsummenspiel vorliegt.

Damit werden die Ausführungen zur Minimierung der Organisationskosten im dritten Kapitel insoweit relativiert, als nicht sicher davon ausgegangen werden kann, daß bei dezentralisierten Kompetenzen für die Bereitstellung politischer Güter die Bürgerpräferenzen generell stärkere Beachtung finden. Mögliche Vorteile dezentraler Strukturen bei der demokratischen Entscheidungsfindung bleiben zwar erhalten, sie sind aber weder zwingend zu erwarten, noch sollte ihre Größenordnung überschätzt werden.

\section{Zusammenfassende Thesen zum vierten Kapitel}

1. Die Public Choice-Theorie betrachtet den Staat nicht als monolithische Einheit, sondern erklärt das Zustandekommen politischer Ergebnisse aus den Interaktionen von Wählern, Politikern, Interessengruppen und Bürokraten. Alle handelnden Akteure werden als eigennützig modelliert, sie agieren aber unter anderen Rahmenbedingungen als im privaten Sektor.

2. Ausgangspunkt ist die These von der Effizienz des politischen Wettbewerbs um Wählerstimmen. Mehrdimensionale Entscheidungen und Log-Rolling, Wahlabstinenz, temporäre Monopolstellungen der Regierung sowie die rationale Uninformiertheit der Wähler liefern den Politikern aber hinreichende Handlungsfreiräume, die sie opportunistisch zu Lasten der Bürger ausnützen können.

3. Auch der Wettbewerb der Interessengruppen führt nur unter restriktiven Annahmen zu effizienten politischen Ergebnissen. Ursachen auftretender Ineffizienzen sind v.a. die mangelnde Organisationsfähigkeit bestimmter gesellschaftlicher Gruppen und die Uninformiertheit der Wähler. Es kommt zur Verschwendung von Ressourcen beim Wettbewerb der pressure groups um Sondervorteile (rent seeking).

4. Die Bürokratie ist die Produktionsagentur der staatlichen Leistungen. Zwischen Politikern als formale Auftraggeber und Bürokraten entsteht ein Principal-Agent-Verhältnis, das aber mit stärkeren Kontrollproblemen behaftet ist als im privaten Sektor. Außerdem tritt die

374 Dies wird deutlich, wenn man die Arbeit Bretons zur "Economic Theory of Representative Government" betrachtet, die den Ausfuhrungen von Breton/Scott explizit (Breton, A.Scott, A. (1978), S. 32) zugrunde gelegt wird. Breton analysiert dort "various activities in which utility-maximizing citizens can engage in an effort to reduce, or even eliminate, the coercion ... that is placed on them by the government's supply of policies." (Breton, A. (1974), S. 74) und subsumiert darunter neben dem Gang zur Wahl auch die Aktivităten in Interessenverbanden. In der Analyse von Breton spielt es folglich keine Rolle, daß die Aktivităten der pressure groups wohlfahrtsverringernd sein können. 
Bürokratie selbst als organisierte Nachfragergruppe im politischen Prozeß auf und verändert so die relativen Gewichte der anderen gesellschaftlichen Gruppierungen am Zustandekommen der politischen Entscheidungen.

5. Föderative Strukturen verändern die Rahmenbedingungen politischen Handelns aller Akteure. So ist anzunehmen, daß in föderativen Systemen die Eindeutigkeit der Ergebnisse ebenso zunimmt wie die Intensität des Wettbewerbs um Wählerstimmen. Mit wachsender Kollektivgröße und damit fallender Zahl von Jurisdiktionen im Bundesstaat nehmen die Vergleichsmöglichkeiten der Bevölkerung ab, der politische Markt erhält zunehmend Monopolcharakter. Damit verringern sich bei einer Dezentralisierung die diskretionären Spielräume der um Wählerstimmen konkurrierenden Politiker.

6. Auf subzentraler Ebene sind die Voraussetzungen für die Organisation latenter Interessen verbessert. Dies bedeutet einerseits, daß Umverteilungsaktivitäten der Regierungen auf größeren politischen Widerstand stoßen. Andererseits zwingt der intensivere politische Wettbewerb die Politiker zu einer verstärkten Begünstigung organisierter Interessen. Diese Anreize sind um so stärker, je geringer die Verhandlungsmacht der Politiker, also je intensiver der Wählerstimmenwettbewerb ist.

7. Die Kontrolle bürokratischer Aktivitäten ist im föderativen System kostengünstiger, so daß verschwenderisches Verhalten besser sanktioniert werden kann. Andererseits ist auf subzentraler Ebene die Nachfragemacht der Staatsbürokratie stärker, und deren Gewicht im politischen Prozeß nimmt tendenziell zu.

8. In einem Totalmodell politischer Prozesse lassen sich keine eindeutigen Auswirkungen einer Dezentralisierung der Bereitstellungskompetenzen auf die politischen Ergebnisse feststellen. Die These, Dezentralisierung führe stets zu einer höheren Übereinstimmung der Politik mit den Wählerpräferenzen, konnte nicht eindeutig bestätigt werden. 


\section{Kapitel: Polit-ökonomische Theorien des Wettbewerbsföderalismus}

\section{A. Die Wesensmerkmale polit-ökonomischer Theorien des Wettbewerbs- föderalismus}

\section{Das Tiebout-Modell als Vorläufer}

In diesem Kapitel soll diskutiert werden, wie Abwanderungsoptionen mobiler Faktoren im föderativen Staat die Kräfteverhältnisse und die Erfolgschancen der an der politischen Entscheidungsfindung Beteiligten verändern. Die Einbeziehung der Abwanderungsoption in die polit-ökonomische Analyse erfolgt im Rahmen verschiedener Ansätze, die unter dem Oberbegriff 'Theorien des Wettbewerbsföderalismus'1 ("Competitive Federalism"2) subsumiert werden können.

Wettbewerbliche Beziehungen zwischen den Gliedstaaten einer Föderation wurden im Rahmen dieser Arbeit bereits bei der Darstellung des Tiebout-Modells und bei der Erörterung der Konzepte des Rangordnungswettbewerbs im vierten Kapitel problematisiert. Die Überlegungen zum Rangordnungswettbewerb beruhten dabei explizit auf der Prämisse, daß keine Faktor- und/oder Güterbewegungen zugelassen sind. Dem Rangordnungswettbewerb kommt, wie noch zu zeigen ist, im Zusammenhang mit der räumlichen Abwanderungsoption zwar möglicherweise sogar verstärkte Bedeutung zu, kann jedoch prinzipiell unabhängig von der Existenz einer exit-Option analysiert werden.

Die Gültigkeit der Tiebout-Hypothese ist dagegen an das Vorliegen von Abwanderungsalternativen und von geringen Mobilitätskosten geknüpft. Die Tiebout-Gemeinden wurden beschrieben als lokale Clubs, die um die mobilen Faktoren Arbeit und Kapital konkurrieren, um die optimale, die Nutzen der Bewohner maximierende, Mitgliederzahl zu erreichen. Der Beitrag von Tiebout darf deshalb zweifelsohne als Meilenstein in der Entwicklung der Theorien des Wettbewerbsföderalismus angesehen werden. ${ }^{3}$ Gleichwohl war die ursprüngliche Intention Tiebouts nicht explizit die Analyse subzentraler politischer Entscheidungsprozesse. Er beabsichtigte vielmehr, die von Samuelson und Musgrave formulierte These zu widerlegen

"... that no 'market type' solution exists to determine the level of expenditures on public goods." 4 Ausgangspunkt seiner Betrachtungen ist die Feststellung

1 Die Verwendung des Plurals 'Theorien des Wettbewerbsfoderalismus' erscheint gerechtfertigt, da ein umfassender Theorieansatz bislang nicht existiert. Vgl. auch Gerken, L. (1995a), S. 10. Im internationalen Zusammenhang wird dagegen von Theorien des "Ordnungs- oder Systemwettbewerbs" oder allgemeiner von "institutional competition" gesprochen. Diese Ansătze sind in Teilfragen auch fur die Analyse des Wettbewerbsfoderalismus fruchtbar anzuwenden, wenngleich nicht alle Aspekte dieses Konzepts hier eine Rolle spielen. Insbesondere soll die Frage eines möglichen Wettbewerbs der Privatrechtsordnungen hier nicht diskutiert werden. Stellvertretend fur die stăndig wachsende Literatur zum Systemwettbewerb seien genannt: Siebert, H./Koop, M.J. (1990); Siebert, H. (1991), Kap. 2; Gerken, L. (1995a) und (1995b); Kerber, W./Vanberg, V. (1995); Vollmer, L. (1996).

2 Breton, $A$. (1987).

3 Wichtigstes Indiz hierfur ist, daß praktisch in allen Arbeiten, die sich mit interjurisdiktioneller Konkurrenz aus der Public Choice-Perspektive beschăftigen, Tiebouts "Pure Theory of Local Expenditures" zitiert wird.

4 Tiebout, C.M. (1956), S. 416. 
"If all consumer-voters could somehow be forced to reveal their true preferences for public goods, then the amount of such goods to be produced and the appropriate benefits tax could be determined. As things now stand, there is no mechanism to force the consumer-voter to state his true preferences; ... The current method of solving this problem operates, unsatisfactorily, through the political mechanism." 5

Zentrales Thema bei Tiebout ist die Präferenzoffenbarung, opportunistisches Verhalten der staatlichen Agenten wird per Annahme ausgeschlossen. ${ }^{6}$ Der Tiebout'sche "... city manager ... follows the preferences of the older residents of the community"7 und "... on the production side it is assumed that communities are forced to keep production costs at a minimum either through the efficiency of city managers or through competition from other communities."8

In beiden Zitaten wird deutlich, daß das Erkenntnisinteresse der normativen konstitutionellen Ökonomik für Tiebout allenfalls sekundär ist; die für die Public Choice-Richtung zentrale Fragestellung, ob die Abwanderungsoption zu einer Beschränkung des Regierungshandelns führt, wird als Problem ausgeklammert. ${ }^{9}$ Ursächlich ist die allen wohlfahrtstheoretischen Ansätzen gemeinsame Prämisse wohlmeinenden Verhaltens der gewählten Vertreter. ${ }^{10}$ Auch die in der Tradition des Tiebout-Modells erfolgten Weiterentwicklungen von Wildasin und anderen sehen in den subzentralen Entscheidern Maximierer lokaler Wohlfahrtsfunktionen, so $\mathrm{da} ß$ es im Kontext der Tiebout-Modelle einer politischen Sanktionierungsfunktion des Abwanderungsmechanismus nicht bedarf. Interjurisdiktioneller Wettbewerb erfüllt im Tiebout-Ansatz ausschließlich eine Informationsfunktion.

In der polit-ökonomischen Sicht gliedstaatlichen Wettbewerbs werden demgegenüber dezentralisierte Entscheidungskompetenzen nur in zweiter Linie als Mittel zur Erreichung einer effizienten Allokation angesehen. Vorrangiges Ziel ist die Prüfung, ob Wettbewerb zwischen den Gebietskörperschaften um mobile Faktoren zur Beschränkung und Sanktionierung der staatlichen Agenten geeignet ist. ${ }^{11}$ Unter diesem Gesichtspunkt sind in jüngerer Zeit mehrere Konzepte polit-ökonomischer Theorien des Wettbewerbsföderalismus im weiteren Sinne entwickelt worden, die vereinfachend unterschieden werden können in

5 Tiebout, C.M. (1956), S. 417.

6 "Charles Tiebout was neither concerned with federalism nor with multi-tier governmental systems. He was searching for a mechanism through which citizens would reveal their true preferences for local public goods. He was, in fact, the first of a long list of scholars who have tried to identify or to invent preference revelation mechanisms." Breton, A. (1993), S. 62. Ebenso Kenyon, D.A./Kincaid, J. (1991), S. 10.

7 Tiebout, C.M. (1956), S. 419.

8 Tiebout, C.M. (1956), S. 422.

9 Tiebout merkt in der bereits oben zitierten Fußnote 18 seines Beitrags sogar an, daß "... as an institutional observation, it may well be that city managers are under greater pressure to minimize costs than their private-market counterparts - firm managers." Tiebout, C.M. (1956), S. 422.

10 Rose-Ackerman resumiert: "Multiple governments were first proposed by Tiebout ... not as a way of integrating politics and economics, but as a way of avoiding the political problems of public choice. ... Tiebout and Samuelson, along with Musgrave, ..., believed that the problem of preference revelation was central to political-economic analysis. Their work did not explicitly consider the possibility that even a government with perfect knowledge about preferences might not choose the 'optimal' solution." RoseAckerman, S. (1983), S. 55. (Hervorhebung H.P.) Ähnlich auch Hamlin, A.P. (1991), S. $199 \mathrm{f}$.

11 "Although both fiscal federalism and competitive federalism are based primarily on economic principles, the two approaches are different. Whereas fiscal federalism focuses on the benefit and cost of public goods provision, competitive federalism focuses on competition among governments as a constraint on government behavior." Kenyon, D.A./Kincaid, J. (1991), S. 9 f. 
- Konzepte des Wettbewerbs zwischen Staaten,

- Konzepte des Wettbewerbs zwischen Regierungen in der Leviathan-Theorie des Staates,

- Konzepte des Wettbewerbs zwischen Regierungen in der Interessengruppentheorie des Staates sowie

- Konzepte des föderativen Wettbewerbs um Kompetenzen.

Diese Ansätze unterscheiden sich vorwiegend durch die zugrundegelegte Betrachtungsebene und stehen teils in enger substitutiver, teils in komplementärer Beziehung. Die dahinter stehenden Grundgedanken sollen im folgenden kurz skizziert werden.

\section{Die Konzepte polit-ökonomischer Theorien des Wettbewerbsföderalismus}

\section{Wettbewerb zwischen Staaten}

Eine erste Theorievariante abstrahiert von den internen Strukturen der subzentralen Einheiten und stellt ausschließlich auf einen möglichen Wettbewerb zwischen den Gliedstaaten als handelnde Einheiten der Föderation $a b$. Die föderativen Subeinheiten werden in diesem Ansatz als "entities composed of citizens and governments" 12 interpretiert, der institutionelle Wettbewerb als "inter-group competition"13 rivalisierender Clubs beschrieben. Relevante Betrachtungsebene ist insofern der Gliedstaat 'an sich'. Aufgrund dessen spielt sich der dort untersuchte wettbewerbliche Prozeß auch nicht auf einem Markt für politische Güter ab, denn die Anbieter und die Nachfrager politischer Güter werden als Einheit (Club) modelliert. ${ }^{14}$

Gerken begründet dieses Vorgehen damit, daß die politischen Akteure die wettbewerblichen Handlungen für die gesamte Gruppe vornehmen und diese somit als Ganzes binden, so daß logischer Anknüpfungspunkt einer Analyse des Wettbewerbs zwischen Staaten die Handlungsmotive und Aktivitäten dieser Akteure sein müßten. 15

Freilich werden in dieser Theorievariante die kollektivinternen Handlungsmotive und Entscheidungsstrukturen als gegeben modelliert: "... for the analysis of the internal structure within the state a distinction between government and the citizens is useful. However that is another perspective and a different setting." 16 Deshalb finden die Überlegungen zum Wettbewerb zwischen Staaten in erster Linie auf internationale Zusammenhänge Anwendung, in denen annahmegemäß ein Konsens über Verfassungsregeln nicht erreicht werden kann.17 Dieses Konzept hat deshalb für die hier betrachtete Fragestellung nur eingeschränkte Relevanz.

\section{Wettbewerb zwischen Regierungen in der Leviathan-Theorie des Staates}

Betrachtungsebene des zweiten Ansatzes zum Competitive Federalism ist der Wettbewerb zwischen Regierungen um mobile Faktoren. Ausgangspunkt dieser Theorievariante ist die

12 Gerken, L. (1995b), S. 25.

13 Gerken, L. (1995b), S. 25.

14 "As such, states do not offer anything on some market, but merely act in order to do better than others, as an athlete strives to do better than his competitors." Gerken, L. (1995b), S. 25.

15 Vgl. Gerken, L. (1995a), S. 13.

16 Gerken, L. (1995b), S. 25.

17 Vgl. Gerken, L. (1995b), S. $25 f$. 
These, daß demokratische Prozesse nur mangelhaft geeignet sind, politische Agenten in ihren Handlungen zu beschränken. Die staatlichen Akteure können mithin wie ein unbeschränkter Leviathan agieren. Die Grundgedanken dieses Ansatzes gehen auf eine Arbeit von Brennan/ Buchanan ${ }^{18}$ zurück, wurden aber von anderen Autoren ebenfalls mehr oder weniger explizit diskutiert. So schreibt North in seinen Ausführungen zur "neoklassischen Theorie des Staates" 19 unter Berufung auf das exit-voice-Konzept von Hirschman:

\footnotetext{
"Der Herrscher hat immer Rivalen: konkurrierende Staaten oder mogliche Herrscher innerhalb seines eigenen Staates. Diese entsprechen den potentiellen Konkurrenten eines Monopolisten. Wo es keine nahen Substitute gibt, ist der gegenwärtige Herrscher ein Despot, ein Diktator oder ein absoluter Monarch. Je năher die Substitute, um so weniger Freiheitsgrade verbleiben dem Herrscher, und um so größer ist der Bruchteil zusătzlichen Einkommens, den die Staatsangehơrigen behalten." 20
}

Wenn demnach politischer Widerspruch keine wirksame Restriktion für opportunistisches staatliches Handeln darstellt, könnte institutionalisierter Wettbewerb zwischen subzentralen Leviathan-Regierungen ein erstrebenswertes "Ziel eigener Art"21 sein, um die Ausbeutungspotentiale der Regierungen zu beschränken. In den Erörterungen dieser Theorievariante ist deshalb zu überprüfen, ob und unter welchen Voraussetzungen die Abwanderungsoption als Ersatz für demokratische Kontrollmechanismen und damit als mögliche Beschränkung des Regierungsverhaltens wirken kann.

Diese Denkrichtung steht insoweit direkt in der Tradition des Tiebout-Ansatzes, als auch dort keine Modellierung der kollektivinternen politischen Entscheidungsprozesse erfolgt. Während jedoch die Tiebout-Welt unpolitisch ist, weil von der Möglichkeit opportunistischen Politikerverhaltens abstrahiert wird, ist der von Brennan und Buchanan propagierte wettbewerbliche Föderalismus explizit als politische Begrenzung des Staatshandelns gedacht. Auf die Modellierung der internen lokalen politischen Prozesse wird verzichtet, weil der demokratischen Widerspruchsoption von vornherein nur geringe Erfolgsaussichten eingeräumt werden.

\section{Wettbewerb zwischen Regierungen in der Interessengruppentheorie des Staates}

Demgegenüber wurde bereits im vorangegangenen Kapitel festgestellt, daß die demokratische Widerspruchsoption zwar eine unvollkommene, aber nichtsdestotrotz zumindest partiell wirksame Restriktion für die staatlichen Agenten darstellt. Gerade auf subzentraler Ebene können die Regierungen nicht uneingeschränkt das Ziel einer Maximierung der Überschüsse aus dem Staatshandeln verfolgen. Im Modell des beschränkten Leviathan geht es vielmehr darum, wie die Renten aus dem Staatshandeln zwischen den staatlichen Akteuren, den organisierten Interessen und den unorganisierten Wählern aufgeteilt werden. In Anbetracht dessen führt North auch weiter aus:

"Die Opportunitătskosten [von Abwanderung und Widerspruch, H.P.] des einzelnen Staatsangehorigen werden verschieden hoch sein und werden die Verhandlungsmacht bestimmen, die jede einzelne Gruppe

18 Siehe Brennan, G./Buchanan, J.M. (1980/1988), Kap. 9.

19 Kapitel 3 in North, D.C. (1981/1988).

20 North, D.C. (1981/1988), S. 27.

21 Brennan, G./Buchanan, J.M. (1980/1988), S. 234. 
bei der Spezifizierung von Eigentumsrechten hat, und ebenso die Steuerlast, die sie tragen muß. Opportunitătskosten werden auch die Verteilung der vom Herrscher bereitgestellten Dienstleistungen ... bestimmen, denn der Herrscher wird jenen, die uber naheliegende Alternativen verfugen, grøßere Leistungen erbringen als jenen, die keine haben." 22

Offensichtlich ist mit der Begrenzungswirkung von Abwanderungsoptionen für die Herrscher nur ein Teil des komplexen Phänomens interjurisdiktionell kompetitiver Beziehungen beschrieben. Die Einbeziehung der Widerspruchsoption, die dem Tiebout-Ansatz und dem Modell des unbeschränkten Leviathan aus angeführten Gründen fremd ist, gewinnt vermutlich vor allem dann an Bedeutung, wenn Abwanderungsmöglichkeiten nicht allen Wirtschaftssubjekten in gleichem Maße zur Verfügung stehen. Existieren in lokalen oder regionalen Einheiten sowohl mobile als auch immobile Individuen, könnten exit-Optionen die Kräfteverhältnisse im kollektivinternen Entscheidungsprozeß verändern. Der Schwerpunkt dieser Konzeption liegt deshalb in der Analyse der Wirkungen von Abwanderungsoptionen auf die Handlungsanreize der politischen Akteure in der transfer society.

\section{Wettbewerb um Kompetenzen}

Während die in den vorangegangenen Abschnitten skizzierten Varianten wettbewerblichen Föderalismus die horizontalen Beziehungen zwischen den Regierungen der Gliedstaaten gleicher Ebene in den Vordergrund stellen, betont das Konzept des Wettbewerbs um Kompetenzen die vertikalen Relationen zwischen unterschiedlichen Ebenen im föderativen Staat. Ausgangspunkt dieser Theorievariante ist die Annahme, daß Politiker und Bürokraten im Streben nach Macht und Einfluß versuchen werden, Kompetenzen an sich zu ziehen, und damit im Ergebnis selbst die föderative Aufgabenverteilung bestimmen. ${ }^{23}$ Der Wettbewerb um Aufgabenverantwortung könnte insbesondere, so Kincaid, "... restrain the monopolistic impulses of ... national government" 24 und unter bestimmten Bedingungen zu einem organisationskostenminimalen Staatsaufbau führen. 25

Wenngleich mit dem Konzept des Wettbewerbs um Kompetenzen zwar ein empirisch relevanter Aspekt föderativer Staatsstrukturen in die wissenschaftliche Diskussion eingebracht wird, soll diesem Ansatz im folgenden allerdings aus drei Gründen nicht näher nachgegangen werden. Erstens bedeuten Aufgabenverlagerungen zwischen den Ebenen eine Aufweichung der Kompetenz-Kompetenz - d.h. das Recht, Verfassungsänderungen vorzunehmen -, die in dem hier vertretenen Ansatz ausschließlich den Bürgern im Stadium der konstitutionellen Beschlußfassung zusteht. ${ }^{26}$ Zweitens können, wie noch zu zeigen ist, Kompetenzverlagerungen der Ausschaltung des horizontalen Wettbewerbs dienen und deshalb per se unerwünscht sein. ${ }^{27}$ Drittens spielen Überlegungen zur räumlichen Abwanderungsoption in dieser Theorievariante keine Rolle, so daß grundsätzlich in Zweifel gezogen werden kann, ob es sich beim

22 North, D.C. (1981/1988), S. 27.

23 So etwa Breton, A./Scott, A. (1978), Kap. 8; Kirsch, G. (1987); Kincaid, J. (1991), S. 89ff.

24 Kincaid, J. (1991), S. 91.

25 Siehe Breton, A./Scott, A. (1978).

26 Vgl. Blankart, C.B. (1994b).

27 Siehe hierzu insbesondere die empirischen Befunde in bezug auf die Europalische Union von Vaubel, $R$. (1992); (1994) und (1995). 
Ringen um Kompetenzen überhaupt um den Ausdruck wettbewerblichen Verhaltens handelt. 28

Aufgrund der vorangegangenen Erörterungen zu den unterschiedlichen Konzepten föderativen Wettbewerbs im weiteren Sinne kann der Schluß gezogen werden, daß für die hier betrachtete Fragestellung vor allem die Konzepte des Wettbewerbs zwischen unbeschränkten LeviathanRegierungen und des Wettbewerbs zwischen Regierungen in der Interessengruppentheorie des Staates von unmittelbarer Relevanz sind.

\section{B. Der Wettbewerb zwischen Regierungen in der Leviathan-Theorie des Staates}

\section{Die Beschränkung des Leviathan durch Abwanderungsoptionen}

\section{Die Dezentralisierungshypothese von Brennan und Buchanan}

\section{a. Die Grundaussagen von Brennan und Buchanan}

In ihrer Arbeit "The Power to Tax" diskutieren Brennan und Buchanan die Möglichkeit, daß die konstitutionelle Verankerung föderativer Strukturen als Substitut für anderweitige finanzwirtschaftliche Beschränkungen des staatlichen Handelns dienen kann. Ausgangspunkt ihrer Ausführungen ist die Annahme eines durch demokratische Strukturen unkontrollierbaren Leviathan-Staates. ${ }^{29}$ In der einfachsten Formulierung wird dessen Zielfunktion durch die Maximierung der (Steuer-)Einnahmen über die Ausgaben für die Bereitstellung von Kollektivgütern beschrieben. Brennan und Buchanan fragen, wie die Möglichkeiten der fiskalischen Ausbeutung der Bürger durch die Regierungen in einer föderativen Staatswirtschaft verändert werden.

In einem ersten Schritt gehen die Autoren von einer "idealisierten Tiebout-Welt" 30 vieler konkurrierender Gemeinwesen aus, die strikt lokal begrenzte Kollektivgüter anbieten und in der die Bürger vollkommen mobil sind. ${ }^{31}$ Nach Ansicht von Brennan und Buchanan kann es hier in Analogie zum perfekten Konkurrenzmarkt keine finanzwirtschaftliche Ausbeutung der Bürger geben, da die lokalen Einheiten den Status von Preisnehmern hätten:

28 Vgl. Gerken, L. (1995a), S. 10, FN 16.

29 Siehe Brennan, G./Buchanan, J.M. (1980/1988), Kap. 9.

30 Brennan, G./Buchanan, J.M. (1980/1988), S. 217.

31 Brennan und Buchanan grenzen ihr Erkenntnisinteresse zum Tiebout-Ansatz aber deutlich ab: "The argument in question is that mobility of citizens constrains the behavior of political agents - that increasing the exit options of the citizenry, as a federal system does, serves to set bounds on the exploitative power of intrinsically coercive states... We are interested here not in the question as to the efficiency of free mobility of consumer/taxpayers among alternative but essentially passive jurisdictions (which is the focus of Tiebout's original article ...) but rather in the implications of such mobility for the behavior of political decision makers. That is, we focus not on the analog to the consumer's choice on a shopping spree, but rather on the anlog to competition between shops." Brennan, G./Buchanan, J.M. (1983b), S. 59f. Hervorhebungen im Original. 
"In diesem extremen Fall gibt es bei einer gleichgewichtigen Ressourcenallokation, die aus den freiwilligen Entscheidungen der Menschen in der gesamten ... Wirtschaft hervorgeht, keinen Überschuß, der von einem potentiellen Leviathan ausgebeutet werden konnte. Jede staatliche Einheit wird es ungeachtet ihrer auf Maximierung des Nettoeinnahmenuberschusses gerichteten Motivationen als notwendig ansehen, offentliche Guter in den gewünschten effizienten Mengen anzubieten und diese Guter in effizienter Weise zu finanzieren." 32

Brennan/Buchanan greifen damit die in der traditionellen Theorie des Fiskalföderalismus bereits abgeleitete Feststellung, daß perfekter Wettbewerb um mobile Faktoren die subzentralen Gebietskörperschaften zu einer Finanzierung der Kollektivgüter nach dem Äquivalenzprinzip zwingt, aus polit-ökonomischer Perspektive wieder auf. ${ }^{33} \mathrm{Im}$ Unterschied zu Tiebout ist ihr theoretisches Ergebnis des gliedstaatlichen Wettbewerbs um mobile Faktoren nicht durch die Separierung unterschiedlicher Nachfragergruppen auf Kommunen mit divergierenden Leistungsangeboten charakterisiert. Vielmehr ist im Brennan/Buchanan-Modell interjurisdiktioneller Konkurrenz ein einheitliches Kollektivgutangebot zu erwarten, das aber produktiv effizient erstellt wird. ${ }^{34}$

Die Vorteile der räumlichen Dezentralisierung im Kontext des Leviathan-Modells werden durch Abbildung 5.1 illustriert. Betrachtet sei die Nachfrage D eines repräsentativen Einwohners einer lokalen Jurisdiktion nach dem Kollektivgut G. Die marginalen Bereitstellungskosten der öffentlichen Leistungen werden mit MC bezeichnet.

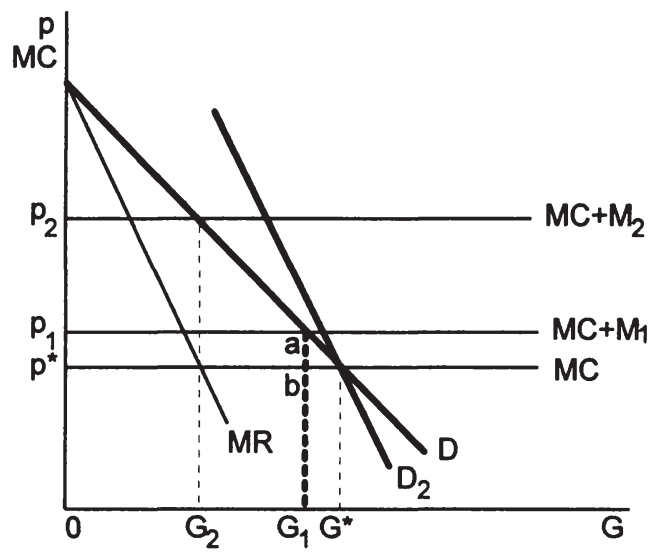

Abbildung 5.1: Jurisdiktionelle Konsolidierung und Ausbeutungspotentiale Quelle: Martin, D.T./McKenzie, R.B. (1975), S. 97.

32 Brennan, G./Buchanan, J.M. (1980/1988), S. 217. Siehe auch Brennan, G./Buchanan, J.M. (1983b), S. 60 sowie Scott, A. (1987), S. 237ff.

33 Vgl. auch Brennan, G./Buchanan, J.M. (1980/1988), S. 225f.

34 Vgl. Hamlin, A.P. (1990), S. $201 \mathrm{ff}$. 
In der fiktiven Situation perfekter Konkurrenz der lokalen Einheiten ohne Migrationskosten wird von den Regierungen der Output $\mathrm{G}^{*}$ angeboten, bei dem der Steuerpreis $\mathrm{p}^{*}$ gleich den Grenzkosten MC ist. Eine aufkommenmaximierende Leviathan-Bürokratie strebt die Steuerpreis-Mengen-Kombination $\left(\mathrm{p}_{2}, \mathrm{G}_{2}\right)$ an, die nur unter echten Monopolbedingungen oder bei vollkommener Immobilität realisierbar ist. Bei Vorliegen positiver Migrationskosten $M_{1}$ in einer ansonsten wettbewerblichen Situation müssen die Regierungen nicht mit einer sofortigen Abwanderung der Individuen rechnen. Somit entstehen diskretionäre Spielräume für die lokale Regierung, die die Aneignung fiskalischer Überschüsse in Höhe von $\mathrm{p}^{*} \mathrm{p}_{1}$ ab bei der Steuerpreis-Mengen-Kombination $\left(\mathrm{p}_{1}, \mathrm{G}_{1}\right)$ ermöglichen.

Durch die Konsolidierung mehrerer Jurisdiktionen zu einer einzigen Regierungseinheit stellen sich zwei Effekte ein. Erstens steigen die Abwanderungskosten, z.B. auf $\mathrm{M}_{2}$, weil aufgrund der größeren räumlichen Entfernungen zwischen den lokalen Einheiten insbesondere die psychischen Kosten der Mobilität ansteigen. Zweitens verringern sich die verfügbaren Alternativen für die Bürger, so daß die Nachfrage weniger elastisch verläuft (Kurve $\left.D_{2}\right) \cdot{ }^{35} \mathrm{Je}$ geringer die Zahl der anbietenden Jurisdiktionen im Staatsgebiet ist, desto höher sind folglich die monopolistischen Spielräume der Regierungen.

Im Vorliegen positiver Migrationskosten sieht Osterfeld ein entscheidendes Argument für eine Dezentralisierung des öffentlichen Sektors. Gerade wenn aufgrund geringerer monetärer und psychischer Mobilitätskosten die Abwanderung zwischen lokalen Einheiten für die Bürger einfacher ist als im großräumigen Zusammenhang, sei die Überantwortung von Kompetenzen an die lokalen Einheiten zur Beschränkung des Leviathan geboten. ${ }^{36}$ Entsprechend vertreten Brennan und Buchanan die Auffassung, daß die Individuen bei der Beschlußfassung auf konstitutioneller Ebene für eine substantielle Dezentralisierung der politischen Entscheidungsverantwortlichkeiten votieren würden, weil "... die Möglichkeiten der finanzwirtschaftlichen Ausbeutung in inverser Beziehung zur Anzahl der konkurrierenden staatlichen Einheiten in dem übergeordneten Gebiet stehen." 37 Diese Argumentation hat in die Literatur als "Dezentralisierungshypothese"38 Eingang gefunden. Nach Brennan und Buchanan ist nämlich

"... die gesamte Einmischung des Staates in die Wirtschaft ... ceteris paribus um so kleiner, je grőßer die Dezentralisierung von Steuern und Ausgaben, je homogener die einzelnen Einheiten, je kleiner die Gebietskörperschaften und je geringer die Netto-Lagerenten sind." 39

\section{b. Die empirische Überprüfung der Dezentralisierungshypothese}

\section{aa. Die methodische Vorgehensweise bei den empirischen Tests}

Diese provokative Aussage veranlaßte eine ganze Reihe von Autoren zu empirischen Tests der Dezentralisierungshypothese. Dabei finden zwei unterschiedliche Methoden Anwendung. Im Rahmen von Zeitreihenuntersuchungen wird versucht $\mathrm{zu}$ zeigen, wie sich Änderungen im Dezentralisierungsgrad des politischen Systems auf die Ausgabentätigkeit des Staates auswir-

35 Vgl. Martin, D.T./McKenzie, R.B. (1975), S. 98.

36 Siehe Osterfeld, D. (1989), S. 154f. Ebenso Lee, D.R./McKenzie, R.B. (1987), S. $72 f$.

37 Brennan, G./Buchanan, J.M. (1980/1988), S. 227.

38 Nelson, M.A. (1986), S. 287; Marlow, M.L. (1988), S. 260.

39 Brennan, G./Buchanan, J.M. (1980/1988), S. 234 (Hervorhebung im Original). 
ken. Diese Vorgehensweise hat den Vorteil, daß alle gebietskörperschaftlichen Ebenen, einschließlich der Zentralebene, in die Untersuchung einbezogen werden können. Sie ist aber mit dem Nachteil verbunden, daß Zeitreihenvergleiche in der Regel nur zuverlässige Aussagen liefern, wenn sich das politische System auch substantiell verändert. Ansonsten können allenfalls marginale Verschiebungen in der relativen Bedeutung der jurisdiktionellen Ebenen beobachtet werden. ${ }^{40}$ Die meisten Studien sind Querschnittsuntersuchungen, in denen das Ausgabenverhalten der Gemeinwesen in Abhängigkeit vom Zentralisierungsgrad analysiert wird. ${ }^{41}$ Damit können Unterschiede auf der unteren, gegebenenfalls auch der mittleren föderativen Ebene ermittelt werden. Eine Untersuchung der Zentralebene kann jedoch naturgemäß nur durch internationale Vergleiche erfolgen, deren Aussagekraft jedoch durch die stark unterschiedlichen politischen Strukturen beeinträchtigt wird. ${ }^{42}$

Unabhängige Variable ist in den empirischen Analysen der Dezentralisierungsgrad der Zuständigkeiten, der durch die Zahl der Entscheidungsebenen ("vertical fragmentation"43), die Zahl autonomer Einheiten auf jeder Entscheidungsebene ("horizontal fragmentation"44), die Zuordnung der Verantwortlichkeiten auf die einzelnen Ebenen ("vertical concentration"45) und die Konzentration der Verantwortlichkeiten innerhalb der Entscheidungsebenen ("horizontal concentration"46) beschrieben werden kann. ${ }^{47}$ Nach der Dezentralisierungshypothese sollten die staatlichen Aktivitäten um so geringer ausfallen, je stärker die vertikale und horizontale Fragmentierung der Struktur des Staates ist. In gleichem Maße würde eine positive Korrelation zwischen der Konzentration vieler Aufgaben bei einer Ebene (bzw. bei einem Entscheidungsträger innerhalb einer Ebene) und einer vermehrten staatlichen Einmischung die Hypothese bestätigen. 48

In der Mehrzahl der Studien wird das Ausgabenverhalten der staatlichen Einheiten untersucht. ${ }^{49}$ Als abhängige Variablen dienen meist der Anteil der Staatsausgaben am Sozialprodukt oder dessen Wachstum (bei Zeitreihenuntersuchungen), bzw. die Pro-Kopf-Ausgaben oder der prozentuale Anteil der Ausgaben am lokalen Einkommen (bei Querschnittsanalysen). Die Fokussierung auf die Ausgabentätigkeit bei Zeitreihen- als auch bei Querschnittsanalysen ist Ausdruck der fundamentalen Probleme bei der direkten Messung der Effizienz staatlicher Tätigkeit, denn höhere Ausgaben können sowohl auf einer größeren Nachfrage nach den bereitgestellten Kollektivgütern als auch auf einer ineffizienten Leistungserstellung beruhen. ${ }^{50}$ In den empirischen Untersuchungen wird deshalb versucht, die Nachfrageeffekte $\mathrm{zu}$ isolieren, indem lokale Einkommen oder demographische Faktoren als Näherungsmaße für

40 Vgl. Wildasin, D.E. (1987), S. 1161 oder Kirchgässner, G./Pommerehne, W.W. (1994), S. 156.

41 Vgl. Boyne, G.A. (1992), S. 343.

42 Vgl. Kirchgässner, G./Pommerehne, W.W. (1994), S. 156.

43 Boyne, G.A. (1992), S. 334.

44 Boyne, G.A. (1992), S. 335.

45 Boyne, G.A. (1992), S. 334.

46 Boyne, G.A. (1992), S. 335.

47 Ähnlich auch Oates, W.E. (1989), S. 579.

48 Zeitreihenanalysen messen ausschließlich die Wirkungen der "vertical concentration" auf die staatlichen Aktivităten. Siehe Oates, W.E. (1989), S. 581f. Joulfaian und Marlow sind der Ansicht, daß nur durch Studien der vertikalen Aufgaben- und Ausgabenkonzentration der Einfluß der Zentralebene richtig wiedergegeben werden könne, vgl. Joulfaian, L./Marlow, M.L. (1991), S. 1611.

49 Wichtige Ausnahmen bilden hier die Studien von Oates, W.E. (1985) und Nelson, M. (1986) und (1987).

50 Vgl. Dowding K./John, P./Biggs, S. (1994), S. 771 f. 
die das Ausgabenverhalten mitbestimmende Nachfrage berücksichtigt werden. ${ }^{51}$ Die Dezentralisierungshypothese beruht außerdem auf der Annahme, daß die lokalen Jurisdiktionen autonom über ihre Einnahmen- und Ausgabenpolitik entscheiden. Die Effekte von Finanzzuweisungen werden deshalb isoliert. Gleiches gilt für Besonderheiten lokaler Einheiten, wie die Verfügbarkeit über standortgebundene natürliche Ressourcen oder politisch-ideologisch bedingte Variationen im Ausgabenverhalten.

Schließlich müssen in den empirischen Tests auch die Quantität und die Qualität der Leistungserstellung Berücksichtigung finden, deren Messung gerade im öffentlichen Sektor mit großen Problemen verbunden ist. ${ }^{52}$ Untersuchungen der Zusammenhänge zwischen Ausgaben und Servicequalität bzw. Bereitstellungsmenge haben ergeben, daß diese Beziehung relativ schwach ausgeprägt ist. ${ }^{53}$ In den Analysen wird deshalb mit der Hypothese gearbeitet, höhere Ausgaben seien nicht mit verbesserten Outputqualitäten oder höheren Versorgungsniveaus verbunden, sondern beruhten ausschließlich auf Ineffizienzen in der Leistungserstellung. Alle Untersuchungen beruhen auf der Annahme einseitiger Wirkungszusammenhänge, nach der der Zentralisierungsgrad die Effizienz der Bereitstellung determiniert. Wie industrieökonomische Untersuchungen zeigen, können die Zusammenhänge von Marktstruktur und Marktergebnis jedoch ebenso in umgekehrter Richtung vorliegen, so daß sich, wie Boyne zu bedenken gibt, im gegebenen Zusammenhang die empirische Evidenz aller Untersuchungen relativieren könnte. 54

\section{bb. Die Ergebnisse der empirischen Untersuchungen}

Die empirischen Tests kommen zu keinem einheitlichen Resultat. Von den 29 hier angefuhrten Studien wird in 13 Fällen die Dezentralisierungshypothese eindeutig bestätigt, allerdings nur in 5 Fällen als klar widerlegt angesehen. In 11 Untersuchungen zeigen sich keine signifikanten Zusammenhänge oder die Resultate variieren je nach gewähltem Dezentralisierungsmaß. In Abbildung 5.2 sind die Ergebnisse der Studien im Überblick zusammengefaßt. Die überwiegende Zahl der zitierten ökonometrischen Tests der Dezentralisierungshypothese erfolgten für die USA, nur jeweils eine für Australien und Kanada. Für die Bundesrepublik Deutschland sind bisher keine Tests durchgeführt worden. In der Tabelle nicht angeführte international vergleichende Querschnittsanalysen kommen zum Schluß, daß kein signifikanter Zusammenhang zwischen der Größe des Staatssektors und dem Dezentralisierungsgrad der Bereitstellungskompetenzen existiert. 55

Aus der Reihe empirischer Tests sind insbesondere die Untersuchung von Oates (1985) und die zweite Studie von Nelson (1987) hervorzuheben. ${ }^{56}$ Die Arbeit von Oates ist deshalb bemerkenswert, weil ihr als erster Studie explizit die Leviathan-These von Brennan und Buchanan zugrunde liegt. Oates findet in seiner Untersuchung weder für die Steuereinnahmen noch für die Ausgabentätigkeit der lokalen Jurisdiktionen eine statistisch signifikante Beziehung zum Dezentralisierungsgrad des öffentlichen Sektors. Er folgert daraus: "Perhaps, after all, Leviathan is a mythical beast." 57

51 Vgl. Boyne, G.A. (1992), S. 342.

52 Siehe etwa Forte, F. (1983).

53 Vgl. Boyne, G.A. (1992), S. 343.

54 Vgl. Boyne, G.A. (1992), S. 343.

55 Vgl. Oates, W.E. (1985); Heil, J.B. (1991).

56 Siehe Oates, W.E. (1985); Nelson, M. (1987).

57 Oates, W.E. (1985), S. 756. 


\begin{tabular}{|c|c|c|c|}
\hline Studie & Jahr & Methodik & $\begin{array}{c}\text { Auswirkungen der Dezentralisierung auf die } \\
\text { Staatstätigkeit }\end{array}$ \\
\hline Adams & 1965 & Q,f,g & geringer \\
\hline Baird/Langdon & 1972 & Q,f,g & $\begin{array}{l}\text { höher, nicht signifikant (je nach Dezentralisie- } \\
\text { rungsmaß) }\end{array}$ \\
\hline Wagner/Weber & 1975 & $\mathrm{Q}, \mathrm{f}, \mathrm{h}$ & geringer \\
\hline Isserman & 1976 & Q,f,g & geringer \\
\hline Gustley & 1977 & $\mathrm{Q}, \mathrm{c}, \mathrm{v}$ & höher \\
\hline Giertz & 1981 & $\mathrm{Q}, \mathrm{c}, \mathrm{v}$ & höher \\
\hline Sjoquist & 1982 & Q,f,g & geringer \\
\hline DiLorenzo & 1983 & Q,c,g & geringer \\
\hline Chicoine/Walzer & 1985 & Q,f,g & $\begin{array}{l}\text { in der Regel höher, teilw. nicht signifikant (je } \\
\text { nach Dezentralisierungsmaß) }\end{array}$ \\
\hline Oates & 1985 & $\begin{array}{l}\text { Q,f,g } \\
Q, c, v\end{array}$ & $\begin{array}{l}\text { nicht signifikant } \\
\text { nicht signifikant }\end{array}$ \\
\hline Schneider & 1986 & Q,f,h & geringer \\
\hline Nelson & 1986 & $\begin{array}{l}\text { Q,f,g } \\
\text { Q,c,v }\end{array}$ & $\begin{array}{l}\text { geringer } \\
\text { geringer }\end{array}$ \\
\hline Nelson & 1987 & Q,f,g & $\begin{array}{l}\text { geringer, nicht signifikant (je nach Dezentralisie- } \\
\text { rungsmaß) }\end{array}$ \\
\hline Bell & 1988 & Q,f,h & geringer \\
\hline $\operatorname{Zax}$ & 1988 & Q,f,g & $\begin{array}{l}\text { geringer, höher, nicht signifikant (je nach Dezen- } \\
\text { tralisierungsmaß) }\end{array}$ \\
\hline Wallis/Oates & 1988 & $\mathrm{Q}, \mathrm{c}, \mathrm{v}$ & höher \\
\hline Marlow & 1988 & $\mathrm{Z}$ & geringer \\
\hline Forbes/Zampelli & 1989 & Q,f,h & höher \\
\hline Raimondo & 1989 & $\mathrm{Q}, \mathrm{Z}$ & geringer \\
\hline
\end{tabular}




\begin{tabular}{|l|c|c|l|}
\hline Studie & Jahr & Methodik & \multicolumn{1}{|c|}{$\begin{array}{c}\text { Auswirkungen der Dezentralisierung auf die } \\
\text { Staatstätigkeit }\end{array}$} \\
\hline Schneider & 1989 & Q,f,h & $\begin{array}{l}\text { geringer } \\
\text { Q,c,h }\end{array}$ \\
\hline Forbes/ signifikant
\end{tabular}

Abbildung 5.2: Ergebnisse empirischer Tests der Dezentralisierungshypothese Quelle: eigene Zusammenstellung in Erweiterung von Boyne, G.A. (1992)

Legende zur Untersuchungsmethodik: Querschnittsanalyse (Q), Zeitreihenanalyse (Z), fragmentation ( $f$ ), concentration (c), horizontale Betrachtung (h), vertikale Betrachtung (v), generelle Betrachtung vertikaler und horizontaler Art (g). 
Nelson kritisiert an der Vorgehensweise von Oates, daß dieser bei der Messung keine Differenzierung von monofunktionalen Einheiten (special districts) und multifunktionalen Einheiten vornimmt. 58 Bei einer Aufbereitung desselben Datenmaterials erhält Nelson unter Berücksichtigung dieser Unterscheidung eine statistisch signifikante Bestätigung der Dezentralisierungshypothese für multifunktionale Jurisdiktionen, jedoch keinen signifikanten Zusammenhang im Falle der special districts. Boyne erklärt diesen Zusammenhang dadurch, $\mathrm{da} ß$ erstens monofunktionale Einheiten häufig kapitalintensive Leistungen bereitstellen und deshalb die Fragmentierung zu nicht-ausgeschöpften Skalenvorteilen führe, und daß zweitens mobile Haushalte voraussichtlich nicht wegen einer einzigen öffentlichen Leistung ihren Wohnort wechseln würden. 59

Geringere Mobilität in größeren räumlichen Dimensionen vermag nach Ansicht von Dowding, John und Biggs ${ }^{60}$ auch zu erklären, weshalb Forbes und Zampelli (1989) die Leviathan-These als widerlegt betrachten. In ihrer Studie untersuchen sie die Effekte der Konkurrenz zwischen counties als den größten lokalen Einheiten in den USA. Die Ergebnisse von Forbes und Zampelli stehen deshalb nicht zwingend im Widerspruch zur Dezentralisierungshypothese, sie bestätigen aber zumindest, daß der Wettbewerbsdruck in räumlich ausgedehnten Gebieten geringere Wirksamkeit hat: "Local government jurisdictions compete in a spatially constrained market." 61

Zusammenfassend betrachtet kann die Dezentralisierungshypothese weder als bestätigt noch als widerlegt angesehen werden. Es fällt allerdings aus mehreren Gründen schwer, hieraus irgendwelche normativen Schlußfolgerungen zu ziehen. ${ }^{62}$ Denn neben dem grundsätzlichen Meßproblem der Effizienz im staatlichen Sektor muß bei der Interpretation der Resultate bedacht werden,

- daß das Leviathan-Modell von Brennan und Buchanan als denkbar schlechtester Fall konstruiert wurde, ohne daß die Autoren dafür unmittelbar empirischen Gehalt reklamieren 63 ,

- daß die "Einmischung des Staates" auch durch nicht unmittelbar einnahmen- oder ausgabenwirksame Regulierungsmaßnahmen erfolgen kann und

- daß der postulierte Zusammenhang nicht festgestellt werden kann, wenn die LeviathanThese oder die Aussagen über die Wirkungen einer Dezentralisierung falsch sind.

Indessen unterliegt auch die Dezentralisierungshypothese ähnlicher Kritik wie das TieboutModell. Im folgenden sind deshalb die Wirkungen von Mobilitätshemmnissen und räumlichen spillover-Effekten zu überprüfen.

58 Siehe Nelson, M. (1987).

59 Vgl. Boyne, G.A. (1992), S. 346.

60 Vgl. Dowding, K./John, P./Biggs, S. (1994), S. 770f. Ebenso Oates, W.E. (1989), S. 580.

61 Dowding, K./John, P./Biggs, S. (1994), S. 772. Vgl. auch Heil, J.B. (1991), S. 335.

62 Ebenso Oates, W.E. (1990), S. 52: "The Brennan-Buchanan proposition on decentralization and publicsector size must, I think, be regarded as an intriguing conjecture. But one for which there is not, at this point at least, compelling evidence."

63 Vgl. Brennan, G./Buchanan, J.M. (1980/1988), S. 37f. 


\section{Immobile Faktoren und Abwanderungsoptionen}

\section{a. Die Ausbeutung immobiler Faktoren durch den Leviathan}

Die Überlegungen von Brennan und Buchanan müssen modifiziert werden, wenn man berücksichtigt, daß sich nicht alle Individuen und Produktionsfaktoren der Besteuerungsgewalt des Leviathan durch Abwanderung entziehen können. Insbesondere das Bodenangebot in den lokalen Jurisdiktionen ist in der Regel zumindest auf mittlere Sicht fix. ${ }^{64}$ Die Erträge des immobilen Faktors Land - genutzt als Produktionsfaktor oder als Konsumgut - könnten damit ohne weitergehende fiskalische Restriktionen dem Zugriff der staatlichen Besteuerungsgewalt ungeschützt ausgeliefert sein. 65

Aus Sicht des subzentralen Leviathan verbessert die Immobilităt einiger Mitglieder der Jurisdiktion die Möglichkeiten einer Abschöpfung von Steuerzahlerrenten. Dies wird deutlich, wenn man unterstellt, daß die Eigentümer von Boden und die Anbieter von hier als räumlich mobil modellierter Arbeit zwei verschiedene Personengruppen sind. Die lokalen LeviathanRegierungen werden dann versuchen, die Renten des immobilen Faktors Boden durch Besteuerung vollkommen abzuschöpfen, ohne überhaupt Kollektivgüter anzubieten. Zwar könnten die staatlichen Agenten durch die Bereitstellung lokaler öffentlicher Konsumgüter zusätzlich mobile Haushalte attrahieren; da aber aufgrund der interkollektiven Mobilität des Faktors Arbeit die Erzielung zusätzlicher Steuererträge aus der Besteuerung von Arbeit nicht möglich ist, unterbliebe jegliches Kollektivgutangebot.

Dieser Aspekt interjurisdiktioneller Konkurrenz wird in einem theoretischen Ansatz von Epple und Zelenitz beleuchtet. ${ }^{66}$ Die Autoren modellieren subzentrale Regierungen im Wettbewerb um mobile Haushalte, die gleichzeitig Konsumenten quasi-privater Kollektivgüter G sind und Wohnraum in den einzelnen Jurisdiktionen nachfragen. Für das Wohnraumangebot wird angenommen, daß es vom erzielbaren Nettopreis des Wohnraums bestimmt wird. Die Regierungen verfolgen das Ziel, über die Wahl des öffentlichen Ausgabenniveaus G und des Steuersatzes $\tau$ einer lokalen property tax auf den Wert der Wohnungen den Überschuß $\mathrm{Z}$ aus der Regierungstätigkeit zu maximieren. Das Modell von Epple und Zelenitz baut auf der Annahme auf, daß sowohl Steuersatzvariationen als auch Änderungen der Ausgabenniveaus von $\mathrm{G}$ in den Wohnraumpreisen kapitalisiert werden. 67

64 Infolgedessen findet auch nur beschrankter interjurisdiktioneller Wettbewerb um Boden statt. Allerdings können Neugliederungen von Verwaltungsbezirken durchaus Ausduck von Konkurrenz lokaler Einheiten um den knappen Faktor Land sein. Martin, D.T./Wagner, R.E. (1978); Mehay, S.L. (1981); Deno, K.T./ Mehay, S.L. (1985) und Gonzalez, R.A./Mehay, S.L. (1987) untersuchen dabei insbesondere die Rolle der local boundary commissions in den USA.

65 Aber auch fur die Bezieher von Arbeitseinkommen konnte festgestellt werden, daß sie vor allem wegen psychologischer Mobilitătsbarrieren voraussichtlich nur in wesentlich geringerem Maße als der Faktor Kapital interjurisdiktionell wandern kőnnen. Zwar wird auch argumentiert, selbst der Faktor Boden sei nicht immobil, denn die Bodeneigentumer konnten ihre Immobilien verkaufen und anschließend abwandern. Allerdings wird dabei ubersehen, daß dies immer noch impliziert, daß die ursprunglichen Eigentumer einen Kaufer finden mußten, was angesichts der Ausbeutung durch den lokalen Leviathan problematisch sein durfte. Vgl. dazu auch Oakerson, R.J./Parks, R.B. (1988), S. 93f.

66 Siehe Epple, D./Zelenitz, A. (1981).

67 Siehe Epple, D./Zelenitz, A. (1981), S. 1212. 
Epple und Zelenitz demonstrieren, daß sich die Regierungen unter diesen Bedingungen selbst bei unendlich großer Zahl konkurrierender Gemeinwesen und perfekter răumlicher Mobilität der Haushalte fiskalische Überschüsse aneignen können. 68 Verantwortlich dafür ist die Tatsache, daß zwar die Wohnraumnachfrage aus Sicht der einzelnen Jurisdiktion in diesem Falle unendlich elastisch ist, das Wohnungsangebot hingegen nicht. "With perfectly elastic housing demand, the price of housing is exogenous, but bureaucratic monopolists can still profit by sharing in the rents of the landowners whose land is confined to some given jurisdiction." 69 Einzig für den wenig wahrscheinlichen Spezialfall eines vollkommen preiselastischen Wohnraumangebotes könne deshalb eine Ausbeutung verhindert werden. Epple und Zelenitz kommen folglich zum Schluß:

"A government given taxing powers in a jurisdiction with fixed boundaries can exploit the immobility of land and share in the rents accruing to that land. Mobility of residents across a large number of jurisdictions can prevent individual governments from exploiting the elasticity of housing demand but not the elasticity of housing supply ... Tiebout does need politics." ${ }^{10}$

Die Autoren verweisen darauf, daß daraus nicht unmittelbar der Schluß gezogen werden könne, die Besteuerung führe zu einer einfachen Umverteilung zwischen Bodeneigentümern und der lokalen Leviathan-Regierung. Sofern das Wohnraumangebot nicht vollkommen unelastisch ist, reduziert die Steuer den erzielbaren Nettopreis des Wohnraums und damit auch dessen Angebot. Damit steigt aufgrund der relativen Wohnraumverknappung der Bruttopreis des Wohnens, und die Nutzer des Wohnraums werden teilweise belastet. ${ }^{71}$

Zusammenfassend betrachtet kann festgehalten werden, daß unter den Modellannahmen von Epple und Zelenitz immobile Faktoren immer von einer Ausbeutung durch den Staat bedroht sind. Dies gilt stets für den Faktor Boden und aufgrund der Annahme großräumiger Immobilität bei zunehmender Jurisdiktionsgröße auch für den Faktor Arbeit. Der Schutz immobiler Faktoren kann nach Auffassung von Epple und Zelenitz regelmäßig nur über den politischen Prozeß erfolgen. ${ }^{72}$

\section{b. Schutz immobiler Faktoren durch Standortwettbewerb?}

Gleichwohl könnte ein Schutz immobiler Faktoren vor Ausbeutung durch den Leviathan-Staat bereits durch die Mobilität anderer Faktoren zu erreichen sein. ${ }^{73}$ Ausgangspunkt dieser These ist die Betrachtung des Standortwettbewerbs als Wettbewerb immobiler Faktoren um mobile Produktionsfaktoren, wie sie von Giersch, Siebert und anderen vertreten wird. ${ }^{74} \mathrm{Im}$ Kern lăuft die Argumentation auf die im dritten Kapitel erörterte Kapitalisierungsthese hinaus.

68 Siehe Epple, D./Zelenitz, A. (1981), S.1206. Vgl. auch Hoyt, W.H. (1990), S. 484ff.

69 Epple, D./Zelenitz, A. (1981), S.1206.

70 Epple, D./Zelenitz, A. (1981), S. 1216 (Hervorhebungen H.P.). Ähnlich Bélanger, G. (1987), S. 140, der zwar von der "inherent weakness of the power of local government" spricht, aber gleichermaßen betont: "This does not mean that there is a total absence of discretionary power at the level of local government."

71 Vgl. Epple, D./Zelenitz, A. (1981), S. 1207.

72 Ähnlich Musgrave, P.B. (1990), S. 293f. und Musgrave, P.B./Musgrave, R.A. (1990), S. $77 \mathrm{f}$.

73 Vgl. etwa Migué. J.L. (1993), S. 33ff.

74 Siehe Giersch, H. (1989), insbes. S. 2; Siebert, H./Koop, M.J. (1990) und (1993); Long, N.V./Siebert, H. (1991); Siebert, H. (1991), Kap. 2. 
Nach dem Henry George-Theorem ist die Bereitstellung lokaler öffentlicher Konsumgüter durch eine vollständige steuerliche Abschöpfung der Bodenrenten zu finanzieren. Das Entstehen dieser Renten ist auf die in den immobilen Werten kapitalisierten Vorteile des gemeinschaftlichen Konsums der angebotenen Kollektivgüter zurückzuführen. Umgekehrt liegt der Schluß nahe, daß ohne Kollektivgutbereitstellung keine locational co-operation rents existieren, die vom Leviathan ausgebeutet werden könnten.

So erhöht z.B. eine Bereitstellung produktiver Vorleistungen H sowohl die Grenzproduktivität des mobilen Kapitals als auch die der immobilen Faktoren. Wandert dagegen Kapital ab, weil das lokale Infrastrukturangebot im Vergleich zu anderen Jurisdiktionen minderwertig ist, sinken die allein besteuerbaren immobilen Einkommen. Abbildung 5.3 illustriert diese Ausführungen. Werden durch eine Ausweitung der öffentlichen Vorleistungen $\mathrm{H}$ die Standortbedingungen in einer Jurisdiktion verbessert, verschiebt sich die MPK-Kurve, welche die marginale Kapitalproduktivität beschreibt, nach außen. Kapital fließt zu, und die Faktoreinkommen steigen an. Von dem Anstieg der Faktorentgelte entfällt bei unveränderter Kapitalverzinsung $r$ die Fläche $k_{1} k_{2}$ ba auf die Eigentümer von Kapital, dagegen die Fläche cabd auf die Eigner immobiler Faktoren. Die Besteuerungsbasis wird entsprechend um diesen Betrag vergrößert. Folglich müßte es das Ziel subzentraler staatlicher Agenten sein, mobile Ressourcen im Standortwettbewerb anzulocken. Die zusätzlich entstandenen Renten der immobilen Faktoren werden zwar durch den staatlichen Leviathan abgeschöpft, müssen jedoch zur Finanzierung der lokalen Infrastrukturinvestitionen eingesetzt werden. Die vermeintliche Ausbeutung immobiler Faktoren ist Ausdruck einer Äquivalenzbesteuerung, und die Erzielung fiskalischer Überschüsse ist nicht möglich. ${ }^{75}$

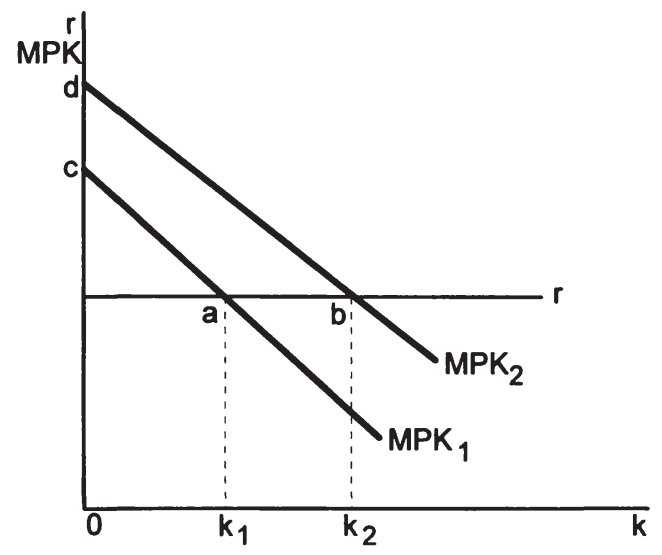

Abbildung 5.3: Öffentliche Vorleistungen und Besteuerungsbasis

Quelle: eigene Darstellung

75 Es erscheint zwar theoretisch sinnvoll anzunehmen, die Renten immobiler Faktoren wie Boden oder z.T. auch Arbeit entstunden nur durch die Attrahierung produktiver Faktoren. Als plausiblere Annahme kann man davon ausgehen, daß der Einsatz von Boden nicht nur auf einen Verwendungszweck beschränkt ist, so daß bereits innerhalb lokaler Einheiten begrenzte Substitutionsmőglichkeiten fur die Faktoreigner bestehen. 
Darüber hinaus, so die Argumentation von Siebert, orientieren sich insbesondere die interregional mobilen Unternehmen nicht nur an den ihnen direkt zufließenden Infrastrukturvorleistungen. ${ }^{76}$ Wie bereits oben angedeutet ${ }^{77}$, profitiert mobiles Kapital auch von öffentlich bereitgestellten Konsumgütern, deren Nutzen primär den immobilen Produktionsfaktoren hier insbesondere Arbeit - zufließen. Ein Unternehmen wird sich daher prinzipiell eher dort niederlassen, wo z.B. der Ausbildungsstand der Bürger oder das lokale Angebot kultureller Infrastruktur angemessen ist. So betrachtet wären lokale Leviathan-Regierungen gezwungen, auch konsumtive Kollektivgüter bereitzustellen - eine Schutzwirkung für die immobilen Faktoreigner würde erreicht.

In analoger Weise könnte argumentiert werden, daß eine nicht-äquivalente steuerliche Belastung der räumlich immobilen Faktoren zu einer Verteuerung des Faktorangebots führen würde, die letztlich nur die Abwanderung von Kapital zur Folge hätte. Dies setzt jedoch voraus, daß die räumlich immobilen Faktoren zumindest kollektivintern Substitutionsalternativen haben, so daß sie Teile ihrer Belastung überwälzen können. ${ }^{78}$ Migué resümiert daher, $\mathrm{da} B$ "... the assumption of full population mobility is therefore unduly restrictive for the reasonable operation of the competitive process between ... governments within common markets."79

Kritisch ist zu dieser Argumentation anzumerken, daß - wie Siebert und Koop einräumen - der postulierte "link between the user and the payer may be weak from the firm's point of view." 80 Je schwächer jedoch der Zusammenhang von bereitgestellter konsumtiver Leistung und Kapitalproduktivität ist, um so geringer ist die damit erzielte Schutzwirkung. Außerdem setzt der Schutz der immobilen Faktoren voraus, daß die Vorteile der Ansiedlung interregional mobiler Faktoren in den immobilen Werten kapitalisiert werden. Folglich erscheint die erzielbare Schutzwirkung in erster Linie in längerfristiger Sicht erreichbar. Zwar könnte der Leviathan mit unendlichem Zeithorizont begrenzt werden, es ist aber dennoch fraglich, ob diese Perspektive auch für die in der Realität systembedingt kurzfristiger planenden staatlichen Agenten gelten kann. Darauf wird noch in Abschnitt C dieses Kapitels zurückzukommen sein.

\section{Interjurisdiktioneller Wettbewerb und räumliche spillover-Effekte}

Damit ist auch aus der Sicht der Leviathan-Theorie noch zu klären, wie die Zuordnung der Bereitstellungskompetenzen über Kollektivgüter mit nationaler Nutzenreichweite ohne

76 Siehe etwa Siebert, H./Koop, M.J. (1990), S. 448f. oder Siebert, H. (1991), S. $21 \mathrm{ff}$.

77 Vgl. S. 128.

78 Ein weiteres Argument konnte uber das Faktorpreisausgleichstheorem abgeleitet werden. Siehe Heckscher, E. (1919); Ohlin, B. (1933) und Samuelson, P.A. (1948) und (1949). Deren Überlegungen zufolge fuhrt ungehinderter zwischenstaatlicher Guterhandel zur Identitat der Faktorpreisrelationen in allen Jurisdiktionen und entfaltet damit dieselben Wirkungen wie eine perfekte raumliche Mobilităt der Faktoren. Aus dieser Sicht könnte Guterhandel Faktorwanderungen vollständig substituieren. Gesetzt den Fall, daß răumlich immobile Faktoren partielle Substitutionsmoglichkeiten innerhalb der lokalen Jurisdiktionen haben, können die subzentralen Regierungen die Brutto-Einkommen auch răumlich immobiler Faktoren nicht beeinflussen, da die Brutto-Faktorpreise vollständig außerhalb der Gebietskorperschaften determiniert werden. Vgl. Migué, J.L. (1993), S. 34. Freilich ist die Gultigkeit des Faktorpreisausgleichstheorems an außerst restriktive Prämissen geknupft. Siehe hierzu etwa Markusen, J.R./Melvin, J.R. (1988), S. $115 \mathrm{ff}$.

79 Migué, J.L. (1993), S. 37.

80 Siebert, H./Koop, M.J. (1990), S. 449. 
Ausschlußmöglichkeit erfolgen soll. Brennan und Buchanan argumentieren, daß zwar bei einer Zuweisung an die zentrale Einheit, den Nationalstaat, răumliche externe Effekte internalisiert werden ${ }^{81}$, daß aber selbst mit der Einführung weiterer konstitutioneller Restriktionen kaum verhindert werden könne, daß sich der zentralstaatliche Leviathan einen gewissen Nettoüberschuß aneigne, der einen Effizienzverlust für die Staatsbürger darstellt. ${ }^{82}$ Erfolgt demgegenüber die Zuordnung der Bereitstellungsverantwortlichkeiten an lokale Jurisdiktionen, wird nach Olsons "Logik des kollektiven Handelns" das nationale öffentliche Gut nicht bereitgestellt, denn jeder Versuch einer subzentralen Gebietskörperschaft, von den Bürgern eine Finanzierungsbeteiligung zu erzwingen, hat deren sofortige Abwanderung zur Folge. In diesem Falle besteht keine Gefahr einer Ausbeutung durch den Staat, allerdings sind Effizienzverluste in Form entgangener Kooperationsgewinne infolge der Nicht-Bereitstellung des Kollektivgutes zu verzeichnen. 83

Dieser offenkundige Zielkonflikt ${ }^{84}$ wird modelltheoretisch von Bell untersucht. ${ }^{85}$ Zur Bestimmung der optimalen Zahl lokaler Jurisdiktionen legt Bell den Ansatz von Epple und Zelenitz zugrunde. ${ }^{86}$ Anstelle der dort getroffenen Annahme, die lokalen Regierungen würden quasi-private Güter bereitstellen, betrachtet Bell den Fall, daß die bereitzustellenden Güter echten Kollektivgutcharakter haben und daß sich deren Nutzenreichweite nicht nur auf die lokalen Einheiten beschränkt, sondern in unterschiedlichem Ausmaß auch den Bewohnern anderer Jurisdiktionen Nutzen stiftet. Die von einem Bewohner der Jurisdiktion i konsumierte Menge des Kollektivgutes $\mathrm{G}$ wird somit beschrieben durch ${ }^{87}$

$$
G_{i}=g_{i}+\alpha \sum_{j \neq i}^{m} g_{j} .
$$

$\mathrm{G}_{\mathrm{i}}$ setzt sich zusammen aus den von der Regierung $\mathrm{i}$ bereitgestellten Kollektivgutmenge $\mathrm{g}_{\mathrm{i}}$ und den Nutzenspillovers aus der Bereitstellung des Kollektivgutes in anderen Jurisdiktionen j. Der Faktor $\alpha(0 \leq \alpha<1)$ bezeichnet die Höhe der spillovereffekte. Für $\alpha=0$ liegen keine

81 Oder analog: Skalenerträge im Konsum der Kollektivguter realisiert werden.

82 Vgl. Brennan, G./Buchanan, J.M. (1980/1988), S. 223.

83 Vgl. Brennan, G./Buchanan, J.M. (1980/1988), S. 223f. und (1983b), S. 61. Anders hingegen, wenn zahlungsunwillige Burger vom Konsum ausgeschlossen werden konnten. Die theoretische Gleichgewichtslosung bei vollkommener Mobilităt fuhrt in diesem Modell zu einer "Konzentration aller Einwohner der ubergeordneten Gebietskörperschaften in nur einer der untergeordneten staatlichen Einheiten." Brennan, G./Buchanan, J.M. (1980/1988), S. 224. (Hervorhebung im Original). Wăhrend jedoch die Zuweisung der Bereitstellungskompetenzen auf die Zentralebene mit potentiellen Effizienzeinbußen einer finanzwirtschaftlichen Ausbeutung verbunden ist, wirkt die interjurisdiktionelle Mobilitat der Ressourcen als Begrenzung der subnationalen Leviathan-Regierungen, so daß hier ein Effizienzgewinn festzustellen ist.

84 "In choosing ... the number of jurisdictions into which to partition their economy, the citizens face a tradeoff. All else equal, a highly decentralized public sector will be preferred due to interjurisdictional competition's ability to constrain each governments's realization of monopoly profits. On the other hand, the greater the incentive each government will have to 'free ride' on the others and provide too little [public goods, H.P.]." Bell, C.R. (1989), S. $210 \mathrm{f}$.

85 Siehe Bell, C.R. (1989).

86 Vgl. Bell, C.R. (1989), S. 208.

87 Vgl. Bell, C.R. (1989), S. 209. 
räumlichen spillover-Effekte vor, für $\alpha=1$ erhält man den Fall eines reinen öffentlichen Gutes mit nationaler Nutzenreichweite.

Zum zweiten modifiziert Bell die Annahme von Epple und Zelenitz über die Art der lokalen Besteuerung. ${ }^{88}$ Er unterstellt, die Regierungen verfügen lediglich über eine Kopfsteuer auf interregional mobile Haushalte $\mathrm{n}$ mit dem von ihnen $\mathrm{zu}$ wăhlenden Satz $\tau_{\mathrm{i}}^{\mathrm{n}}$. Die diskretionären Überschüsse der um mobile Haushalte konkurrierenden lokalen Leviathan-Regierungen sind damit abhängig von ihrer eigenen Steuer- und Ausgabenpolitik und von der Politik der anderen Jurisdiktionen. ${ }^{89}$ Bei der Ableitung einer aus dieser Perspektive optimalen Zahl von Jurisdiktionen (bzw. des optimalen Zentralisierungsgrades) stehen die Individuen auf konstitutioneller Ebene vor folgendem Problem: Mit steigender Zahl konkurrierender Gebietskörperschaften

- verringern sich wegen des Abwanderungsdrucks der mobilen Haushalte die erzielbaren Überschüsse der Leviathan-Regierungen, d.h., es werden tendenziell von jeder Einheit weniger Steuern erhoben und mehr Ausgaben für die Bereitstellung von Kollektivgütern getătigt,

- entstehen soziale Wohlfahrtsverluste, weil räumliche spillover-Effekte nicht internalisiert werden. Mit wachsendem Öffentlichkeitsgrad $\alpha$ der bereitzustellenden Güter verstärkt sich dieser Effekt.

Auch bei vollkommen homogener Bevölkerungsstruktur im gesamten Staatsgebiet und einer nationalen Nutzenreichweite des bereitzustellenden Kollektivgutes würden die Individuen im konstitutionellen Konvent die Dezentralisierung einer unitarischen Lösung vorziehen. 90 Der Grund dafür ist einleuchtend: Überträgt man die Verantwortlichkeiten auf nur ein Kollektiv im Staat, entfällt für die Regierung dieses Gebildes der Abwanderungsdruck. Selbst wenn alle spillover-Effekte internalisiert werden könnten, würde das betreffende Kollektivgut in suboptimaler Menge, unter den genannten Modellannahmen sogar überhaupt nicht, angeboten. Die Überschüsse des Leviathan sind maximiert, wenn die Steuereinnahmen maximal sind; Ausgaben für Kollektivgüter muß die Regierung auf Zentralebene nicht leisten, wenn sie nicht im politischen Prozeß oder durch weitergehende fiskalische Restriktionen dazu gezwungen wird.

Wie im dritten Kapitel gezeigt, stehen den positiven spillover-Effekten bei der Bereitstellung öffentlicher Leistungen als logischer Gegenpol die negativen spillovers durch den Export von steuerlichen Belastungen auf Gebietsfremde gegenüber. Die Wohlfahrtstheorie sah im Steuerexport die Gefahr einer supraoptimalen Kollektivgutbereitstellung auf lokaler Ebene. Zu klären bleibt, wie die Beurteilung aus der Leviathan-Perspektive des Staates zu erfolgen hat. Ausgangspunkt der Betrachtungen ist die Annahme răumlich immobiler Faktoren; ein Steuerexport kann folglich nur über den Güterhandel erfolgen. ${ }^{91}$ In diesem Falle verfolgen subzentrale Regierungen, egal ob wohlwollend oder ausbeuterisch, bei ihrer Steuerpolitik identische Ziele. Beide werden versuchen, Steuerlasten zu exportieren, jedoch mit dem Unterschied, daß die erzielten Aufkommen unterschiedlichen Verwendungszwecken zukommen würden.

88 Vgl. Bell, C.R. (1989), S. 208.

89 Vgl. Bell, C.R. (1989), S. 210.

90 Siehe Bell, C.R. (1989), S. 218.

91 Siehe zum folgenden Brennan, G./Buchanan, J.M. (1980/1988), S. 213ff. 
Während im Fall der benevolenten Regierung die Mehreinnahmen zur Finanzierung des Kollektivgutangebotes für die Jurisdiktionsmitglieder eingesetzt werden, resultieren im Leviathan-Fall höhere diskretionäre Überschüsse der staatlichen Agenten, "... das Individuum wird im Endeffekt mit seinen Mitbürgern die Kosten der öffentlichen Güter und Leistungen zahlen, die von den Bürgern anderer Staaten konsumiert werden, und zusätzlich den Überschuß der nach Art des Leviathan in diesen Staaten Herrschenden finanzieren." 92

Dabei gibt es, so Brennan und Buchanan, aus diesem Dilemma keinen Ausweg. Sie kommen deshalb zu diesem Schluß, weil in ihrem Ansatz nur der Fall internationaler Zusammenhänge betrachtet wird. ${ }^{93}$ Einerseits kann im hier betrachteten nationalstaatlichen Zusammenhang durch die Zuordnung steuerlicher Bemessungsgrundlagen mit begrenzter lokaler Radizierbarkeit auf konstitutioneller Ebene das Problem des Steuerexports zumindest verringert werden. Andererseits ist mit dieser Zuordnung von Besteuerungskompetenzen der Nachteil verbunden, daß in erster Linie räumlich immobile Güter und Faktoren getroffen werden. Auch hier wäre also abzuwägen, ob die entstandenen Nachteile der Ausbeutung immobiler Mitglieder von den möglichen Vorteilen des verringerten Exports von Steuerlasten auf Gebietsfremde kompensiert werden.

\section{Die Beschränkung der Abwanderungsoptionen durch den Leviathan}

\section{Die Beschränkung der Abwanderungsoptionen als Ziel subzentraler Leviathan- Regierungen}

In ihren Ausführungen betonen Brennan und Buchanan die Parallele zwischen dem wettbewerblichen Modell der privaten Märkte und dem von ihnen vertretenen Föderalismusansatz. ${ }^{94}$ Bislang wurde stets implizit von der Annahme ausgegangen, daß die im Wettbewerb um mobile Faktoren stehenden Regierungseinheiten sich wie Unternehmer auf vollkommenen Konkurrenzmärkten verhalten, die alle Marktdaten - darunter v.a. die Zahl und das Verhalten der konkurrierenden Einheiten sowie die Mobilität bzw. Immobilität der Faktoren - als gegeben ansehen und ihre Bereitstellungsentscheidungen überschußmaximierend anpassen. Der Konkurrenzdruck zwingt in diesem Modell die lokalen Regierungen zu Maßnahmen, die die Attraktivität des Standortes steigern, angebotene öffentliche Leistungen ständig auf ihre Effizienz zu prüfen und die Steuerbelastung der mobilen Faktoren zu reduzieren. Aus dieser Notwendigkeit heraus verringern sich die für die lokalen Regierungen erzielbaren diskretionären Überschüsse.

Allein, genausowenig, wie das Streben nach besseren Leistungen das Verhalten privater Anbieter auf privaten Konkurrenzmärkten vollständig beschreiben kann, gilt dies für den

92 Brennan, G./Buchanan, J.M. (1980/1988), S. 216. Interessanterweise bietet hier aber auch die zunehmende Zentralisierung von Kompetenzen keinen sinnvollen Losungsansatz, sofern die Pramisse eines durch andere finanzwirtschaftliche Mittel nicht begrenzbaren Leviathans aufrechterhalten wird. Eine Internalisierung der negativen spillover-Effekte von Steuerexport kann nur in einem System erfolgen, in dem die staatlichen Agenten durch die Burger auch durch demokratische Mechanismen kontrolliert werden. Siehe etwa Rose-Ackerman, S. (1981), S. 153.

93 "Es wăre fur alle besser, wenn jeder Staat der Beschränkung unterworfen wăre, daß kein Steuerexport zulässig ist. Aber das Individuum befindet sich auch gedanklich nicht in der Position, uber 'die Steuerverfassung furr die Welt' zu entscheiden." Brennan, G./Buchanan, J.M. (1980/1988), S. $215 f$. Vgl. Brennan, G./Buchanan, J.M. (1980/1988), S. 234. 
beschriebenen idealtypischen "Standortwettbewerb"95 lokaler Gebietskörperschaften. Hier wie dort bietet (bei Nicht-Existenz von Widerspruch) die Abwanderungsoption für die Nachfrager die einzige Möglichkeit, ein Fehlverhalten der Anbieter wirkungsvoll zu sanktionieren und einer Ausbeutung zu entgehen. Und hier wie dort werden die Anbieter nach Wegen suchen, den Zwängen intensiven Wettbewerbs zu entgehen.

Nach Hirschman sind die Erfolgsaussichten der Funktionsweise Abwanderung durch die Zahl der verfügbaren Abwanderungsalternativen und die Kosten der Abwanderung bestimmt, mithin also vom externen Konkurrenzdruck, der auf die Betreiber der Organisation ausgeht. 96 Brennan und Buchanan folgern, daß überschußmaximierende lokale Leviathan-Regierungen versuchen werden, exit-Optionen zu beseitigen. ${ }^{97}$ Es dürfte "... von seiten der in Konkurrenz stehenden Körperschaften der unteren Ebenen ständiger Druck auf institutionelle Neuordnungen zur Verminderung des Wettbewerbsdrucks" 98 bestehen.

Als Ansatzpunkte können die beiden Bestimmungsfaktoren der Abwanderungsoption dienen. Danach wird der Migrationsdruck für die subzentralen staatlichen Agenten gemildert, wenn es den Leviathan-Regierungen gelingt, die Mobilitätskosten der abwanderungswilligen Individuen zu steigern oder die verfügbaren Substitutionsalternativen zu verringern. In beiden Fällen werden Monopolstellungen verstärkt, womit sich die Möglichkeiten einer Ausbeutung der Steuerzahler verbessern.

\section{Praktiken zur Steigerung von Abwanderungskosten}

\section{a. Emigrationssteuern als Austrittsgebühren}

Die offenkundigste Politikvariante zur Erhöhung der Abwanderungskosten ist die Besteuerung und/oder anderweitige finanzielle Belastungen der Migration, die bis zu einer Konfiskation des Vermögens des Migranten reichen können.99 Mit Hilfe solcher politischer Mobilitätskosten 100 wird ein Verbleib in der Jurisdiktion erzwungen, denn, wie Hirschman ausführt:

"Wenn eine Organisation die Möglichkeit hat, für die Abwanderung einen hohen Preis zu verlangen, gewinnt sie damit ein starkes Abwehrmittel gegen eine der schäfsten Waffen der Mitglieder, nămlich die Abwanderungsdrohung." 101

95 Giersch, H. (1989), S. 2.

96 Vgl. Hirschman, A.O. (1970/1974), S. $20 \mathrm{f}$.

97 Vgl. Brennan, G./Buchanan, J.M. (1980/1988), S. 229ff. und S. 234. Ähnlich McKenzie, R.B./Staaf, R.J. (1978); Lee, D.R. (1985); Kenyon, D.A./Kincaid, J. (1991), S. 9; Buchanan, J.M./Lee, D.R. (1995); Kerber, W./Vanberg, V. (1995), S. 56f.

98 Brennan, G./Buchanan, J.M. (1980/1988), S. 229.

99 Vgl. Tietzel, M. (1995), S. 132, der zu den Mobilitătsschranken auch rechtliche Maßnahmen zăhlt, wie die Voraussetzung gültiger Reisepapiere o.ă., die allerdings vorwiegend im internationalen Zusammenhang von Bedeutung sein durften.

100 Unter 'politischen Mobilitătskosten' seien die Kosten der Abwanderung verstanden, die eine Regierung den potentiellen Migranten auferlegt, um die Abwanderung zu erschweren. Ähnlich Tietzel, M./Weber, $M$. (1993), S. 294f.

101 Hirschman, A.O. (1970/1974), S. 82. 
Dennoch finden sich in der einschlägigen wohlfahrtstheoretischen Literatur Vorschläge zur Internalisierung der negativen fiskalischen Externalitäten einer Abwanderung für die verbleibenden Jurisdiktionsmitglieder. Prominentes Beispiel ist der Vorschlag von Bhagwati, Emigrationssteuern zur Verringerung des Brain Drain, d.h. der Abwanderung gut ausgebildeter Fachkräfte, einzuführen. ${ }^{102}$ Auch andere Steuern können de facto als politisch gewollte Mobilitätshemmnisse funktionieren. So verweisen Martin und McKenzie darauf, daß die Besteuerung von Verkaufserlösen bei der Veräußerung von Immobilien als Instrument subzentraler Leviathan-Regierungen zur Erhöhung der Migrationskosten interpretiert werden könne. 103

\section{b. Stärkung der lokalen Identität}

Durch die Verstärkung der emotionalen Bindung der Bürger an die Gebietskörperschaft kann eine Loyalitätsbeziehung der Bürger zu ihrer Heimatjurisdiktion im Sinne von Hirschman erzeugt werden. Damit wird eine lokale "uniqueness" 104 geschaffen, die indirekt die Kosten des Austritts erhöht. Man könnte diese Politikvariante deshalb auch als bewußte Erzeugung von Lokalpatriotismus oder Nationalismus, je nach betrachteter interjurisdiktioneller Beziehung, bezeichnen.

Wie Breton betont, sind subzentrale Einheiten, die sich in erster Linie durch ihre sprachliche, kulturelle oder ethnische Identität definieren, einem kompetitiven Druck weit weniger ausgesetzt. ${ }^{105}$ Aus dieser Perspektive sind Präferenzunterschiede der gesellschaftlichen Subgruppen nicht Vorbedingung föderativer Strukturen, wie es das Dezentralisierungstheorem voraussetzt, sondern, gerade umgekehrt, deren Ergebnis. ${ }^{106}$ Freilich wird damit nicht nur der exit-Druck gemildert, in gleichem Maße sinkt auch die Zuwanderungswahrscheinlichkeit mobiler Individuen aus anderen Gliedstaaten.

\section{c. Immigrationssteuern als versunkene Kosten?}

Eine dritte Politikvariante zur Erzeugung von Loyalität wird von Hirschman in hohen Aufnahmegebühren in die Organisation gesehen. ${ }^{107}$ Aufnahmegebühren sind versunkene Kosten, die in der Regel beim Austritt aus der Organisation nicht wieder rückerstattet werden und deshalb die Abwanderung verteuern. Von einer echten Abwanderungsbarriere kann jedoch allenfalls dann gesprochen werden, wenn die Eintrittsgebühren nicht den durch die Mitgliedschaft verursachten Ballungskosten entsprechen. Zu prüfen ist daher, ob subzentrale Leviathan-Regierungen den Anreiz haben, überhöhte Eintrittsgebühren (Immigrationssteuern) festzulegen, und unter welchen Bedingungen sie diese durchsetzen können.

Bei der Analyse im dritten Kapitel wurde festgestellt, daß die Regierungen lokaler Einheiten zur Maximierung der Renten immobiler Faktoren, bzw. der Renten der bereits ansässigen

102 Vgl. Bhagwati, J.N./Partington, M. (1976). Siehe auch Welter, P. (1995), S. 132 und Tietzel, M. (1995), S. 125.

103 Vgl. Martin, D.T./Mc Kenzie, R.B. (1975), S. 98.

104 Grewal, B.S. (1988), S. 171.

$105 \mathrm{Vgl}$. Breton, A. (1987), S. 294ff.

106 Ähnlich Scott, A. (1987), S. 234.

107 Vgl. Hirschman, A.O. (1970/1974), S. 79. 
Einwohner, auf das Instrument der Ballungssteuer zurückgreifen werden. Potentielle Jurisdiktionsmitglieder müßten nach diesem Konzept in Höhe der von ihnen bei einer Zuwanderung verursachten negativen Externalitäten belastet werden, um effiziente Gemeindegrössen zu realisieren. 108

Aus Sicht der Leviathan-Theorie sind Immigrationssteuern allerdings ein zweischneidiges Schwert. 109 Einerseits ermöglichen sie eine Diskriminierung der zuwanderungswilligen Gebietsfremden und sind deshalb ein geeignetes Instrument zur steuerlichen Ausbeutung, solange die Zuwanderungswilligen noch höhere Nutzen in der Zieljurisdiktion erzielen können, als ihnen durch die Eintrittsgebühr entzogen wird. Andererseits würde ohne ein solches Instrument die ungehinderte Zuwanderung die Renten der Ortsansässigen aufzehren. Bei intensivem wettbewerblichem Druck könnte allerdings die Strategie, durch überhöhte Immigrationssteuern zusätzliche Renten abzuschöpfen, nicht durchgesetzt werden. Wettbewerb um mobile Faktoren erzwingt von den Leviathan-Regierungen die Festlegung der Eintrittsgebühren auf einem Niveau, das den Migrationsexternalităten entspricht. 110

Indessen wäre denkbar, daß konkurrierende Leviathan-Regierungen in einer gemeinschaftlichen Übereinkunft prohibitive Einwanderungsgebühren erheben, denn Emigration ist nur möglich, wenn auch Immigration erlaubt ist. ${ }^{111}$ Ein kollusives Verhalten der Regierungen könnte für sie zum Vorteil gereichen. Diesem Aspekt wird im folgenden Abschnitt nachgegangen.

\section{Interjurisdiktionelle Kooperation als Kollusion}

\section{a. Die Kollusionshypothese}

Aus Sicht der Leviathantheorie verfügen staatliche Anbieter von Kollektivgütern auf zentraler Ebene über eine uneingeschränkte Monopolposition. Dezentrale Strukturen brechen die Monopolstellungen auf und verringern die für die staatlichen Agenten erzielbaren Überschüsse aus dem Staatshandeln. Es erscheint deshalb folgerichtig, Überlegungen zu kollusiven Praktiken privater Anbieter ${ }^{112}$ zur Beschränkung des Wettbewerbs auf das Brennan/ Buchanan'sche Politikmodell zu übertragen. 113 Danach verfolgen die Regierungen der lokalen Einheiten das Ziel, durch interjurisdiktionelle Kooperation die angebotenen SteuerLeistungspakete zu vereinheitlichen und Auswahlmöglichkeiten der interjurisdiktionell mobilen Individuen zu beschränken, denn "... monopolization through elimination of exit options allows policymakers to provide policies that mobile taxpayers would tend to flee."114

108 Siehe dazu die Ausfuhrungen in Abschnitt C.II.3.b.c im dritten Kapitel, S. 104.

109 Siehe zu diesem Punkt ausfuhrlich Welter, P. (1995), S. 133ff.

110 Andererseits könnte man argumentieren, daß lokale Regierungen durch suboptimale Immigrationssteuern versuchen würden, zu viel mobile Faktoren zu attrahieren. Dies hătte jedoch zur Folge, daß die abschøpfbaren Renten der Ortsansässigen sinken würden, was zum einen die maximalen Steueraufkommen schmälern würde und zum anderen wieder zur Abwanderung der mobilen Faktoren fuhren würde.

111 Vgl. Tietzel, M. (1995), S. 119.

112 Zu Kollusion bei privatwirtschaftlicher Konkurrenz siehe etwa Jacquemin, A./Slade, M.E. (1989).

113 So etwa McLure, C.E. (1986), S. 346, Vaubel, R. (1986), insbes. S. 44ff. oder Benson, B.L. (1990).

114 Marlow, M.L. (1992), S. 86. 
Aus dem Blickwinkel der Leviathan-Theorie birgt Kooperation immer die Gefahr der Kollusion, einer Verhaltensabstimmung staatlicher Akteure zum Nachteil der Bürger. ${ }^{115}$

Die Vorteile der Kooperation für die Leviathan-Regierungen können durch Abbildung 5.4 veranschaulicht werden. Betrachtet sei eine kleine lokale Einheit i, die mit den übrigen (M-1) Einheiten des Bundesstaates im Wettbewerb um Mitglieder steht. Alle M Jurisdiktionen bieten ein quasi-privates Kollektivgut $G$ an und können zur Finanzierung der Bereitstellung von $\mathrm{G}$ die interregional mobilen Individuen steuerlich belasten. Unter den Bedingungen vollkommener interjurisdiktioneller Konkurrenz kann die lokale Leviathan-Regierung in i, wie auch alle anderen (M-1) identischen Einheiten, aus der Besteuerung der Individuen keine fiskalischen Überschüsse erzielen. Jede steuerliche Belastung, die nicht von einer entsprechenden Verbesserung des Leistungsangebots begleitet wird, führt zu einer Abwanderung der Bewohner in die anderen Jurisdiktionen. Die unter wettbewerblichen Bedingungen realisierte Steuerpreis-Output-Kombination ist $\left(\mathrm{p}^{*}, \mathrm{G}^{*}\right)$, bei der die Grenzkosten MC der Bereitstellung des Kollektivgutes $\mathrm{G}$ der Nachfrage $\mathrm{D}_{0}$ entsprechen.

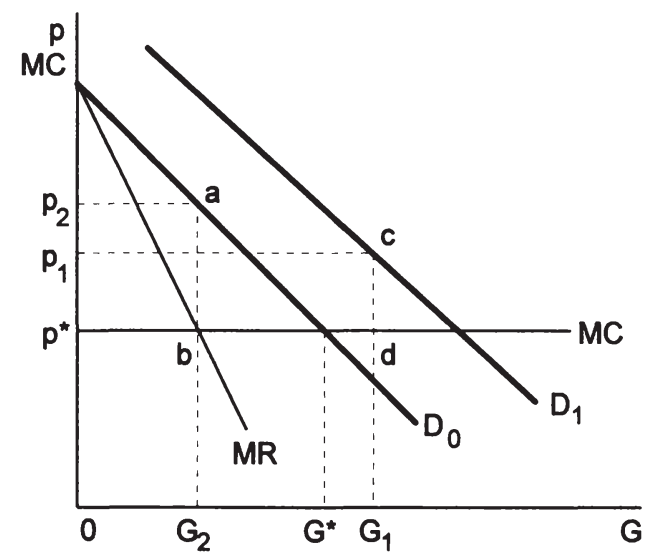

Abbildung 5.4: Steuerharmonisierung und Kollusionshypothese Quelle: eigene Darstellung

Gelingt es den M lokalen Einheiten, die Besteuerung der interregional mobilen Individuen zu harmonisieren, können sie sich auf den aufkommensmaximierenden Monopol-Steuerpreis $\mathbf{p}_{2}$ einigen und die Versorgung auf $\mathrm{G}_{2}$ in jeder Jurisdiktion beschränken. Jede der $M$ Regierungen in der Föderation erzielt fiskalische Überschüsse in Höhe von $\mathrm{p}^{*} \mathrm{p}_{2} \mathrm{ab}$. Die räumliche Allokation der mobilen Individuen bleibt von der einheitlichen Erhöhung der Steuersätze unberührt, daher verändert sich die lokale Nachfrage nach dem Kollektivgut G nicht. 116 Unter der Annahme überschußmaximierenden Verhaltens der staatlichen Agenten ist die Harmonisie-

115 "The 'proof' that co-operation in federations is beneficial has traditionally been based on sentimentalism and romanticism." Breton, A. (1987), S. 278.

116 Der Effekt der verringerten Auswahlmoglichkeiten auf die Elastizităt der Nachfrage nach $G$ wird hier vernachlässigt. 
rung der Besteuerung, analog zur Bildung von Preiskartellen am Markt, ein Instrument der fiskalischen Ausbeutung der Bürger.

Abbildung 5.4 illustriert auch die Probleme der Stabilität des Steuerkartells. Der von den Jurisdiktionen durchgesetzte überhöhte Kartellpreis $\mathrm{p}_{2}$ hat den Charakter eines reinen öffentlichen Gutes für die lokalen Regierungen. Jede einzelne Jurisdiktion kann sich durch eine Abweichung von der Kartellvereinbarung besser stellen, jedoch nur unter der Voraussetzung, daß sich die übrigen Anbieter des Kollektivgutes an die Abmachung halten. Senkt beispielsweise Jurisdiktion i den Steuerpreis für $\mathrm{G}$ auf $\mathrm{p}_{1}$, erfolgt eine Zuwanderung, welche die lokale Nachfrage auf $D_{1}$ vergrößert. Unter diesen Bedingungen kann in $i$ ein Überschuß von $p^{*} p_{1} c d$ erreicht werden, der den fiskalischen Überschuß bei Einhaltung der Kartellvereinbarung übertrifft. Reagieren die Mitglieder des Steuerkartells nicht, so erzielt die Regierung in i Extragewinne. Deshalb besteht für die Kartellmitglieder stets ein Anreiz, als free rider von der Vereinbarung abzuweichen. Die Stabilität des Steuerkartells ist damit gefährdet. ${ }^{117}$

Da alle lokalen Regierungen vor diesem Dilemma stehen, kommt eine Kooperation nur zustande, wenn für die Jurisdiktionen die Bedingungen einer freiwilligen Kooperation vorliegen, auf die bereits mehrfach und ausführlich in anderem Zusammenhang eingangen wurde. Die Stabilität des Steuerkartells ist durch die Höhe der mit der Organisation und Aufrechterhaltung der getroffenen Vereinbarungen verbundenen externen Koordinationskosten bestimmt. Freilich, so Pecquet, könnten Kartelle staatlicher Anbieter mit einem geringerem Transaktionskosteneinsatz stabilisiert werden als dies privaten Wettbewerbern möglich ist. Im einzelnen führt er hierfür folgende Argumente an: 118

- Die interjurisdiktionellen Kooperationsarrangements sind, im Gegensatz zu den Absprachen von Konkurrenten am Markt, nicht illegal.

- Da nicht ohne weiteres neue Wettbewerber (neue Gebietskörperschaften) gegründet werden können, besteht nur geringe potentielle Konkurrenz.

- Kartellmitglieder können Absprachen nicht durch "secret price reductions" 119 unterlaufen, da die angebotenen Steuer-Ausgabenbündel "public knowledge"120 sind.

- Die festgelegten Steuer-Ausgabenpakete der lokalen Einheiten sind für einen längeren Zeitraum gültig und unterliegen damit keinem permanenten Revisionsdruck.

Dennoch lassen sich die grundsätzlichen Aussagen über privatwirtschaftliche Kollusionen übertragen. ${ }^{121}$ Die Bildung und Aufrechterhaltung von Steuerkartellen lokaler Einheiten dürfte danach um so schwerer sein, je größer die Zahl der involvierten Gebietskörperschaften ist und je größer die Unterschiede der Jurisdiktionen, insbesondere in ihrer Ausstattung mit natürlichen Lagerenten, sind.

117 "Private sector cartels are extremely tenuous arrangements if they can be achieved at all. The same appears to hold true of public cartels." Benson, B.L. (1990), S. 78.

118 Siehe Pecquet, G.M. (1985), S. 278.

119 Pecquet, G.M. (1985), S. 278.

120 Pecquet, G.M. (1985), S. 278.

121 Siehe etwa Telser, L.G. (1988), S. 204ff. 
Den Verfechtern einer horizontalen Kooperation liegt offenkundig die Hypothese von den staatlichen Agenten als wohlmeinenden Akteuren zugrunde, die koordiniertes Verhalten der subzentralen Entscheidungsträger als Mittel zur besseren Verwirklichung gesellschaftlicher Ziele interpretieren. Aus der Perspektive der Public Choice-Theorie führt subnationale Kooperation dagegen zu einer Unterminierung des interkollektiven Wettbewerbs und damit zu einer Aushöhlung des kompetitiven Elements in föderativen Staaten. 122

Dem Kartellierungsargument, ursprünglich für den Bereich der subzentralen Steuerpolitiken entwickelt, wurde in den letzten Jahren v.a. von Vaubel in der Diskussion um die internationale Koordination der Konjunkturpolitiken verstärkt Aufmerksamkeit gewidmet. ${ }^{123}$ In Analogie zum Denkansatz von Brennan und Buchanan argumentiert Vaubel, internationale Zusammenarbeit im Bereich der Makropolitik verfolge vornehmlich die Ziele, die Verantwortung für unpopuläre Maßnahmen auf die von den Bürgern schlechter kontrollierbare Zentralebene zu verlagern und durch eine Angleichung der subzentralen Wirtschaftspolitiken die zwischenstaatliche Vergleichbarkeit der Ergebnisse zu erschweren, wenn nicht völlig auszuschalten. Damit wird in doppelter Hinsicht der auf den subzentralen Regierungen lastende Wettbewerbsdruck abgebaut. Erstens erfolgt durch die Einebnung der Unterschiede zwischen den lokalen Einheiten eine Einschränkung des Abwanderungsdrucks mobiler Faktoren, und zweitens verschwinden die Anhaltspunkte für die Bevölkerung, eine Bewertung der relativen Ergebnisse der Regierungstätigkeit im Rangordnungswettbewerb vorzunehmen. ${ }^{124}$ Letztlich verringert jede ex ante-Harmonisierung fiskalischer Aktionsparameter, also nicht nur der Einnahmenpolitik, sondern auch der Ausgabenpolitik, den Konkurrenzdruck für die lokalen Politiker und Bürokraten.

\section{b. Kollusion durch vertikale Verflechtung}

aa. Vertikale Finanzzuweisungssysteme

Die Lösung des Koordinationsproblems für die subzentralen Leviathan-Regierungen liegt auf der Hand. Wenn durch freiwillige Übereinkunft aufgrund des öffentlichen Gutscharakters die Einhaltung der Kartellvereinbarungen nicht garantiert ist, ermöglicht die Etablierung einer übergeordneten Sanktionsinstanz die Durchsetzung der Abmachungen. In Analogie zur Theorie des rent seeking, wo private Anbieter versuchen, als Nachfrager staatlicher Interventionen und Regulierungen Kartelle abzusichern und Marktzutrittsschranken für potentielle Konkurrenten zu errichten, könnten subzentrale Einheiten sich zur Durchsetzung eines Steuerkartells der Zentralregierung bedienen. Geeignetes Instrument könnten vertikale Finanztransfersysteme sein. 125

122 Vgl. Breton, A. (1987), S. 275. Ebenso drastisch urteilt Giersch uber Steuerharmonisierungsbestrebungen in der EU: "Naturlich wird aus solchen Grunden ein Kartell der Steuerstaaten angestrebt, in der EU unter dem werbenden Namen der Harmonisierung ... An Kartellbestrebungen fehlt es nicht. Niedrige Lohne in Lăndern mit niedriger Produktivităt werden in Hochlohnländern als 'Billiglohn-Konkurrenz' denunziert; die Sozialstandards der reichen Lănder sollen verallgemeinert werden, um das zu verhindern, was als 'Sozialdumping' abgewertet wird und was nicht mehr ist als der Versuch der armen Lănder, ihren Vorteil des reichlichen Angebots an einfacher Arbeit in die Waagschale zu werfen." Giersch, H. (1995), S. 42f.

123 Siehe etwa Vaubel, R. (1980), S. 21 ff. und (1985).

124 Vgl. Vaubel, R. (1985), S. 235.

125 Siehe McKenzie, R.B./Staaf, R.J. (1978), S. 94f.; Brennan, G./Buchanan, J.M. (1980/1988), S. 229ff., Lee, D.R. (1994), S. 78f.; Vaubel, R. (1994), S. 244 oder Buchanan, J.M./Lee, D.R. (1995), S. 223. 
Nach traditionell wohlfahrtstheoretischer Argumentation dienen Finanzzuweisungen 'von oben nach unten' der Internalisierung räumlicher spillover-Effekte, der Angleichung von Unterschieden fiskalischer Restwerte und der Schließung fiskalischer Aufkommenslücken, die vermeintlich entstehen, wenn subzentrale Einheiten zur Finanzierung ihrer Ausgabentätigkeit auf eine mobile Besteuerungsbasis zugreifen müssen. In der wohlfahrtsökonomischen Debatte über die Allokations- und Distributionswirkungen alternativer Finanztransfersysteme wird allerdings häufig der Aspekt vernachlässigt, daß die zentralstaatliche Ebene selbst zunächst ein entsprechendes Steueraufkommen realisieren muß, welches sie an die Empfängerjurisdiktionen transferieren kann. Da die Zentralregierung nicht mit der Abwanderung mobiler Faktoren zu rechnen braucht, ist ihre mögliche Besteuerungsbasis breiter, mit der Folge, daß auf der nationalen Ebene ein höheres Maximalaufkommen realisiert werden kann.

Der Vorteil einer Finanztransferlösung gegenüber der Zentralisierung wird darin gesehen, daß die subnationalen Einheiten zumindest hinsichtlich ihrer Ausgabenpolitik autonom und Informationsvorteile bei der Ausgestaltung ihrer Politiken daher vermeintlich bestehen blieben. Der Trugschluß, der hinter dieser Annahme steckt, wurde bereits im dritten Kapitel erörtert. Lokale Regierungen, deren Ziel die Wohlfahrtsmaximierung der Bürger ihrer Jurisdiktion ist, werden versuchen, durch Informationsverzerrung und überhöhte Angaben der lokalen Bedarfe Zuweisungen zu erlangen. Schon aus der Perspektive der Wohlfahrtstheorie mit unvollständiger Information ist damit die Nützlichkeit vertikaler Finanztransfersysteme in Frage gestellt. ${ }^{126}$

Die Leviathan-Theorie des Staates erweitert diese kritische Sichtweise um einen neuen Aspekt. Finanzzuweisungen der Zentralebene dienen nach Auffassung von Brennan und Buchanan nicht den vermeintlich wohlfahrtssteigernden Zielsetzungen, sondern der Verfestigung des Steuerkartells subnationaler Gliedstaaten. Der Zentralstaat ist nach dieser alternativen Theorie gewissermaßen die "Überwachungsinstanz eines Kartells zwischen den unteren Ebenen des Staates"127; "... just as a successful private-sector cartel, established and policed through regulation, raises revenue through a centralized pricing policy, federal centralized tax collection and subsequent distribution to the states tend to raise total tax revenues and state government expenditures." 128

Die Funktionsweise der Finanzzuweisungen gleicht der von finanziellen Sanktionen für diejenigen Körperschaften, die sich nicht an die impliziten Kartellvereinbarungen halten. Lokale Einheiten, die durch niedrige Steuersätze den Vorteil der Kartellaußenseiter einnehmen wollen, werden nach dieser Auffassung durch die Reduzierung der zentral verwalteten Zuweisungsanteile bestraft. ${ }^{129}$ Anreize zu kompetitivem Verhalten werden so von vornherein geschwächt, ein Aspekt der seit langem aus der Theorie der Sozialtransfers bekannt ist. ${ }^{130}$

126 Wie oben dargestellt, erlaubt nur die Annahme unvollstăndiger Information uberhaupt eine mogliche Vorteilhaftigkeit vertikaler Finanzzuweisungen. Unter der Prämisse perfekter Information - und folglich Transaktionskosten von Null - laßt sich uberhaupt keine Organisationsform des Staates als vorteilhaft gegenuber anderen begrunden.

127 Brennan, G./Buchanan, J.M. (1980/1988), S. 231.

128 Benson, B.L. (1990), S. 83.

129 Vgl. Brennan, G./Buchanan, J.M. (1980/1988), S. 230.

130 Siehe etwa den kurzen Úberblick bei Boadway, R.W.Wildasin, D.E. (1984), Kap. 14. 
Zuweilen wird selbst von Vertretern eines wettbewerblichen Föderalismus die Notwendigkeit eines zentral organisierten Finanztransfersystems erörtert. So befürwortet beispielsweise Breton Finanztransfers der Zentralebene zum Ausgleich wettbewerblicher Ungleichgewichte der gliedstaatlichen Einheiten. ${ }^{131}$ Seiner Auffassung nach sind Ausgleichszahlungen erforderlich, um die Wettbewerbschancen der Jurisdiktionen anzugleichen, nicht jedoch die Wettbewerbsergebnisse. Breton verweist zwar auf das Risiko, daß die Finanztransfers den interjurisdiktionellen Wettbewerb eliminieren. Er sieht aber das eigentliche Hauptproblem in der Festlegung einer Ausgleichsformel, denn diese "... requires a judgement about the relative competitive ability of provincial governments." 132 Konsequenterweise spricht er der Zentralebene ein deutlich höheres Gewicht bei Verhandlungen über die Transferhöhe zu, damit diese ihre Aufgabe als Überwachungsinstanz des gebietskörperschaftlichen Wettbewerbs erfüllen könne. 133

Diese Argumentation setzt implizit voraus, daß die konkurrierenden Einheiten für einen funktionierenden interjurisdiktionellen Wettbewerb gleich groß sein müßten. Zweifelsohne muß und kann bereits auf konstitutioneller Ebene dafür Sorge getragen werden, daß sich die subzentralen Jurisdiktionen größenmäßig nicht zu sehr unterscheiden, so daß von Beginn an deutliche Wettbewerbsvorteile für einige wenige Gebietskörperschaften bestehen. Andererseits zeigen auch empirische Erfahrungen mit fiskalischem Wettbewerb, daß flächen- und bevölkerungsmäßig kleine Einheiten durchaus konkurrenzfähig und keineswegs den größeren Wettbewerbern unterlegen sind. 134

Größere Bedeutung kommt in diesem Zusammenhang natürlichen Lagerenten, im besonderen z.B. klimatisch und geographisch bedingten Standortvorteilen, einzelner Regionen zu. Die Verfügbarkeit dieser Vorteile ermöglicht subzentralen Körperschaften eine höhere steuerliche Belastung der ansässigen Bürger und Unternehmen und stellt mitunter einen erheblichen Wettbewerbsvorteil dar. Allerdings kann auch hieraus kaum eine Forderung nach zentralen Ausgleichszahlungen zur Verringerung der interjurisdiktionellen Unterschiede abgeleitet werden, denn aus der hier vertretenen clubtheoretischen Perspektive sind die höheren Steuereinnahmen der bevorzugten Regionen ein Preis für die Nutzung bestehender Lagerenten durch die Jurisdiktionsmitglieder. Auch hier käme die Angleichung der wettbewerblichen Ausgangspositionen durch Transferleistungen der übergeordneten Ebene an weniger leistungsfähige Körperschaften einer Unterminierung des fiskalischen Wettbewerbs gleich.

131 Siehe Breton, A. (1987), S. 298ff. und S. $310 \mathrm{ff}$. sowie (1991), S. 50ff. Ähnlich McGuire, T. (1991).

132 Breton, A. (1987), S. 312 . Breton vermutet deshalb auch, daß der Konsens der kanadischen Provinzen uber die grundsatzliche Notwendigkeit von Zuweisungen der Zentralebene primär auf der allokativen Funktion einer Sicherung intergovernmentaler Konkurrenz beruhe, die schließlich allen Beteiligten zugute komme. Siehe Breton, A. (1987), S. 312.

133 "Indeed, a neutral role on the part of the federal government would eliminate the 'monitoring' function that must be played by the central government. In some circumstances, it may even be necessary for the federal government to act unilaterally ..., that is, to forego all negotiations with the provinces." Breton, $A$. (1987), S. 315 ,

134 Siehe etwa den empirischen Befund von Kirchgdissner, G./Pommerehne, W.W. (1996) fur die Wirkungen des Steuerwettbewerbs in der Schweiz. Diese These wird auch vehement von Wildovsky vertreten: "In recent decades, however, thought and observation have revealed that it is much more difficult to establish an effective monopoly than had previously been thought ... Opinion is yet not unanimous but agreement is growing that only government can guarantee a monopoly. Thus, in principle, there is no obstacle to a competitive federalism even if one competitor is much larger than the others in certain fields." Wildavsky, A. (1990), S. 52. 
Insgesamt dürfte daher die Argumentation von Breton für regionale Ausgleichszuweisungen zur Sicherung des gliedstaatlichen Wettbewerbs auf eher schwachen Füßen stehen.

\section{bb. Steuerverrechnungssysteme}

Bislang blieb unbeachtet, daß in föderativen Systemen bei uneingeschränkter Autonomie der staatlichen Ebenen prinzipiell alle Jurisdiktionen auf dieselbe Steuerbemessungsrundlage zugreifen können. Im Rahmen der wohlfahrtstheoretischen Überlegungen wurde festgestellt, daß a priori nichts gegen die mögliche Doppelbesteuerung spricht, solange die Regierungen der verschiedenen Ebenen durch eine aufeinander abgestimmte Steuerpolitik eine konfiskatorische Besteuerung der einheitlichen Steuerbasis vermeiden. ${ }^{135}$ Als eine denkbare Regelung wurde die Abzugsfähigkeit der lokalen Steuern von der Steuerschuld gegenüber der Bundesebene erwähnt. Zu prüfen ist deshalb, ob sich diese Ergebnisse ändern, wenn von der Annahme ausbeuterischer Leviathan-Regierungen ausgegangen wird.

Zur Analyse dieser Fragestellung wird auf ein Modell von Flowers zurückgegriffen. ${ }^{136}$ Es wird angenommen, daß zwei staatliche Ebenen, Zentralebene $\mathrm{Z}$ und Ebene der Gliedstaaten S, existieren, die beide eine einheitlich definierte Bemessungsgrundlage $Q$ besteuern können. Die Regierungen aller Jurisdiktionen verhalten sich als Steueraufkommensmaximierer und wählen deshalb stets einen aufkommensmaximalen Steuersatz $t^{*}$, der sich analog zur Monopolpreisbildung ergibt.

Zur Ableitung des Besteuerungsverhaltens der unterschiedlichen Ebenen wird unterstellt, daß sich beide Ebenen $Z$ und $S$ sich gemäß der Cournot-Nash-Annahme verhalten und die Wahl ihrer Steuersätze $t_{z}$ bzw. $t_{s}$ aufkommensmaximierend an den von der jeweils anderen jurisdiktionellen Ebene gewählten Steuersatz anpassen. Es lassen sich somit Reaktionsfunktionen ableiten, wie sie in Abbildung 5.5a illustriert sind. Dabei sei zunächst davon ausgegangen, daß die subzentralen Einheiten nicht konkurrieren und sich wie die Zentralebene $\mathrm{Z}$ als Monopolisten verhalten könnten. Je größer die Zentralregierung $t_{z}$ wählt, desto kleiner wird die für die Gliedstaaten der Ebene $\mathrm{S}$ verbleibende Besteuerungsbasis und desto geringer wird der von den Jurisdiktionen $\mathrm{S}$ gewählte aufkommensmaximale Steuersatz $\mathrm{t}_{\mathrm{s}}$, et vice versa. Die Verläufe der Reaktionskurven ZZ und SS der Ebenen Z und S illustrieren diesen Zusammenhang. ${ }^{137}$ Unter diesen Bedingungen stellt sich ein Cournot-Nash-Gleichgewicht in Punkt E ein. Punkt $E$ ist durch Steuersätze $t_{s}$ und $t_{z}$ charakterisiert, die in der Summe größer als der aufkommensmaximale Steuersatz $t^{*}$ sind ${ }^{138}$; durch die unterbrochene $t^{*}$-Linie werden alle Kombinationen von $t_{s}$ und $t_{z}$ angezeigt, die in der Summe für die beiden föderativen Ebenen bei separater Besteuerung ein Maximalaufkommen ergeben.

135 Vgl. die Erorterungen im 3. Kapitel, Abschnitt C.V.3, S. 139.

136 Siehe Flowers, M. (1988).

137 Die Steigung von ZZ (bzw. SS) ist stets kleiner (größer) als Eins, siehe Flowers, M. (1988), S. 76.

138 "If two revenue-maximizing units of government at different levels in a federal system share a common tax base, combined tax rates applied to that base will lie on the backward-bending portion of the Laffer curve. Tax rates consistent with joint revenue maximization will be exceeded ..." Flowers, M. (1988), S. 68. 

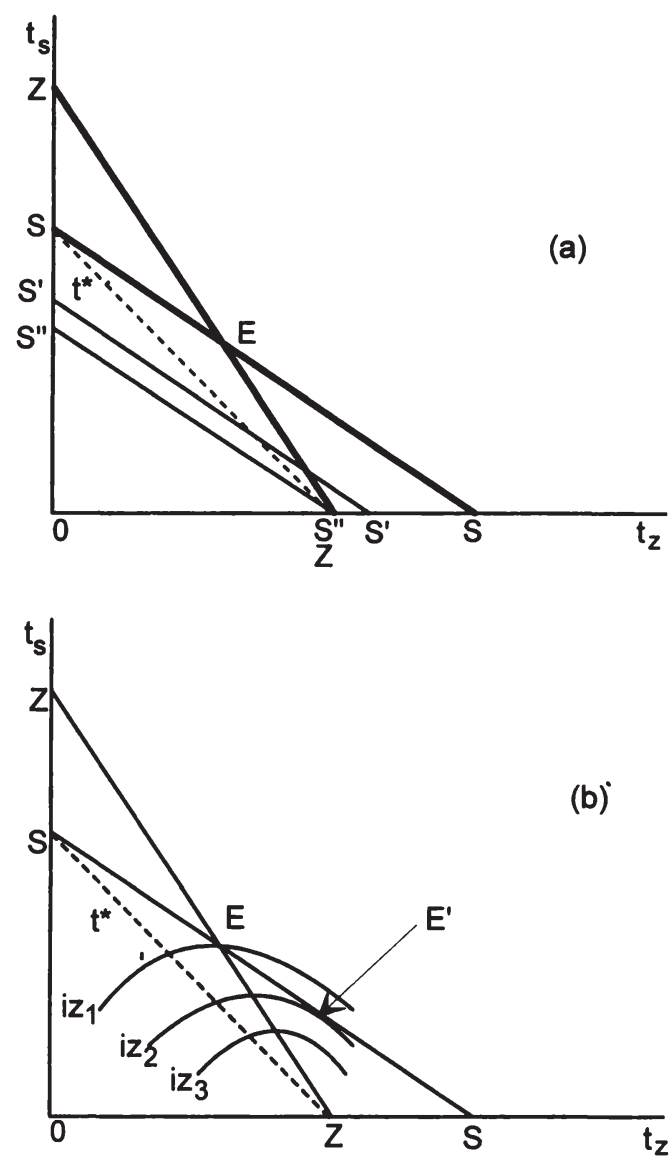

Abbildung 5.5: Gemeinsame Steuerbasis föderativer Ebenen im Leviathan-Staat Quelle: Flowers, M. (1988), S. 71 und S. 72.

Liegt zwischen den Einheiten der Ebene S eine wettbewerbliche Situation vor, die für alle (identischen) Gliedstaaten einheitliche, geringere Steuersätze induziert, verschiebt sich die Reaktionsfunktion SS parallel nach unten auf S'S'. Da die Zentralebene keinem Wettbewerbsdruck ausgesetzt ist, bleibt ZZ unverändert. Das summierte Steueraufkommen beider Ebenen steigt ebenso wie der Anteil der Zentralebene am Steueraufkommen. Dennoch liegt das Gesamtaufkommen immer noch unterhalb des Maximums. Dieses wird erst erreicht, wenn der Konkurrenzdruck auf der subzentralen Ebene so groß ist, daß diese Steuersätze $t_{s}$ von Null wählen (in der Abbildung $5.5 a$ bei einer Reaktionsfunktion S"S") und das gesamte Aufkommen aus der Besteuerung von $\mathrm{Q}$ der Zentralebene zufließt.

Allerdings dürfte laut Flowers die Modellierung der Verhaltensannahmen nicht den tatsächlichen Machtverhältnissen zwischen der Zentral- und der Gliedstaatenebene entsprechen. Eine 
plausiblere Annahme sei, daß sich die vielen lokalen Einheiten als Anpasser an der Politik der Zentralebene orientieren. Damit kann sich die Regierung $\mathrm{Z}$ strategisch als Stackelberg-Führer verhalten. In Abbildung $5.5 b$ sind für die Zentralebene Iso-Steueraufkommenskurven (iz $\mathrm{iz}_{2}$ $i z_{3}$ ) eingezeichnet, die für jede Wahl von $t_{s}$ den Satz $t_{z}$ anzeigen, der für die Zentralebene dasselbe Steueraufkommen erbringt. ${ }^{139}$ Je niedriger die iz-Kurven verlaufen, um so höher ist das Aufkommen der Zentralebene. Als Stackelberg-Führer kann die Zentralregierung den Steuersatz gemäß Punkt E' wählen, wo die niedrigste iz-Kurve die Reaktionslinie SS tangiert, und ein Maximalaufkommen $\mathrm{iz}_{2}$ realisieren. Die subnationalen Gliedstaaten passen ihre Sătze $t_{z}$ entprechend an. Im Ergebnis erhält man kombinierte Steuersätze $t_{z}$ und $t_{s}$ die das gemeinsame Maximalaufkommen übersteigen und größer sind als bei beiderseitigem Cournot-NashVerhalten. Erhöhen kann die Zentralregierung ihr Aufkommen nur "... by claiming a larger share of the smaller total." 140 Daraus können folgende Schlüsse gezogen werden:

- Die Zusammenarbeit der verschiedenen Ebenen im föderativen Staat würde im Sinne einer joint profit maximization zu einem Anstieg des Steueraufkommens fuhren, da ohne Kooperation die zur Realisierung des Maximalaufkommens erforderlichen Steuersätze überschritten werden.

- In diesem Falle wäre eine Kooperation der föderativen Ebenen sogar aus der Sicht der Leviathan-Theorie wünschenswert, weil die Zusatzlasten mit steigenden Steuersätzen überproportional ansteigen, so daß die Verringerung der addierten Marginalsteuersätze die Bürger trotz steigendem Steueraufkommen auf einem insgesamt höheren Nutzenniveau beläßt.

- Wettbewerbsdruck für die Jurisdiktionen auf subzentraler Ebene führt zu einer relativen Stärkung der Zentralebene und zu einer Reduzierung der addierten Marginalsteuersätze. Je stärker die strategische Position der Zentralebene ist, desto niedriger sind die Anteile der subzentralen Jurisdiktionen am Gesamtaufkommen.

Wird allerdings die Abzugsfähigkeit lokaler Steuern von den Bundessteuern vereinbart, ergeben sich Beschränkungen der interjurisdiktionellen Konkurrenz: Die subzentralen Einheiten haben geringere Anreize zu Steuersatzsenkungen, denn die Steuerschuld eines mobilen Unternehmens (Haushalts) wird durch hohe subzentrale Steuersätze bei völliger Abzugsfähigkeit nicht vergrößert. Damit lastet die bundesstaatliche Steuerschuld vorwiegend auf Gliedstaaten mit niedrigen Steuersätzen. ${ }^{141}$ Benson resümiert daher:

"Deductibility protects those [high-tax, H.P.] states from competition, at least to a degree, and elimination of deductibility would force them to lower their tax rates substantially or face significant losses as business activity shifts to other states. Politicians from low-tax states also benefit from deductibility in the sense that it reduces the incentives to compete in terms of tax rates, thus possibly allowing them to set rates that are higher than they would otherwise be." 142

139 Der nach unten gekrummte Verlauf der iz-Linien kann wie folgt erklärt werden. Die ZZ-Linie zeigt an, welcher Steuersatz $t_{z}$ fur die Zentralebene bei gegebenem $t_{3}$ ein Aufkommensmaximum erbringt. Da jede Abweichung von der ZZ-Linie eine 'suboptimale' Entscheidung der Zentrale, gegeben $\mathrm{t}_{\boldsymbol{s}}$, bedeutet, kann das gleiche Steueraufkommen iz nur bei niedrigeren Steuersatzen der Subeinheiten $t_{3}$ realisiert werden. Im Schnittpunkt der iz-Kurven mit der Reaktionslinie ZZ haben die iz-Kurven folglich eine Steigung von Null.

140 Flowers, M. (1988), S. 73.

141 Vgl. Benson, B.L. (1990), S. $80 \mathrm{ff}$.

142 Benson, B.L. (1990), S. 81 f. 
Aus polit-ökonomischer Sicht ist deshalb eine strikte Trennung der Steuerquellen, auf die die unterschiedlichen Staatsebenen Zugriff haben, erforderlich. Der gemeinsame Zugriff auf eine Steuerbasis erweist sich als worst case, dem sogar eine wettbewerbsbeschränkende Kooperation der föderativen Ebenen vorzuziehen wäre. Ursächlich hierfür ist die auch durch föderative Strukturen im Leviathan-Modell ohne weitergehende fiskalische Restriktionen nicht begrenzbare Besteuerungsgewalt der Zentralregierung.

\section{Die Implikationen für die föderative Aufgabenverteilung}

\section{Radikale Dezentralisierung}

Faßt man die bisherigen Gedanken zusammen, so kann man feststellen, daß die exit-Option offenbar aus dem Blickwinkel der Leviathan-Theorie ein durchaus wirksames Substitut für demokratische Entscheidungsverfahren und andere finanzwirtschaftliche Beschränkungen sein kann. ${ }^{143}$ Den Vertretern dieses Ansatzes, insbesondere Brennan und Buchanan, ist die Auffassung gemeinsam, daß die Abwanderungsoption ein deutlich wirksamerer Schutz gegen den Leviathan sei als jede Form von Widerspruch. Osterfeld betont:

\footnotetext{
"Although not irrelevant, the type of government (democracy, dictatorhip, etc.) is actually much less important than the range of jurisdictions. Provided that exit is not barred, a large democracy would be less responsive, and therefore provide less utility to its citizens, than a local dictatorship." 144
}

Der besondere Vorteil der exit-Option gegenüber den Mechanismen der voice-Option kommt dadurch zur Geltung, daß Abwanderung eine rein individuelle Entscheidung ist, deren Erfolg auch nur an individuelles Handeln gebunden ist. Im Gegensatz dazu sind die Chancen, durch politischen Widerspruch eine Veränderung der persönlichen Situation zu erreichen, stets an gemeinsames Handeln geknüpft. 145

Die Entscheidung, in einer Jurisdiktion zu verbleiben, ist - vorausgesetzt, die Mobilitätskosten sind gering - letztlich Ausdruck von Konsens mit den politischen Verhältnissen der lokalen Einheit. ${ }^{146}$ Der freiwillige marktliche Tausch ist das Äquivalent zu politischen Entscheidungen unter Einstimmigkeit ${ }^{147}$, und die Annäherung an das Ideal des Wettbewerbsmarktes durch einen stark dezentralen Staatsaufbau, bei dem die Zahl der Abwanderungsalternativen groß ist, sei daher auch eine Annäherung an das konstitutionelle Ideal der Konsensregel auf operationeller Ebene. "If consent is a positive function of ease of exit, and if ease of exit is correlated with the number of governmental units, it follows that 'government by consent' applies to local but not to national governments." 148

\footnotetext{
143 Vgl. Brennan, G./Buchanan, J.M. (1980/1988), S. $232 \mathrm{f}$.

144 Osterfeld, D. (1989), S. 155. (Hervorhebungen im Original).

$145 \mathrm{Vgl}$. Osterfeld, D. (1989), S. 155.

$146 \mathrm{Vgl}$. Osterfeld, D. (1989), S. 155ff. und S. 166f.

147 Vgl. Buchanan, J.M. (1954), S. 153.

148 Osterfeld, D. (1989), S. 156.
} 


\section{Der organisationskostenminimale Staatsaufbau aus Sicht der Leviathan-Theorie}

Brennan und Buchanan verfolgen bei ihren Ausführungen explizit nicht das Ziel, eine normative Theorie der Staatsstruktur zu entwickeln. ${ }^{149}$ Gleichwohl identifizieren sie die vier Elemente, die im Leviathan-Theorieansatz die optimale föderative Struktur des Staates bestimmen. Nach ihrer Auffassung sind dies 150

- die Kosten der Mobilität,

- das Kollusionspotential,

- der Ausdehnungsbereich der Öffentlichkeit bzw. die Skalenerträge im Konsum und

- die Kosten der Verwaltung und Organisation.

Im Hinblick auf die Abwanderungskosten liefern die Überlegungen der Leviathan-Theorie zur Gestaltung des Staatsaufbaus keine wesentlich neuen Erkenntnisse gegenüber dem Ansatz von Breton und Scott. Es sei hier aber hervorgehoben, daß die Begründung für die Berücksichtigung der Mobilitätskosten in der konstitutionellen Entscheidung nicht in der Informationswirkung der exit-Option, sondern in deren Sanktionspotential liegt. 151

Mit der Einbeziehung des Kollusionspotentials kommt im Leviathan-Ansatz ein neues Element zur Geltung. Wie gezeigt, steigen die Kosten der Durchsetzung von Kollusionsabkommen mit größerer Zahl unabhängiger Jurisdiktionen überproportional an. ${ }^{152}$ Je stärker dezentralisiert daher der Staatsaufbau ist, um so weniger ist mit einer Politikkartellierung zu Lasten der Bürger zu rechnen. Konträr zur Position der Theorie des Fiskalföderalismus geht es im polit-ökonomischen Zusammenhang nicht darum, die externen Koordinationskosten im Sinne von Breton/Scott zu minimieren, sondern den Staatsaufbau so zu gestalten, daß das Kollusionspotential minimiert wird. 153

In die entgegengesetzte Richtung wirken spillover-Effekte, Skalenvorteile im Konsum und Verwaltungskosten. Analog zu den Überlegungen des Fiscal Federalism lassen sich hier prinzipiell Vorteile stärker zentralisierter Bereitstellungskompetenzen vermuten, die sich in geringeren externen und internen Koordinationskosten äußern. Unklar bleibt bei Brennan/Buchanan jedoch, worin sie die Unterschiede in den Komponenten Skalenvorteile und Verwaltungskosten sehen. Da die Bereitstellungseinheiten als collective consumption units zu verstehen sind, ist mit den Skalenerträgen im Konsum das Kostenelement 'administrative Organisation' abgedeckt. Skalenvorteile in der Produktion der Kollektivgüter sind hingegen, wie im dritten Kapitel erörtert, für die organisatorische Gestaltung des Staatsauf-

149 Siehe Brennan, G./Buchanan, J.M. (1980/1988), S. 228.

150 Vgl. Brennan, G./Buchanan, J.M. (1980/1988), S. 227f.

151 In der oben zitierten Rezension zur Arbeit von Breton und Scott (1978) betont Brennan: "The crucial role of mobility as a source of constraint on the behavior of government ... is essentially ignored in the BretonScott analysis. Yet it does, in my view, undo a significant part of their theory." Brennan, G. (1979), S. 1052.

152 Vgl. Brennan, G./Buchanan, J.M. (1980/1988), S. 228.

153 Vgl. auch Brennan, G. (1979), S. 1051f. Darin kommt ein allgemeiner ordnungspolitischer Grundgedanke in der Leviathan-Theorie zum Tragen: "Ordnungspolitisch sind of hohe Transaktionskosten durchaus sinnvoll, da sie gesellschaftlich unerwünschte Vertragsabschlüsse erschweren. Es werden sogar durch die Ordnungspolitik bewußt zusätzliche Transaktionskosten geschaffen." Ribhegge, H. (1991), S. 46. 
baus - die Zuordnung von property rights - von sekundärer Bedeutung. Insofern beinhaltet die Betrachtung von Brennan und Buchanan entweder ein irrelevantes Element oder eine Doppelzăhlung. 154

$\mathrm{Da}$ in der Perspektive der Leviathan-Theorie die Abwanderungsoption die einzig wirksame Beschränkung der staatlichen Akteure darstellt ${ }^{155}$, gewinnt das Element der Mobilitätskosten bei Brennan und Buchanan für die optimale föderative Organisation überragende Bedeutung. Je zentralisierter die Staatsorganisation ist, desto weniger wirkt die Mobilitätsrestriktion und um so wahrscheinlicher ist es, daß eine Koordination nicht zur präferenzadäquaten Bereitstellung von Kollektivgütern führt, sondern zur fiskalischen Ausbeutung der Bürger. Mit zunehmender Zentralisierung sinken die Koordinationsnutzen für die Bürger. Die Opportunitätskosten einer interjurisdiktionellen Kooperation, nämlich die Kosten des Vertragsarrangements und die Kosten eines opportunistischen Regierungsverhaltens, sind dann stets größer, als dies in der Analyse von Breton und Scott angenommen wird.

Ein weiterer Unterschied zwischen der Leviathan-Theorie und dem Breton/Scott'schen Organisationskostenmodell besteht darin, daß die Regierungsaktivitäten im Leviathan-Ansatz niemals Substitut für politisches Engagement der Bürger sein können, weil die Politiker annahmegemäß ihre Aktivitäten auf eine Ausbeutung der Bürger richten. Dies bedeutet, daß verstärkte interjurisdiktionelle Kooperation nicht nur zu einer größeren Abschöpfung von Steuerzahlerrenten, sondern auch zu einem Anstieg der Mobilitätskosten führt.

In der Summe sind die Organisationskosten des Staatsaufbaus, also die Opportunitätskosten einer präferenzgerechten Bereitstellung, bei Brennan und Buchanan für jeden Zentralisierungsgrad $\gamma$ höher als bei Breton/Scott, der optimale Zentralisierungsgrad $\gamma *$ ist folglich in der Leviathan-Theorie stets kleiner. "The constitutional norm shifts strongly in the direction of greater decentralization than the Breton-Scott analysis would imply" ${ }^{156}$, da in der Fiskalföderalismus-Theorie von der Möglichkeit opportunistischen Verhaltens der staatlichen Akteure abstrahiert wird.

Die Leviathan-These impliziert damit zusammenfassend betrachtet

- eine weitgehende Dezentralisierung ("radical federalism"157), die nach Auffassung von Osterfeld mit Ausnahme der protektiven Staatstätigkeit alle Funktionen staatlicher Tätigkeit umfassen sollte ${ }^{158}$,

- eine strenge Trennung der Verantwortlichkeiten und insbesondere das Verbot jeglicher Mischfinanzierung ${ }^{159}$,

- eine strenge Trennung der Zugriffsmöglichkeiten auf Finanzierungsquellen, mithin v.a. ein gebundenes Trennsystem bei den Steuerhoheiten und

154 Denkbar wäre gleichwohl, daß Brennan und Buchanan in den Verwaltungskosten die oben (S. 77) als Suchkosten bezeichnete Komponente sehen. Freilich ist an keiner Stelle ihrer Arbeit ein Hinweis zu finden, der diese Vermutung bestătigen kőnnte.

155 Von anderweitigen fiskalischen Restriktionen sei weiterhin abstrahiert.

156 Brennan, G. (1979), S. 1052.

157 Osterfeld, D. (1989).

$158 \mathrm{Vgl}$. Osterfeld, D. (1989), S. 171.

159 Vgl. Brennan, G./Buchanan, J.M. (1980/1988), S. 231. 
- zunehmend strengere fiskalische Restriktionen, je höher der Zentralisierungsgrad der Zuständigkeiten ist.

Ein Sonderproblem stellt die Begrenzung der Fiskalmacht der Zentralebene dar. Der Konstruktion möglicher fiskalischer Restriktionen für den unitarischen Staat gilt daher auch das Hauptaugenmerk der "Power to Tax" von Brennan und Buchanan. Zur Finanzierung der Zentralebene sind nach ihrer Auffassung wohl "... Steuerinstrumente mit begrenztem Aufkommenspotential (möglicherweise Verbrauchsteuern auf spezielle Güter)..."160 in Verbindung mit weitergehenden finanzwirtschaftlichen Begrenzungsregeln am besten geeignet. Auf einen in jüngerer Zeit entwickelten Vorschlag der Begrenzung der Zentralebene durch "reverse revenue sharing" 161 soll erst in Abschnitt C.IV dieses Kapitels eingegangen werden.

Im Hinblick auf das Instrument der Staatsverschuldung finden sich in der Leviathan-Theorie des Wettbewerbsföderalismus keine Aussagen. Die öffentliche Verschuldung wird als Finanzierungsquelle ohnehin nahezu generell abgelehnt, da sie im Kontext des Leviathan-Modells eine gefährliche Lockerung der Budgetrestriktion der staatlichen Akteure darstellt. 162 Aus diesem Blickwinkel wäre allenfalls denkbar, eine an strenge Restriktionen gebundene Kreditaufnahme auf subzentraler Ebene zuzulassen, da dort die marktlichen Sanktionseffekte einer exzessiven Verschuldung voraussichtlich deutlich stärker ausfallen. ${ }^{163}$ Das Argument gegen Finanzzuweisungen 'von oben nach unten' gilt in diesem Falle sogar noch verstärkt, denn sie kämen der Institutionalisierung einer bail-out-Klausel gleich. 164

\section{Der Wettbewerb zwischen Regierungen in der Interessengruppen- theorie des Staates}

\section{Methodische Vorüberlegungen}

Im folgenden soll diskutiert werden, wie sich die Anreize zur Formulierung von politischem Widerspruch und die Erfolgschancen der Widerspruchsoption verändern, wenn die Möglichkeit der Abwanderung gegeben ist. Hierzu wird auf den oben entwickelten Modellrahmen der Interessengruppentheorie des Staates zurückgegriffen. Als handelnde Akteure im politischen Willensbildungsprozeß werden betrachtet:

- Politiker, deren Ziel die Errreichung maximaler Überschüsse aus dem Staatshandeln ist, die jedoch durch die Wahlrestriktion gebunden sind und gleichzeitig die Abwanderung der Steuerzahler zu fürchten haben,

- unorganisierte und unvollständig informierte Wähler sowie

- organisierte und über spezielle Aspekte gut informierte Interessengruppen, die partikulare Vorteile zu Lasten der Allgemeinheit der Wähler erzielen wollen.

160 Brennan, G./Buchanan, J.M. (1980/1988), S. 232.

161 Lee, D.R. (1985).

162 Siehe etwa Buchanan, J.M./Wagner, R.E. (1977).

$163 \mathrm{Vgl}$. die Ausfuhrungen zur Verschuldungskompetenz in Abschnitt C.V.2.b des 3. Kapitels, S. $137 \mathrm{ff}$.

164 Ebenso fur die Europäische Union Heinemann, F. (1995), S. $612 \mathrm{ff}$. 
Von der Rolle der staatlichen Bürokratie soll abstrahiert werden, da sie im hier betrachteten Zusammenhang dieselben Ziele wie räumliche immobile Mitglieder organisierter Interessengruppen verfolgen.

Im vierten Kapitel wurde festgestellt, daß der intensivere Wettbewerb um Wählerstimmen den staatlichen Leviathan in seinen Handlungsfreiräumen zur Realisierung eigener Interessen weitgehend beschränkt. Es konnte jedoch nicht ermittelt werden, wem die freigewordenen politischen Renten zufließen. Einerseits könnten die unorganisierten Wählergruppen im Willensbildungsprozeß auf dezentraler Ebene eine höhere Durchsetzungsfähigkeit haben, andererseits steigt auch die Verhandlungsmacht spezieller Interessengruppen.

Da sich die grundlegenden Zusammenhänge der politischen Entscheidungsfindung auch durch die Verfügbarkeit von Abwanderungsoptionen nicht ändern, ist hier insbesondere von Interesse, wie die relativen Positionen unterschiedlich mobiler gesellschaftlicher Gruppen berührt werden und welche Konsequenzen für die Politik subzentraler Regierungen abzuleiten sind. $\mathrm{Zu}$ unterscheiden sind demnach Fälle, in denen die unorganisierten Wähler mobil sind, und Konstellationen, in denen die organisierten Interessen interregional mobil sind.

Zu klären sind insbesondere die Fragestellungen:

- Begünstigt oder behindert die Verfügbarkeit von Abwanderungsoptionen die Entwicklung von politischem Widerspruch?

- Wie wirken unterschiedlich verteilte exit-Optionen auf die Durchsetzungschancen im politischen Prozeß?

Ausgehend von dieser Problemstellung soll untersucht werden, welche Implikationen sich für die Zuordnung von Bereitstellungskompetenzen ergeben.

\section{Abwanderung und Widerspruch bei Mobilităt der unorganisierten Wähler}

\section{Die Widerspruchsoption der Wăhler}

\section{a. Dominanz der Abwanderungsoption?}

Aus Sicht der Bürger sind Abwanderung und Widerspruch zwei alternative Möglichkeiten, politischen Druck auszuüben und ein Fehlverhalten der staatlichen Akteure zu sanktionieren. Beide Optionen erfordern den Einsatz von Ressourcen, sind also mit Opportunitätskosten verbunden. Wäre Abwanderung kostenlos, bedürfte es keiner Widerspruchsoption, damit die Kollektivmitgliedschaft nicht als Zwang empfunden wird. ${ }^{165}$ Das Vorliegen einer exit-Option könnte damit dazu führen, daß die Wähler geringere Anreize zur Formulierung von politischem Widerspruch haben. Hirschman trifft daher die Feststellung, daß

"... das Vorhandensein der Abwanderung als Reaktionsmoglichkeit die Wahrscheinlichkeit eines umfangreichen und wirksamen Einsatzes der Reaktionsweise Widerspruch stark verringern [kann]."166

165 Vgl. Kirsch, G. (1993), S. 47ff.

166 Hirschman, A.O. (1970/1974), S. 65. 
Danach würde die Bereitschaft, ein mit Kosten der Information und der Partizipation verbundenes politisches Engagement zu zeigen, um so geringer sein, je mehr und je kostengünstigere Abwanderungsalternativen zur Verfügung stehen. Herder-Dorneich und Groser stellen deshalb fest: "Wo Abwanderung leicht fällt, werden wenige Leute die Mühen des Widerspruchs auf sich nehmen. Fehlt dagegen, wie im Falle des reinen Monopols, die Möglichkeit der Abwanderung, so ist ceteris paribus eine größere Tendenz zum Widerspruch zu erwarten." 167

Hirschman veranschaulicht diese Überlegung mit einer einfachen Grafik, die hier in leicht modifizierter und ergänzter Form als Abbildung 5.6 wiedergegeben ist. Im oberen Teil des Schaubilds ist auf der Ordinate die Qualität $q$ einer angebotenen Leistung abgetragen. Die Qualität q nimmt mit zunehmender Entfernung vom Ursprung ab. Die Nachfragefunktionen $D_{0}$ und $D_{1}$ spiegeln unterschiedlich elastische Reaktionen der Konsumenten auf Qualitätsveränderungen bei gegebenem Preis p der Leistung wider.

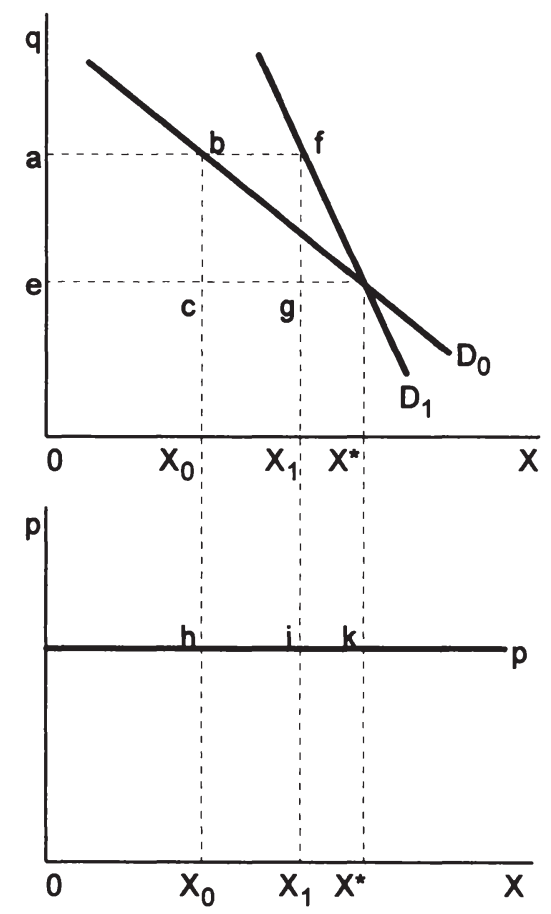

Abbildung 5.6: Abwanderungsoptionen und die Formulierung von Widerspruch

Quelle: in Anlehnung an Hirschman, A.O. (1970/1974), S. 109. 
Da angenommen werden kann, daß die Qualitätselastizität der Nachfrage von der Zahl und der Erreichbarkeit der Abwanderungsalternativen bestimmt ist, deutet die elastisch verlaufende $D_{0}$-Kurve gut verfügbare, die unelastische $D_{1}-$ Kurve schlecht verfügbare exit-Optionen an. Bei einer Ausgangsqualität $0 \mathrm{e}$ wird in beiden Fällen die Menge $\mathrm{X}^{*}$ nachgefragt. Im unteren Teil von Abbildung 5.6 ist der konstante Preis p auf der Ordinate abgetragen, so daß die Fläche unter der Preisgeraden die Erlöse aus dem Verkauf der Leistung X bezeichnet.

Verschlechtert sich die Qualität des Gutes X bei konstantem Preis p von 0e auf 0a, führt dies zu einem Rückgang der nachgefragten Menge (Abwanderung) auf $\mathrm{X}_{0}$ bzw. $\mathrm{X}_{1}$, je nach Verlauf der D-Kurven. Die zu erwartenden Einnahmenverluste des Anbieters betragen bei elastischer Reaktion $\left(\mathrm{D}_{0}\right) \mathrm{X}_{0} \mathrm{hkX}$ und bei unelastischer Reaktion $\left(\mathrm{D}_{1}\right) \mathrm{X}_{1} \mathrm{ikX}$. Im oberen Teil des Schaubilds bezeichnen die korrespondierenden Flächen abce $\left(D_{0}\right)$ und afge $\left(D_{1}\right)$ die Unzufriedenheit der beim Anbieter verbleibenden Konsumenten, die sich in Widerspruch gegen die Qualitätsverschlechterung artikulieren wird. Je besser die Verfügbarkeit von Abwanderungsoptionen ist, um so weniger muß der Anbieter mit der Formulierung von Widerspruch rechnen, weil die unzufriedenen Kunden einfach abwandern. Unter diesen Bedingungen könnte das Vorhandensein von exit-Optionen die Formulierung von Widerspruch unterdrücken. 168

Allerdings, so Hirschman, wird Widerspruch bei mitgliedschaftlichen Organisationen eine wichtigere Rolle spielen als die Abwanderung der Kunden bei Firmen. Er führt dies darauf zurück, daß erstens diese Organisationen weit weniger zahlreich sind als die Zahl der konkurrierenden Marktanbieter. Zweitens führt die größere Zahl der in Organisationen als Leistungspaket angebotenen und konsumierten Produkte dazu, daß die Kreuz-Nachfragelastizitäten höher sind und folglich die Qualitätsverschlechterung bei nur einem der Produkte die Abwanderungswahrscheinlichkeit nur unwesentlich erhöht. ${ }^{169}$ Für den hier betrachteten Zusammenhang bedeutet dies, daß nur die Verschlechterung der kompletten Leistungspakete von subzentralen Gebietskörperschaften oder die nachlassende Qualität zentraler öffentlicher Leistungen eine Dominanz der Abwanderung gegenüber dem Widerspruch zu begründen vermag.

Demgegenüber betonen andere Autoren, daß gerade im Hinblick auf das Ziel der Verbesserung der individuellen Nutzenposition das Verhältnis von Kosten und Nutzen der Abwanderung im Vergleich zur Kosten-Nutzen-Relation einer Veränderung der politischen Ergebnisse durch Wahlen günstiger ist. Dieser Vorteil der Abwanderungsoption beruht darauf, daß kein kollektives Handeln und keine Kompromißbildung bei der Abwanderung erforderlich ist:

\footnotetext{
"[Exit] allows for an individual satisfaction of a preference via substitution without being dependent on consenting voices of a majority of other individuals and on the loyalty of political agents and bureaucrats sticking to their promises. By employing the exit-option, dissenting individuals may realize their plans, without directly hampering others to realize theirs." 170
}

Folgt man dieser Auffassung, wäre die Abwanderungsreaktion auch im politischen Prozeß die gegenüber der Artikulation von Widerspruch dominante Alternative. Nach Lee und McKenzie

$168 \mathrm{Vgl}$. Hirschman, A.O. (1970/1974), S. 65.

169 Siehe Hirschman, A.O. (1970/1974), S. 33.

170 Wohlgemuth, M. (1995), S. 86. 
"... at the local level people can move to any number of other jurisdictions if they do not like the tax and spending decisions in their communities, and a move is far more decisive in determining individual welfare than a vote in an election." 171 Dieser Zusammenhang könnte auch erklären, weshalb - entgegen den Aussagen der ökonomischen Wahltheorie172 - die Wahlbeteiligung auf lokaler Ebene in der Regel geringer ist als auf nationaler Ebene, obwohl dort die Zahl der Wahlberechtigten größer ist. 173

\section{b. Gestiegene Anreize zur Formulierung von politischem Widerspruch?}

Andererseits könnte die Existenz einer exit-Option auch eine entgegengesetzt gerichtete Wirkung entfalten. Anstelle des oben beschriebenen substitutiven Zusammenhangs wird in der Literatur oftmals der komplementäre Zusammenhang von Abwanderung und Widerspruch betont. So führt auch Hirschman aus:

"Die Chancen eines wirksamen Funktionierens von Widerspruch als Gesundungsmechanismus steigen beträchtlich, wenn der Widerspruch durch eine Abwanderungsdrohung unterstutzt wird, mag sie nun offen ausgesprochen werden oder bloß allen Beteiligten als Faktor der Situation klar bewußt sein." 174

Und Wiseman vertritt die Auffassung:

"The existence of separate jurisdictions with some protected powers within a constitutional federation adds an extra dimension to the constitutional arrangements to inhibit coercive behavior of government, so improving the power of indivdual 'voice'." 175

Im Lichte dieser Aussagen betrachtet, dürften die Erfolgsaussichten politischen Widerspruchs gerade für Individuen, die über hinreichende Abwanderungsoptionen verfügen, wachsen. ${ }^{176}$

In der Tat lassen sich Argumente finden, die aus der Existenz von Abwanderungsoptionen zumindest ein besseres Informationsniveau der Bürger und damit eine geringere Anfälligkeit gegenüber Informationsverzerrungen durch politische Werbung seitens der Kandidaten und organisierten Interessen vermuten lassen.

So nimmt Eichenberger an, daß exit-Optionen aus drei Gründen die Informationsbereitschaft der Wähler stärken. ${ }^{177}$ Erstens erhält die Information über die verfügbaren politischen Alternativen außerhalb und innerhalb der eigenen Jurisdiktion stärker den Charakter eines privaten Gutes, da individuelle Migrationsentscheidungen unabhängig von den Kollektivbeschlüssen sind. Damit wird der Anreiz, politische Informationen zu akquirieren, gestärkt. Zweitens verfügen die Individuen auf subzentraler Ebene, wie im vierten Kapitel betont, über Vergleichsmöglichkeiten. Der Anreiz, interjurisdiktionelle Vergleiche anzustellen, wird aber um so stärker sein, je eher Abwanderungsoptionen offen stehen. Und drittens erwartet Eichenberger,

171 Lee, D.R./McKenzie, R.B. (1987), S. 72 (Hervorhebungen H.P.).

172 Siehe oben, Kapitel 3, Abschnitt B.II.3.c, S. 158ff.

173 Vgl. Lee, D.R./McKenzie, R.B. (1987), S. 72. Siehe dazu auch Eichenberger, R. (1994), S. 411 , FN 7.

174 Hirschman, A.O. (1970/1974), S. 70 (Hervorhebung im Original).

175 Wiseman, J. (1990), S. 12f. (Hervorhebung H.P.).

176 Ähnlich Lücke, M. (1975), S. 259; Osterfeld, D. (1989), S. 167; Eichenberger, R. (1994), S. $410 \mathrm{ff}$.

177 Siehe zum folgenden Eichenberger, R. (1994), S. $411 \mathrm{f}$. 
daß die stärkere sozio-psychologische Bindung in lokalen Einheiten "... counteracts the direct effects of decentralization on the incentive to migrate." 178 In der Summe dieser Faktoren sei deshalb zu erwarten, daß Fehlentwicklungen durch verstärkte Widerspruchsbemühungen und nicht sofort durch Abwanderung sanktioniert werden. Er folgert

"... decentralization not only fortifies the exit option of individuals, firms and interest groups, but it also
strengthens their incentives and instruments to articulate their preferences, i.e., to take up the voice option.
Thus, decentralization puts pressure on the political decision makers to follow the citizens' preferences by
bolstering exit and voice." 179

Ein weiterer Aspekt, der diese Auffassung stärken könnte, wird von Wagner in die Diskussion eingebracht. 180 Wagners Argumentation beruht auf den indirekten Informationswirkungen, die durch die Kapitalisierung fiskalischer Variablen ausgehen und damit 'von den Wanderungen selbst' erzeugt werden. Nach dem Kapitalisierungsargument drückt sich eine ineffiziente Politik der subzentralen Einheiten (überhöhte Steuern, geringe oder qualitativ schlechte Leistungen) in einer geringen Nachfrage nach immobilen Werten aus, so daß die am Markt erzielbaren Preise der wohnortgebundenen Güter fallen. Ein ständiger Preisverfall der immobilen Werte liefert somit Informationen für politische Herausforderer und für die Bürger einer Jurisdiktion, daß die Leistungen der amtierenden Regierung mangelhaft sind. ${ }^{181}$

Natürlich begründet die Abwanderungsdrohung nur dann die propagierte Schutzwirkung im politischen Prozeß, wenn mit ihr auch ein Sanktionspotential verbunden ist. Betrachtet man hierzu die Ziele und Nebenbedingungen der Zielfunktion der Regierung, kann vermutet werden, daß die exit-Drohung voraussichtlich nur dann die political voice verstärkt, wenn durch die Abwanderung das Ausbeutungspotential der Regierung verringert wird und wenn der politische Widerspruch selbst schon eine Bedrohung für die Herrschenden im Sinne von North darstellt.

Das Ausbeutungspotential der Regierung wird durch eine Abwanderung nur dann geschwächt, wenn Individuen, die aus der Sicht der Regierung Netto-Zahler sind, abzuwandern drohen. Mithin dürfte also der Einfluß von vermögenden Steuerzahlern durch eine Abwanderungsdrohung eher gestärkt werden als der politische Einfluß von Transferempfängern. Selbst bei gleicher Mobilität von Armen und Reichen wird durch die Existenz von Abwanderungsoptionen die vermutliche Durchsetzungskraft der Wohlhabenden im politischen Prozeß ceteris paribus ansteigen. ${ }^{182}$

Aufgrund der angestellten Überlegungen ist deshalb kein eindeutiges Ergebnis für die Auswirkungen von exit-Optionen und exit-Drohungen für den politischen Widerspruch der Wähler zu ermitteln. Es ist denkbar, daß die Abwanderung den Widerspruch dominiert;

178 Eichenberger, R. (1994), S. 411. Ähnlich bereits Hirschman: "Wo keine Loyalitătsgefuhle vorhanden sind, dort ist die Abwanderung an sich im wesentlichen kostenlos, abgesehen von den Kosten der Beschaffung von Informationen uber andere Produkte und Organisationen." Hirschman, A.O. (1970/1974), S. 70.

179 Eichenberger, R. (1994), S. 412 (Hervorhebung im Original).

180 Vgl. Wagner, R.E. (1988b), S. $431 \mathrm{ff}$.

181 Vgl. Wagner, R.E. (1988b), S. 432. Eine Analogie findet diese Überlegung in den Informationswirkungen sinkender Aktienkurse fur die Anteilseigner an großen Kapitalgesellschaften. Vgl. Kallfass, H.H. (1992).

182 Siehe dazu auch die freilich sehr spekulativen Überlegungen von Scott, A. (1987), S. $241 \mathrm{ff}$. und Scott, A./Bloss, G. (1988), S. 195ff. 
ebenso ist es vorstellbar, daß die Abwanderungsdrohung - zumindest für einige Teile der Bevölkerung - den politischen Einfluß erhöht.

\section{Die rent seeking-Anreize der speziellen Interessengruppen}

\section{a. Der Effekt gesunkener Abwanderungskosten der Organisationsmitglieder}

Doch nicht nur die Informations- und Partizipationsanreize für die Bürger werden durch die Verfügbarkeit von Abwanderungsalternativen tendenziell verringert. Ungeachtet der aufgrund kleinerer Mitgliederzahl und homogenerer Interessen verbesserten Organisationsfähigkeit latenter Gruppen in dezentralen Systemen dürfte die Existenz einer exit-Option aus denselben Gründen, die zu einer Verringerung der Partizipationsanreize der Wähler führen, die Organisierbarkeit spezieller Interessen verschlechtern.

Ein potentielles Verbandsmitglied wird nach dem Opportunitätskostenkalkül maximal so viele Ressourcen zum Erreichen des Lobbying-Ziels beitragen, wie die Realisierung der Ziele eine Besserstellung gegenüber der nächstbesten individuellen Ressourcenverwendung bedeutet. Es kann davon ausgegangen werden, daß die durch politische Einflußnahme erzielbaren Renten geringer werden, weil eventuell die Abwanderungsalternativen für die Verbandsmitglieder selbst bessere Opportunitäten darstellen. ${ }^{183}$ Die Existenz von Abwanderungsoptionen dürfte deshalb den Anreiz spezieller Interessen zur Einflußnahme auf politische Entscheidungen schwächen. Damit sinken die Chancen einer Organisierbarkeit partikularer Interessen in einem 'wanderungsoffenen' Staat.

\section{b. Der Effekt gesunkener Abwanderungskosten der unorganisierten Wähler}

Während der in Abschnitt a genannte Effekt in der einschlägigen Literatur wenig beachtet wird, stellen die meisten Betrachtungen des Interessengruppeneinflusses - in Analogie zur Leviathan-These - auf die Verringerung der exit-Kosten für die potentiell belasteten Individuen im dezentralisierten System ab. ${ }^{184}$ Wie oben gezeigt, führt perfekte Mobilität der Faktoren dazu, daß die Regierungen der subzentralen Einheiten eine Abwanderung nur durch Äquivalenz von bereitgestellten Leistungen und steuerlicher Belastung verhindern können. Bei Existenz von Ausweichoptionen 185 verringern sich die für die organisierten Interessen erzielbaren Vorteile, weil die unorganisierten Wähler einer Belastung, die ihnen keine Vorteile einbringt, entgehen können. Für die lokalen pressure groups steigen die Kosten der Erlangung von Transfers. ${ }^{186}$

183 Ähnlich Hettich, W./Winer, S. (1987), S. 48.

184 Siehe hierzu insbesondere Olson, M. (1982/1991), S. 167ff. und Aranson, P.H. (1990), S. 23.

185 Hierzu zăhlt nicht nur die physische Abwanderung der Burger, sondern auch die Möglichkeit, auf importierte, gunstigere Konkurrenzprodukte auszuweichen.

186 In aller Deutlichkeit wurde dies durch von Hayek in seinem Aufsatz "Die wirtschaftlichen Voraussetzungen foderativer Zusammenschlusse" (1939) herausgearbeitet. Seine Auffassung sei hier mit einem lăngeren Zitat belegt: "Der Wegfall von Zollmauern und die freie Beweglichkeit von Menschen und Kapital zwischen den Staaten des Bundes ... beschräken den Spielraum der Wirtschaftspolitik der einzelnen Staaten in beträchtlichem Maß. Wenn Guter, Menschen und Geld frei uber die Grenzen hin beweglich sind, so wird es unmøglich, durch eine einzelstaatliche Maßnahme auf die Preise der verschiedenen Erzeugnisse einzuwirken ... Fast die ganze heutige Wirtschaftspolitik nun, die darauf gerichtet ist, bestimmte Industrien 
Die beschränkende Wirkung von Freizügigkeit und ungehindertem Güterhandel für die subzentralen Interessengruppen ist in Abbildung 5.7 veranschaulicht. Betrachtet sei die Situation lokaler Anbieter eines Gutes X, das unter kompetitiven Bedingungen zu einem Preis $\mathrm{p}^{*}$, der den Grenzkosten MC entspricht, gehandelt wird. Der wettbewerbliche Output beträgt $\mathrm{X}^{*}$. Angenommen sei nun, die lokale Regierung könne durch Regulierungsmaßnahmen den Marktzutritt für potentielle Konkurrenten innerhalb der Jurisdiktion beschränken, so daß die lokalen Anbieter den Preis auf $\mathrm{p}_{\mathrm{M}}$ erhöhen. Wenn die Nachfrager nach $\mathrm{X}$ keine räumliche Ausweichmöglichkeit haben, ist die relevante Nachfragekurve $D_{0}$ unelastisch. Die maximal durch Lobbying erzielbaren Renten betragen in diesem Fall p*abp $\mathrm{p}_{\mathrm{M}}$.

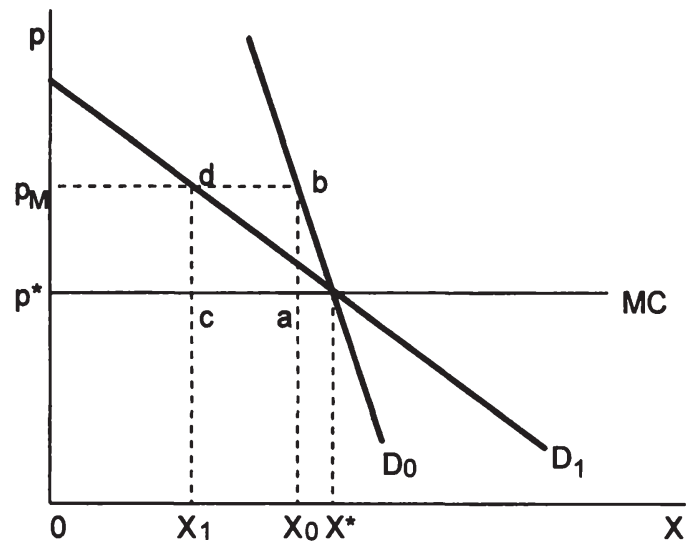

\section{Abbildung 5.7: Rent seeking bei elastischer und unelastischer Nachfrage Quelle: eigene Darstellung}

Können die Konsumenten jedoch auf Importe ausweichen oder durch räumlichen exit der höheren Belastung entgehen, ist die relevante Nachfragekurve durch die flacher verlaufende $D_{1}$-Linie dargestellt. Die maximal erzielbaren Renten sind nun kleiner, denn Fläche $p^{*} c d p_{M}<$ $\mathrm{p}^{*} a b \mathrm{p}_{\mathrm{M}}$. Die Bedingungen für erfolgreiches Rentenstreben der Anbieter sind um so günstiger, je unelastischer die Nachfrage nach dem Gut ist. Da die Elastizität der Nachfrage u.a. auch von den externen Substitutionsmöglichkeiten bestimmt ist, sinkt in einer kleinen offenen Volkswirtschaft, in der Konkurrenzprodukte importiert werden und/oder in der die potentiell Belasteten mobil sind, der Anreiz zum Lobbying.

Die Geltung des Ursprungslandprinzips impliziert, daß lokale Unternehmen der Konkurrenz nicht-lokaler Anbieter auf allen Märkten ausgesetzt sind. Daraus folgt, daß sie direkt die

zu unterstutzen, versucht das durch Beeinflussung der Preise. Ob sie das nun durch Verkaufsorganisationen, staatliche Monopole oder andere Maßnahmen zur Angebotsbeschrănkung macht ... - der Zweck ist immer, das Angebot zu beschrănken und auf diese Weise den Preis zu erhø̋hen. Das alles wird für die einzelnen Staaten innerhalb des Bundes naturlich unmoglich ... Wenn sie weiter bestimmte Produzentengruppen unterstutzen wollen, so wurden sie das durch direkte Subventionen aus Mitteln leisten mussen, die durch geworhnliche Steuern aufgebracht werden." Hayek, F.A. von (1939/1952), S. $328 \mathrm{f}$. 
Unterschiedlichkeit der subzentralen Regulierungen verspüren.187 Eine Regelung, die auf einem abgeschlossenen lokalen Markt partikulare Vorteile für die lokalen Anbieter zu Lasten der Konsumenten mit sich bringt, kann bei offenen Märkten unter Umständen sogar zu einer relativen Benachteiligung der organisierten Regulierungsnachfrage führen. 188 Organisierte Interessen haben deshalb ein vitales Interesse an der Beschränkung von sachlichen und räumlichen Ausweichmöglichkeiten der Konsumenten. Darauf wird in Abschnitt C.III dieses Kapitels zurückzukommen sein.

\section{Die Implikationen für den politischen Entscheidungsprozeß: Standortpolitik}

Aus den bislang erfolgten Überlegungen können Konsequenzen für die vermuteten Ergebnisse der politischen Entscheidungsvorgänge abgeleitet werden. Für die unorganisierten Wähler konnte nicht eindeutig ermittelt werden, ob durch die Verfügbarkeit von Abwanderungsoptionen der Anreiz zur Äußerung von politischem Widerspruch steigt, fällt oder unverändert bleibt. Dagegen gilt für die organisierten Verbände, daß die potentielle Mobilität der Verbandsmitglieder und die exit-Optionen der nicht organisierten gesellschaftlichen Gruppierungen ihre rent seeking-Aktivitäten tendenziell verteuern, so daß von einer verringerten politischen Einflußnahme der pressure groups ausgegangen werden kann.

Betrachtet sei hierzu Abbildung 5.8. Die aus Sicht der Politiker relevante Iso-Stimmenkurve VV dürfte deshalb eine flachere Steigung als in einer geschlossenen lokalen Wirtschaft haben, denn jede Ausweitung der Partikularvorteile $P_{i}$ bringt bei geringeren Lobby-Aktivitäten weniger Stimmengewinne.

Die Wanderungsoffenheit der lokalen Jurisdiktionen führt zu einer Änderung in der staatlichen Budgetrestriktion. Die Abwanderungsdrohung der nichtorganisierten Wähler hat zur Konsequenz, daß die Regierung die volkswirtschaftlichen Ressourcen nicht mehr beliebig zwischen unorganisierten und organisierten Interessen umverteilen kann. Jede Geldeinheit des von nichtorganisierten Wählergruppen aufgebrachten Steueraufkommens, der keine entsprechende Gegenleistung gegenübersteht, führt zu einer Abwanderung von Steuerzahlern. Dies bedeutet, daß $E_{u}$ und $E_{i}$ im politischen Prozeß nicht mehr zum gleichen Verhältnis wie in einer geschlossenen Volkswirtschaft substituiert werden können. Das ursprüngliche politische Tauschverhältnis $\left(E_{\mathrm{u}}: \mathrm{E}_{\mathrm{i}}\right)$ steigt an, da für jede zusätzliche Geldeinheit $\mathrm{E}_{\mathrm{i}}$ nicht nur eine Geldeinheit $E_{u}$ aufgegeben werden muß, sondern sich darüber hinaus das Steueraufkommen durch Abwanderung verringert. Damit wachsen die Opportunitätskosten der Bereitstellung von Partikularvorteilen.

187 "Das Monopol in einem kleinen Teil des integrierten Marktes ist naturlich aberhaupt kein Monopol: niemand wird einem Zunftmitglied einen Monopolpreis zahlen, wenn man zu einem geringeren Preis von Anbietern außerhalb des Kartells kaufen kann." Olson, M. (1982/1991), S. 168. Vgl. auch Siebert, H. (1991), S. 7; Gerken, L. (1995a), S.24; Streit, M. (1995), S. $124 f$.

188 Die als Diskriminierung potentieller ortsansässiger Konkurrenten gedachte Regulierungsmaßnahme würde sich umkehren zu einer Inländerdiskriminierung, wenn die auswärtigen Konkurrenten keinen oder geringeren einschrănkenden Regulierungen unterliegen. 


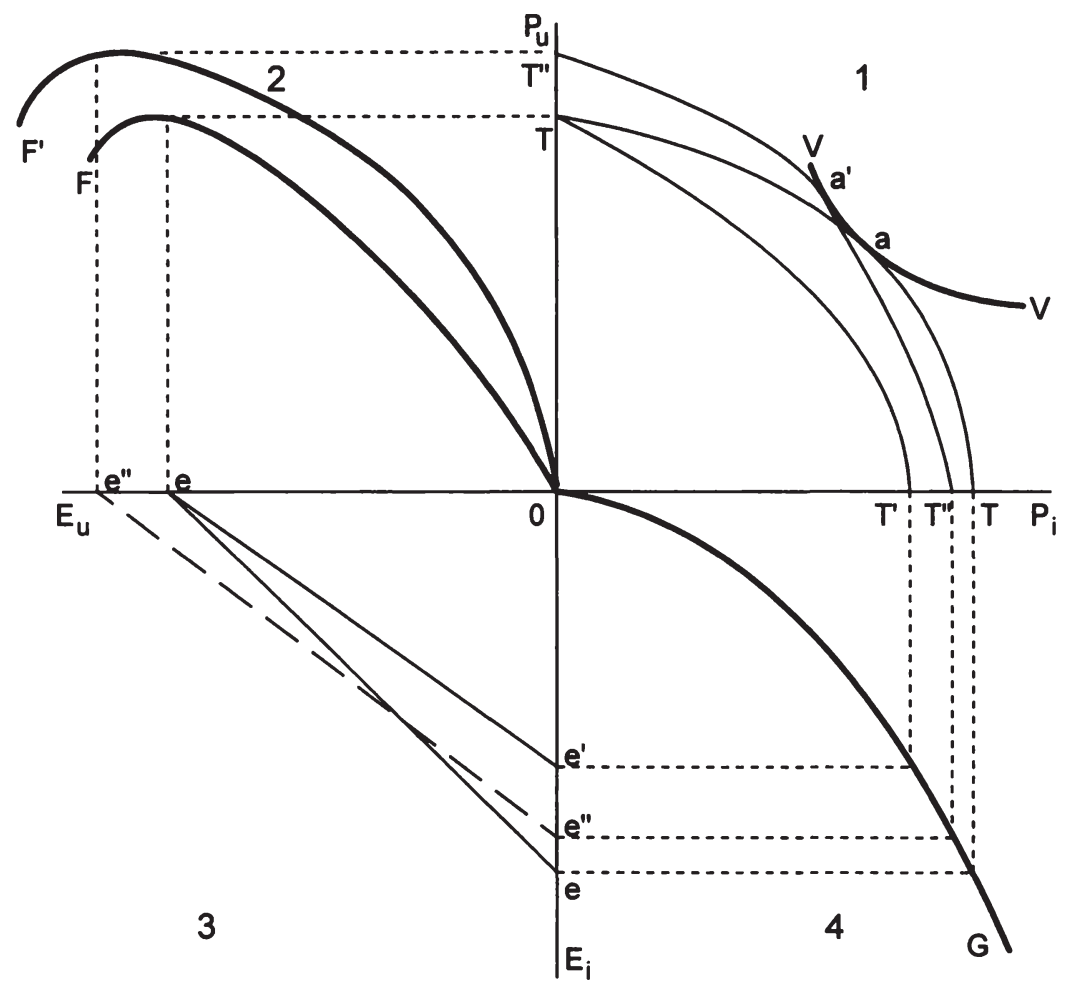

Abbildung 5.8: Beschränkung staatlicher Transfertätigkeit bei Mobilität der Steuerzahler Quelle: eigene Darstellung

Ausgangspunkt der Überlegungen ist eine geschlossene lokale Volkswirtschaft mit den politischen Produktionsfunktionen für general interest-Güter (OF) und Partikularvorteile (0G), die in den Quadranten 2 und 4 abgebildet sind. Die relevante Budgetlinie der Politiker in Quadrant 3 ist ee, es ergibt sich die Transformationsfunktion TT in Quadrant 1. Bei einer IsoStimmenfunktion VV erhält man ein Verteilungsergebnis gemäß Punkt a auf TT.

Nun sei angenommen, die unorganisierten Wähler könnten sich durch Abwanderung der Steuerbelastung entziehen. Die relevante Budgetgerade dreht sich auf ee', weil mit der Umverteilung von $\mathrm{E}_{\mathrm{u}}$ nach $\mathrm{E}_{\mathrm{i}}$ mobile Steuerzahler, die für ihre Belastung nicht durch ein verbessertes Leistungsangebot kompensiert werden, in konkurrierende Jurisdiktionen mit besserem Kollektivgüterangebot abwandern. Die Steigung von ee' reflektiert die Höhe der Mobilitätskosten der unorganisierten Wähler. Je geringer die Kosten der Migration sind, um so flacher verläuft die ee'-Linie. ${ }^{189}$

189 Bei perfekter Mobilitat fallt sie mit der Abszisse ( $E_{u}$-Linie) zusammen. In diesem Fall wăre es fur die Politiker nicht moglich, $E_{u}$ zugunsten von $E_{i}$ einzuschrănken, denn jede nicht-äquivalente Besteuerung fuhrt zur sofortigen Abwanderung der Steuerzahler. 
Die neue Budgetlinie ee' führt bei gegebenen politischen Produktionsfunktionen OF und 0G zu einer Transformationslinie TT'. Entlang TT' kann die den Wahlsieg sichernde Kombination a nicht mehr finanziert werden. Damit ist das Wiederwahlziel der Regierung nur erreichbar, wenn sie durch ihre Aktivitäten eine neue politische Transformationskurve schaff, die die Iso-Stimmenkurve VV tangiert. Existieren keine diskretionären Überschüsse der Regierung, ist das nur durch eine attraktive Standortpolitik möglich, bei der versucht wird, mobile Ressourcen aus anderen Jurisdiktionen anzulocken. 190

Eine Zuwanderung mobiler Steuerzahler kommt in der Grafik durch die Verschiebung der politischen Produktionsfunktion OF nach oben auf OF' zum Ausdruck. ${ }^{191} \mathrm{Da}$ das hypothetische Steueraufkommensmaximum ansteigt, verschiebt sich die Budgetlinie ee' parallel auf $e^{\prime \prime} e$. Die neue relevante Transformationslinie T"T" verläuft steiler als die ursprüngliche TTLinie, sie tangiert die Iso-Stimmenkurve VV in a'. Der neue politische Gleichgewichtspunkt a' liegt stets links oberhalb von a, so daß insgesamt eine höhere gesellschaftliche Wohlfahrt erreicht wird.

Als Fazit kann festgehalten werden, daß es für die organisierten Interessen in lokalen Einheiten schwerer ist, Privilegien zu Lasten der mobilen Bürger/Steuerzahler durchzusetzen. Die Abwanderungsoption bietet nicht nur einen Schutz der Wähler vor dem ausbeuterischen Leviathan, sondern auch einen Schutz vor der Ausbeutung durch spezielle Interessengruppen. Der Spielraum zur Umverteilung zugunsten organisierter Interessen wird eingeengt, und der Abwanderungsdruck der Steuerzahler zwingt die Regierung zu Maßnahmen, die die Attraktivität der Jurisdiktion für gebietsfremde und für ortsansässige Investoren erhöhen.

Damit ergibt sich ein wesentlicher Unterschied zum Ergebnis des im vierten Kapitel konstatierten intensivierten politischen Wettbewerb auf subzentraler Ebene. Während dort die Verteilungswirkungen unklar bleiben, ist die Richtung in kleinen offenen Volkswirtschaften, aus denen die potentiellen Verlierer der transfer society abwandern können, eindeutig zu ermitteln. Der oben beschriebene Effekt, daß die politischen Renten im föderativen System von Politikern und Bürokraten zu den organisierten Interessen umverteilt werden, tritt nur dann auf, wenn die belasteten gesellschaftlichen Gruppen räumlich immobil sind. 192

\section{Abwanderung und Widerspruch bei Mobilität der organisierbaren Interessen}

\section{Zur Abwanderungsdrohung spezieller Interessengruppen}

Interessanterweise wird der umgekehrte Fall, daß die unorganisierten Wähler/Steuerzahler im wesentlichen also die Anbieter der Faktoren Boden und Arbeit - räumlich immobil sind, die organisierten Interessen dagegen abwandern können, im einschlägigen Schriftum der Interessengruppentheorie des Wettbewerbsfoderalismus kaum thematisiert. Im vorangegangenen Abschnitt wurde festgestellt, daß die potentielle Mobilität der nicht organisierten Steuerzahler die staatlich forcierte Umverteilung zu Gunsten der organisierten Interessen erschwert.

190 Die Abwanderung von mobilem Kapital fuhrt zu einem Sozialproduktruckgang und damit auch zu Wahlerstimmenverlusten. Vgl. Gerken, L. (1995b), S. 12.

191 Ähnlich auch Sinn, S. (1992), S. $185 f$.

192 So auch die Auffassung von Joulfaian, /Marlow, M.L. (1991), S. 1604, FN 5. 
Umgekehrt muß gefolgert werden, daß die Immobilität der potentiell Belasteten eine Verbesserung der Durchsetzungschancen für die lokalen pressure groups bewirkt. 193

$\mathrm{Da}$ auch auf dezentraler Ebene im Staat der Einfluß der organisierten Interessen nicht verneint werden kann, könnte die potentielle Mobilität der Verbandsmitglieder bei räumlicher Immobilität der nicht-organisierten gesellschaftlichen Gruppen den politischen Einfluß subzentraler Lobbies stärken. Lücke meint:

\begin{abstract}
"Das konstatierte Unvermögen des Widerspruchsmechanismus, den verschiedenen Gruppen einer Gesellschaft gleiche Chancen zur Durchsetzung ihrer Interessen einzuräumen, wird durch die Existenz des Abwanderungsmechanismus nicht ausgeglichen, sondern noch verstärkt. Gerade die Gruppen, die bereits eine starke Widerspruchsoption haben, erhalten durch die Abwanderungsoption eine noch starkere Stellung." 194
\end{abstract}

Nun könnte man argumentieren, die Abwanderungsdrohung organisierter Interessen sei für die regierenden Politiker wenig bedeutsam, denn ex definitione sind die pressure groups keine Steuerzahler, sondern lediglich Vorteilsempfänger. Bei dieser Argumentation würde jedoch übersehen, daß durchsetzungsfähige spezielle Interessen in der Regel als Nebenprodukt ihrer Lobbying-Aktivitäten Kollektivgüter produzieren, deren Nutzen einer Vielzahl von Wählern zukommen. 195

Die Wirksamkeit der Abwanderungsdrohung der Mitglieder spezieller Interessenverbände im politischen Prozeß lokaler Einheiten beruht deshalb darauf, daß immobile Steuerzahler negativ von der Abwanderung betroffen sein könnten. Augenfällig ist dieser Zusammenhang bei der Betrachtung von Gemeinden, in denen ortsansässige Unternehmen für den lokalen Arbeitsmarkt als Bereitsteller von Arbeitsplätzen eine herausragende Bedeutung haben. Oben konnte gezeigt werden, daß die privaten Haushalte aus der Bereitstellung lokaler Infrastruktur, die die Produktivität der lokalen Unternehmen erhöht, Nutzen ziehen. Ausgaben für öffentliche Vorleistungen sind Ausdruck eines leistungsorientierten Standortwettbewerbs.

Damit wird jedoch nicht das komplette Spektrum möglicher Strategien der Regierungen im interjurisdiktionellen Wettbewerb beschrieben. 196 Unzweifelhaft würden benevolente lokale Regierungen den ortsansässigen Unternehmen nur Leistungen gewähren, wenn diese auch indirekt den Bürgern zugute kommen. Politiker, die auf Wählerstimmen, Informationen und finanzielle Unterstützung von organisierten Interessen angewiesen sind, könnten in einem System des Wettbewerbsföderalismus aber auch Maßnahmen ergreifen, die nicht darauf abzielen, den Standort für gebietsfremde Investoren attraktiver zu machen. Fisher vertritt die Auffassung:

"If the objective of interjurisdictional competition is to acquire more resources to some individuals, the appropriate policy is sometimes to use or encourage the operation of markets toward that end, such as publicizing the availability of fiscal incentives and encouraging mobility to take advantage of those

193 Ähnlich die Argumentation von Aranson, P.H. (1990), S. 23.

194 Lücke, M. (1975), S. 266f.

195 "Wealth transfers are normally supplied to interest groups in a disguised fashion, often bundled with the provision of some kind of public good." Anderson, G.M./Tollison, R.D. (1988), S. 531.

196 Vgl. etwa Gerken, L. (1995a), S. 16ff. 
incentives, whereas sometimes the objective can be served by blocking the operations of markets - for instance, by using regulations to restrict market entry or exit." 197

Nur in einer geschlossenen Volkswirtschaft ohne ökonomische Außenbeziehungen brauchen die Wirtschaftssubjekte ex definitione keine ausländische Konkurrenz zu fürchten. Es ist deshalb denkbar, daß lokale Interessengruppen darauf hinwirken, potentielle Konkurrenz aus anderen Gliedstaaten durch protektionistische Maßnahmen abzuwehren. Der Analyse dieser Fragestellungen widmet sich im internationalen Zusammenhang die Politische Ökonomie des Protektionismus, deren Grundgedanken im folgenden Abschnitt skizziert werden sollen.

\section{Die Politische Ökonomie des Protektionismus}

\section{a. Erklärungsinteresse und Grundidee der Politischen Ökonomie des Protektionismus}

Die ökonomische Standardtheorie des internationalen Handels betont, daß die Etablierung von Freihandel zwischen Ländern optimal ist und mithin die gesellschaftliche Wohlfahrt durch Handel und internationale Arbeitsteilung, die keinen staatlich gesetzten Beschränkungen unterliegen, maximiert wird. 198 Es wird argumentiert, daß bereits der einseitige Übergang eines Landes zu Freihandel für die Bewohner dieses Landes zu Wohlfahrtsgewinnen fuhrt, selbst wenn alle anderen Nationen ihre protektionistische Strategie beibehalten. Damit steht die von der traditionellen Außenhandelstheorie postulierte Optimalität des Freihandels in krassem Widerspruch zur Realität internationaler Handelsbeziehungen. Wohlfahrtsmindernde protektionistische Aktivităten scheinen eher die Regel als die Ausnahme zu sein. ${ }^{199}$

Nun wird auch in der traditionellen Theorie darauf hingewiesen, daß unter bestimmten Bedingungen ein Land durch protektionistische Maßnahmen die gesellschaftliche Wohlfahrt seiner Bürger, z.B. durch die Erhebung optimaler Zölle, steigern kann. ${ }^{200}$ Die erzielten inländischen Wohlfahrtsgewinne gehen allerdings mit negativen Externalitäten für die ausländischen Handelspartner einher, so daß mit protektionistischen Gegenmaßnahmen der negativ betroffenen Länder zu rechnen ist. Aus dieser Perspektive ist der Abbau tarifärer und nicht-tarifärer Handelshemmnisse als internationales Gefangenendilemma zu charakterisieren, mit der Konsequenz, daß eine gemeinsame Übereinkunft zur Rückführung der ineffizienten Schutzmaßnahmen nur erreicht werden kann, wenn die Beteiligten die Einhaltung ihrer Versprechungen glaubhaft garantieren können.

Die These, die Abschaffung administrativer Marktzugangsregelungen sei ein internationales offentliches $\mathrm{Gut}^{201}$ und daher durch die Gefangenendilemmasituation adäquat umschrieben, ist nicht unwidersprochen geblieben. So führt Schuknecht aus:

197 Fisher, R.C. (1991), S. 263 (Hervorhebungen H.P).

198 Siehe hierzu die Ausfuhrungen in den einschlägigen Lehrbuchern, etwa Rose, K./Sauernheimer, K. (1995).

199 Zwar wurden tarifare Handelshemmnisse, d.h. Zolle, im Zuge der Verhandlungsrunden des GATT im internationalen Leistungsverkehr abgebaut, stattdessen gewinnen nicht-tarifare Hemmnisse augenscheinlich immer stärkere Bedeutung. Siehe hierzu etwa Langhammer, R.J. (1993), S. 50ff.

200 Siehe Rose, K./Sauernheimer, K. (1995), IV. Teil.

201 Prominenter Vertreter dieser These ist Kindleberger, C.P. (1986). 
"The international PD-[prisoners' dilemma, H.P.] explanation of protection may serve to explain some selected protection. It is rather unsuitable, however, to explain the emergence of widespread protection as being due to three major shortcomings of the underlying optimum-tariff and strategic protection arguments." 202

Im einzelnen wird kritisiert, daß erstens die Annahmen und Bedingungen für die Erhebung von Optimalzöllen und für den Einsatz einer strategischen Handelspolitik äußerst restriktiv seien. Darüber hinaus würden die zu erwartenden handelspolitischen Vergeltungsmaßnahmen von den Regierungen antizipiert, so daß diese freiwillig auf den Einsatz dieses Instrumentariums verzichten. 203 Zweitens stehen, so Krugman, die Regierungen vor nahezu unlösbaren Informationsproblemen im Hinblick auf die Ausgestaltung der optimalen handelspolitischen Maßnahmen. ${ }^{204}$ Und drittens wird angeführt, daß die Standardtheorie unzulässigerweise von der Annahme ausgeht, "... that countries basically act as unit actors with governments maximizing the country's welfare." 205

Die Politische Ökonomie des Protektionismus (auch: Endogene Zolltheorie oder Politische Ökonomie der Handelspolitik ${ }^{206}$ ) versucht dagegen, das Entstehen und die Dauerhaftigkeit internationaler Handelshemmnisse als "... Ergebnis rationaler Überlegungen der Entscheidungsträger in einer Demokratie"207 zu erklären. Zölle und nicht-tarifäre Hemmnisse zwischenstaatlicher Güter- und Faktorbewegungen werden als Resultat des Zusammenspiels verschiedener Kräfte auf einem politischen Markt für Protektionismus interpretiert. ${ }^{208}$ Auf diesem Markt wird, so Frey, "Zollschutz ... von bestimmten Gruppen von Wählern, Firmen und dazugehörigen Interessengruppen und Parteien nachgefragt, und ... von Politikern und der öffentlichen Verwaltung angeboten." 209 Handelsbeschränkungen sind nach dem positiv-theoretischen Ansatz politische Güter; ihre Existenz ist auf das Rentenstreben von Politikern, Bürokraten und organisierten Interessen zurückzuführen. Zölle und andere administrative Handelshemmnisse sind daher "... prices that clear political markets." 210 Die Politische Ökonomie des Protektionismus löst sich somit von der Vorstellung wohlmeinender Alleinherrscher, wie sie der traditionellen Außenhandelstheorie zugrunde liegt. ${ }^{211}$

202 Schuknecht, L. (1990), S. 43.

$203 \mathrm{Vgl}$. Schuknecht, L. (1990), S. 43.

204 Vgl. Krugman, P.R. (1987).

205 Schuknecht, L. (1990), S. 47.

206 Als deren herausragende Vertreter durfen Baldwin, R.E. (1982); Bhagwati, J.N. (1982) und Hillman, A.L./Ursprung, W. (1988) genannt werden. Auch die Pionierartikel zur Theorie des rent seeking von Tullock und Krueger sind explizit der polit-ઠkonomischen Erklärung von Zollen gewidmet. Vgl. Tullock, G. (1967); Krueger, A.O. (1974). Zu einem Überblick uber die Literatur siehe Frey, B.S. (1985), S. 12ff.; Nelson, D. (1988); Baldwin, R.E. (1989) und Hillman, A.L. (1989).

207 Weck-Hannemann, H. (1991), S. 126.

$208 \mathrm{Vgl}$. Frey, B.S. (1985), S. 30. "Protectionist decisions are the outcome of a political process that establishes legislated restrictions on international trade in particular goods, or specifies circumstances more broadly warranting trade intervention ..." Hillman, A.L. (1989), S. 24.

209 Frey, B.S. (1985), S. 20 (Hervorhebungen im Orginal).

210 Magee, S.P./Brock, W.A./Young, L. (1989), S. 102.

211 Vgl. Hillman, A.L. (1992), S. 7. 


\section{b. Die wichtigsten Ergebnisse der Politischen Ökonomie des Protektionismus}

Die Politische Ökonomie des Protektionismus stellt bei ihren Betrachtungen darauf ab, daß zwar bereits der unilaterale Abbau von Handelshemmnissen die gesamtgesellschaftliche Wohlfahrt eines Landes steigert, daß sich aber die hieraus resultierenden Vorteile nicht gleichmäßig auf die Gesellschaftmitglieder verteilen. Der Übergang zu Freihandel führt in der Regel zu einer Besserstellung einiger Mitglieder eines Staates, wohingegen andere Bürger des Landes Nachteile erleiden. Da aber die Verlierer nicht zwingend von den Gewinnern entschädigt werden, stehen sich nach gängiger Auffassung auf der Nachfrageseite im politischen Prozeß Protektionsgegner und -befürworter gegenüber. ${ }^{212}$

Hier wird erneut die Bedeutung der Transaktionskosten im politischen Prozeß deutlich. In einer transaktionskostenfreien Welt könnten die Gewinner und die Verlierer des Abbaus der Handelshemmnisse perfekte und durchsetzbare Verträge über die Verteilung der entstehenden Wohlfahrtsgewinne abschließen. Nach der traditionellen Außenhandelstheorie sind diese Gewinne so groß, daß die Begünstigten des Übergangs zum Freihandel die Verlierer für ihre erlittenen Verluste vollständig kompensieren könnten. Erst die Existenz positiver Transaktionskosten vermag zu erklären, weshalb diese potentiell wohlfahrtssteigernden Transaktionen unterbleiben. Schuknecht identifiziert Protektionismus daher als ein "Intra-national Prisoners' Dilemma"213.

Die demokratischen politischen Prozessen inhärente kurzfristige Sichtweise impliziert, daß nicht die für alle Gesellschaftsmitglieder langfristigen Vorteile des Schrittes zum Freihandel zur Geltung kommen, sondern daß die kurz- und mittelfristig gegensätzlichen Interessen bei der Entscheidungsfindung dominieren. Magee, Brock und Young argumentieren, daß die Interessendivergenzen nicht zwischen den Produktionsfaktoren Arbeit und Kapital auftreten, sondern vielmehr zwischen einzelnen Wirtschaftszweigen bestehen. ${ }^{214}$ Diese Annahme, die sie auch empirisch bestätigt sehen, begründen sie damit, daß auf kurze Sicht die Faktoren auch intersektoral immobil sind 215 und daß deshalb die Lobbyingkosten, einschließlich der Kosten der Überwindung von Trittbrettfahrerverhalten, für Industrielobbies geringer seien als für Interessenvertretungen der Produktionsfaktoren. ${ }^{216}$ Protektionistische Interessen werden folglich vorwiegend von importkonkurrierenden Wirtschaftssektoren (Unternehmen einschließlich der dort beschäftigten Arbeitnehmer) vertreten, wohingegen exportorientierte Industrien und die Konsumenten Freihandel bevorzugen würden. 217

212 Vgl. etwa Frey, B.S. (1985), S. 18ff.; Weck-Hannemann, H. (1991), S. $127 \mathrm{ff}$.

213 Schuknecht, L. (1990).

214 Siehe Magee, S.P./Brock, W.A./Young, L. (1989), S. 101ff. Ebenso Frey, B.S. (1985), S. 25f. und Hillman, A.L. (1989), S. 12ff.

215 Magee, Brock und Young stutzen diese These auf ein "... sector-specific human capital and high-technology physical capital" in fortgeschrittenen Industriestaaten. Magee, S.P./Brock, W.A./Young, L. (1989), S. 103. Nelson hălt dagegen ein "specific-factor model", bei dem ein Faktor (Arbeit) intersektoral mobil ist und andere Faktoren sektorenspezifisch eingesetzt werden, fur realistischer. Er folgert, daß "... the interests of the specific factors will be tied to their respective industries, while the mobile factors will have factorbased preferences." Nelson, D. (1988), S. 803.

216 Vgl. Magee, S.P./Brock, W.A./Young, L. (1989), S. 103.

217 Ein Beispiel wäre das gemeinsame Vorgehen von Arbeitgebern und Arbeitnehmern in der deutschen Bauindustrie zur Durchsetzung von Mindestlohnen als Schutz gegen ausländische Billiglohnkonkurrenz. Derselben Auffassung ist Prosi, M. (1991), S. 125: "Die Unterstutzung der deutschen Arbeitgeberverbănde fur die Forderungen nach sozialen Mindeststandards ist mit deren Wettbewerbsbeschrănkung fur auslandische Anbieter leicht zu erklären." 
In den Modellen der polit-ð̋konomischen Theorie des Protektionismus wird unterstellt, daß die potentiellen Verlierer eines Zollabbaus generell besser organisiert sind und größeren politischen Einfluß geltend machen als die möglichen Gewinner des Übergangs zu Freihandel. Hierfür werden insbesondere Argumente aus der Theorie der Interessengruppen angeführt:218

- Konsumenten sind aufgrund der großen Interessenheterogenität schwer organisierbar, so da $\beta$ von ihrer Seite kein nennenswerter politischer Widerstand gegen protektionistische Aktivitäten zu erwarten ist. Produzenteninteressen sind dagegen leichter organisierbar. 219

- Für importkonkurrierende Industrien kann angenommen werden, daß sie von der Aufhebung der Handelsbeschränkungen direkt negativ betroffen sind. Die Folgen einer neuen ausländischen Konkurrenz sind unmittelbar als Rentenverluste für die Unternehmer und die Beschäftigten in diesem Sektor spürbar. Entsprechend dürfte der politische Widerspruch gegen den Übergang zu Freihandel groß sein.

- Exportorientierte Sektoren werden schließlich, so die These, in geringerem Maße gegen protektionistische Praktiken der Regierung opponieren, weil erstens die Nachteile, die ihnen aus den protektionistischen Gegenmaßnahmen des Auslands drohen, nur schwer quantifizierbar sind; zweitens können sie selbst von gewährten Exportsubventionen profitieren, so daß ein genereller Widerspruch gegen tarifäre und nicht-tarifäre Handelshemmnisse wenig wahrscheinlich ist. 220

Insgesamt muß deshalb davon ausgegangen werden, daß Freihandelsinteressen im politischen Entscheidungsprozeß ein geringeres Gewicht beikommt und die Nachfrage nach Protektion daher größer ist als der Widerstand der Verlierer durch protektionistische Praktiken.

Auf der Angebotsseite des Marktes für Protektionismus stehen die Politiker und Bürokraten. Das Interesse der Politiker am Aufbau von Handelsbarrieren ist evident, wenn sie dadurch per saldo Wählerstimmen gewinnen können. Die Interessengruppentheorie des Staates impliziert, daß Regierungen, die einer positiven Nachfrage nach gruppenspezifischer Vorteilsgewährung gegenüberstehen, dieser Nachfrage nachgeben und ein entsprechendes Angebot bereitstellen. Schon allein deshalb werden im politischen Prozeß protektionistische Regulierungen angeboten. Darüber hinaus ist das Eigeninteresse der Regierung gemäß der Leviathan-These auch auf die Erzielung fiskalischer Überschüsse gerichtet. Aus dieser Perspektive ist die Erhebung von Zöllen eine zusätzliche Einnahmenquelle, die unter bestimmten Bedingungen zumindest partiell zu Lasten der ausländischen Anbieter geht. Die Erhebung von Zöllen ist dann mit einem Lastentransfer (Steuerexport) auf Nichtmitglieder des Staates verbunden. ${ }^{221}$ Schließlich betont die polit-ökonomische Theorie des Protektionismus das Desinteresse der Bürokratie an Deregulierungen des internationalen Handels, da diese mit einem Abbau originärer Aufgabengebiete öffentlicher Verwaltungen und mit Beschränkungen diskretionärer Freiräume verbunden wären. ${ }^{222}$

218 Zu einem Überblick siehe Frey, B.S. (1985), S. 24ff.; Hillman, A.L. (1989), S. 24ff.

219 Siehe hierzu auch insbesondere Downs, A. (1957/1968), S. 249ff. Der Produzentenbegriff von Downs schließt explizit die Arbeitnehmer als Anbieter des Faktors Arbeit mit ein.

220 Vgl. dazu Schuknecht, L. (1990), S. 48.

221 So auch Brennan, G./Buchanan, J.M. (1980/1988), S. 215.

222 Siehe hierzu Messerlin, P. (1981) oder Frey, B.S. (1985), S. 28ff. 
Schon der kursorische Überblick über das Erkenntnisinteresse und die wichtigsten Aussagen der theoretischen Ansätze zeigt, daß die Politische Ökonomie des Protektionismus vor allem ein anwendungsorientierter Forschungszweig im Rahmen der Interessengruppentheorie des Staates ist. Obwohl in der Neuen Politischen Ökonomie noch ein junges Forschungsgebiet ${ }^{223}$, liegen bereits viele empirische Studien vor, die die Prognosen der Public Choice-Theorie zur Handelspolitik im wesentlichen bestätigen. 224

\section{Protektionismus und polit-ökonomische Theorie des Wettbewerbsföderalismus}

\section{a. Zur Relevanz der Argumentation im Bundesstaat}

Die von der polit-ökonomischen Theorie des Protektionismus formulierten Gedanken fanden bislang in der Theorie des Wettbewerbsföderalismus nur wenig Beachtung. Das geringe Interesse an der Fragestellung, ob die Politik lokaler Gebietskörperschaften von protektionistischen Erwägungen geprägt sein könnte, könnte auf zwei Faktoren zurückzuführen sein. Erstens ist in der Realität föderativ organisierter Staaten die Auferlegung von Importzöllen, als das protektionistische Instrument par excellence, für die subnationalen Körperschaften aufgrund der Geltung des Ursprungslandprinzips ausgeschlossen. Zweitens wird Protektionismus auf subzentraler Ebene in der einschlägigen Literatur deshalb kaum untersucht, da Regulierungen des Produktions- und des Warenverkehrs meist in den Zuständigkeitsbereich der Zentralebene fallen. ${ }^{225}$ In den theoretischen Analysen wird deshalb davon ausgegangen, daß die Gliedstaaten ein hinreichendes Interesse an interjurisdiktioneller Freizügigkeit und interregionalem Freihandel haben. Im Rahmen der hier vertretenen polit-ökonomischen Perspektive muß eine solche Argumentation aus drei Gründen relativiert werden:

- Zwar wird angenommen, daß subzentrale Regierungen aus fiskalischem Interesse das Ziel verfolgen, Abwanderungsmöglichkeiten zu beschränken und die Zuwanderung potentieller Steuerzahler zu fördern. Aber auch hinter der Limitierung der Zuwanderungen von Gütern und Faktoren könnten fiskalische Motive stehen. Immigrationssteuern wirken ebenso als Steuerexport wie Importzölle. Fiskalisch motiviert könnten darüber hinaus auch Zuwanderungsrestriktionen sein, wenn damit die Zuwanderung der Empfänger von Sozialtransfers eingedämmt werden kann.

- Ein auf konstitutioneller Ebene vereinbartes generelles Verbot, Binnenzölle zu erheben, begrenzt zwar den protektionistischen Maßnahmenkatalog. Das gesamte Spektrum einsetzbarer protektionistischer Instrumente ist jedoch vielseitig und wird wohl allenfalls durch den Einfallsreichtum der politischen Akteure begrenzt. 226

- Schließlich wurde gezeigt, daß der in der Politischen Ökonomie des Protektionismus furr die Begründung von Handelhemmnissen zentrale Interessengruppeneinfluß selbst auf

223 Allerdings hat bereits im Jahre 1935 Elmar Schattschneider einen polit-økonomischen Erklärungsansatz fur das Zustandekommen protektionistischer Strategien entwickelt. Siehe Schattschneider, E.E. (1935).

$224 \mathrm{Zu}$ einem Überblick uber empirische Studien siehe etwa Frey, B.S. (1985), S. 36ff.

225 Vgl. Gerken, L. (1995a), S. 7, FN 9.

$226 \mathrm{Zu}$ einem Überblick uber die Erscheinungsformen nicht-tarifarer Handelshemmnisse siehe etwa Donges, J.B. (1981). Magee, S.P./Brock, W.A./Young, L. (1989), S. 259ff. zeigen, daß Politiker, wenn sie mit großerem Widerstand der Wahler gegen Zoblle rechnen mussen, zu weniger offensichtlichen protektionistischen Strategien ubergehen. Sie vermuten, daß die dabei erzeugten volkswirtschaftlichen Verluste sogar großer sind als die Verluste, die die Volkswirtschaft erlitten hătte, wenn die Zollpolitik beibehalten worden ware. 
kommunaler Ebene nicht auszuschließen ist; das gilt insbesondere dann, wenn die Bürger/Steuerzahler räumlich immobil sind.

Insofern kann davon ausgegangen werden, daß auch auf subzentraler Ebene im föderativen Staat protektionistische Praktiken zur Anwendung kommen. Prominentes Beispiel hierfür ist das Instrument der öffentlichen Auftragsvergabe. ${ }^{227}$ So vermutet Finsinger, daß ein Großteil der zwischen lokalen und nicht-ortsansässigen Anbietern diskriminierenden öffentlichen Auftragsvergabe an private Unternehmen auf kommunaler Ebene protektionistisch motiviert ist. ${ }^{228}$ In einer empirischen Untersuchung der ökonomischen Wirkungen der in den USA verbreiteten "purchasing preference laws"229 ermitteln Craig und Sailors, daß Bundesstaaten, in denen diese Gesetze zur Anwendung kommen, im Mittel um 3\% höhere pro-Kopf Ausgaben haben als Bundesstaaten ohne gesetzlich fixierte Vorzugsbehandlung ansässiger Anbieter. Die Autoren führen dies darauf zurück, daß "... own state residents are not all weighted equally. For the case of purchasing preferences we find evidence of considerable within-state redistribution."230 Ähnliche handelshemmende Wirkungen können auch durch subzentrale Qualitätsregulierungen oder Sicherheitsstandards erreicht werden.231 Weitere nicht-tarifäre Strategien zur Abwehr gebietsfremder Konkurrenz sind die steuerliche Begünstigung oder die direkte Subventionierung der ortsansässigen Anbieter, die zu einer relativen Verteuerung der importierten Produkte führen.

\section{b. Protektionismus auf dezentraler Ebene und interjurisdiktionelle Faktormobilität}

Die analoge Übertragung der Argumente in bezug auf den interregionalen Handel ist jedoch nicht uneingeschränkt möglich. Die polit-ökonomische Theorie des Protektionismus geht in der Regel davon aus, daß die durch Handelshemmnisse begünstigten Unternehmen (Sektoren) räumlich immobil sind. 232 Wird diese Annahme im interregionalen Zusammenhang aufgehoben, besteht für die protektionistischen Interessen die Gefahr, daß die Zuwanderung konkurrierender Anbieter aus anderen Jurisdiktionen zur Aufzehrung der durch rent seeking erzielten

227 Blankart, C.B. (1994b), S. 441 vertritt die Auffassung, daß "... das heute oft geăußerte Unbehagen uber das offentliche Vergabewesen ... das Ergebnis langjahriger Bestrebungen der Politiker [ist], diese Institution als Instrument im Wettbewerb um Wahlerstimmen einzusetzen. Politiker versuchen, durch gezielte Vergabe von Aufträgen die Stimmen marginaler Wăhlergruppen zu gewinnen und dadurch im Wahlkampf zu siegen."

228 Siehe Finsinger, J. (1988). Breton und Salmon entgegnen, daß eine Diskriminierung nicht zwangslaufig auf protektionistischen Motiven beruht. Sie argumentieren, daß lăngerfristige Geschăftsbeziehungen zwischen den staatlichen Auftraggebern und den (lokalen) Anbietern Opportunismusgefahren bei der offentlichen Auftragsvergabe reduzieren könnten, so daß "... preferential purchasing can guarantee the efficient delivery of ... unverifiable services." Breton, A./Salmon, P. (1996), S. 67.

229 Je nach Ausgestaltung der Gesetze werden bundesstaatliche Anbieter bei offentlichen Ausschreibungen entweder nur bevorzugt, wenn sie zu gleichen Bedingungen wie außerstaatliche Produzenten anbieten oder wenn die Leistungen bis zu einem bestimmten Maximalprozentsatz (in der Regel 5\%) teurer sind. Siehe Craig, S.G./Sailors, J.W. (1988), S. 122f. Zu dieser Problematik im kommunalen Haushaltswesen BadenWurttembergs aus juristischer Perspektive siehe Faiß, K. (1986), S. 176f.

230 Craig, S.G./Sailors, J.W (1988), S. 129. Siehe dazu auch Fisher, R.C. (1991), S. $263 \mathrm{f}$.

231 Vgl. etwa Pelkmans, J. (1990), S. 103, der explizit die Bauvorschriften (building codes) der states als technische Handelsschranke in den USA erwăhnt.

232 Siehe etwa Hillman, A.L. (1989), S. 12ff. 
Vorteile führt. ${ }^{233}$ Subzentrale protektionistische Politik zur Begünstigung organisierter Interessen kann deshalb dauerhaft nur erfolgreich sein, wenn die belasteten Konsumenten/Steuerzahler immobil sind und wenn die konkurrierenden Anbieter nicht durch Zuwanderung in den Genuß der gewährten Privilegien kommen können. 234

In einem specific-factor-Modell demonstrieren Findlay und Wellisz, welche Konsequenzen sich im internationalen Zusammenhang durch die Mobilität der Faktoren für die protektionistischen Interessen ergeben. 235 Sie betrachten eine einfache Ökonomie, in der nur Agrarprodukte und Industriegüter hergestellt werden. Agrarprodukte werden durch den Einsatz des unvermehrbaren, spezifischen Faktors Boden in Kombination mit dem Faktor Arbeit erstellt, Industrieprodukte dagegen durch den Einsatz von sektorspezifischem Kapital und Arbeit. Arbeit sei ein intersektoral mobiler Produktionsfaktor. Findlay und Wellisz gehen vereinfachend davon aus, daß das betrachtete Land Industriegüter importiert und Agrarerzeugnisse exportiert. Entsprechend formieren sich die Lobbies für und gegen einen protektionistischen Importzoll auf Industrieprodukte. Der sich in einem einfachen politischen Gleichgewichtsmodell ergebende markträumende Zolltarif auf importierte Industriegüter führt im Vergleich mit einer Ausgangssituation ohne Handelsrestriktion zu einem relativen Anstieg der Kapitaleinkommen und zu einem relativen Rückgang der Bodeneinkommen. 236

Nimmt man mit Findlay und Wellisz an, Kapital sei răumlich mobil, würde der LobbyingErfolg der Industrieorganisation zu einem Kapitalzufluß aus dem Ausland führen. Als Folge der Kapitalzuwanderung würden nicht nur die Einkommen der einheimischen Kapitaleigner, sondern auch die der Bodeneigentümer fallen. Der intersektoral mobile Faktor Arbeit würde von der Zuwanderung profitieren, da die relative Knappheit des Arbeitsangebotes steigt, "... so that we would have a coalition of foreign capital and domestic labor against a coalition of domestic capitalists and landowners on the issue of the extent to which foreign capital should be permitted to enter the country." 237

Diese Ausführungen werden durch Abbildung 5.9 illustriert und auf einen interregionalen Zusammenhang übertragen. Betrachtet sei eine Jurisdiktion i, deren Bewohner einen Kapitalstock $k_{1}$ besitzen, mit dem ein lokales Sozialprodukt $0 \mathrm{fdk}_{1}$ erwirtschaftet werden kann. Bei ungehinderter Mobilität des Faktors Kapital und vollkommen elastischem bundesstaatlichem Kapitalangebot würde Kapital aus den übrigen Gliedstaaten zufließen und die sozialproduktmaximierende Allokation $\mathbf{k}^{*}$ realisiert, bei der die Grenzproduktivität des Kapitals (MPKKurve) in der Jurisdiktion i dem bundesstaatlich einheitlichen Zins $r$ entspricht. Den heimischen Kapitaleignern kommen insgesamt Kapitaleinkünfte in Höhe von Oabk $\mathbf{z u}_{1}$, die Zinszahlungen an gebietsfremde Kapitaleigner betragen dagegen $\mathbf{k}_{1}$ bck*. Die Rente der immobilen Faktoren entspricht in diesem Fall der Fläche acf.

233 Vgl. etwa auch Finsinger, J. (1988), S. $70 \mathrm{f}$.

234 Siehe dazu insbesondere Olson, M. (1982/1991), S. 188ff.

235 Siehe Findlay, R./Wellisz. S. (1983).

$236 \mathrm{Vgl}$. Findlay, R./Wellisz. S. (1983), S. 473f.

237 Findlay, R./Wellisz. S. (1983), S. 474. 


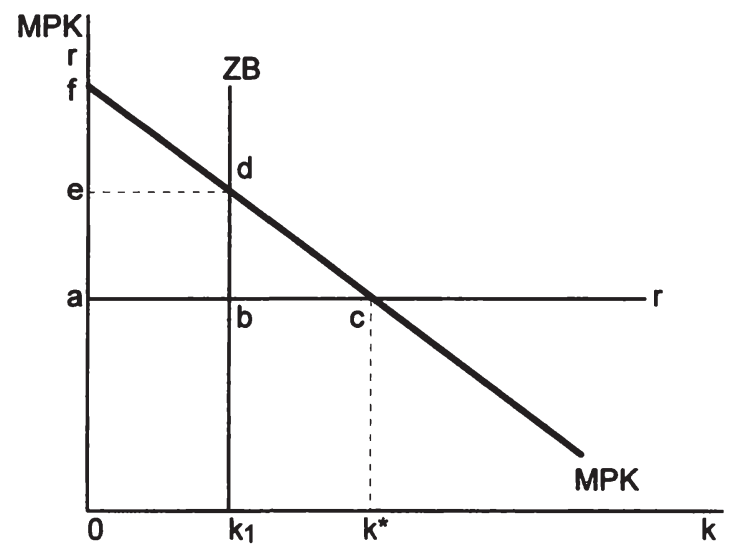

\section{Abbildung 5.9: Protektionistische Strategie und Rentenverluste immobiler Faktoren Quelle: eigene Darstellung}

Können organisierte Eigentümer von Kapital in i eine Zugangsbeschränkung (ZB) durchsetzen, wird ein weiterer Zufluß von Kapital aus den ubrigen Gebietskörperschaften des Bundesstaates verhindert. Die heimischen Kapitalanbieter erzielen bei einem Kapitalbestand $\mathbf{k}_{1}$ eine um ae höhere Verzinsung je eingesetzter Kapitaleinheit, ihre Verteilungsgewinne durch erfolgreiches Lobbying betragen daher abde, die voll zu Lasten der immobilen Faktoren gehen. Zugleich entstehen den Eignern immobiler Faktoren zusätzliche Wohlfahrtsverluste, in Höhe von bcd, so daß sie im Vergleich zur Situation bei unbeschränktem interjurisdiktionellem Wettbewerb um die Rentenverluste acde schlechter gestellt sind. Die tatsächlich realisierte Rente der immobilen Faktoren beträgt edf.

Aus dieser Analyse wäre zu folgern, daß bei interregionaler Mobilităt der Unternehmen eine handelspolitische Restriktion zur Begünstigung spezieller Interessen auf lokaler Ebene nicht ausreichend ist. Die dauerhafte staatliche Garantie von Privilegien setzt voraus, daß nicht nur die Konkurrenzprodukte, sondern auch die Konkurrenten vom lokalen Markt ausgeschlossen bleiben. 238

Zwar wäre denkbar, daß zuwandernde Anbieter von der staatlichen Vorteilsgewährung ausgenommen werden. ${ }^{239}$ Diese Strategie ist allerdings politisch schwerer durchsetzbar, weil sie zu einer intrajurisdiktionellen Diskriminierung führt. Im Kern läuft sie auf eine firmenspezifische Vorteilsgewährung hinaus, die freilich eine im Vergleich $\mathrm{zu}$ anderen handelspolitischen Maßnahmen besonders merkliche Begünstigung ist. Weck-Hannemann vermutet, daß der politische Widerstand der unorganisierten Wähler gegen firmenspezifische Sondervorteile

238 Es erscheint einleuchtend, daß die Konsumenten und/oder die Eigentumer der immobilen Faktoren diese Rentenverluste im politischen Proze $B$ zu verhindern suchen, "... aber diese Konsumenten und Arbeiter moggen durch die Propaganda derer, die tatsächlich verlieren, dazu uberredet werden, daß dieser ausländische Eintritt unerwunscht ist." Olson, M. (1982/1991), S. 189.

239 Vgl. Finsinger, J. (1988), S. 70. 
tendenziell größer ausfallen dürfte als bei Privilegien, die für die Gruppe der Begünstigten Kollektivgutcharakter haben. 240

\section{Die Implikationen für die Ausgestaltung der foderativen Staatsverfassung}

\section{Dezentralisierung zur Beschränkung der Rentenumverteilung}

Die bislang vorgetragenen Argumente lassen den Schluß zu, daß auch im Modell der Interessengruppentheorie des Staates der Mobilität nicht organisierter Wähler/Steuerzahler eine wichtige Bedeutung zur Begrenzung opportunistischen Verhaltens der Regierung zukommt. Auch der Gefahr der Ausbeutung durch organisierte Interessen wird durch die exit-Option begegnet. Analog zur Leviathan-Theorie ist deshalb die radikale Dezentralisierung der Politikkompetenzen zu empfehlen, um die Migrationskosten der Bürger gering zu halten.

Je unwirksamer die Abwanderungsrestriktion ist, um so stärker dürfte der Einfluß der organisierten Interessen sein. Lokale Interessengruppen werden deshalb bemüht sein, eine weitgehende Harmonisierung der subnationalen Finanz- und Regulierungspolitiken zu erreichen. Da die Angleichung der lokalen Politiken zu einer Schwächung der exit-Option für die Konsumenten führt, kann die Harmonisierung der Rechtsvorschriften faktisch zur Schwächung des privaten Wettbewerbs beitragen. ${ }^{241}$ Das Kartellierungsargument, oben furr die durch den politischen Prozeß nicht begrenzten Leviathan-Regierungen abgeleitet, besitzt demnach analog für die Interessengruppentheorie Gültigkeit.

Die Interessengruppentheorie beleuchtet noch einen zweiten Aspekt, der in der LeviathanTheorie aufgrund der dort getroffenen Annahmen nicht auftritt. Das Rentenstreben organisierter Interessen kann zur Schließung der lokalen Märkte führen. Nicht der interjurisdiktionelle Standortwettbewerb um mobile Steuerzahler, sondern vielmehr die Behinderung der Zuwanderung potentieller Konkurrenten von nach Partikularvorteilen strebenden Gruppen wird zur Politikstrategie subzentraler Regierungen. Die Vorstellung, allein durch die Dezentralisierung des politischen Systems werde Wettbewerb zwischen den lokalen Anbietern politischer Güter gesichert und die Effizienz politischer Entscheidungen erhöht, kann deshalb nicht uneingeschränkt geteilt werden.

\section{Aspekte einer föderativen Wettbewerbsordnung}

\section{a. Die Notwendigkeit einer föderativen Wettbewerbsordnung}

Diese Darlegungen zeigen, daß sich die 'Segnungen' des interjurisdiktionellen Wettbewerbs dezentraler politischer Akteure, wie sie insbesondere im Leviathan-Ansatz von Brennan und Buchanan, aber auch von Vertretern der Interessengruppentheorie des Staates wie Olson, betont werden, nicht automatisch einstellen. Ebenso wie auf ökonomischen Märkten der Wettbewerb zwischen privaten Anbietern durch den Einsatz systemkonformer wie auch systemwidriger Instrumente erfolgt, ist der Wettbewerb der föderativen Gliedstaaten durch den Gebrauch systemkonformer und systemwidriger Strategien gekennzeichnet. Im neueren

240 So zumindest Weck-Hannemann, H. (1991), S. 134 f.

241 Die Empirie zeigt, daß gerade organisierte Interessen aus hochregulierten Lăndern Regulierungen auf Zentralebene anstreben. Vgl. Streit, M./Mussler, W. (1995), S. 82f. 
Schriftum wird allerdings betont, daß die Verhaltensweisen der Anbieter politischer Güter im föderativen Wettbewerb nur teilweise in Analogie zu wettbewerbsbeschränkenden Strategien der Anbieter auf ökonomischen Märkten gesehen werden können. 242

Standortpolitik ist das Äquivalent zum Eucken'schen "Leistungswettbewerb"243. Die politischen Entscheidungsträger versuchen im Standortwettbewerb, durch attraktive Leistungsangebote mobile Faktoren anzulocken. Das Eigeninteresse der Politiker an einer Steigerung des lokalen Sozialprodukts, an Steuermehreinnahmen und an der Wiederwahl führt nach dieser Theorie zu einem unmittelbaren Schutz der mobilen Faktoren und einem mittelbaren Schutz der Eigentümer immobiler Faktoren. Die vielfach v.a. in der Wohlfahrtstheorie vorgebrachte Argumentation, Wettbewerb um mobile Faktoren führe zu einer relativen Benachteiligung der immobilen Faktoren, konnte zumindest nicht generell bestätigt werden. Die Strategie der Standortpolitik ist somit systemkonform.

Das Trachten nach einer Maximierung der Steuereinnahmen der Politiker einerseits und die Durchsetzungsfähigkeit organisierter lokaler Interessen andererseits führen freilich zu Bestrebungen der subzentralen Regierungen, die Wirtschaftspolitiken durch kooperative Vereinbarungen zu harmonisieren, um den Reaktionsmechanismus der Abwanderung auszuschalten. Diese wettbewerbsbeschränkenden Strategien finden in den Kartellabsprachen privater Anbieter ihre Parallele. Insofern bestehen, wie im privatwirtschaftlichen Kontext, Tendenzen der handelnden Akteure im gliedstaatlichen Wettbewerb, die Konkurrenz zu eliminieren.

Die konstatierten Gemeinsamkeiten von Beschränkungen des privatwirtschaftlichen und des föderativen Wettbewerbs werden demgegenüber schwächer, wenn die Regierungen von politisch auferlegten Migrationsbarrieren ( $\mathrm{Zu}$ - und Abwanderungsbeschränkungen) Gebrauch machen. Der ökonomische Wettbewerb auf privaten Märkten kennt hierzu, wie Streit hervorhebt, keine unmittelbaren Parallelen. 244

Es stellt sich deshalb die Frage, wie in einem föderativen System, dessen gliedstaatlichen Einheiten Entscheidungsautonomie zugestanden wird, die Offenheit der Märkte aufrechterhalten werden kann. Aus institutionenökonomischer Sicht müßte ein Regelsystem geschaffen werden, das die Handlungen der subzentralen Regierungen so kanalisiert, daß die politischen Aktionsparameter wettbewerblichen Handelns systemkonform eingesetzt werden. Im privatwirtschaftlichen Kontext ist dies die Aufgabe der Wettbewerbspolitik, deren Ziel die Erhaltung und die Förderung des privaten Wettbewerbs ist. ${ }^{245} \mathrm{Zu}$ folgern wäre, daß auch für die gliedstaatliche Konkurrenz in föderativen Staaten eine Wettbewerbsordnung erforderlich ist. 246

242 Siehe dazu Streit, M. (1995), S. 127 f.

243 Eucken, W. (1952), S. 42.

244 Vgl. Streit, M. (1995), S. 128.

245 Wenngleich in der wissenschaftlichen Diskussion weder ein Konsens uber den Wettbewerbsbegriff an sich noch uber die konkreten Wettbewerbsfunktionen herrscht, kann die Erhaltung und Förderung von Wettbewerb als kleinster gemeinsamer Nenner aller Anforderungen an eine Wettbewerbspolitik gesehen werden. Siehe dazu die Ausfuhrungen bei Herdzina, K. (1993), insbes. S. 12ff.

246 Vgl. Siebert, H. (1991), S. 40ff. Gerken, L. (1995a), S. 19; Streit, M. (1995), S. 127f,; Kerber, W./Vanberg, V. (1995), S. 56f. 


\section{b. Ausgestaltungs- und Zuordnungsprobleme}

Obwohl die generelle Notwendigkeit einer föderativen Wettbewerbsordnung auf konstitutioneller Ebene allgemeine Akzeptanz findet, ist ihre Ausgestaltung mit Problemen verbunden, die im folgenden kurz skizziert werden sollen. Gerken identifiziert drei Anforderungen, denen eine Ordnung für den föderativen Wettbewerb zu genügen habe. ${ }^{247}$ Erforderlich ist nach seiner Ansicht

1. die Abgrenzung zwischen zulässigen und unzulässigen Wettbewerbshandlungen der gliedstaatlichen Regierungen,

2. die Schaffung der Voraussetzungen für die Gewährleistung und Sicherung des gliedstaatlichen Wettbewerbs und

3. die Etablierung einer Ordnungsinstanz, die mit der Überwachung und Durchsetzung der Wettbewerbsregeln betraut ist.

Bereits die Umsetzung des ersten Kriteriums stellt die Individuen auf konstitutioneller Ebene vor schwerwiegende Probleme. Dabei sind insbesondere zwei Gesichtspunkte von Bedeutung. Erstens ist die Frage, welche Aktivităten zulässig (wettbewerbskonform) und unzulässig (systemwidrig) sein sollen, auch auf konstitutioneller Ebene bestenfalls unvollkommen zu beantworten. Hierbei spielt zum einen eine Rolle, daß dem Erfindungsreichtum der politischen Akteure bei der Suche nach neuen wettbewerbsbeschränkenden Politiken kaum Grenzen gesetzt sind. ${ }^{248}$ Zum anderen ist die Abgrenzung zwischen wettbewerbskonformem und wettbewerbswidrigem Verhalten der Akteure oftmals nur ein graduelles Problem. ${ }^{249}$ Es stellt sich hier die Frage, ob für bestimmte Praktiken der föderativen Einheiten (z.B. Importzollerhebung) ein Per se-Verbot ausgesprochen werden soll, oder ob im Sinne einer Rule of Reason im Einzelfall beurteilt werden sollte, ob eine bestimmte Maßnahme den föderativen Wettbewerb beschränkt. 250

Die zweite Funktion der föderativen Wettbewerbsordnung impliziert, daß die politische Entscheidungssouveränität der Teileinheiten des Bundesstaates begrenzt werden müßte. ${ }^{251}$

247 Vgl. Gerken, L. (1995a), S. 20.

248 "Die Erfahrung in diesen Bundesstaaten [gemeint sind die USA und die Schweiz, H.P.] zeigt, daß es kaum genugt, Zolle und andere Schranken fur den zwischenstaatlichen Handel zu verbieten ... Die Umgehung solcher Gesetze durch einen Einzelstaat, der mit Hilfe administrativer Regelungen sich auf die Bahn der nationalen Planwirtschaft begeben hat, hat sich als so leicht erwiesen, daß alle Wirkungen des Zollschutzes erreicht werden können mit Mitteln wie sanitäre Vorschriften und die Anrechnung von Gebuhren fur diese oder andere administrative Kontrollen. Wenn man bedenkt, wie erfinderisch sich die Gesetzgeber in dieser Hinsicht erwiesen haben, scheint es klar zu sein, daß keine speziellen Verbote in der Bundesverfassung hinreichen würden, um solche Entwicklungen zu verhindern ..." Hayek, F.A. von (1939/1952), S. 338.

249 Dies gilt insbesondere bei politischen Praktiken subzentraler Anbieter, die keine Parallele in den marktlichen Wettbewerbsprozessen haben. Zu fragen wăre hier beispielsweise, ob die Subventionierung lokaler Unternehmen Ausdruck eines wettbewerblichen Verhaltens (Standortpolitik) oder einer protektionistischen Strategie (Exportsubvention) ist. Vgl. auch Gerken, L. (1995a), S. 20.

250 Zur Diskussion "Per se rule versus Rule of Reason" in der praktischen Wettbewerbspolitik siehe z.B. Schmidt, I. (1981).

251 Streit und Mussler sprechen im Hinblick auf das Binnenmarktprogramm der EU von einem "... Konflikt zwischen Binnenmarkt und nationaler Regierungssouverănităt", der letztlich ein Abwăgen zwischen den beiden Zielvorstellungen erforderlich mache. Streit, M./Mussler, W. (1995), S. 94. 
Die Offenhaltung der Märkte setzt den Verzicht auf Zutritts- und Austrittsschranken voraus. Eindeutig konsensfähig dürfte freilich nur ein Verbot der Errichtung von politischen exitBarrieren sein. ${ }^{252}$ Aus clubtheoretischer Sicht gibt es jedoch Argumente für eine zumindest nur "selektive Offenheit"253 gegenüber potentiellen Zuwanderern. ${ }^{254}$ Hierfür werden vor allem zwei Argumente angefuhrt. Da mit der Bereitstellung lokaler Kollektivgüter steigende Überfüllungskosten verbunden sind, würden erstens bei unregulierter Zuwanderung die Vorteile für die ortsansässigen Bürger aufgezehrt werden. ${ }^{255}$ Eine im interkollektiven Wettbewerb erfolgreiche Regierung würde für ihre Anstrengungen, die Nutzen der Wähler zu maximieren, bestraft, wenn sie den Zugang zur Kollektivgutnutzung nicht reglementieren kann. ${ }^{256}$ Zweitens ist auch das einschlägige Argument, ohne die Option einer Beschränkung der Zuwanderung bestehe die Gefahr der zero regulation, nicht gänzlich von der Hand zu weisen.

Auf der anderen Seite führt die Reglementierung der Zuwanderung durch politische Anbieter zu einer Umverteilung der Verfügungsrechte an den locational co-operation rents von den Bürgern zu den Regierungen oder speziellen Interessengruppen. ${ }^{257}$ Ein Abwägen des Für und Wider läßt vermuten, daß kontrollierte Zuwanderungsbeschränkungen auf lokaler Ebene in der föderativen Wettbewerbsordnung gestattet sein könnten (Rule of Reason), dies jedoch nur bei gleichzeitiger Per se-Offenhaltung der Abwanderungsoption. 258

Das dritte Kriterium, die Notwendigkeit einer kontrollierenden Ordnungsinstanz zur Durchsetzung der in der föderativen Wettbewerbsordnung gesetzten Regeln, hat Parallelen zur Argumentation hinsichtlich der optimalen Größe des protektiven Staates. In der Tat ist die Aufgabe, die Einhaltung föderalstaatlicher Wettbewerbsregeln zu überwachen, gleichzusetzen mit der ordnenden und schützenden Funktion des Buchanan'schen Rechtsschutzstaates. Das für den protektiven Staat postulierte Neutralitätsgebot bei der Regeldurchsetzung gilt auch fur die Durchsetzung der in einer konstitutionellen Phase festgelegten föderativen Wettbewerbsregeln. Die Frage nach der Zuordnung der Zuständigkeiten - die im Grunde genommen der eines 'Kartellamtes zur Überwachung des föderativen Wettbewerbs' entsprächen - wirft daher ähnliche Probleme auf. Der räumliche Ausdehnungsbereich der Zuständigkeiten wird dementsprechend mit der Größe des protektiven Staates, und damit der Zentralebene, übereinstimmen müssen. 259 Die Logik einer einheitlichen Rechtsordnung, sei es die Privatrechtsordnung oder

252 Vgl. Welter, P. (1995), S. 132.

253 Schwarz, G. (1993), S. 266.

254 Nach Gerken ist es zumindest fraglich, "... warum es dem Club (Staat) verwehrt sein sollte, die Zahl seiner Mitglieder (Burger) also die Einwanderung, zu begrenzen. Das gleiche Argument gilt fur die Entscheidung eines Clubs, bestimmte Guter, die von den Mitgliedern (Burgern) konsumiert werden, intern herzustellen und den Verkauf von Gutern durch Nicht-Clubmitglieder auf dem Territorium zu verbieten, also Importe zu beschränken. Wem eine solche Club-Politik nicht zusagt, hat das Recht auszutreten, also zu emigrieren." Gerken, L. (1995a), S. 18.

255 Vgl. die Ausfuhrungen zum Tiebout-Modell, S. 104.

256 Siehe dazu thnlich Tiebout, C.M. (1956), S. $419 f$.

$257 \mathrm{Vgl}$. Welter, P. (1995), S. 135. Außerdem wirken Zuwanderungsbeschrankungen einer subzentralen Einheit immer auch als Abwanderungshemmnis fur die Bürger anderer Jurisdiktionen.

258 Dahinter steht die allgemein akzeptierte Auffassung, daß die Per se-Rule einen besseren Schutz vor opportunistisch geprägten diskretionären Entscheidungen bietet. Vgl. z.B. Hoppmann, E. (1972), S. 63.

259 Nach Stehn, J. (1993), S. 44 gehort z.B. die Beihilfenaufsicht aus fiskalføderalistischer Sicht zu den Aufgaben der Zentralebene, "... denn die Aufstellung und Durchsetzung allgemeingultiger Regeln zum Schutz des Wettbewerbs ist eine wesentliche Voraussetzung fur die Verwirklichung des Gemeinsamen 
die föderative Gliedstaatenwettbewerbsordnung, impliziert die räumliche Zuständigkeit der Durchsetzungsinstanz für den territorialen Gültigkeitsbereich des Rechtssystems.

Indessen ist der idealtypisch unabhängige Rechtsschutzstaat eine Fiktion. ${ }^{260}$ Dies gilt auch, und gerade, für die Unabhängigkeit der Kartellbehörden, da jede de jure-Verankerung der Unabhängigkeit de facto von opportunistischen (politischen) Entscheidungen aufgeweicht werden kann. ${ }^{261}$ Aus der Public Choice-Perspektive ist dem Anforderungskatalog deshalb ein viertes Kriterium hinzuzufuigen. Danach muß sichergestellt werden, daß die Instanz zur Sicherung des Ordnungswettbewerbs Anreize zur Verfolgung der ihr zugewiesenen Aufgaben hat, mithin das Ausbeutungspotential der Zentralebene begrenzt werden kann.

\section{Spezifisch föderative Arrangements zur Begrenzung der Zentralebene}

\section{a. Die Notwendigkeit und das Problem einer Begrenzung der Zentralebene}

Sowohl die Diskussion der Leviathan-These als auch der Interessengruppentheorie des Staates hat gezeigt, daß die Ausbeutungsmacht staatlicher Akteure und organisierter Interessen gegenüber den Bürgern durch Abwanderungsoptionen geschwächt wird. Sieht man von internationalen Güter- und Faktorbewegungen $a b$, bedeutet dies auf der Zentralebene eine ständige Bedrohung für die unorganisierten Wähler und Konsumenten. Die polit-ökonomische Aufgabenzuweisungsdebatte ist deshalb vor allem von der Auffassung geprägt, daß der obersten Ebene im föderativen Staat nur in eingeschränktem Maße Kompetenzen zugewiesen werden sollten. 262

Obwohl aus der Public Choice-Perspektive die Skepsis in bezug auf eine zentralstaatliche Aufgabenwahrnehmung groß ist, wird dennoch nicht ubersehen, daß zumindest für die Zuständigkeiten des protektiven Staates - die Garantie innerer und äußerer Sicherheit, die Aufrechterhaltung eines wettbewerblichen Marktsystems und die Offenhaltung der Märkte eine nationale Kompetenz vonnöten ist. ${ }^{263}$ Die Vermeidung des Rückfalls in die Anarchie wird zwar im Buchanan'schen Ideal von einer außenstehenden neutralen Institution gewährleistet, die aber nicht kostenlos agiert. Auch die Zentralebene benötigt mithin Ressourcen, die damit einer Verwendung im privaten Sektor entzogen werden.

Die normative Bestimmung der Optimalgröße des protektiven Staates wurde unter der Annahme vorgenommen, daß der optimale Spezifikationsgrad und der optimale Durchsetzungsgrad der privaten Verfugungsrechte exogen vorgegeben sind bzw. bereits im konstitutionellen Entscheidungsprozeß festgelegt werden. Wenngleich diese Prämisse zur analytischen Herausarbeitung der Bestimmungsfaktoren der Staatsgröße sinnvoll ist, wird damit

Marktes." Ähnlich auch Breton, A. (1987), S. 298, der jedoch der zentralstaatlichen Ebene nicht nur eine reine Überwachungsfunktion zuspricht, sondern daruber hinaus die Wettbewerbsfähigkeit der subzentralen Einheiten durch die Zentralebene kontrolliert sehen will. Dies ist aus der hier vertretenen Sicht keine Funktion der Überwachungs- und Durchsetzungsinstanz.

260 So insbesondere Wagner, R.E./Gwartney, R.D. (1988), S. $40 \mathrm{ff}$.

261 Zu einem knappen Überblick siehe Baum, T. (1982).

262 Sie ist zumindest, wie die vorangegangenen Ausfuhrungen deutlich gemacht haben, gegenuber einer zentralstaatlichen Bereitstellungskompetenz weitaus skeptischer eingestellt als die traditionelle, von wohlfahrtstheoretischen Erwägungen geprägte, Theorie des Fiskalfoderalismus.

$263 \mathrm{Vgl}$. die Ausfuhrungen von Buchanan, J.M. (1975/1984). 
jedoch von der realiter existierenden Notwendigkeit einer Festlegung dieser Größen im politischen Prozeß abstrahiert. Der Grad an äußerer und innerer Sicherheit, der auch die Produktionskosten dieses Kollektivgutes bestimmt, ist folglich ebenfalls Gegenstand einer Kollektiventscheidung im Leistungsstaat, die denselben Unzulänglichkeiten unterliegt, wie sie bei Entscheidungen über die Bereitstellung anderer Kollektivgüter anzutreffen sind.

Überdies ist bei allen Vorbehalten gegenüber einer zentralen Aufgabenwahrnehmung nicht auszuschließen, daß die Individuen in der konstitutionellen Beschlußphase bestimmte Kompetenzen des produktiven Staates auf zentralstaatlicher Ebene angesiedelt sehen wollen. Zu nennen wären hier beispielsweise die Durchsetzung von Standards für die private Produktion (Sicherheitsvorschriften u.ä.) oder die Wahrnehmung von Aufgaben, deren Nutzenstreuung das gesamte Bundesgebiet umfaßt oder sogar überschreitet - man denke etwa an internationale Umweltprobleme. ${ }^{264}$ Die in der nach-konstitutionellen Phase auftretenden Probleme kollektiver Entscheidungen, insbesondere die Einflußnahme spezieller Interessengruppen in diesen Bereichen, sind evident. 265

Es kann daher angenommen werden, daß trotz der Bedenken gegen zentralstaatliche Aufgabenhoheiten ein nicht unerheblicher Teil der staatlichen Aufgabenkompetenzen der höchsten föderativen Ebene zugeordnet wird. Demzufolge sind Regelungen zu treffen, die sicherstellen, daß die zugewiesenen Entscheidungshoheiten nicht zu Lasten der Bürger ausgeübt werden. Die einschlägige Literatur zu fiskalischen Restriktionen ist nahezu ausschließlich auf die Begrenzung eines unitarischen Staates ausgerichtet. Sie soll deshalb auch nicht näher betrachtet werden. 266 Hier sind in erster Linie Vorschläge von Interesse, die die föderative Dimension des Staatsaufbaus explizit berücksichtigen. Die wichtigsten Ansätze sollen im folgenden skizziert werden.

\section{b. Reverse Revenue Sharing}

Unter diesem Aspekt wurde in der Literatur der Vorschlag gemacht, auf ein Besteuerungsrecht der Zentraleinheit gänzlich zu verzichten und stattdessen die übergeordnete nationale Jurisdiktion ausschließlich durch Finanzbeiträge der subzentralen Einheiten zu alimentieren ("reverse revenue sharing"267). Auf den ersten Blick ähnelt dieser Lösungsvorschlag der horizontal-kooperativen Lösung zur Internalisierung räumlicher externer Effekte, wie sie im dritten Kapitel behandelt wurde. ${ }^{268}$ Das dort vorgeschlagene Arrangement beruhte auf allokativen Effizienzüberlegungen, wonach die Besteuerung auf subzentraler Ebene mit Informationsvorteilen verbunden sei und deshalb regional und lokal differierenden Präfenzen besser entsprochen werden könne. Dort wurde allerdings auf die Probleme eines Trittbrettfahrerverhaltens der subzentralen Gemeinwesen verwiesen, die die Koordinationskosten gemein-

264 Siehe hierzu etwa Barrett, S. (1990).

265 Zum Einfluß von Interessengruppen in der Wahl umweltpolitischer Instrumente siehe z.B. Caesar, $R$. (1994b), S. 99ff.

266 Siehe etwa den kursorischen Überblick bei Folkers, C. (1983).

267 Siehe insbesondere Lee, D.R. (1985) und (1994); Buchanan, J.M./Lee, D.R. (1995). Der Begriff reverse revenue sharing wird von Lee in Analogie zum revenue sharing-Arrangement (Gemeinschaftssteuern) gewahlt, bei dem die Zentralebene Steuern erhebt und sie dann auf die gliedstaatlichen Einheiten mittels ungebundener Finanztransfers verteilt.

268 Siehe oben, S. $91 \mathrm{ff}$. 
schaftlicher Bereitstellungsarrangements bei einer Vielzahl von Beteiligten anwachsen lassen. Aus der Perspektive der Public Choice-Richtung wären aber die Koordinationskosten a priori kein Hindernis, denn sie sorgen zum einen für eine als erstrebenswert angesehene Labilität des Steuerkartells. ${ }^{269}$ Zum anderen steht nicht unmittelbar die allokative Effizienz des reverserevenue-sharing-Arrangements im Zentrum der polit-ökonomischen Überlegungen, sondern die Begrenzung der Zentralebene. Deshalb könnten, so Buchanan und Lee, allokative Vorteile regional differenzierter Beitragssätze von nachrangiger Bedeutung sein.

Die Vertreter dieses Konzepts schlagen vor, daß die Finanzbeiträge der nachgeordneten Gemeinwesen durch einen ex ante fixierten und für alle Einheiten identischen, proportionalen Abgabesatz auf die von ihnen erzielten Steueraufkommen ermittelt werden sollten. Die Festlegung des Beitragssatzes solle mit einer konsensnahen qualifizierten Mehrheit der beteiligten Jurisdiktionen erfolgen. ${ }^{270}$ Im einzelnen würden dadurch folgende Vorteile erzielt:

- Ein Trittbrettfahrerverhalten der Jurisdiktionsregierungen würde ausgeschlossen, denn keine subzentrale Einheit könnte ihre Beitragsleistung verringern, ohne gleichzeitig das eigene Steueraufkommen zu reduzieren. Der einzige Weg, die Finanzbeiträge an die Zentraleinheit zu reduzieren, wäre, die eigenen Leistungen effizienter zu erstellen. 271

- Der Wettbewerb der subnationalen Einheiten würde sogar verschärft, denn einer Fiskalillusion der Bürger würde entgegengewirkt. Wie Lee anmerkt: "... the differences in state fiscal decisions would not be masked over by an overlay of centrally imposed taxes." 272

- Jede Form der Mischfinanzierung entbindet die lokalen Einheiten von der Notwendigkeit, eigene Finanzierungsquellen auszuschöpfen. Damit würde in Konsequenz aber auch das Aufkommen der übergeordneten Ebene geringer. ${ }^{273}$ Die Einmischung der Zentralebene in lokale Entscheidungen würde folglich unterbleiben.

- Stattdessen würde sich die Zentralebene zur Maximierung ihrer fiskalischen Erträge auf die Wahrnehmung von Aufgaben konzentrieren, die sich im gesamten Bundesstaat sozialproduktsteigernd auswirken und daher auch zur Maximierung der subnationalen Steueraufkommen beitragen. 274 Dagegen ist allerdings kritisch einzuwenden, daß Kartellierungsbestrebungen der subzentralen Einheiten von der Zentralebene zumindest nicht entgegengetreten würde, weil diese zu einer Steigerung der gliedstaatlichen Steueraufkommen und zu einer Erhöhung der zentralstaatlichen Steuereinnahmen führen würden.

Insgesamt, so die Folgerung von Buchanan und Lee, könnte durch reverse revenue sharing das kompetitive Element im föderativen System gestärkt und eine Begrenzung des zentralen Leviathan und des Interessengruppeneinflusses erreicht werden. 275 Die möglicherweise aus

269 Siehe auch Caesar, R. (1996), S. 19.

$270 \mathrm{Vgl}$. Buchanan, J.M./Lee, D.R. (1995), S. 224. Siehe auch Lee, D.R. (1985), S. 282 und S. 288, FN 11.

271 Vgl. Lee, D.R. (1985), S. 283. Wahrend damit z.B. die Beteiligung der EU-Ebene an den nationalen Umsatzsteueraufkommen diesem Vorschlag sehr nahe kommt, wäre die BSP-Abgabe aus dieser Perspektive abzulehnen, denn wenn die Mitgliedsstaaten der EU durch Deregulierung und Steuersenkungen sozialproduktsteigernde Wirkungen erzielen, werden sie durch høhere Abgaben an die Zentralebene bestraft.

272 Lee, D.R. (1985), S. 283.

273 Vgl. Lee, D.R. (1994), S. 81f. und Buchanan, J.M./Lee, D.R. (1995), S. $228 \mathrm{f}$.

274 Vgl. Buchanan, J.M./Lee, D.R. (1995), S. $226 \mathrm{f}$.

275 Vgl. Buchanan, J.M./Lee, D.R. (1995), S. 230. 
den für alle gliedstaatlichen Einheiten gleichen Beitragssătzen resultierenden allokativen Nachteile wären als Preis für die Beschränkung des zentralstaatlichen Leviathan hinzunehmen. 276

\section{c. Die Stärkung subzentraler Einflüsse bei zentralstaatlichen Entscheidungen}

Wie Knut Wicksell in seiner Abhandlung "Ueber ein neues Prinzip der gerechten Besteuerung"277 hervorgehoben hat, ist bei einer Anwendung der Einstimmigkeitsregel bei Kollektiventscheidungen die Bildung von Umverteilungskoalitionen nicht möglich. Er schlägt deshalb, um die Impraktikabilităt der Einstimmigkeitsregel wissend, die Geltung qualifizierter Mehrheitsregeln jenseits der 50\%-Grenze vor, was eine politisch erzwungene Umverteilung zwar nicht gänzlich ausschließen kann, aber doch zumindest erschwert. ${ }^{278}$ Wagner und Gwartney befürworten daher für die Gliedstaaten auf höheren Ebenen im föderativen System, zwischen denen das kompetitive Element nicht so ausgeprägt ist, die Geltung von qualifizierten Mehrheitserfordernissen. 279

Nach Buchanan und Tullock ist ein ähnliches Ergebnis mittels eines Zwei-Kammern-Systems ("bicameral legislature"280) zu erreichen. Im Kern beruht die Begrenzungswirkung eines Zwei-Kammern-Systems darauf, daß für bestimmte Entscheidungen die Zustimmung beider Parlamente erforderlich ist. Buchanan/Tullock zeigen, daß die simultane Mehrheitserfordernis zu einer Reduzierung der expected external costs führen kann, ohne die costs of decision making all zu stark zu erhöhen. ${ }^{281}$ Dies setzt jedoch voraus, daß die Auswahl der Delegierten in den Parlamenten auf der Basis verschiedener Abgrenzungskriterien erfolgen muß: "Translated into more practical terms, this means that unless the bases for representation are significantly different in the two houses, there would seem to be little excuse for the twohouse system." 282

Diese Differenzierung kann z.B. auch nach geographischen Erwägungen erfolgen, indem die Zusammensetzung des Abgeordnetenhauses der Zentralebene durch nationale Wahlen bestimmt wird und die zweite Kammer sich aus Vertretern der subzentralen Ebene zusammensetzt, wie es etwa in den USA, in der Schweiz und in der Bundesrepublik Deutschland der Fall ist. ${ }^{283}$ In noch schärferer Weise würde ein Vetorecht der gliedstaatlichen Einheiten gegen Beschlüsse der Bundesregierung eine Begrenzung des Zentralstaates bedeuten. ${ }^{284}$ Ziel dieser unterschiedlichen Ansätze intensiverer Beteiligung der Gliedstaaten an der zentralen Entscheidung ist es, das Ausmaß der interregionalen Umverteilungspolitik, wie von Weingast, Shepsle und Johnsen 285 beschrieben, einzudämmen. Föderative Subeinheiten, die von der

276 Siehe ausfuhrlich Lee, D.R. (1985), S. 284ff.

277 Wicksell, $K$. (1896).

278 Siehe Wicksell, K. (1896), S. $110 \mathrm{ff}$. und die Ausfuhrungen im 2. Kapitel.

279 Siehe Wagner, R.E./Gwartney, R.D. (1988), S. 48f.

280 Buchanan, J.M./Tullock, G. (1962), S. 233.

281 Siehe Buchanan, J.M./Tullock, G. (1962), Kap. 16 oder auch Mueller, D.C. (1996), S. $192 \mathrm{ff}$.

282 Buchanan, J.M./Tullock, G. (1962), S. 236.

283 Siehe Laufer, H. (1992), S. 97ff. zur Rolle des Bundesrates in der Bundesrepublik Deutschland. Die Begrenzungswirkung des Bundesrates wird freilich bei unterschiedlichen Mehrheiten in Bundestag und Bundesrat oftmals als 'Blockadepolitik' empfunden.

284 Siehe Niskanen, W.A. (1978), S. 173.

285 Vgl. Weingast, B./Shepsle, K./Johnsen, M. (1981). Siehe die Ausfuhrungen S. 198. 
zentralstaatlichen Maßnahme negativ betroffen sind, könnten solche Politiken verhindern, wenn ihnen entsprechende Mitentscheidungsrechte bei zentralstaatlichen Bereitstellungsentscheidungen eingeräumt werden.

Als ultima ratio könnte schließlich ein Sezessionsrecht für die Gliedstaaten, gewissermaßen die Institutionalisierung einer exit-Option für die Jurisdiktionen, Schutz vor oktroyierten Gemeinschaftsentscheidungen bieten. Der Befürchtung, das Recht auf Sezession führe zu einer unannehmbaren Instabilität des Bundesstaates, kann entgegengehalten werden, daß die Kosten der Abspaltung für einen einzelnen Gliedstaat sehr hoch sein dürften. ${ }^{286}$

\section{d. Funktionale Differenzierung und Separierung der Delegationsfelder}

In ähnlicher Weise würde die stärker funktional orientierte Gliederung der Staatswirtschaft zur Begrenzung der Zentralebene beitragen können. Die bislang angestellten Überlegungen beziehen sich ausschließlich auf einen territorialen Aspekt des Föderalismus. ${ }^{287}$ Indessen ist, worauf Kirsch bereits vor einiger Zeit hingewiesen hat, "... nicht einzusehen, warum die Gebietsgebundenheit von Kollektiven das criterium distinctionis der noch interessierenden Zusammenschlüsse sein soll. Gerade, wenn die Mobilitäts- und die Kommunikationskosten etwa als Folge der technischen Entwicklung sinken, ist zu erwarten, daß die funktionalen gegenüber den regionalen Kollektiven an Bedeutung gewinnen werden." 288

In diesem Sinne, so ein Vorschlag von Kruse, sei die "institutionelle Separierung der politischen Entscheidungsfelder"289 auf Fachparlamente, deren Zusammensetzung durch separate Wahlgänge bestimmt wird, als radikalster Reformvorschlag anzusehen. Eine Begrenzungswirkung ergibt sich nicht nur durch die beschränkte Möglichkeit des impliziten log rolling, sondern darüber hinaus durch die Offenlegung der Zielbeziehungen zwischen unterschiedlichen Politikfeldern. Damit wird für die Wähler erstens die Transparenz politischer Entscheidungen erhöht und zweitens werden die Opportunitätskosten politischer Einzelmaßnahmen besser ersichtlich. 290

\section{Zusammenfassende Thesen zum fünften Kapitel}

1. Nach der Dezentralisierungshypothese ist die exit-Option eine wirksame Beschränkung für subzentrale Leviathan-Regierungen. Je stärker dezentralisiert der Staatsaufbau ist, um so weniger können opportunistische staatliche Entscheidungsträger Steuerzahlerrenten abschöpfen. Eine klare empirische Bestätigung der Hypothese von Brennan und Buchanan steht allerdings noch aus.

2. Die Existenz natürlicher Mobilitätsbarrieren für die Eigentümer des Faktors Boden und für die Anbieter des Faktors Arbeit stärkt das Ausbeutungspotential des Leviathan. Allerdings kann die interjurisdiktionelle Mobilität des Kapitals einen gewissen vorbeugenden Schutz

286 Siehe dazu Buchanan, J.M./Faith, R. (1987); Buchanan, J.M. (1991), S. 135; Buchanan, A.E. (1991), Kap. 4; Zarkovic-Bookman, M. (1992); Young, R.A. (1994); Chen, Y./Ordeshook, P.C. (1994).

$287 \mathrm{Zu}$ einem ersten Ansatz fur eine Theorie des funktionalen Foderalismus siehe Tiepelmann, K./van der Beek, G. (1992).

288 Kirsch, G. (1977), S. 12.

289 Kruse, J. (1995), S. 28.

290 Vgl. Kruse, J. (1995), S. $29 \mathrm{f}$. 
für immobile Individuen bieten. Eine zweite Relativierung ergibt sich durch das Vorliegen răumlicher Nutzen- und Kostenexternalitäten bei der Bereitstellung von Kollektivgütern, die einer Dezentralisierung entgegenstehen. Auf konstitutioneller Ebene ist abzuwägen, ob die (erwarteten) Nutzenverluste der Bürger durch suboptimale Bereitstellungsmengen oder durch opportunistisches Regierungsverhalten überwiegen.

3. Um den Abwanderungsdruck zu mindern, werden Leviathan-Regierungen versuchen, die Kosten interjurisdiktioneller Migrationen für die Bürger zu erhöhen. Neben dem Einsatz diverser Instrumente zur Steigerung der politischen Mobilitätskosten ist v.a. zu erwarten, daß die subzentralen Regierungen die Harmonisierung finanzpolitischer Aktionsparameter anstreben. Der Kollusionsgefahr muß aus dieser Perspektive durch eine weitgehende Dezentralisierung, durch ein Verbot vertikaler Finanztransfers 'von oben nach unten' und durch die strenge Separierung der Zugriffsberechtigung der einzelnen föderalen Ebenen auf unterschiedliche Steuerbemessungsgrundlagen entgegengetreten werden.

4. Insgesamt ergibt sich aus der Leviathan-Theorie ein deutlich geringerer optimaler Zentralisierungsgrad, als er in den Darlegungen der Theorie des Fiskalföderalismus abgeleitet wurde.

5. Die Analyse des Zusammenwirkens von exit und voice in der Interessengruppentheorie des Staates läßt für die Gruppe der unorganisierten Wähler keinen eindeutigen Schluß im Hinblick auf die absoluten politischen Einflußchancen zu. Deutlich ist dagegen, daß der relative Einfluß der organisierten Interessen fällt, wenn die potentiell Belasteten der rent seeking-Aktivitäten abwandern können. Der Migrationsdruck zwingt die politischen Agenten zu einer Rücknahme von Sondervorteilen und zur Steigerung der Attraktivität der Jurisdiktion fur mobile Faktoren durch eine effiziente Standortpolitik. Lokal organisierte Interessen verfolgen deshalb das Ziel, durch eine Harmonisierung der subzentralen Politiken die exit-Optionen der Bürger zu beschränken.

6. Je weniger die räumliche Abwanderungsdrohung der Bürger wirksam ist, um so größer wird der Einfluß mobiler Mitglieder der organisierten pressure groups. Da die Konservierung von im politischen Prozeß erzielten Sondervorteilen voraussetzt, daß keine Konkurrenz aus anderen föderativen Subeinheiten zuwandert, ist zu erwarten, daß die rent seekingAktivităten auf protektionistische Zuwanderungsbegrenzungen gerichtet sind.

7. Die Interessengruppentheorie des Staates legt deshalb aus denselben Gründen wie der Leviathan-Ansatz eine weitgehende Dezentralisierung der Entscheidungskompetenzen nahe. Darüber hinaus wird das Erfordernis einer foderativen Wettbewerbsordnung zur Regelung der interjurisdiktionellen Konkurrenz abgeleitet, deren Durchsetzungsinstanz die Zentralebene sein sollte.

8. Die Notwendigkeit einer Begrenzung der zentralstaatlichen Ebene, die sich aus beiden Theorievarianten ergibt, führt zu mehreren, spezifisch föderative Elemente enthaltenden Verfassungsvorschlägen. Eine Begrenzung kann erreicht werden durch die Arrangements des reverse revenue sharing, durch die verstärkte subzentrale Entscheidungsbeteiligung an zentralstaatlichen Entscheidungen und durch eine am Funktionalprinzip orientierte Differenzierung der Entscheidungsrechte. 


\section{Kapitel: Möglichkeiten für eine föderative Finanzverfassung}

\section{A. Theorie des Fiskalföderalismus und Public Choice}

Ausgangspunkt der vorliegenden Arbeit ist die hypothetische Frage: "Wie würde die Organisationsform des Staates aussehen, die rationale Individuen in einem konstitutionellen Konvent hinter einem Schleier des Nichtwissens über ihre zukünftigen Positionen in freiwilliger Übereinkunft wählen?" Es wurde versucht, einige Antworten auf die Fragen zum optimalen Design einer föderativen Finanzverfassung zu geben.

Wenngleich sowohl aus der Perspektive des Fiscal Federalism als auch aus der Sicht der Public Choice-Theorie die Vorteilhaftigkeit foderativer Entscheidungsstrukturen hervorgehoben wird, ergeben sich im Detail beträchtliche Unterschiede in den Empfehlungen der beiden Theorievarianten. Die der Theorie des Fiskalföderalismus eigene Betrachtungsweise deutet tendenziell stärker zentralisierte Lösungen an; auch werden horizontale und vertikale Kooperationserfordernisse zwischen den gebietskörperschaftlichen Entscheidungträgern hervorgehoben. Aus Sicht der Public Choice-Theorie sind demgegenüber stärker dezentrale Lösungen mit streng ebenenspezifisch getrennten finanzpolitischen Zuständigkeiten zu empfehlen.

Im Kern liegen die Unterschiede darin begründet, daß dem fiskalföderalistischen Ansatz ein größeres Vertrauen in die Kontroll- und Steuerungsfähigkeit demokratischer politischer Prozesse eigen ist als der Public Choice-Theorie. ${ }^{1}$ Die hier gefulhrte Diskussion um den optimalen Staatsaufbau spiegelt damit einen Teil der grundsätzlichen Kontroverse 'Marktversagen-Staatsversagen' wider. Isoliert betrachtet sind die Argumentationslinien beider Theorievarianten plausibel; es macht aber wenig Sinn, sich bei der Frage nach dem anzustrebenden Verfassungsdesign nur von einer der beiden Varianten leiten zu lassen. In seiner Monographie "The New Federalist" bringt Gordon Tullock diese Auffassung sehr deutlich zum Ausdruck, wenn er schreibt:

"Human institutions are imperfect, government is imperfect, and the market is imperfect, because humans are imperfect. It is wise to select the best among a number of possible alternatives, none of which is perfect." 2

Aus dieser Sicht relativieren sich die Unterschiede der beiden Theorievarianten. Der optimale föderative Staatsaufbau ist nicht so sehr eine Frage des Standpunktes, sondern vor allem eine Frage der vernünftigen Kompromißbildung. Es erscheint darum sinnvoll, zentrale Gemeinsamkeiten des Fiscal Federalism und der Public Choice-Schule über die Gestaltung des Staatsaufbaus hervorzuheben:

- In beiden Theorieansätzen fällt die schützende Staatsaufgabe der Zentralebene zu. Der Ausdehnungsbereich der protektiven Staatstätigkeit bildet zwangsläufig die Obergrenze für die leistungsstaatlichen Funktionen.

1 Vgl. Aranson, P.H. (1990), S. $19 \mathrm{ff}$.

2 Tullock, G. (1994), S. 18. 
- Beide Ansätze betonen die Vorteilhaftigkeit dezentraler Entscheidungsstrukturen; die Beweislast für die Begründung zentraler Verantwortlichkeiten liegt bei den 'Zentralisten' und nicht bei den Befurrwortern dezentraler Kompetenzen.

- Beide Theorievarianten stellen auf die Bedeutung der Eigenverantwortlichkeit der gliedstaatlichen Ebenen ab, die nicht nur die Ausgabensouveränităt, sondern auch die Finanzierungsautonomie umschließt.

- Vertikale Verflechtungen, die unter den Stichworten 'Gemeinschaftsaufgaben' oder 'kooperativer Föderalismus' diskutiert werden, werden aus Public Choice-Sicht abgelehnt und auch im fiskalföderalistischen Ansatz in neuerer Zeit zunehmend kritischer beurteilt.

- Sowohl die Theorie des Fiskalföderalismus als auch die Public Choice-Theorie verweisen auf die politikbegrenzende Wirkung der Abwanderungsoption. Umverteilungspolitik wird deshalb auf subzentraler Ebene erschwert. Dabei spielt es keine Rolle, ob die Umverteilung aus Gründen der sozialen Sicherung befürwortet wird oder der Ausdruck einer interessengeleiteten Politik in der transfer society ist. In jedem Fall machen föderative Strukturen die Effizienzkosten staatlicher Umverteilungstätigkeit für die Bürger besser ersichtlich.

Indessen erscheint es wichtig, nochmals herauszustreichen, daß keiner der beiden Ansätze eine Kleinstaaterei zum Ideal erklärt. Im Gegenteil:

"... on the whole, governments work best if we have a mix of different levels instead of a single centralized government ... This system makes it possible to have geographically larger governments at the top level than one would expect if the whole government were a unified block. Different levels of government dealing with different problems is the ideal ..."3

\section{B. Eine Skizze einer föderativen Finanzverfassung}

Wenngleich in die Überlegungen zur Gestaltung einer föderativen Finanzverfassung Aspekte beider Theorievarianten einzubeziehen sind, liefert die konstitutionelle Wirtschaftstheorie mit dem Argument der "Quasi-Risikoaversion"4 der Individuen eine Begründung dafür, daß beim Design von Koordinationsarrangements eine Tendenz zur Auswahl von restriktiveren Regeln vorliegen sollte. Brennan und Buchanan zeigen, daß rationale Individuen bei der Bewertung unterschiedlicher institutioneller Arrangements der Tatsache Rechnung tragen müssen, da $\beta$ die potentiellen Verluste bei Eintreten des worst case die potentiellen Gewinne bei Eintreten des bestmöglichen Falles übersteigen; insofern ist auf konstitutioneller Ebene eine natürliche Verzerrung in Richtung einer stärkeren Begrenzung des Staatshandelns zu erwarten. ${ }^{5}$

Vor diesem Hintergrund zeichnen sich zumindest die Konturen eines optimalen föderativen Staatsgebildes ab, das etwa wie folgt skizziert werden könnte 6

3 Tullock, G. (1994), S. 18.

4 Brennan, G./Buchanan, J.M. (1985/1993), S. 73. Damit ist nicht gemeint, daß Individuen per se risikoavers sind, sondern "... daß spezielle Charakteristika der Entscheidungssituation die Individuen veranlassen, so zu handeln, als ob sie risikoavers wären ..." Brennan, G./Buchanan, J.M. (1985/1993), S. 74f. (Hervorhebung im Original).

5 Vgl. Brennan, G./Buchanan, J.M. (1985/1993), S. $73 \mathrm{ff}$.

6 Vgl. dazu auch den Vorschlag furr eine Europăische Verfassung von Bernholz, P. (1992), S. 56ff., der von ahnlichen Überlegungen ausgeht. 
1. Aufgabenverantwortlichkeiten

a) Der Zentralebene sollte primär die Gewährleistung innerer und äußerer Sicherheit sowie die außenpolitische Vertretung des Bundesstaates obliegen. Darüber hinaus ist es Aufgabe der nationalstaatlichen Ebene, die Märkte gegenüber protektionistischen Praktiken der subzentralen Einheiten offen zu halten. Die geldpolitischen und wettbewerbspolitischen Kompetenzen fallen ebenfalls in den Zuständigkeitsbereich der Zentralebene. Finanzpolitische Verantwortlichkeiten bieten sich in Bereichen an, in denen bundesweite externe Effekte vorliegen. So ist denkbar, der nationalstaatlichen Ebene umweltpolitische Kompetenzen, ggfs. auch einer regelgebundenen Stabilisierungspolitik zuzuweisen. Zur Begrenzung der Ausbeutungsmacht der Zentralebene erscheint es in den genannten Bereichen gangbar, Kompetenzen an funktional differenzierte Fachparlamente oder an autonome Fachinstitutionen mit demokratischer Legitimation $\mathrm{zu}$ übertragen. ${ }^{7}$ Eine funktionale Gewaltenteilung würde somit zu mehreren Zentralregierungen führen.

b) Die Jurisdiktionen der mittleren Ebene (Bundesländer, Kantone, states) scheinen für die Wahrnehmung redistributiver Aufgaben prinzipiell am besten geeignet zu sein. Es ist zu vermuten, daß in diesen Gebietskörperschaften die Mischung aus Abwanderungsdruck und Mobilitätshemmnissen die staatlichen Entscheidungsträger vor einer ausufernden Umverteilungspolitik bewahrt, ohne sie gleich - wie dies auf kommunaler Ebene der Fall sein dürfte - ihren verteilungspolitischen Spielräumen nahezu gänzlich zu berauben. Auch überlokale Versorgungsleistungen im Bereich der Verkehrsinfrastruktur könnten in den Verantwortungsbereich der mittleren Ebene angesiedelt sein.

c) Auf kommunaler Ebene sind die übrigen Staatsaufgaben anzusiedeln. Ein abschießender Aufgabenkatalog ist dabei kaum zu erstellen, denn welche Aufgaben eine Gemeinde wahrnimmt, sollte dem jeweiligen politischen Entscheidungsträger überlassen werden.

d) Darüber hinaus kann für einzelne Funktionen die Einrichtung weiterer Ebenen (Regionalverbände o.ä.) in Erwägung gezogen werden. Die übliche Dreiteilung des Staatsaufbaus in Bund, Länder und Gemeinden ist nicht zwingend geboten.

e) Es ist stets eine subzentrale Beteiligung an den Entscheidungen der jeweils höheren gliedstaatlichen Ebene durch die Einrichtung einer zweiten Kammer zu gewährleisten.

2. Finanzierungsregeln

a) Der Finanzbedarf der Zentralebene sollte primär durch Finanzbeiträge 'von unten nach oben' gedeckt werden (reverse revenue sharing). Die Festlegung der Beitragssätze erfolgt durch Verhandlungen der Subeinheiten mit qualifizierten Mehrheitserfordernissen. Eigene Besteuerungsrechte mit instrumentalem Charakter (z.B. Umweltsteuern) sind mit strengen fiskalischen Restriktionen zu versehen.

b) Die Logik des Äquivalenzgedankens läßt vermuten, daß der mittleren Ebene im föderativen Staat Vermögen- und Einkommensteuern zugestanden werden. Denkbar wäre auch eine allgemeine Verbrauchsteuer.

c) Aufgrund des herrschenden Migrationsdrucks wirken tendenziell alle auf lokaler Ebene erhobenen Steuern wie Nutzungsgebühren. Grundsteuern scheinen für die Kommunen ein geeignetes Finanzierungsinstrument zu sein. Darüber hinaus müssen die Gemeinden über Möglichkeiten verfügen, mobile Haushalte und Unternehmen zu besteuern. Lokale Haushalts- und Unternehmensteuern sind aus dieser Sicht zu befürworten.

7 Siehe hierzu Kruse, J. (1995), S. 20ff. 
d) Um die finanzpolitische Verantwortlichkeit der Gebietskörperschaften zu stärken, sind direkte Steuern grundsätzlich nach dem Quellenprinzip und indirekte Steuern nach dem Ursprungslandprinzip zu erheben.

e) Die Zentralebene verfügt über kein eigenes Verschuldungsrecht. Den subnationalen Einheiten können an strenge finanzwirtschaftliche Begrenzungsregeln gebundene Verschuldungsrechte eingeräumt werden.

f) Vertikale Finanzzuweisungen 'von oben nach unten' und andere Formen der Mischfinanzierung sind entweder gänzlich auszuschließen oder an die Zustimmung aller subnationaler Einheiten in den gemeinschaftlichen Entscheidungsgremien zu binden. Generell sollten Finanzierungsverantwortungen klar getrennt werden, um den Bürgern die aus den staatlichen Aktivitäten der jeweiligen Aufgabenträger resultierenden Belastungen ersichtlich zu machen.

3. Weitere konstitutionelle Regelungen

a) Um die exit-Option auf dezentraler Ebene offen zu halten, ist ein verfassungsmäßiges Verbot von Emigrationssteuern und Importzöllen sowie von Regelungen, die diesen Abwanderungsbelastungen entsprechen, zu verankern.

b) Zuwanderungsbegrenzungen sind allenfalls auf lokaler Ebene gestattet.

c) Vertragliche Vereinbarungen zwischen den Jurisdiktionen der gleichen Ebene, die sich auf die Harmonisierung von Steuersätzen oder auf die Festlegung von Mindestsätzen beziehen, sind verboten.

d) Die Durchsetzung dieser Beschränkungen obliegt einer unabhängigen Instanz auf der Zentralebene, die von allen Bürgern des Staates und allen gebietskörperschaftlichen Institutionen angerufen werden kann.

\section{Kompetenz-Kompetenz}

Kompetenzverlagerungen, v.a. Änderungen der Finanzierungskompetenzen, bedürfen der mehrheitlichen Zustimmung der Mandatsträger aller kompetenzabgebenden Einheiten sowie der Zustimmung in einem Referendum.

\section{Einige Anmerkungen zur Implementierung konstitutioneller Reformen}

Der hier vertretene vertragstheoretisch-konstitutionelle Ansatz sieht sich stets mit den beiden Kritikpunkten eines "rationalistischen Konstruktivismus"8 und der Reformunwilligkeit bzw. unfähigkeit nicht nur der politischen Kräfte ${ }^{9}$ konfrontiert. Beides sind ernstzunehmende Einwände, die zu einer intensiven Diskussion über die Sinnhaftigkeit vertragstheoretischer Denkansätze geführt haben, die hier nicht im einzelnen nachgezeichnet werden muß. ${ }^{10} \mathrm{Die}$ im vorangegangenen Abschnitt angedeuteten Vorschläge zur Gestaltung einer föderativen Finanzverfassung erheben selbstverständlich auch weder den Anspruch auf einen vollständigen Verfassungsentwurf ${ }^{11}$, noch darf vermutet werden, daß solche Reformen aus dem politi-

8 Hayek, F.A. von (1981b), S. 43 fuhrt dazu aus: "... wir könen immer nur an Teilen eines gegebenen Ganzen herumbasteln, aber es niemals gänzlich neu entwerfen."

9 Siehe hierzu die Auflistung der (möglichen) Gegner konstitutioneller Reformen bei Buchanan, J.M. (1984).

$10 \mathrm{Zu}$ einem Überblick siehe Vanberg, $V$. (1981).

11 Zum Unterschied zwischen Verfassungsdesign und Verfassungsreform siehe Brennan, G./Buchanan, J.M. (1985/1993), S. 14ff. 
schen Prozeß heraus allein aufgrund der Einsicht und des Reformwillens der politischen Akteure zustandekommen.

Dem erstgenannten Einwand sei gleichwohl mit Brennan und Buchanan entgegengehalten:

\begin{abstract}
"Wenn die Regeln des sozio-økonomischen und politischen Spiels nicht aktiv gestaltet und konstruktiv verăndert werden können, bleibt nicht viel mehr ubrig, als sich dem Strom der Geschichte anzuvertrauen." 12
\end{abstract}

Folgt man dieser Auffassung, ist ein passives Zuwarten auf schrittweise Reformen sicher nicht geboten. Gerade in dem fortschreitenden Maße, wie historische Erfahrungen und Wissen über den Erfolg und den Mißerfolg von (Verfassungs-)Regeln existieren, sollte es zur Aufgabe der Sozialwissenschaften (Sozialwissenschaftler) werden, Regelentwürfe vorzulegen, die den Hayek'schen Prozeß der kulturellen Evolution ${ }^{13}$ aus den konstatierten sozialen Dilemmata in die gewünschte Richtung lenken. ${ }^{14}$

Wie aber, um zum zweiten Einwand gegen den vertragstheoretischen Konstitutionalismus zu kommen, kann es angesichts bestehender politischer Widerstände und Beharrungstendenzen auf demokratischem Wege zur Durchsetzung von wirklichen Reformen kommen? In diesem Zusammenhang unterstreichen Wagner und Gwartney, daß

"... it is common, and probably comforting, to think that the destructive consequences of contemporary, majoritarian democracy can be escaped by electing better politicians. But this is not the case. The expansion in powers of government ... and the accompanying erosion of wealth and liberty is not the result of incompetent public officials motivated by evil intentions. Rather the core of the problem emanates from the incentives that ordinary people confront within the prevailing system of majoritarian democracy." 15

Wenn aber die Aussicht auf den "better politician" ad acta gelegt werden muß, müssen wir uns dann nicht doch "... auf langsame, unbewußte, unbeabsichtigte Prozesse der sozio-kulturellen Evolution verlassen? Das würde bedeuten, sich von der frommen Hoffnung tragen zu lassen, die sich im Evolutionsprozeß ergebenden Änderungen würden uns zu einem Zustand führen, der am Ende - theoretisch gesehen - Pareto-optimal wäre."16

Brennan und Buchanan selbst vertreten einen moderaten Optimismus im Hinblick auf die Durchsetzbarkeit konstitutioneller Reformen. ${ }^{17}$ Sie begründen ihre Auffassung mit der Erfahrung, daß in der Menschheitsgeschichte schon häufig der Prozeß vernunftgeleiteter Diskussion ein öffentliches Interesse an konstitutionellen Radikalreformen und das Entstehen einer "Zivil-Moral" 18 bewirkt habe. Sie verbinden damit die Hoffnung einer allgemeinen Rückbesinnung auf einen gesunden Skeptizismus gegenüber staatlichem Handeln, die letztlich in

12 Brennan, G./Buchanan, J.M. (1985/1993), S. 27.

13 Hayek, F.A. von (1981b), S. 211.

14 Vgl. dazu Vanberg, V./Buchanan, J.M. (1991) und Brennan, G./Buchanan, J.M. (1985/1993), S. 197.

15 Wagner, R.E./Gwartney, R.D. (1988), S. 54 (Hervorhebungen H.P.).

16 Brennan, G./Buchanan, J.M. (1985/1993), S. 191.

17 Siehe v.a. Brennan, G./Buchanan, J.M. (1980/1988), S. 259ff. und (1985/1993), Kap. 9.

18 Brennan, G./Buchanan, J.M. (1985/1993), S. 196. 
dem Bewußtsein zum Ausdruck kommt, daß die Schaffung und die Begrenzung des Staates durch verfassungsmäßige Regeln gleichermaßen notwendig ist.

In dieser Hinsicht könnte der vielzitierte zwischenstaatliche Ordnungswettbewerb konstitutionelle Reformen beschleunigen. Zwar hat die Rivalität zwischen Staaten oftmals zu kriegerischen Auseinandersetzungen geführt; sie ist aber nach gängiger Auffassung ebenso für die Entwicklung von Demokratie und Rechtsstaat förderlich gewesen. ${ }^{19}$ Und warum sollte der Systemwettbewerb nicht auch zur Weiterentwicklung dieser Institutionen führen können? Auch aus diesem Blickwinkel ergibt sich somit ein gewichtiges Argument gegen einen Weltstaat. Möglicherweise vermag gerade ein ungeplanter zwischenstaatlicher Systemwettbewerb den notwendigen Druck zu erzeugen, der zur innerstaatlichen Realisierung einer kompetitiven föderativen Ordnung führt.

19 Siehe etwa Kammler, H. (1996), S. 279. 


\begin{abstract}
ANHANG
Die Vorteile einer dezentralen Besteuerungslösung bei kooperativer Bereitstellung eines Kollektivgutes mit räumlichen spillover-Effekten können durch Abbildung A.1. dargestellt werden. $\mathrm{D}_{\mathrm{A}}$ und $\mathrm{D}_{\mathrm{B}}$ bezeichnen die Nachfragefunktionen der Subgruppen A und $\mathrm{B}$. In der Ausgangssituation stelle $A$ das Kollektivgut $G$ allein in der $M$ enge $G_{A}$ bereit; die Jurisdiktion $B$ verhalte sich als free-rider. Durch interkollektive Verhandlungen werde die Pareto-optimale Versorgung $G_{Z}$ realisiert. Die erforderlichen marginalen Kompensationszahlungen von $B$ an A sind durch die $S_{B}-$ Gerade dargestellt. Bei der effizienten Konsummenge $G_{Z}$ entsprechen die marginalen Belastungen der Gemeinwesen A und B den Finanzierungsanteilen 0a bzw. Ob. Sie bestimmen die Steueraufkommen in A und B.

Da bei einer Bereitstellungsverantwortung der zentralen Ebene keine Differenzierung möglich ist, könnten die Finanzierungsbeteiligungen der Bürger in den Gliedstaaten A und B paritätisch bestimmt werden (in der Abbildung MC/2). Beide Gemeinwesen befinden sich bei dieser Lösung nicht im Optimum. Die Bürger aus Gemeinwesen A konsumieren bei dieser Kostenaufteilung 'zu wenig', die Bürger aus B 'zu viel' von G. Die Wohlfahrtsverluste sind durch die schraffierten Flächen gekennzeichnet.
\end{abstract}

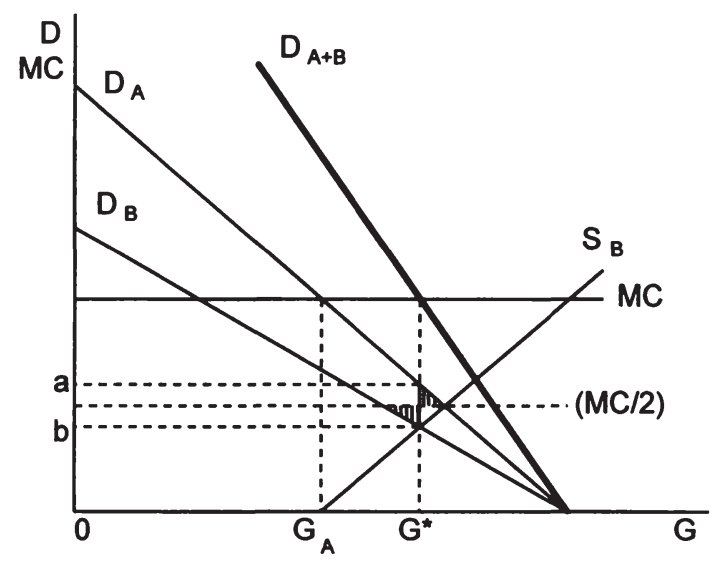

Abbildung A.1: Allokative Vorteile der Verhandlungslösung Quelle: eigene Darstellung 
Hans Pitlik - 978-3-631-75479-5

Downloaded from PubFactory at 01/11/2019 04:28:26AM

via free access 


\section{LITERATURVERZEICHNIS}

ABRAMS, B.A./ButKIEWICZ, J.L. (1995): The Influence of State-Level Economic Conditions on the 1992 U.S. Presidential Election, in: Public Choice 85, S. 1-10.

ABRAMS, J.D./KEnNY, L.W. (1989): The Retention of State Governors, in: Public Choice 62, S. 1-13.

ADAMS, R. (1965): On the Variation in the Consumption of Public Services, in: Review of Economics and Statistics 47, S. 400-405.

AKAI, N. (1994): Ricardian Equivalence for Local Government Bonds. Budget Constraint Approach, in: Economics Letters 44, S. 191-195.

AKERLOF, G.A. (1970): The Market for 'Lemons': Quality Uncertainty and the Market Mechanism, in: Quarterly Journal of Economics 84, S. 488-500.

AKERLOF, G.A. (1982): Labor Contracts as Partial Gift Exchange, in: Quarterly Journal of Economics 97, S. 543-569.

AKERLOF, G.A./YELLEN, J.L. (1987): Rational Models of Irrational Behavior, in: American Economic Review 77, S. 137-142.

ALBERT, H. (1977): Individuelles Handeln und soziale Steuerung. Die ökonomische Tradition und ihr Erkenntnisprogramm, in: Lenk, H. (Hrsg.): Handlungstheorien - interdisziplinär, Bd. IV. Sozialwissenschaftliche Handlungstheorien und spezielle systemwissenschaftliche Ansätze, München, S. 177-225.

Alchian, A.A. (1977): Some Economics of Property Rights, in: Alchian, A.A. (Hrsg.): Economic Forces at Work, Indianapolis, S. 127-149.

Alchian, A.A./DEMSETZ, H. (1972): Production, Information Costs, and Economic Organization, in: American Economic Review 62, S. 777-795.

ALCHIAN, A.A./WOODWARD, S. (1987): Reflections on the Theory of the Firm, in: Journal of Institutional and Theoretical Economics 143, S. 110-136.

Alchian, A.A./Woodward, S. (1988): The Firm is Dead, Long Live the Firm: A Review of Oliver Williamson's The Economic Institutions of Capitalism, in: Journal of Economic Literature 26, S. 65-79.

Alesina, A./Perotti, R./SPOlaORE, E. (1995): Together or Separately? Issues on the Costs and Benefits of Political and Fiscal Unions, in: European Economic Review 39, S. 751758.

Allen, L./AMACHER, R./Tollison, R.D. (1974): The Economic Theory of Clubs: A Geometric Exposition, in: Public Finance 29, S. 386-391. 
Althammer, W. (1995): Das Henry George-Theorem, in: Wirtschaftswissenschaftliches Studium 24, S. 249-252.

AlthammER, W./BuchHolz, W. (1995): Die Bereitstellung eines öffentlichen Gutes aus spieltheoretischer Sicht: Die Grundsachverhalte, in: Ökonomie und Gesellschaft 12, S. 92-128.

AmaCher, R./Tollison, R.D./Willett, T. (1976): Risk Avoidance and Political Advertising: Neglected Issues in the Literature on Budget Size in a Democracy, in: Amacher, R./Tollison, R.D./Willett, T. (Hrsg.): The Economic Approach to Public Policy, Ithaca, S. 405-433.

ANDERSON, G.M./TOLLISON, R.D. (1988): Legislative Monopoly and the Size of Government, in: Southern Economic Journal 54, S. 529-545.

ANDERSON, S.P./GLOMM, G. (1992): Incumbency Effects in Political Campaigns, in: Public Choice 74, S. 207-219.

ANDERson, T.L./Hill, P.J. (1975): The Evolution of Property Rights: A Study of the American West, in: Journal of Law and Economics 18, S. 163-179.

ANDERSON, T.L./HiLl, P.J. (1980): The Birth of a Transfer Society, Stanford.

ANDERSON, T.L./HiLl, P.J. (1983): Privatizing the Commons: An Improvement?, in: Southern Economic Journal 50, S. 438-450.

ANDERSON, T.L./Hill, P.J. (1986): Constraining the Transfer Society. Constitutional and Moral Dimensions, in: Cato Journal 6, S. 317-339.

ARANSON, P.H. (1989): The Democratic Order and Public Choice, in: Brennan, G./Lomasky, L.E. (Hrsg.): Politics and Process: New Essays in Democratic Thought, Cambridge,S. 97148.

ARANSON, P.H. (1990): Federalism: The Reason of Rules, in: Cato Journal 10, S. 17-38.

ARISTOTELES (1989): Politik. Schriften zur Staatstheorie, ubersetzt und herausgegeben von Schwarz, F.W., Stuttgart.

ARNIM, H.H. vON (1984): Staatslehre der Bundesrepublik Deutschland, München.

ARNOLD, V. (1992): Theorie der Kollektivgüter, München.

ARNOTT, R.J./STIGLITZ, J.E. (1979): Aggregate Land Rents, Expenditure on Public Goods, and Optimal City Size, in: Quarterly Journal of Economics 93, S. 471-500.

ARONSON, J.R. (1971): A Comment on Optimality in Local Debt Limitation, in: National Tax Journal 24, S. 107-108. 
ARROW, K.J. (1963A): Uncertainty and the Welfare Economics of Medical Care, in: American Economic Review 53, S. 941-973.

ARROw, K.J. (1963B): Social Choice and Individual Values, 2. Aufl., New York.

ARROW, K.J. (1974): The Limits of Organization, New York.

ARROw, K.J. (1977): The Organization of Economic Activity: Issues Pertinent to the Choice of Market Versus Nonmarket Allocation, in: Haveman, R.H./Margolis, J. (Hrsg.): Public Expenditure and Policy Analysis, 2. Aufl., Boston u.a., S. 67-81.

ARrow, K.J. (1985): The Economics of Agency, in: Pratt, J.W./Zeckhauser, R.J. (Hrsg.):

Principals and Agents. The Structure of Business, Boston, S. 37-51.

ARrow, K.J./HAHN, E.F. (1971): General Competitive Analysis, San Francisco u.a.

AsCHAuER, D.A.(1989): Is Public Expenditure Productive?, in: Journal of Monetary Economics 24, S. 171-188.

Atkinson, A.B./Stiglitz, J.E. (1980): Lectures on Public Economics, Maidenhead.

AtZRouni, M./Komlos, J. (1994): The Formation of the European State System: A 'Predatory' Model, Münchner Wirtschaftswissenschaftliche Beiträge der Volkswirtschaftlichen Fakultät der Ludwig-Maximilians-Universität München 94-08.

Auster, R.D./SILVER, M. (1979): The State as a Firm, Boston u.a.

AXELROD, R. (1988): Die Evolution der Kooperation, München.

AzARIADIS, C./Stiglitz, J.E. (1983): Implicit Contracts and Fixed Price Equilibria, in: Quarterly Journal of Economics 98, S. 1-22.

BAIRD, R./LANGDON, J. (1972): Political Fragmentation, Income Distribution, and the Demand for Local Government Services, in: Nebraska Journal of Economics and Business 11, S. 171-184.

BALDwIN, R.E. (1982): The Political Economy of Protectionism, in: Bhagwati, J.N. (Hrsg.): Import Competition and Response, Chicago, S. 263-292.

BALDWIN, R.E. (1989): The Political Economy of Trade Policy, in: Journal of Economic Perspectives 3, S. 119-135.

BARRETT, S. (1990): The Problem of Global Environmental Protection, in: Oxford Review of Economic Policy 6, S. 68-79.

BARRO, R.J. (1974): Are Government Bonds Net Wealth?, in: Journal of Political Economy 82, S. 1094-1117. 
BARRow, M.M. (1986): Central Grants to Local Governments: A Game Theoretic Approach, in: Environment and Planning C: Government and Policy 4, S. 155-164.

BARROw, M.M. (1989): Local Authority Responses to Grants: Different Types of Response and Equilibrium, in: Environment and Planning C: Government and Policy 7, S. 313-320.

BARRY, B. (1974): Review Article: Exit, Voice, and Loyalty, in: British Journal of Political Science 4, S. 79-107.

BARTLETT, R. (1973): Economic Foundations of Political Power, New York, London.

BARZEL, Y. (1969): Two Propositions on the Optimum Level of Producing Public Goods, in: Public Choice 6, S. 31-37.

BARzEL, Y. (1989): Economic Analysis of Property Rights, Cambridge u.a.

BARZEL, Y./Silberberg, E. (1973): Is the Act of Voting Rational?, in: Public Choice 16, S. 51-58.

BATOR, F. (1957): The Simple Analytics of Welfare Maximization, in: American Economic Review 47, S. 22-59.

BAUM, T. (1982): Per se Rule versus Rule of Reason und Kartellamtsautonomie, in: Wirtschaft und Wettbewerb 32, S. 912-919.

BAumol, W.J./OATES, W.E. (1988): The Theory of Environmental Policy, 2. Aufl., Cambridge.

BEAN, R. (1973): War and the Birth of the Nation State, in: Journal of Economic History 33, S. 203-221.

BECKER, G. (1968): Crime and Punishment. An Economic Approach, in: Journal of Political Economy 76, S. 169-217.

BeCKer, G. (1983): A Theory of Competition Among Pressure Groups for Political Influence, in: Quarterly Journal of Economics 98, S. 371-400.

Becker, G. (1985): Public Policies, Pressure Groups, and Deadweight Costs, in: Journal of Public Economics 28, S. 329-347.

BEER, S.H. (1977): A Political Scientist's View of Fiscal Federalism, in: Oates, W.E. (Hrsg.): The Political Economy of Fiscal Federalism, Lexington, S. 21-46.

BÉLANGER, G. (1987): Federalism and Local Government, in: European Journal of Political Economy 3, S. 131-149.

BELL, C.R. (1988): The Assignment of Fiscal Responsibility in a Federal State: An Empirical Assessment, in: National Tax Journal 41, S. 191-207. 
BELL, C.R. (1989): Between Anarchy and Leviathan: A Note on the Design of Federal States, in: Journal of Public Economics 39, S. 207-221.

BENNETT, J./DiLoRENZO, T.J. (1983): Underground Government: The Off-Budget Public Sector, Washington.

BENNETT, J./ORZECHOWSKI, W. (1983): The Voting Behavior of Bureaucrats, in: Borcherding, T.E. (Hrsg.): Budgets and Bureaucrats: The Sources of Government Growth, Durham, S. 271-283.

BENNETT, R.J. (1980): The Geography of Public Finance. Welfare under Fiscal Federalism and Local Government Finance, London, New York.

BENSON, B.L. (1984): Rent Seeking from a Property Rights Perspective, in: Southern Economic Journal 51, S. 388-400.

BENSON, B.L. (1989): Spontaneous Evolution of Commercial Law, in: Southern Economic Journal 55, S. 644-661.

BENSON, B.L. (1990): Interstate Tax Competition, Incentives to Collude, and Federal Influences, in: Cato Journal 10, S. 75-90.

Bentley, A.F. (1908/1967): The Process of Government, Chicago.

BERglas, E. (1976): On the Theory of Clubs, in: American Economic Review 66, S. 116-121.

Berglas, E./PInes, D. (1981): Clubs, Local Public Goods, and Transportation Models, in: Journal of Public Economics 15, S. 141-162.

Bergstrom, T.C./Goodman, R.P. (1973): Private Demands for Public Goods, in: American Economic Review 63, S. 280-196.

BERNHARDT, M.D./INGBERMAN, D.E. (1985): Candidate Reputation and the 'Incumbency Effect', in: Journal of Public Economics 27, S. 47-67.

BERnhOlz, P. (1969): Einige Bemerkungen zur Theorie des Einflusses der Verbände auf die politische Willensbildung in der Demokratie, in: Kyklos 22, S. 276-288.

BeRnholz, P. (1973): Logrolling, Arrow Paradox, and Cyclical Majorities, in: Public Choice 15 , S. 87-95.

BERNHOLZ, P. (1992): Constitutional Aspects of the European Integration, in: Barner, S./Grubel, H. (Hrsg.): The European Community after 1992. Perspectives from the Outside, London, S. 45-60.

Bernholz, P./BREYER, F. (1984): Grundlagen der Politischen Ökonomie, 2. Aufl., Tübingen.

BERnHOlz, P./BREYER, F. (1994): Grundlagen der politischen Ökonomie, Bd. 2: Ökonomische Theorie der Politik, 3. Aufl., Tübingen. 
BERNHOLZ, P./FABER, M. (1986): Überlegungen zu einer normativen ökonomischen Theorie der Rechtsvereinheitlichung, in: Rabels Zeitschrift für ausländisches und internationales Privatrecht 50, S. 35-60.

BERRY, J.M. (1984): The Interest Group Society, Boston, Toronto.

BERTHOLD, N. (1993): 'Fiscal Federalism' in Europa: Voraussetzungen für eine erfolgreiche Wirtschafts- und Währungsunion?, in: Gröner, H./Schüller, A. (Hrsg.): Die europäische Integration als ordnungspolitische Aufgabe, Stuttgart u.a., S. 147-171.

BESLEY, T./CASE, A. (1995): Incumbent Behavior: Vote-Seeking, Tax-Setting, and Yardstick Competition, in: American Economic Review 85, S. 25-45.

Bewley, T.F. (1981): A Critique of Tiebout's Theory of Local Expenditures, in: Econometrica 49, S. 713-740.

Bhagwati, J.N. (1982): Directly Unproductive Profit-Seeking (DUP) Activities: A WelfareTheoretic Synthesis and Generalization, in: Journal of Political Economy 90, S. 988-1002.

BhagWati, J.N. (1983): DUP Activities and Rent-Seeking, in: Kyklos 36, S. 634-637.

Bhagwati, J.N./Partington, M. (1976): Taxing the Brain Drain: A Proposal, Amsterdam.

BIEHL, D. (1990): Financing the EEC Budget, in: Prud'homme, R. (Hrsg.): Public Finance With Several Levels of Government, Brüssel, S. 137-152.

BIEHL, D. (1991): Die EG-Finanzverfassung: Struktur, Mängel und Reformmöglickeiten, in: Wildenmann, R. (Hrsg.): Staatswerdung Europas?, Baden-Baden, S. 355-391.

BiRCH, A.H. (1975): Economic Models in Political Science: The Case of 'Exit, Voice and Loyalty', in: British Journal of Political Science 5, S. 69-82.

BIRD, R.M. (1993): Threading the Fiscal Labyrinth: Some Issues in Fiscal Decentralization, in: National Tax Journal 46, S. 207-227.

BisH, R. (1988): Federalism: A Market Economics Perspective, in: Gwartney, J.D./Wagner, R.E. (Hrsg.): Public Choice and Constitutional Economics, S. 351-368.

Bish, R./OSTROM, V. (1979): Understanding Urban Government, Washington.

Bish, R./WARREN, R. (1972): Scale and Monopoly Problems in Urban Government Services, in: Urban Affairs Quarterly 8, S. 97-122.

BLACK, D. (1948): On the Rationale of Group Decision-Making, in: Journal of Political Economy 56, S. 23-34.

BLACK, G.S. (1972): A Theory of Political Ambition: Career Choices and the Role of Structural Incentives, in: American Political Science Review 66, S. 144-159. 
BlanKarT, C.B. (1975): Zur ökonomischen Theorie der Bürokratie, in: Public Finance 30, S. 166-185.

BLANKART, C.B. (1978): Zunehmende Skalenerträge in der Nutzung als wohlfahrtsökonomisches Problem, in: Helmstädter, E. (Hrsg.): Neuere Entwicklungen in den Wirtschaftswissenschaften, Schriften des Vereins für Socialpolitik N.F., Bd. 98, Berlin, S. 319-337.

BlanKarT, C.B. (1994A): Öffentliche Finanzen in der Demokratie, 2. Aufl., München.

BlanKART, C.B. (1994B): Club Governments and Representative Governments, in: Constitutional Political Economy 5, S. 273-285.

BLuM, U./DudLeY, L. (1991): A Spatial Model of the State, in: Journal of Institutional and Theoretical Economics 147, S. 312-336.

BlÜMel, W./Pethig, R./von Dem Hagen, O. (1986): The Theory of Public Goods: A Survey of Recent Issues, in: Journal of Institutional and Theoretical Economics 142, S. 241-309.

Boadway, R.W. (1992): The Constitutional Division of Powers. An Economic Perspective, Ottawa.

BOADWAY, R.W./BRUCE, N. (1979): Depreciation and Interest Deductions and the Effect of the Corporation Income Tax on Investment, in: Journal of Public Economics 11, S. 93105.

BOADWAY, R.W./FLATTERS, F.R. (1982): Efficiency and Equalization Payments in a Federal System of Government: A Synthesis and Extension of Recent Results, in: Canadian Journal of Economics 15, S. 613-633.

BoadWAY, R.W./WILDASIN, D.E. (1984): Public Sector Economics, 2. Aufl., Boston, Toronto.

BÖBEL, I. (1988): Eigentum, Eigentumsrechte und institutioneller Wandel, Berlin u.a.

BoETTCHER, E. (1983): Einleitung: Der Neue Institutionalismus als Teil der Lehre von der Neuen Politischen Ökonomie, in: Jahrbuch für Neue Politische Ökonomie 2, S. 1-15.

BoHLEY, P. (1993): Europäische Einheit, föderatives Prinzip und Währungsunion: Wurde in Maastricht der richtige Weg beschritten?, in: Aus Politik und Zeitgeschichte B1/93, S. 34-45.

BOHNET, I./FrEY, B.S. (1994): Direct-Democratic Rules: The Role of Discussion, in: Kyklos 47, S. 341-354.

BÖKEMANN, D. (1982): Raumplanung, München, Wien.

Bolton, P./Roland, G./SPOLAORE, E. (1996): Economic Theories of the Break-Up and Integration of Nations, in: European Economic Review 40, S. 697-705. 
BorCHERDING, T.E./Bush, W.C./SpanN, R.M. (1977): The Effects of Public Spending on the Divisibility of Public Outputs in Consumption, Bureaucratic Power, and the Size of the Tax-Sharing Group, in: Borcherding, T.E. (Hrsg.): Budgets and Bureaucrats: The Sources of Government Growth, Durham, S. 127-156.

BORCHERDING, T.E./DEACON, R.T. (1972): The Demand for the Services of Non-Federal Governments, in: American Economic Review 62, S. 891-901.

Bös, D. (1983): An Optimal Taxation Approach to Fiscal Federalism. Commentary, in: McLure, C.E. (Hrsg.): Tax Assignment in Federal Countries, Canberra, S. 43-47.

BöSSMANN, E. (1981): Weshalb gibt es Unternehmungen? Der Erklärungsansatz von Ronald H. Coase, in: Journal of Institutional and Theoretical Economics 137, S. 667-674.

BOYNE, G.A. (1992): Local Government Structure and Performance: Lessons from America?, in: Public Administration 70, S. 333-357.

BRADFORD, D.F./OATES, W.E. (1974): Suburban Exploitation of Central Cities and Government Structure, in: Hochman, H.M./Petersen, G.E. (Hrsg.): Redistribution Through Public Choice, New York, S. 43-90.

BREAK, G.F. (1967): Intergovernmental Fiscal Relations in the United States, Washington.

BREAK, G.F. (1980): Financing Government in a Federal System, Washington.

BRECHT, A. (1932): Internationaler Vergleich der öffentlichen Ausgaben, Leipzig, Berlin.

BREIT, W. (1968): Public-Goods Interaction in Stackelberg Geometry, in: Western Economic Journal 6, S. 161-164.

BrenNan, G. (1973): Pareto Desirable Redistribution: The Non-Altruistic Dimension, in: Public Choice 14, S. 43-68.

BrenNAN, G. (1979): Besprechung zu Breton, A./Scott, A.: The Economic Constitution of Federal States, in: Journal of Economic Literature 17, S. 1051-1052.

BRENNAN, G. (1981): Tax Limits and the Logic of Constitutional Restrictions, in: Ladd, H.F./Tideman, T.N. (Hrsg.): Tax and Expenditure Limitations, Washington, S. 121-138.

BRENNAN, G. (1983): Commentary on R.A. Musgrave, in: McLure, C.E. (Hrsg.): Tax Assignment in Federal Countries, Canberra, S. 21-22.

Brennan, G. (1984): Constitutional Constraints on the Fiscal Powers of Government, in: McKenzie, R.B. (Hrsg.): Constitutional Economics. Containing the Economic Powers of Government, Lexington, S. 115-132.

BRENNAN, G./BuChanAN, J.M. (1977): Towards a Tax Constitution for Leviathan, in: Journal of Public Economics 8, S. 555-573. 
Brennan, G./Buchanan, J.M. (1980/1988): The Power to Tax. Analytical Foundations of a Fiscal Constitution, Cambridge u.a. 1980. Zitiert nach der dt. Übersetzung: Besteuerung und Staatsgewalt. Analytische Grundlagen einer Finanzverfassung, Hamburg 1988.

BRENNAN, G./Buchanan, J.M. (1981): Der verteilende Staat: Ansätze zu einer Theorie der Umverteilung, in: Zeitschrift für Wirtschaftspolitik 30, S. 103-128.

Brennan, G./Buchanan, J.M. (1983A): Predictive Power and the Choice Among Regimes, in: Economic Journal 93, S. 89-105.

Brennan, G./Buchanan, J.M. (1983B): Normative Tax Theory for a Federal Polity: Some Public Choice Preliminaries, in: McLure, C.E. (Hrsg.): Tax Assignment in Federal Countries, Canberra, S. 52-65.

BRENNAN, G./Buchanan, J.M. (1984): Voter Choice: Evaluating Political Alternatives, in: American Behavioral Scientist 28, S. 185-201.

BREnNAN, G./Buchanan, J.M. (1985/1993): The Reason of Rules. Constitutional Political Economy, Cambridge 1985. Zitiert nach der dt. Übersetzung: Die Begründung von Regeln. Konstitutionelle Politische Ökonomie, Tübingen 1993.

BRETON, A. (1965): A Theory of Government Grants, in: Canadian Journal of Economics and Political Science 31, S. 175-187.

Breton, A. (1970): Public Goods and the Stability of Federalism, in: Kyklos 23, S. 882-901.

BRETON, A. (1974): The Economic Theory of Representative Government, Chicago.

Breton, A. (1977): The Theory of Local Government Finance and the Debt Regulation of Local Governments, in: Public Finance 32, S. 16-28.

BRETON, A. (1978): Die ökonomische Föderalismustheorie und die Zuweisung der Stabilitätszuständigkeiten, in: Quartalshefte der Girozentrale und Bank der österreichischen Sparkassen Aktiengesellschaft 13, S. 43-52.

BRETON, A. (1987): Towards a Theory of Competitive Federalism, in: European Journal of Political Economy 3, S. 263-329.

BRETON, A. (1991): The Existence and Stability of Interjurisdictional Competition, in: Kenyon, D.A./Kincaid, J. (Hrsg.): Competition Among States and Local Governments, Washington, S. 37-56.

Breton, A. (1993): Toward a Presumption of Efficiency in Politics, in: Public Choice 77, S. 53-65.

Breton, A./SAlmon, P. (1996): Are Discriminatory Procurement Policies Motivated by Protectionism?, in: Kyklos 49, S. 47-68. 
Breton, A./ScotT, A. (1977): The Assignment Problem in Federal Structures, in: Feldstein, M./Inman, R.P. (Hrsg.): The Economics of Public Services, London u.a., S. 344-357.

Breton, A./ScotT, A. (1978): The Economic Constitution of Federal States, Toronto u.a.

Breton, A./ScotT, A. (1980): The Design of Federations, Montreal.

Breton, A./Wintrobe, R. (1975): The Equilibrium Size of a Budget-Maximizing Bureau: A Note on Niskanen's Theory of Bureaucracy, in: Journal of Political Economy 83, S. 195207.

Breton, A./WINTROBE, R. (1986): The Bureaucracy of Murder Revisited, in: Journal of Political Economy 94, S. 905-926.

BROCK, W.A./MAgEE, S.P. (1978): The Economics of Special Interest Politics: The Case of the Tariff, in: American Economic Review 68, S. 246-250.

Broder, J.M./SchMid, A.A. (1983): Public Choice in Local Judicial Systems, in: Public Choice 40, S. 7-19.

Brown, C.C./OAtes, W.E. (1987): Assistance to the Poor in a Federal System, in: Journal of Public Economics 32, S. 307-330.

BRUNNER, K. (1979): Alternative Erklärungen hartnäckiger Inflation und Anti-Inflationspolitik, in: Woll, A. (Hrsg.): Inflation. Definitionen, Ursachen, Wirkungen und Bekämpfungsmöglichkeiten, München, S. 99-133.

BRUNNER, K./MELTZER, A.H. (1981): The Costs and Consequences of Inflation, Amsterdam.

Buchanan, A.E. (1991): Secession: The Morality of Political Divorce from Fort Sumner to Lithuania and Quebec, Boulder.

BuChanan, J.M. (1950): Federalism and Fiscal Equity, in: American Economic Review 40, S. 583-599.

Buchanan, J.M. (1954): Social Choice, Democracy, and Free Markets, in: Journal of Political Economy 16, S. 114-123.

Buchanan, J.M. (1962): Marginal Notes on Reading Political Philosophy, in: Buchanan, J.M./Tullock, G.: The Calculus of Consent. Logical Foundations of Constitutional Democracy, Ann Arbor, S. 307-322.

Buchanan, J.M. (1965): An Economic Theory of Clubs, in: Economica 32, S. 1-14.

Buchanan, J.M. (1967A): Cooperation and Conflict in Public-Goods Interaction, in: Western Economic Journal 5, S. 109-121.

Buchanan, J.M. (1967B): Public Finance in Democratic Process, Chapel Hill. 
Buchanan, J.M. (1968): The Demand and Supply of Public Goods, Chicago.

BUCHANAN, J.M. (1969): Überfüllung der öffentlichen Einrichtungen: Ein Argument für Staatseingriffe, in: ORDO 20, S. 261-276.

Buchanan, J.M. (1974): Who Should Distribute What in a Federal System?, in: Hochman, H.M./Peterson, G.E. (Hrsg.): Redistribution Through Public Choice, New York, S. 22-41.

BuCHANAN, J.M. (1975/1984): The Limits of Liberty. Between Anarchy and Leviathan, Chicago, London 1975. Zitiert nach der dt. Übersetzung: Die Grenzen der Freiheit. Zwischen Anarchie und Leviathan, Tübingen 1984.

BuchanaN, J.M. (1977): Freedom in Constitutional Contract, College Station.

BuChanAN, J.M. (1980A): Procedural and Quantitative Constitutional Constraints on Fiscal Authority, in: Moore, W.S./Penner, R.G. (Hrsg.): The Constitution and the Budget, Washington, London, S. 80-84.

BuchanAN, J.M. (1980B): Rent Seeking and Profit Seeking, in: Buchanan, J.M./Tollison, R.D./Tullock, G. (Hrsg.): Toward a Theory of the Rent-Seeking Society, College Station, S. 3-15.

BUCHANAN, J.M. (1981): Möglichkeiten institutioneller Reformen im Rahmen kulturell geformter abstrakter Verhaltensregeln, in: Vanberg, V.: Liberaler Evolutionismus oder vertragstheoretischer Konstitutionalismus? Zum Problem institutioneller Reformen bei F.A. von Hayek und J.M. Buchanan, Tübingen.

Buchanan, J.M. (1984): Sources of Opposition to Constitutional Reform, in: McKenzie, R.B. (Hrsg.): Constitutional Economics. Containing the Economic Powers of Government, Lexington, S. 21-34.

BuchanAN, J.M. (1987A): Constitutional Economics, in: Eatwell, J./Milgate, M./Newman, P. (Hrsg.): The New Palgrave - A Dictionary of Economics, Bd. 1, London u.a., S. 585-588.

Buchanan, J.M. (1987B): The Constitution of Economic Policy, in: American Economic Review 77, S. 243-250.

Buchanan, J.M. (1990): The Domain of Constitutional Economics, in: Constitutional Political Economy 1, S. 1-18.

BUCHANAN, J.M. (1991): Möglichkeiten für eine europäische Verfassung: Eine amerikanische Sicht, in: ORDO 42, S. 127-137.

BUCHANAN, J.M./FAITH, R. (1987): Secession and the Limits of Taxation: Toward a Theory of Internal Exit, in: American Economic Review 77, S. 1023-1031.

Buchanan, J.M./GoeTZ, C.J. (1972): Efficiency Limits of Fiscal Mobility: An Assessment of the Tiebout-Model, in: Journal of Public Economics 1, S. 25-43. 
Buchanan, J.M./Kafoglis, M. (1963): A Note on Public Goods Supply, in: American Economic Review 53, S. 403-414.

Buchanan, J.M./LeE, D.R. (1995): On a Fiscal Constitution for the European Union, in: Journal des Economistes et des Etudes Humaines 5, S. 219-233.

Buchanan, J.M./Stubblebine, C.W. (1962): Externality, in: Economica 29, S. 371-384.

Buchanan, J.M./Tullock, G. (1962): The Calculus of Consent. Logical Foundations of Constitutional Democracy, Ann Arbor.

BuChanAN, J.M./WAGNER, R.E. (1970): An Efficiency Basis for Federal Fiscal Equalization, in: Margolis, J. (Hrsg.): The Analysis of Public Output, New York, S. 139-162.

Buchanan, J.M./WAGNER, R.E. (1977): Democracy in Deficit, New York u.a.

BUCOVETSKY, S. (1981): Optimal Jurisdiction Fragmentation and Mobility, in: Journal of Public Economics 16, S. 171-192.

BucovetSKy, S. (1991): Asymmetric Tax Competition, in: Journal of Urban Economics 30, S. 167-181.

Bulutoglu, K. (1976): Fiscal Decentralization. A Survey of Normative and Positive Contributions, in: Finanzarchiv 35, S. 1-34.

BUNDESMINISTERIUM DER FINANZEN (1995): Einnahmenverteilung zwischen Bund und Ländern. Probleme und Lösungsmöglichkeiten. Gutachten erstattet vom Wissenschaftlichen Beirat beim Bundesministerium der Finanzen, Bonn.

BuRDA, M./WYPLOSZ, C. (1992): Human Capital, Investment, and Migration in an Integrating Europe, in: European Economic Review 36, S. 677-684.

BÜSCHGES, G. (1983): Einführung in die Organisationssoziologie, Stuttgart.

BuSH, W.C. (1972): Individual Welfare in Anarchy, in: Tullock, G. (Hrsg.): Explorations in the Theory of Anarchy, Blacksburg, S. 5-18.

Bush, W.C./DENZAU, A.T. (1977): The Voting Behavior of Bureaucrats and Public Sector Growth, in: Borcherding, T.E. (Hrsg.): Budgets and Bureaucrats: The Sources of Government Growth, Durham, S. 90-99.

CAESAR, R. (1980): Die Unabhängigkeit der Notenbank im demokratischen Staat. Argumente und Gegenargumente, in: Zeitschrift für Politik 27, S. 347-377.

CAESAR, R. (1990): Fiscal Stabilization in Economic Unions, in: List Forum für Wirtschaftsund Finanzpolitik 16, S. 323-341.

CAESAR, R. (1993): Rechtfertigungsansätze öffentlicher Verschuldung, in: Das Wirtschaftsstudium 22, S. 140-145. 
CAESAR, R. (1994A): Koordinierung der nationalen Finanzpolitiken in der Wirtschafts- und Währungsunion, in: Caesar, R./Scharrer, H.-E. (Hrsg.): Maastricht: Königsweg oder Irrweg zur Wirtschafts- und Währungsunion?, Bonn, S. 236-268.

CAESAR, R. (1994B): Umweltsonderabgaben oder Umweltsteuern?, in: Hansmeyer, K.H./Ewringmann, D./Gawel, E. (Hrsg.): Umweltpolitik mit hoheitlichen Zwangsabgaben?, Berlin, S. 91-106.

CAESAR, R. (1996): Zur Reform des Einnahmensystems der Europäischen Union, in: Zohlnhöfer, W. (Hrsg.): Europa auf dem Wege zur Politischen Union? Probleme und Perspektiven der europäischen Integration vor 'Maastricht II', Schriften des Vereins für Socialpolitik, N.F., Bd. 247, Berlin, S. 145-173.

CAESAR, R./KOPS, M. (1983): Abbau des Dotationswesens zwischen Ländern und Gemeinden? Eine Untersuchung am Beispiel Nordrhein-Westfalens, in: Archiv für Kommunalwissenschaften 22 , S. 50-73.

CALVERT, R.L./MoRan, M.J./Weingast, B. (1987): Congressional Influence over Policy Making: The Case of the FTC, in: McCubbins, M./Schwartz, T. (Hrsg.): Congress: Structure and Policy, Cambridge, S. 493-522.

CARlberg, M. (1990): Long-Run Limits to Local Public Debt, in: Friedrich, P./Rompuy, P. van (Hrsg.): Fiscal Decentralization, Baden Baden, S. 172-185.

CARroll, K.A. (1993): The Effects of Multiple Objectives in the Theory of Public Sector Supply, in: Public Choice 75, S. 1-20.

CASE, A. (1993): Interstate Tax Competition After TRA86, in: Journal of Policy Analysis and Management 12, S. 136-148.

Cebula, R.J. (1973): Labor Migration and the Cost of Living, in: Review of Regional Studies 3, S. 121-124.

Chandler, W.M./ChandleR, M.A. (1987): Federalism and Political Parties, in: European Journal of Political Economy 3, S. 87-110.

CHAPMAN, R.G./PALDA, K.S. (1984): Assessing the Influence of Campaign Contributions on Voting Behavior Within a Comprehensive Electoral Market Model, in: Marketing Science 3, S. 207-226.

Chaudry-ShaH, A. (1988): Capitalization and the Theory of Local Public Finance: An Interpretative Essay, in: Journal of Economic Surveys 2, S. 209-243.

CHEN, Y./ORDESHOOK, P.C. (1994): Constitutional Secession Clauses, in: Constitutional Political Economy 5, S. 45-60.

Cheung, N.S. (1970): The Structure of a Contract and the Theory of a Non-exclusive Resource, in: Journal of Law and Economics 13, S. 49-70. 
Chicorne, D./WALZER, L. (1985): Governmental Structure and Local Public Finance, Boston.

ClOWER, R.W. (1965): The Keynesian Counter-Revolution: A Theoretical Appraisal, in: Hahn, F.H./Brechling, F.P. (Hrsg.): The Theory of Interest Rates, London, New York, S. 103-125.

CNossen, S. (1990): The Case for Tax Diversity in the European Community, in: European Economic Review 34, S. 471-479.

CNossen, S./Shoup, C.S. (1987): Coordination of Value-Added-Taxes, in: Cnossen, S.

(Hrsg.): Tax Coordination in the European Community, Amsterdam, S. 59-84.

COASE, R.H. (1937): The Nature of the Firm, in: Economica 4, S. 233-261.

COASE, R.H. (1960): The Problem of Social Cost, in: Journal of Law and Economics 3, S. 144.

COASE, R.H. (1984): The New Institutional Economics, in: Journal of Institutional and Theoretical Economics 140, S. 229-231.

COE, R.D./WILBER, C.K. (1985): Capitalism and Democracy: Schumpeter Revisited, Indiana.

Coleman, J.L. (1984): The Foundations of Constitutional Economics, in: McKenzie, R.B. (Hrsg.): Constitutional Economics. Containing the Economic Powers of Government, Lexington, S. 141-155.

Coleman, J.S. (1971): Internal Processes Governing Party Positions in Elections, in: Public Choice 40, S. 89-94.

Coleman, J.S. (1974): Process of Concentration and Dispersal of Power in Social Systems, in: Social Science Information 13, S. 7-18.

COLEMAN, J.S. (1979): Macht und Gesellschaftsstruktur, Tübingen.

ComanoR, W.S. (1976): The Median Voter Rule and the Theory of Political Choice, in: Journal of Public Economics 5, S. 169-177.

ConyBEARE, J.A.C. (1984): Bureaucracy, Monopoly, and Competition: A Critical Analysis of the Budget-Maximizing Model of Bureaucracy, in: American Journal of Political Science 28, S. 479-502.

CONYBEARE, J.A.C./MURDoCH, J.C./SANDLER, T. (1994): Alternative Collective-Goods Models of Military Alliances: Theory and Empirics, in: Economic Inquiry 32, S. 525-542.

COOPER, R.N. (1985): Economic Interdependence and Coordination of Economic Policies, in: Jones, R.W./Kenen, P.B. (Hrsg.): Handbook of International Economics, Vol. II, S. 11951234. 
CORNES, R. (1980): External Effects: An Alternative Formulation, in: European Economic Review 14, S. 307-321.

CoRnes, R./SANDLER, T. (1986): The Theory of Externalities, Public Goods, and Club Goods, Cambridge u.a.

Coughlin, P./Mueller, D.C./Murrell, P. (1990A): Electoral Politics, Interest Groups, and the Size of Government, in: Economic Inquiry 28, S. 682-705.

Coughlin, P./Mueller, D.C./Murrell, P. (1990B): A Model of Electoral Competition With Interest-Groups, in: Economics Letters 32, S. 307-311.

CRAIG, S.G./SAILORS, J.W. (1988): State Government Purchases in a Federalist Economy, in: Public Choice 56, S. 121-130.

CRAIN, W.M. (1979): Cost and Output in the Legislative Firm, in: Journal of Legal Studies 8, S. 607-621.

Crain, W.M./ShugarT, W.F./Tollison, R.D. (1988): Voters as Investors: A Rent-Seeking Resolution of the Paradoy of Voting, in: Rowley, C.K./Tollison, R.D./Tullock, G.

(Hrsg.): The Political Economy of Rent-Seeking, Boston u.a., S. 241-249.

Crain, W.M./Tollison, R.D. (1979): The Executive Branch in an Interest-Group Perspective in: Journal of Legal Studies 8, S. 555-567.

Crew, M.A./Jones-LeE, M.W./Rowley, C.K. (1971): X-Theory versus Management Discretion Theory, in: Southern Economic Journal 37, S. 173-184.

CREW, M.A./Rowley, C.K. (1988): Toward a Public Choice Theory of Monopoly Regulation, in: Public Choice 57, S. 49-67.

Crew, M.A./Twight, C. (1990): On the Efficiency of Law: A Public Choice Perspective, in: Public Choice 66, S. 15-36.

DAfFLON, B. (1977): Federal Finance in Theory and Practice. With Special Reference to Switzerland, Bern, Stuttgart.

DAHL, R. (1967): Who Governs?, 2. Aufl., New Haven

Dahlman, C.J. (1979): The Problem of Externality, in: Journal of Law and Economics 22, S. 141-162.

DALY, G.G. (1969): The Burden of the Debt and Future Generations in Local Finance, in: Southern Economic Journal 36, S. 44-51.

DAvis, O.A./HINICH, M.J./ORdeshoOK, P.C. (1970): An Expository Development of a Mathematical Model of the Electoral Process, in: American Political Science Review 64, S. 426-448. 
DAXHAMMER, R. (1995): Special Interest Groups and Economic Policy in Democratic Societies, Bern.

DAY, K.M. (1992): Interprovincial Migration and Local Public Goods, in: Canadian Journal of Economics 25, S. 123-144.

DE ALESSI, L. (1969): Implications of Property Rights for Government Investment Choices, in: American Economic Review 59, S. 13-24.

De Alessi, L. (1980): The Economics of Property Rights: A Review of the Evidence. in: Research in Law and Economics 2, S. 1-47.

DE AlessI, L. (1983): Property Rights, Transaction Costs, and X-Efficiency: An Essay in Economic Theory, in: American Economic Review 73, S. 64-81.

DE Alessi, L. (1990): Development of the Property Rights Approach, in: Journal of Institutional and Theoretical Economics 146, S. 6-11, 19-23.

DeBreU, G. (1959): The Theory of Value, New York.

DelBRÜCK, C./RAFFELHÜSCHEN, B. (1993): Die Theorie der Migration, in: Jahrbuch für Nationalökonomie und Statistik 212, S. 341-356.

DemsetZ, H. (1964): The Exchange and Enforcement of Property Rights, in: Journal of Law and Economics 7, S. 11-26.

DemsetZ, H. (1967): Towards a Theory of Property Rights, in: American Economic Review 57, S. 347-359.

DEMSETZ, H. (1968): Why Regulate Utilites?, in: Journal of Law and Economics 11, S. 55-65.

DEMSETZ, H. (1969): Information and Efficiency: Another Viewpoint, in: Journal of Law and Economics 11, S. 1-22.

DemsetZ, H. (1982): Economic, Legal, and Political Dimensions of Competition, Amsterdam.

DENO, K.T./MEHAY, S.L. (1985): Institutional Constraints on Local Jurisdiction Formation, in: Public Finance Quarterly 13, S. 450-463.

DENZAU, A./Munger, M.C. (1986): Legislators and Interest Groups: How Unorganized Interests Get Represented, in: American Political Science Review 80, S. 89-106.

DiLorenzo, T. (1983): Economic Competition and Political Competition: An Empirical Note, in: Public Choice 40, S. 203-209.

DINKEL, R. (1980A): Die Interdependenz von Wahlen und ihre wirtschaftspolitischen Konsequenzen, in: Boettcher, E./Herder-Dorneich, P./Schenk, K.-E. (Hrsg.): Neue Politische Ökonomie als Ordnungstheorie, Tübingen, S. 66-81. 
DINKEL, R. (1980B): Die Theorien des Politischen Konjunkturzyklus, in: Rippe,W./Haarland, H.-P./(Hrsg.): Wirtschaftstheorie als Verhaltenstheorie, Berlin, S. 129-149.

DolAN, D. (1990): Local Government Fragmentation: Does It Drive Up the Cost of Government?, in: Urban Affairs Quarterly 26, S. 28-45.

DONAT, M. voN (1995): Das Subsidiaritätsprinzip in der Europäischen Union aus der Perspektive der Europäischen Kommission, in: Hrbek, R. (Hrsg.): Das Subsidiaritätsprinzip in der Europäischen Union - Bedeutung und Wirkung für ausgewählte Politikbereiche, Baden-Baden, S. 9-16.

DoNGES, J.B. (1981): Handelshemmnisse, nicht-tarifäre, in: Albers, W. u.a. (Hrsg.):

Handwörterbuch der Wirtschaftswissenschaften, Bd. 3, Stuttgart, S. 784-794.

Dowding, K./JoHN, P./BIGGS, S. (1994): Tiebout: A Survey of the Empirical Literature, in: Urban Studies 31, S. 767-797.

Downs, A. (1957/1968): An Economic Theory of Democracy, New York 1957. Zitiert nach der dt. Übersetzung: Ökonomische Theorie der Demokratie, Tübingen 1968.

Downs, A. (1967): Inside Bureaucracy, Boston.

Dunleavy, P. (1991): Democracy, Bureaucracy, and Public Choice, New York.

EASTERBROOK, F.H. (1994): Federalism and European Business Law, in: International Review of Law and Economics 14, S. 125-132.

EBERTS, R./GRONBERG, T. (1988): Can Competition Among Local Governments Constrain Government Spending?, in: Economic Review of the Federal Reserve Bank of Cleveland 1, S. 2-9.

EdEL, M./SclaR, E. (1974): Taxes, Spending and Property Values: Supply Adjustment in a Tiebout-Oates Model, in: Journal of Political Economy 82, S. 941-954.

EGgERTSSON, T. (1990): Economic Behavior and Institutions, Cambridge.

EHRLICH, I./PoSNER, R.A. (1974): An Economic Analysis of Legal Rulemaking, in: Journal of Legal Studies 2, S. 257-286.

EICHENBERGER, R. (1994): The Benefits of Federalism and the Risk of Overcentralization, in: Kyklos 47, S. 403-420.

EISEN, R. (1988): 'Versicherungsprinzip' und Umverteilung - Einige theoretische Überlegungen zu den Grenzen des Versicherbaren, in: Rolf, G./Spahn, P.B./Wagner, G. (Hrsg.): Sozialvertrag und Sicherung. Zur ökonomischen Theorie staatlicher Versicherungs- und Umverteilungssysteme, Frankfurt/M., New York, S. 117-127. 
EKELUND, R.B./Tollison, R.D. (1981): Mercantilism as a Rent Seeking Society, College Station.

ElaZAR, D.J (1984): American Federalism: A View from the States, 3. Aufl., New York.

ELSNER, W. (1986): Ökonomische Institutionenanalyse, Berlin.

ELSNER, W. (1987): Institutionen und ökonomische Institutionentheorie, in: Wirtschaftswissenschaftliches Studium 16, S. 5-14.

EMONS, W. (1994): Kommentar zu Schmidtchen, D./Schmidt-Trenz, H.-J.: Theorie optimaler Rechtsräume. Die Regulierung sozialer Beziehungen durch die Kontrolle von Territorien, in: Jahrbuch für Neue Politische Ökonomie 13, S. 30-31.

ENELOW, J.L./HINICH, M.J. (1990): Advances in the Spatial Theory of Voting, Cambridge u.a.

EPPLE, D./ZelEnITZ, A. (1981): The Implications of Competition Among Jurisdictions: Does Tiebout Need Politics?, in: Journal of Political Economy 89, S. 1197-1217.

EpPle, D./ZelENITZ, A./VisscheR, M. (1978): A Search for Testable Implications of the Tiebout Hypothesis, in: Journal of Political Economy 83, S. 405-425.

EPSTEIN, R.A. (1988): Taxation, Regulation, and Confiscation, in: Gwartney, J.D./Wagner, R.E. (Hrsg.): Public Choice and Constitutional Economics, Greenwich, S. 181-205.

EsCHENBURG, R.. (1977): Der ökonomische Ansatz zu einer Theorie der Verfassung, Tübingen.

EsCHENBURG, R.. (1978): Mikroökonomische Aspekte von Property Rights, in: Schenk, K.-E. (Hrsg.): Ökonomische Verfügungsrechte und Allokationsmechanismen in Wirtschaftssystemen, Berlin, S. 9-27.

EUCKEN, W. (1952): Grundsätze der Wirtschaftspolitik, Tübingen.

Evans, A.W. (1973): The Pure Theory of City Size in an Industrial Economy, in: Urban Studies 9, S. 49-77.

FAIB, K. U.A. (1986): Kommunales Wirtschaftsrecht in Baden-Württemberg, 4. Aufl., Stuttgart.

FAITH, R. (1980): Rent-Seeking Aspects of Bureaucratic Competition, in: Buchanan, J.M./Tollison, R.D./Tullock, G. (Hrsg.): Toward a Theory of the Rent Seeking-Society, College Station, S. 332-343.

FAMA, E.F./JENSEN, M.C. (1983): Separation of Ownership and Control, in: Journal of Law and Economics 26, S. 301-326.

FARRELL, J. (1987): Information and the Coase Theorem, in: Journal of Economic Perspectives 1, S. 113-129. 
FEHL, U. (1978): Abwanderung und Widerspruch. Bemerkungen zu dem gleichnamigen Buch von Albert O. Hirschman, in: ORDO 29, S. 402-412.

FELDMANN, H. (1995): Eine institutionalistische Revolution? Zur dogmenhistorischen Bedeutung der modernen Institutionenökonomik, Berlin.

FERRIS, J.M./WINKLER, D.R. (1990): Agency Theory and Intergovernmental Relationships, in: Prud'homme, R. (Hrsg.): Public Finance With Several Levels of Government, Brüssel, S. 155-166.

Findlay, R./Wellisz. S. (1983): Some Aspects of the Political Economy of Trade Restrictions, in: Kyklos 36, S. 469-483.

FINDLAY, R./WILSON, J.D. (1987): The Political Economy of Leviathan, in: Razin, A./Sadka, E. (Hrsg.): Economic Policy in Theory and Practice, London, S. 289-304.

FINSINGER, J. (1988): Non-Competitive and Protectionist Government Purchasing Behavior, in: European Economic Review 32, S. 69-80.

FIORINA, M. (1981): Retrospective Voting in American National Elections, New Haven.

FISCHEL, W.A. (1975): Fiscal and Environmental Considerations in the Location of Firms in Suburban Communities, in: Mills, E.S./Oates, W.E. (Hrsg.): Fiscal Zoning and Land Use Controls, Lexington, S. 119-173.

FISCHER, H. (1988): Finanzzuweisungen. Theoretische Grundlagen und praktische Ausgestaltung im bundesstaatlichen Finanzausgleich Australiens und der Bundesrepublik Deutschland, Berlin.

FISCHER, P.A./STRAUBHAAR, T. (1994): Ökonomische Integration und Migration in einem Gemeinsamen Markt: 40 Jahre Erfahrung im Nordischen Arbeitsmarkt, Bern.

FISHER, R.C. (1988): State and Local Public Finance, Glenview.

FISHER, R.C. (1991): Interjurisdictional Competition: A Summary Perspective and Agenda for Research, in: Kenyon, D.A./Kincaid, J. (Hrsg.): Competition Among States and Local Governments, Washington, S. 261-273.

Flatters, F./HENDERSON, V./MieszKowski, P. (1974): Public Goods, Efficiency, and Regional Fiscal Equalization, in: Journal of Public Economics 3, S. 99-112.

FLOWERS, M. (1988): Shared Tax Sources in a Leviathan Model of Government, in: Public Finance Quarterly 16, S. 67-77.

FoldVary, F. (1994): Public Goods and Private Communities, Aldershot.

FOLKERS, C. (1983): Begrenzung von Steuern und Staatsausgaben in den USA, Baden-Baden. 
FORBES, K./ZAMPELLI, E. (1989): Is Leviathan a Mythical Beast ?, in: American Economic Review 79, S. 568-577.

FORTE, F. (1983): Monitoring the Productivity of Bureaucratic Behavior, in: Hanusch, H.

(Hrsg.): Anatomy of Government Deficiencies, Heidelberg, S. 149-160.

FRENKEL, M. (1986): Föderalismus und Bundesstaat, Bd. II: Bundesstaat, Bern.

FreY, B.S. (1971): Why Do High-Income People Participate More in Politics, in: Public Choice 11, S. 101-106.

FREY, B.S. (1981A): Theorie demokratischer Wirtschaftspolitik, München.

FREY, B.S. (1981B): Elemente einer zukünftigen Theorie der Wirtschaftspolitik, in: Zeitschrift für Wirtschafts- und Sozialwissenschaften 101, S. 361-377.

FREY, B.S. (1985): Internationale Politische Ökonomie, München.

FrEY, B.S. (1990): Ökonomie ist Sozialwissenschaft, München.

FREY, B.S. (1994): Direct Democracy: Politico-Economic Lessons from Swiss Experience, in: American Economic Review 84, S. 338-342.

FREY, B.S./KIRCHGÄSSNER, G. (1994): Theorie demokratischer Wrtschaftspolitik, 2. Aufl., München.

FREY, B.S./LAU, L.J. (1968): Towards a Mathematical Model of Government Behavior, in: Zeitschrift für Nationalökonomie 28, S. 355-380.

FREY, B.S./POMMEREHNE, W.W. (1982): How Powerful are Bureaucrats as Voters?, in: Public Choice 38, S. 253-262.

FREY, R.L. (1977): Zwischen Föderalismus und Zentralismus, Bern, Frankfurt/M.

FRIEDMAN, D. (1979): A Theory of the Size and Shape of Nations, in: Journal of Political Economy 85, S. 59-78.

FRITSCH, M. (1983): Ökonomische Ansätze zur Legitimation kollektiven Handelns, Berlin.

FRITSCH, M. (1985): Verteilungspolitische Implikationen der Vertragstheorie, in: Jahrbuch für Neue Politische Ökonomie 4, S. 160-177.

FroHlich, N./OPPENHEIMER, J.A./Young, O.R. (1971): Political Leadership and Collective Goods, Princeton.

FÜCHSEL, W.-D. (1985): Gemeinschaftsaufgaben. Eine finanzwissenschaftliche Analyse der Gemeinschaftsaufgaben nach Art. 91a, b GG und der Investititionshilfen nach Art. 104a Abs. 4 GG, Spardorf. 
FUEST, C. (1995): Eine Fiskalverfassung für die Europäische Union, Köln.

FURUBOTN, E.G. (1986): Efficieny and the Maximization Postulate: Another Interpretation, in: Journal of Behavioral Economics 15, S. 41-48.

Furubotn, E.G./PEJovich, S. (1972): Property Rights and Economic Theory: A Survey of Recent Literature, in: Journal of Economic Literature 10, S. 1137-1162.

FURUBOTN, E.G./RICHTER, R. (1984): Editorial Preface, in: Journal of Institutional and Theoretical Economics 140, S. 1-6.

FURUBOTN, E.G./RICHTER, R. (1991): The New Institutional Economics: An Assessment, in: Furubotn, E.G./Richter, R. (Hrsg.): The New Institutional Economics. A Collection of Articles From the Journal of Institutional and Theoretical Economics, Tübingen, S. 1-32.

Galbraith, J.K. (1952): American Capitalism: The Concept of Countervailing Power, Boston.

GALEOTTI, G. (1987): Political Exchanges and Decentralisation, in: European Journal of Political Economy 3, S. 111-129.

GALEOTTI, G. (1992): Decentralisation and Political Rents, in: King, D.N. (Hrsg.): Local Government Economics in Theory and Practice, London, New York, S. 5-15.

Galeotti, G./Breton, A. (1986): An Economic Theory of Political Parties, in: Kyklos 39, S. 47-65.

GANDENBERGER, O. (1981): Theorie der öffentlichen Verschuldung, in: Neumark, F. (Hrsg.): Handbuch der Finanzwissenschaft, 3.Aufl., Bd. III, Tübingen, S. 4-49.

GARDNER, R./Ostrom, E./WALKER, J. (1990): The Nature of Common-Pool Resource Problems, in: Rationality and Society 2, S. 335-358.

GENSER, B./HAUfLER, A. (1990): Steuerpolitik in offenen Volkswirtschaften, in: Das Wirtschaftsstudium 19, S. 313-319.

GERKEN, L. (1995A): Vertikale Kompetenzverteilung in Wirtschaftsgemeinschaften - Bestimmungsgründe und Probleme, in: Gerken, L. (Hrsg.): Europa zwischen Ordnungswettbewerb und Harmonisierung, Berlin u.a., S. 3-33.

GERKEN, L. (1995B): Institutional Competition: An Orientative Framework, in: Gerken, L. (Hrsg.): Competition Among Institutions, London, S. 1-31.

GiERSCH, H. (1989): Anmerkungen zum weltwirtschaftlichen Denkansatz, in: Weltwirtschaftliches Archiv 125, S. 1-16.

GIERSCH, H. (1995): Diskussionsbeitrag, in: Gerken, L. (Hrsg.): Europa zwischen Ordnungswettbewerb und Harmonisierung, Berlin u.a., S. 35-43. 
GIERTZ, F. (1981): Centralisation and Government Budget Size, in: Publius: The Journal of Federalism 11, S. 119-128.

GiovanNINI, A. (1989): National Tax Systems versus the European Capital Market, in: Economic Policy 9, S. 364-384.

GolDBERG, V.P. (1976): Regulation and Administered Contracts, in: Bell Journal of Economics 7, S. 426-448.

GonZaleZ, R.A./MeHAY, S.L. (1987): Municipal Annexation and Local Monopoly Power, in: Public Choice 52, S. 245-255.

GoODSPEED, T.J. (1989): A Re-Examination of the Use of Ability to Pay Taxes by Local Governments, in: Journal of Public Economics 38, S. 319-342.

Gordon, H.S. (1954): The Economic Theory of a Common Property Resource: The Fishery, in: Journal of Political Economy 62, S. 124-142.

GoRDON, R.H. (1983): An Optimal Taxation Approach to Fiscal Federalism, in: Quarterly Journal of Economics 98, S. 567-586.

GORDON, R.J. (1982): Inflation, Flexible Exchange Rates, and the Natural Rate of Unemployment, in: Baily, M.N. (Hrsg.): Workers, Jobs, and Inflation, Washington, S. 88155.

GORDON, R.J. (1985): Understanding Inflation in the 1980s, in: Brookings Papers on Economic Activity 1, S. 263-299.

GRAMLICH, E.M. (1977): Intergovernmental Grants: A Review of the Empirical Literature, in: Oates, W.E. (Hrsg.): The Political Economy of Fiscal Federalism, Lexington, Toronto, S. 219-239.

GRAMLICH, E.M. (1987): Federalism and Federal Deficit Reduction, in: National Tax Journal 40, S. 299-313.

GREENWOOD, M.J./ANDERSON, E.J. (1974): A Simultaneous-Equations Model of Migration and Economic Change in Rural Areas: The Case of the South, in: Review of Regional Studies 4, S. 37-47.

GREWAL, B.S. (1988): Locational Surplus and Its Relevance for Subnational Taxation and Inter-Governmental Grants in a Federation, in: Brennan, G./Grewal, B.S./Groenewegen, P. (Hrsg.): Taxation and Fiscal Federalism, Sydney u.a., S. 166-179.

Groenewegen, P. (1990): Taxation and Decentralization: A Reconsideration of the Costs and Benfits of a Decentralized Tax System, in: Bennett, R.J. (Hrsg.): Decentralization, Local Governments, and Markets: Towards a Post-Welfare Agenda, Oxford, S. 87-115. 
GRÖNER, H. (1983): Property Rights-Theorie und staatlich regulierte Industrien, in: Schüller, A. (Hrsg.): Property Rights und ökonomische Theorie, München, S. 219-239.

GROSSEKETTLER, H. (1982): Konzepte zur Beurteilung der Effizienz von Koordinationsmechanismen, in: Jahrbuch für Neue Politische Ökonomie 1, S. 213-257.

Grossman, P.J. (1989A): Federalism and the Size of Government, in: Southern Economic Journal 55, S. 580-593.

Grossman, P.J. (1989B): Fiscal Decentralization and Government Size: An Extension, in: Public Choice 62, S. 63-69.

Grossman, P.J. (1992): Fiscal Decentralization and Public Sector Size in Australia, in: Economic Record 68, S. 240-246.

Grossman, P.J./WEST, E.G. (1994): Federalism and the Growth of Government Revisited, in: Public Choice 79, S. 19-32.

GuSTLEY, R. (1977): The Allocational and Distributional Impacts of Governmental Consolidation, in: Urban Affairs Quarterly 12, S. 349-364.

GutTMAN, J.M. (1987): A Non-Cournot Model of Voluntary Collective Action, in: Economica 54, S. 1-19.

GWARTNEY, J.D./WAGNER, R.E. (1988): Public Choice and Constitutional Order, in: Gwartney, J.D./Wagner, R.E. (Hrsg.): Public Choice and Constitutional Economics, Greenwich, S. 29-56.

HAgEN, J. voN/FratianNi, M. (1991): Monetary and Fiscal Policy in a European Monetary Union: Some Public Choice Considerations, in: Welfens, P.J.J. (Hrsg.): European Monetary Integration, 2. Aufl., Berlin, S. 275-302.

HALleR, H. (1968): Wandlungen in den Problemen föderativer Staatswirtschaften, in: Finanzarchiv 27, S. 249-270.

HAMADA, K. (1985): The Political Economy of International Monetary Interdependence, Cambridge.

Hamilton, B.W. (1975): Property Taxes and the Tiebout Hypothesis: Some Empirical Evidence, in: Mills, E.S./Oates, W.E. (Hrsg.): Fiscal Zoning and Land Use Controls, Lexington, S. 13-29.

HAmilton, B.W. (1976): Zoning and Property Taxation in a System of Local Governments, in: Urban Studies 12, S. 205-211.

Hamilton, B.W. (1983): A Review: Is the Property Tax a Benefit Tax?. in: Zodrow, G.R. (Hrsg.): Local Provision of Public Services: The Tiebout Model After Twenty-Five Years, New York, S. 85-108. 
Hamlin, A.P. (1984): Constitutional Control of Processes and Their Outcomes, in: Public Choice 42, S. 133-145.

Hamlin, A.P. (1985A): The Political Economy of Constitutional Federalism, in: Public Choice 46, S. 187-195.

Hamlin, A.P. (1985B): Federalism, Horizontal Equity and the Optimal Grant, in: Public Finance Quarterly 13, S. 115-131.

Hamlin, A.P. (1991): Decentralization, Competition, and the Efficiency of Federalism, in: Economic Record 67, S. 193-204.

Hamlin, A.P./UlPh, A. (1991): Tax Harmonisation, in: McKenzie, G./Venables, A.J. (Hrsg.): The Economics of the Single European Act, London, S. 71-97.

Hansen, S./Palfrey, T.R./Rosenthal, H. (1987): The Downsian Model of Electoral Participation: Formal Theory and Empirical Analysis of the Constitutency Size Effect, in: Public Choice 52, S. 15-33.

HANSMEYER, K.-H. (1967): Das Popitz'sche Gesetz von der Anziehungskraft des zentralen Etats, in: Timm, H./Haller, H. (Hrsg.): Beiträge zur Theorie der öffentlichen Ausgaben, Berlin, S. 197-229.

HANSMEYER, K.-H. (1968): Ziele und Träger regionaler Wirtschaftspolitik, in: Schneider, H.K. (Hrsg.): Beiträge zur Regionalpolitik, Schriften des Vereins für Socialpolitik N.F., Bd. 41, Berlin, S. 36-60.

HANSMEYER, K.-H./KOPS, M. (1984): Die Kompetenzarten der Aufgabenzuständigkeit und deren Verteilung im föderativen Staat, in: Hamburger Jahrbuch für Wirtschafts- und Gesellschaftspolitik 29, S. 127-140.

HANSMEYER, K.-H./MACKSCHEIDT, K. (1973): Die Free-Rider-Position der Finanzpolitik Notenbankpolitik und Staatsaktivität, in: Duwendag, D. (Hrsg.): Macht und Ohnmacht der Bundesbank, Frankfurt/Main, S. 132-148.

Hansson, I./StuarT, C. (1984): Voting Competitions With Interested Politicians: Platforms Do Not Converge to the Preferences of the Median Voter, in: Public Choice 44, S. 431441.

HANUSCH, H. (1978): Ökonomische Stabilisierung, in: Assmann, K./Goppel, T. (Hrsg.): Föderalismus, München u.a., S. 97-111.

HANUSCH, H. (1979): Erfüllung von Staatsaufgaben im Föderalismus. Eine ökonomisch-politische Analyse auftretender Konflikte, in: Bohley, P./Tolkemitt, C. (Hrsg.): Wirtschaftswissenschaft als Grundlage staatlichen Handelns, Tübingen, S. 359-381.

HARBERGER, A. (1954): Monopoly and Resource Allocation, in: American Economic Review 44, S. 77-87. 
HARDIN, G. (1968): The Tragedy of the Commons, in: Science 162, S. 1243-1248.

HARDING, F.O. (1959): Politisches Modell zur Wirtschaftstheorie, Freiburg.

HARrington, J.E. (1993): Economic Policy, Economic Performance, and Elections, in: American Economic Review 83, S. 27-42.

HART, O. (1982): A Model of Imperfect Competition With Keynesian Features, in: Quarterly Journal of Economics 97, S. 109-138.

HART, O. (1990): An Economist's Perspective on the Theory of the Firm, in: Williamson, O.E. (Hrsg.): Organization Theory - From Chester Barnard to the Present, New York, Oxford, S. 154-171.

HARTwIG, K.-H. (1988): Ordnungstheorie und die Tradition des ökonomischen Denkens, in: Cassel, D./Ramb, B.-T./Thieme, H.J. (Hrsg.): Ordnungspolitik, München, S. 31-51.

HAUSER, H. (1993): Harmonisierung oder Wettbewerb nationaler Regulierungssysteme in einem integrierten Wirtschaftsraum, Aussenwirtschaft 48, S. 459-476.

HAYEK, F.A. VON (1939/1952): The Economic Conditions of Interstate Federalism, in: New Commonwealth Quarterly 5, S. 131-149. Zitiert nach der dt. Übersetzung: Die wirtschaftlichen Voraussetzungen föderativer Zusammenschlüsse, in: Hayek, F.A. von (Hrsg.): Individualismus und wirtschaftliche Ordnung, Zürich 1952, S. 324-344.

HAYEK, F.A. VON (1945): The Use of Knowledge in Society, in: American Economic Review 35, S. 519-530.

HAYEK, F.A. vON (1968): Wettbewerb als Entdeckungsverfahren, Tübingen.

HAYEK, F.A. vON (1969): Freiburger Studien. Gesammelte Aufsätze, Tübingen.

HAYEK, F.A. vON (1971): Die Verfassung der Freiheit, Tübingen.

HAYEK, F.A. vON (1977): Entnationalisierung des Geldes, Tübingen.

HAYEK, F.A. VON (1980): Regeln und Ordnung, München.

HAYEK, F.A. vON (1981A): Die Illusion der sozialen Gerechtigkeit, Landsberg/Lech.

HAYEK, F.A. VON (1981B): Die Verfassung einer Gesellschaft freier Menschen, Landsberg/Lech.

HEAD, J. (1962): Public Goods and Public Policy, in: Public Finance 17, S. 197-219.

HECKSCHER, E. (1919): The Effect of Foreign Trade on the Distribution of Income, Ekonomisk Tidskrift 21. 
HeIL, J.B. (1991): The Search for Leviathan Revisited, in: Public Finance Quarterly 19, S. 334-346.

HEINEMANN, F. (1995): Bailout- und Bonitätseffekte in der Wirtschafts- und Währungsunion, in: Zeitschrift für Wirtschafts- und Sozilawissenschaften 115, S. 605-622.

Henderson, V. (1979): Theories of Group, Jurisdiction, and City Size, in: Mieszkowski, P./Straszheim, M. (Hrsg.): Current Issues in Urban Economics, Baltimore S. 235-269.

Hercowitz, Z./PINES, D. (1991): Migration with Fiscal Externalities, in: Journal of Public Economics 46, S. 163-180.

HERDER-DORNEICH, P. (1973): Verbände am Markt - Gleichgewicht am verbandsorganisierten Markt, in: Herder-Dorneich, P. (Hrsg.): Zur Verbandsökonomik. Ansätze zu einer ökonomischen Theorie der Verbände, Berlin, S. 26-109.

HERDER-DORNEICH, P./GROSER, M. (1977): Ökonomische Theorie des politischen Wettbewerbs, Göttingen.

HERdziNA, K. (1993): Wettbewerbspolitik, 4. Aufl., Tübingen.

HerrmanN, A./Leibfritz, W./SöRensen, P.B./WegneR, M. (1992): Probleme und Chancen einer Koordinierung der Finanzpolitik in der EG, Berlin, München.

Hesse, J.J. (1978): Einführung, in: Hesse, J.J. (Hrsg.): Politikverflechtung im föderativen Staat. Studien zum Planungs- und Finanzierungsverbund zwischen Bund, Ländern und Gemeinden, Baden-Baden, S. 9-17.

HeTtiCH, W./WINER, S. (1987): Federalism, Special Interests, and the Exchange of Political Resources, in: European Journal of Political Economy 3, S. 33-54.

Higgins, R.S./ShugaRT, W.F./Tollison, R.D. (1988): Free Entry and Efficient RentSeeking, in: Rowley, C.K./Tollison, R.D./Tullock, G. (Hrsg.): The Political Economy of Rent-Seeking, Boston u.a., S. 247-258.

HiLl, J.S. (1985): Why So Much Stability? The Impact of Agency Determined Stability, in: Public Choice 46, S. 275-287.

Hillman, A.L. (1989): The Political Economy of Protection, Chur u.a.

Hillman, A.L. (1992): International Trade Policy: Benevolent Dictators and Optimizing Politicians, in: Public Choice 74, S. 1-15.

Hillman, A.L./KatZ, E. (1984): Risk-Averse Rent-Seekers and the Social Cost of Monopoly Power, in: Economic Journal 94, S. 104-110.

Hillman, A.L./Ursprung, W. (1988): Domestic Politics, Foreign Interests, and International Trade Policy, in: American Economic Review 78, S. 729-745. 
HINICH, M.J. (1978): The Mean Versus the Median in Spatial Voting Games, in: Ordeshook, P. (Hrsg.): Game Theory and Political Science, New York, S. 357-374.

HINICH, M.J./Munger, M.C. (1989): An Equilibrium Spatial Model of Voters, Legislators, and Interest Groups, in: Ordeshook, P. (Hrsg.): Models of Strategic Choice in Politics, New York, S. 49-67.

HINICH, M.J./ORDESHOOK, P.C. (1969): Abstensions and Equilibrium in the Electoral Process, in: Public Choice 7, S. 81-106.

HiNICH, M.J./ORDESHOOK, P.C. (1970): Plurality Maximization vs. Vote Maximization: A Spatial Analysis with Variable Participation, in: American Political Science Review 64, S. 772-791.

HiRSCH, W.Z. (1964): Local Versus Areawide Urban Government Services, in: National Tax Journal 17, S. 331-339.

HiRSCHMAN, A.O. (1970/1974): Exit, Voice, and Loyalty, Cambridge 1970. Zitiert nach der dt. Übersetzung: Abwanderung und Widerspruch, Tübingen 1974.

Hirschman, A.O. (1981): Essays in Trespassing. Economics to Politics and Beyond, Cambridge.

Hirschman, A.O. (1987): Exit and Voice, in: Eatwell, J./Milgate, M./Newman, P. (Hrsg.): The New Palgrave - A Dictionary of Economics, Bd. 2, London u.a., S. 219-224.

HiRShleIfER, J. (1985): The Expanding Domain of Economics, in: American Economic Review 75, S. 53-66.

HoBbes, T. (1651/1984): Leviathan or the Matter, Form, and Power of a Commonwealth Ecclesiastical and Civil 1651. Zitiert nach der dt. Übersetzung: Leviathan oder Stoff, Form und Gewalt eines kirchlichen und bürgerlichen Staates, Frankfurt/M.

Hochman, H.M./Rodgers, J.D. (1969): Pareto Optimal Redistribution, in: American Economic Review 59, S. 542-557.

Hogan, T.D./Shelton, R.B. (1973): Interstate Tax Exportation and States' Fiscal Structures, in: National Tax Journal 26, S. 553-564.

Holcombe, R.G./GWARTNEY, J.D. (1989): Political Parties and the Legislative PrincipalAgent Relationship, in: Journal of Institutional and Theoretical Economics 145, S. 669675.

Holcombe, R.G./Sobel, R.S. (1995): Empirical Evidence on the Publicness of State Legislative Activities, in: Public Choice 83, S. 47-58.

Holler, M./ILling, G. (1993): Einfuhhrung in die Spieltheorie, 2. Aufl., Berlin u.a. 
HolmSTRÖM, B. (1979): Moral Hazard and Observability, in: Bell Journal of Economics 10, S. 74-91.

HomanN, K. (1983): Markt, Staat und Freiheit im Liberalismus, in: Jahrbuch für Neue Politische Ökonomie 2, S. 325-350.

HOMANN, K. (1985): Legitimation und Verfassungsstaat. Vertragstheoretische Interpretation der Demokratie, in: Jahrbuch für Neue Politische Ökonomie 4, S. 48-72.

HOPPMANN, E. (1972): Fusionskontrolle, Tübingen.

HotelliNG, H. (1929): Stability in Competition, in: Economic Journal 39, S. 41-57.

HoYT, W.H. (1990): Local Government Inefficiency and the Tiebout-Hypothesis: Does Competition Among Municipalities Limit Local Government Inefficiency?, in: Southern Economic Journal 57, S. 481-496.

HoYT, W.H. (1991): Property Taxation, Nash Equilibrium, and Market Power, in: Journal of Urban Economics 30, S. 123-131.

HUPPERTZ, P.H. (1977): Gewaltenteilung und antizyklische Finanzpolitik, Baden Baden.

HUTCHISON, T.W. (1984): Institutionalist Economics Old and New, in: Journal of Institutional and Theoretical Economics 40, S. 20-29.

INMAN, R.P. (1987): Markets, Governments, and the 'New' Political Economy, in: Auerbach, A.J./Feldstein, M. (Hrsg.): Handbook of Public Economics, Vol. 2, Amsterdam, S. 647777.

InMAN, R.P./RuBINFIELD, D.L. (1992): Fiscal Federalism in Europe. Lessons From the United States Experience, in: European Economic Review 36, S. 654-660.

IPPOLITO, D.S./WALKER, T.G. (1980): Political Parties, Interest Groups, and Public Policy, Englewood Cliffs.

ISENSEE, J. (1990): Der Föderalismus und der Verfassungsstaat der Gegenwart, in: Archiv des öffentlichen Rechts, S. 248-271.

IsSERMAN, A. (1976): Interjurisdictional Spillovers, Political Fragmentation, and the Level of Local Public Services: A Re-Examination, in: Urban Studies 13, S. 1-12.

JaARSma, B./Schram, A./Winden, F. van (1986): On the Voting Participation of Public Bureaucrats, in: Public Choice 48, S. 183-187.

JACKSON, P.M. (1982): The Political Economy of Bureaucracy, Deddington.

JACOBSON, G.C. (1985): Money and Votes Reconsidered: Congressional Elections 19721982, in: Public Choice 47, S. 7-62. 
JACQUEMIN, A./SlADE, M.E. (1989): Cartels, Collusion, and Horizontal Merger, in: Schmalensee, E./Willig, R.D. (Hrsg.): Handbook of Industrial Organization, Bd. 1, S. 415-473.

JENSEN, M.C. (1983): Organization Theory and Methodology, in: Accounting Review 58, S. 319-339.

JENSEN, M.C./MECKLING, W.H. (1976): Theory of the Firm: Managerial Behavior, Agency Costs, and Ownership Structure, in: Journal of Financial Economics 3, S. 305-360.

JoHNSON, W.R. (1988): Income Redistribution in a Federal System, in: American Economic Review 78, S. 570-573.

JOHNSON, W.R. (1991): Decentralized Income Redistribution Reconsidered, in: Economic Inquiry 29, S. 69-78.

JöHR, W.A.(1976): Die kollektive Selbstschädigung durch Verfolgung des eigenen Vorteils, in: Neumark, F./Thalheim, K.C./Hölzler, H. (Hrsg.): Wettbewerb, Konzentration und wirtschaftliche Macht, Berlin, S. 127-159.

JoRgENSON, D.W. (1963): Capital Theory and Investment Behavior, in: American Economic Review 53, S. 247-259.

Joulfaian, D.Marlow, M.L. (1991): Public Sector Employment, Competition, and Government Size, in: Public Finance 46, S. 222-235.

Kallfass, H.H. (1992): Managementkontrolle in Publikumsgesellschaften, in: Hamburger Jahrbuch für Wirtschafts- und Gesellschaftspolitik 37, S. 277-290.

KALT, J.P. (1981): The Economics and Politics of Oil-Price Regulation, Cambridge.

KaLT, J.P./ZuPAN, M.A. (1990): The Apparent Ideological Behavior of Legislators: Testing for Principal-Agent Slack in Political Institutions, in: Journal of Law and Economics 33, S. 103-132.

KAMMLER, H. (1996): Pluralismus als Vorbedingung der Vitalität Europas - Nachteile der Größe, in: Caesar, R./Ohr, R. (Hrsg.): Maastricht und Maastricht II: Vision oder Abenteuer?, Baden-Baden, S. 277-283.

KAU, J.B./KeENAN, D./RUBIN, P.H. (1982): A General Equilibrium Model of Congressional Voting, in: Quarterly Journal of Economics 97, S. 271-293.

KAU, J.B./RUBIN, P.H. (1979): Self-Interest, Ideology, and Logrolling in Congressional Voting, in: Journal of Law and Economics 22, S. 365-384.

KaU, J.B./RubIN, P.H. (1993): Ideology, Voting and Shirking, in: Public Choice 76, S. 151172. 
KAU, J.B./SiRmaNS, C.F. (1976): New, Repeat and Return Migrations: A Study of Migrant Types, in: Southern Economic Journal 43, S. 1144-1148.

KAUFER, E. (1981): Theorie der öffentlichen Regulierung, München.

KEEN, M. (1989): Pareto-Improving Indirect Tax Harmonization, in: European Economic Review 33, S. 1-12.

KENYON, D.A./KINCAID, J. (1991): Introduction, in: Kenyon, D.A./Kincaid, J. (Hrsg.): Competition Among States and Local Governments, Washington, S. 1-33.

KERBER, W./VANBERG, V. (1995): Competition Among Institutions: Evolution Within Constraints, in: Gerken, L. (Hrsg.): Competition Among Institutions, London, S. 35-64.

KInCAID, J. (1991): The Competitive Challenge to Cooperational Federalism: A Theory of Federal Democracy, in: Kenyon, D.A./Kincaid, J. (Hrsg.): Competition Among States and Local Governments, Washington, S. 87-114.

KINDLEBERgER, C.P. (1986): International Public Goods without International Government, in: American Economic Review 76, S. 1-13.

KING, D.N. (1984): Fiscal Tiers. The Economics of Multi-Level Government, London.

KING, D.N. (1992): Current Issues in the Theory of Fiscal Federalism, in: King, D.N. (Hrsg.): Local Government Economics in Theory and Practice, London, New York, S. 23-42.

KIRCHGÄSSNER, G. (1984): Optimale Wirtschaftspolitik und die Erzeugung politisch-ökonomischer Konjunkturzyklen, Hain.

KIRCHGÄSSNER, G. (1988): Wirtschaftspolitik und Politiksystem: Zur Kritik der traditionellen Ordnungstheorie aus der Sicht der Neuen Politischen Ökonomie, in: Cassel, D./Ramb, B.T./Thieme, H.J. (Hrsg.): Ordnungspolitik, München, S. 53-75.

KIRCHGÄSSNER, G. (1994): Constitutional Economics and Its Relevance for the Evolution of Rules, in: Kyklos 47, S. 321-339.

KIRCHGÄSSNER, G./POMMEREHNE, W.W. (1993): Low Cost Decisions as a Challenge to Public Choice, in: Public Choice 77, S. 107-115.

KIRCHGÄSSNER, G./POMMEREHNE, W.W. (1996): Tax Harmonization and Tax Competition in the European Union: Lessons From Switzerland, in: Journal of Public Economics 60, S. 351-371.

KIRSCH, G. (1977): Einleitung, in: Kirsch, G. (Hrsg.): Föderalismus, Stuttgart, New York, S. 1-14. 
KIRSCH, G. (1978): Föderalismus - die Wahl zwischen intrakollektiver Konsenssuche und interkollektiver Auseinandersetzung, in: Dreißig, W. (Hrsg.): Probleme des Finanzausgleichs I, Schriften des Vereins für Socialpolitik, Bd. 96, Berlin, S. 9-43.

KIRSCH, G. (1980): Ordnungspolitik und interkollektive Beziehungen, in: Dettling, W. (Hrsg.): Die Zähmung des Leviathan, Baden-Baden, S. 163-184.

KIRSCH, G. (1984): Fiscal Federalism, in: Wirtschaftswissenschaftliches Studium 13, S. 118124.

KIRSCH, G. (1987): Über zentrifugale und zentripetale Kräfte im Föderalismus, in: Schmidt, K. (Hrsg.): Beiträge zu ökonomischen Problemen des Föderalismus, Schriften des Vereins für Socialpolitik N.F., Bd. 166, Berlin, S. 13-34.

KIRSCH, G. (1988): Der redistributionspolitische Interventionismus: Von der Lenkung der Wirtschaft zur Zerstörung des Staates, in: Cassel, D./Ramb, B.-J./Thieme, H.J. (Hrsg.): Ordnungspolitik, München, S. 107-133.

KIRSCH, G. (1993): Neue Politische Ökonomie, 3. Aufl., Tübingen, Düsseldorf.

KLEIN, B./CRAWFORD, R./AlChIAN, A.A. (1978): Vertical Integration, Appropriable Rents, and the Competitive Contracting Process, in: Journal of Law and Economics 21, S. 297326.

KLIEMT, H. (1992): Das Denken in Ordnungen und die Möglichkeiten ordnungspolitischen Handelns, in: Walter Eucken Institut (Hrsg.): Ordnung in Freiheit. Symposium aus Anlaß des 100. Jahrestages des Geburtstages von Walter Eucken am 17. Januar 1991, Tübingen, S. 31-59.

KLUXEN, K. (1957/1969): Die Herkunft der Lehre von der Gewaltenteilung, in: Aus Mittelalter und Neuzeit. Festschrift für Gerhard Kallen, Bonn 1957, S. 219-236. Zitiert nach dem Wiederabdruck in: Rausch, H. (Hrsg.): Zur heutigen Problematik der Gewaltenteilung, Darmstadt 1969, S. 131-152.

KNAPPE, E. (1985): Die Bedeutung zyklischer Mehrheiten in der Demokratie, in: Jahrbuch für Neue Politische Ökonomie 4, S. 90-107.

KocK, H. (1975): Stabilitätspolitik im föderalistischen System der Bundesrepublik Deutschland, Köln.

KOFORD, B.K. (1982): An Optimistic View of the Possibility of Rational Legislative Decisionmaking, in: Public Choice 38, S. 3-19.

KoHN, R.M./VEDDER, R.K./CEBULA, R.J. (1973): Determinants of Interstate Migration by Race, 1965-1970, in: Annals of Regional Science 7, S. 100-112.

KollewE, W. (1979): Zur ökonomischen Theorie der Verbände. Die Entwicklung des Gesetzes gegen Wettbewerbsbeschränkungen, Frankfurt/M. 
KOPS, M. (1984): Formen und Grundprinzipien des Finanzausgleichs I, II und III, in: Das Wirtschaftsstudium 13, S. 239-246, S. 289-293, S. 341-345.

Koven, S.G./Shelley, M.C. (1989): Public Policy Effects on Net Urban Migration, in: Policy Studies Journal 17, S. 705-718.

KRAMER, J. (1993): Föderalismus zwischen Integration und Sezession. Chancen und Risiken bundesstaatlicher Ordnung, Baden-Baden.

KREPS, D.M./WILSON, R. (1982): Sequential Equilibria, in: Econometrica 50, S. 864-894.

KROMPHARDT, J./BRÜCKMANN, F. (1977): Die kommunalen Haushalte im Rahmen der selektiven Fiskalpolitik, in: Wirtschaftsdienst 57, S. 135.

KRONMAN, A.T. (1985): Contract Law and the State of Nature, in: Journal of Law, Economics, and Organization 1, S. 5-32.

KRUEGER, A.O. (1974): The Political Economy of the Rent-Seeking Society, in: American Economic Review 64, S. 291-303.

Krugman, P.R. (1987): Is Free Trade Passé?, in: Economic Perspectives 1, S. 131-144.

KRUSE, J. (1985): Ökonomie der Monopolregulierung, Göttingen.

KRUSE, J. (1987): Vertragsökonomische Interpretation der Regulierung, in: Jahrbuch für Neue Politische Ökonomie 6, S. 93-107.

KRUSE, J. (1989): Das ideal-repräsentative und das dialektische Prinzip der kollektiven Delegation, in: Jahrbuch für Neue Politische Ökonomie 8, S. 243-258.

KRUSE, J. (1995): Demokratiedefizite und Funktionsmängel in der Politik. Ein Essay über Strukturprobleme der repräsentativen Demokratie und Vorschläge für konstitutionelle Reformen, in: Kruse, J./Mayer, G. (Hrsg.): Aktuelle Probleme der Wettbewerbs- und Wirtschaftspolitik, Baden-Baden, S. 9-41..

LADD, H.F. (1975): Local Education Expenditures, Fiscal Capacity, and the Composition of the Property Tax Base, in: National Tax Journal 28, S. 145-158.

LADD, H.F./TIDEMAN, T.N. (1981): Tax and Expenditure Limitations, Washington.

LANDMANN, O. (1982): Die Stabilisierungspolitik im Spannungsfeld von Gleichgewichts- und Ungleichgewichtstheorie, in: Kyklos 35, S. 3-38.

LANG, E. (1992): Stabilisierungspolitik im föderativen Staat, in: Wirtschaftswissenschaftliches Studium 21, S. 9-13. 
LANGHAMMER, R.J. (1993): Wirtschaftstheoretische und ordnungspolitische Aspekte NichtTarifärer Handelshemmnisse am Beispiel der EG und ihres Binnenmarktprogramms, in: Zippel, W. (Hrsg.): Ökonomische Grundlagen der europäischen Integration, München, S. 41-59.

Latham, E. (1952): The Group Basics of Politics, Ithaca.

LATZKo, D.A. (1993): The Concept of 'Military Economies of Scale', in: Explorations in Economic History 30, S. 470-484.

LAUfeR, H. (1992): Das föderative System der Bundesrepublik Deutschland, Bonn.

LAZEAR, E.P./RosEN, S. (1981): Rank Order Tournaments as Optimal Labor Contracts, in: Journal of Political Economy 89, S. 841-864.

LEE, D.R. (1985): Reverse Revenue Sharing: A Modest Proposal, in: Public Choice 45, S. 279-289.

LeE, D.R. (1988): Politics, Ideology, and the Power of Public Choice, in: Virginia Law Review 74, S. 191-198.

LEE, D.R. (1994): Reverse Revenue Sharing: A Return to Fiscal Federalism, in: Cato Journal 14 , S. 75-85.

LeE, D.R./MCKenZie, R.B. (1987): Regulating Government. A Preface to Constitutional Economics, Lexington.

LEIBENSTEIN, H. (1966): Allocative Efficiency vs. X-Efficiency, in: American Economic Review 56, S. 392-415.

LEIPOLD, H. (1989): Das Ordnungsproblem in der ökonomischen Institutionentheorie, in: ORDO 40, S. 129-146.

LEVAGGI, R. (1991): Fiscal Federalism and Grants-in-Aid, Aldershot.

LeVaggi, R./SMith, P. (1994): On the Intergovernmental Fiscal Game, in: Public Finance 49, S. 72-86.

LEVERNIER, W. (1992): The Effect of Relative Performance on the Outcome of Gubernational Elections, in: Public Choice 74, S. 181-190.

LEVI, M. (1988): Of Rule and Revenue, Berkeley u.a.

LIEB, R. (1992): Direkte Steuerprogression. Geschichtliche Entwicklung und kritische Würdigung ihrer Begründungen, Wiesbaden.

LINDBLOM, C.E. (1965): The Intelligence of Democracy, New York, London. 
LIPNOWSKI, I./MaITAL, S. (1983): Voluntary Provision of a Pure Public Good as the Game of 'Chicken', in: Journal of Public Economics 20, S. 381-386.

LITTMANN, K. (1977): Ausgaben, öffentliche II: Die 'Gesetze' ihrer langfristigen Entwicklung, in: Albers, W. u.a. (Hrsg.): Handwörterbuch der Wirtschaftswissenschaft, Bd. 1, Stuttgart u.a., S. 349-363.

LitVACK, J.M./OATES, W.E. (1970): Group Size and the Output of Public Goods. Theory and an Application to State-Local Finance in the United States, in: Public Finance 25, S. $42-$ 58.

LOCKE, J. (1690/1977): Two Treatises of Government, 1690. Zitiert nach der dt. Übersetzung: Zwei Abhandlungen über die Regierung, Frankfurt/M 1977.

LONG, N.V./SIEBERT, H. (1991): Institutional Competition versus Ex-ante Harmonization: The Case of Environmental Policy, in: Journal of Institutional and Theoretical Economics 147, S. 341-348.

LOWENBERG, A.D./YU, B.T. (1990): Constitutional Environments and the Contractual State: The Cases of South Africa and Hong Kong, in: Journal of Comparative Economics 14, S. 51-69.

LOWENBERG, A.D./YU, B.T. (1992): Efficient Constitution Formation and Maintenance: The Role of Exit, in: Constitutional Political Economy 3, S. 51-72.

LÜCKE, M. (1975): Kollektive Planungs- und Entscheidungsprozesse, Tübingen.

LUCKENBACH, H. (1991): Zur optimalen Verteilung wirtschaftspolitischer Aktivitäten auf volks- und weltwirtschaftliche Organisationen, in: Wirtschaftswissenschaftliches Studium 20, S. 419-422.

LuHManN, N. (1975): Legitimation durch Verfahren, 2. Aufl., Neuwied, Darmstadt.

LyNDE, C./Richmond, J. (1992): The Role of Public Capital in Production, in: Review of Economics and Statistics 74, S. 37-44.

MACKAY, R.J./WEAVER, C.L. (1981): Agenda Control by Budget-Maximizers in a MultiBureau Setting, in: Public Choice 37, S. 447-472.

MACKSCHEIDT, K./STEINHAUSEN, J. (1977): Finanzpolitik II: Grundfragen versorgungspolitischer Eingriffe, Tübingen, Düsseldorf.

MACNEIL, J.R. (1974): The Many Futures of Contract, in: Southern California Law Review 47, S. 691-816.

MACNEIL, J.R. (1985): Reflections on Relational Contract, in: Journal of Institutional and Theoretical Economics 141, S. 541-546. 
MAgEE, S.P./BrocK, W.A./Young,L. (1989): Black Hole Tariffs and Endogenous Policy Theory. Political Economy in General Equilibrium, Cambridge.

MalinVaud, E. (1977): The Theory of Unemployment Reconsidered, Oxford.

Margolis, J. (1974): Public Policies for Private Profits: Urban Government, in: Hochman, H.M./Peterson, G.E. (Hrsg.): Redistribution Through Public Choice, New York, S. 289319.

MARGOLIS, J. (1975): Comment, in: Journal of Law and Economics 18, S. 645-659.

MARKuSEN, J.R./MElvin, J.R. (1988): The Theory of International Trade, New York u.a.

Marlow, M.L. (1988): Fiscal Decentralization and Government Size, in: Public Choice 56, S. $259-270$.

MARLOW, M.L. (1992): Intergovernmental Competition, Voice and Exit Options and the Design of Fiscal Structure, in: Constitutional Political Economy 3, S. 73-88.

Marshall, A. (1948): Principles of Economics, 8. Aufl., London.

Martin, D.T./McKenzIE, R.B. (1975): Bureaucratic Profits, Migration Costs, and the Consolidation of Local Government, in: Public Choice 23, S. 95-100.

MARTIN, D.T./SchMIDT, J.R. (1983): Expenditure Effects of Metropolitan Tax Base Sharing: A Public Choice Analysis, in: Public Choice 40, S. 175-186.

MARTIN, D.T./WAGNER, R.E. (1978): The Institutional Framework for Municipal Incorporation: An Economic Analysis of Local Agency Formation Commissions in California, in: Journal of Law and Economics 21, S. 409-425.

MÄRTZ, T. (1990): Interessengruppen und Gruppeninteressen in der Demokratie, Frankfurt/M.

MatThews, R. (1983): Tax Effectiveness and Tax Equity in Federal Countries, in: McLure, C.E. (Hrsg.): Tax Assignment in Federal Countries, Canberra, S. 70-99.

MAYHEW, D.R. (1987): The Electoral Connection and the Congress, in: McCubbins, M./Schwartz, T. (Hrsg.): Congress: Structure and Policy, Cambridge, S. 18-29.

MCCHESNEY, F.S. (1987): Rent Extraction and Rent Creation in the Theory of Economic Regulation, in: Journal of Legal Studies 16, S. 101-118.

MCCORMICK, R.E./Tollison, R.D. (1981): Politicians, Legislation, and the Economy. An Inquiry to the Interest Group Theory of Government, Boston.

McCubbins, M. (1985): The Legislative Design of Regulatory Structure, in: American Journal of Political Science 29, S. 721-748. 
MCCubbins, M./SchwarTz, T. (1984): Congressional Oversight Overlooked: Police Patrols vs. Fire Alarms, in: American Journal of Political Science 28, S. 165-179.

MCGuiRE, M.C. (1973): Notes on Grants-In-Aid and Economic Interactions Among Governments, in: Canadian Journal of Economics 6, S. 207-221.

MCGuIRE, M.C. (1979): The Analysis of Federal Grants-In-Aid into Price and Income Components, in: Mieszkowski, P./Oakland, W.H. (Hrsg.): Fiscal Federalism and GrantsIn-Aid, Washington, S. 31-50.

MCGuire, T. (1991): Federal Aid to States and Localities and the Appropriate Competitive Framework, in: Kenyon, D.A./Kincaid, J. (Hrsg.): Competition Among States and Local Governments, Washington, S. 153-166.

McGuire, T.G./CoIner, M./SpanCAKe, L. (1979): Budget Maximizing Agencies and Efficiency in Government, in: Public Choice 34, S. 333-357.

MCKelveY, R.D. (1976): Intransitivities in Multidimensional Voting Models and Some Implications for Agenda Control, in: Journal of Economic Theory 12, S. 472-482.

MCKenZIE, R.B./StAAF, R.J. (1978): Revenue Sharing and Monopoly Government, in: Public Choice 33, S. 93-97

MCLURE, C.E. (1967): The Inter-Regional Incidence of General Regional Taxes, in: Public Finance 24, S. 457-483.

MCLuRE, C.E. (1969): The Interstate Exporting of State and Local Taxes:Estimates for 1962, in: National Tax Journal 20, S. 49-77.

MCLuRE, C.E. (1983A): Introduction: The Revenue Side of the Assignment Problem, in: McLure, C.E. (Hrsg.): Tax Assignment in Federal Countries, Canberra, S. xii-xix.

MCLuRE, C.E. (1983B): Assignment of Corporate Income Taxes in a Federal System, in: McLure, C.E. (Hrsg.): Tax Assignment in Federal Countries, Canberra, S. 101-126.

MCLuRE, C.E. (1986): Tax Competition: Is What's Good For the Private Goose Also Good For the Public Gander?, in: National Tax Journal 39, S. 341-348.

MCLuRE, C.E./MIESZKowSKI, P. (1981): Fiscal Federalism and the Taxation of Natural Resources, Lexington, Toronto.

MEADE, J.E. (1973): The Theory of Economic Externalities, Genf.

MECKLING, W.H. (1976): Values and the Choice of the Model of the Individual in the Social Sciences, in: Schweizerische Zeitschrift für Volkswirtschaft und Statistik 112, S. 545560 . 
MEHAY, S.L. (1981): The Expenditure Effects of Municipal Annexation, in: Public Choice 36, S. 53-62.

MENKHOFF, L./SELL, F.L. (1991): Optimaler Währungsraum. Wie weit sollte der Geltungsbereich einer europäischen Währung reichen?, in: Wirtschaftswissenschaftliches Studium 20, S. 577-580.

MeRville, L.J./OsboRne, D.K. (1990): Constitutional Democracy and the Theory of Agency, in: Constitutional Political Economy 1, S. 21-47.

Messerlin, P. (1981): The Political Economy of Protection: The Bureaucratic Case, in: Weltwirtschaftliches Archiv 117, S. 469-496.

MEYeR, W. (1983): Entwicklung und Bedeutung des Property Rights-Ansatzes in der Nationalökonomie, in: Schüller, A. (Hrsg.): Property Rights und ökonomische Theorie, München, S. 1-44.

MIESZKowsKI, P. (1976): The Distributive Effects of Local Taxes: Some Extensions, in: Grieson, R.E. (Hrsg.): Public and Urban Economics, Lexington, S. 293-312.

MieszKowsKi, P. (1983): Taxation of Energy Resources, in: McLure, C.E./Mieszkowski, P. (Hrsg.): Fiscal Federalism and the Taxation of Natural Resources, Lexington, Toronto, $\mathrm{S}$. 65-92.

MiesZKowSKI, P./ZodRow, G.R. (1989): Taxation and the Tiebout-Model, in: Journal of Economic Literature 27, S. 1098-1146.

MiguÉ, J.L./BÉLANGER, G. (1974): Toward a General Theory of Managerial Discretion, in: Public Choice 17, S. 27-43.

MiguÉ. J.L. (1993): Federalism and Free Trade, London.

Milgrom, P./NORTH, D.C./WEINGAST, B. (1990): The Role of Institutions in the Revival of Trade, in: Economics and Politics 2, S. 1-24.

MilleR, G.J. (1992): Managerial Dilemmas. The Political Economy of Hierarchy, Cambridge u.a.

Mills, E.S./OATES, W.E. (1975): The Theory of Local Public Services and Finance: Its Relevance to Urban Fiscal and Zoning Behavior, in: Mills, E.S./Oates, W.E. (Hrsg.): Fiscal Zoning and Land Use Controls, Lexington, S. 1-12.

MINTZ, J./TulKens, H. (1986): Commodity Tax Competition Between Member States of a Federation: Equilibrium and Efficiency, in: Journal of Public Economics 29, S. 133-172.

MitChell, W.C./MungeR, M.C. (1991): Economic Models of Interest Groups: An Introductory Survey, in: American Journal of Political Science 35, S. 512-546. 
Mitchell, W.C./Simmons, R.T. (1994): Beyond Politics: Markets, Welfare, and the Failure of Bureaucracy, Boulder u.a.

MOE, T. (1980): The Organization of Interests: Incentives and the Internal Dynamics of Political Interest Groups, Chicago.

MOE, T. (1984): The New Economics of Organization, in: American Journal of Political Science 28, S. 739-777.

MoE, T. (1987): An Assessment of the Positive Theory of 'Congressional Dominance', in: Legislative Studies Quarterly 12, S. S. 475-520.

MOE, T. (1990): Political Institutions: The Neglected Side of the Story, in: Journal of Law, Economics, and Organization 6, S. 213-253.

MOE, T. (1991): Politics and the Theory of Organization, in: Journal of Law, Economics, and Organization 7, Special Issue, S. 106-129.

MOENE, K. (1986): Types of Bureaucratic Interaction, in: Journal of Public Economics 29, S. 333-345.

MORAN, M.J./WEINGAST, B. (1982): Congress as the Source of Regulatory Decisions: The Case of the Federal Trade Commission, in: American Economic Review 72, S. 109-113.

Moss, L.S. (1980): Optimal Jurisdiction and the Economic Theory of the State: Or, Anarchy and World Government are Only Corner Solutions, in: Public Choice 35, S. 17-26.

Mueller, D.C. (1971): Fiscal Federalism in a Constitutional Democracy, in: Public Policy 19, S. 567-593.

MuelLeR, D.C. (1987): The Voting Paradox, in: Rowley, C.K. (Hrsg.): Democracy and Public Choice, Oxford, S. 77-99.

MuelLeR, D.C. (1989): Public Choice II, Cambridge.

MuelLER, D.C. (1991): Constitutional Rights, in: Journal of Law, Economics, and Organization 7, S. 313-333.

MuelleR, D.C. (1993): The 'Virginia School' and Public Choice, in: Mueller, D.C. (Hrsg.): The Public Choice Approach to Politics, Aldershot, S. 431-444.

Mueller, D.C. (1996): Constitutional Democracy, New York, Oxford.

MUELLER, D.C./MurRell, P. (1986): Interest Groups and the Size of Government, in: Public Choice 48, S. 125-145.

MÜNCH, I. voN (1993): Staatsrecht, Bd. I, 5. Aufl., Stuttgart, Berlin, Köln. 
MUNDUCH, G./NITSCHKE, E. (1988): Klubtheorie, in: Wirtschaftswissenschaftliches Studium 17 , S. 318-321.

MURRELL, P. (1984): An Examination of the Factors Affecting the Formation of Interest Groups in OECD Countries, in: Public Choice 43, S. 151-171.

MUSGRAVE, P.B. (1987): Interjurisdictional Coordination of Taxes on Capital Income, in: Cnossen, S. (Hrsg.): Tax Coordination in the EC, Amsterdam, S. 197-225.

Musgrave, P.B. (1990): Merits and Demerits of Fiscal Competition, in: Prud'homme, R. (Hrsg.): Public Finance With Several Levels of Government, Brüssel, S. 281-297.

Musgrave, P.B./Musgrave, R.A. (1990): Fiscal Coordination and Competition in an International Setting, in: McLure, C.E. (Hrsg.): Influence of Tax Differentials on International Competitiveness, Boston, S. 61- 85.

Musgrave, R.A. (1959/1969): The Theory of Public Finance, New York u.a. 1959. Zitiert nach der dt. Übersetzung: Finanztheorie, 2. Aufl., Tübingen 1969.

MusGrave, R.A. (1961): Approaches to a Fiscal Theory of Political Federalism, in: National Bureau of Economic Research (Hrsg.): Public Finances: Needs, Sources, and Utilization, Princeton, S. 97-122.

MusGrave, R.A. (1969A): Provison for Social Goods, in: Margolis, J./Guitton, H. (Hrsg.): Public Economics, London, S. 124-144.

MusGrave, R.A. (1969B): Theories of Fiscal Federalism, in: Public Finance 24, S. 521-532.

MusGrave, R.A. (1969C): Fiscal Systems, New Haven.

MusGrave, R.A. (1970): Pareto Optimal Redistribution: Comment, in: American Economic Review 60, S. 991-994.

MusGrave, R.A. (1983): Who Should Tax, Where, and What?, in: McLure, C.E. (Hrsg.): Tax Assignment in Federal Countries, Canberra, S. 2-19.

Musgrave, R.A./Musgrave, P.B./Kullmer, L. (1992): Die öffentlichen Finanzen in Theorie und Praxis, Bd. 3, 4. Aufl., Tübingen.

Musgrave, R.A./Musgrave, P.B./Kullmer, L. (1994): Die öffentlichen Finanzen in Theorie und Praxis, Bd. 1; 6. Aufl., Tübingen.

MUSHKIN, S.J./ADAMS, R.F. (1966): Emerging Patterns of Federalism, in: National Tax Journal 19 , S. 225-247.

MYERSON, R.B./SATTERTHWAITE, M.A. (1983): Efficient Mechanisms for Bilateral Bargaining, in: Journal of Economic Theory 29, S. 265-281. 
NALEBUFF, B.J./STIGLITZ, J.E. (1983): Information, Competition, and Markets, in: American Economic Review 73, S. 278-284.

NELSON, D. (1988): Endogenous Tariff Theory: A Critical Survey, in: American Journal of Political Science 32, S. 796-837.

NELSON, D./SILBERBERG, E. (1987): Ideology and Legislator Shirking, in: Economic Inquiry 25, S. $15-25$.

Nelson, M. (1986): An Empirical Analysis of State and Local Tax Structure in the Context of the Leviathan Model of Government, in: Public Choice 49, S. 283-294.

NeLSON, M. (1987): Searching for Leviathan: Comment and Extension, in: American Economic Review 77, S. 198-204.

NETZER, D. (1974): State-Local Finance and Intergovernmental Relations, in: Blinder, A.S. u.a. (Hrsg.): The Economics of Public Finance, Washington, S. 361-421.

NG, Y.-K. (1971): Public Goods and the Stability of Federalism: An Extension, in: Kyklos 24, S. 562-563.

NG, Y.-K. (1973): The Economic Theory of Clubs: Optimal Tax/Subsidy, in: Economica 41, S. 308-321.

NIEMI, R.G. (1969): Majority Decision Making With Partial Unidimensionality, in: American Political Science Review 63, S. 488-497.

NiSKANEN, W.A. (1971): Bureaucracy and Representative Government, Chicago, New York.

NisKaneN, W.A. (1974): Comment zu Migué, J.L./Bélanger, G.: Toward A General Theory of Managerial Discretion, in: Public Choice 17, S. 43-45.

NisKaneN, W.A. (1975): Bureaucrats and Politicians, in: Journal of Law and Economics 18, S. 617-643.

NISKANEN, W.A. (1978): The Prospect for Liberal Democracy, in: Buchanan, J.M./Wagner, R.E. (Hrsg.): Fiscal Responsibility in Constitutional Democracy, Leiden, S. 157-174.

NISKANEN, W.A. (1990): Conditions Affecting the Survival of Constitutional Rules, in: Constitutional Political Economy 1, S. 53-62.

NoAM, E.M. (1980): The Efficiency of Direct Democracy, in: Journal of Political Economy 88, S. 803-810.

NoRdhaus, W.D. (1975): The Political Business Cycle, in: Review of Economic Studies 42, S. 1969-1990.

NoRDHAUS, W.D. (1989): Alternative Approaches to the Political Business Cycle, in: Brookings Papers on Economic Activity 2, S. 1-68. 
NORTH, D.C. (1981/1988): Structure and Change in Economic History, New York 1981. Zitiert nach der dt. Übersetzung: Theorie des institutionellen Wandels, Tübingen 1988.

NORTH, D.C. (1986): The New Institutional Economics, in: Journal of Institutional and Theoretical Economics 142, S. 230-237.

NORTH, D.C. (1989): Institutional Change and Economic History, in: Journal of Institutional and Theoretical Economics 145, S. 238-245.

NORTH, D.C. (1990/1992): Institutions, Institutional Change, and Economic Performance, Cambridge u.a. 1990. Zitiert nach der dt. Übersetzung: Institutionen, institutioneller Wandel und Wirtschaftsleistung, Tübingen 1992.

NORTH, D.C./WALLIS, J.J. (1982): Longer-run Determinants of the Economic Role of the U.S. Government, in: American Economic Review 72, S. 336-340.

NowotNY, E. (1979): Zur öffentlichen Verschuldung der nachgeordneten Gebietskörperschaften, in: Nowotny, E. (Hrsg.): Öffentliche Verschuldung, Stuttgart, New York, S. 162-177.

NozICK, R. (1974/1976): Anarchy, State, Utopia, New York 1974. Zitiert nach der dt. Übersetzung: Anarchie, Staat, Utopia, München 1976.

OAKerson, R.J./PARKS, R.B. (1988): Citizen Voice and Public Entrepreneurship: The Organizational Dynamic of a Complex Metropolitan County, in: Publius: The Journal of Federalism 18, S. 91-112.

OAKLAND, W.H. (1987): Theory of Public Goods, in: Auerbach, A.J./Feldstein, M. (Hrsg.): Handbook of Public Economics Vol. II, Amsterdam u.a., S. 485-535.

OATES, W.E. (1968): The Theory of Public Finance in a Federal System, in: Canadian Journal of Economics 1, S. 37-54.

OATES, W.E. (1969): The Effects of Property Taxes and Local Public Spending on Property Values: An Empirical Study of Tax Capitalization and the Tiebout Hypothesis, in: Journal of Political Economy 77, S. 957-971.

OATES, W.E. (1972): Fiscal Federalism, New York.

OATES, W.E. (1977A): An Economist's Perspective on Fiscal Federalism, in: Oates, W.E. (Hrsg.): The Political Economy of Fiscal Federalism, Lexington, Toronto, S. 3-20.

OATES, W.E. (1977в): 'Finanz-Föderalismus' (Fiscal Federalism) in Theorie und Praxis: Lehren für die Europäische Gemeinschaft, in: Kommission der Europäischen Gemeinschaft (Hrsg.): Bericht der Sachverständigengruppe zur Untersuchung der Rolle der öffentlichen Finanzen bei der europäischen Integration, Bd. II, Brüssel, S. 293-331.

OATES, W.E. (1985): Searching for Leviathan: An Empirical Study, in: American Economic Review 75, S. 748-757. 
OATES, W.E. (1988A): On the Measurement of Congestion in the Provision of Local Public Goods, in: Journal of Urban Economics 24, S. 85-94.

OATES, W.E. (1988B): On the Nature and Measurement of Fiscal Illusion: A Survey, in: Brennan, G. u.a. (Hrsg.): Taxation and Fiscal Federalism, Sydney, S. 65-82.

OATES, W.E. (1989): Searching for Leviathan: A Reply and Some Further Reflections, in: American Economic Review 79, S. 578-583.

OATES, W.E. (1990): Decentralization of the Public Sector: An Overview, in: Bennett, R.J. (Hrsg.): Decentralization, Local Governments, and Markets: Towards a Post-Welfare Agenda, Oxford, S. 43-58.

OATES, W.E./SchWAB, R. (1991): The Allocative and Distributive Implications of Local Fiscal Competition, in: Kenyon, D.A./Kincaid, J. (Hrsg.): Competition Among States and Local Governments, Boston, S. 87-114.

OHLIN, B. (1933): Interregional Trade and International Trade, Cambridge.

Olson, M. (1965/1992): The Logic of Collective Action. Public Goods and the Theory of Groups, Harvard 1965. Zitiert nach der dt. Übersetzung: Die Logik kollektiven Handelns, 3. Aufl., Tübingen 1992.

Olson, M. (1969): The Principle of 'Fiscal Equivalence': The Division of Responsibilities Among Different Levels of Government, in: American Economic Review 59, S. 479-487.

Olson, M. (1970): Comment on the Paper of G.F. Break: Changing Roles of Different Levels of Government, in: Margolis, J. (Hrsg.): The Analysis of Public Output, London, S. 210218.

Olson, M. (1982/1991): The Rise and Decline of Nations: Economic Growth, Stagflation, and Social Rigidities, New Haven 1982. Zitiert nach der dt. Übersetzung: Aufstieg und Niedergang von Nationen, Tübingen 1991.

Olson, M. (1983): The Political Economy of Comparative Growth Rates, in: Mueller, D.C. (Hrsg.): The Political Economy of Growth, New Haven, London, S. 7-52.

Olson, M. (1984): Comment, in: McKenzie, R.B. (Hrsg.): Constitutional Economics. Containing the Economic Powers of Government, Lexington, S. 89-94.

Olson, M. (1986): Toward a More General Theory of Governmental Structure, in: American Economic Review 76, S. 120-125.

Olson, M./ZECKHAUSER, R. (1966): An Economic Theory of Alliances, in: Review of Economics and Statistics 48, S. 266-279.

Olson, M./ZeCKhauser, R. (1970): The Efficient Production of External Economies, in: American Economic Review 60, S. 512-517. 
OPP, K.-D. (1994): The Role of Voice in a Future Europe, in: Kyklos 47, S. 385-402.

ORR, L.L. (1976): Income Transfers as a Public Good: An Application to AFDC, in: American Economic Review 66, S. 359-371.

ORZECHOWSKI, W. (1977): Economic Models of Bureaucracy: Survey, Extensions, and Evidence, in: Borcherding, T.E. (Hrsg.): Budgets and Bureaucrats: The Sources of Government Growth, Durham, S. 229-259.

OSTERFELD, D. (1989): Radical Federalism: Responsiveness, Conflict, and Efficiency, in: Brennan, G./Lomasky, L.E. (Hrsg.): Politics and Process - New Essays in Democratic Thought, Cambridge, S. 149-173.

Ostrom, E. (1983): A Public Choice Approach to Metropolitan Institutions: Structure, Inventives, and Performance, in: Social Science Journal 20, S. 79-96.

Ostrom, V. (1971): The Political Theory of a Compound Republic, Blacksburg.

Ostrom, V. (1973): The Intellectual Crisis in American Public Administration, Alabama.

Ostrom, V./Ostrom, E. (1971): Public Choice: A Different Approach to the Study of Public Administration, in: Public Administration Review 31, S. 203-216.

PAsour, E.C. (1994): Redistribution and Constitutional Political Economy, in: Constitutional Political Economy 5, S. 81-98.

Pauly, M.V. (1967): Clubs, Commonality, and the Core: An Integration of Game Theory and Theory of Public Goods, in: Economica 34, S. 314-324

Pauly, M.V. (1968): The Economics of Moral Hazard: Comment, in: American Economic Review 58, S. 531-537.

Pauly, M.V. (1970): Optimality, 'Public' Goods, and Local Governments: A General Theoretical Analysis, in: Journal of Political Economy 78, S. 572-585.

Pauly, M.V. (1973): Income Redistribution as a Local Public Good, in: Journal of Public Economics 2, S. 35-58.

PEACOCK, A.T. (1983): Public X-Inefficiency: Informational and Institutional Constraints, in: Hanusch,H. (Hrsg.): Anatomy of Government Deficiencies, Heidelberg, S. 125-148.

Pecquet, G.M. (1985): The Effects of Voter Mobility on Agenda Controllers, in: Public Choice 45, S. 269-278.

Peffekoven, R. (1975): Zur Theorie des Steuerexports, Tübingen.

Peffekoven, R. (1980): Finanzausgleich I: Wirtschaftstheoretische Grundlagen, in: Albers, W. u.a. (Hrsg.): Handwörterbuch der Wirtschaftswissenschaft, Bd. 2, Stuttgart, S. 608636. 
Peffekoven, R. (1983): Probleme der internationalen Finanzordnung, in: Neumark, F. (Hrsg.): Handbuch der Finanzwissenschaft, Bd. IV, 3. Aufl., S. 219-271.

PefFekoven, R. (1990): Deutsche Einheit und Finanzausgleich, in: Staatswissenschaften und Staatspraxis 1, S. 485-492.

PEIRCE, W.S. (1981): Bureaucratic Failure and Public Expenditure, New York.

PEIRCE, W.S. (1991): After 1992: The European Community and the Redistribution of Rents, in: Kyklos 44, S. 521-536.

PEJOVICH, S. (1990): The Economics of Property Rights: Towards a Theory of Comparative Systems, Dordrecht u.a.

Pelkmans, J. (1990): Regulation and the Single Market: An Economic Perspective, in:

Siebert, H. (Hrsg.): The Completion of the Internal Market, Tübingen, S. 91-117.

Peltzman, S. (1976): Towards a More General Theory of Regulation, in: Journal of Law and Economics 19, S. 211-240.

Peltzman, S. (1987): Economic Conditions and Gubernational Elections, in: American Economic Review 77, S. 293-297.

Peltzman, S. (1989): The Economic Theory of Regulation after a Decade of Deregulation, in: Brookings Papers on Economic Activity, Microeconomics, S. 1-59.

Peltzman, S. (1990): How Efficient Is the Voting Market?, in: Journal of Law and Economics 33, S. 27-63.

PENNOCK, J. (1959): Federal and Unitary Government: Disharmony and Frustration, in: Behavioral Science 4, S. 147-157.

PENNOCK, J. (1989): The Justification of Democracy, in: Brennan, G./Lomasky, L.E. (Hrsg.): Politics and Process - New Essays in Democratic Thought, Cambridge, S. 11-41.

Pestieau, P. (1977): The Optimality Limits of the Tiebout-Model, in: Oates, W.E. (Hrsg.): The Political Economy of Fiscal Federalism, Lexington, Toronto, S. 173-186.

Pestieau, P. (1983): Fiscal Mobility and Local Public Goods: A Survey of the Empirical and Theoretical Studies of the Tiebout Model, in: Thisse, J.F./Zoller, H.G. (Hrsg.): Locational Analysis of Public Facilities, Amsterdam, S. 11-41.

PETHIG, R. (1988): Bürokratische Produktion im staatlichen und privaten Sektor, in: Das Wirtschaftsstudium 17, S. 686-691.

PICOT, A. (1991): Subsidiaritätsprinzip und ökonomische Theorie der Organisation, in: Faller, P./Witt, D. (Hrsg.): Dienstprinzip und Erwerbsprinzip, Baden-Baden, S. 102-116. 
PICOT, A./WolfF, B. (1994): Institutional Economics of Public Firms and Administrations. Some Guidelines for Efficiency-Oriented Design, in: Journal of Institutional and Theoretical Economics 150, S. 211-232.

PIES, I. (1993): Normative Institutionenökonomik. Zur Rationalisierung des politischen Liberalismus, Tübingen.

PIgOU, A.C. (1932): The Economics of Welfare, 4. Aufl., London, New York.

PLOTT, C.R. (1967): A Notion of Equilibrium and Its Possibility under Majority Rule, in: American Economic Review 57, S. 787-806.

POMMEREHNE, W.W. (1987): Präferenzen für öffentliche Güter. Ansätze zu ihrer Erfassung, Tübingen.

PoMmereHNE, W.W./Feld, L.P. (1994): Manipulation for Political Profit: A Quantification of Commonsense, Paper presented at the Annual Meeting of the European Public Choice Society, Valencia April 6-9.

POMMEREHNE, W.W./KIRCHGÄSSNER, G. (1988): Gesamtwirtschaftliche Effizienz, gesellschaftliche Umverteilung und Wachstum der Staatstätigkeit: Ein Überblick, in: Zimmermann, H. (Hrsg.): Die Zukunft der Staatsfinanzierung, Marburg, S. 206-241.

PoPITZ, A. (1929): Die Wandlungen in den Aufgaben und im Zuständigkeitsverhältnis von Reich und Ländern auf Grund der Weimarer Verfassung, in: Harms, B. (Hrsg.): Recht und Staat im neuen Deutschland, Bd. 1, Berlin, S. 152ff.

POSNER, R.A. (1975): The Social Costs of Monopoly and Regulation, in: Journal of Political Economy 83, S. 807-827.

POSNER, R.A. (1977): Economic Analysis of Law, 2. Aufl., Boston, Toronto.

Pratt, J.W./ZeCKhauser, R.J. (1985): Principals and Agents: An Overview, in: Pratt, J.W./Zeckhauser, R.J. (Hrsg.): Principals and Agents. The Structure of Business, Boston, S. 1-35.

PROSI, G. (1991): Europäische Integration durch Wettbewerb? Eine politisch-ökonomische Analyse, in: Radnitzky, G./Bouillon, H. (Hrsg.): Ordnungstheorie und Ordnungspolitik, Berlin u.a., S. 119-135.

QUIGLEY, M. (1980): Local Residential Mobility and Local Government, in: Clark, W.A.V./ Moore, E.G. (Hrsg.): Residential Mobility and Public Policy, Beverly Hills, London, S. 39-55.

RAE, D.W. (1969): Decision-Rules and Individual Values in Constitutional Choice, in: American Political Science Review 63, S. 40-56. 
RAIMONDO, H. (1989): Leviathan and Federalism in the United States, in: Public Finance Quarterly 17, S. 204-215.

RAMSER, H.J. (1981): Stand und Entwicklungsperspektiven der Konjunkturtheorie, in: Timmermann, M. (Hrsg.): Nationalökonomie morgen, Stuttgart u.a., S. 27-58.

RAWLS, J. (1971/1975): A Theory of Justice, Cambridge u.a 1971. Zitiert nach der dt. Übersetzung: Eine Theorie der Gerechtigkeit, Frankfurt/M. 1975.

RAZIN, A./SADKA, E. (1990): Capital Market Integration: Issues of International Taxation, in: Siebert, H. (Hrsg.): Reforming Capital Income Taxation, Tübingen, S. 155-165.

RAZIN, A./SADKA, E. (1991): International Tax Competition and Gains From Tax Harmonization, in: Economics Letters 37, S. 69-76.

RESZAT, B. (1986): Wirtschaftliche Interdependenz und internationale Kooperation, in: Gutowski, A./Molitor, B. (Hrsg.): Hamburger Jahrbuch für Wirtschafts- und Gesellschaftspolitik, Tübingen, S. 267-291.

REUTER, N. (1994): Institutionalismus, Neo-Institutionalismus, Neue Institutionelle Ökonomie und andere "Institutionalismen". Eine Differenzierung konträrer Konzepte, in: Zeitschrift für Wirtschafts- und Sozialwissenschaften 114, S. 5-23.

RIBHEGGE, H. (1991): Der Beitrag der neuen Institutionenökonomik zur Ordnungspolitik, in: Jahrbuch für Neue Politische Ökonomie 10, S. 38-60.

RICHTER, R. (1990A): Sichtweise und Fragestellungen der Institutionenökonomik, in: Zeitschrift für Wirtschafts- und Sozialwissenschaften 110, S. 571-591.

RICHTER, R. (1990B): Geldtheorie: Vorlesung auf der Grundlage der Allgemeinen Gleichgewichtstheorie und der Institutionenökonomik, 2. Aufl., Berlin u.a.

RICHTER, R. (1994): Institutionen ökonomisch analysiert. Zur jüngeren Entwicklung auf einem Gebiet der Wirtschaftstheorie, Tubingen.

RICHTER, R./BINDSEIL, U. (1995): Neue Institutionenökonomik, in: Wirtschaftswissenschaftliches Studium 24, S. 132-140.

RICHTER, W.F./WIEGARD, W. (1993): Zwanzig Jahre "Neue Finanzwissenschaft", Teil I: Überblick und Theorie des Marktversagens, in: Zeitschrift fur Wirtschafts- und Sozialwissenschaften 113, S. 169-224.

RIKER, W.H. (1962): The Theory of Political Coalitions, New Haven, London.

RIKER, W.H. (1964): Federalism. Origin, Operation, Significance, Boston.

RIKER, W.H./BRAMS, S.J. (1973): The Paradox of Vote Trading, in: American Political Science Review 67, S. 1235-1247. 
RIKER, W.H./ORDESHOOK, P.C. (1968): A Theory of the Calculus of Voting, in: American Political Science Review 62, S. 25-42.

Riley, P. (1973): The Origins of Federal Theory in International Relations Ideas, in: Polity, S. 87-121.

Rogerson, W.P. (1982): The Social Costs of Monopoy and Regulation: A Game-Theoretic Analysis, in: Bell Journal of Economics and Mangament Science 13, S. 391-401.

RoKKAN, S. (1975): Dimensions of State Formation and Nation-Building: A Possible Paradigm for Research on Variations Within Europe, in: Tilly, C. (Hrsg.): The Formation of Nation States in Western Europe, Princeton, S. 562-600.

ROMER, T./Rosenthal, H. (1983): Voting and Spending: Some Empirical Relationships in the Political Economy of Local Public Finance, in: Zodrow, G. R. (Hrsg.): Local Provision of Public Services: The Tiebout-Model after Twenty-Five Years, New York, S. 165-183.

ROPPEL, U (1979): Ökonomische Theorie der Bürokratie, Freiburg.

ROPPEL, U. (1982): Wettbewerbs- versus Monopolmodell des öffentlichen Sektors, in: Jahrbuch für Neue Politische Ökonomie 1, S. 178-212.

Rose, K./SAuernHeIMER, K. (1995): Theorie der Außenwirtschaft, 12. Aufl., München.

Rose-ACKerman, S. (1978): Corruption, New York.

ROSE-ACKERMAN, S. (1980): Risk-Taking and Reelection: Does Federalism Promote Innovation?, in: Journal of Legal Studies 9, S. 593-616.

Rose-Ackerman, S. (1981): Does Federalism Matter? Political Choice in a Federal Republic, in: Journal of Political Economy 89, S. 152-165.

Rose-Ackerman, S. (1983): Beyond Tiebout: Modeling the Political Economy of Local Government, in: Zodrow, G.R. (Hrsg.): Local Provision of Public Services: The Tiebout Model After Twenty-Five Years, New York, S. 55-83.

Rosen, H.S./Fullerton, D.J. (1977): A Note on Local Tax Rates, Public Benefit Levels, and Property Values, in: Journal of Political Economy 85, S. 433-440.

RosenfELD, M. (1993): The Failures of Federalism in the United States, in: Kramer, J. (Hrsg.): Föderalismus zwischen Integration und Sezession. Chancen und Risiken bundesstaatlicher Ordnung, Baden-Baden, S. 247-265.

Ross, S.A. (1973): The Economic Theory of Agency: The Principal's Problem, in: American Economic Review 63, S. 134-139. 
ROTHENBERG, J. (1970): Local Decentralization and the Theory of Optimal Government, in: Margolis, J. (Hrsg.): The Analysis of Public Output, London, S. 31-64.

RowLEY, C.K. (1984): The Relevance of the Median Voter Theorem, in: Journal of Institutional and Theoretical Economics 140, S. 104-126.

RowLEY, C.K. (1990): The Reason of Rules: Constitutional Contract versus Political Market Conflict, in: Annual Review of Conflict Knowledge and Conflict Resolution 2, S. 195228.

RowLEY, C.K. (1992): The Right to Justice. The Political Economy of Legal Service in the United States, Aldershot.

ROWLEY, C.K./ELGIN, R. (1988): Governments and Its Bureaucracy: Bargaining Versus a Principal-Agent Approach, in: Rowley, C.K./Tollison, R.D./Tullock, G. (Hrsg.): The Political Economy of Rent Seeking, Boston u.a., S. 267-290.

Rowley, C.K./VACHRIS, M. (1993): Snake Oil Economics versus Public Choice, in: Rowley, C.K. (Hrsg.): Public Choice, Bd. 3, S. 573-584.

RUBinfield, D.L. (1987): The Economics of the Local Public Sector, in: Auerbach, A.J./ Feldstein, M. (Hrsg.): Handbook of Public Economics, Vol. II, Amsterdam u.a., S. 571645.

RufFIN, R.J. (1984): International Factor Movements, in: Jones, R.W./Kenen, P.B. (Hrsg.): Handbook of International Economics, Vol. I, Amsterdam, S. 237-288.

SACK, R. (1986): Human Territoriality. Its Theory and History, Cambridge.

SAliSBURY, R.H. (1975): Interest Groups, in: Greenstein, F.I./Polsby, N.W. (Hrsg.): Nongovernmental Politics, Reading.

SALMON, P. (1987A): Decentralisation as an Incentive Scheme, in: Oxford Review of Economic Policy 3, S. 24-42.

Salmon, P. (1987B): The Logic of Pressure Groups and the Structure of the Public Sector, in: European Journal of Political Economy 3, S. 261-322.

SALMON, P. (1991): Checks and Balances and International Openness, in: Breton, A. u.a. (Hrsg.): The Competitive State, Dordrecht, S. 169-184.

SAmuelson, L. (1984): Electoral Equilibria With Restricted Strategies, in: Public Choice 43, S. 307-327.

SAMUelson, P.A. (1948): International Trade and the Equalization of Factor Prices, in: Ecnomic Journal 58, S. 165-184. 
SAmuelson, P.A. (1949): International Factor Price Equalization Once Again, in: Economic Journal 59, S. 181-187.

SAMuelson, P.A. (1954): The Pure Theory of Public Expenditure, in: Review of Economics and Statistics 36, S. 387-389.

SANDLER, T. (1992): Collective Action, Ann Arbor.

SANDLER, T./Shelton, R.B. (1972): Fiscal Federalism, Spillovers and the Export of Taxes, in: Kyklos 25, S. 736-753.

SANDLER, T./TsCHIRHART, J.T. (1980): The Economic Theory of Clubs: An Evaluative Survey, in: Journal of Economic Literature 18, S. 1481-1521.

SANDMO, A. (1980): Anomaly and Stability in the Theory of Externalities, in: Quarterly Journal of Economics 94, S. 799-807.

SCHARPF, F.W. (1976): Theorie der Politikverflechtung, in: Scharpf, F.W./Reissert, B./Schnabel F. (Hrsg.): Politikverflechtung: Theorie und Empirie des kooperativen Föderalismus in der Bundesrepublik, Kronberg, S. 13-66.

SCHARPF, F.W. (1978): Die Theorie der Politikverflechtung: ein kurzgefaßter Leitfaden, in: Hesse, J.J. (Hrsg.): Politikverflechtung im föderativen Staat. Studien zum Planungs- und Finanzierungsverbund zwischen Bund, Ländern und Gemeinden, Baden-Baden, S. 21-31.

SCHATTSCHNEIDER, E.E. (1935): Politics, Pressure, and the Tariff, New York.

SCHEIDE, J./TRAPP, B. (1991): Erfordert eine europäische Wăhrungsunion die Harmonisierung der Finanzpolitik?, in: Siebke, J. (Hrsg.): Monetäre Konfliktfelder der Weltwirtschaft, Schriften des Vereins für Socialpolitik, N.F., Bd. 210, S. 429-446.

SCHENK, K.-E. (1983): Institutional Choice und Ordnungstheorie, in: Jahrbuch fur Neue Politische Ökonomie 2, S. 70-85.

SCHENK, K.-E. (1988): Property Rights und Theorie der Institutionen, in: Das Wirtschaftsstudium 17, S. 226-231.

SCHENK, K.-E. (1992): Die neue Institutionenökonomie: Ein Überblick über wichtige Elemente und Probleme der Weiterentwicklung, in: Zeitschrift für Wirtschafts- und Sozialwissenschaften 112, S. 337-378.

SCHMIDT, I. (1981): Per se Rule oder Rule of Reason, in: Wirtschaftswissenschaftliches Studium 10, S. 282-284.

SCHMIDT, K. (1976): Entwicklungstendenzen der öffentlichen Ausgaben im demokratischen Gruppenstaat, in: Blümle, K./Wittmann, W. (Hrsg.): Verbände, Stuttgart, New York, S. 14-21. 
SCHMIDT-TRENZ, H.-J. (1990): Außenhandel und Teritorialităt des Rechts. Grundlegung einer Neuen Institutionenökonomik des Außenhandels, Baden-Baden.

SchmidTCHEN, D./SchmidT-TRENZ, H.-J. (1990): The Division of Labor is Limited by the Extent of the Law. A Constitutional Approach to International Private Law, in: Constitutional Political Economy 1, S. 49-71.

SCHMIDTCHEN, D./SCHMIDT-TRENZ, H.-J. (1994): Theorie optimaler Rechtsräume. Die Regulierung sozialer Beziehungen durch die Kontrolle von Territorien, in: Jahrbuch für Neue Politische Ökonomie 13, S. 8-29.

SCHMÖLDERS, G. (1965): Das Selbstbild der Verbände, Berlin.

SCHMÖLDERS, G. (1970): Finanzpolitik, 3. Aufl., New York.

SCHMÖLDERS, G./HANSMEYER, K.-H. (1980): Allgemeine Steuerlehre, 5. Aufl., Berlin.

SCHNEIDER, H.K. (1968): Über die Notwendigkeit regionaler Wirtschaftpolitik, in: Schneider, H.K. (Hrsg.): Beiträge zur Regionalpolitik, Schriften des Vereins für Socialpolitik N.F., Bd. 41, Berlin, S. 3-17.

SCHNEIDER, M. (1986): Fragmentation and the Growth of Local Government, in: Public Choice 48, S. 255-263.

SCHNEIDER, M. (1989): Intermunicipal Competition, Budget-Maximising Bureaucrats, and the Level of Suburban Competition, in: American Journal of Political Science 33, S. 612-628.

SCHOFIELD, N. (1981): The Relationship Between Voting and Party Strength in an Electoral System, in: Holler, M. (Hrsg.): Power, Voting and Voting Power, Würzburg, S. 121-134.

SCHOTTER, A. (1981): The Economic Theory of Social Institutions, Cambridge u.a.

SCHUKNECHT, L. (1990): Protectionism - an Intra-National Prisoners' Dilemma, in: Außenwirtschaft 45 , S. 39-55.

SchÜlleR, A. (1983A): Einführung, in: Schüller, A. (Hrsg.): Property Rights und ökonomische Theorie, München, S. VII-XXI.

SCHÜLLER, A. (1983B): Property Rights, Theorie der Firma und wettbewerbliches Marktsystem, in: Schüller, A. (Hrsg.): Property Rights und ökonomische Theorie, München, S. 145-183.

SChUMANN, J. (1992): Grundzüge der mikroökonomischen Theorie, 6. Aufl., Berlin u.a.

SCHUMPETER, J. (1942/1950): Capitalism, Socialism, and Democracy, New York 1942. Zitiert nach der dt. Übersetzung: Kapitalismus, Sozialismus und Demokratie, München 1950.

SCHUMPETER, J.A. (1964): Theorie der wirtschaftlichen Entwicklung, 6. Aufl., Berlin. 
SCHWARTING, G. (1979): Zum konjunkturpolitischen Einsatz von Finanzzuweisungen, in: Konjunkturpolitik 25, S. 295-319.

SCHWARZ, G. (1993): Der Bodenmarkt zwischen Freizügigkeit und lokaler Identitätsbewahrung: Einige möglicherweise gar nicht so ketzerische Überlegungen, in: Gröner, H./ Schüller, A. (Hrsg.): Die europäische Integration als ordnungspolitische Aufgabe, Stuttgart, S. 261-277.

SCHWARZE, J. (1986): Mathematik für Wirtschaftswissenschafter, Bd. 2, 6. Aufl., Herne, Berlin.

SCHWEIZER,U. (1988): Externalities and the Coase Theorem: Hypothesis or Result?, in: Journal of Institutional and Theoretical Economics 144, S. 245-266.

SCITOVSKy, T. (1954): Two Concepts of External Economies, in: Journal of Political Economy 17, S. 143-151.

ScoTT, A. (1987): Tax Harmonization in the Comparison of Federal and Other States, in: Journal of Political Economy 3, S. 219-250.

ScoTT, A./BLoss, G. (1988): Inter-provincial Competition, in: Brennan, G. u.a. (Hrsg.): Taxation and Fiscal Federalism, Sydney, u.a., S. 180-201.

SEN, A. (1967): Isolation, Assurance, and the Social Rate of Discount, in: Quarterly Journal of Economics 81, S. 112-124.

SHEPSLE, K. (1979): Institutional Arrangements and Equilibrium in Multidimensional Voting Models, in: American Journal of Political Science 23, S. 27-59.

SHEPSLE, K./WEINGAST, B. (1981): Structure-induced Equilibrium and Legislative Choice, in: Public Choice 37, S. 189-202.

SHUBIK, M. (1968): A Two-Party System, General Equilibrium, and the Voter's Paradox, in: Zeitschrift für Nationalökonomie 28, S. 141-154.

SIEBERT, H. (1967): Zur Theorie des regionalen Wirtschaftswachstums, Tübingen.

SIEBERT, H. (1991): The New Economic Landscape in Europe, Oxford.

SIEBERT, H. (1993): Internationale Wanderungsbewegungen - Erklärungsansätze und Gestaltungsfragen, in: Schweizerische Zeitschrift für Volkswirtschaft und Statistik 129, S. 229255.

SIEBERT, H./KoOP, M. (1990): Institutional Competition. A Concept for Europe?, in: Aussenwirtschaft 45, S. 439-462.

SIEBERT, H./KoOP, M. (1993): Institutional Competition versus Centralization: Quo Vadis Europe?, in: Oxford Review of Economic Policy 9, S. 15-30. 
Simon, D.M./Ostrom, C.W./MARRA, F. (1991): The President Referendum Voting, and Subnational Elections in the United States, in: American Political Science Review 85, S. 1177-1192.

SIMON, H. (1957): Models of Man, New York.

SINGH, N./THOMAS, R. (1989): Matching Grants versus Block Grants with Imperfect Information, in: National Tax Journal 42, S. 191-203.

SINN, H.-W. (1988): Die Grenzen des Versicherungsstaates - Theoretische Bemerkungen zum Thema Einkommensumverteilung, Versicherung und Wohlfahrt, in: Rolf, G./Spahn, P.B./Wagner, G. (Hrsg.): Sozialvertrag und Sicherung. Zur ökonomischen Theorie staatlicher Versicherungs- und Umverteilungssysteme, Frankfurt/M., New York, S. 65-84.

SINN, H.W. (1990): Tax Harmonization and Tax Competition in Europe, in: European Economic Review 34, S. 489-504.

SINN, H.W. (1994): Wieviel Brüssel braucht Europa? Subsidiarität, Zentralisierung und Fiskalwettbewerb im Lichte der ökonomischen Theorie, Wirtschaftswissenschaftliche Beiträge der Volkswirtschaftlichen Fakultät der Ludwig-Maximilians-Universität München 94-14.

SINN, H.W. (1995): Implikationen der vier Grundfreiheiten für eine nationale Fiskalpolitik, in: Wirtschaftsdienst 75, S. 240-249.

SINN, S. (1992): The Taming of Leviathan: Competition Among Governments, in: Constitutional Political Economy 3, S. 177-198.

SINN, S. (1993): Competition for Capital. On the Role of Governments in an Integrated World Economy, Tübingen.

SJAASTAD, L.A. (1962): The Costs and Returns of Human Migration, in: Journal of Political Economy 70, S. 80-93.

SJOQuIST, D. (1982): The Effect of the Number of Local Governments on Central City Expenditures, in: National Tax Journal 35, S. 79-87.

SLEMROD, J. (1990): Tax Havens, Tax Bargains and Tax Addresses: The Effect of Taxation on the Spatial Allocation of Capital, in: Siebert, H. (Hrsg.): Reforming Capital Income Taxation, Tübingen, S. 24-46.

SMITHIES, A. (1941): Optimal Location in Spatial Competition, in: Journal of Political Economy 49, S. 429-439.

Sonstelie, J./PORTNEY, P. (1980): Gross Rents and Market Values: Testing the Implications of Tiebout's Hypothesis, in: Journal of Urban Economics 7, S. 102-118. 
SPAHN, P.B. (1988): On the Assignment of Taxes in Federal Polities, in: Brennan, G./Grewal, B.S./Groenewegen, P. (Hrsg.): Taxation and Fiscal Federalism, Sydney u.a., S. 148-165.

SPAHN, P.B. (1993): The Community Budget for an Economic and Monetary Union, Houndmills u.a.

SPAHN, P.B./KAISER, H. (1988): Soziale Sicherheit als offentliches Gut? - Zur Problematik der Steuerfinanzierung sozialer Sicherung, in: Rolf, G./Spahn, P.B./Wagner, G. (Hrsg.): Sozialvertrag und Sicherung. Zur ökonomischen Theorie staatlicher Versicherungs- und Umverteilungssysteme, Frankfurt/M., New York, S. 195-218.

SPENCE, M. (1973): Job Market Signaling, in: Quarterly Journal of Economics 87, S. 355-374.

SPENCE, M./ZECKHAUSER, R.J. (1971): Insurance, Information, and Individual Action, in: American Economic Review 61, S. 380-387.

SPENCER, B. (1980): Outside Information and the Degree of Monopoly Power of a Public Bureau, in: Southern Economic Journal 47, S. 228-233.

STALEY, S.R./BlaIR, J.P. (1995): Institutions, Quality Competition and Public Service Provision: The Case of Public Education, in: Constitutional Political Economy 6, S. 2133.

STEFFANI, W. (1969): Gewaltenteilung im demokratisch-pluralistischen Rechtsstaat, in: Rausch, H. (Hrsg.): Zur heutigen Problematik der Gewaltenteilung, Darmstadt, S. 313352.

STEHN, J. (1993): Theorie des fiskalischen Föderalismus: Ein Referenzmaßstab zur Beurteilung der Beschlüsse von Maastricht, in: Siebert, H. (Hrsg.): Die zweifache Integration: Deutschland und Europa, Tübingen, S. 33-48.

STEIN, E. (1993): Staatsrecht, 14. Aufl., Tübingen.

STEIN, R.M. (1990): Economic Voting for Governor and U.S. Senator: The Electoral Consequences of Federalism, in: Journal of Politics 52, S. 29-53.

STIGLER, G.J. (1961): The Economics of Information, in: Journal of Political Economy 69, S. 213-225.

STIGLER, G.J. (1962): The Tenable Range of Functions of Local Government, in: Phelps, E.S. (Hrsg.): Private Wants and Public Needs. Issues Surrounding the Size and Scope of Government Expenditure, New York, S. 137-146.

STIGLER, G.J. (1966): The Theory of Price, 3. Aufl., New York.

STIGLER, G.J. (1971): The Theory of Economic Regulation, in: Bell Journal of Economics and Management Science 2, S. 3-21. 
StigleR, G.J. (1972): Economic Competition and Political Competition, in: Public Choice 13, S. 91-106.

STIGLER, G.J. (1973): General Economic Conditions and National Elections, in: American Economic Review 63, S. 160-167.

STIGLER, G.J. (1974): Free Riders and Collective Action, in: Bell Journal of Economics and Management Science 5, S. 359-365.

STIGLER, G.J. (1976): The Xistence of X-Efficiency, in: American Economic Review 66, S. 213-216.

StiglitZ, J.E. (1977): The Theory of Local Public Goods, in: Feldstein, M./Inman, R.P. (Hrsg.): The Economics of Public Services, London u.a., S. 274-333.

StiglitZ, J.E. (1983): The Theory of Local Public Goods Twenty-Five Years after Tiebout: A Perspective, in: Zodrow, G.R. (Hrsg.): Local Provision of Public Services: The TieboutModel after Twenty-Five Years, New York, S. 17-54.

StiglitZ, J.E. (1987): Principal and Agent (II), in: Eatwell, J./Milgate, M./Newman, P. (Hrsg.): The New Palgrave - A Dictionary of Economics, Bd. 3, London u.a., S. 966-972.

StigliTZ, J.E. (1989): On the Economic Role of the State, in: Heertje, A. (Hrsg.): The Economic Role of the State, Cambridge, S. 9-85.

Stolz, O.G. (1974): Revenue Sharing. Legal and Policy Analysis, New York u.a.

STREIT, M.E. (1994): Westeuropas Wirtschaftsverfassungen unter dem Druck des Systemwettbewerbs, in: List Forum für Wirtschafts- und Finanzpolitik 20, S. 111-124.

STREIT, M.E. (1995): Dimensionen des Wettbewerbs - Systemwandel aus ordnungsökonomischer Sicht, in: Zeitschrift für Wirtschaftspolitik 44, S. 113-134.

STREIT, M.E./MUSSLER, W. (1995): Wettbewerb der Systeme und das Binnenmarktprogramm in der Europäischen Union, in: Gerken, L. (Hrsg.): Europa zwischen Ordnungwettbewerb und Harmonisierung, Berlin u.a., S. 75-107.

STURM, R. (1995): Das Subsidiaritătsprinzip im Bereich der Forschungs- und Technologiepolitik, in: Hrbek, R. (Hrsg.): Das Subsidiaritätsprinzip in der Europäischen Union Bedeutung und Wirkung für ausgewählte Politikbereiche, Baden-Baden, S. 57-72.

SÜSTERHENN, A. (1956/1969): Das Subsidiaritătsprinzip als Grundlage der vertikalen Gewaltenteilung, in: Vom Bonner Grundgesetz zur gesamtdeutschen Verfassung. Festschrift für Hans Nawiasky, München 1956, S. 141-155. Zitiert nach dem Wiederabdruck in: Rausch, H. (Hrsg.): Zur heutigen Problematik der Gewaltenteilung, Darmstadt 1969, S. 113-130. 
TANZI, V./BOVENBERG, A.L. (1990): Is There a Need For Harmonizing Capital Incomes Taxes Within EC Countries?, in: Siebert, H. (Hrsg.): Reforming Capital Income Taxation, Tübingen, S. 171-197.

TAYLOR, L. (1992): Infrastructural Competition Among Jurisdictions, in: Journal of Public Economics 49, S. 241-259.

TAYLOR, M. (1976): Anarchy and Cooperation, London u.a.

TELSER, L.G. (1980): A Theory of Self-enforcing Agreements, in: Journal of Business 53, S. 27-44.

TELSER, L.G. (1988): Theories of Competition, New York u.a.

TERBERger, E. (1994): Neo-institutionalistische Ansätze. Entstehung and Wandel - Anspruch und Wirklichkeit, Wiesbaden.

TEUTEMANN, M. (1992): Rationale Kompetenzverteilung im Rahmen der europäischen Integration: ein Beitrag zur finanzwirtschaftlichen Ordnungspolitik, Berlin.

THEILER, J. (1977): Föderalismus - Voraussetzung oder Ergebnis rationaler Politik? Zur ökonomisch optimalen Struktur kollektiver Entscheidungsverfahren, Bern u.a.

ThOMPSON, E.A. (1973): Besprechung zu Niskanen, W.A. (1971), Journal of Economic Literature 11, S. $950-953$.

THÖNI, E. (1986): Politökonomische Theorie des Föderalismus. Eine kritische Bestandsaufnahme, Baden-Baden.

THÜRMER, L. (1984): Bürokratie und Effizienz des staatlichen Handelns, Berlin.

Thurow, L. (1971): The Income Redistribution as a Pure Public Good, in: Quarterly Journal of Economics 85, S. 327-336.

Tiebout, C.M. (1956): A Pure Theory of Local Expenditures, in: Journal of Political Economy 64, S. 416-424.

TIEBout, C.M. (1961): An Economic Theory of Fiscal Decentralization, in: National Bureau of Economic Research (Hrsg.): Public Finances: Needs, Sources, and Utilization, Princeton, S. 79-96.

TIEBout, C.M./Houston, D.B. (1962): Metropolitan Finance Reconsidered: BudgetFunctions and Multi-Level Governments, in: Review of Economics and Statistics 44, S. 412-417.

TiepelmanN, K./VAn Der Beek, G. (1992): Theorie der Parafisci, Berlin, New York. 
TIETZEL, M. (1988): Ethische und theoretische Probleme interventionistischer Wirtschaftspolitik, in: Cassel, D./Ramb, B.-T./Thieme, H.J. (Hrsg.): Ordnungspolitik, München, S. 77-105.

TIETZEL, M. (1991): Der Neue Institutionalismus auf dem Hintergrund der alten Ordnungsdebatte, in: Jahrbuch für Neue Politische Ökonomie 10, S. 3-37.

TIETZEL, M. (1995): Zur Politischen Ökonomie der internationalen Migration, in: Jahrbuch für Neue Politische Ökonomie 14, S. 117-142.

TIETZEL, M./WeBER, M. (1993): Autokratische Mobilitätspolitik, in: ORDO 44, S. 291-305.

TIROLE, J. (1986): Hierarchies and Bureaucracies: On the Role of Collusion in Organizations, in: Journal of Law, Economics, and Organization 2, S. 181-214.

Tollison, R.D. (1982): Rent Seeking: A Survey, in: Kyklos 35, S. 575-602.

TOLLISON, R.D. (1987): Is the Theory of Rent-Seeking Here to Stay?, in: Rowley, C.K.

(Hrsg.): Democracy and Public Choice, Oxford, New York, S. 143-157.

Tollison, R.D. (1988): Public Choice and Legislation, in: Virginia Law Review 74, S. 339371.

ToQueVILLE, A. DE (1955): Die Demokratie in Amerika, übersetzt, eingeleitet und erläutert von Heydte, F.A., Regensburg.

TresCH, R. (1981): Public Finance. A Normative Theory, Plano.

Truman, D. (1951): The Governmental Process: Political Interests and Public Opinion, New York.

TUCHTFELD, E./STRAUBHAAR, T. (1985): Internationale Arbeitskräftewanderungen - ein vernachlässigtes Kapitel in der Außenwirtschaftspolitik, in: ORDO 36, S. 89-109.

TULLOCK, G. (1959): Some Problems of Majority Voting, in: Journal of Political Economy 67, S. 571-579.

TUllock, G. (1965A): Entry Barriers in Politics, in: American Economic Review 55, S. 458471.

Tullock, G. (1965B): The Politics of Bureaucracy, New York.

TULLOCK, G. (1967A): Toward a Mathematics of Politics, Ann Arbor.

Tullock, G. (1967B): The Welfare Costs of Tariffs, Monopolies, and Theft, in: Western Economic Journal 5, S. 224-232.

Tullock, G. (1969A): Federalism: Problems of Scale, in: Public Choice 6, S. 19-29. 
TULLOCK, G. (1969B): Social Cost and Government Action, in: American Economic Review 59, S. 189-197.

TUlLock, G. (1971A): Public Decisions as Public Goods, in: Journal of Political Economy 79, S. 913-918.

TULLOCK, G. (1971B): The Cost of Transfers, in: Kyklos 24, S. 629-642.

TULLOCK, G. (1974): The Social Dilemma. The Economics of War and Revolution, Blacksburg.

TULLOCK, G. (1975): The Transitional Gains Trap, in: Bell Journal of Economic and Management Science 6, S. 671-678.

TULLOCK, G. (1976): The Vote Motive, London.

TULLOCK, G. (1980A): Rent-Seeking as a Negative-Sum Game, in: Buchanan, J.M./Tollison, R.D./Tullock, G. (Hrsg.): Toward a Theory of the Rent-Seeking Society, College Station, S. 16-36.

TULLOCK, G. (1980B): Efficient Rent-Seeking, in: Buchanan, J.M./Tollison, R.D./Tullock, G. (Hrsg.): Toward a Theory of the Rent-Seeking Society, College Station, S. 97-112.

Tullock, G. (1981A): Why So Much Stability?, in: Public Choice 37, S. 487-501.

TUlLoCK, G. (1981B): Lobbying and Welfare: A Comment, in: Journal of Public Economics 16, S. 391-394.

TULLOCK, G. (1983): Economics of Income Redistribution, Boston.

TUllock, G. (1984): A (Partial) Rehabilitation of the Public Interest Theory, in: Public Choice 42, S. 89-99.

TUlLocK, G. (1985): Adam Smith and the Prisoners' Dilemma, in: Quarterly Journal of Economics 100, S. 1073-1081.

TULLOCK, G. (1988): Efficient Rent-Seeking Revisited, in: Rowley, C.K./Tollison, R.D./Tullock, G. (Hrsg.): The Political Economy of Rent-Seeking, Boston u.a., S. 91-94.

TUlLOCK, G. (1989): The Economics of Special Privilege and Rent Seeking, Boston.

Tullock, G. (1993): Rent Seeking, in: Rowley, C.K. (Hrsg.): Property Rights and the Limits of Democracy, Aldershot.

TULLOCK, G. (1994): The New Federalist, Vancouver.

TURNBULL, G.K./DJOUNDOURIAN, S.S. (1993): Overlapping Jurisdictions: Substitutes or Complements?, in: Public Choice 75, S. 231-245. 
TwiGHT, C. (1988): Government Manipulation of Constitutional-Level Transaction Costs: A General Theory of Transaction-Cost Augmentation and the Growth of Government, in: Public Choice 56, S. 131-152.

UlRICH, P. (1987): Transformation der ökonomischen Vernunft, Bern, Stuttgart.

VAN DEN Doel, H. (1979): Democracy and Welfare Economics, Cambridge u.a.

VANBERG, V. (1981): Liberaler Evolutionismus oder vertragstheoretischer Konstitutionalismus? Zum Problem institutioneller Reformen bei F.A. von Hayek und J.M. Buchanan, Tubingen.

VANBERG, V. (1982): Markt und Organisation. Individualistische Sozialtheorie und das Problem korporativen Handelns, Tübingen.

VANBERG, V. (1983): Der individualistische Ansatz zu einer Theorie der Entstehung und Entwicklung von Institutionen, in: Jahrbuch für Neue Politische Ökonomie 2, S. 50-69.

VANBerg, V. (1992): Organizations as Constitutional Systems, in: Constitutional Political Economy 3, S. 223-253.

VANBERG, V./BUCHANAN, J.M. (1991): Constitutional Choice, Rational Ignorance, in: Jahrbuch für Neue Politische Ökonomie 10, S. 61-78.

VANBERG, V./KeRBER, W. (1994): Institutional Competition Among Jurisdictions, in: Constitutional Political Economy 5, S. 193-217.

VAnhove, N./KLAasSEN, L.H. (1980): Regional Policy. A European Approach, Farnborough.

VARIAN, H.R. (1980): Redistributive Taxation as Social Insurance, in: Journal of Public Economics 14, S. 49-68.

VARIAN, H.R. (1985): Mikroökonomie, 2. Aufl., München, Wien.

VAUBEL, R. (1980): Internationale Absprachen oder Wettbewerb in der Konjunkturpolitik, Tübingen.

VAubel, R. (1984): The Government's Money Monopoly: Externalities or Natural Monopoly?, in: Kyklos 37, S. 27-58.

VAubel, R. (1985): International Collusion or Competition for Macroeconomic Policy Coordination? A Restatement, in: Récherches Economiques de Louvain 51, S. 223-240.

VAubel, R. (1986): A Public Choice Approach to International Organization, in: Public Choice 51, S. 39-57.

VAUBEL, R. (1992): Die politische Ökonomie der wirtschaftspolitischen Zentralisierung in der Europäischen Gemeinschaft, in: Jahrbuch für Neue Politische Ökonomie 11, S. 30-65. 
VAUBEL, R. (1993): Perspektiven der europäischen Integration: Die politische Ökonomie der Vertiefung und Erweiterung, in: Siebert, H. (Hrsg.): Die zweifache Integration: Deutschland und Europa, Tübingen, S. 3-31.

VAubel, R. (1994): The Public Choice Analysis of European Integration. A Survey, in: European Journal of Political Economy 10, S. 227-249.

VAubel, R. (1995): The Centralisation of Western Europe. The Common Market, Political Integration, and Democracy, London.

VAuGHAN, R.J. (1979): The Use of Federal Grants for Countercyclical Job Creation, in: Mieszkowski, P./Oakland, W.H. (Hrsg.): Fiscal Federalism and Grants-in-Aid, Urban Institute, S. 143-161.

VelJANOvSKy, C.G. (1982): The Coase Theorems and the Economic Theory of Markets and Law, in: Kyklos 35, S. 53-74.

VIELER, A. (1986): Interessen, Gruppen und Demokratie, Tübingen.

VihaNTo, M. (1992): Competition Between Local Governments as a Discovery Procedure, in: Journal of Institutional and Theoretical Economics 148, S. 411-436.

VINER, J. (1931): Cost Curves and Supply Curves, in: Zeitschrift für Nationalökonomie 111, S. 23-46.

Vollmer, L. (1996): Fordert das System des Wettbewerbs einen Wettbewerb der Systeme?, in: Caesar, R./Ohr, R. (Hrsg.): Maastricht und Maastricht II: Vision oder Abenteuer?, Baden-Baden, S. 227-238.

VOSGERAU, H.-J. (1987): Zur ökonomischen Analyse internationaler Organisationen, in: Henn, R. (Hrsg.): Technologie, Wachstum und Beschäftigung, Berlin, Heidelberg.

WAGNER, H. (1996): Stabilitătspolitik, 3. Aufl., München.

WAGNER, R.E. (1966): Pressure Groups and Political Entrepreneurs: A Review Article, in: Papers on Non-Market Decision Making, Charlottesville, S. 161-170.

WAGNER, R.E. (1970): Optimality in Local Debt Limitation, in: National Tax Journal 23, S. 297-305.

WAGNER, R.E. (1971): Optimality in Local Debt Limitation: Reply, in: National Tax Journal 24, S. 109-111.

WAGNER, R.E. (1983): Public Finance. Revenues and Expenditure in a Democratic Society, Boston, Toronto.

WAGNER, R.E. (1987): Parchment, Guns, and the Maintenance of Constitutional Contract, in: Rowley, C.K. (Hrsg.): Democracy and Public Choice, Oxford, S. 105-121. 
WAGNER, R.E. (1988A): The Calculus of Consent: A Wicksellian Retrospective, in: Public Choice 56, S. 153-166.

WAGNER, R.E. (1988B): Agency, Economic Calculation, and Constitutional Construction, in: Rowley, C.K./Tollison, R.D./Tullock, G. (Hrsg.): The Political Economy of Rent Seeking, Boston u.a., S. 423-445.

WAGNER, R.E./GWARTNEY, R.D. (1988): Public Choice and Constitutional Order, in: Gwartney, J.D./Wagner, R.E. (Hrsg.): Public Choice and Constitutional Economics, S. 2956.

WAGNER, R.E./WEBER, W.E. (1975): Competition, Monopoly, and the Organisation of Government in Metropolitan Areas, in: Journal of Law and Economics 18, S. 661-684.

WALKER, L.J. (1969): The Diffusion of Innovation Among the American States, in: American Political Science Review 63, S. 880-899.

WALlis, J.J./OATES, W.E. (1988): Does Economic Sclerosis Set In With Age ? An Empirical Study of the Olson Hypothesis, in: Kyklos 44, S. 397-417.

WALSH, C. (1993): Fiscal Federalism: An Overview of Issues and a Discussion of Their Relevance to the European Community, in: European Economy, Reports and Studies 5, S. 25-62.

WEBER, M. (1922): Grundriß der Sozialökonomik III, Wirtschaft und Gesellschaft, Tübingen.

Weck-Hannemann, H. (1991): Politische Ökonomie des Protektionismus: Ein institutioneller Ansatz, in: Siebke, J. (Hrsg.): Monetäre Konfliktfelder der Weltwirtschaft, Schriften des Vereins für Socialpolitik N.F., Bd. 210, S. 125-142.

WEGEHENKEL, L. (1980): Coase-Theorem und Marktsystem, Tübingen.

WeIngast, B. (1981): Regulation, Reregulation, and Deregulation: The Political Foundations of Agency-Clientele Relationships, in: Law and Contemporary Problems 44, S. 147-177.

Weingast, B. (1984): The Congressional-Bureaucratic System: A Principal-Agent Perspective. With Application to the SEC, in: Public Choice 44, S. 147-191.

Weingast, B. (1993): Constitutions as Governance Structures: The Political Foundations of Secure Markets, in: Journal of Institutional and Theoretical Economics 149, S. 286-311.

WeIngast, B./MORAN, M.J. (1983): Bureaucratic Discretion or Congressional Control? Regulatory Policymaking by the Federal Trade Commission, in: Journal of Political Economy 91, S. 765-800.

Weingast, B./ShePsle, K./Johnsen, C. (1981): The Political Economy of Benefits and Costs: A Neoclassical Approach to Distribution Politics, in: Journal of Political Economy 89, S. 642-664. 
WEITZMAN, M. (1982): Increasing Returns and Foundations of Unemployment Theory, in: Economic Journal 92, S. 787-804.

WeLlisCH, D. (1995): Dezentrale Finanzpolitik bei hoher Mobilităt, Tübingen.

Welter, P. (1995): International Migration and Institutional Competition: An Application of Hayek's Evolutionary Theory, in: Gerken, L. (Hrsg.): Competition Among Institutions, London, S. 119-151.

WeSSELS, J. (1993): Redistribution From a Constitutional Perspective, in: Constitutional Political Economy 4, S. 425-448.

WeST, E.G./CORKE, C. (1980): Tax Constraints on Leviathan. Some Second Thoughts on the Constitutional Choice Calculus, in: Journal of Public Economics 13, S. 395-401.

WeST, E.G./WINER, S.L. (1980): Optimal Fiscal Illusion and the Size of Government, in: Public Choice 35, S. 607-622.

Whynes, D.K./Bowles, R.A. (1981): The Economic Theory of the State, New York.

WICKSELL, K. (1896): Finanztheoretische Untersuchungen, Jena.

WILDASIN, D.E. (1986): Urban Public Finance, Chur u.a.

Wildasin, D.E. (1987): Theoretical Analysis of Local Public Economies, in: Mills, E.S. (Hrsg.): Handbook of Regional and Urban Economics, Vol. II, S. 1131-1178.

WILDASIN, D.E. (1988): Nash Equilibria in Models of Fiscal Competition, in: Journal of Public Economics 35, S. 229-240.

WILDASIN, D.E. (1989): Interjurisdictional Capital Mobility: Fiscal Externalities and a Corrective Subsidy, in: Journal of Urban Economics 25, S. 193-212.

WILDASIN, D.E. (1991): Income Redistribution in a Common Labor Market, in: American Economic Review 81, S. 757-774.

WILDASIN, D.E. (1992): Relaxation of Barriers to Factor Mobility and Income Redistribution, in: Public Finance 47, Supplement, S. 216-230.

WILDASIN, D.E. (1996): Introduction: Fiscal Aspects of Evolving Federations, in: International Tax and Public Finance 3, S. 121-135.

WildavsKy, A. (1990): A Double Security: Federalism as Competition, in: Cato Journal 10, S. 39-58.

WILDE, J. (1968): The Expenditure Effects of Grant-In-Aid Programs, in: National Tax Journal 21, S. 340-348. 
Williams, A. (1966): The Optimal Provision of Public Goods in a System of Local Government, in: Journal of Political Economy 74, S. 9-33.

WILliAMSON, O.E. (1964): The Economics of Discretionary Behavior: Managerial Objectives in a Theory of the Firm, Englewood Cliffs.

WiLliamson, O.E. (1967): Hierarchical Control and Optimum Firm Size, in: Journal of Political Economy 75, S. 123-138.

WILliamsON, O.E. (1975): Markets and Hierarchies. Analysis and Anti-Trust Implications, New York.

Williamson, O.E. (1976): Franchise Bidding for Natural Monopolies - in General and with Respect to CATV, in: Bell Journal of Economics 7, S. 73-104.

WiLliamson, O.E. (1985): The New Institutional Economics, in: Journal of Institutional and Theoretical Economics 141, S. 187-195.

Williamson, O.E. (1985/1990): The Economic Institutions of Capitalism, New York 1985. Zitiert nach der dt. Übersetzung: Die ökonomischen Institutionen des Kapitalismus, Tübingen 1990.

Williamson, O.E. (1993): Transaktionskostenökonomik, Münster.

WiLson, J. (1986): A Theory of Inter-Regional Tax Competition, in: Journal of Urban Economics 19, S. 296-315.

WINDEN, F. VAN (1983): On the Interaction Between State and the Private Sector, Amsterdam u.a.

Wintrobe, R. (1987A): The Market for Corporate Control and the Market for Political Control, in: Journal of Law, Economics, and Organization 3, S. 435-448.

WINTROBE, R. (1987в): Competitive Federalism and Bureaucratic Power, in: European Journal of Political Economy 3, S. 9-31.

Wiseman, J. (1989): Cost, Choice and Political Economy, Aldershot.

Wiseman, J. (1990): Principles of Political Economy. An Outline Proposal, Illustrated by Application to Fiscal Federalism, in: Constitutional Political Economy 1, S. 101-124.

WITT, U. (1992): The Emergence of a Protective Agency and the Constitutional Dilemma, in: Constitutional Political Economy 3, S. 255-266.

Wittman, D. (1989): Why Democracies Produce Efficient Results, in: Journal of Political Economy 97, S. 1395-1424. 
WitTMan, D. (1990): Spatial Strategies When Candidates Have Policy Preferences, in: Enelow, J.L./Hinich, M.J. (Hrsg.): Advances in the Spatial Theory of Voting, Cambridge u.a., S. 66-98.

WITTMAN, D. (1991): Nations and States: Mergers and Acquisitions; Dissolutions and Divorce, in: American Economic Review 81, S. 126-129.

WITTMANN, W. (1976): Verbände in der politischen Willensbildung, in: Blümle, K./ Wittmann, W. (Hrsg.): Verbände, Stuttgart, New York, S. 2-5.

Wohlgemuth, M. (1995): Economic and Political Competition in Neoclassical and Evolutionary Perspective, in: Constitutional Political Economy 6, S. 71-96.

WUST, H.F. (1981): Föderalismus. Grundlage für Effizienz in der Staatswirtschaft, Göttingen.

WyCKoff, P.G. (1990A): The Simple Analytics of a Slack-Maximizing Bureaucracy, in: Public Choice 67, S. 35-47.

WyCKoff, P.G. (1990B): Bureaucracy, Inefficiency, and Time, in: Public Choice 67, S. 169179.

YARBROUGH, B.V./YARBROUGH, R.M. (1994): International Contracting and the Boundary Question, in: Journal of Institutional and Theoretical Economics 150, S. 239-264.

YINGER, J. (1982): Capitalization and the Theory of Local Public Finance, in: Journal of Political Economy 90, S. 917-943.

Young, R.A. (1994): The Political Economy of Secession: The Case of Quebec, in: Constitutional Political Economy 5, S. 221-245.

Zarkovic-Bookman, M. (1992): The Economics of Secession, New York.

ZAX, J. (1988): The Effects of Jurisdiction Types and Numbers on Local Public Finance, in: Rosen, H. (Hrsg.): Fiscal Federalism, Chicago, S. 79-106.

ZAX, J. (1989): Is There A Leviathan In Your Neighborhood ?, in: American Economic Review 79, S. 560-567.

ZEITEL, W. (1981): Gebühren und Beiträge, in: Albers, W. u.a. (Hrsg.): Handwörterbuch der Wirtschaftswissenschaft, Bd. 3, Stuttgart u.a., S. 347-355.

ZIEGLER, J.A. (1976): Interstate Black Migration: Comment and Further Evidence, in: Economic Inquiry 14, S. 449-453.

ZIFFZER, S. (1980): Ökonomische Grenzen der staatlichen Kreditaufnahme, Berlin.

ZIMMERMAN, D. (1983): Resource Misallocation from Interstate Tax Exportation: Estimates of Excess Spending and Welfare Loss in a Median Voter Framework, in: National Tax Journal 36, S. 183-202. 
ZiMMERMANN, H. (1983): Finanzausgleich auf nationaler Ebene, in: Neumark, F. (Hrsg.): Handbuch der Finanzwissenschaft, Bd.IV, 3. Aufl., Tübingen, S. 3-52.

ZIMMERMANN, H. (1987): Föderalismus und "Einheitlichkeit der Lebensverhältnisse". Das Verhältnis regionaler Ausgleichsziele zu den Zielen des foderativen Staatsaufbaus, in: Schmidt, K. (Hrsg.): Beiträge zu ökonomischen Problemen des Föderalismus, Schriften des Vereins für Socialpolitik N.F., Bd. 166, Berlin, S. 35-69.

ZiMmermanN, H./HENKE, K.D. (1994): Einführung in die Finanzwissenschaft, 7. Aufl., München.

ZiMMERMANN, R. (1995): Konturen eines Europäischen Vertragsrechts, in: Juristenzeitung 50, S. 477-491.

ZODROW, G.R./MIESZKOWSKI, P. (1983): The Incidence of the Property Tax: The Benefit View Versus the New View, in: Zodrow, G.R. (Hrsg.): Local Provision of Public services: The Tiebout Model After Twenty-Five Years, New York, S. 109-130.

ZoDRow, G.R./MIESZKOWSKI, P. (1986): Pigou, Property Taxation, and the Underprovision of Local Public Goods, in: Journal of Urban Economics 19, S. 356-370.

Zupan, M.A. (1990): The Last Period Problem in Politics: Do Congressional Representatives Not Subject to a Reelection Constraint Alter Their Voting Behavior?, in: Public Choice 65 , S. $167-180$. 


\section{HOHENHEIMER VOLKSWIRTSCHAFTUICHE SCHRIFTEN}

Band 1 Walter Deffaa: Anonymisierte Befragungen mit zufallsverschlüsselten Antworten. Die Randomized-Response-Technik (RRT). Methodische Grundlagen, Modelle und Anwendungen. 1982.

Band 2 Thomas Michael Baum: Staatsverschuldung und Stabilisierungspolitik in der Demokratie. Zur neoinstitutionalistischen Kritik der keynesianischen Fiskalpolitik. 1982.

Band 3 Klaus Schröter: Die wettbewerbspolitische Behandlung der leitungsgebundenen Energiewirtschaft. Dargestellt am Beispiel der Fernwărmewirtschaft der Bundesrepublik Deutschland. 1986.

Band 4 Hugo Mann: Theorie und Politik der Steuerreform in der Demokratie. 1987.

Band 5 Max Christoph Wewel: Intervallarithmetische Dependenzanalyse in der Ökonometrie. Ein konjekturaler Ansatz. 1987.

Band 6 Heinrich Pascher: Die U.S.-amerikanische Deregulation Policy im Luftverkehrs- und Bankenbereich. 1987.

Band 7 Harald Lob: Die Entwicklung der französischen Wettbewerbspolitik bis zur Verordnung Nr. 86-1243 vom 01. Dezember 1986. Eine exemplarische Untersuchung der Erfassung der Behinderungsstrategie auf der Grundlage des Konzepts eines wirksamen Wettbewerbs. 1988.

Band 8 Ulrich Kirschner: Die Erfassung der Nachfragemacht von Handelsunternehmen. Eine Analyse der ökonomischen Beurteilungskriterien und der wettbewerbsrechtlichen Instrumente im Bereich der Verhaltenskontrolle.1988.

Band 9 Friedhelm Herb: Marktwirtschaftliche Innovationspolitik. 1988.

Band 10 Claus Schnabel: Zur ökonomischen Analyse der Gewerkschaften in der Bundesrepublik Deutschland. Theoretische und empirische Untersuchungen von Mitgliederentwicklung, Verhalten und Einfluß auf wirtschaftliche Größen. 1989.

Band 11 Jan B. Rittaler: Industrial Concentration and the Chicago School of Antitust Analysis. A Critical Evaluation on the Basis of Effective Competition. 1989.

Band 12 Thomas Mărtz: Interessengruppen und Gruppeninteressen in der Demokratie. Zur Theorie des Rent-Seeking. 1990.

Band 13 Andreas Maurer: Statistische Verfahren zur Ermittlung von oligopolistischen Strukturen. 1990.

Band 14 Peter Mendler: Zur ökonomischen und politisch-institutionellen Analyse öffentlicher Kredithilfen. 1992.

Band 15 Heinrich J. Engelke: Die Interpretation der Rundfunkfreiheit des Grundgesetzes: Eine Analyse aus ókonomischer Sicht. 1992.

Band 16 Thomas Fischer: Staat, Recht und Verfassung im Denken von Watter Eucken. Zu den staats- und rechtstheoretischen Grundlagen einer wirtschaftsordnungspolitischen Konzeption. 1993.

Band 17 Stefan EIßer: Innovationswettbewerb. Determinanten und Unternehmensverhalten. 1993.

Band 18 Reinhard Scharff: Regionalpolitik und regionale Entwicklungspotentiale. Eine kritische Analyse. 1993.

Band 19 Karin Beckmann: Probleme der Regionalpolitik im Zuge der Vollendung des Europäischen Binnenmarktes. Eine ökonomische Analyse. 1995. 
Band 20 Bernd Nolte: Engpaßfaktoren der Innovation und Innovationsinfrastruktur. Eine theoretische und empirische Analyse für lăndliche Wirtschaftsrăume in Baden-Württemberg. 1996.

Band 21 Klaus-Rainer Brintzinger: Die Nationalókonomie an den Universităten Freiburg, Heidelberg und Tübingen 1918 - 1945. Eine institutionenhistorische, vergleichende Studie der wirtschaftswissenschaftlichen Fakultäten und Abteilungen südwestdeutscher Universitäten. 1996.

Band 22 Steffen Binder: Die Idee der Konsumentensouverănität in der Wettbewerbstheorie. Teleokratische vs. nomokratische Auffassung. 1996.

Band 23 Alexander Burger: Deregulierungspotentiale in der Gesetzlichen Rentenversicherung. Reformnotwendigkeiten versus Reformmöglichkeiten. 1996.

Band 24 Burkhard Scherer: Regionale Entwicklungspolitik. Konzeption einer dezentralisierten und integrierten Regionalpolitik. 1997.

Band 25 Frauke Wolf: Lorenzkurvendisparităt. Neuere Entwicklungen, Erweiterungen und Anwendungen. 1997.

Band 26 Hans Pitlik: Politische Ökonomie des Föderalismus. Föderative Kompetenzverteilung im Lichte der konstitutionellen Ökonomik. 1997. 